Érica Fernanda Aiko Kimura

\title{
Análise termoestrutural de pilares de aço em situação de incêndio
}

Dissertação apresentada à Escola de Engenharia de São Carlos como parte dos requisitos necessários para obtenção do Título de Mestre em Engenharia de Estruturas.

Área de concentração: Estruturas Metálicas Orientador: Prof. Dr. Jorge Munaiar Neto 
AUTORIZO A REPRODUÇÃO E DIVULGAÇ̃̃O TOTAL OU PARCIAL DESTE TRABALHO, POR QUALQUER MEIO CONVENCIONAL OU ELETRÔNICO, PARA FINS DE ESTUDO E PESQUISA, DESDE QUE CITADA A FONTE.

Ficha catalográfica preparada pela Seção de Tratamento da Informação do Serviço de Biblioteca - EESC/USP

\footnotetext{
Análise termoestrutural de pilares de aço em situação de incêndio / Érica Fernanda Aiko Kimura ; orientador Jorge Munaiar Neto. -- São Carlos, 2009.

Dissertação (Mestrado-Programa de Pós-Graduação e Área de Concentração em Engenharia de Estruturas) -- Escola de Engenharia de São Carlos da Universidade de São Paulo, $20 \odot 9$.
}

1. Estruturas metálicas. 2. Pilares de aço.

3. Situação de incêndio. 4. Análise numérica. 5. Análise termo-estrutural. I. Título. 


\section{FOLHA DE JULGAMENTO}

Candidata: Engenheira ÉRICA FERNANDA AIKO KIMURA

Dissertação defendida e julgada em 15/04/2009 perante a Comissão Julgadora:

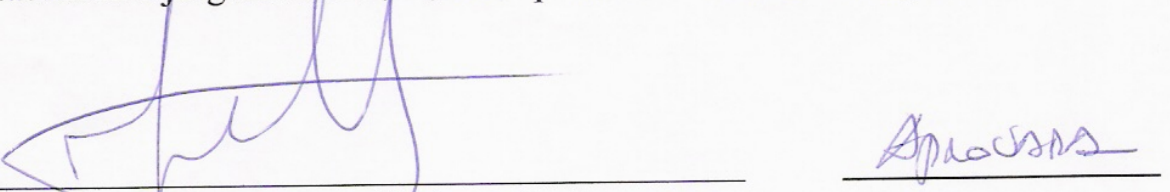

Prof. Dr. JORGE MUNAIAR NETO (Orientador)

(Escola de Engenharia de São Carlos/USP)

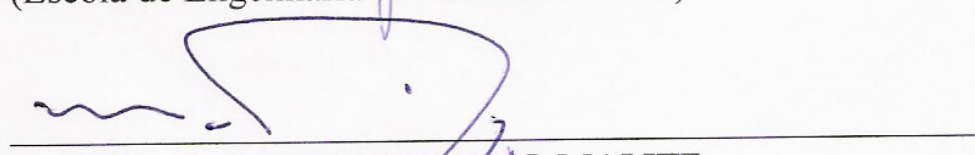

APROUADA

Prof. Associado MAXIMILIANO MALITE

(Escola de Engenharia des São Carlos/USP)
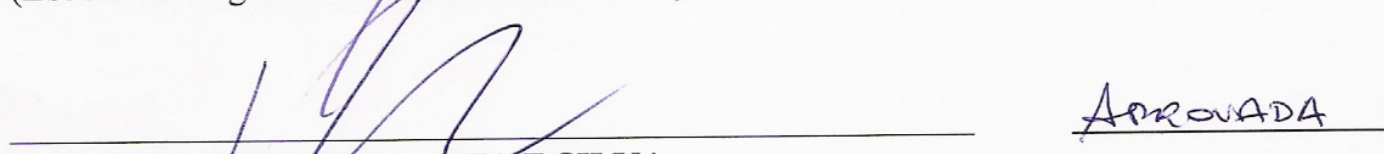

Prof. Dr. VALDIR/PIGNATTA E SILVA

(Escola Polizécnika/USP)
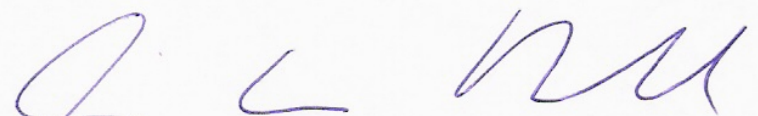

Prof. Associado MARCIO ANTONIO RAMALHO

Coordenador do Programa de Pós-Graduação em

Engenharia Civil (Engenharia de Estruturas)

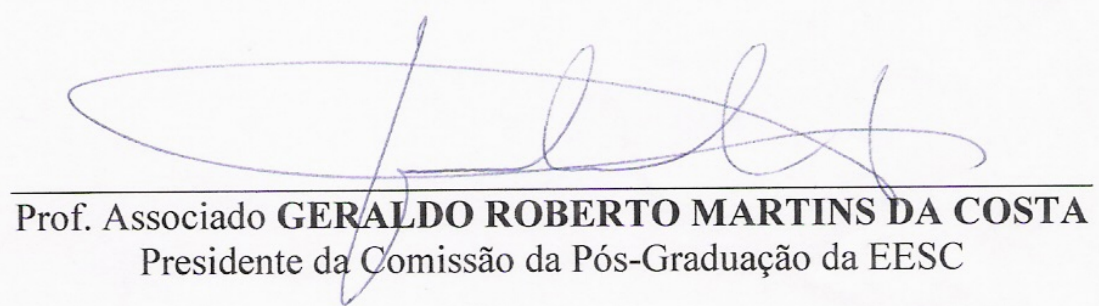



Aos meus pais Luiz e Neuza, meus irmãos Henrique e Cíntia, meu cunhado João e meus acolhedores avós, tios e primos dedico esse trabalho com muito carinho e gratidão. 



\section{AGRADECIMENTOS}

Primeiramente, agradeço a Deus.

Ao Conselho Nacional de Desenvolvimento Científico e Tecnológico, CNPq e a Fundação de Amparo a Pesquisa do Estado de São Paulo, FAPESP, pelo apoio financeiro para a realização desta pesquisa.

Ao professor Jorge Munaiar Neto pela confiança, paciência, incentivo e por todos os conhecimentos transmitidos na realização de mais um trabalho.

Aos professores Maximiliano Malite e Valdir Pignatta e Silva pelas importantes contribuições no exame de qualificação e ao longo do desenvolvimento deste trabalho.

Aos professores do Departamento de Engenharia de Estruturas pelo vasto conhecimento adquirido durante esses meses de mestrado, em especial ao professor João Batista de Paiva.

Aos professores da Escola de Engenharia de São Carlos, da Universidade de São Paulo pela formação profissional.

Aos meus amigos da graduação, em especial ao Anthony.

Aos funcionários do Departamento de Engenharia de Estruturas do laboratório, secretaria, e seção de informática por todo apoio, Raquel, Sylvia, Junior, Toninho, aos estagiários e, em especial, Rosi, Nadir, Eli, Masaki, Melina e Rodrigo Paccola.

Os meus “irmãos” Rodrigo, Ronaldo e Saulo, sempre presentes e ajudando a entender as ferramentas do ANSYS em todas as etapas das simulações matemáticas e ao Manoel Dênis pela ajuda na implementação de rotinas no ANSYS.

À turma ingressante em 2007, pelas horas de estudo durante as provas e pelos momentos de descontração "pós-provas". À turma com quem dividi a majestosa sala 5ME, às turmas anteriores pela calorosa recepção, à turma ingressante em 2008 e 2009 a quem desejo que a dedicação ao trabalho resulte em sucesso na carreira profissional. A todos que fazem ou fizeram parte da delegação olímpica do SET, em especial da seleção de vôlei. A todas as nossas reuniões que acabaram em pizzas, yakissobas e risotos. Resumindo, a todos os meus amigos que tornaram o dia-a-dia do mestrado ainda melhores: Marcelo, Nero, Rodrigo Pagnussat, Charles, Luiz Henrique, Emerson, Rafael Camargo, Juliana, Eunice, Indara, Orieta, Ana Paula Arquez, Giovanni, Bruno, César, Cynthia, Denise, Fabio Rocha, Fabio 
Sawasaki, Freddy, Ieda, Ísis, Jefferson, José Brasílio, Leandro Cavalcanti, Marcela Kataoka, Socorro, Ricardo Patriota, Rodrigo Barros, Tobias, Igor, Camila, Ana Paula Ferreira, Antônio, Edmar, João César, Jesus Sanches, Luiz Álvaro, Michell, Rodrigo (Eli), Rômulo, Vinícius, Wanderson, Wesley Góis, André, Andreilton e Aline, Calil, Cátia, Danielle, Dênis Delázari, Ellen K-Ellen, Francisco Quim, Gabriela, Hidelbrando, Higor, Luiz Fernando, Fernando Menezes, Marliane, Raphael Mairal, Rodolfo Medeiros, Valmiro e Christiane, William Bessa e Wellison. E agradeço especialmente aos amigos Aref, Dorival, Jesus Daniel, Marcela "Mana" Filizola, Eduardo (Edut), Fernanda Madrona, Jonas (Maninho), Jônatas Barreto, Karla Miller, Marlos Mangini (que veio visitar os amigos distantes sempre que possivel!), Luiz Aquino, Raimundo e Flaviana, Walter "Mercado" Oliveira (pelas aulas de Word, Power Point, Excel, Autocad, etc), Carlos Marek e Wagner.

Aos professores e às escolas do ensino fundamental e do ensino médio.

A todos os familiares, em especial aos tios, primos e avós que me acompanham desde o ensino médio, realizado em Ribeirão Preto.

Aos meus irmãos Henrique e Cíntia e meu cunhado João pela torcida.

Aos meus pais Luiz e Neuza que, com muito trabalho e abdicação mostraram o verdadeiro valor do ensino e da busca pelo conhecimento para um mundo melhor. 
"A vida sem ciência é uma espécie de morte."

(Sócrates).

"Seja você mesmo as mudanças que quer ver no mundo."

(Mahatma Gandhi)

A mente que se abre a uma nova idéia jamais voltará ao seu tamanho original.

O único lugar onde o sucesso vem antes do trabalho é no dicionário.

O ser humano vivencia a si mesmo, seus pensamentos como algo separado do resto do universo - numa espécie de ilusão de ótica de sua consciência. E essa ilusão é uma espécie de prisão que nos restringe aos nossos desejos pessoais, conceitos e ao afeto por pessoas mais próximas. Nossa principal tarefa é a de nos livrarmos dessa prisão, ampliando o nosso círculo de compaixão, para que ele abranja todos os seres vivos e toda a natureza em sua beleza. Ninguém conseguirá alcançar completamente esse objetivo, mas lutar pela sua realização já é por si só parte de nossa liberação e o alicerce de nossa segurança interior.

(Albert Einstein) 



\section{RESUMO}

KIMURA, E. F. A. Análise termoestrutural de pilares de aço em situação de incêndio. 2009. 212p. Dissertação (mestrado) - Departamento de Engenharia de Estruturas, Escola de Engenharia de São Carlos, Universidade de São Paulo, São Carlos, São Paulo. 2009.

Os pilares de aço, assim como outros elementos constituídos de outros materiais, quando expostos à temperaturas elevadas têm suas propriedades mecânicas de resistência e rigidez reduzidas em resposta ao aquecimento provocado pela ação térmica, podendo ocasionar o colapso prematuro da estrutura. Com base nesse aspecto, o objetivo do presente projeto de pesquisa foi analisar numericamente o comportamento de pilares de aço em situação de incêndio, considerando condições de compartimentação do ambiente em chamas. Para tanto, foram elaborados modelos numéricos desenvolvidos com o código computacional ANSYS v9.0 para fins de realização da análise acoplada termoestrutural em caráter transiente com relação ao gradiente térmico. Foram elaborados, inicialmente modelos bidimensionais para validar as informações referentes à temperatura na seção transversal. Posteriormente, foram construídos modelos tridimensionais térmicos e estruturais que levam em conta as não linearidades do material e geométrica, na forma de imperfeição geométrica inicial do tipo global, com vistas à análise termoestrutural do elemento. Os resultados obtidos nas análises termo-estruturais foram comparados com resultados obtidos por meio de procedimentos normativos das normas ABNT NBR14323:1999 e EC3-1.2. Os métodos simplificados propostos por tais normas aplicam o fator de massividade, definido como a relação entre o perímetro exposto ao fogo e a área total da seção transversal, na determinação da temperatura máxima do elemento estrutural que, conseqüentemente, influencia no dimensionamento em temperaturas elevadas. Os resultados dos exemplos apresentados mostram que, em situações onde a distribuição da temperatura ocorre de forma não-uniforme, o fator de massividade (parâmetro que consiste de artifício matemático para a determinação de valores de temperatura máxima no elemento) conduz a valores de temperatura e conseqüente comportamento estrutural não condizente com a real situação de interesse na análise. Acredita-se que os resultados aqui obtidos poderão ser de grande importância na contribuição em futuras revisões da norma brasileira ABNT NBR 14323:1999, atualmente em vigor.

Palavras-chave: Estruturas metálicas, Pilares de aço, Situação de incêndio, Análise numérica, Análise termoestrutural. 



\begin{abstract}
KIMURA, E. F. A. Coupled Thermal and structural analysis of steel columns under fire condition. 2009. 200p. Dissertation (master) - Departamento de Engenharia de Estruturas, Escola de Engenharia de São Carlos, Universidade de São Paulo, São Carlos, São Paulo. 2009.

The most part of materials whose constitute fire protection elements or structural elements, such as steel columns, when exposed to high temperature have their strength and elasticity modulus reduced caused by thermal action. Therefore the structure can collapse earlier than in an ambient temperature situation. Based in this aspect, the objective of the presented work is to develop steel columns numerical analysis to consider its behavior under fire situation, including compartment condition of the room. The thermal and coupled thermal structural numerical analyses were carried out using the computational code ANSYS v9.0. In an initial stage, 2-D models are proposed in order to obtain cross sections thermal gradient, considering also the numerical result of the code TCD v5.5 in sense to compare with ANSYS thermal result. Afterwards, three-dimensional models taking account coupled thermal and structural analysis, considering materials and geometric non-linearity were showed. The obtained results were compared with method proposed by standard ABNT NBR: 14323-1999 and EC3-1.2, in which are used the section factor, i.e., the parameter defined by the ratio between exposed perimeter to fire and total cross section area in order to determine the maximum structural element temperature and, consequently, the design in elevated temperature with respect to the collapse load. The results, obtained by numerical analysis, drive in sense to signalize that, for the situations where non-uniform heating conditions occurs, the use of section factor $(F)$, used as a alternative simplified parameter which the objective to determine the maximum temperature at the element, can carry out, eventually, to an unsatisfactory and nonrepresentative response if compared with a real fire situation. These presented results can be converted to an important contribution for future reviews of Brazilian standard code ABNT NBR14323:1999 currently in action.
\end{abstract}

Key-words: Steel structures, steel columns, fire condition, numerical analysis, thermal and structural analysis, Non linear analysis. 



\section{SUMARIO}

RESUMO

ABSTRACT

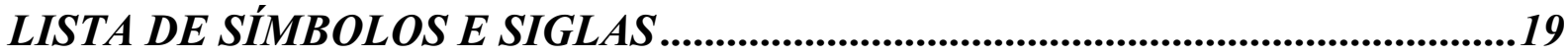

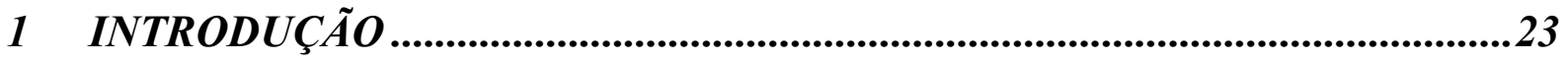

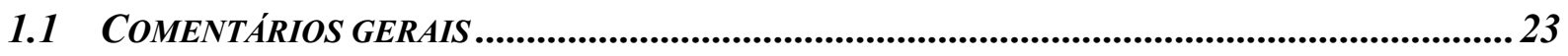

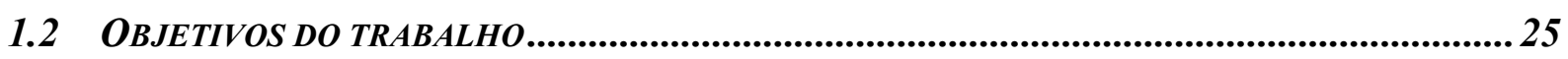

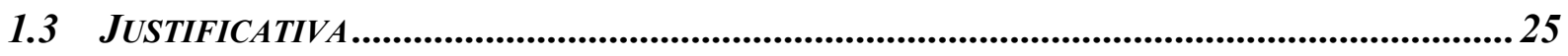

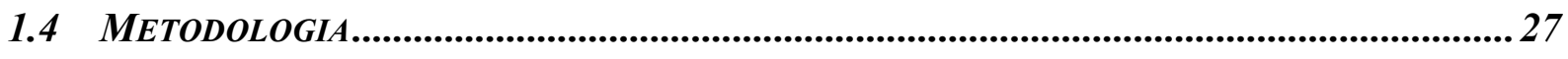

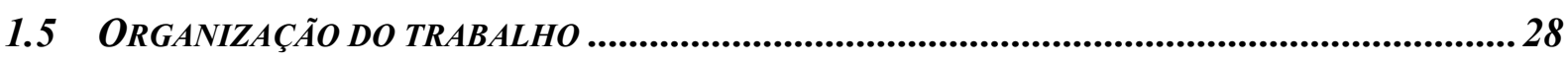

2 BREVE ABORDAGEM DA AÇÃO TÉRMICA NAS ESTRUTURAS

METALICAS ..............................................................................................

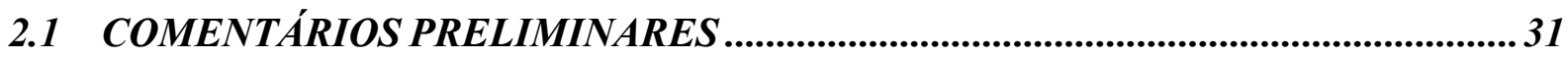

2.2 PESQUISAS REALIZADAS - CONTEXTO EXPERIMENTAL..............................................35

2.3 PESQUISAS REALIZADAS - CONTEXTO NUMÉRICO ........................................................39

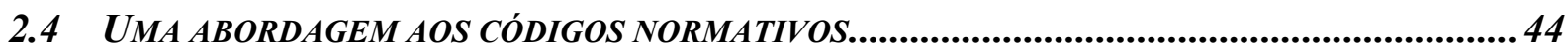

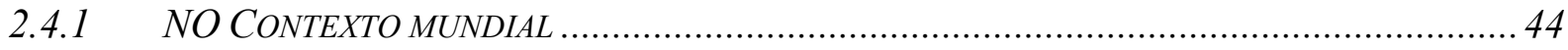

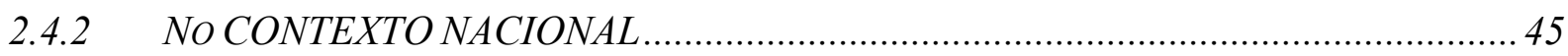

3 O INCÊNDIO: ORIGEM, AÇÃO TÉRMICA E OS PROCEDIMENTOS

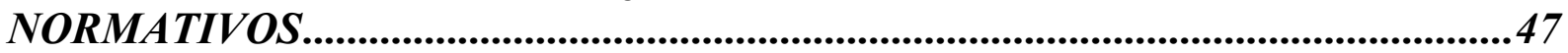

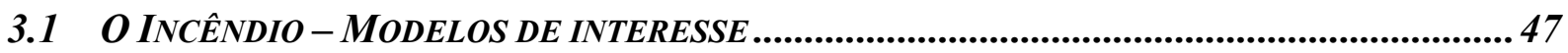

3.1.1 MODELO DE INCENDIO REAL - TEMPERATURA X TEMPO …....................................... 48

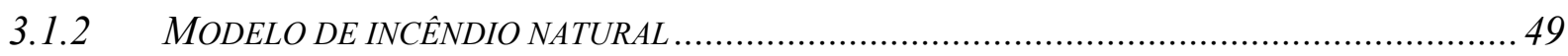

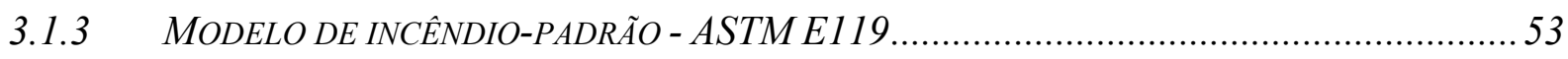

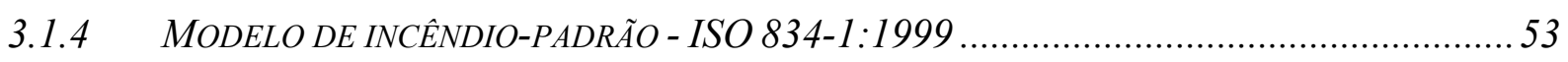

3.1.5 MODELO DE INCENNDIO-PADRÃO - EUROCODE 1 PART 1-2 …............................................. 54

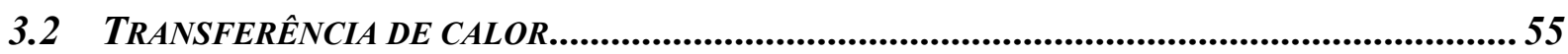

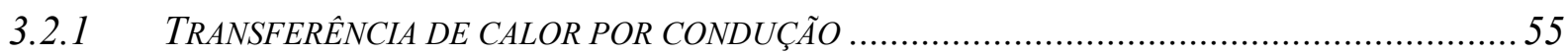

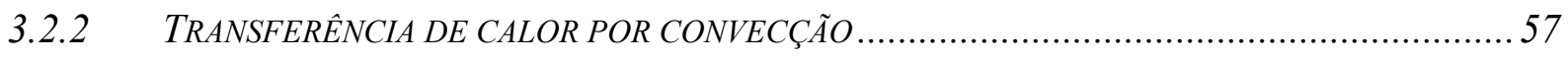

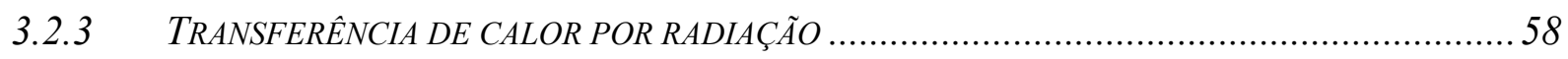

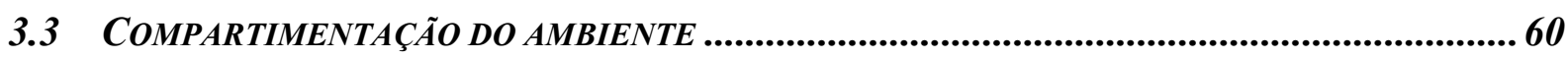

3.4 PROPRIEDADES FÍSICAS DO AÇO-SOB AÇÃO TÉRMICA.......................................... 62

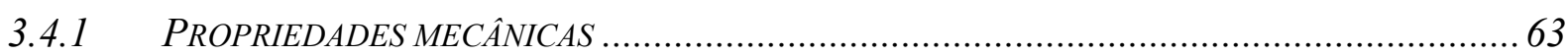

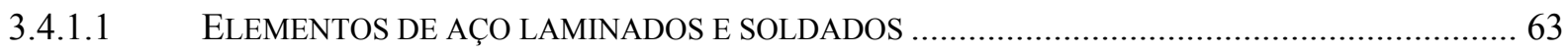

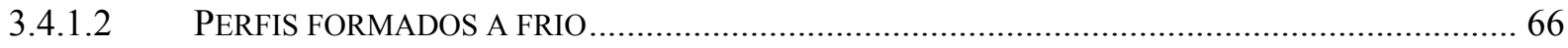

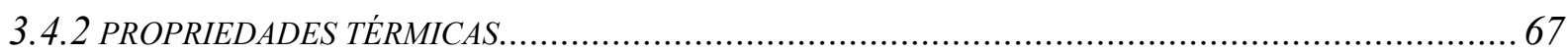


3.5 PROPRIEDADES FÍSICAS DO CONCRETO ....................................................................... 69

3.6 MÉTODO DE DIMENSIONAMENTO - EUROCODE 3 PART 1- 2......................................... 74

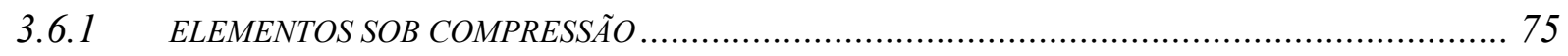

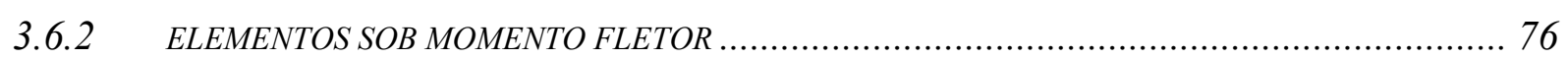

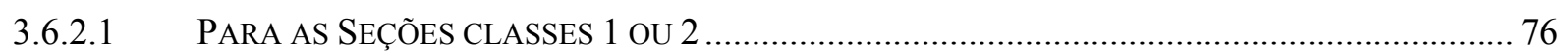

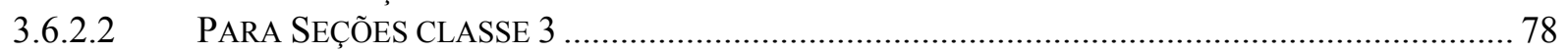

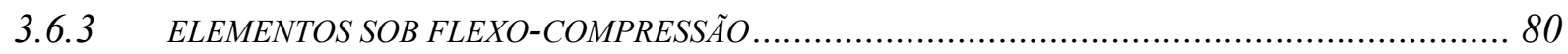

\section{MODELAGEM NUMÉRICA - ELEMENTOS ADOTADOS E} CONSIDERAÇÕES DE INTERESSE. 83

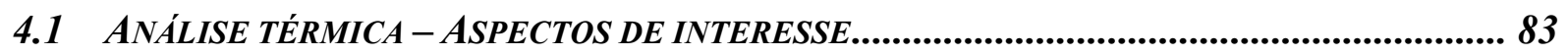

4.1.1 ANÁLISE TÉRMICA BIDIMENSIONAL - ELEMENTOS FINITOS ADOTADOS ............................. 86

4.1.2 ANÁLISE TÉRMICA TRIDIMENSIONAL - ELEMENTOS FINITOS ADOTADOS ................................ 88

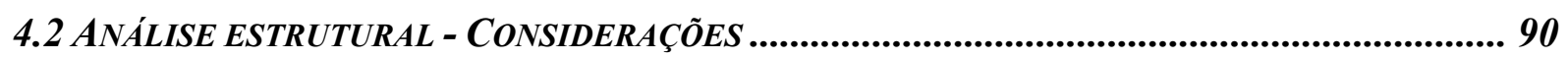

4.2.1 ANÁLISE DE INSTABILIDADE - CONSIDERAÇÃO DE IMPERFEIÇÕES ................................ 91

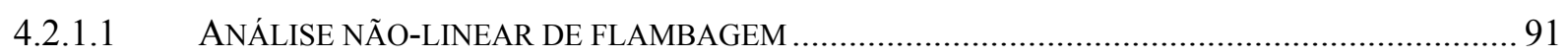

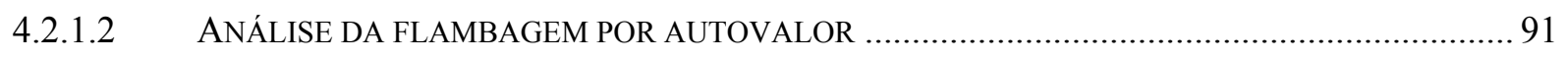

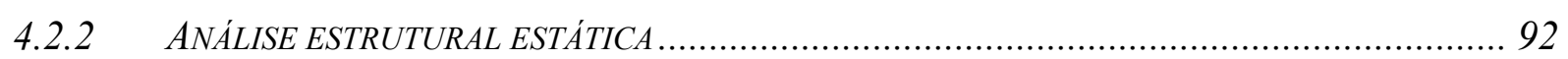

4.2.3 ANÁLISES ESTRUTURAIS EM CAMPO TRIDIMENSIONAL - ELEMENTOS FINITOS UTILIZADOS 92

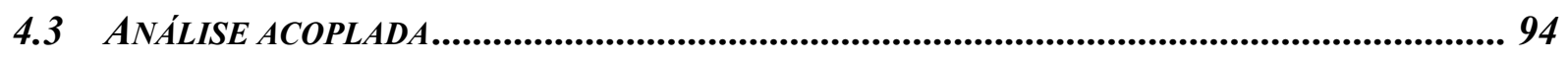

5 MODELOS NUMÉRICOS EM CAMPO TÉRMICO - AVALIAÇÃO DA EFICIÊNCIA .................................................................................................................... 95

5.2 MODELOS NUMÉRICOS ANALISADOS - PARÂMETROS E RESULTADOS OBTIDOS EM CAMPO

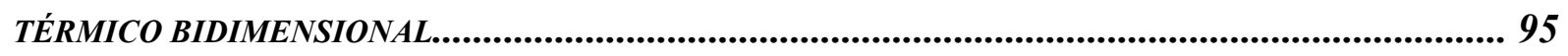

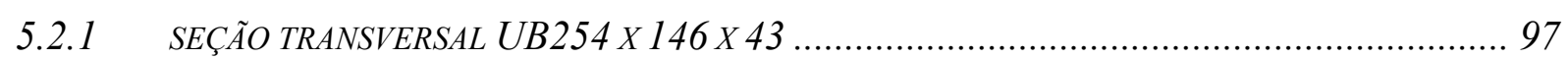

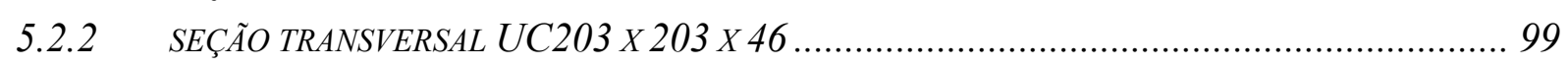

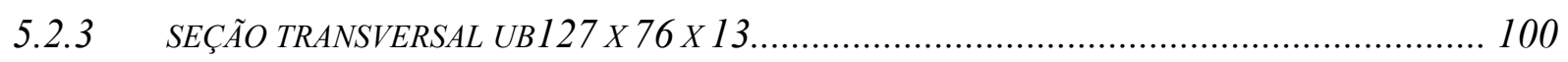

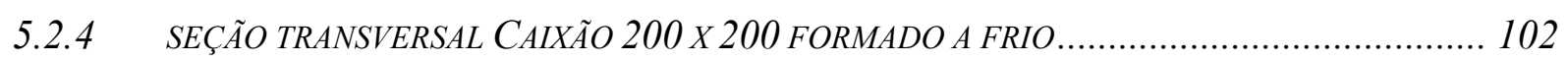

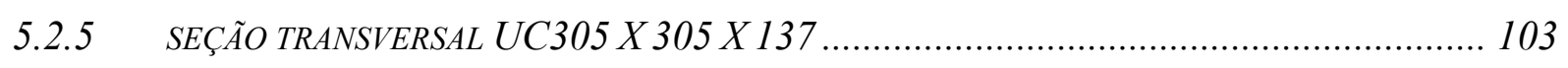

5.2.6 RESULTADOS DA ANÁLISE TÉRMICA APRESENTADA - AVALIAÇÃO.................................. 105

5.3 ANÁLISE TÉRMICA TRIDIMENSIONAL CONSIDERANDO A ASSIMETRIA DO CAMPO TÉRMICO 110

5.3.1 CONSIDERAÇÃO DA COMPARTIMENTAÇÃO NA DISTRIBUIÇÃO DA TEMPERATURA-

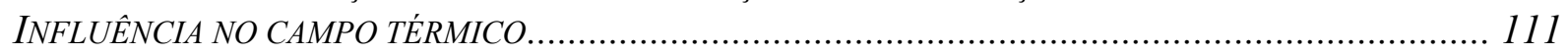

5.3.1.1 SITUAÇ̃̃O I - PILAR ISOLADO …………..................................................................... 111

5.3.1.2 SITUAÇ̃̃o II - PAREDES DE ALVENARIA EM CONTATO COM AMBAS AS MESAS .................. 113

5.3.1.3 SITUAÇ̃̃O III - PAREDES DE ALVENARIA EM CONTATO COM A ALMA ............................... 115

5.3.1.4 SITUAÇ̃̃O IV - PILAR COM PAREDES EM CONTATO COM A ALMA E COM UMA DAS MESAS 117

5.3.1.5 SituaÇÃo V - Pilar de CANTO 
5.3.2 ESTUDO DE CASO - INSTITUTO FÁBRICA DO MILÊNIO. 121

5.3.2.1 EXEMPLO 1: PILAR PERTENCENTE AO COMPARTIMENTO CENTRAL .................................. 122

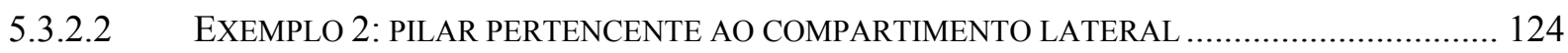

6 ANALISE ESTRUTURAL EM TEMPERATURA AMBIENTE PROCEDIMENTOS E RESULTADOS......................................................................127

6.1 ELEMENTOS FINITOS CONSIDERADOS - COMPARAÇÕES ...................................... 130

6.1.1 MODELOS ELABORADOS COM ELEMENTO FINITO TIPO CASCA .................................... 130

6.1.2 MODELOS ELABORADOS COM ELEMENTO FINITO DO TIPO SÓLIDO................................ 131

6.2 CONSTRUÇÃO DOS MODELOS NUMÉRICOS............................................................ 132

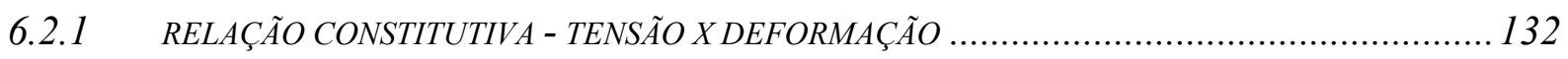

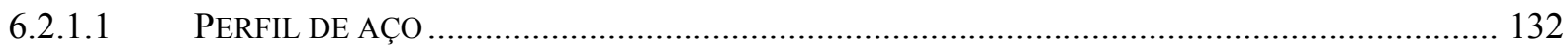

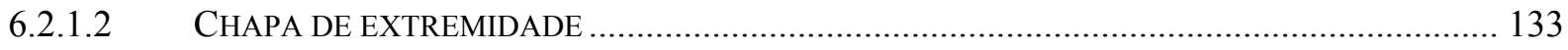

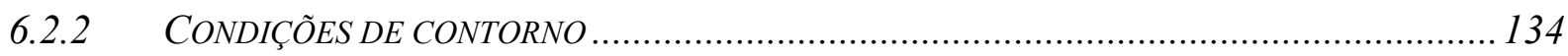

6.2.2.1 CONDIÇÃO DE CONTORNO DIRETAMENTE SOBRE O PERFIL ……....................................... 134

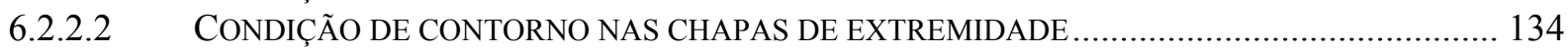

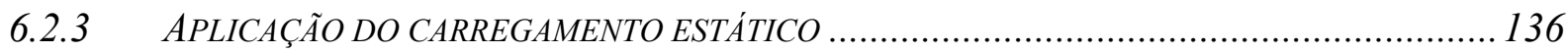

6.3 COMPARAÇÃO ENTRE ENSAIO EXPERIMENTAL E ANÁLISE NUMÉRICA ......................... 137

6.4 DIMENSIONAMENTO EM TEMPERATURA AMBIENTE - PROCEDIMENTOS DOS PRINCIPAIS

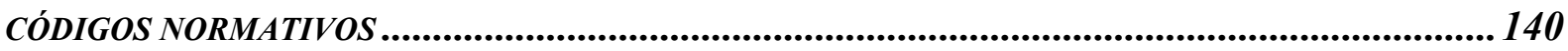

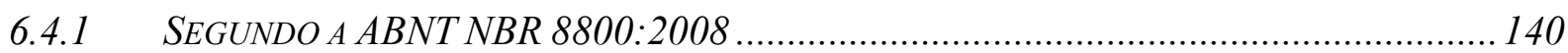

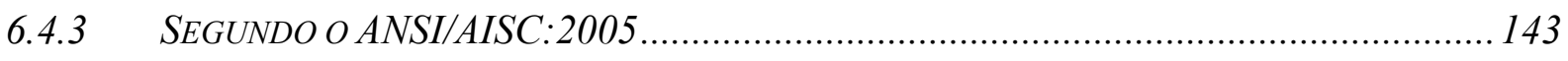

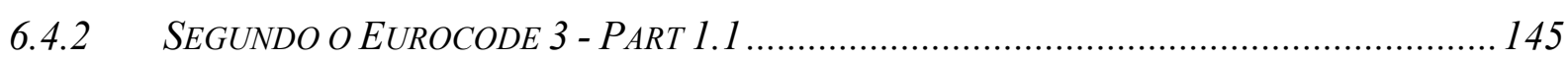

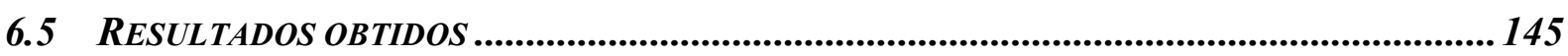

7 RESPOSTA NUMÉRICA DOS PILARES COM BASE EM ANALISE

TERMOESTRUTURAL .................................................................................................. 151

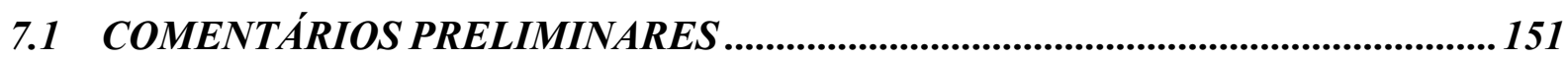

7.2 INFLUÊNCIA DO SENTIDO DA IMPERFEIÇÃO GEOMÉTRICA INICIAL NA RESPOSTA

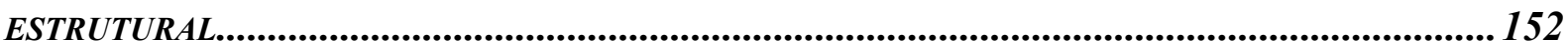

7.3 PILAR ISOLADO-CARGA TÉRMICA POR TODOS OS LADOS.............................................. 154

7.3.1 RESULTADOS NUMÉRICOS - COM ELEMENTO FINITO SOLID45 …............................... 154

7.3.2 RESULTADOS EXPERIMENTAIS - WANG E DAVIES (2003) ............................. 158

7.3.3 RESULTADOS NUMÉRICOS - COM ELEMENTO FINITO SHELL 181 ................................. 162

7.4 PILAR DE BORDA - PAREDES NA ALMA E EM UMA DAS MESAS ..................................... 164

7.4.1 RESULTADOS NUMÉRICOS - COM ELEMENTO FINITO SOLID45 …................................... 165

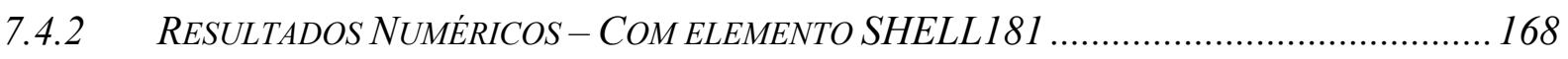

7.5 PILAR DE CANTO - PAREDES NA ALMA E EM UMA DAS MESAS.................................... 171

7.6 PILAR EXTERNO - PAREDES APENAS NA ALMA ...................................................... 179

7.7 PILAR DE BORDA OU INTERNO - COM PAREDES APENAS NA MESA ................................ 183

7.8 ESTUDO DE CASO - INSTITUTO FÁBRICA DO MILÊNIO............................................ 191 


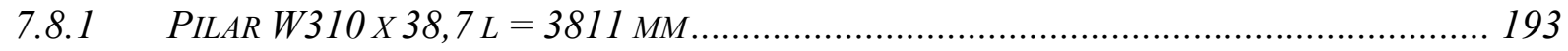

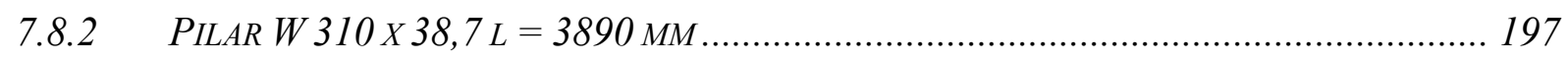

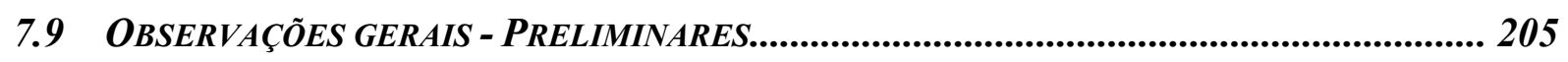

8 CONSIDERAÇÕES E CONCLUSÕES.................................................207

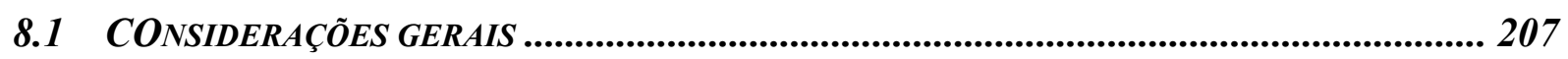

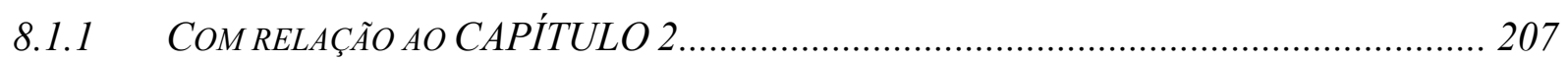

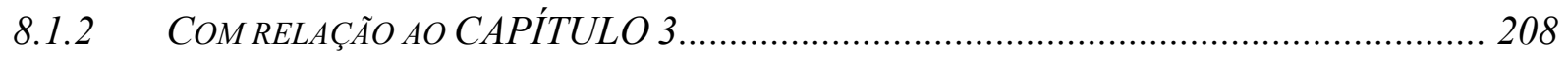

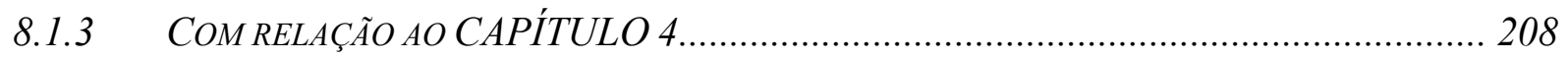

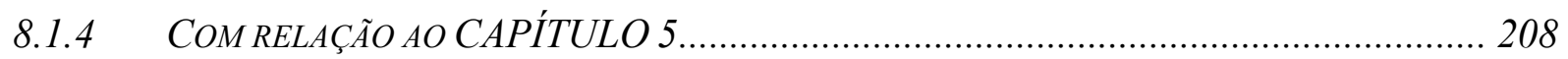

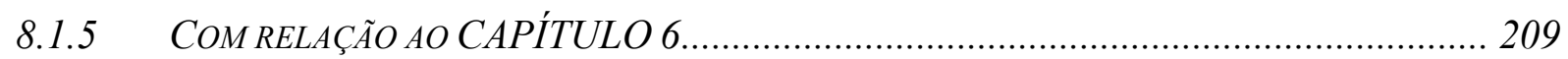

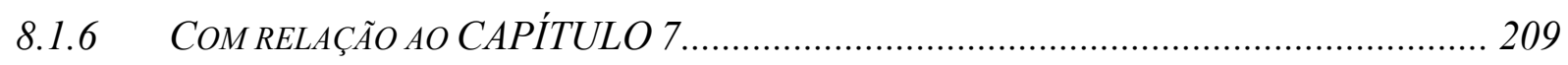

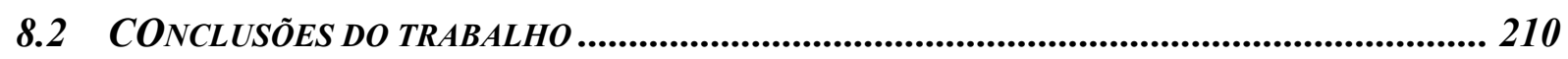

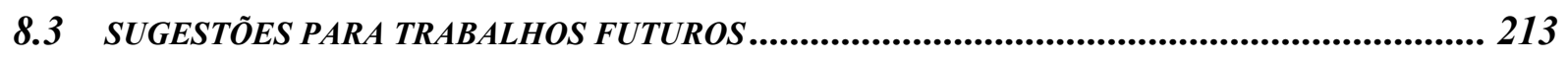

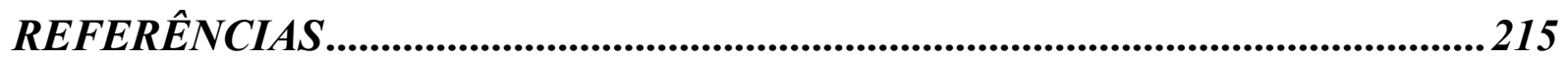

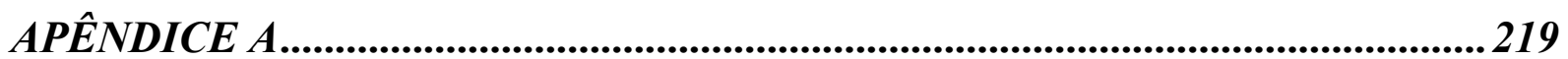




\section{LISTA DE SÍMBOLOS E SIGLAS}

ABNT NBR14323:1999 Dimensionamento de estruturas de aço de edifícios em situação de incêndio - Procedimento;

$\mathrm{A}_{\mathrm{ef}} \quad$ área efetiva da seção transversal;

$\mathrm{A}_{\mathrm{g}} \quad$ área bruta da seção transversal;

$\mathrm{A}_{\mathrm{t}} \quad \mathrm{a}$ área total do compartimento (paredes, teto e piso, incluído as aberturas) $\left[\mathrm{m}^{2}\right]$;

$\mathrm{A}_{\mathrm{v}} \quad$ área total das aberturas verticais nas paredes $\left[\mathrm{m}^{2}\right]$;

b a absortividade térmica do material de vedação do compartimento, válido dentro do intervalo $100 \leq \mathrm{b} \leq 2200\left[\mathrm{~J} / \mathrm{m}^{2} \mathrm{~s}^{1 / 2} \mathrm{~K}\right]$;

$\mathrm{b}_{\mathrm{f}} \quad$ largura da mesa do perfil I;

$b_{\text {ef }} \quad$ largura efetiva do elemento AA comprimido;

c calor específico do material de vedação do compartimento [J/kgK];

d altura total da seção transversal;

E módulo de elasticidade;

$\mathrm{E}_{\mathrm{a}, \theta} \quad$ módulo de elasticidade na fase elástica;

EC3 1.2 Eurocode 3 part 1.2;

$\mathrm{E}_{\mathrm{b}} \quad$ quantidade de radiação térmica;

$\mathrm{F}_{\mathrm{cr}} \quad$ tensão de flambagem;

$\mathrm{f}_{\mathrm{p}, \theta} \quad$ limite de proporcionalidade;

$\mathrm{f}_{\mathrm{y}, \theta} \quad$ tensão efetiva de escoamento;

h altura da alma do perfil I;

$\mathrm{h}_{\mathrm{eq}}$ média ponderada das alturas das aberturas em relação à área total das aberturas $[\mathrm{m}]$;

$\mathrm{I}_{\mathrm{n}} \quad$ radiação térmica na direção normal à superfície emissora;

$\mathrm{I}_{\mathrm{x}} \quad$ momento de inércia à flexão segundo o eixo $\mathrm{x}$;

I $\quad$ momento de inércia à flexão segundo o eixo $\mathrm{y}$;

$\mathrm{I}_{\theta} \quad$ intensidade da radiação térmica a um ângulo $\theta$ da direção normal da superfície emissora;

KL comprimento de flambagem por flexão;

$\mathrm{k}_{\mathrm{sh}} \quad$ fator de correção devido ao efeito de sombra;

$\mathrm{k}_{\mathrm{y}, \theta, \text { com }}$ fator de redução para a resistência ao escoamento com máxima temperatura na mesa comprimida $\theta_{\text {,acom }}$ atingida no tempo t;

$\mathrm{k}_{\mathrm{E}, \theta} \quad$ fator de redução do módulo de elasticidade linear do aço à uma temperatura $\theta_{\mathrm{a}}$; 
$\mathrm{k}_{\mathrm{y}, \theta} \quad$ fator de redução relacionado à resistência ao escoamento do aço à uma temperatura $\theta_{\mathrm{a}}$;

$\mathrm{K}_{\mathrm{c}, \theta}$ fator de redução, relativo ao valor de $20^{\circ} \mathrm{C}$, da resistência característica a compressão do concreto de densidade normal;

L comprimento do perfil;

$\mathrm{M}_{\mathrm{b}, \mathrm{fi}, \mathrm{t}, \mathrm{Rd}} \quad$ momento resistente de cálculo para barras submetidas a flambagem lateral com torção;

$\mathrm{M}_{\mathrm{fi}, \theta, \mathrm{Rd}} \quad$ momento fletor resistente da seção transversal quando submetida a uma temperatura uniforme $\theta_{a}$;

$\mathrm{M}_{\mathrm{Rd}}$ momento fletor resistente de cálculo em temperatura ambiente;

$\mathrm{N}_{\mathrm{b}, \mathrm{fi}, \mathrm{t}, \mathrm{Rd}} \quad$ força de compressão resistente de cálculo;

$\mathrm{N}_{\mathrm{c}, \mathrm{Rd}} ; \mathrm{N}_{\mathrm{b}, \mathrm{Rd}} \quad$ força resistente de cálculo de pilares de ao axialmente comprimidos;

$\mathrm{N}_{\mathrm{e}} \quad$ força de compressão de flambagem elástica;

$\mathrm{O}$ fator de abertura ou grau de ventilação, que varia dentro dos limites $0,02 \leq \mathrm{O} \leq 0,20$ $\left[\mathrm{m}^{1 / 2}\right]$

$\mathrm{P}_{\mathrm{n}} \quad$ resistência a compressão nominal, segundo o ANSI/AISC:2005;

$\mathrm{q}_{\mathrm{t}, \mathrm{d}} \quad$ valor de cálculo da carga de incêndio referido a área total da superfície $\mathrm{A}_{\mathrm{t}}$ do compartimento, $\left[\mathrm{MJ} / \mathrm{m}^{2}\right]$;

$\mathrm{Q}_{\mathrm{s}} \quad$ parcela do fator de redução referente ao elemento com borda livre (denominado $A L$ );

$\mathrm{Q}_{\mathrm{a}} \quad$ parcela referente ao elemento com bordas enrijecidas (elementos AA);

Q fator de redução associado à flambagem local;

$\mathrm{R}_{\mathrm{i}, \mathrm{i}+1}$ resistência térmica do material componente do compósito;

$\mathrm{r}_{\mathrm{x}} \quad$ raios de giração segundo o eixo $\mathrm{x}$;

$\mathrm{r}_{\mathrm{y}}$ raios de giração segundo o eixo y;

STC SuperTempcalc;

t tempo, em minutos;

$\mathrm{t}^{*} \quad$ tempo fictício $[\mathrm{h}]$;

TCD Temperature calculation and design;

$t_{h}$ tempo $[\mathrm{h}] ; \mathrm{t}_{\text {lim }}$ tempo em que ocorre a máxima temperatura do gás no caso de um incêndio com carga de incêndio controlada;

$t_{\max }$ tempo em que ocorre a temperatura máxima do gás num modelo de incêndio natural $[\mathrm{h}]$;

$t_{\max }$ tempo em que ocorre a temperatura máxima do gás num modelo de incêndio natural $[\mathrm{h}]$; 
$\mathrm{t}_{\text {lim }} \quad$ tempo em que ocorre a máxima temperatura do gás no caso de um incêndio com carga de incêndio controlada;

$\mathrm{t}_{\mathrm{w}} \quad$ espessuras da alma;

$t_{\mathrm{f}} \quad$ espessuras da mesa;

u/A fator de massividade de elementos prismáticos sem revestimento de proteção contra incêndio, em $\mathrm{m}^{-1}$;

$\mathrm{W}_{\mathrm{el}, \mathrm{x}}$ módulo elástico de resistência à flexão segundo o eixo $\mathrm{x}$;

$\mathrm{W}_{\mathrm{el}, \mathrm{y}}$ módulo elástico de resistência à flexão segundo o eixo y;

$\mathrm{Z}_{\mathrm{x}}$ módulo plástico de resistência à flexão segundo o eixo $\mathrm{x}$, para seções duplamente simétricas;

$\mathrm{Z}_{\mathrm{y}}$ módulo plástico de resistência à flexão segundo o eixo y para seções duplamente simétricas;

z distância do eixo neutro plástico ao centróide do elemento de área $\mathrm{A}$;

$\alpha \quad$ difusidade térmica; absortividade;

$\alpha_{c} \quad$ coeficiente de transferência de calor por convecção em $\left[\mathrm{W} / \mathrm{m}^{2} \mathrm{~K}\right]$;

$\gamma \quad$ condutividade térmica do material de vedação do compartimento [W/mK];

$\gamma_{\mathrm{a} 1}$ coeficiente de ponderação da resistência ao escoamento, flambagem e instabilidade no estado limite último;

$\gamma_{\mathrm{c}} \quad$ peso especifico do concreto, em $\mathrm{kN} / \mathrm{m}^{3}$;

$\gamma_{\mathrm{M}, 0} \quad$ coeficiente de ponderação aplicado à resistência do aço em temperatura ambiente;

$\gamma_{\mathrm{M}, \mathrm{fi}}$ coeficiente de ponderação aplicado à resistência do aço em situação de incêndio;

$\Delta \mathrm{t} \quad$ intervalo de tempo;

$\varepsilon \quad$ emissividade; deformação;

$\varepsilon_{\mathrm{p}, \theta} \quad$ limite de proporcionalidade na deformação;

$\varepsilon_{\mathrm{y}, \theta}$ deformação de escoamento;

$\varepsilon_{t, \theta} \quad$ limite de deformação para a resistência ao escoamento;

$\varepsilon_{\mathrm{u}, \theta} \quad$ deformação de ruptura;

$\varphi \quad$ fluxo de calor;

$\kappa_{1}$ fator de adaptação para a temperatura não uniforme na seção transversal;

$\kappa_{2}$ fator de adaptação para a temperatura não uniforme ao longo do perfil;

$\bar{\lambda}_{\theta} \quad$ índice de esbeltez reduzido;

$\Gamma \quad$ fator de correção do tempo, fornecido em função do fator de abertura e da absorção térmica para todo compartimento;

$\lambda_{0} \quad$ índice de esbeltez reduzido 
$\bar{\lambda}_{\theta} \quad$ índice de esbeltez reduzido;

$\rho \quad$ massa específica do material de vedação do compartimento $\left[\mathrm{kg} / \mathrm{m}^{3}\right]$; refletividade;

$\sigma \quad$ constante de Stefan-Boltzmann, igual a 5,67 x $10^{-8} \mathrm{~W} /\left(\mathrm{m}^{2} \mathrm{~K}^{4}\right)$;

$\tau \quad$ transmitância;

$\theta_{\mathrm{g}} \quad$ temperatura dos gases quentes em ${ }^{\circ} \mathrm{C}$

$\theta_{0} \quad$ temperatura dos gases no instante $\mathrm{t}_{0}$ (temperatura ambiente), em ${ }^{\circ} \mathrm{C}$;

$\chi \quad$ fator de redução associado à resistência a compressão;

$\chi_{\mathrm{fi}}$ fator de redução da resistência de barras axialmente comprimidas em situação de incêndio;

$\chi_{\mathrm{LT}, \mathrm{fi}}$ fator de redução para a flambagem lateral com torção em situação de incêndio; 


\section{INTRODUÇÃO}

\subsection{COMENTÁRIOS GERAIS}

O incêndio é um dos fenômenos mais temidos pela humanidade e, se não controlado em tempo hábil, pode trazer conseqüências graves quanto ao risco à vida ou no referente ao aspecto patrimonial.

Segundo Wang (2002), as medidas de combate ao incêndio evoluíram ao longo dos anos em resposta aos desastres ocorridos. No entanto, os procedimentos consagrados em regulamentos e códigos normativos atualmente voltados à engenharia de segurança contra incêndio ainda fazem uma abordagem denominada "prescritiva" para fins de propostas de métodos de dimensionamento, que podem conduzir a projetos anti-econômicos, razão pela qual vêm sendo continuamente questionados.

Por outro lado, uma nova forma de compreensão do problema físico envolvendo a ação térmica na análise estrutural tem permitido a substituição da abordagem prescritiva por uma abordagem baseada no desempenho da estrutura, o qual proporciona um projeto mais seguro e econômico. A diferença essencial entre a abordagem prescritiva e aquela baseada no desempenho estrutural é descrita neste texto de forma simplificada.

$\mathrm{Na}$ abordagem prescritiva, a temperatura é limitada a um valor crítico pré-definido, quando exposto a uma situação de incêndio padronizado por norma. Acima dessa temperatura, considera-se que a estrutura não oferecerá mais segurança enquanto capacidade portante. Todavia, essa abordagem não considera circunstâncias específicas, tais como: intensidade do incêndio a que a estrutura está exposta, características do material combustivel, importância de diferentes elementos estruturais e a interação entre eles.

Na abordagem baseada no desempenho, todas as circunstâncias específicas citadas são relevantes. Logo, o campo de temperatura passa a ser uma das variáveis do projeto. Assim sendo, o modelo se torna mais representativo para uma situação real de incêndio, incluindo análises que consideram não somente as curvas de incêndio padronizadas, mas também de incêndio natural baseado em estudos experimentais já realizados e em andamento

Um fato importante a ser comentado diz respeito ao processo de fabricação dos perfís, seja por laminação, soldagem de chapas (no caso das vigas e pilares soldados) ou 
conformação dos formados a frio (por meio de perfiladeiras ou dobradeiras). Em todos os processos surgem tensões residuais nas regiões de dobras, de intersecções entre os elementos componentes da seção transversal e na extremidade de elementos pertencentes à seção transversal de perfis soldados (devido o processo de corte). A elevação da temperatura faz com que essas tensões residuais se alterem, porém, a uma proporção ainda desconhecidas em relação às outras propriedades mecânicas.

Com relação às barras de aço comprimidas, objeto de interesse do presente trabalho, na maioria das referências consultadas (livros, artigos, trabalhos técnicos, etc.) voltados para as estruturas metálicas em situação de incêndio, a influência de parâmetros como rigidez rotacional e axial e índice de esbeltez são analisadas no dimensionamento de barras isoladas expostas a uma relação "temperatura dos gases $x$ tempo de incêndio", incêndio esse padronizado por normas técnicas. Dessa forma, as pesquisas mais recentes voltadas para a ação térmica de um incêndio natural (definido no Capítulo 3) em sistemas estruturais não são abordadas com o devido aprofundamento.

Ainda com relação às hipóteses consideradas em projetos para as condições de vinculação da barra, sejam consideradas rótulas, engastes perfeitos ou situações intermediárias às duas últimas, a rigidez em cada extremidade, por hipótese (simplificação), se mantém constante durante toda fase de aquecimento. Como simplificação, considera-se campo térmico simétrico e uniforme em toda seção transversal e ao longo do comprimento.

Com relação ao contexto estrutural, sabe-se que o pilar, enquanto elemento estrutural interage com outros componentes do sistema ao qual pertence, tais como vigas e lajes, e seu comportamento real não será o mesmo de um elemento isolado, sujeito às condições supracitadas.

Por fim, cabe comentar que o próprio processo construtivo faz com que a força de compressão atuante no pilar seja excêntrica. Essa excentricidade de carga, juntamente com as imperfeições geométricas iniciais contribui com o efeito da não linearidade geométrica, porém, ainda não são suficientemente explorados por pesquisas na área de incêndio.

Nota-se, portanto, que são muitas as considerações que podem (ou mesmo devem) ser feitas quando da adoção de uma estratégia, tanto numérica como experimental com vistas à análise de pilares de aço (e outros materiais, a citar, o concreto, madeira ou mesmo os materiais de proteção) em situação de incêndio, se considerado o contexto do sistema estrutural ao qual o elemento pertence. 
No que segue, se faz uma apresentação dos objetivos do trabalho, a justificativa para a escolha do tema em questão, a metodologia a ser empregada, bem como uma breve descrição do conteúdo de cada capítulo que irá compor o trabalho final.

\subsection{OBJETIVOS DO TRABALHO}

O presente trabalho tem como proposta estudar, em caráter puramente numérico o comportamento de pilares de aço constituídos de perfis pesados (laminados ou soldados) em situação de incêndio, dando ênfase à consideração das condições de compartimentação do ambiente em chamas.

O estudo do campo de temperatura em função do tempo, ou seja, a análise transiente do gradiente térmico foi abordada inicialmente em campo bidimensional dentro do contexto da seção transversal do elemento de interesse. As informações referentes ao campo térmico, uma vez validado, foram levadas para os modelos tridimensionais com vistas à análise acoplada, considerando carga térmica integral (em todo o contorno da seção) e também parcial (em parte do contorno da seção) associadas ao carregamento estático.

A análise estrutural foi realizada sobre o perfil submetido aos efeitos de imperfeições geométricas do tipo global. Por se tratar essencialmente de perfis soldados ou laminados, não foi abordado o modo distorcional, cuja evidência é mais comum em perfis formados a frio. Com a análise acoplada termoestrutural, foi avaliada a força resistente de compressão em correspondência a um determinado tempo crítico, lembrando novamente que os pilares foram submetidos a diversas condições de assimetria de campo térmico em decorrência do contato com a alvenaria de revestimento. Acredita-se que os resultados das análises numéricas serão de importante contribuição para avaliar os procedimentos normativos atuais e para futuras revisões das normas técnicas.

\subsection{JUSTIFICATIVA}

Quando submetidos a elevadas temperaturas (ação térmica), os materiais que constituem os elementos estruturais têm suas propriedades mecânicas penalizadas (reduzidas), fato que, na maioria das vezes, conduz a um colapso prematuro de um dado elemento estrutural de interesse (ou mesmo da estrutura), o que pode não garantir a desocupação total 
da edificação com o mínimo de segurança. A influência da temperatura na resistência e rigidez do aço e do concreto é ilustrada na Figura 1.1.
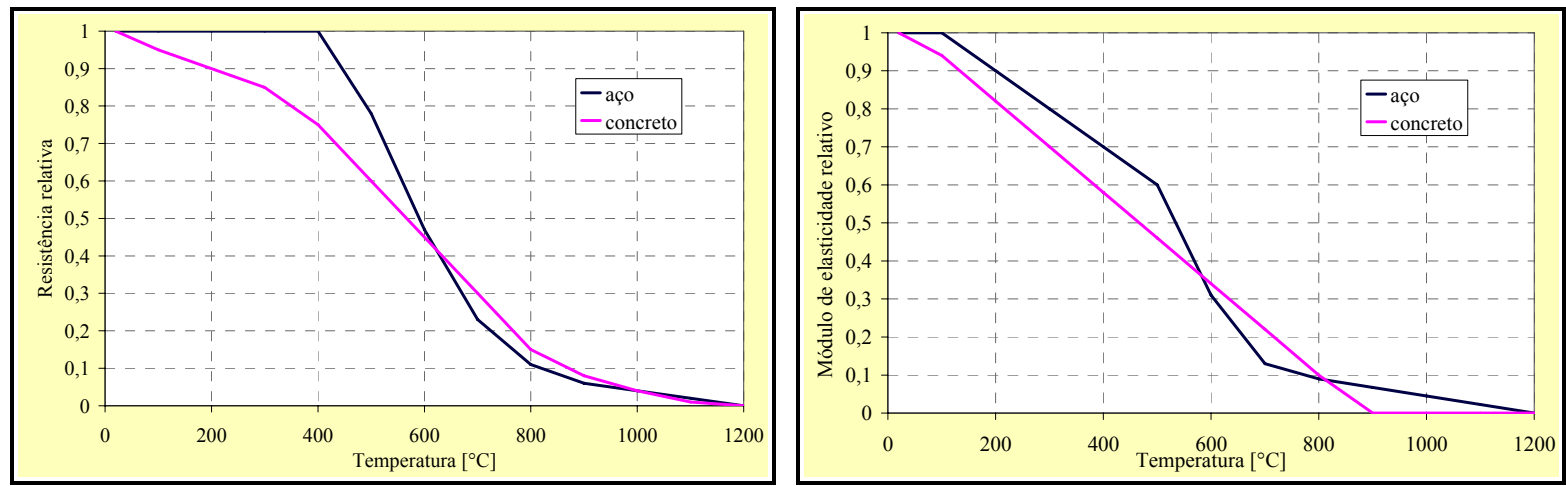

Figura 1.1: Reduções da resistência ao escoamento e do módulo de elasticidade, respectivamente, do aço e do concreto, em função da temperatura. Fonte: ABNT NBR 14323:1999

A ABNT NBR 14323:1999, intitulada Dimensionamento de estruturas de aço de edifícios em situação de incêndio - Procedimento, norma brasileira que trata do dimensionamento de estruturas de aço e mistas em situação de incêndio, recomenda que o dimensionamento de uma estrutura em situação de incêndio deve ser realizado por meio de resultados de ensaios (análise experimental) ou por meios de métodos analíticos de cálculo. Nesse último caso, podem ser usados o método avançado ou o método simplificado de dimensionamento.

No método simplificado de cálculo, a análise transiente do campo térmico na seção transversal e ao longo do comprimento do perfil está diretamente relacionada ao parâmetro denominado fator de massividade (F). Para barras prismáticas, o fator de massividade é dado pela relação entre o perímetro exposto ao fogo $(\mathrm{u})$ e a área total da seção transversal $\left(\mathrm{A}_{\mathrm{g}}\right)$. Esse método se aplica unicamente a perfis isolados, submetidos às situações em que a distribuição da temperatura é uniforme e simétrica, tanto na seção transversal como no eixo longitudinal do perfil.

Sendo assim, o método simplificado de calculo é aplicável a um número limitado de casos. Nas situações em que não haja simetria ou uniformidade na propagação do calor pelo elemento estrutural, esse método analítico de resolução pode conduzir a resultados que não estejam em concordância com aqueles que de fato venham a ocorrer na prática.

Por outro lado, o método avançado de dimensionamento, conforme proposta do presente trabalho proporciona uma análise mais realística dos elementos estruturais e do cenário dessa submetida a elevadas temperaturas, por conduzirem a uma situação de análise 
mais próxima (portanto mais confiável) daquela observada para os componentes estruturais em situação de incêndio quando inseridos no contexto do comportamento estrutural global.

A modelagem numérica consiste, portanto, de ferramenta de interesse para análises mais precisas de pilares de aço em situação de incêndio, devendo-se essa estar, sempre que possível, associada a resultados de análises experimentais.

\subsection{METODOLOGIA}

No presente trabalho, foram realizadas simulações numéricas por meio do código computacional ANSYS ${ }^{\circledR}$ V9.0 que disponibiliza ao pesquisador as ferramentas necessárias para as análises térmicas e estruturais. O programa permite considerar os três modos primários de transferência de calor: condução, convecção e radiação. A análise de interesse é do tipo térmico transiente, ou seja, que permite determinar a variação em função do tempo da distribuição da temperatura.

Destaca-se ainda que o presente trabalho representa uma continuidade daquele iniciado em REGOBELLO (2007), no qual foi utilizado o código computacional ANSYS ${ }^{\circledR}$ V9.0, elaborado com base no método dos elementos finitos, para a construção dos modelos matemáticos. A referência citada enfatizou o efeito da elevação térmica em seções transversais de perfis metálicos e mistos de aço e concreto, envolvidos ou não por material de proteção térmica, considerando várias condições de assimetria e o seu efeito na resposta estrutural de vigas sob aquecimento uniforme no sentido longitudinal.

Para a análise acoplada termoestrutural, foram elaborados modelos bidimensionais para fins de obtenção e validação do campo térmico na seção transversal. Posteriormente, foram elaborados modelos tridimensionais para os quais foram transferidos os campos térmicos com distribuição não-uniforme de temperatura. Em seguida, neste mesmo perfil é aplicado um carregamento estático juntamente com a consideração de imperfeição geométrica global, obtida por meio de análise de autovalor (a ser detalhada nos próximos capítulos), com vistas a determinar os esforços resistentes de pilares de aço em ambientes compartimentados.

Os resultados obtidos por meio das simulações numéricas foram comparados a outros trabalhos já publicados, tanto numéricos como no campo experimental, envolvendo apenas pilares de aço isolados submetidos ao incêndio com ênfase na compartimentação do edifício. Os resultados das análises numéricas serão de importante contribuição para avaliar os procedimentos normativos atuais e para futuras revisões das normas técnicas. Vale mencionar 
que as simulações numéricas realizadas ao longo do presente trabalho foram realizadas com base em algumas hipóteses simplificadoras:

- a força de compressão é aplicada de forma centrada;

- as tensões residuais na região de intersecção e extremidade dos elementos da seção transversal (almas e mesas) não são consideradas. A não-uniformidade das tensões nessas regiões é decorrente do processo de fabricação do perfil, por meio de laminação ou soldagem de chapas;

- o índice de esbeltez, para todos os perfis, foi adotado como um valor dentro do intervalo entre 60 e 100, como é comumente encontrado em edificios;

- inicialmente, não serão consideradas restrições axiais e rotacionais nas análises;

\subsection{ORGANIZAÇÃO DO TRABALHO}

No Capítulo 1 se faz a apresentação do trabalho proposto, incluindo objetivos, justificativa e metodologia. O Capítulo 2 apresenta um breve histórico de acidentes envolvendo incêndio na humanidade. Em seguida, são comentados alguns dos importantes trabalhos realizados no campo experimental e, principalmente no campo numérico. Serão citadas as normas em vigor no Brasil e outros países.

O Capitulo 3 aborda os principais conceitos sobre o incêndio (gases aquecidos), os princípios de transferência de calor (dos gases para os elementos), bem como a influência da elevação de temperatura nas propriedades mecânicas do aço. O Capítulo 4 apresenta a proposta de estratégia numérica utilizadas na elaboração dos modelos. São citados os elementos finitos utilizados, todas as hipóteses consideradas e as etapas de construção.

No Capítulo 5 se faz a obtenção do campo bidimensional e tridimensional de temperatura para diversas seções transversais e configurações de não-simetria provocada pela presença de paredes de alvenaria, via ANSYS, cujos resultados são comparados a valores, obtidos por meio do código SuperTempCalc, gentilmente cedidos pelo professor Valdir Pignatta e Silva da Escola Politécnica da USP. Também, são expostos os resultados das estratégias numéricas para a determinação do campo térmico no campo tridimensional.

O Capítulo 6 aborda os resultados encontrados na análise estrutural de autovalor (para imposição do modo imperfeito da barra) e estática (para determinação da força última de ruptura), em contexto de temperatura ambiente, em que se faz a comparação entre dois tipos de elemento finito utilizados. O Capítulo 7 mostra resultados obtidos da análise acoplada 
termoestrutural referente ao desempenho estrutural de perfis de aço, bem como um estudo de caso de pilares inseridos no Edifício Fábrica do Milênio, pertencente ao Departamento de Engenharia de Produção da Escola de Engenharia de São Carlos.

O Capítulo 8 traz algumas conclusões que podem ser feitas a respeito do trabalho apresentado, além de sugestões de outros projetos de pesquisa que possam dar continuidade a mesma linha de pesquisa. 


\section{BREVE ABORDAGEM DA AÇÃO TÉRMICA NAS ESTRUTURAS METÁLICAS}

\subsection{COMENTÁRIOS PRELIMINARES}

Os acidentes envolvendo incêndio foram documentados desde a era cristã, como, por exemplo, aquele que ficou conhecido como o Grande Incêndio de Roma, um grande desastre ocorrido no ano de 64 d.C., no núcleo comercial da antiga cidade de Roma.

Os edifícios daquela época, que já chegavam a cinco pavimentos, eram construídos basicamente de madeira, o que favoreceu a rápida propagação das chamas. A versão mais conhecida para as causas desse incêndio é a de que os habitantes dessas edificações usavam fogo para se aquecer e, num pequeno incidente, o fogo se alastrou e tomou proporções destruidoras. A segunda versão é a de que o imperador Nero ordenou o incêndio, pois pretendia construir uma cidade de Roma mais majestosa.

Já em período mais atual, pode ser citado o grande incêndio ocorrido na cidade de Londres, Inglaterra, datado de 1666, conforme ilustra a Figura 2.1, o qual foi considerado uma das maiores catástrofes da capital inglesa.

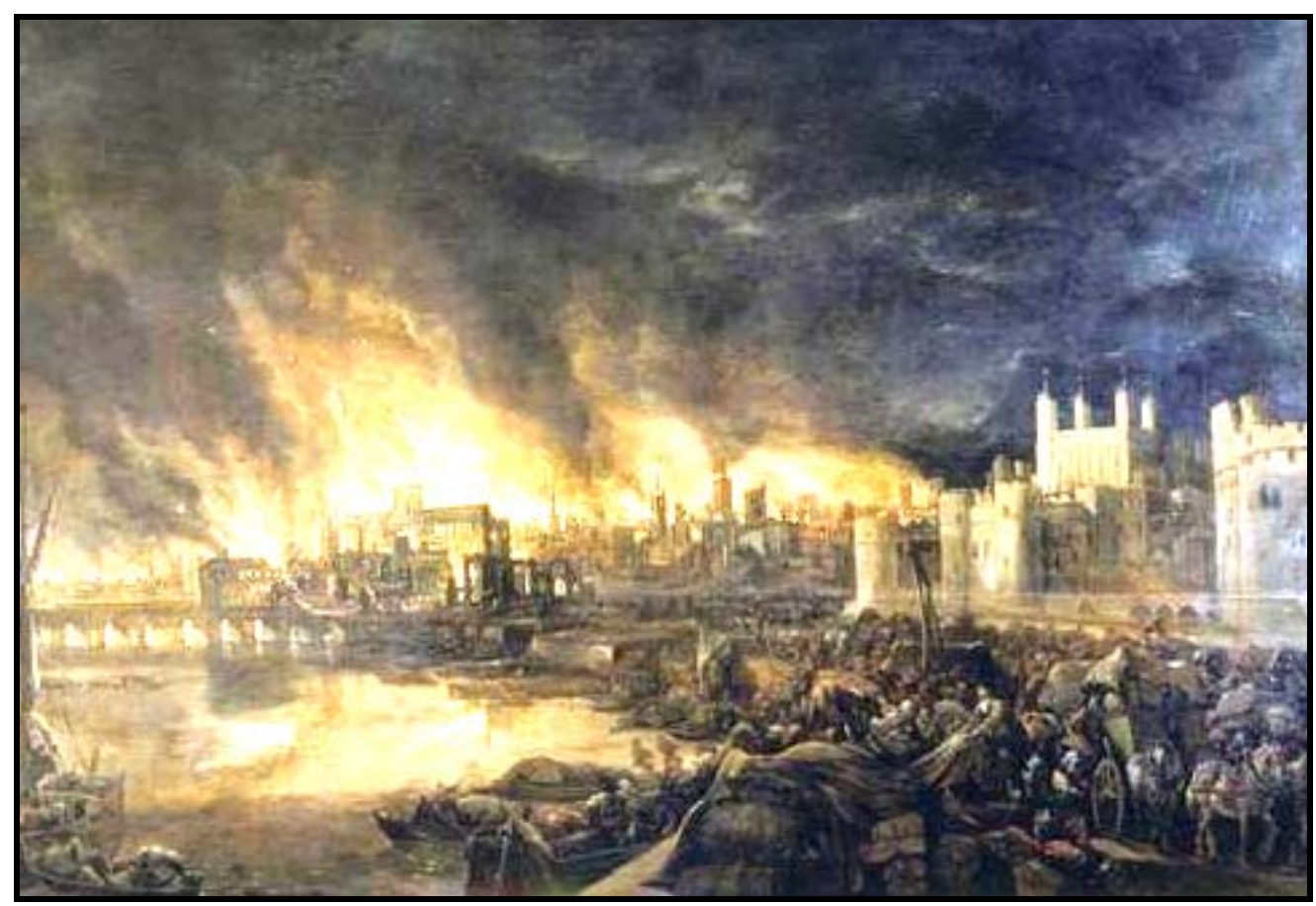

Figura 2.1: Detalhe de um quadro de 1666, retratando o grande incêndio. 
A região central da cidade, incluindo 13.200 casas, 87 igrejas, a Catedral de Saint Paul e a maior parte das construções das autoridades da cidade foram destruídas. Esse acontecimento foi o passo inicial para se impor as primeiras exigências de proteção contra incêndio.

No ano de 1755, a cidade de Lisboa foi abalada por um terremoto, que resultou na destruição quase que completa da cidade. O sismo foi seguido de um maremoto e de vários focos de incêndio, deixando quase dez mil vítimas fatais. No século XIX, a cidade de Chicago nos EUA tinha a maioria de seus edifícios, alguns com até seis pavimentos construídos, basicamente em madeira. De acordo com relatos da época, em um dos estabelecimentos um animal esbarrou numa lâmpada de querosene e logo o fogo deu inicio a um desastre. A Figura 2.2 retrata a cidade após o acidente.

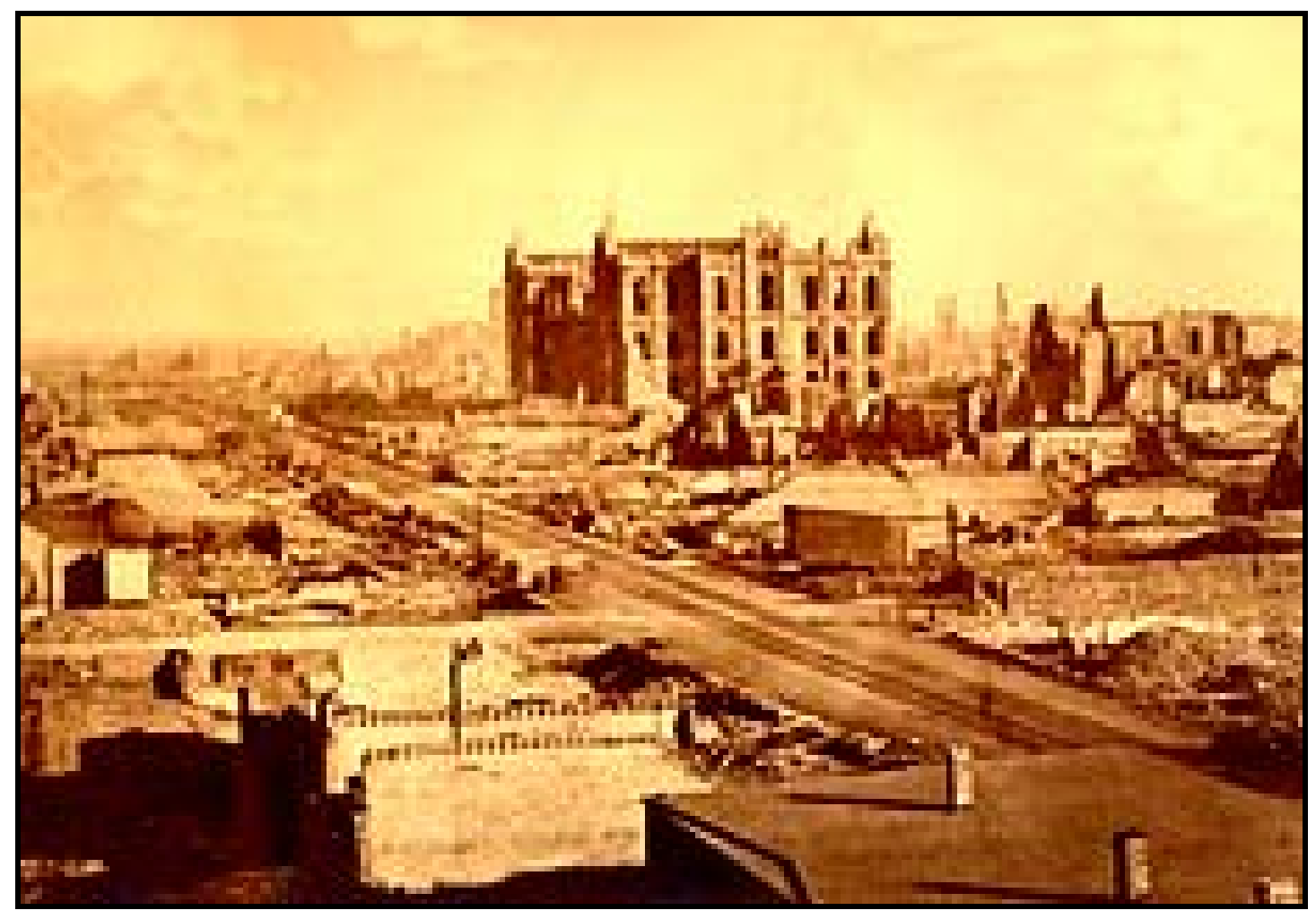

Figura 2.2: Retrato do incêndio em Chicago no século XIX.

No Brasil, os maiores desastres fazem parte de uma história bem mais recente. No ano de 1972, um grande incêndio ocorreu no Edifício Andraus, lugar que reunia escritórios empresariais no centro da cidade de São Paulo. A causa mais provável do acidente foi uma sobrecarga no sistema elétrico, porém, era sabido que o edifício não possuía sistemas de segurança - chuveiros automáticos, sinalização de saídas de emergência e alarme de detecção automática. 
Dois anos depois, outro grande incêndio destruiu quatorze dos vinte e cinco pavimentos, além de seis pavimentos de subsolo do Edifício Joelma, também localizado na cidade de São Paulo. Assim como no caso anteriormente citado, a causa desse incêndio foi uma sobrecarga elétrica.

Uma das características desse edifício era a escada em forma triangular e situadas no centro dos pavimentos, fato que dificultou a desocupação do mesmo. O telhado de placas de cimento amianto impossibilitou o pouso de helicópteros de resgate. Internamente, havia muitas divisões feitas de madeira e de cortinas que facilitavam o caminho do fogo. As imagens de ambos os acidentes estão ilustrados nas Figuras 2.3 (a) e (b).

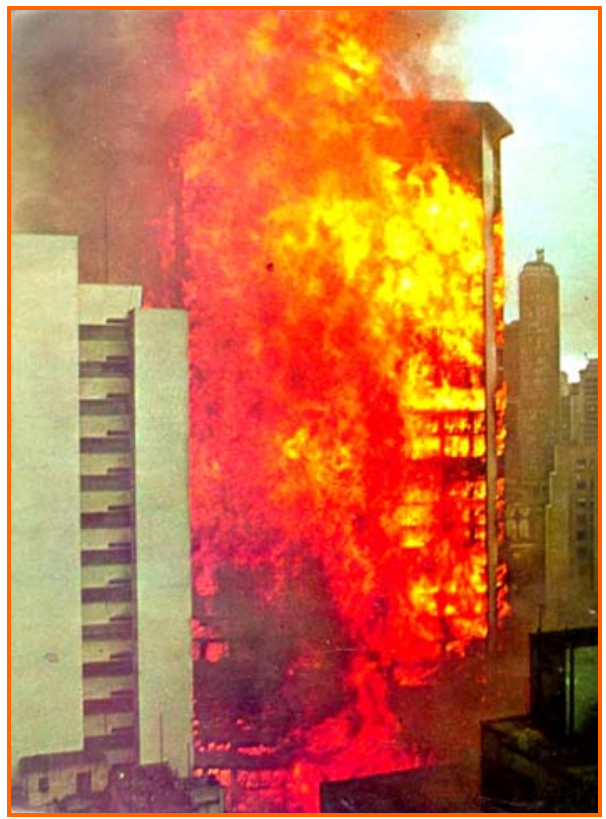

(a)

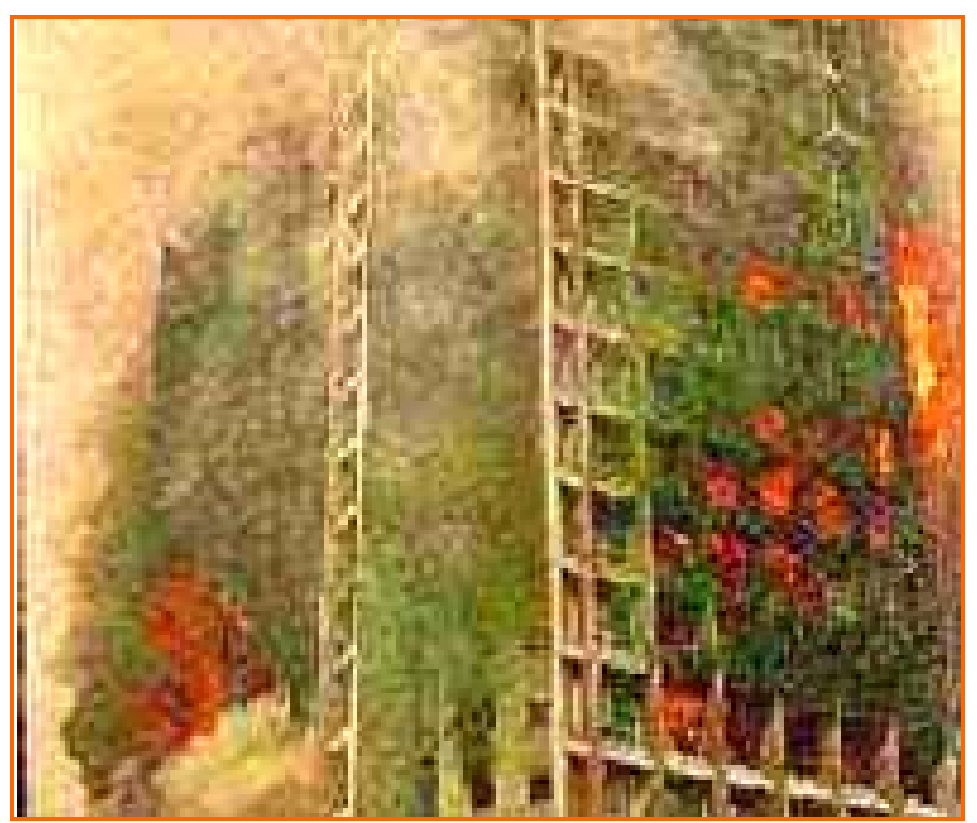

(b)

Figura 2.3: Fotos dos incêndios ocorridos nos edifícios: (a) Andraus e (b) Joelma.

Nesse mesmo ano o edifício da Caixa Econômica Federal, no Rio de Janeiro, teve perdas materiais significativas em decorrência do incêndio que destruiu dezenove dos trinta e um andares de escritórios, porém não houve vítimas fatais. Embora tenha havido chuveiros automáticos em parte dos andares, os forros e acabamentos eram combustíveis.

As fotos apresentadas nas Figuras 2.4 (a) a (f) e 2.5 (a) e (b), ilustram alguns casos de incêndio da história recente. Em caráter complementar, as Tabelas A.1 a A.6, inseridas no Anexo A apresentam alguns dos notáveis casos de edifícios e de outras estruturas que, de alguma forma, foram expostos à ação térmica. 

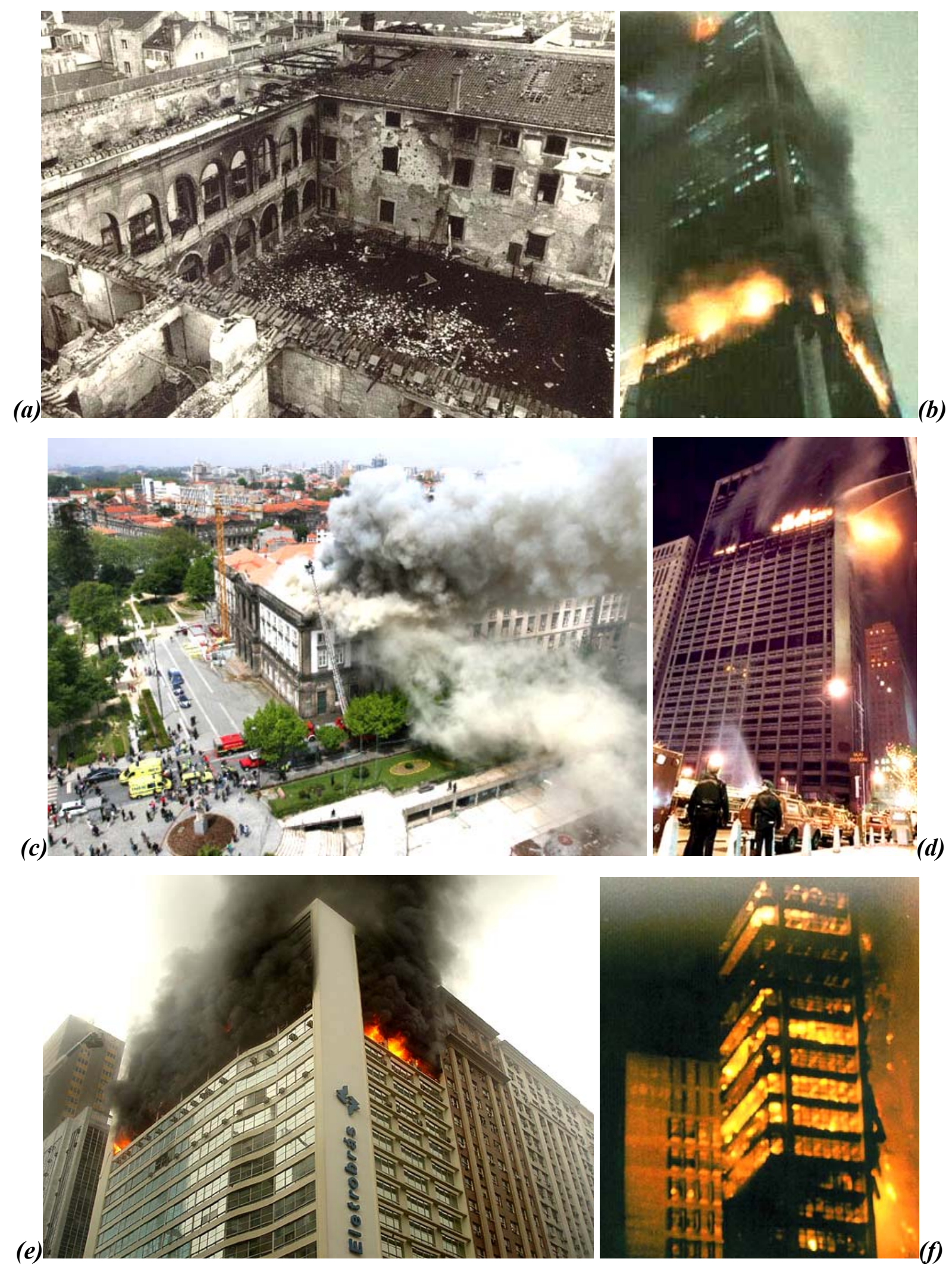

Figura 2.4: (a) Museu Colonial de Lisboa; (b) Edifício do First Interstate Bank (1988); (c)

Universidade do Porto em maio de 2008; (d) Meridian Plaza na Filadélfia, EUA, em 1991; (e)

Edifício da Eletrobrás, no RJ, em 2004; (f) Edifício da CESP, em São Paulo - 1987; 


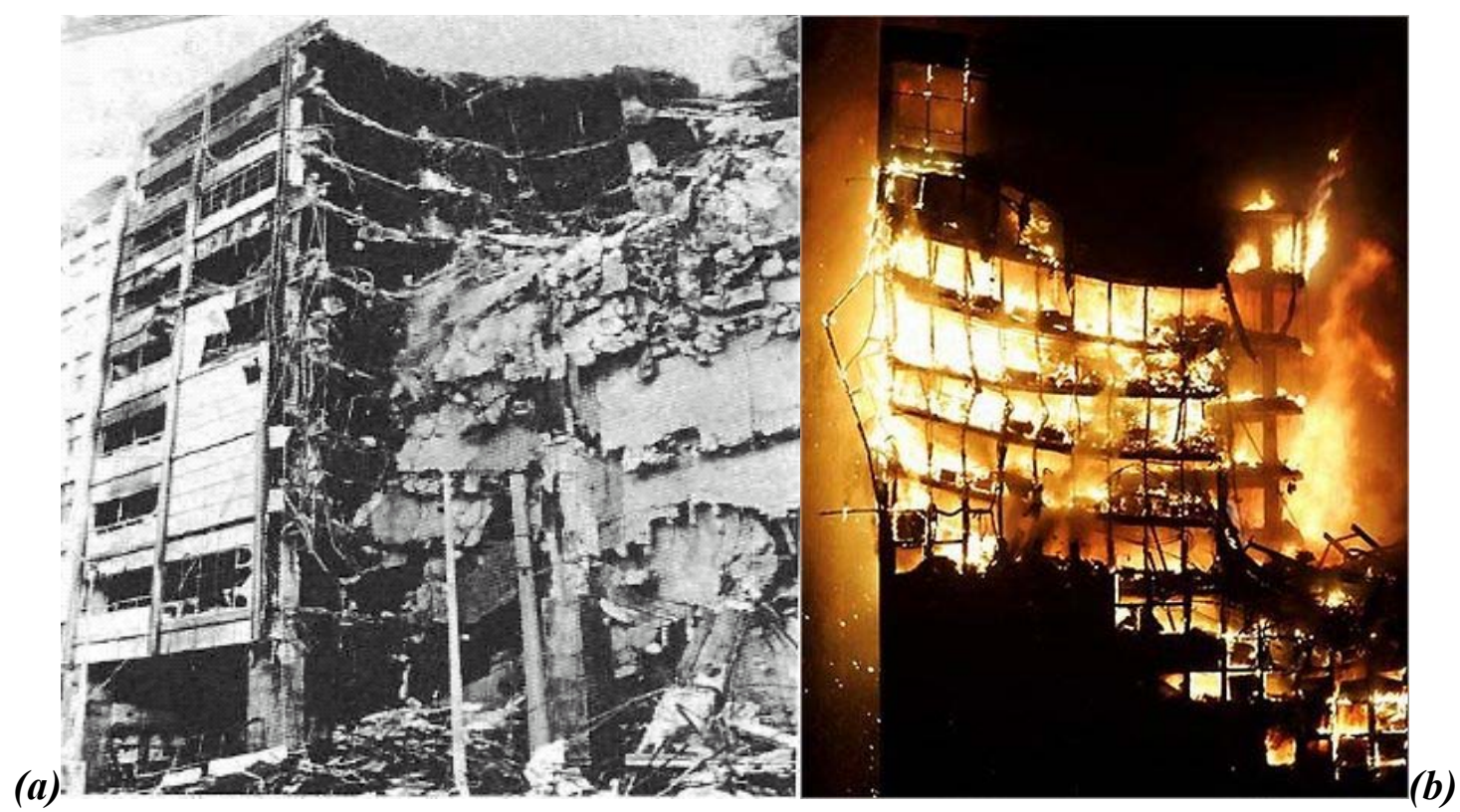

Figura 2.5 - (a) Edifício Katrantzos Sport, em Atenas, na Grécia - 1987; (b) Torre Windsor, Madrid, 2005. Fonte: http://www.lmc.ep.usp.br/people/valdir/?page_id=16

Diante desse contexto e de outros casos não citados neste item, em WANG (2002) é mencionado que intensas atividades e avanços vêm sendo desenvolvidos no campo das estruturas metálicas em situação de incêndio. Esse progresso, conforme apresentados nos itens seguintes, permite uma compreensão mais cuidadosa do assunto e acelera a aplicação dos resultados na engenharia, conforme descritos nos itens que se seguem, por meio das mais recentes pesquisas, realizadas nos campos experimental e teórico.

\subsection{PESQUISAS REALIZADAS - Contexto experimental}

No presente item, destacam-se, em caráter complementar, alguns dos principais trabalhos desenvolvidos em campo experimental. Cabe observar que a grande maioria dos trabalhos realizou ensaios de resistência de elementos isolados sob ação térmica por meio de fornos apropriados, com controle de temperatura determinado pela curva de incêndio padronizada por normas estrangeiras. Isso se deve ao fato de que a realização de testes utilizando estruturas em escala real submetidas à ação de incêndio real deve ser muito custosa e requer grande planejamento e área para a execução.

Nas últimas décadas, houve um crescente interesse, em muitos países, de simular uma situação de exposição ao fogo tomando como ponto de partida uma condição real ou natural de incêndio. 
Em WICKSTROÖM (1982) se desenvolveu um método que permite aproximar a temperatura do compartimento em chamas no período pós-flashover de uma curva de incêndio natural. Dessa forma, o tempo é modificado para levar em consideração fatores como a condição da ventilação e as propriedades das paredes. Vale aqui destacar que a adequada definição de incêndio natural e flashover, entre outros termos, serão devidamente apresentados no Capítulo 3 do presente trabalho.

Nas análises da última referência, foram assumidas como hipóteses: ocorrência da combustão sob ventilação constante e controlada, distribuição uniforme de temperatura e ruina das paredes proporcional a sua inércia térmica. Foi analisado o comportamento de pilares metálicos sob a ação térmica e desenvolvido um método (equação) analítico para obter de forma aproximada a resposta térmica do aço. Também foi exposto que a temperatura pósflashover de um incêndio natural é uma função apenas do tempo modificado por um fator $\gamma$, relacionado às características de abertura e propriedade das paredes do compartimento em chamas.

EM WANG (2000) são apresentados resultados de análises experimentais voltadas ao comportamento global da estrutura de um edifício, construído em escala real composto por oito pavimentos em estruturas metálicas, realizados no Building Research Establishment (BRE), em Cardington, na Inglaterra. Os testes tinham a finalidade de investigar o desempenho das estruturas (de madeira, de concreto e mista de aço e concreto) sob condições de um incêndio real, bem como fornecer informações experimentais qualitativas para a validação dos vários modelos numéricos publicados por outros autores em demais trabalhos futuros.

Com relação à edificação mista, a intensidade de incêndio foi controlada limitando a quantidade de material combustível. O concreto da laje foi considerado como um elemento contribuinte no isolamento do ambiente em chamas. Tanto no ensaio realizado numa das extremidades do edifício, como aquele realizado num compartimento mais amplo, os pilares (neste caso, metálicos) foram densamente protegidos para evitar instabilidade global na estrutura e limitar o dano causado pelo incêndio. Dessa forma, o campo térmico registrou valores relativamente baixos de temperatura nesses elementos, e os resultados não foram suficientes para quantificar o seu comportamento no estado limite de incêndio.

A expansão térmica da viga acarretou um aumento do momento fletor no pilar. Porém, em temperaturas mais altas, conforme o pilar fosse se deslocando, o momento fletor adicional reduziu a um nível insignificante devido à viga aquecida mudar sua trajetória de deslocamento 
(configuração de catenária). Os efeitos provocados pelo momento fletor adicional, neste estudo experimental, não foram analisados no instante em que o pilar se aproxima do colapso.

Os elementos estruturais secundários em temperatura ambiente, como travamentos laterais e contraventamentos, contribuíram para a resistência em incêndio dos elementos estruturais. Com relação ao mesmo programa experimental, em BAILEY (2000) é relatado que quando o deslocamento transversal da viga se torna significante, o deslocamento lateral do pilar é aliviado.

Em WANG e DAVIES (2003) é apresentada uma gama de resultados experimentais, realizados em forno, de pilares conectados a um sistema de vigas simulando parte de um pórtico. Assim, o pilar estaria sujeito à variação de força axial, momento fletor (simétrico ou não, devido à força aplicada nas vigas) e condições de contorno (vinculações) caracterizadas pelo comprimento efetivo. Nesse mesmo estudo, a variação da temperatura dos gases seguiu a curva de incêndio padronizada pela norma ISO 834:1975.

Os resultados extraídos da última referência indicam que o momento fletor no pilar do pórtico sofre uma complexa mudança sob a ação térmica. Quando submetido a uma força de compressão axial elevada em relação ao momento fletor de primeira ordem, a configuração desse momento no pilar tem o sentido revertido logo na fase inicial de exposição ao fogo. Com a aplicação de uma força axial reduzida, o momento fletor no pilar também tem o sentido revertido, mas isso ocorre nos últimos estágios de exposição ao fogo, imediatamente antes do colapso.

Com relação ao colapso, o comprimento efetivo não foi sensível ao tipo de ligação com a viga. O comportamento das extremidades do pilar conectadas às vigas, mesmo com a consideração da restrição rotacional, se aproximou de um apoio fixo. A temperatura de colapso do pilar se mostrou significantemente dependente da força axial total aplicada. A magnitude do momento fletor inicialmente aplicado e o tipo de ligação viga/pilar não tiveram a mesma influência.

Outra importante análise experimental, relatada em FENG, WANG e DAVIES (2003), aborda o comportamento de pilares compostos de perfis formados a frio de parede delgada, de seções transversais U simples e enrijecido, com e sem furos na alma. Esse estudo permitiu compreender o comportamento físico e os modos de falha desse tipo de perfil além de fornecer alguns resultados experimentais para estudos numéricos detalhados.

Vale aqui lembrar que na região das dobras o trabalho a frio aumenta a resistência ao escoamento, mas diminui a ductilidade. Porém, esses efeitos resistentes são reduzidos em temperaturas elevadas. Os perfis de paredes delgadas também são mais propensos a sofrer 
instabilidade local, distorcional ou ambos conjugados. O efeito da perfuração na alma de um perfil submetido à ação térmica, até então não tem sido explorado pelos pesquisadores.

Os ensaios foram realizados em temperatura ambiente e em níveis de temperaturas iguais a $250^{\circ} \mathrm{C}, 400^{\circ} \mathrm{C}, 550^{\circ} \mathrm{C}, 700^{\circ} \mathrm{C}$. Dessa forma, a análise não se deu em caráter transiente. Todos os testes em temperaturas elevadas foram realizados sob condição estática. A temperatura do forno foi controlada até atingir um nível desejado e mantido por vinte minutos para certificar-se de que o corpo-de-prova estaria sujeito a um campo térmico uniforme. Após a temperatura ter atingido o nível desejado, a força axial foi aplicada de maneira incremental.

Como conclusões, as análises provam que, independentemente da temperatura, o modo de falha do pilar está relacionada ao tipo de imperfeição geométrica inicial do perfil. As forças de colapso para os diferentes modos, em cada nível de temperatura, alcançaram valores muito próximos. Em relação à presença de abertura na alma, essa pode ter um efeito significante na capacidade resistente do pilar, principalmente sob o efeito térmico.

Em TAN et al. (2007), é relatada uma investigação experimental cujo objetivo era determinar o tempo de colapso de um pilar metálico não-protegido submetido à elevação térmica e sujeito às várias condições de restrições axial e rotacional, considerando ainda imperfeições iniciais e excentricidade de força. Para estudar o efeito das restrições axiais no tempo de colapso, foi aplicada uma força de compressão constante correspondente a $50 \%$ da força resistente do pilar em temperatura ambiente. Em seguida, aplicou-se um aquecimento uniforme a uma taxa de $8^{\circ} \mathrm{C} / \mathrm{min}$ durante um intervalo de tempo necessário para que o pilar atinja a instabilidade global.

Os ensaios mostraram que os pilares de baixo índice de esbeltez $(\lambda=45)$ têm um encurtamento gradual antes da flambagem, enquanto que os pilares esbeltos flambam abruptamente. Além disso, os efeitos de segunda ordem, provocadas pela excentricidade de força e imperfeições geométricas iniciais, aliadas ao incremento de temperatura, contribuíram significativamente na redução do tempo de colapso. Ao aumentar as restrições axiais no pilar, as forças internas também aumentaram. A influência da fricção nas ligações retardou o tempo de colapso do pilar durante a fase de aquecimento. Em geral, os efeitos da fricção foram mais notáveis em pilares curtos. 


\subsection{PESQUISAS REALIZADAS - Contexto numérico}

Estudos realizados e apresentados em VALENTE e NEVES (1999) buscaram analisar a influência das restrições elásticas axiais e rotacionais, impostas pela estrutura, no valor da temperatura crítica nos pilares, variando, além das próprias restrições, parâmetros como excentricidade da força axial e esbeltez do pilar.

Os resultados obtidos mostram que para carregamentos centrados, quanto maior a rigidez da restrição axial, maior a resistência do pilar, porém, mais cedo ela é ultrapassada e, consequentemente em níveis mais baixos de temperatura. Em outras palavras, quanto maior a rigidez axial, menor é a temperatura crítica no pilar. Em contrapartida, valores elevados de rigidez à rotação fazem com que a temperatura crítica seja maior em relação aos valores mais baixos de rigidez rotacional.

Na última referência, cita-se que a situação de projeto proposta pelo Eurocode 3 Parte 1.2 considera as extremidades das barras engastadas e sem restrição axial. Em pilares menos esbeltos submetidos à compressão centrada e com rigidez rotacional proveniente do sistema estrutural suficientemente elevada, o cálculo da temperatura crítica sem considerar essas restrições axiais produz resultados satisfatórios. Porém, para pilares esbeltos, essas simplificações, conforme propõe o Eurocode 3 Parte 1.2, conduz a valores de temperatura crítica acima do esperado e, portanto, contra a segurança.

Em FENG, WANG e DAVIES (2004), são relatados estudos numéricos realizados com relação a pilares compostos por perfil formado a frio submetido à ação térmica. O objetivo é avaliar a capacidade resistente considerando o efeito das imperfeições geométricas iniciais. Porém, neste caso, não foi realizada uma análise térmica transiente, mas sim do tipo estática, com campo de temperatura uniforme.

Os resultados apresentados na última referência mostram que as amplitudes das imperfeições geométricas, combinadas com a ação térmica, interferem significativamente na força resistente do pilar. Como conclusões, o trabalho enfatiza a importância dos estudos no campo experimental para se determinar com maior clareza a alteração da relação constitutiva do material quando submetido à ação térmica.

Em LANDESMANN e BATISTA (2005) é apresentado um modelo numérico computacional elaborado para fins de investigação do comportamento de estruturas em pórtico constituídas de perfis de aço em situação de incêndio. A análise aplicou o modelo refinado de rótulas plásticas para a determinação dos limites de resistência. Foram considerados os efeitos plásticos de material e mudança de geometria. 
O campo de temperaturas na referência citada foi determinado na seção transversal e considerou-se a distribuição longitudinal uniforme de temperaturas. Os resultados apresentados dessa análise foram comparados ao código SAFIR. Uma vez que o modelo numérico é implementado com algumas hipóteses simplificadoras, as diferenças entre as respostas obtidas em ambas as análises foram consideradas satisfatórias.

Em AZEVEDO, FERREIRA e SILVA (2006) é apresentado um estudo inicial sugerindo um método para determinação da temperatura de elementos de aço externos a edificação. A mesma referência cita que a posição do pilar externo em relação às aberturas do edifício tem influência no valor do fluxo de calor recebido por este. Outros fatores que também mostraram exercer influência sobre a variação da temperatura do pilar externo são a geometria, a condição de abertura e a carga de incêndio do compartimento, bem como as dimensões do pilar.

Em SILVA e FILHO (2007) é proposto um procedimento de cálculo para se obter um índice global de segurança contra incêndio em edificações que leve em conta fatores como adução de água, treinamento, extintores, hidrantes, detecção, chuveiros automáticos, transmissão do alarme, brigada contra incêndio, resistência ao fogo das estruturas e das vedações de fachada, carga de incêndio, dimensões do edifício, mobilidade das pessoas, entre outros fatores.

O trabalho propõe o uso de um método analítico em que cada um desses fatores é determinado por meio de expressões. A vantagem do método analítico exposto na referência citada está em facilitar a automatização do procedimento. Este método tem como base o método tabular de avaliação de risco denominado Método de Gretener, porém com alguns ajustes.

Em HUANG e TAN (2007) são apresentados estudos numéricos realizados em complemento ao trabalho experimental relatado em TAN et al. (2007). A análise foi realizada no campo bidimensional, utilizando o código computacional denominado FEMFAN2D, desenvolvido com base no método dos elementos finitos. A adoção do código FEMFAN2D se justificou pela sua capacidade de considerar as não-linearidades do material e geométrica. A distribuição da temperatura pela seção transversal foi considerada não-uniforme.

O modelo reológico aplicado, conforme Figura 2.6, inclui uma série de molas para simular a rigidez axial imposta ao pilar metálico pelos demais elementos conectados e pelo pórtico de reação. Também foram considerados os efeitos de fricção (atrito) provocados pela ligação entre o pilar e os aparelhos de apoio. Esse efeito, inevitavelmente ocasionou restrição à rotação no pilar quando submetido à ação térmica. 


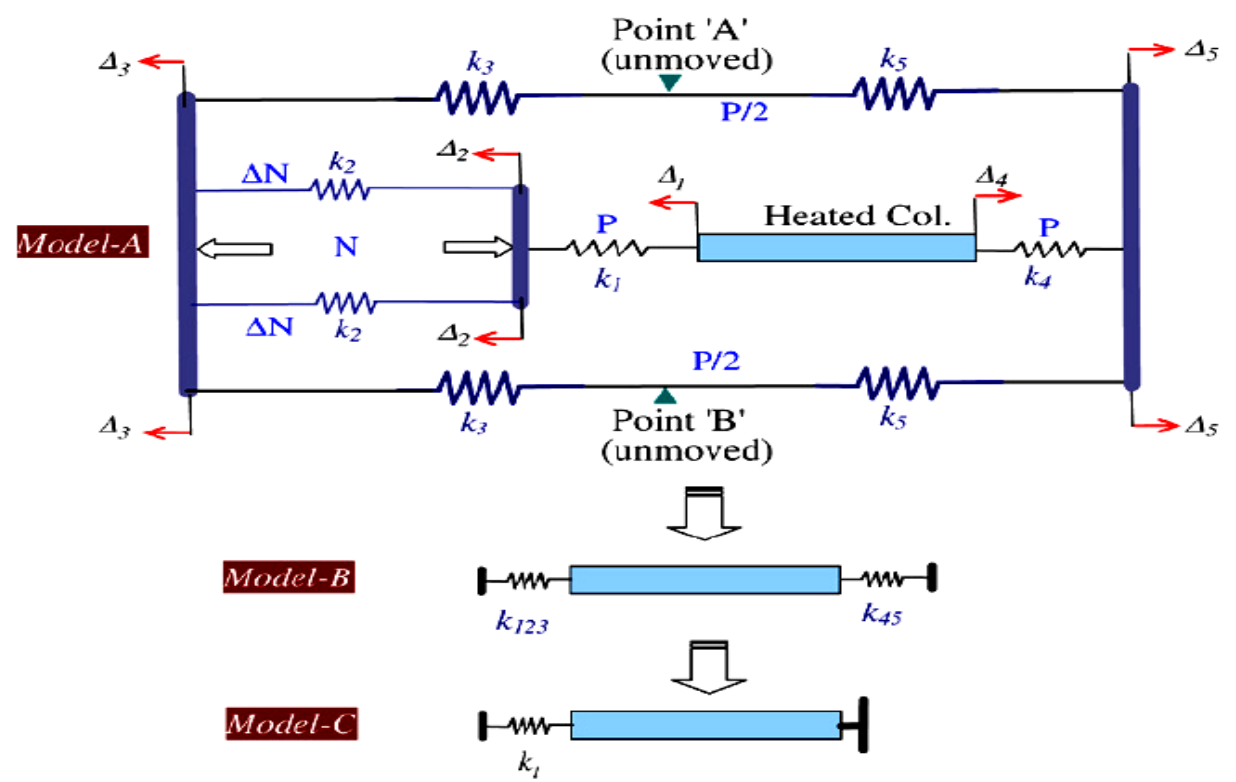

Figura 2.6 - Modelo reológico proposto em HUANG e TAN (2007) para simular a rigidez das restrições axiais

A análise foi realizada em caráter transiente, com taxa incremental de temperatura de $8^{\circ} \mathrm{C} / \mathrm{min}$ para diferentes índices de esbeltez e amplitudes de imperfeições globais iniciais. Os resultados obtidos mostram que, sob o aumento de temperatura, o pilar esteve sujeito a dois fatores combinados: expansão térmica (alongamento) e contração mecânica (encurtamento). Para baixos níveis de temperatura, a expansão térmica foi o fator dominante, tendo como conseqüência direta um aumento da força interna.

Por outro lado, no último estágio de aquecimento, a contração mecânica se tornou mais significante devido à rápida degradação das propriedades dos materiais, em particular o módulo de elasticidade e a resistência ao escoamento, fato que conduziu a uma redução da força interna. O efeito de fricção nas extremidades foi comparável ao das restrições rotacionais, provocando um retardamento na flambagem do pilar.

A utilização do método dos elementos finitos forneceu como resposta valores de flecha muito menor quando comparado àquele identificado nos ensaios experimentais. As diferenças foram atribuídas à dificuldade de se medir as imperfeições iniciais e a excentricidade de carregamento. Embora sejam de pequenas dimensões, a não consideração desses deslocamentos (excentricidade e flecha inicial) resultou em diferenças notáveis nos valores numéricos, principalmente em pilares esbeltos.

Segundo o estudo divulgado em TAN \& YUAN (2008), a resposta estrutural de um pilar em situação de incêndio depende amplamente da distribuição da temperatura na seção 
transversal e na direção longitudinal. Dessa forma, foi apresentado um estudo analítico de pilares submetidos a uma distribuição não-uniforme de temperatura. Nesse trabalho, foram analisados duas diferentes idealizações de distribuição de temperatura, o modelo com distribuição linear e o modelo com trechos de distribuição linear. As Figuras 2.7 (a) e (b) ilustram a distribuição da temperatura idealizada.
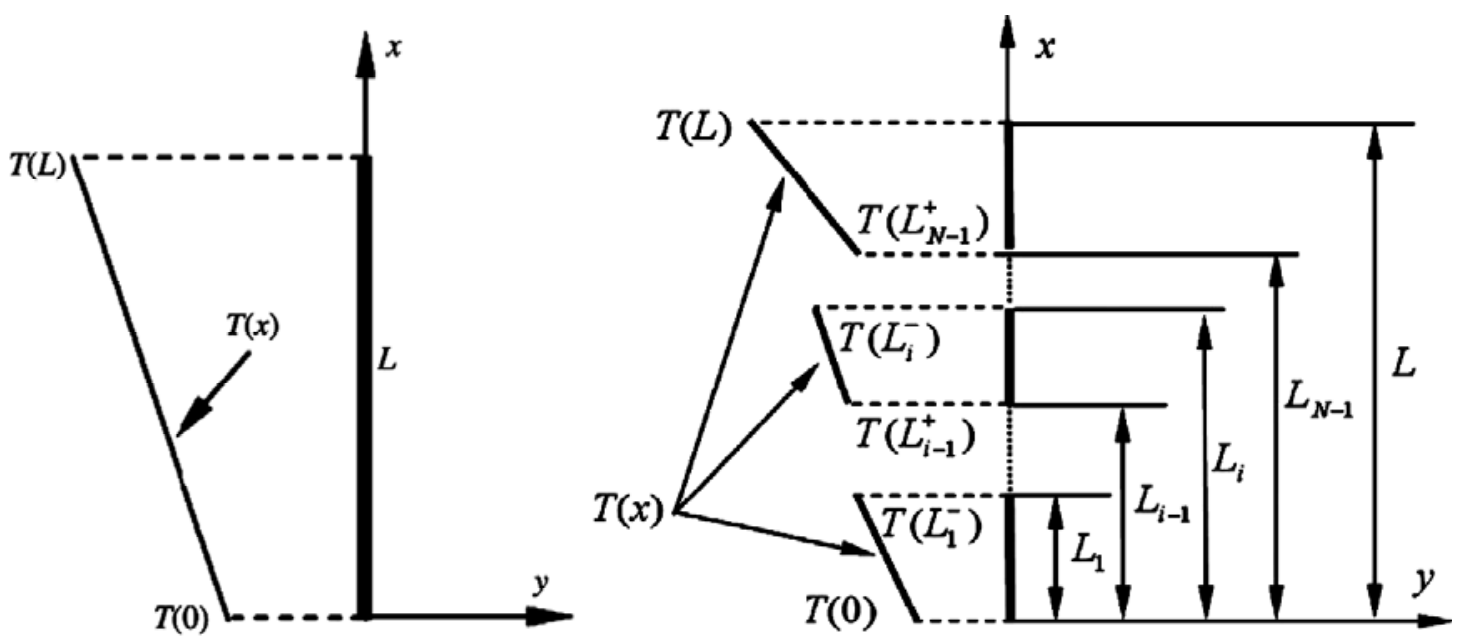

Figura 2.7: (a) Distribuição linear de temperatura e (b) distribuição da temperatura em trechos.

O objetivo foi obter soluções analíticas de tal modo que permitisse aos engenheiros averiguar de maneira simples a estabilidade do pilar sob ação térmica. No entanto, tal solução, que seria um recurso mais simples frente à complexidade da modelagem por meio do Método dos Elementos Finitos, cobre apenas o período pré-flashover e não o período pós-flashover, que é o de interesse para o projeto estrutural.

Em relação ao modelo reológico, se adotou a hipótese de extremidades anexadas a molas simulando a restrição axial provocada pela conexão com os componentes não aquecidos da estrutura. $\mathrm{O}$ valor da rigidez da mola foi adotado arbitrariamente, uma vez que a proposta é puramente analítica. Não foram consideradas restrições rotacionais nas mesmas extremidades.

A força interna no pilar foi analisada por meio da equação diferencial de segunda ordem do deslocamento. Nesse caso, sabendo que o módulo de elasticidade varia com a temperatura do material, consequentemente, o pilar apresentou variação longitudinal de rigidez e resistência. A distribuição da temperatura levou em consideração a dimensão do incêndio, as aberturas usuais de um compartimento, as propriedades térmicas das paredes e do teto e a variação temporal da temperatura do gás. 
Os resultados mostraram que, mesmo com a temperatura em uma das extremidades do pilar permanecendo constante, quanto maior a temperatura na outra extremidade, maior o valor da força axial interna devido à expansão térmica. Segundo a mesma referência, tal fato ocorre em razão de a dilatação térmica ser proporcional ao aumento de temperatura e, portanto, para temperaturas mais elevadas maior será a tendência de expansão (apesar de restringida axialmente), conduzindo a uma maior força axial induzida.

Na comparação com os resultados numéricos, utilizando o código FEMFAN3D, ficou claro que o procedimento analítico apresentado não cobre os casos em que ocorre plastificação do material. Logo, em casos cuja necessidade de estudo de elevação térmica de longa duração se faz presente, é aconselhável desenvolvê-lo mediante a análise transiente, a fim de capturar informações referentes à plasticidade e fluência. Além disso, foi relatado também que a flambagem elástica pode ser observada quando o pilar está submetido a altas temperaturas.

Em SANTOS (2009) se apresenta, em caráter numérico, análise semelhante àquela relatada em FENG, WANG e DAVIES (2003), porém no campo dos pilares mistos curtos preenchidos com concreto. De acordo com a mesma referência, a ação térmica pode exercer influência na variação do efeito de confinamento nesse tipo de estrutura. Os resultados apresentados mostraram que o efeito positivo do confinamento, em termos de força resistente, em pilares mistos curtos de seção circular se anula após um tempo de 10 a 15 minutos de exposição ao incêndio padrão.

De forma geral, se percebe que as análises numéricas, dadas as dificuldades inerentes aos aspectos a serem considerados para melhor representar o comportamento de pilares em incêndio, tendem a adotar algumas hipóteses simplificadoras, tais como:

- A interação com os demais membros estruturais não-aquecidos é representada por um sistema de molas simulando as rigidezes axial e rotacional impostas pela estrutura;

- O campo térmico na direção longitudinal do pilar, após a combustão de todo material inflamável é considerado sempre uniforme;

- Na maioria dos trabalhos publicados, a determinação da variação da força resistente de compressão em função do tempo não considera a interação do pilar com o revestimento, a laje e o sistema de contraventamento.

- A variação térmica segue modelos de incêndio padronizados por normas técnicas. Para os casos em que se procura reproduzir trabalhos experimentais, o incremento de temperatura seguiu o mesmo valor daquele utilizado no controle do forno de ensaio. 


\subsection{UMA ABORDAGEM AOS CÓDIGOS NORMATIVOS}

Em BUCHANAN (2002) se relata que as primeiras brigadas e normas de incêndio documentadas foram desenvolvidas por companhias de seguro, as quais se importavam mais com a proteção à propriedade do que com a vida. No entanto, os anos recentes mostram a tendência de inversão de valores, dando mais ênfase à proteção da vida.

\subsubsection{NO CONTEXTO MUNDIAL}

Como citado em CLARET (2000), as primeiras normas que padronizam os testes de resistência ao fogo foram desenvolvidas pela ASTM, American Society for Testing and Materials que, em 1911 estabeleceu a norma Standart Tests for Fireproofs Constructions. De acordo com SILVA (2001), a curva de incêndio-padrão adotada pela ASTM desde 1918 teve como fundamento a proposta do Underwriters Laboratory (UL) de Chicago, o qual utilizava essa curva para a fase de aquecimento dos ensaios de pilares realizados na época. Supõe-se que os dados da curva de incêndio-padrão tenham sido obtidos de incêndios reais.

Em 1932, a British Standart Institution publicou a norma BS476, intitulada Fire tests on buildings materials and structures que, com as devidas revisões e ampliações, é aplicada atualmente. A comunidade técnica sueca Swedish Building Regulations (SBN), por meio da norma SBN 67 foi a primeira a permitir que os conceitos de incêndio natural fossem empregados na determinação da ação térmica.

Em 1975, a International Organization for Standartization (ISO), federação mundial de padronização de órgãos nacionais, desenvolveu uma norma internacional que padroniza a metodologia de ensaio de resistência em situação de incêndio. Surgiu, então, a primeira versão da norma ISO 834:1975, intitulada Fire Resistance Tests, Elements of Building Construction. Essa norma foi revisada e substituída pela ISO 834:1975 e é referência para as normas desenvolvidas em outros países, inclusive o Brasil. De acordo com a ISO 834:1975, a temperatura média do forno deverá ser monitorada e controlada de acordo com a equação abaixo 2.1 .

$$
\theta_{g}(t)=345 \log (8 t+1)+20
$$


Na equação 2.1, $\theta_{\mathrm{g}}$ é a temperatura dos gases quentes em graus Celsius e t é o tempo, em minutos. A curva de incêndio padronizada pela norma ISO 834:1975 é aplicável tanto aos elementos estruturais como aos materiais de proteção.

$\mathrm{Na}$ década de 1980 foram lançados os primeiros códigos europeus, os Eurocodes que, em 1989 se tornariam as Normas Européias EN. O conjunto abrange um total de dez normas técnicas, divididas em partes. A parte que trata exclusivamente de da ação térmica em estruturas é EN1991 Eurocode 1 part 2, Actions on structures exposed to fire.

O dimensionamento da estrutura seguindo as recomendações do Eurocode 1 prevê três curvas de incêndio-padrão: a curva de incêndio da ISO 834:1975, a curva de incêndio para elementos exteriores e a curva de incêndio em ambientes com material combustível a base de hidrocarbonetos. No capítulo seguinte, são detalhadas as equações que descrevem as três curvas de incêndio-padrão.

\subsubsection{NO CONTEXTO NACIONAL}

Várias tentativas foram feitas para o estabelecimento de normas técnicas de projeto de estruturas metálicas em situação de incêndio. Porém, somente em 1995 representantes do meio universitário e do corpo técnico, contando com a participação do Corpo de Bombeiros/SP, dos fabricantes de estruturas metálicas e de materiais de revestimento contra fogo, de representantes das siderúrgicas, de representante do IPT, etc., elaboraram as normas de interesse no contexto nacional.

Basicamente, foram elaboradas e publicadas as normas brasileiras ABNT NBR 14323:1999 intitulada "Dimensionamento de estruturas de aço de edificios em situação de incêndio" e ABNT NBR 14432:2000, intitulada "Exigências de resistência ao fogo de elementos construtivos das edificações", em que são apresentados critérios para dimensionamento de elementos isolados e determinação do tempo que as estruturas devem resistir antes do colapso (tempo requerido de resistência ao fogo - TRF), respectivamente.

No capítulo que se segue, serão devidamente abordadas as prescrições referentes ao dimensionamento de pilares de aço em situação de incêndio, inseridas nas principais normas voltadas para esse fim, sejam elas nacionais ou internacionais. No entanto, é importante ressaltar que maiores atenções serão direcionadas a ABNT NBR 14323:1999, tendo em vista ser este um trabalho desenvolvido com atenções especiais para a verificação da eficiência dessa no dimensionamento de pilares de aço não revestidos sob elevadas temperaturas. 


\section{O INCÊNDIO: ORIGEM, AÇÃO TÉRMICA E OS PROCEDIMENTOS NORMATIVOS}

\subsection{O INCÊNDIO - Modelos de interesse}

Como citado em DRYSDALE (1998), embora o fogo seja uma manifestação química, que aparece em resposta à existência de uma fonte de calor, comburente (ar) e combustível, o modo (velocidade) com que ele se propaga depende de alguns aspectos, tais como: condições de abertura da edificação (janelas, portas, etc), existência de compartimentos (paredes, divisórias, etc), do estado físico e da distribuição do combustível. De um modo geral, no caso de edificações correntes, os combustíveis mais comuns são os sólidos orgânicos, como madeira e seus derivados, algodão e polímeros, os quais consistem de materiais cujas moléculas são compostas basicamente de átomos de carbono e hidrogênio.

Segundo BUCHANAN (2002), de forma simplificada, a combustão é uma reação química exotérmica, ou seja, com liberação de calor, envolvendo a oxidação da matéria orgânica e a liberação de vapor d'água e dióxido de carbono. O processo de combustão de qualquer material requer a disponibilidade de oxigênio, para que a oxidação possa ocorrer. $\mathrm{Na}$ maioria dos incêndios em edifícios, a intensidade da combustão depende da quantidade de gases inflamáveis (gás liquefeito de petróleo) que entram em contato com o ar dentro da edificação, por meio dos movimentos convectivos das chamas e dos produtos da combustão na fumaça que se forma sobre o fogo.

O processo de queima de um objeto requer a presença de uma fonte de calor externa para aumentar sua temperatura até atingir o ponto de ignição. Em seguida, as chamas crescem até que a sua intensidade se torne estável. A partir desse momento, as chamas se tornam grandes o suficiente para manter a reação de combustão sem a necessidade de qualquer fonte de calor externa.

Existem numerosas fontes de calor comumente encontradas em edificações. Nelas estão inclusas as fontes de chamas tais como fósforos, velas, aquecedores a gás e lareiras, as fontes fumegantes, tais como cigarros, fontes elétricas, a citar as falhas nos circuitos elétricos, e as fontes radiantes, as superficies quentes, fricção, relâmpagos e outras. 
A quantidade de calor e a temperatura requerida para causar a ignição dependem das propriedades térmicas, tamanho e forma do material combustível e do tempo de exposição ao calor. O tempo para ocorrer ignição do material depende da sua inércia térmica, parâmetro definido como o produto entre a condutividade térmica, densidade e calor específico do material. Quando exposto a uma mesma fonte de calor, a superfície do material com menor inércia térmica aquecerá mais rapidamente se comparada aos materiais com maior inércia térmica, conduzindo a uma ignição mais rápida.

Em relação às formas de ignição, existem duas possíveis: a ignição-piloto que ocorre na presença de uma chama ou faísca; e a auto-ignição que causa a combustão espontânea dos gases voláteis de uma fonte combustível na ausência de chama ou faísca. Para as superfícies expostas ao fluxo de calor por radiação, a intensidade do fluxo de calor requerida para causar a auto-ignição é maior do que aquela exigida para causar a ignição-piloto.

Após a ocorrência da ignição, a segurança depende da rapidez com que o incêndio se alastra pelos objetos e materiais combustíveis, a qual, por sua vez, depende da localização e do tamanho das labaredas (aquecimento por radiação), da direção da corrente de ar (aquecimento por convecção), das propriedades térmicas do combustível (afetando a taxa de aumento da temperatura) e da flamabilidade do combustível.

A seguir são comentados sobre as estratégias usadas na modelagem do incêndio, o comportamento do incêndio real, o modelo de incêndio natural e os modelos de incêndio padronizados pelas principais normas em vigor no contexto mundial.

\subsubsection{MODELO DE INCÊNDIO REAL - Temperatura $x$ tempo}

No que concerne ao estudo da segurança das estruturas, o incêndio pode ser caracterizado por uma curva que fornece a temperatura dos gases em função do tempo (http://www.lmc.ep.usp.br/people/valdir/pef5705/capitulo1/Cap1INC.html). Essa curva é o ponto de partida para o dimensionamento da estrutura sob a ação térmica. Por meio da Figura 3.1, é possível distinguir três fases de um incêndio real.

Durante a primeira fase, ou seja, de ignição, as temperaturas ainda são baixas e o incêndio é considerado de pequenas proporções. O aquecimento acontece de forma relativamente lenta, na qual o fogo permanece bem localizado, embora uma quantidade significativa de fumaça comece a ser produzida. Essa fase determina o período denominado pré-flashover, em que as medidas de proteção contra incêndio (detectores de calor e fumaça, chuveiros automáticos e brigada de incêndio) são suficientes no combate às chamas. 


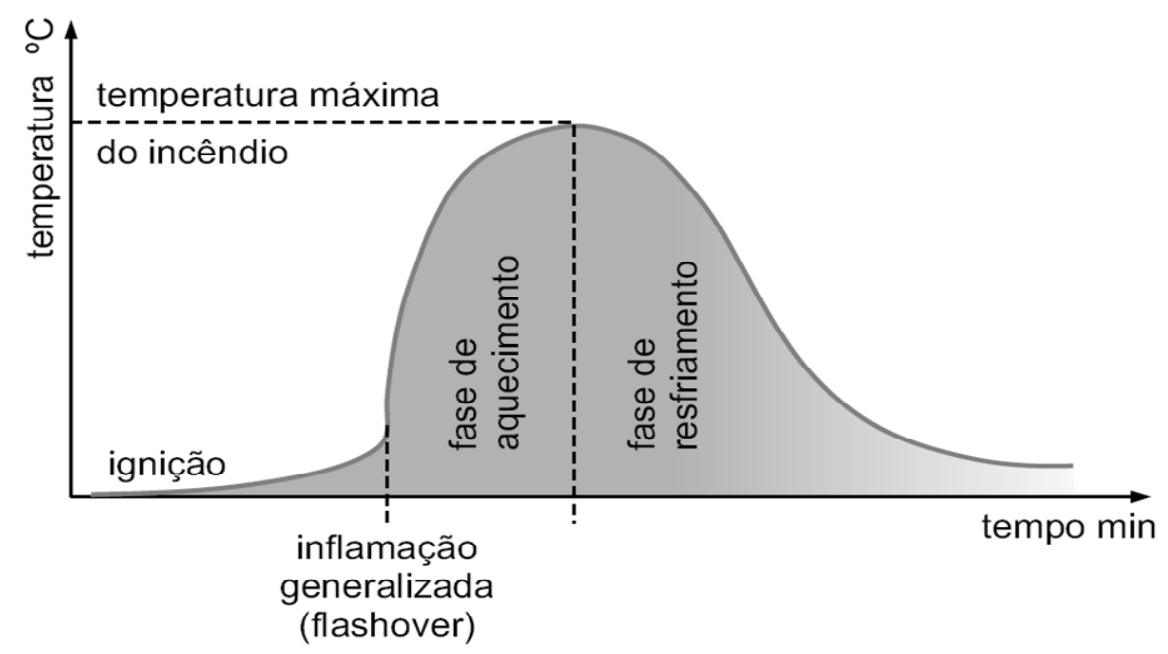

Figura 3.1: Curva temperatura $\mathrm{x}$ tempo de um incêndio real.

A transição da fase localizada para a tomada completa do compartimento é geralmente repentina, representada pelo aumento brusco da curva Temperatura $\mathrm{x}$ tempo, denominada flashover. A partir desse instante, se inicia uma fase de forte aquecimento, em que o incêndio toma proporções generalizadas e a superfície de toda carga combustível entra em combustão. Nessa fase (pós-flashover), a temperatura aumenta rapidamente até atingir seu valor máximo. Por fim, quando todo o material (combustível) é consumido, inicia-se a fase de resfriamento, com redução gradativa da temperatura.

A curva representativa de um incêndio real é de difícil determinação, uma vez que está relacionada a parâmetros como disposição das aberturas, quantidade de cargas combustíveis, fator de ventilação, que são de grande variabilidade a depender do tipo de edificação. Em resposta a essas dificuldades, os principais órgãos de pesquisa formularam métodos para que o comportamento da curva Temperatura $x$ Tempo de um incêndio possa ser modelado de forma simplificada, porém, que seja representativa para os casos encontrados na prática. Dentre os modelos, serão citados o modelo de incêndio natural e aqueles desenvolvidos pelos principais órgãos normativos em vigor no contexto mundial.

\subsubsection{MODELO DE INCÊNDIO NATURAL}

O modelo de incêndio natural, conforme Figura 3.2, corresponde a uma simplificação das condições de incêndio real, em que se desconsidera a fase de ignição (por se entender que as temperaturas não atingem níveis que possam afetar a capacidade portante da estrutura) e se faz um ajuste na fase de resfriamento por meio de uma reta. Portanto, a curva "temperatura $x$ 
tempo" de um incêndio natural aborda tanto a fase de aquecimento após o flashover (de interesse), como a fase de resfriamento dos gases e utiliza o conceito de tempo efetivo para que o modelo de incêndio atinja os mesmos efeitos de um incêndio real.

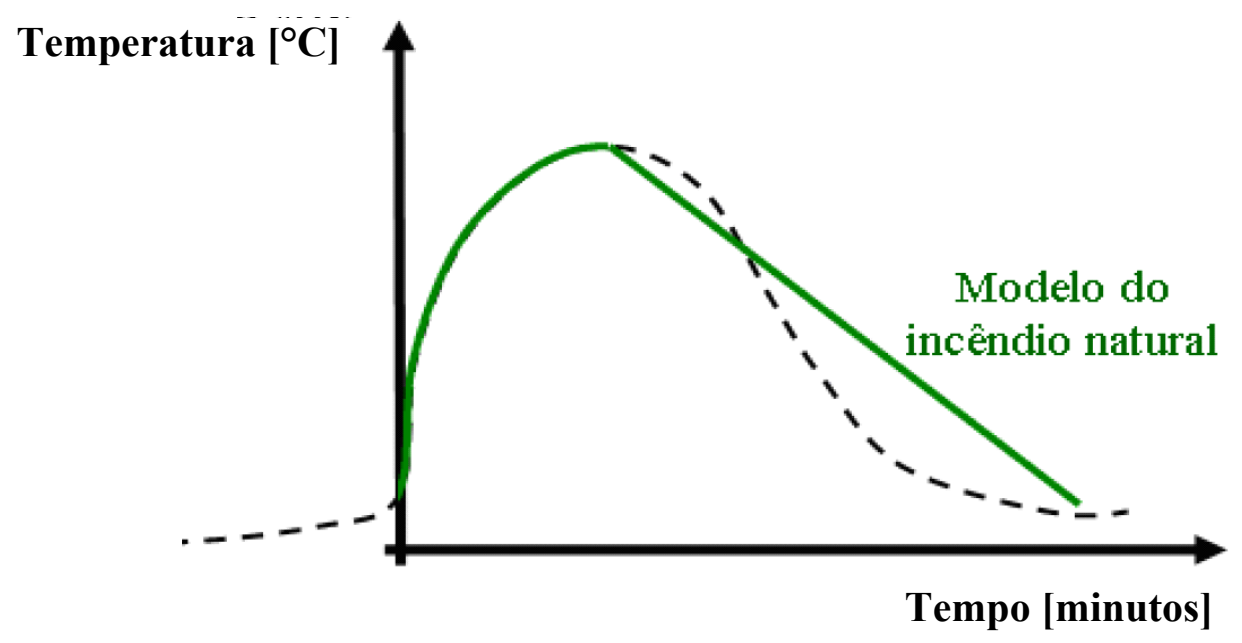

Figura 3.2: Modelo de um incêndio natural.

Segundo SILVA (2001), e em concordância com os aspectos mencionados no capítulo anterior, a norma sueca Swedish Building Regulations (SBN) foi a primeira a adotar os conceitos de incêndio natural para a determinação da ação térmica em edificações. $O$ EUROCODE 1 Part 2 apresenta dois modelos de incêndio natural: o modelo simplificado e o modelo avançado.

O modelo simplificado é baseado em parâmetros físicos específicos com limitado campo de aplicação. Num incêndio compartimentado, é assumida uma distribuição uniforme de temperatura. A temperatura dos gases deve ser determinada considerando pelo menos a densidade da carga de incêndio e a condição de ventilação. O comportamento da curva "temperatura $x$ tempo" é determinado por meio da curva parametrizada, cujos comentários serão feitos em momento oportuno. Em caso de incêndios localizados, em que o flashover é pouco provável de se acontecer, a distribuição de temperatura é assumida como sendo nãouniforme.

Por sua vez, o modelo avançado de incêndio natural deve levar em conta as propriedades dos gases e a troca de massa e energia. Além disso, sua implementação pode ser feita por duas formas distintas: por meio do modelo de uma zona, assumindo que o compartimento terá distribuição de temperatura uniforme e variável no tempo; ou por meio do modelo de duas zonas, assumindo tanto a camada superior aquecida como a camada inferior em menor temperatura terá espessura variável no tempo. 
O método avançado exige que a modelagem seja realizada utilizando códigos computacionais específicos de dinâmica dos fluidos, que fornece a evolução da temperatura no compartimento em função do tempo e do espaço. A obtenção dos parâmetros necessários para se modelar uma curva "temperatura dos gases $x$ tempo" de um incêndio natural é feito por meio de ensaios ou modelos matemáticos aferidos com ensaios, que busquem simular situações reais de incêndio.

No que segue, serão brevemente abordadas as prescrições para a determinação da elevação da temperatura dos gases, em função do tempo, inseridos em um ambiente em chamas, compartimentado, extraídas do Eurocode 1 part 2, o qual apresenta uma curva “temperatura dos gases $x$ tempo", expressa pela equação 3.1, válida para compartimentos com área menor ou igual a $500 \mathrm{~m}^{2}$ (em planta), sem abertura no telhado e com altura de, no máximo, 4 metros. Nessa função, é assumido que todo compartimento é tomado pelo fogo.

$\theta_{\mathrm{g}}=20+1325\left(1-0,324 \mathrm{e}^{-0,2 \mathrm{t}^{*}}-0,204 \mathrm{e}^{-1,7 \mathrm{t}^{*}}-0,472 \mathrm{e}^{-19 \mathrm{t}^{*}}\right)$

$\mathrm{Na}$ equação $3.1, \theta_{\mathrm{g}}$ é a temperatura dos gases no compartimento $\left[{ }^{\circ} \mathrm{C}\right]$, e os demais parâmetros são definidos da seguinte forma:

$\mathrm{t}^{*}=\mathrm{t} . \Gamma$

t* é o tempo fictício, em h;

$\mathrm{t}_{\mathrm{h}}$ é o tempo em $\mathrm{h}$;

$\mathrm{Na}$ equação 3.2, $\Gamma$ é o fator de correção do tempo, fornecido em função do fator de abertura do compartimento e da absorção térmica para todo compartimento, dado pela equação 3.3 .

$$
\begin{aligned}
& \Gamma=\left[\frac{\frac{\mathrm{O}}{\mathrm{b}}}{\frac{0,04}{1160}}\right]^{2} \\
& \mathrm{O}=\mathrm{A}_{\mathrm{v}} \frac{\sqrt{\mathrm{h}_{\mathrm{eq}}}}{\mathrm{A}_{\mathrm{t}}} \\
& \mathrm{b}=\sqrt{\rho \mathrm{cc \lambda}}
\end{aligned}
$$


Das equações 3.4 e 3.5, valem as definições:

$\mathrm{O}$ : fator de abertura ou grau de ventilação, que varia dentro dos limites $0,02 \leq \mathrm{O} \leq 0,20\left[\mathrm{~m}^{1 / 2}\right]$; $\mathrm{A}_{\mathrm{v}}$ : área total das aberturas verticais nas paredes $\left[\mathrm{m}^{2}\right]$;

$\mathrm{h}_{\mathrm{eq}}$ : média ponderada das alturas das aberturas em relação à área total das aberturas [m];

$\mathrm{A}_{\mathrm{t}}$ : é a área total do compartimento (paredes, teto e piso, incluído as aberturas) $\left[\mathrm{m}^{2}\right]$;

b: é a absortividade térmica do material de vedação do compartimento, válido dentro do intervalo $100 \leq \mathrm{b} \leq 2200\left[\mathrm{~J} / \mathrm{m}^{2} \mathrm{~s}^{1 / 2} \mathrm{~K}\right]$;

$\rho$ : massa específica do material de vedação do compartimento $\left[\mathrm{kg} / \mathrm{m}^{3}\right]$;

c: calor específico do material de vedação do compartimento $[\mathrm{J} / \mathrm{kgK}] \mathrm{e}$;

$\gamma$ : condutividade térmica do material de vedação do compartimento $[\mathrm{W} / \mathrm{mK}]$.

Cabe aqui observar que quando $\Gamma=1$, a equação 3.1 se aproxima da curva "temperatura $x$ tempo" de um outro tipo de modelo de incêndio, denominado incêndiopadrão, o qual será apresentado a seguir. A temperatura máxima ocorre num tempo máximo $\mathrm{t}_{\max }$ que, representado em termos do tempo fictício, resulta na equação 3.6.

$\mathrm{t}_{\max }^{*}=\mathrm{t}_{\max } \cdot \Gamma$

$\mathrm{t}_{\max }=\max \left[\left(0,2 \cdot 10^{-3} \cdot \frac{\mathrm{q}_{\mathrm{t}, \mathrm{d}}}{\mathrm{O}}\right) ; \mathrm{t}_{\lim }\right]$

Das equações 3.6 e 3.7, seguem as seguintes definições:

$\mathrm{q}_{\mathrm{t}, \mathrm{d}}$ : valor de cálculo da carga de incêndio referido a área total da superfície $\mathrm{A}_{\mathrm{t}}$ do compartimento, $\left[\mathrm{MJ} / \mathrm{m}^{2}\right]$;

$\mathrm{t}_{\text {lim: }}$ : é dado conforme a equações 3.8.

$$
\begin{aligned}
& \left\{\begin{array}{lll}
\theta_{\mathrm{g}}=\theta_{\text {max }}-625\left(\mathrm{t}^{*}-\mathrm{t}_{\text {max }}^{*} \cdot \mathrm{x}\right) & \mathrm{t}_{\text {max }}^{*} \leq 0,5 \\
\theta_{\mathrm{g}}=\theta_{\text {max }}-250\left(3-\mathrm{t}_{\text {max }}^{*}\right)\left(\mathrm{t}^{*}-\mathrm{t}_{\text {max }}^{*} \cdot \mathrm{x}\right) & \text { para } & 0,5 \leq \mathrm{t}_{\text {max }}^{*} \leq 2 \\
\theta_{\mathrm{g}}=\theta_{\text {max }}-250\left(\mathrm{t}^{*}-\mathrm{t}_{\text {max }}^{*} \cdot \mathrm{x}\right) & & \mathrm{t}_{\text {max }}^{*} \geq 2
\end{array}\right. \\
& \mathrm{x}=1,0 \text { se } \mathrm{t}_{\max }>\mathrm{t}_{\text {lim }}, \\
& \mathrm{x}=\mathrm{t}_{\lim } \cdot \frac{\Gamma}{\mathrm{t}_{\text {max }}^{*}} \text { se } \mathrm{t}_{\max }=\mathrm{t}_{\text {lim }}
\end{aligned}
$$

Obs.: $\mathrm{t}^{*}$ é dado por $3.2 \mathrm{e}_{\max }^{*}$ por 3.6. 


\subsubsection{MODELO DE INCÊNDIO-PADRÃO - ASTM E119}

A curva da ASTM E 119 é definida por um número discreto de pontos, conforme mostra a Tabela 3.1. Segundo BUCHANAN (2002), dentre as várias equações desenvolvidas para descrever essa curva, a equação 3.9, em que $\theta_{\mathrm{g}}$ é a temperatura dos gases $\left(\mathrm{em}^{\circ} \mathrm{C}\right)$, é aquela que melhor representa os valores da tabela.

Tabela 3.1: pontos discretos da curva temperatura x tempo recomendado pela ASTM E 119.

\begin{tabular}{cccc}
\hline \multicolumn{4}{c}{ Curva discretizada da ASTM E 119 } \\
\hline Tempo $(\min )$ & Temperatura $\left({ }^{\circ} \mathrm{C}\right)$ & Tempo $(\min )$ & Temperatura $\left({ }^{\circ} \mathrm{C}\right)$ \\
\hline 0 & 20 & 55 & 916 \\
5 & 538 & 60 & 927 \\
10 & 704 & 65 & 937 \\
15 & 760 & 70 & 946 \\
20 & 795 & 75 & 955 \\
25 & 821 & 80 & 963 \\
30 & 843 & 85 & 971 \\
35 & 862 & 90 & 978 \\
40 & 878 & 120 & 1010 \\
45 & 892 & 240 & 1093 \\
50 & 905 & 480 & 1260 \\
\hline
\end{tabular}

$\theta_{\mathrm{g}}=750\left[1-\mathrm{e}^{-3,79553 \sqrt{\mathrm{t}_{\mathrm{h}}}}\right]+170,41 \sqrt{\mathrm{t}_{\mathrm{h}}}+20$

Com relação à equação 3.9 , $\mathrm{t}_{\mathrm{h}}$ é o tempo decorrido, em horas (h).

\subsubsection{MODELO DE INCÊNDIO-PADR ÃO - ISO 834-1:1999}

Segundo as especificações da ISO 834-1:1999, a temperatura dos gases quentes é descrita pela equação 3.10. Esse modelo serviu de base para a norma brasileira ABNT NBR 14323:1999, que estabelece prescrições para o dimensionamento de elementos de aço e mistos de aço e concreto em situação de incêndio.

$\theta_{\mathrm{g}}=20+345 \log _{10}(8 \mathrm{t}+1)$

Com relação à equação $3.10, \theta_{\mathrm{g}}$ é a temperatura dos gases $\left[{ }^{\circ} \mathrm{C}\right]$ e t é o tempo decorrido em minutos. 


\subsubsection{MODELO DE INCÊNDIO-PADRÃO - EUROCODE 1 PART 1-2}

O método proposto pelo Eurocode para a elevação da temperatura apresenta as seguintes curvas nominais de incêndio:

- Curva "temperatura $\left[{ }^{\circ} \mathrm{C}\right] x$ tempo [min]" de incêndio-padrão da ISO 834:1975, cuja equação é apresentada no sub-ítem anterior. Esse modelo se aplica aos ambientes cuja carga combustível é formada principalmente por materiais celulósicos;

- Curva "temperatura $\left[{ }^{\circ} \mathrm{C}\right] \times$ tempo [min]", equação 3.12 , destinada ao dimensionamento dos elementos estruturais internos ao compartimento, cujo material combustível é composto principalmente por hidrocarbonetos.

$\theta_{g}(t)=1080\left(1-0,325 \mathrm{e}^{-0,167 t}-0,67 \mathrm{e}^{-2,5 \mathrm{t}}\right)+20$

A Figura 3.3 compara as curvas obtidas pelos três modelos apresentados nos sub-ítens anteriores.

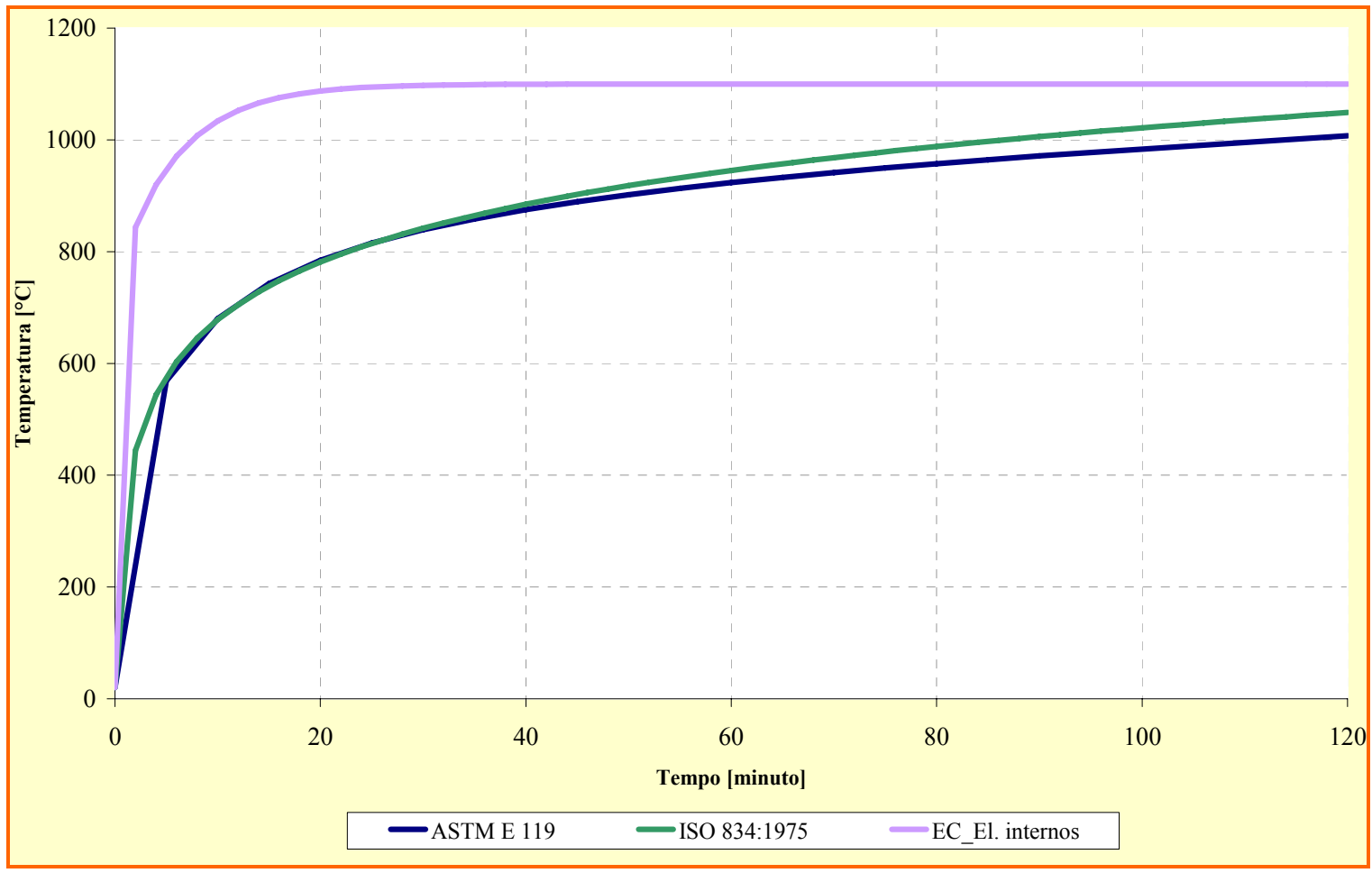

Figura 3.3: Curvas temperatura $\mathrm{x}$ tempo propostas pelas principais normas estrangeiras.

Cabe aqui ressaltar que a ação térmica na estrutura é descrita pelo fluxo de calor provocado pela diferença de temperatura entre os gases quentes do ambiente e os 
componentes da estrutura. O aumento da temperatura nos elementos estruturais, em conseqüência da ação térmica, causa redução da resistência, da rigidez e o aparecimento dos esforços solicitantes adicionais nas estruturas hiperestáticas.

Os próximos ítens deste capítulo buscam esclarecer ao leitor como o incêndio interfere no desempenho físico dos elementos e, portanto, das estruturas de forma geral. É apresentado um breve comentário sobre os conceitos necessários para descrever a ação térmica nas estruturas, bem como o efeito dessa ação nas propriedade mecânicas dos materiais.

\subsection{TRANSFERENCIA DE CALOR}

Segundo WANG (2002), pela definição fenomenológica de transferência de calor, essa interação ocorre quando dois sistemas, ou um determinado sistema e o meio em que se insere, apresentam temperaturas diferentes e são colocados em contato.

Em um ambiente em chamas, a temperatura dos elementos estruturais após certo intervalo de tempo, tende a se aproximar da temperatura dos gases quentes. Para que a elevação térmica nos elementos seja determinada, é necessário conhecer os mecanismos de transferência de calor envolvidos, conhecidos por condução, convecção e radiação. Em outras palavras, é importante saber o modo pela qual a energia calorífica é gerada e dissipada no ambiente.

No que segue, são brevemente descritos os três mecanismos de transferência de calor, cujas informações foram extraídas de REGOBELLO (2007), destacando-se que na última referência são encontradas informações mais detalhadas a respeito dos conceitos de transferência térmica aplicados ao estudo do incêndio nas estruturas, além do campo térmico modelado numericamente para diversas seções transversais de aço e mistos de aço e concreto.

\subsubsection{TRANSFERÊNCIA DE CALOR POR CONDUÇÃO}

Em BUCHANAN (2002), a condução é descrita como um mecanismo de transferência de calor entre materiais sólidos, envolvendo elétrons livres. Dessa forma, materiais considerados bons condutores elétricos também são bons condutores de calor. Em materiais de baixa condutividade térmica, o calor é conduzido por uma vibração mecânica da cadeia molecular. A condução de calor é um importante fator na ignição das superfícies sólidas e na resistência à ação térmica das estruturas. 
Para que o cálculo da transferência de calor por condução seja possível, é necessário conhecer algumas propriedades dos materiais de interesse: a densidade, $\boldsymbol{\rho}$ é a massa do material por unidade de volume; o calor específico, c é o calor requerido para aquecer uma unidade de massa de um material em uma unidade de temperatura e; a condutividade térmica, $\lambda$ representa a taxa de calor transferido através de uma unidade de espessura por uma variação unitária de temperatura. Há ainda outras propriedades derivadas que também são necessárias: a difusividade térmica, dada por $\alpha=\frac{\lambda}{\rho . c}$ e a inércia térmica $(\rho . c . \lambda)$.

Quando materiais com baixa inércia térmica são expostos ao calor, a temperatura na superfície aumenta rapidamente, sendo, portanto, mais propensos à ignição. Para uma dada carga de incêndio, ambientes forrados com materiais de baixa inércia térmica terão temperaturas mais altas que os ambientes forrados com materiais de inércia térmica mais elevada.

Numa condição estacionária, a transferência de calor por condução é diretamente proporcional ao gradiente de temperatura entre dois pontos, ponderado por uma constante de proporcionalidade conhecida como condutividade térmica.

\section{- Condução no estado estacionário em campo unidimensional}

Em campo unidimensional, a equação de calor segue a Lei de Fourier de condução de calor, e é expressa conforme mostra a equação 3.13 .

$$
\varphi=-\lambda \frac{d \theta}{d x}
$$

O sinal "menos" (-) indica que o calor flui do ponto de temperatura mais alta para o de temperatura mais baixa. Da equação $3.13, \varphi$ é o fluxo de calor por unidade de área, $\left[\mathrm{W} / \mathrm{m}^{2}\right], \lambda$ é a condutividade térmica $[\mathrm{W} / \mathrm{mK}], \theta$ é a temperatura $\left[\mathrm{K}\right.$ ou $\left.{ }^{\circ} \mathrm{C}\right]$ e $\mathrm{x}$ a distância na direção do fluxo de calor, [m].

\section{- Condução no estado estacionário em campo unidimensional de materiais compósitos}

Em compósitos, assume-se que a condutividade térmica de cada material independe da temperatura. De acordo com o princípio da conservação de energia (fluxo de calor através de cada camada permanece constante). Usando a equação 3.14 e conhecendo a temperatura nas duas faces externas do compósito, é possível obter o fluxo de calor. 
$\theta_{1}-\theta_{\mathrm{n}, \mathrm{n}+1}=\varphi \sum_{\mathrm{i}=1}^{\mathrm{n}} \mathrm{R}_{\mathrm{i}, \mathrm{i}+1}$

Da equação 3.14, seguem:

$\theta_{1}$ e $\theta_{\mathrm{n}, \mathrm{n}+1}$ são as temperaturas nas faces externas do compósito;

$\varphi$ é o fluxo de calor através do compósito;

$\mathrm{R}_{\mathrm{i}, \mathrm{i}+1}=\frac{\Delta \mathrm{x}_{\mathrm{i}, \mathrm{i}+1}}{\lambda_{\mathrm{i}, \mathrm{i}+1}}$ é a resistência térmica de cada material componente do compósito;

$\lambda_{\mathrm{i}, \mathrm{i}+1}$ é a condutividade térmica da camada;

$\Delta \mathrm{x}_{\mathrm{i}, \mathrm{i}+1}$ é a espessura da camada.

Com esse valor de $\varphi$, as temperaturas nas faces de cada camada são obtidas através da equação 3.15 .

$\theta_{\mathrm{i}}-\theta_{\mathrm{i}+1}=\varphi \frac{\Delta \mathrm{x}_{\mathrm{i}, \mathrm{i}+1}}{\lambda_{\mathrm{i}, \mathrm{i}+1}}$

Para o fluxo transiente de calor, a quantidade de calor dissipada na mudança de temperatura do meio (material) dever ser incluída. Para o campo unidimensional, a transferência de calor por condução em um material sem calor interno liberado, é governada pela equação 3.16, em que t é o tempo [s] e $\alpha$ é a difusividade térmica $\left[\mathrm{m}^{2} / \mathrm{s}\right.$ ]

$\frac{\partial^{2} \theta}{\partial \mathrm{x}^{2}}=\frac{1}{\alpha} \frac{\delta \theta}{\delta \mathrm{t}}$

\subsubsection{TRANSFERENCIA DE CALOR POR CONVECÇÃO}

No mecanismo de convecção, a transferência de calor ocorre na interface formada entre duas superfícies de estados físicos diferentes. A transferência de calor por convecção ocorre pelo movimento dos fluidos, sejam eles gases ou líquidos, e é um importante fator no espalhamento das chamas, bem como no transporte ascendente de fumaça e gases quentes até o teto ou para o exterior do compartimento em chamas através das aberturas. 
Os cálculos relacionados à transferência de calor por convecção usualmente envolvem transferência de calor entre um sólido e um fluido circundante, que aquece ou resfria o material. A taxa de aquecimento ou resfriamento depende da velocidade do fluido na superfície. Para uma dada condição, a transferência é usualmente tomada como diretamente proporcional à diferença de temperatura entre os dois materiais, tal que o fluxo de calor por unidade de área seja dado pela equação 3.17 .

$\varphi=\alpha_{c} \cdot \Delta \theta$

$\mathrm{Na}$ equação 3.17, $\alpha_{c}$ é o coeficiente de transferência de calor por convecção em $\left[\mathrm{W} / \mathrm{m}^{2} \mathrm{~K}\right]$ e $\Delta \theta$ é a diferença de temperatura entre a superfície sólida e o fluido $\left[\mathrm{K}\right.$ ou $\left.{ }^{\circ} \mathrm{C}\right] . \mathrm{O}$ valor do coeficiente de transferência de calor por convecção $\alpha_{c}$ pode variar dependendo de fatores como a geometria e rugosidade da superfície, além da natureza do fluxo. O valor adotado pelo Eurocode 3 part $1-2$ é $\alpha_{c}=25 \mathrm{~W} / \mathrm{m}^{2} \mathrm{~K}$.

\subsubsection{TRANSFERENCIA DE CALOR POR RADIAÇÃO}

A transferência de calor ocorre por meio de vibrações de ondas eletromagnéticas e, neste caso, independe de um meio material.

Quando a energia térmica radiante passa por um meio, qualquer objeto dentro desse caminho pode absorver, refletir ou transmitir a radiação térmica incidente. Para tanto, os parâmetros denominados absortividade $(\alpha)$, refletividade $(\rho)$ e transmitância $(\tau)$ permitem representar frações de radiação térmica incidente que um dado corpo absorve, reflete ou transmite, respectivamente, dado pela equação 3.18 .

$\alpha+\rho+\tau=1$

\section{- Radiação de corpo negro}

Os parâmetros que descrevem a equação 3.18 dependem da temperatura, do comprimento das ondas eletromagnéticas e das propriedades da superfície do corpo incidente. A engenharia voltada ao estudo de incêndio admite algumas simplificações na consideração da energia térmica radiante. Um caso extremo é considerar que toda radiação térmica é absorvida pelo corpo, isto é $\alpha=1$. Tal corpo é denominado corpo negro. 
A radiação de corpo negro é de fundamental importância para a transferência de calor. Ele tem propriedades muito particulares, mas a mais importante é a de ser um perfeito emissor. Isso significa que nenhum outro corpo pode emitir mais radiação térmica por unidade de área superficial que um corpo negro em uma mesma temperatura. A quantidade total de radiação térmica $\left(\mathrm{E}_{\mathrm{b}}\right)$ emitida por uma superfície de corpo negro é uma função somente da sua temperatura, dada pela lei de Stefan-Boltzmann, expressa pela equação 3.19.

$$
\mathrm{E}_{\mathrm{b}}=\sigma \theta^{4}
$$

$\mathrm{Na}$ equação 3.19, $\sigma$ é a constante de Stefan-Boltzmann, igual a 5,67 x $10^{-8} \mathrm{~W} /\left(\mathrm{m}^{2} \mathrm{~K}^{4}\right)$, e $\theta$ é a temperatura absoluta em $\mathrm{K}$.

\section{- Intensidade da radiação térmica direcional}

Uma vez que a radiação térmica não é uniformemente distribuída no espaço, é necessário considerar um direcional para a radiação incidente fora da direção normal do emissor (corpo negro). Esse direcional, equação 3.20, é expresso pela Lei de Lambert. $\mathrm{I}_{\theta}=\mathrm{I}_{\mathrm{n}} \cos \theta$

Na 3.20, $I_{\theta}$ é a intensidade da radiação térmica a um ângulo $\theta$ da direção normal da superfície emissora e $\mathrm{I}_{\mathrm{n}}$ representa a radiação térmica na direção normal à superfície emissora, dado por $I_{n}=\frac{E_{b}}{\pi}$.

\section{- Fator de configuração ou fator de visada $\Phi$}

$\mathrm{Na}$ maioria dos casos, a radiação térmica incidente numa superfície é muito menor que do que a radiação total emitida por um corpo. Assim sendo, o fator de configuração é usado para representar a fração da radiação térmica emitida por uma superfície $\mathrm{dA}_{1}$ que incide numa superfície $\mathrm{dA}_{2}$.

A quantificação do fator de visada exige a resolução de uma complexa expressão analítica. No entanto, uma vez que essa expressão dependa apenas do arranjo espacial da superfície emissora e o ponto de visada, os valores do fator de configuração para muitas situações, já tem sido determinados. 
Nos casos reais, geralmente é requerido calcular a radiação térmica incidente de uma área finita $A_{1}$ em uma outra área finita $A_{2}$. Dessa forma, o fluxo de calor por radiação da área $\mathrm{A}_{1}$ para a área $\mathrm{A}_{2}$ é definido conforme a equação 3.21.

$$
\varphi_{\mathrm{r}_{\mathrm{A}_{1} \rightarrow \mathrm{A}_{2}}}=\iint_{\mathrm{A}_{1}, \mathrm{~A}_{2}} \mathrm{E}_{\mathrm{b} 1} \frac{\cos \theta_{1} \cos \theta_{2}}{\pi \mathrm{r}^{2}} \mathrm{dA}_{1} \mathrm{dA}_{2}=\mathrm{F}_{1 \rightarrow 2} \mathrm{~A}_{1} \mathrm{E}_{1}
$$

O fator $F_{1 \rightarrow 2}$, fator de configuração integrado, representa a fração de um fluxo de calor radiante emitido por uma superfície $\mathrm{A}_{1}$ e incidente na superfície $\mathrm{A}_{2}$.

\section{- Fluxo de calor de uma superfície de corpo cinzento}

Nenhum material real emite ou absorve radiação de acordo com a lei de corpo negro. Em geral, é necessário um termo adicional para definir a energia radiante de uma superfície emissora. Esse fator é a emissividade $\varepsilon$, definido como a relação entre a energia total emitida por uma superfície e a energia emitida pela superfície de um corpo negro a uma mesma temperatura. Dessa forma, a energia total emitida pela radiação por uma superfície qualquer é expressa segundo a equação 3.22 .

$$
\mathrm{E}=\varepsilon \sigma \theta^{4}
$$

A emissividade depende do comprimento de onda da energia radiante, da temperatura da superfície e do ângulo de radiação. No entanto, se a emissividade for considerada independente desses fatores, a superfície radiante é chamada de superfície de corpo cinzento, a qual é adotada nos cálculos da engenharia de segurança contra incêndio. A troca de calor entre duas superfícies de corpo cinzento é complexa e equações analíticas podem ser obtidas apenas pra casos muito simples.

\subsection{COMPARTIMENTAÇÃO DO AMBIENTE}

Chama-se compartimentação à técnica de interposição de elementos de construção resistentes ao fogo, destinadas a separar um ou mais locais do restante da edificação, de forma a evitar a propagação do fogo, calor e gases aquecidos, interna ou externamente, no mesmo pavimento ou em pavimentos diferentes. 
O alastramento do incêndio em uma edificação pode ser restrito se subdividido, separados entre si por paredes e/ou pisos resistentes ao fogo. Dessa forma, a compartimentação pode ser horizontal ou vertical. A compartimentação também condiciona a distribuição não-uniforme da temperatura nos elementos estruturais de interesse, a exemplo dos pilares.

Em relação à seção transversal, o gradiente térmico em pilares internos é diferente daqueles de extremidade. Em relação à seção longitudinal, embora as informações mais importantes para o projeto estrutural sejam obtidas na fase pós-flashover, o período que determina a distribuição não-uniforme do campo térmico é a fase pré-flashover. Nesse estágio, ocorre o transporte dos gases aquecidos, menos densos, por meio de uma corrente convectiva, até a parte superior do compartimento.

A camada formada por esses gases tem espessura e temperatura variáveis, conforme cresce a intensidade das chamas. A camada inferior consiste de corrente de ar com temperatura próxima à ambiente, que entra pelas aberturas e é aquecida por radiação provinda da camada superior. Conforme o incêndio prossegue, o volume de fumaça e gases quentes da camada superior aumenta, reduzindo a espessura da interface entre a camada aquecida superior e a inferior em temperaturas mais baixas.

Em WANG (2002) é observado que a representação em forma numérica de um incêndio compartimentado é um processo muito elaborado. Dentre as ferramentas utilizadas, três merecem destaque, sendo estas: o método analítico, a modelagem de zonas $e$ a modelagem computacional utilizando dinâmica dos fluidos (CFD).

O método analítico é o que fornece soluções mais simples. No entanto, o ajuste de parâmetros, para que se obtenha uma relação plausível entre os dados de entrada (grau de ventilação e carga de incêndio, por exemplo) e os resultados (tais como temperatura e tamanho das chamas), necessita de inúmeras análises. Dessa forma e devido à complexidade do problema físico, as soluções analíticas são feitas para casos muito limitados.

Em alternativa, na modelagem com $\boldsymbol{C F D}$, o fogo compartimentado é dividido em um grande número de volume de controle. As soluções são obtidas por meio das equações fundamentais da dinâmica dos fluidos, termodinâmica, das reações químicas e da mecânica. Trata-se de um conjunto de equações diferenciais parciais de massa e transferência de energia escritas para cada volume de controle.

Em seguida, são aplicadas condições de contorno apropriadas para encontrar as soluções numéricas dessas equações. Claramente, a modelagem em CFD é versátil e tem o potencial de fornecer resultados mais precisos e detalhados para um vasto campo de 
problemas. O método utilizando o CFD é aplicado principalmente para prever a produção e o movimento de fumaça e gases tóxicos na fase pré-flashover. Porém, o uso do CFD tem sido estendido para simular o espalhamento das chamas e a ignição.

Se as aproximações apresentadas representam dois extremos da modelagem, uma alternativa intermediaria é a modelagem de zonas de incêndio na fase pré-flashover dividindo o compartimento em duas zonas: a zona superior tomada por gases quentes e a zona inferior com corrente de ar em temperatura ambiente. Para cada zona, assume-se que as propriedades são uniformes, por exemplo, temperatura e concentração de fumaça.

O modelo de zonas é muito menos complicado do que os modelos do CFD, mas fornecem informações menos detalhadas. Eles também são menos versáteis e requerem um pré-conhecimento sobre o comportamento do fogo, por exemplo, como ele se divide no compartimento em zonas apropriadas e a interação entre eles. Porém, esse método é conveniente para a maioria das aplicações na engenharia onde a geometria do compartimento não é complicada e, consequentemente o comportamento do fogo é menos complexo.

O modelo de zonas pode ser usado para prever o comportamento de ambas as fases, tanto do pré-flashover como do flashover. Para o modelo de incêndio na fase flashover, que é de particular interesse para a engenharia de segurança contra incêndio, considera-se o compartimento com uma zona de temperatura.

\subsection{PROPRIEDADES FÍSICAS DO AÇO - Sob ação térmica}

A ação térmica, que tem como conseqüência direta a elevação de temperatura, afeta o comportamento de uma estrutura metálica em função dos seguintes aspectos:

a) alteração das propriedades mecânicas do aço, do concreto e do revestimento, fazendo com que os mesmos tenham sua resistência e rigidez reduzidas e se tornem, consequentemente, mais flexiveis;

b) deformações adicionais induzidas pelo efeito da temperatura (expansão).

A ABNT NBR 14323:1999 apresenta as variações das propriedades mecânicas e térmicas dos aços estruturais, submetidos a elevadas temperaturas, permitidos pela ABNT NBR 8800:1986 e pela ABNT NBR 14762:2001, as quais prescrevem equações para o 
dimensionamento de estruturas metálicas constituídas por perfis pesados e perfis formados a frio, respectivamente.

É importante ressaltar que a ABNT NBR 14323:1999 sugere que aços estruturais com propriedades diferentes das apresentadas em seu texto, ou que tenha suas propriedades alteradas em virtude dos trabalhos realizados para a conformação ou revestimento dos perfis ou composição da estrutura, tenham seus valores utilizados. Entretanto, tais valores devem ser obtidos por meio de especificação estrangeira ou ensaios realizados em laboratório nacional ou estrangeiro, de acordo com norma nacional ou estrangeira.

Atualmente, a ABNT NBR 14323:1999 se encontra em processo de revisão e, portanto, seu texto base ainda não é definitivo. Tendo em vista esses fatores, para o presente trabalho considerou adequado, na presente data, tomar como base os métodos de cálculo propostos pelo EUROCODE 3 part 1-2. Em data futura, quando a norma brasileira possuir seu novo texto em vigor, novas considerações com base nas prescrições nela atualizadas serão abordadas em futuros projetos de pesquisa.

\subsubsection{PROPRIEDADES MECÂNICAS}

\subsubsection{Elementos de aço laminados e soldados}

A relação constitutiva do aço em temperaturas elevadas, proposta pelo Eurocode é determinada por meio de ensaio térmico transiente, com taxa de aquecimento de $10^{\circ} \mathrm{C} / \mathrm{min}$, como ocorre na maioria dos casos reais de estruturas metálicas expostas ao fogo, cuja aplicação de forças externas ocorre antes da exposição à ação térmica. A Figura 3.4 ilustra o gráfico da relação constitutiva do aço utilizada pelo EUROCODE 3 Part 2.

São quatro estágios na curva "tensão $x$ deformação", sendo que o primeiro consiste de uma resposta linear da deformação para o nível de tensão aplicado. Essa resposta é linear até que o elemento atinja a tensão de proporcionalidade. No segundo estágio, a relação constitutiva segue o comportamento elasto-plástico com encruamento, observando que para uma dada tensão o trecho elástico da deformação sofreu alteração em posição e tamanho. $\mathrm{O}$ terceiro estágio representa o escoamento da barra, ou seja, o acréscimo de deformação sem variação do nível de tensão. A última parte da curva é caracterizada pelo decrescimento linear da tensão (amolecimento) até que a tensão seja nula. 


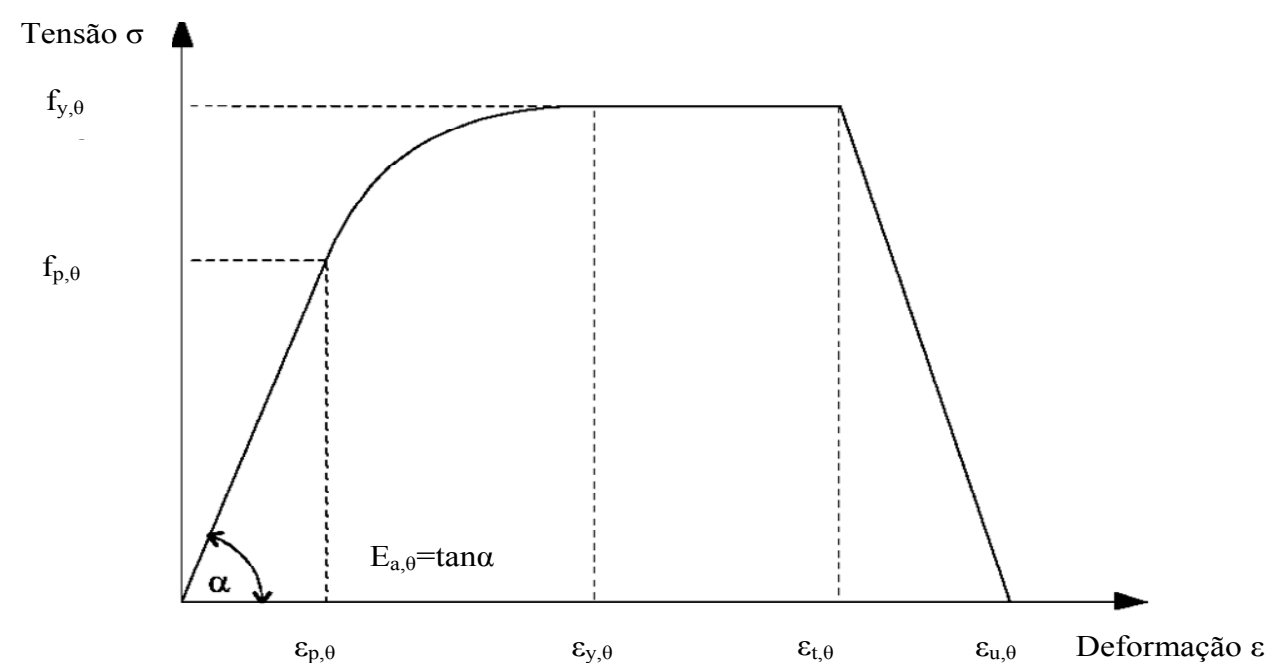

Figura 3.4: Relação constitutiva do aço-carbono em função da temperatura $\theta$.

Com relação à figura 3.4, considerando a variação com a temperatura, tem-se que $\mathrm{f}_{\mathrm{y}, \theta}$ é a resistência ao escoamento, $\mathrm{f}_{\mathrm{p}, \theta}$ é o limite de proporcionalidade, $\mathrm{E}_{\mathrm{a}, \theta}$ é o modulo de elasticidade na fase elástica, $\varepsilon_{\mathrm{p}, \theta}$ é o limite de proporcionalidade na deformação, $\varepsilon_{\mathrm{y}, \theta}$ é a deformação de escoamento, $\varepsilon_{\mathrm{t}, \theta}$ é o limite de deformação para a resistência ao escoamento e $\varepsilon_{\mathrm{u}, \theta}$ é a deformação de ruptura.

A Tabela 3.2 fornece a descrição matemática usada pelo Eurocode. Para usar esse modelo, a resistência e a rigidez do aço em temperaturas elevadas são requeridas como dados de entradas, e a Tabela 3.3 dá esses valores na forma de fatores de redução expressos como a relação entre a resistência e o módulo de elasticidade a uma determinada temperatura $\theta$ e em temperatura ambiente. A Figura 3.5 ilustra a variação das propriedades, na forma de fatores de redução, em função da temperatura. 
Tabela 3.2: Equações da relação constitutiva a uma determinada temperatura $\theta$ Deformações Módulo de elasticidade Tensão

\begin{tabular}{|c|c|}
\hline$\varepsilon \leq \varepsilon_{\mathrm{o}, \theta}$ & $\mathrm{E}_{\mathrm{t}, \theta}=\mathrm{E}_{\mathrm{a}, \theta}$ \\
\hline$\varepsilon_{\mathrm{p}, \theta} \leq \varepsilon \leq \varepsilon_{\mathrm{y}, \theta}$ & $\mathrm{E}_{\mathrm{t}, \theta}=\frac{\mathrm{b}\left(\varepsilon_{\mathrm{y}, \theta}-\varepsilon\right)}{\mathrm{a} \sqrt{\mathrm{a}^{2}-\left(\varepsilon_{\mathrm{y}, \theta}-\varepsilon\right)^{2}}} \quad \sigma=\mathrm{f}_{\mathrm{p}, \theta}-\mathrm{c}+\frac{\mathrm{b}}{\mathrm{a}} \sqrt{\mathrm{a}^{2}-\left(\varepsilon_{\mathrm{y}, \theta}-\varepsilon\right)^{2}}$ \\
\hline$\varepsilon_{\mathrm{y}, \theta} \leq \varepsilon \leq \varepsilon_{\mathrm{t}, \theta}$ & $\mathrm{E}_{\mathrm{t}, \theta}=0$ \\
\hline$\varepsilon_{\mathrm{t}, \theta} \leq \varepsilon \leq \varepsilon_{\mathrm{u}, \theta}$ & $-\quad \sigma=\mathrm{f}_{\mathrm{y}, \theta}\left[1-\frac{\left(\varepsilon-\varepsilon_{\mathrm{t}, \theta}\right)}{\left(\varepsilon_{\mathrm{u}, \theta}-\varepsilon_{\mathrm{t}, \theta}\right)}\right]$ \\
\hline$\varepsilon \geq \varepsilon_{\mathrm{u}, \theta}$ & $\sigma=0,0$ \\
\hline Parâmetros & $\varepsilon_{\mathrm{y}, \theta}=0,02 \quad \varepsilon_{\mathrm{t}, \theta}=0,15 \quad \varepsilon_{\mathrm{u}, \theta}=0,20$ \\
\hline Funções & $\begin{array}{c}\mathrm{b}^{2}=\mathrm{c}\left(\varepsilon_{\mathrm{y}, \theta}-\varepsilon_{\mathrm{p}, \theta}\right) \mathrm{E}_{\mathrm{a}, \theta}+\mathrm{c}^{2} \\
\mathrm{c}=\frac{\left(\mathrm{f}_{\mathrm{y}, \theta}-\mathrm{f}_{\mathrm{p}, \theta}\right)^{2}}{\left(\varepsilon_{\mathrm{y}, \theta}-\varepsilon_{\mathrm{p}, \theta}\right) \mathrm{E}_{\mathrm{a}, \theta}-2\left(\mathrm{f}_{\mathrm{y}, \theta}-\mathrm{f}_{\mathrm{p}, \theta}\right)}\end{array}$ \\
\hline
\end{tabular}

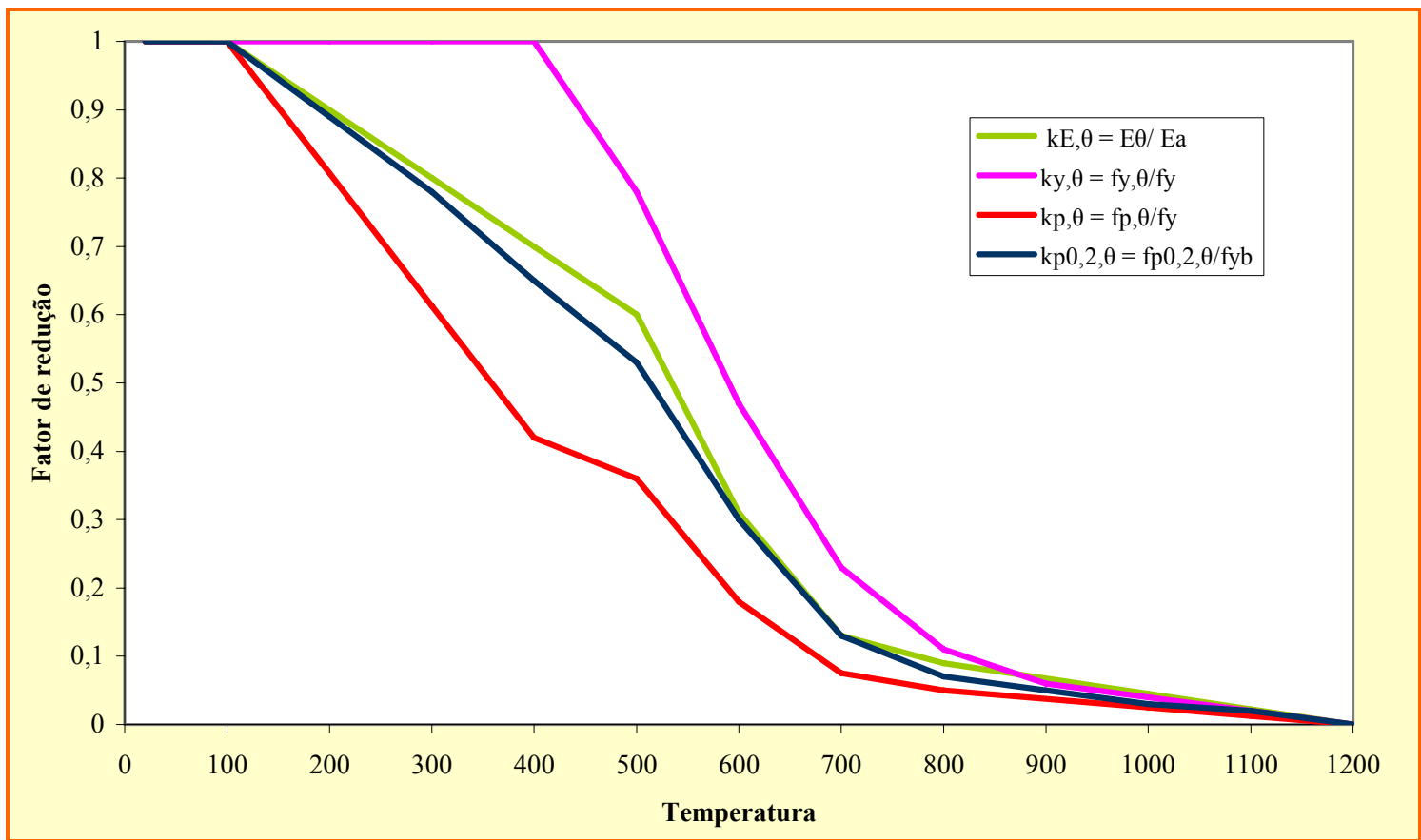

Figura 3.5: Representação gráfica da redução das propriedades mecânicas do aço, em função da temperatura $\left(\mathrm{em}^{\circ} \mathrm{C}\right)$. 


\subsubsection{Perfis formados a frio}

Em MALITE (2001) é relatado que trabalho a frio altera as propriedades mecânicas do aço virgem, aumentando a resistência ao escoamento do elemento e diminuindo a ductilidade. O material na região das dobras é o que mais sofre influência do trabalho a frio. Por essa razão, o escoamento sempre se inicia na parte plana, pois nessa região, a resistência ao escoamento é menor, ocorrendo uma redistribuição de tensões das partes planas para os cantos da seção. Num cenário de incêndio, esse acúmulo de resistência ao escoamento devido ao trabalho a frio é reduzido.

Além disso, a seção delgada tende a ter mais influência da ação térmica se comparado aos perfis pesados, de modo que os fatores de redução para os perfis formados a frio resultam mais severos se comparados àqueles dos perfis pesados. Isso se deve ao fato de os perfis formados a frio apresentarem flambagens localizadas, o que é menos pronunciado nos perfis robustos.

A Tabela 3.3 apresenta valores de fatores de redução, extraídos do Eurocode, para perfis compostos por elementos esbeltos, classificados como Perfis Classe 4, que também são arbitrariamente aplicados aos perfis formados a frio. A representação gráfica desses coeficientes também está contemplada na figura 3.5. 
Tabela 3.3: Fatores de redução para as propriedades mecânicas do aço.

\begin{tabular}{|c|c|c|c|c|}
\hline \multirow{3}{*}{$\begin{array}{c}\text { Temperatura do } \\
\text { aço } \theta_{\mathrm{a}}\left[{ }^{\circ} \mathrm{C}\right]\end{array}$} & \multirow{2}{*}{$\begin{array}{l}\text { Fator de redução } \\
\text { (relativo a E) para o } \\
\text { módulo de elasticidade } \\
\text { no comportamento } \\
\text { elástico-linear }\end{array}$} & \multicolumn{2}{|c|}{ Perfis laminados e soldados } & \multirow{2}{*}{$\begin{array}{c}\begin{array}{c}\text { Seções transversais } \\
\text { esbeltas }\end{array} \\
\begin{array}{c}\text { Fator de redução (em } \\
\text { relação a } \mathrm{f}_{\mathrm{yb}} \text { ) para a } \\
\text { resistência de escoamento } \\
\mathrm{f}_{\mathrm{yb}, \theta}\end{array}\end{array}$} \\
\hline & & $\begin{array}{l}\text { Fator de redução } \\
\text { (relativo a } \mathrm{f}_{\mathrm{y}} \text { ) para a } \\
\text { resisntência ao } \\
\text { escoamento, } \mathrm{f}_{\mathrm{y}, \theta}\end{array}$ & $\begin{array}{l}\text { Fator de redução } \\
\text { (relativo a } \mathrm{f}_{\mathrm{y}} \text { ) para o } \\
\text { limite de } \\
\text { proporcionalidade, } \mathrm{f}_{\mathrm{p}, \theta}\end{array}$ & \\
\hline & $k_{E, \theta}=E_{\theta} / E_{a}$ & $k_{y, \theta}=f_{y, \theta} / f_{y}$ & $k_{p, \theta}=f_{p, \theta} / f_{y}$ & $k_{p 0,2, \theta}=f_{p 0,2, \theta} / f_{y b}$ \\
\hline 20 & 1 & 1 & 1 & 1 \\
\hline 100 & 1 & 1 & 1 & 1 \\
\hline 200 & 0,9 & 1 & 0,807 & 0,89 \\
\hline 300 & 0,8 & 1 & 0,613 & 0,78 \\
\hline 400 & 0,7 & 1 & 0,42 & 0,65 \\
\hline 500 & 0,6 & 0,78 & 0,36 & 0,53 \\
\hline 600 & 0,31 & 0,47 & 0,18 & 0,3 \\
\hline 700 & 0,13 & 0,23 & 0,075 & 0,13 \\
\hline 800 & 0,09 & 0,11 & 0,05 & 0,07 \\
\hline 900 & 0,0675 & 0,06 & 0,0375 & 0,05 \\
\hline 1000 & 0,045 & 0,04 & 0,025 & 0,03 \\
\hline 1100 & 0,0225 & 0,02 & 0,0125 & 0,02 \\
\hline 1200 & 0 & 0 & 0 & 0 \\
\hline
\end{tabular}

\subsubsection{PROPRIEDADES TÉRMICAS}

\subsubsection{Condutividade térmica}

De acordo com a ABNT NBR 14323:1999, a condutividade térmica varia com a temperatura segundo a equação 3.23 e Figura 3.6:

$$
\begin{array}{ll}
\lambda_{\mathrm{a}}=54-\frac{\theta_{\mathrm{a}}}{300} & \text { para } \\
\lambda_{\mathrm{a}}=27,3 & 20^{\circ} \mathrm{C} \leq \theta_{\mathrm{a}} 800^{\circ} \mathrm{C} \\
800^{\circ} \mathrm{C} \leq \theta_{\mathrm{a}} 1200^{\circ} \mathrm{C}
\end{array}
$$




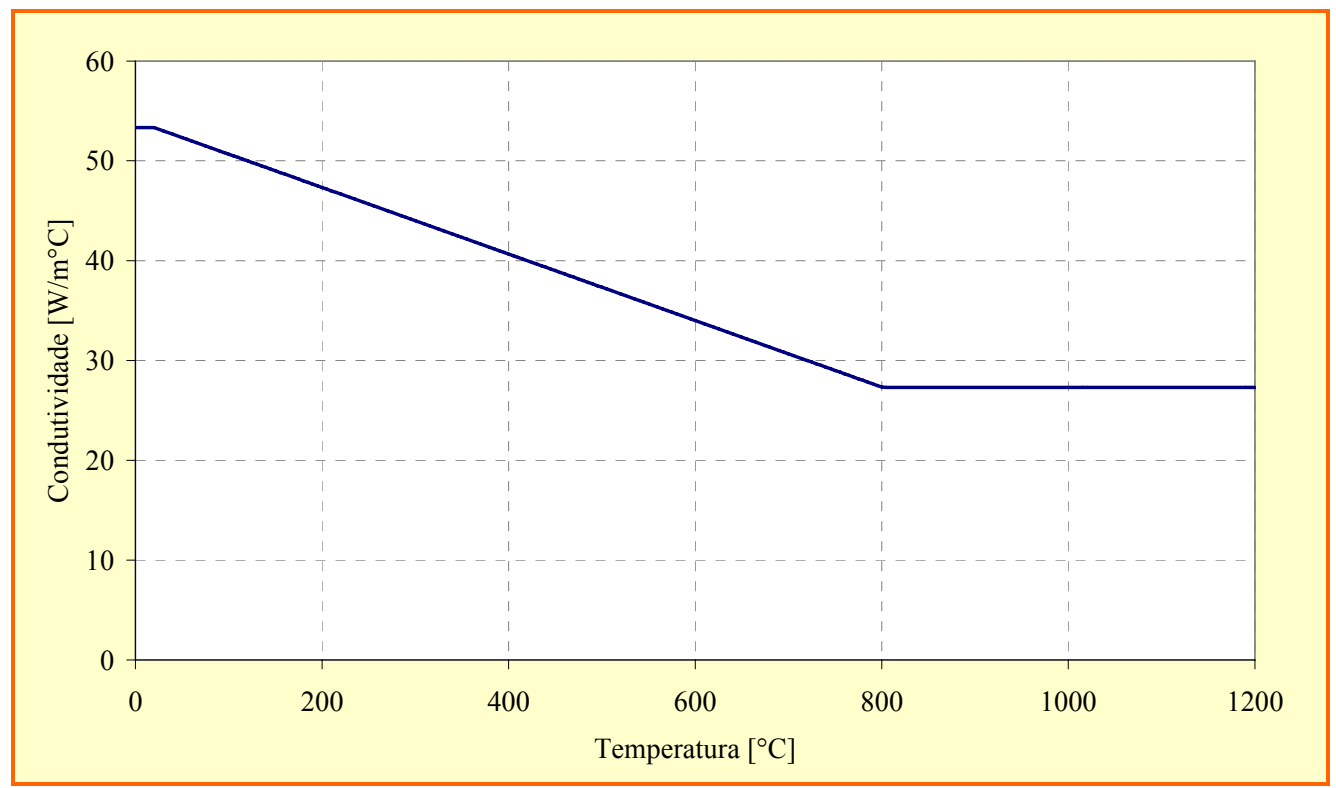

Figura 3.6: Gráfico da condutividade térmica em função da temperatura.

\subsubsection{Alongamento (dilatação térmica)}

O alongamento do aço é determinado, conforme a equação 3.24, e a variação da dilatação térmica é ilustrada na Figura 3.7.

$$
\begin{array}{lrlrl}
\frac{\Delta \mathrm{l}}{1}=1,2 \cdot 10^{-5} \theta_{\mathrm{a}}+0,4 \cdot 10^{-8} \cdot \theta_{\mathrm{a}}-2,416 \cdot 10^{-4} & & 20^{\circ} \mathrm{C}<\theta_{\mathrm{a}} \leq 750^{\circ} \mathrm{C} \\
\frac{\Delta \mathrm{l}}{1}=1,1 \cdot 10^{-2} & \text { para } & 750^{\circ} \mathrm{C}<\theta_{\mathrm{a}} \leq 860^{\circ} \mathrm{C} \\
\frac{\Delta \mathrm{l}}{1}=2.10^{-5} \theta_{\mathrm{a}}-6,2.10^{-3} & & 860^{\circ} \mathrm{C}<\theta_{\mathrm{a}} \leq 1200^{\circ} \mathrm{C}
\end{array}
$$

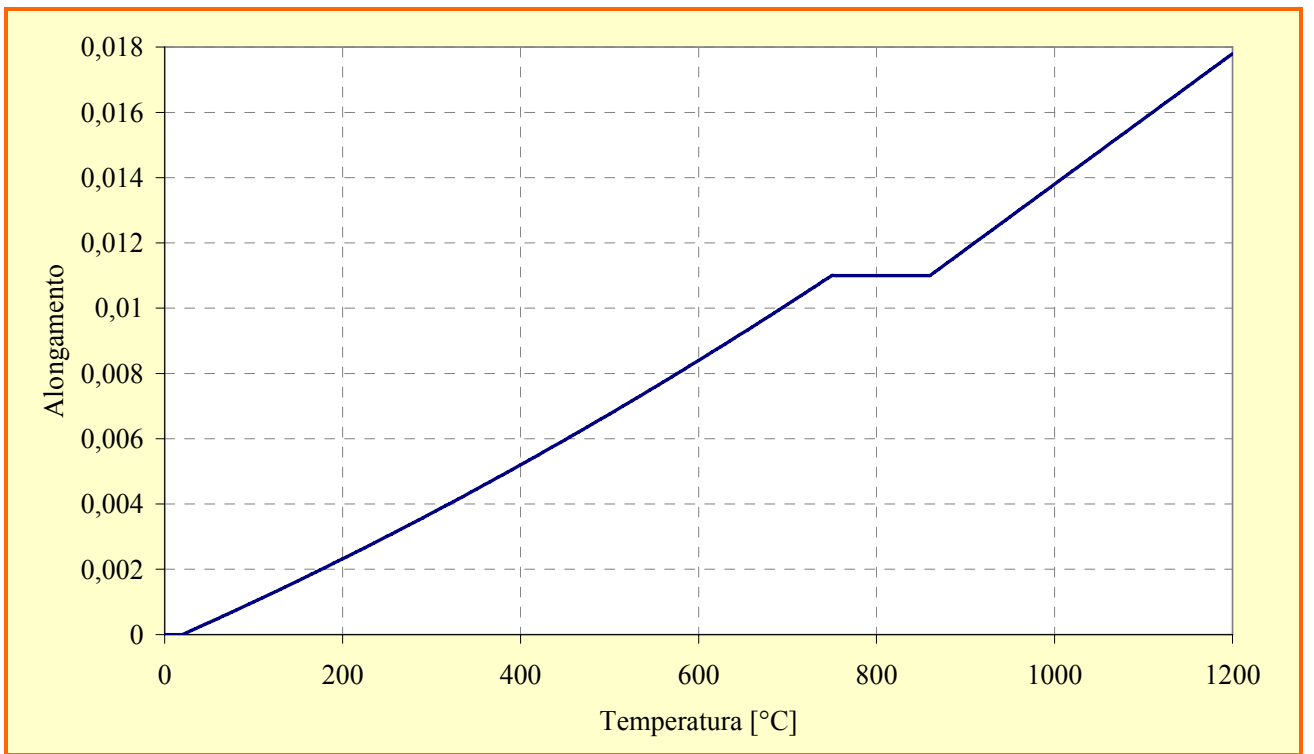

Figura 3.7: Gráfico da dilatação térmica em função da temperatura. 


\subsubsection{Calor específico}

$\mathrm{O}$ calor específico do aço, $\mathrm{c}_{\mathrm{a}}$, em $\mathrm{J} / \mathrm{kg}^{\circ} \mathrm{C}$, pode ser determinado conforme a equação 3.25. A Figura 3.8 mostra a representação gráfica do conjunto de equações em 3.25.

$$
\begin{array}{lr}
c_{a}=425+0,773 \theta_{a}-1,69.10^{-3} \theta_{a}^{2}+2,22.10^{-6} \theta_{a}^{-3} & 20{ }^{\circ} \mathrm{C} \leq \theta_{a} \leq 600^{\circ} \mathrm{C} \\
c_{a}=666+\frac{13002}{738-\theta_{a}} & \text { para } \\
c_{a}=545+\frac{17820}{\theta_{a}-731} & 735^{\circ} \mathrm{C}<\theta_{a} \leq 900^{\circ} \mathrm{C} \\
c_{a}=650 & 900^{\circ} \mathrm{C}<\theta_{a} \leq 1200^{\circ} \mathrm{C}
\end{array}
$$

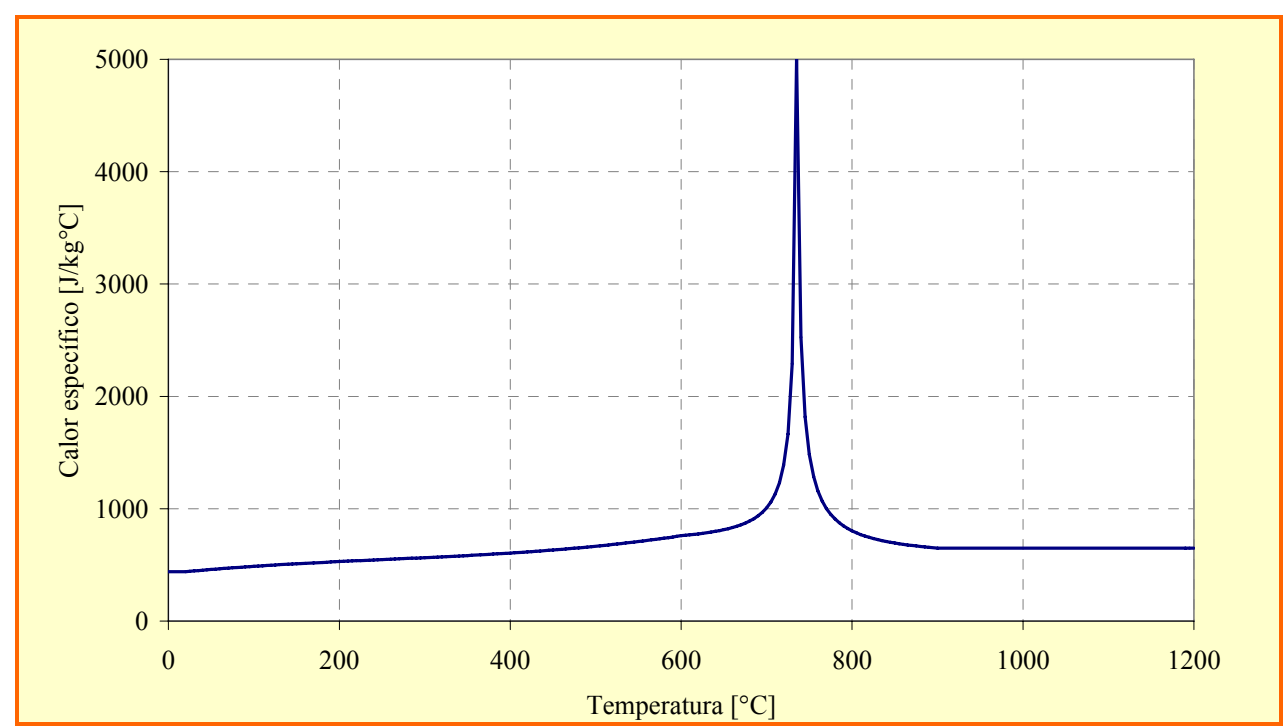

Figura 3.8: Gráfico do calor específico em função da temperatura.

\subsection{PROPRIEDADES FÍSICAS DO CONCRETO}

Embora a presente pesquisa não abranja estruturas em concreto, a citação de suas características físicas se faz importante, uma vez que a laje, composta deste material participa da compartimentação do edifício. Segundo WANG (2002), o concreto é um material higroscópico que contem água. Devido à migração da água, o processo de transferência de calor é afetado. Para avaliar as temperaturas nesse tipo de material de forma precisa, deve ser realizada uma análise combinada de transferência de temperatura e massa. Porém, essa análise é complexa e muito custosa computacionalmente.

As propriedades físicas de resistência e deformação do concreto e a influência exercida pela elevação térmica é citada no Eurocode 2 part 1-2 para os concretos de densidade 
normal. A relação constitutiva, para uma temperatura $\theta$ qualquer, é descrita pela equação 3.26 .

$$
\sigma(\theta)=\frac{3 \cdot \varepsilon \cdot \mathrm{f}_{\mathrm{c}, \theta}}{\varepsilon_{\mathrm{c}, 1, \theta}\left(2+\left(\frac{\varepsilon}{\varepsilon_{\mathrm{c}, 1, \theta}}\right)^{3}\right)} \text { para } \varepsilon \leq \varepsilon_{\mathrm{c}, 1, \theta}
$$

Para $\varepsilon_{\mathrm{c}, 1, \theta} \leq \varepsilon \leq \varepsilon_{\mathrm{c}, \mathrm{u}, \theta}$, pode ser adotado um ramo descendente linear ou não-linear. A equação 3.26 é representada pelo gráfico da Figura 3.9.

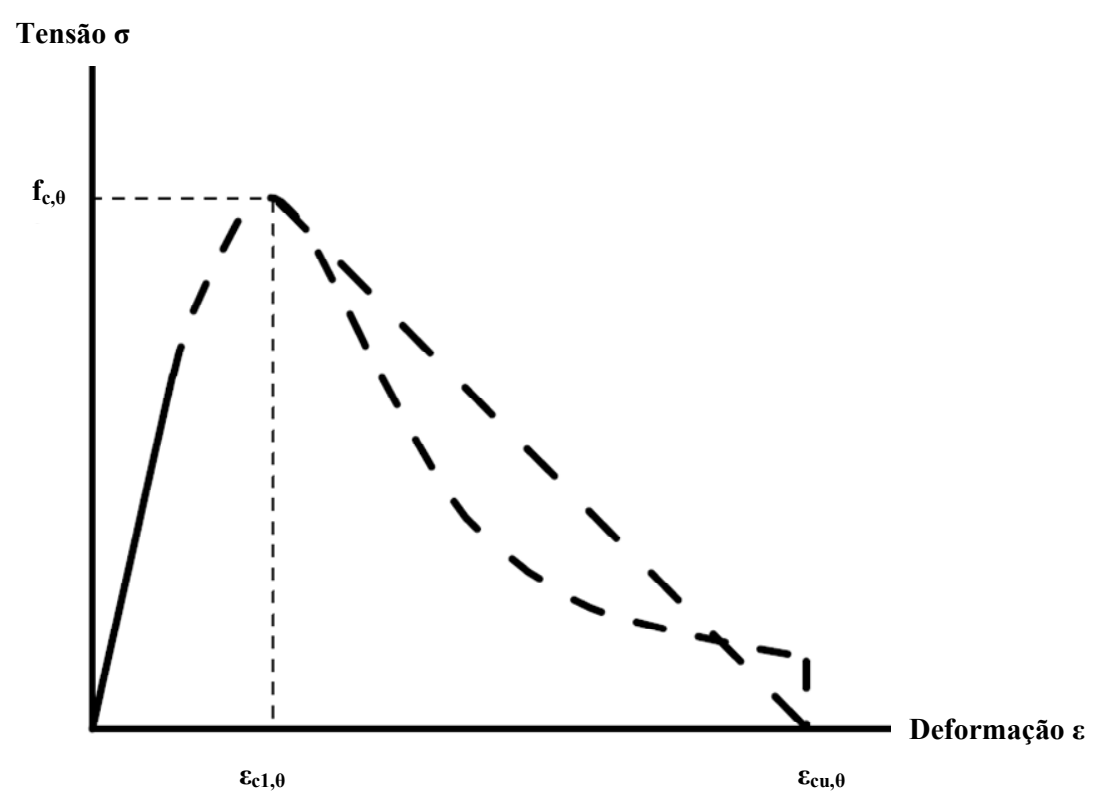

Figura 3.9: Relação constitutiva do concreto de densidade normal, segundo o Eurocode.

Com relação à equação 3.26, considerando a variação com a temperatura, $\sigma(\theta)$ é a tensão aplicada no concreto, $\varepsilon$ é a deformação correspondente a uma tensão $\sigma, \varepsilon_{\mathrm{cu}, \theta}$ é a deformação última a compressão, $\varepsilon_{\mathrm{c} 1, \theta}$ é a deformação a compressão correspondente a $\mathrm{f}_{\mathrm{c}, \theta}$ e $\mathrm{f}_{\mathrm{c}, \theta}$ é a resistência do concreto à compressão.

A Tabela 3.4 apresenta os fatores de redução das propriedades mecânicas do concreto apresentadas pelo Eurocode, para o concreto a base de agregado silicoso e agregado calcáreo. A ABNT NBR 14323:1999 cita as especificações do concreto normal e o concreto de baixa densidade. A Tabela 3.5 apresenta os fatores de redução das propriedades mecânicas do concreto de densidade normal e de baixa densidade. 
Tabela 3.4: Fatores de redução para o concreto, segundo o Eurocode

\begin{tabular}{ccccccc}
\hline & \multicolumn{3}{c}{ Concreto com agregado silicoso } & \multicolumn{3}{c}{ Concreto com agregado calcáreo } \\
\cline { 2 - 7 } $\begin{array}{c}\text { Temperatura } \\
\text { do concreto } \theta_{c} \\
{\left[{ }^{\circ} \mathrm{C}\right]}\end{array}$ & $\begin{array}{c}\text { Resistência a a } \\
\text { compressão }\end{array}$ & $\begin{array}{c}\text { Deformação } \\
\text { correspondente } \\
\text { ao limite de } \\
\text { compressão }\end{array}$ & $\begin{array}{c}\text { Deformação } \\
\text { última de } \\
\text { compressão }\end{array}$ & $\begin{array}{c}\text { Resistência a a } \\
\text { compressão }\end{array}$ & $\begin{array}{c}\text { Deformação } \\
\text { correspondente } \\
\text { ao limite de } \\
\text { compressão }\end{array}$ & $\begin{array}{c}\text { Deformação } \\
\text { última de } \\
\text { compressão }\end{array}$ \\
\hline 20 & 1,000 & 0,003 & 0,020 & 1,000 & 0,00 & 0,020 \\
100 & 1,000 & 0,004 & 0,023 & 1,000 & 0,00 & 0,023 \\
200 & 0,950 & 0,006 & 0,025 & 0,970 & 0,01 & 0,025 \\
300 & 0,850 & 0,007 & 0,275 & 0,910 & 0,01 & 0,028 \\
400 & 0,750 & 0,010 & 0,030 & 0,850 & 0,01 & 0,030 \\
500 & 0,600 & 0,015 & 0,033 & 0,740 & 0,02 & 0,033 \\
600 & 0,450 & 0,025 & 0,035 & 0,600 & 0,03 & 0,035 \\
700 & 0,300 & 0,025 & 0,038 & 0,430 & 0,03 & 0,038 \\
800 & 0,150 & 0,025 & 0,040 & 0,270 & 0,03 & 0,040 \\
900 & 0,080 & 0,025 & 0,043 & 0,150 & 0,03 & 0,043 \\
1000 & 0,040 & 0,025 & 0,045 & 0,060 & 0,03 & 0,045 \\
1100 & 0,010 & 0,025 & 0,048 & 0,020 & 0,03 & 0,048 \\
1200 & 0,000 & - & - & 0,000 & - & - \\
\hline
\end{tabular}

Tabela 3.5: Fatores de redução do concreto apresentadas pela ABNT NBR 14323:1999

\begin{tabular}{ccc}
\hline Temperatura do concreto & $\begin{array}{c}\text { Fator de redução para a } \\
\text { resistência característica à } \\
\text { compressão do concreto de } \\
\theta_{\mathrm{a}}\left[{ }^{\circ} \mathrm{C}\right]\end{array}$ & $\begin{array}{c}\text { Fator de redução para a } \\
\text { resistência característica à } \\
\text { compressão do concreto de } \\
\text { baixa densidade } \\
K_{c, \theta}\end{array}$ \\
\hline 20 & 1 & $K_{c b, \theta}$ \\
100 & 0,95 & 1 \\
200 & 0,9 & 0,95 \\
300 & 0,85 & 0,9 \\
400 & 0,75 & 0,85 \\
500 & 0,6 & 0,75 \\
600 & 0,45 & 0,6 \\
700 & 0,3 & 0,45 \\
800 & 0,15 & 0,3 \\
900 & 0,08 & 0,15 \\
1000 & 0,04 & 0,08 \\
1100 & 0,01 & 0,04 \\
1200 & 0 & 0,01 \\
\hline
\end{tabular}

Nota: Para valores intermediários de temperatura, pode ser feita interpolação linear. 
A ABNT NBR 14323:1999 ainda sugere que o módulo de elasticidade longitudinal do concreto de densidade normal, em qualquer temperatura, seja calculado por meio da equação 3.27, em que $\gamma_{\mathrm{c}}$ é o peso especifico do concreto, em $\mathrm{kN} / \mathrm{m}^{3}$ (valor mínimo previsto de 15 $\mathrm{kN} / \mathrm{m}^{3}$ ) e $\mathrm{K}_{\mathrm{c}, \theta}$ é o fator de redução, relativo ao valor de $20^{\circ} \mathrm{C}$, da resistência característica a compressão do concreto de densidade normal.

$$
\mathrm{E}_{\mathrm{c}, \theta}=42 \gamma_{\mathrm{c}}^{1,5} \sqrt{\mathrm{K}_{\mathrm{c}, \theta} \cdot \mathrm{f}_{\mathrm{ck}}}
$$

O Eurocode 2 part 1.2 traz distinções entre o concreto silicoso e o concreto calcáreo. A variação das propriedades térmicas pode ser analisada na Tabela 3.6, bem como por meio dos gráficos ilustrados nas figuras 3.10, 3.11 e 3.12 .

No item que segue serão apresentados alguns aspectos sobre o dimensionamento de pilares de aço propostos pelo método simplificado do Eurocode.

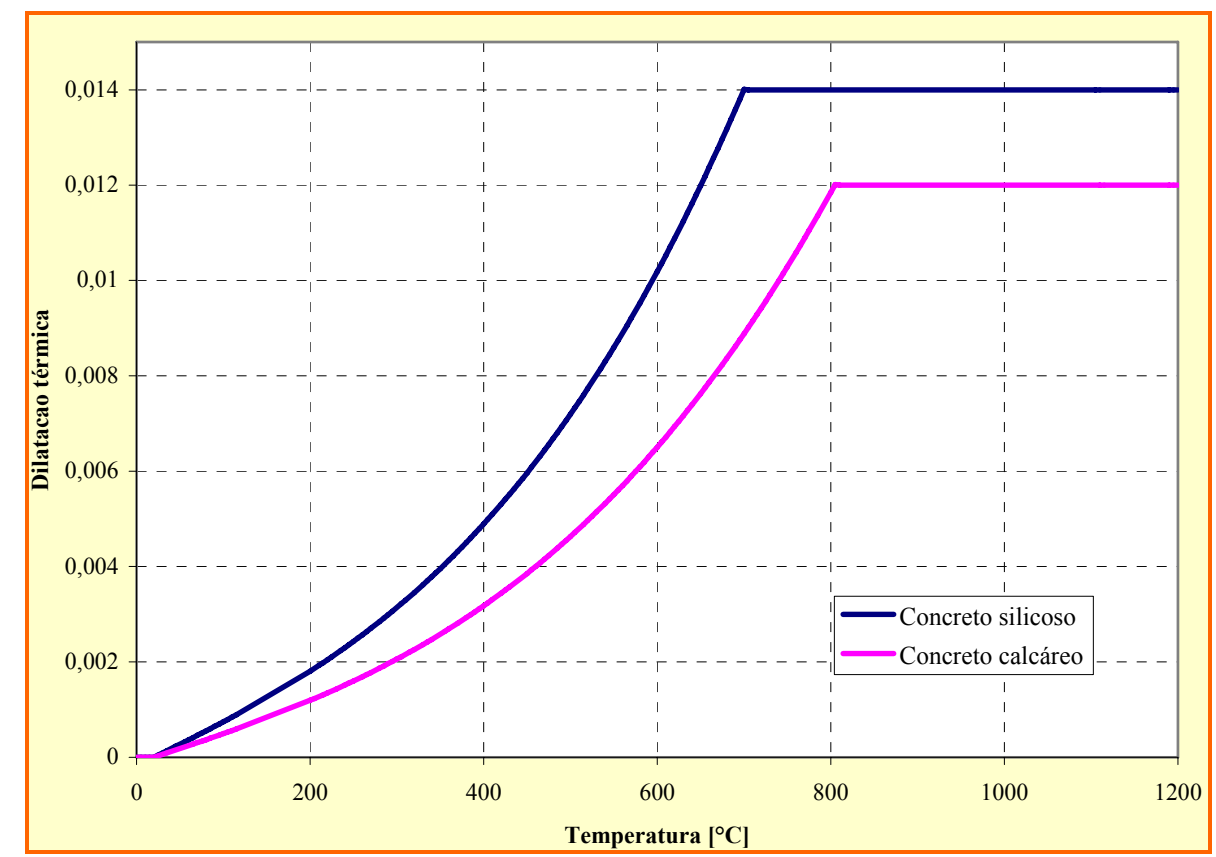

Figura 3.10: Alongamento térmico do concreto, segundo o Eurocode 2 part 1-2. 
Tabela 3.6: Propriedades térmicas do concreto segundo o Eurocode

\begin{tabular}{|c|c|}
\hline & Propriedades térmicas \\
\hline \multirow{2}{*}{$\begin{array}{c}\text { Dilatação } \\
\text { térmica, } \varepsilon_{c}(\theta)\end{array}$} & $\begin{array}{l}\varepsilon_{\mathrm{c}}(\theta)=-1,8 \times 10^{-4}+9 \times 10^{-6} \theta+2,3 \times 10^{-11} \theta^{3} \\
\text { para } 20^{\circ} \mathrm{C} \leq \theta_{\mathrm{c}} \leq 700^{\circ} \mathrm{C} \\
\varepsilon_{\mathrm{c}}(\theta)=14 \times 10^{-3} 700^{\circ} \mathrm{C} \leq \theta_{\mathrm{c}} \leq 1200^{\circ} \mathrm{C}\end{array}$ \\
\hline & $\begin{array}{l}\varepsilon_{\mathrm{c}}(\theta)=-1,2 \times 10^{-4}+6 \times 10^{-6} \theta+1,4 \times 10^{-11} \theta^{3} \\
\text { para } 20^{\circ} \mathrm{C}<\theta_{\mathrm{c}} \leq 805^{\circ} \mathrm{C} \\
\varepsilon_{\mathrm{c}}(\theta)=12 \times 10^{-3} 805^{\circ} \mathrm{C} \leq \theta_{\mathrm{c}} \leq 1200^{\circ} \mathrm{C}\end{array}$ \\
\hline $\begin{array}{c}\text { Calor } \\
\text { específico, } \mathrm{c}_{\mathrm{p}} \\
{[\mathrm{J} / \mathrm{kgK}]}\end{array}$ & $\begin{array}{l}c_{p}(\theta)=900 \text { para } 20^{\circ} \mathrm{C} \leq \theta_{c} \leq 700^{\circ} \mathrm{C} \\
c_{p}(\theta)=900+(\theta-100) \text { para } 20^{\circ} \mathrm{C} \leq \theta_{c} \leq 700^{\circ} \mathrm{C} \\
c_{p}(\theta)=1000+\frac{(\theta-200)}{2} \text { para } 20^{\circ} \mathrm{C} \leq \theta_{c} \leq 700^{\circ} \mathrm{C} \\
c_{p}(\theta)=1100 \text { para } 20^{\circ} \mathrm{C} \leq \theta_{c} \leq 700^{\circ} \mathrm{C}\end{array}$ \\
\hline
\end{tabular}

Calor específico de pico, $\mathrm{c}_{\mathrm{p} \text {, pico }}$ $\mathrm{c}_{\mathrm{p} \text {,pico }}=900$ para umidade de $0 \%$ do peso do concreto; $\mathrm{c}_{\mathrm{p} \text {, pico }}=1470$ para umidade de $1,5 \%$ do peso do concreto; $[\mathrm{J} / \mathrm{kgK}]$ $\mathrm{c}_{\mathrm{p} \text {,pico }}=2020$ para umidade de $3,0 \%$ do peso do concreto; $\rho(\theta)=\rho\left(20^{\circ} \mathrm{C}\right)$ para $20^{\circ} \mathrm{C} \leq \theta_{\mathrm{c}} \leq 115^{\circ} \mathrm{C}$ $\rho(\theta)=\rho\left(20^{\circ} \mathrm{C}\right) \cdot\left(1-0,02 \frac{(\theta-115)}{85}\right)$ para $115^{\circ} \mathrm{C} \leq \theta_{\mathrm{c}} \leq 200^{\circ} \mathrm{C}$

Densidade $\left[\mathrm{kg} / \mathrm{m}^{3}\right]$ $\rho(\theta)=\rho\left(20^{\circ} \mathrm{C}\right) \cdot\left(0,98-0,03 \frac{(\theta-200)}{200}\right)$ para $200^{\circ} \mathrm{C} \leq \theta_{\mathrm{c}} \leq$ $400^{\circ} \mathrm{C}$ $\rho(\theta)=\rho\left(20^{\circ} \mathrm{C}\right) \cdot\left(0,95-0,07 \frac{(\theta-400)}{800}\right)$ para $400^{\circ} \mathrm{C} \leq \theta_{\mathrm{c}} \leq$ $1200^{\circ} \mathrm{C}$

Condutividade Limite superior: $\lambda_{c}=2-0,2451\left(\frac{\theta_{c}}{100}\right)+0,0107\left(\frac{\theta_{c}}{100}\right)^{2}$ térmica $\lambda_{\mathrm{cn}} \quad$ para $20^{\circ} \mathrm{C} \leq \theta_{\mathrm{c}} \leq 1200^{\circ} \mathrm{C}$

$[\mathrm{W} / \mathrm{mK}] \quad$ Limite inferior: $\lambda_{\mathrm{c}}=1,36-0,136\left(\frac{\theta_{\mathrm{c}}}{100}\right)+0,0057\left(\frac{\theta_{\mathrm{c}}}{100}\right)^{2}$ para $20^{\circ} \mathrm{C} \leq \theta_{\mathrm{c}} \leq 1200^{\circ} \mathrm{C}$ 


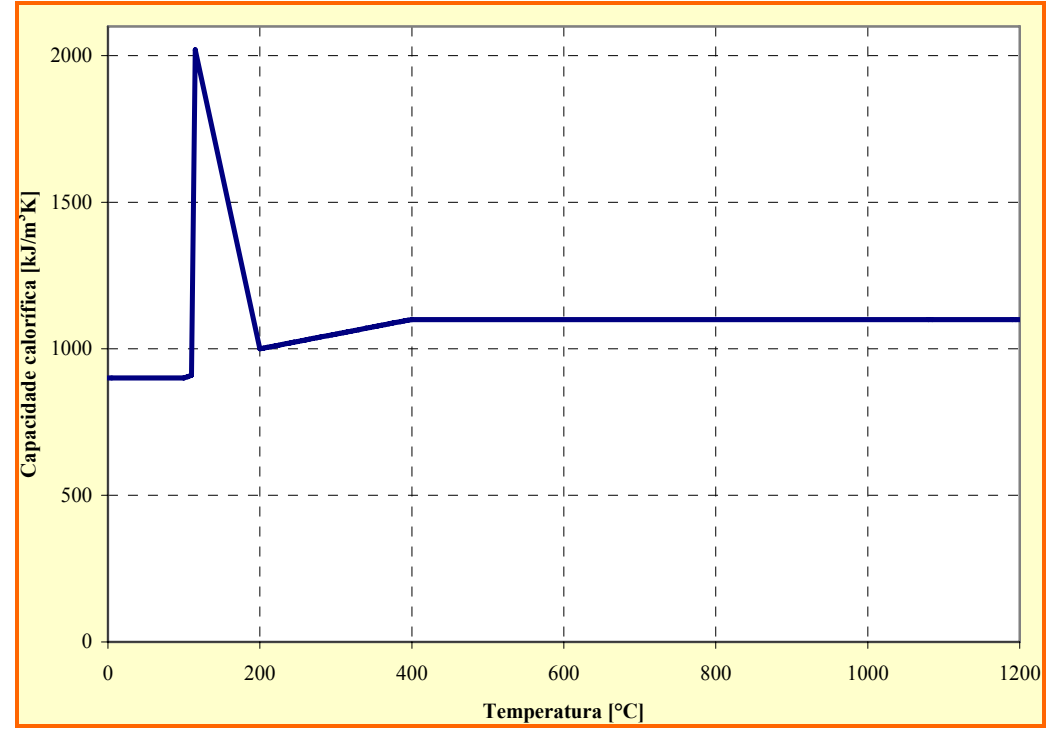

Figura 3.11: Capacidade calorífica do concreto, segundo o Eurocode 2 part 1-2.

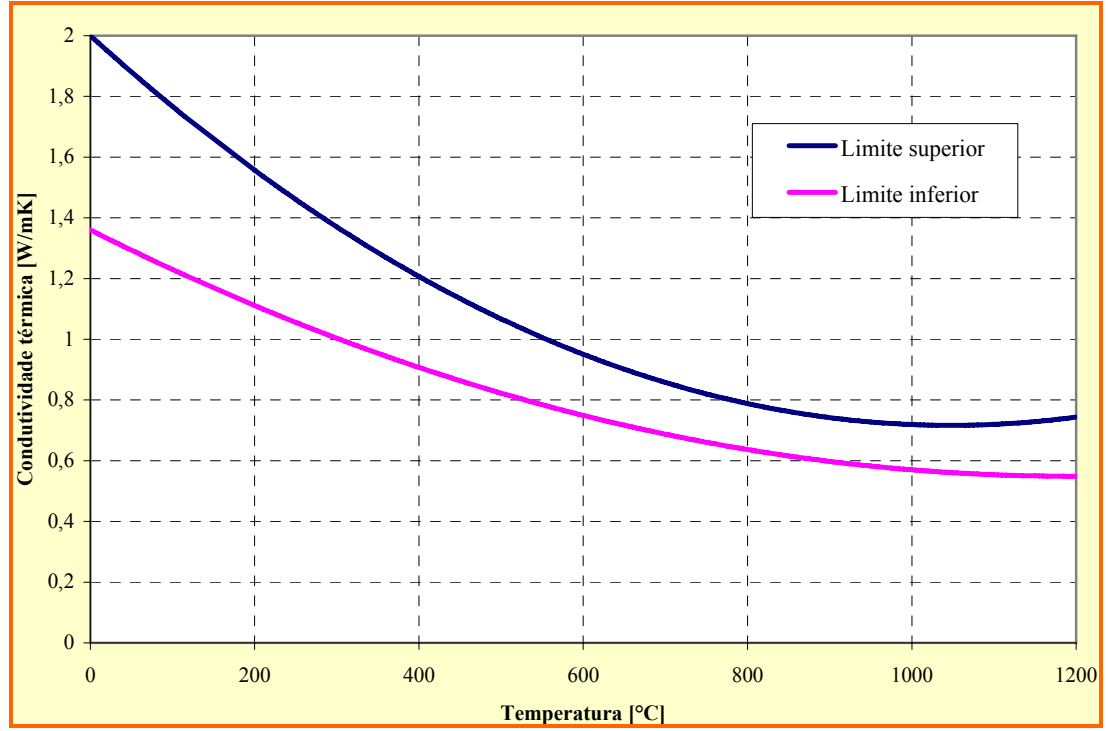

Figura 3.12: Condutividade térmica do concreto, segundo o Eurocode 2 part 1-2.

\subsection{MÉTODO DE DIMENSIONAMENTO - EUROCODE 3 PART 1- 2}

Para as estruturas submetidas ao incêndio, a condição de segurança é atendida quando a seguinte relação é respeitada:

$\mathrm{E}_{\mathrm{fi}, \mathrm{d}} \leq \mathrm{R}_{\mathrm{fi}, \mathrm{d}, \mathrm{t}}$ 
$\mathrm{Na}$ equação 3.28, $\mathrm{E}_{\mathrm{fi}, \mathrm{d}}$ representa os efeitos das ações de cálculo para $\mathrm{o}$ dimensionamento em situação de incêndio, determinada com base no Eurocode 1 Part 1.2, e $\mathrm{R}_{\mathrm{fi}, \mathrm{d}, \mathrm{t}}$ é a resistência de cálculo correspondente do elemento de aço, para a situação de incêndio, no respectivo tempo t.

Uma vez que os perfis metálicos são constituídos por chapas esbeltas, em VILA REAL (2003) atenta-se para a possibilidade de o perfil ter sua capacidade resistente limitada pela esbeltez da seção transversal antes que o limite elástico seja alcançado. Para prever o colapso por flambagem local da mesa ou alma a norma européia classifica as seções transversais da seguinte forma:

- Classe 1: os elementos mobilizam a resistência plástica com redistribuição dos esforços, permitindo a formação de uma rótula plástica, sem risco de ocorrência de flambagem local;

- Classe 2: os elementos mobilizam a resistência plástica sem redistribuição dos esforços, o que não permite a formação de uma rótula plástica, e também não há risco de ocorrência de flambagem local;

- Classe 3: os elementos apresentam flambagem elástica nas fibras extremas, com risco de ocorrência de flambagem local;

- Classe 4: os elementos apresentam flambagem elástica antes de atingir a tensão de escoamento.

\subsubsection{ELEMENTOS SOB COMPRESSÃO}

Para seções de classes 1, 2 ou 3, definidas no item 5.5.2 do Eurocode 3 Part 1.1, a força de compressão resistente de cálculo, $\mathrm{N}_{\mathrm{b}, \mathrm{fi}, \mathrm{t}, \mathrm{Rd}}$, a uma determinada temperatura $\theta_{\mathrm{a}}$, é determinada de acordo com a seguinte expressão:

$\mathrm{N}_{\mathrm{b}, \mathrm{fi}, \mathrm{t}, \mathrm{Rd}}=\chi_{\mathrm{fi}} \mathrm{Ak}_{\mathrm{y}, \theta} \mathrm{f}_{\mathrm{y}} / \gamma_{\mathrm{M}, \mathrm{fi}}$

Em relação à expressão 3.29 , $\chi_{\mathrm{fi}}$ é o fator de redução da resistência de barras axialmente comprimidas em situação de incêndio, cujo valor é definido conforme a equação 3.30 , enquanto $\mathrm{k}_{\mathrm{y}, \theta}$ é o fator de redução relacionado à resistência ao escoamento do aço à uma temperatura $\theta_{\mathrm{a}}$, num determinado tempo $\mathrm{t}$ e $\gamma_{\mathrm{M}, \mathrm{fi}}$ é o coeficiente de ponderação aplicado à resistência do aço em situação de incêndio, com valor igual a 1,0. 
$\chi_{\mathrm{fi}}=\frac{1}{\varphi_{\theta}+\sqrt{\varphi_{\theta}^{2}-\bar{\lambda}_{\theta}^{2}}}$

Na equação 3.30, valem:

$\varphi_{\theta}=\frac{1}{2}\left[1+\alpha \bar{\lambda}_{\theta}+\bar{\lambda}_{\theta}^{2}\right]$

$\alpha=0,65 \sqrt{235 / f_{y}}$

O índice de esbeltez reduzido $\bar{\lambda}_{\theta}$ para uma temperatura $\theta_{\mathrm{a}}$, é dado por:

$\bar{\lambda}_{\theta}=\bar{\lambda}\left[\mathrm{k}_{\mathrm{y}, \theta} / \mathrm{k}_{\mathrm{E}, \theta}\right]^{0,5}$

Da equação 3.33, são definidos $\mathrm{k}_{\mathrm{y}, \theta}$ como o fator de redução relacionando a resistência ao escoamento do aço à uma temperatura $\theta_{\mathrm{a}}$, num determinado tempo $\mathrm{t}$, bem como $\mathrm{k}_{\mathrm{E}, \theta}$ como o fator de redução do módulo de elasticidade linear do aço à uma temperatura $\theta_{\mathrm{a}}$, num determinado tempo t.

\subsubsection{ELEMENTOS SOB MOMENTO FLETOR}

\subsubsection{Para as Seções classes 1 ou 2}

- Sob temperatura uniforme pela seção transversal:

O momento fletor resistente de cálculo para esta situação é dado pela seguinte equação:

$\mathrm{M}_{\mathrm{fi}, \theta, \mathrm{Rd}}=\mathrm{k}_{\mathrm{y}, \theta}\left[\gamma_{\mathrm{M}, 0} / \gamma_{\mathrm{M}, \mathrm{fi}}\right] \mathrm{M}_{\mathrm{Rd}}$

Da equação 3.34, seguem os parâmetros:

$\gamma_{\mathrm{M}, 0}$ é o coeficiente de ponderação aplicado à resistência do aço em temperatura ambiente, tomado com valor igual a 1,0 ;

$\mathrm{M}_{\mathrm{Rd}}$ é o momento fletor resistente de cálculo em temperatura ambiente; 
$\mathrm{k}_{\mathrm{y}, \theta}$ é o fator de redução relacionado a resistência ao escoamento do aço à uma temperatura $\theta_{\mathrm{a}}$, num determinado tempo t;

- Sob temperatura não-uniforme pela seção transversal:

Em situações cuja distribuição da temperatura não ocorre uniformemente por toda seção transversal, o momento fletor resistente, no tempo t pode ser determinado pela equação 3.35 .

$\mathrm{M}_{\mathrm{fi}, \mathrm{t}, \mathrm{Rd}}=\sum_{\mathrm{i}=1}^{\mathrm{n}} \mathrm{A}_{\mathrm{i}} \mathrm{z}_{\mathrm{i}} \mathrm{k}_{\mathrm{y}, \theta, \mathrm{i}} \mathrm{f}_{\mathrm{y}, \mathrm{i}} / \gamma_{\mathrm{Mfi}}$

Na equação 3.35, valem as definições:

$\mathrm{Z}_{\mathrm{i}}$ é a distância do eixo neutro plástico ao centróide do elemento de área $\mathrm{A}_{\mathrm{i}}$;

$\mathrm{f}_{\mathrm{y}, \mathrm{i}}$ é a tensão nominal de escoamento para o elemento de área $\mathrm{A}_{\mathrm{i}}$ tomado como positivo no lado da compressão do eixo neutro plástico e negativo no lado da tração;

$A_{i}$ é a área da seção transversal com temperatura $\theta_{i}$;

$\mathrm{k}_{\mathrm{y}, \theta, \mathrm{i}}$ é a temperatura no elemento de área $\mathrm{A}_{\mathrm{i}}$.

Um procedimento alternativo para o cálculo do momento resistente $\mathrm{M}_{\mathrm{fi}, \mathrm{t}, \mathrm{Rd}}$ em um tempo $\mathrm{t}$, de uma seção transversal de classe 1 ou 2 com distribuição não-uniforme de temperatura, pode ser definida pela equação 3.36 .

$\mathrm{M}_{\mathrm{fi}, \mathrm{t}, \mathrm{Rd}}=\mathrm{M}_{\mathrm{fi}, \theta, \mathrm{Rd}} / \kappa_{1} \cdot \kappa_{2}$

Da equação 3.36, seguem:

$\mathrm{M}_{\mathrm{fi}, \theta, \mathrm{Rd}}$ é o momento fletor resistente da seção transversal quando submetida a uma temperatura uniforme $\theta_{\mathrm{a}}$ num dado tempo t, sendo que a seção transversal não é influenciada pelas condições de contorno (restrições);

$\kappa_{1}$ é o fator de adaptação para a temperatura não uniforme na seção transversal;

$\kappa_{2}$ é o fator de adaptação para a temperatura não uniforme ao longo do perfil.

\section{- Flambagem lateral com torção:}

O momento resistente de cálculo, analisando a flambagem lateral com torção $\mathrm{M}_{\mathrm{b}, \mathrm{fi}, \mathrm{t}, \mathrm{Rd}}$ de elementos estruturais não restringidos lateralmente com seções transversais de classe 1 ou classe 2 deve ser determinado pela equação: 


$$
\mathrm{M}_{\mathrm{b}, \mathrm{fi}, \mathrm{t}, \mathrm{Rd}}=\chi_{\mathrm{LT}, \mathrm{fi}} \mathrm{W}_{\mathrm{pl}, \mathrm{y}} \mathrm{k}_{\mathrm{y}, \theta, \mathrm{com}} \mathrm{f}_{\mathrm{y}} / \gamma_{\mathrm{M}, \mathrm{fi}}
$$

Da equação 3.37, $\chi_{\mathrm{LT}, \mathrm{fi}}$ é o fator de redução para a flambagem lateral com torção em situação de incêndio e $\mathrm{k}_{\mathrm{y}, \theta \text {,com }}$ é o fator de redução para a resistência ao escoamento com máxima temperatura na mesa comprimida $\theta_{\mathrm{a}, \mathrm{com}}$ atingida no tempo $\mathrm{t}$.

O valor de $\chi_{\mathrm{LT}, \mathrm{fi}}$ deve ser determinado de acordo com as equações:

$$
\begin{aligned}
& \chi_{\mathrm{LT}, \mathrm{fi}}=\frac{1}{\Phi_{\mathrm{LT}, \theta, \mathrm{com}}+\sqrt{\left[\Phi_{\mathrm{LT}, \theta, \mathrm{com}}\right]^{2}-\left[\bar{\lambda}_{\mathrm{LT}, \theta, \mathrm{com}}\right]^{2}}} \\
& \Phi_{\mathrm{LT}, \theta, \mathrm{com}}=\frac{1}{2}\left[1+\alpha \cdot \bar{\lambda}_{\mathrm{LT}, \theta, \mathrm{com}}+\left(\bar{\lambda}_{\mathrm{LT}, \theta, \mathrm{com}}\right)^{2}\right] \\
& \alpha=0,65 \sqrt{235 / \mathrm{f}_{\mathrm{y}}} \\
& \bar{\lambda}_{\mathrm{LT}, \theta, \mathrm{com}}=\lambda_{\mathrm{LT}}\left[\mathrm{k}_{\mathrm{y}, \theta, \mathrm{com}} / \mathrm{k}_{\mathrm{E}, \theta, \mathrm{com}}\right]^{0,5}
\end{aligned}
$$

$\mathrm{Na}$ equação 3.41, $\mathrm{k}_{\mathrm{E}, \theta}$, com representa o fator de redução do módulo de elasticidade para o aço em temperatura máxima na mesa comprimida $\theta_{\mathrm{a}}$,com atingida num tempo $\mathrm{t}$.

\subsubsection{Para Seções classe 3}

- Distribuição de temperatura uniforme:

Nesta situação, o momento fletor resistente de cálculo é expresso de acordo com a seguinte equação:

$$
\mathrm{M}_{\mathrm{fi}, \mathrm{t}, \mathrm{Rd}}=\mathrm{k}_{\mathrm{y}, \theta} \cdot \mathrm{M}_{\mathrm{Rd}}\left[\gamma_{\mathrm{M}, 0} / \gamma_{\mathrm{M}, \mathrm{fi}}\right]
$$


$\mathrm{Na}$ equação 3.42, $\mathrm{M}_{\mathrm{Rd}}$ é o momento fletor plástico resistente calculado para temperatura ambiente de acordo com o Eurocode 3 part 1, ou a resistência reduzida ao momento fletor, permitindo os efeitos de cisalhamento se necessário, conforme o Eurocode 3 part 1 , enquanto $\mathrm{k}_{\mathrm{y}, \theta}$ é o fator de redução para a resistência ao escoamento do aço a uma temperatura $\theta_{a}$;

- Distribuição de temperatura não-uniforme:

Para casos de distribuição de temperatura não uniforme na seção transversal, o momento fletor resistente de cálculo é descrito da seguinte forma:

$\mathrm{M}_{\mathrm{fi}, \mathrm{t}, \mathrm{Rd}}=\mathrm{k}_{\mathrm{y}, \theta, \max } \cdot \mathrm{M}_{\mathrm{Rd}}\left[\gamma_{\mathrm{M}, 0} / \gamma_{\mathrm{M}, \mathrm{fi}}\right] / \kappa_{1} \cdot \kappa_{2}$

Na equação 3.43, tem-se:

$\mathrm{M}_{\mathrm{Rd}}$ é o momento fletor plástico resistente calculado para temperatura ambiente de acordo com o Eurocode 3 part 1, ou a resistência reduzida ao momento fletor, permitindo os efeitos de cisalhamento se necessário, conforme o Eurocode 3 part 1;

$\mathrm{k}_{\mathrm{y}, \theta, \max }$ é o fator de redução para a resistência ao escoamento na máxima temperatura do aço, $\theta_{\mathrm{a}, \max }$, atingida no tempo t;

$\kappa_{1}$ é o fator de adaptação para temperatura não uniforme na seção transversal.

- Momento resistente de flambagem na ausência de restrição lateral.

$\mathrm{O}$ dimensionamento do momento resistente à flambagem de um elemento sem restrição lateral constituídos de seção transversal de classe 3 é determinado pela seguinte equação:

$\mathrm{M}_{\mathrm{b}, \mathrm{fi}, \mathrm{t}, \mathrm{Rd}}=\chi_{\mathrm{LT}, \mathrm{fi}} \cdot \mathrm{W}_{\mathrm{el}} \cdot \mathrm{k}_{\mathrm{y}, \theta, \mathrm{com}} \cdot \mathrm{f}_{\mathrm{y}} / \gamma_{\mathrm{M}, \mathrm{fi}}$

Na equação 3.44, $\chi_{\mathrm{LT}, \mathrm{fi}}$ é dado pela equação 3.36 já apresentada. 


\subsubsection{ELEMENTOS SOB FLEXO-COMPRESSÃO}

O dimensionamento da resistência a flambagem no tempo t de um elemento sujeito aos efeitos combinados de momento fletor e compressão, é verificado conforme as equações 3.45 e 3.46 para as seções de classe 1 e 2 , e equações 3.47 e 3.48 para as seções de classe 3 .

$\frac{\mathrm{N}_{\mathrm{fi}, \mathrm{Ed}}}{\chi_{\min , \mathrm{fi}} \cdot A \cdot \mathrm{k}_{\mathrm{y}, \theta} \cdot \frac{\mathrm{f}_{\mathrm{y}}}{\gamma_{\mathrm{M}, \mathrm{fi}}}}+\frac{\mathrm{k}_{\mathrm{y}} \cdot \mathrm{M}_{\mathrm{y}, \mathrm{fi}, \mathrm{Ed}}}{\mathrm{W}_{\mathrm{pl}, \mathrm{y}} \cdot \mathrm{k}_{\mathrm{y}, \theta} \frac{\mathrm{f}_{\mathrm{y}}}{\gamma_{\mathrm{M}, \mathrm{fi}}}}+\frac{\mathrm{k}_{\mathrm{z}} \cdot \mathrm{M}_{\mathrm{z}, \mathrm{fi}, \mathrm{Ed}}}{\mathrm{W}_{\mathrm{pl}, \mathrm{z}} \cdot \mathrm{k}_{\mathrm{y}, \theta} \frac{\mathrm{f}_{\mathrm{y}}}{\gamma_{\mathrm{M}, \mathrm{fi}}}} \leq 1$

$\frac{\mathrm{N}_{\mathrm{fi}, \mathrm{Ed}}}{\chi_{\mathrm{z}, \mathrm{fi}} \cdot \mathrm{A} \cdot \mathrm{k}_{\mathrm{y}, \theta} \frac{\mathrm{f}_{\mathrm{y}}}{\gamma_{\mathrm{M}, \mathrm{fi}}}}+\frac{\mathrm{k}_{\mathrm{LT}} \cdot \mathrm{M}_{\mathrm{y}, \mathrm{fi}, \mathrm{Ed}}}{\chi_{\mathrm{LT}, \mathrm{fi}} \cdot \mathrm{W}_{\mathrm{pl}, \mathrm{y}} \cdot \mathrm{k}_{\mathrm{y}, \theta} \frac{\mathrm{f}_{\mathrm{y}}}{\gamma_{\mathrm{M}, \mathrm{fi}}}}+\frac{\mathrm{k}_{\mathrm{z}} \cdot \mathrm{M}_{\mathrm{y}, \mathrm{fi}, \mathrm{Ed}}}{\mathrm{W}_{\mathrm{pl}, \mathrm{z}} \cdot \mathrm{k}_{\mathrm{y}, \theta} \frac{\mathrm{f}_{\mathrm{y}}}{\gamma_{\mathrm{M}, \mathrm{fi}}}} \leq 1$

$\frac{\mathrm{N}_{\mathrm{fi}, \mathrm{Ed}}}{\chi_{\min , \mathrm{fi}} \cdot A \cdot \mathrm{k}_{\mathrm{y}, \theta} \frac{\mathrm{f}_{\mathrm{y}}}{\gamma_{\mathrm{M}, \mathrm{fi}}}}+\frac{\mathrm{k}_{\mathrm{y}} \cdot \mathrm{M}_{\mathrm{y}, \mathrm{fi}, \mathrm{Ed}}}{\mathrm{W}_{\mathrm{el}, \mathrm{y}} \cdot \mathrm{k}_{\mathrm{y}, \theta} \frac{\mathrm{f}_{\mathrm{y}}}{\gamma_{\mathrm{M}, \mathrm{fi}}}}+\frac{\mathrm{k}_{\mathrm{z}} \cdot \mathrm{M}_{\mathrm{z}, \mathrm{fi}, \mathrm{Ed}}}{\mathrm{W}_{\mathrm{el}, \mathrm{z}} \cdot \mathrm{k}_{\mathrm{y}, \theta} \frac{\mathrm{f}_{\mathrm{y}}}{\gamma_{\mathrm{M}, \mathrm{fi}}}} \leq 1$

$\frac{\mathrm{N}_{\mathrm{fi}, \mathrm{Rd}}}{\chi_{\mathrm{z}, \mathrm{fi}} \cdot \mathrm{A} \cdot \mathrm{k}_{\mathrm{y}, \theta} \frac{\mathrm{f}_{\mathrm{y}}}{\gamma_{\mathrm{M}, \mathrm{fi}}}}+\frac{\mathrm{k}_{\mathrm{LT}} \mathrm{M}_{\mathrm{y}, \mathrm{fi}, \mathrm{Ed}}}{\chi_{\mathrm{LT}, \mathrm{fi}} \mathrm{W}_{\mathrm{el}, \mathrm{y}} \cdot \mathrm{k}_{\mathrm{y}, \theta} \frac{\mathrm{f}_{\mathrm{y}}}{\gamma_{\mathrm{M}, \mathrm{fi}}}}+\frac{\mathrm{k}_{\mathrm{z}} \cdot \mathrm{M}_{\mathrm{z}, \mathrm{fi}, \mathrm{Ed}}}{\mathrm{W}_{\mathrm{el}, \mathrm{z}} \cdot \mathrm{k}_{\mathrm{y}, \theta} \frac{\mathrm{f}_{\mathrm{y}}}{\gamma_{\mathrm{M}, \mathrm{fi}}}} \leq 1$

Para as equações 3.47 a 3.48 , valem:

$\mathrm{k}_{\mathrm{LT}}=1-\frac{\mu_{\mathrm{LT}} \cdot \mathrm{N}_{\mathrm{fi}, \mathrm{Ed}}}{\chi_{\mathrm{z}, \mathrm{fi}} \cdot \mathrm{A} \cdot \mathrm{k}_{\mathrm{y}, \theta} \frac{\mathrm{f}_{\mathrm{y}}}{\gamma_{\mathrm{M}, \mathrm{fi}}}} \leq 1$

$\operatorname{Com} \mu_{\mathrm{LT}}=0,15 \bar{\lambda}_{\mathrm{z}, \theta} \beta_{\mathrm{M}, \mathrm{LT}}-0,15 \leq 0,9$

$\mathrm{k}_{\mathrm{y}}=1-\frac{\mu_{\mathrm{y}} \cdot \mathrm{N}_{\mathrm{fi}, \mathrm{Ed}}}{\chi_{\mathrm{y}, \mathrm{fi}} \cdot \mathrm{A} \cdot \mathrm{k}_{\mathrm{y}, \theta} \frac{\mathrm{f}_{\mathrm{y}}}{\gamma_{\mathrm{M}, \mathrm{fi}}}} \leq 3$

$\operatorname{Com} \mu_{\mathrm{y}}=\left(1,2 \beta_{\mathrm{M}, \mathrm{y}}-3\right) \bar{\lambda}_{\mathrm{y}, \theta}+0,44 \beta_{\mathrm{M}, \mathrm{y}}-0,29 \leq 0,8$ 


$$
\mathrm{k}_{\mathrm{z}}=1-\frac{\mu_{\mathrm{z}} \cdot \mathrm{N}_{\mathrm{fi}, \mathrm{Ed}}}{\chi_{\mathrm{z}, \mathrm{fi}} \cdot \mathrm{A} \cdot \mathrm{k}_{\mathrm{y}, \theta} \frac{\mathrm{f}_{\mathrm{y}}}{\gamma_{\mathrm{M}, \mathrm{fi}}}} \leq 3
$$

$\operatorname{Com} \mu_{\mathrm{z}}=\left(2 \beta_{\mathrm{M}, \mathrm{z}}-5\right) \bar{\lambda}_{\mathrm{z}, \theta}+0,44 \beta_{\mathrm{M}, \mathrm{z}}-0,29 \leq 0,8$ e $\bar{\lambda}_{\mathrm{z}, \theta}=1,1$

Conhecidas as propriedades térmicas do aço, é possível determinar a variação da temperatura de um elemento submetido a uma variação uniforme de temperatura, num intervalo de tempo $\Delta \mathrm{t}$, por meio da equação 3.52 .

$$
\Delta \theta_{\mathrm{a}, \mathrm{t}}=\frac{\mathrm{u} / \mathrm{A}}{\mathrm{c}_{\mathrm{a}} \rho_{\mathrm{a}}} \varphi \Delta \mathrm{t}
$$

Da equação 3.52, adotada tanto pelo Eurocode 3 part 1.2 como pela NBR14323:1999, tem-se:

u/A é o fator de massividade de elementos prismáticos sem revestimento de proteção contra incêndio, em $\mathrm{m}^{-1}$;

$\Delta$ t é o intervalo de tempo, em s, não adotado maior que $5 \mathrm{~s}$;

$\mathrm{c}_{\mathrm{a}}$ é o calor especifico do aço, em $\mathrm{J} / \mathrm{kg} \cdot{ }^{\circ} \mathrm{C}$;

$\rho_{\mathrm{a}}$ é a massa especifica do aço, em $\mathrm{kg} / \mathrm{m}^{3}$;

$\varphi$ é o fluxo de calor por unidade de área, em $\mathrm{W} / \mathrm{m}^{2}$. O valor de $\varphi$, dado pela equação 3.53 é formado pela parcela referente ao fluxo de calor devido à convecção e pela parcela referente ao fluxo por radiação, dadas pelas equações 3.54 e 3.55, respectivamente.

$\varphi=\varphi_{\mathrm{c}}+\varphi_{\mathrm{r}}$

$\varphi_{\mathrm{c}}=\alpha_{\mathrm{c}}\left(\theta_{\mathrm{g}}-\theta_{\mathrm{a}}\right)$

$\varphi_{\mathrm{r}}=5,67 \times 10^{-8} \varepsilon_{\text {res }}\left[\left(\theta_{\mathrm{g}}+273\right)^{4}-\left(\theta_{\mathrm{a}}+273\right)^{4}\right]$ 
$\mathrm{Na}$ equação $3.55, \varepsilon_{\text {res }}$ é a emissividade resultante, podendo ser tomada igual a 0,5 , conforme sugere a ABNT NBR 14323:1999. O valor de 5,67 $\times 10^{-8}$ refere-se ao valor da constante de Stefan-Boltzman.

O Eurocode 3 part 1.2 ainda introduz na equação 3.52 um fator de correção denominado fator de sombra $\left(\mathrm{k}_{\mathrm{sh}}\right)$. Para perfis I isolados, sujeitos a um gradiente térmico uniforme provocado por uma curva de incêndio-padrão, o fator de sombra é determinado pela equação 3.56 .

$$
\mathrm{k}_{\mathrm{sh}}=0,9 \frac{[\mathrm{u} / \mathrm{A}]_{\mathrm{b}}}{[\mathrm{u} / \mathrm{A}]}
$$

Da equação 3.56, tem-se:

u/A é o fator de massividade calculado como se o perfil tivesse uma proteção em caixão, podendo ser expressa pela relação 3.57 ;

u/A é a relação entre o perímetro exposto ao fogo e a área total da seção transversal.

$$
\left[\frac{\mathrm{u}}{\mathrm{A}}\right]_{\mathrm{b}}=\frac{2(\mathrm{~b}+\mathrm{d})}{\mathrm{A}_{\mathrm{g}}}
$$

$\mathrm{Na}$ equação $3.57, \mathrm{~b}, \mathrm{~d}$ e $\mathrm{A}_{\mathrm{g}}$ são, respectivamente a largura da mesa, a altura total e a área da seção transversal do perfil. 


\section{MODELAGEM NUMÉRICA-Elementos adotados $e$ considerações de interesse}

Ao elaborar os modelos bidimensionais para a determinação do campo térmico e, em seguida, os modelos tridimensionais para a análise termoestrutural, foram utilizadas ferramentas do pacote computacional ANSYS ${ }^{\circledR}$ V9.0, o qual disponibiliza ao usuário uma biblioteca diversificada de elementos finitos adequados para vários tipos de análises, dos tipos térmica, fluido ou fluido-dinâmica, bem como análise estrutural, seja ela estática, modal, transiente, harmônica, auto-valor, análise espectral e análise de subestrutura, permitindo tornar o procedimento de modelagem mais realístico.

A construção dos modelos numéricos aqui estudados consiste de quatro etapas. A primeira etapa se refere à realização da análise transiente do gradiente térmico. A determinação da ação térmica e do campo térmico nos modelos é de fundamental importância para entender a alteração no comportamento do material e da barra na estrutura.

O segundo passo consiste de análise estrutural dos modos de instabilidade, feita por meio da análise de auto-valor, que permite determinar o modo de falha (forma da imperfeição geométrica) para uma determinada força crítica elástica. A terceira etapa se refere à análise estrutural estática, em temperatura ambiente, considerando a barra com sua geometria imperfeita, a fim de se determinar a força última de colapso por compressão. Na quarta etapa, a análise estrutural é realizada considerando a variação da temperatura na barra por meio do acoplamento das respostas da análise térmica. Os detalhes de todas as etapas serão comentados nos itens que se seguem.

\subsection{ANÁLISE TÉRMICA - Aspectos de interesse}

A análise térmica pode ser executada por duas formas distintas, conforme informações disponibilizadas no pacote do ANSYS, por meio do Thermal analysis guide - Types of Thermal Analysis:

- Análise estacionária: determina a distribuição da temperatura e outras grandezas térmicas sob condição de cargas estacionárias, ou seja, a variação das grandezas térmicas dentro de um 
período de tempo pode ser ignorada. Esta análise ainda pode ser do tipo linear, com propriedades dos materiais constantes, ou do tipo não-linear com propriedades dos materiais dependentes da temperatura;

- Análise transiente: determina temperatura e outras grandezas térmicas em função do tempo. Na engenharia, são comumente usadas temperaturas calculadas por meio da análise térmica transiente, as quais servirão como dados de entrada em análises estruturais para avaliação das tensões induzidas pela temperatura. Muitas aplicações em transferência de calor, tais como problemas de tratamento térmico, sistemas de tubulação, vasos de pressão, estruturas em situação de incêndio, etc., envolvem análise térmica transiente.

Portanto, é possível perceber que a análise térmica transiente segue basicamente os mesmos procedimentos de uma análise térmica estacionária. A principal diferença é que a maioria das forças aplicadas em uma análise transiente é considerada em função do tempo.

A base para a análise térmica no ANSYS é a equação de equilíbrio térmico, obtida do princípio de conservação de energia. A solução por elementos finitos calcula a temperatura nodal, que será utilizada para obter outros parâmetros térmicos. O ANSYS considera os três modos primários de transferência de calor: condução, convecção e radiação.

- Condução: Como citado em REGOBELlO (2007), o problema da condução de calor ocorre entre os elementos sólidos, o qual envolve as temperaturas nodais, como carregamento nos nós, e o fluxo de calor entre esses elementos. O ponto de partida de um problema de condução ocorre no inicio da troca de calor entre o ambiente em incêndio e a estrutura, pelo processo de convecção ou radiação. Para a resolução do problema térmico de condução, devem ser fornecidas ao ANSYS duas propriedades físicas: condutividade térmica (nas direções $x, y$ e z) e densidade. (ANSYS guide - How ANSYS Treats Thermal Modeling).

- Convecção: É especificada como um carregamento de superfície aplicada a um elemento finito do tipo sólido ou casca. A transferência de calor por este mecanismo ocorre por meio da aplicação de uma superfície de convecção, com coeficiente de transferência de calor por convecção $\alpha_{c}$, e da maior parte da temperatura do fluido incidente na superfície do elemento. Se o coeficiente do filme é uma função da temperatura, deve ser especificada uma tabela de temperatura com o correspondente valor do coeficiente do filme de convecção.

- Radiação: O ANSYS pode resolver os problemas de radiação, que são não-lineares, por quatro formas distintas (Ansys thermal guide - Radiation): 
a-) Pelo uso do elemento linear de radiação (LINK31): para problemas simples envolvendo dois pontos ou vários pares de pontos. O LINK31 é um elemento não-linear de dois nós, que calcula o fluxo de calor causado pela radiação entre dois pontos. Devem ser fornecidos os seguintes dados: Área efetiva da superfície radiante; Fator de forma; Emissividade; Constante de Stefan-Boltzmann. O uso do elemento LINK 31 é limitado para casos simples onde é possível calcular manualmente os fatores de forma da radiação.

b-) Pelo uso do elemento de superfície de contato com a opção radiação (SURF151 em modelos 2-D ou SURF 152 em modelos 3-D): para introduzir o efeito da radiação entre uma superfície e um ponto, se utilizam elementos de efeito de superfície modelados sobre os elementos sólidos, capazes de emitir ou receber radiação. Este será o método utilizado nas análises termo-estruturais apresentadas no decorrer do presente trabalho.

c-) Pela geração de uma matriz de radiação e usando esta matriz como um superelemento em uma análise térmica: esse método é aplicável em problemas de radiação generalizada envolvendo várias superfícies de radiação. A matriz é constituída pelos fatores de visada entre as superfícies radiantes. Também podem ser incluídas superfícies ocultas ou parcialmente ocultas, assim como um nó espacial que pode absorver energia radiante.

d-) Pelo uso do método solução da radioatividade: este método também trabalha com problemas generalizados de radiação, envolvendo duas ou mais superfícies receptoras ou emissoras de radiação. O método pode ser adotado por todos os elementos 3-D e 2-D tendo a temperatura como grau de liberdade. Ele consiste de cinco passos: definir as superfícies de radiação; definir as opções de solução; definir as opções do fator de visada; calcular e verificar o fator de visada; definir as opções de carregamento;

Nos itens que se seguem, serão apresentados alguns dos elementos finitos utilizados na construção dos modelos numéricos para análise térmica. Esses elementos apresentam características em comum, tais como: temperatura nodal como único grau de liberdade, aplicáveis tanto na análise transiente como na análise térmico-estacionária e, por fim, todos os elementos para construção de modelos térmicos possuem elementos finitos estruturais compatíveis, para os casos em que se realizam análise termoestrutural. 


\subsubsection{ANÁLISE TÉRMICA BIDIMENSIONAL - Elementos finitos adotados}

O ANSYS apresenta aproximadamente 40 elementos finitos apropriados para aplicações em análise térmica. Todos os elementos se aplicam tanto para análise térmica estacionária como para análise térmica transiente. Dentre os elementos apresentados na Tabela 4.1, o elemento PLANE77, ilustrado na Tabela 4.2, apresentou maior adequação para a construção dos modelos bidimensionais.

Tabela 4.1: Descrição dos elementos finitos para construção dos modelos bidimensionais.

\begin{tabular}{lll}
\hline Elemento & Forma & Características \\
\hline
\end{tabular}

PLANE35 Triangular; 6 nós A forma triangular faz com que esse elemento seja adequado para modelos com malhas irregulares.

Usado como um elemento plano ou como um elemento anelar

PLANE55 Quadrilateral; 4 nós axissimétrico. Pode compensar o fluxo de calor com transporte de massa para um campo de velocidade constante.

É usado como um elemento anelar axissimétrico com uma

PLANE75 Harmônico; 4 nós capacidade de condução no espaço 3-D, em que se permite forças não-axissimétricas.

PLANE77 Quadrilateral; 8 nós São adequados para modelos com contornos curvos. PLANE78 Harmônico; 8 nós $\begin{aligned} & \text { Permite o carregamento não-axissimetrico. São adequados para } \\ & \text { modelos curvos. }\end{aligned}$

A aplicação da ação térmica se faz por meio do elemento SURF151, o qual é sobreposto aos elementos bidimensionais da Tabela 4.2 e usado para varias aplicações de cargas e efeitos de superfície. É definido por dois, três ou quatro nós, e pelas propriedades do material. Pode ser utilizado um nó extra (fora do elemento de base) para introduzir os efeitos de convecção ou radiação. Os efeitos de convecção ou fluxo de calor são impostos como forças de superfície no elemento.

A Figura 4.1 ilustra o elemento finito SURF151, o qual também está descrito, e com mais detalhes, caso seja de interesse do leitor, em REGOBELLO (2007). 
Tabela 4.2: Forma dos elementos finitos para construção dos modelos bidimensionais.

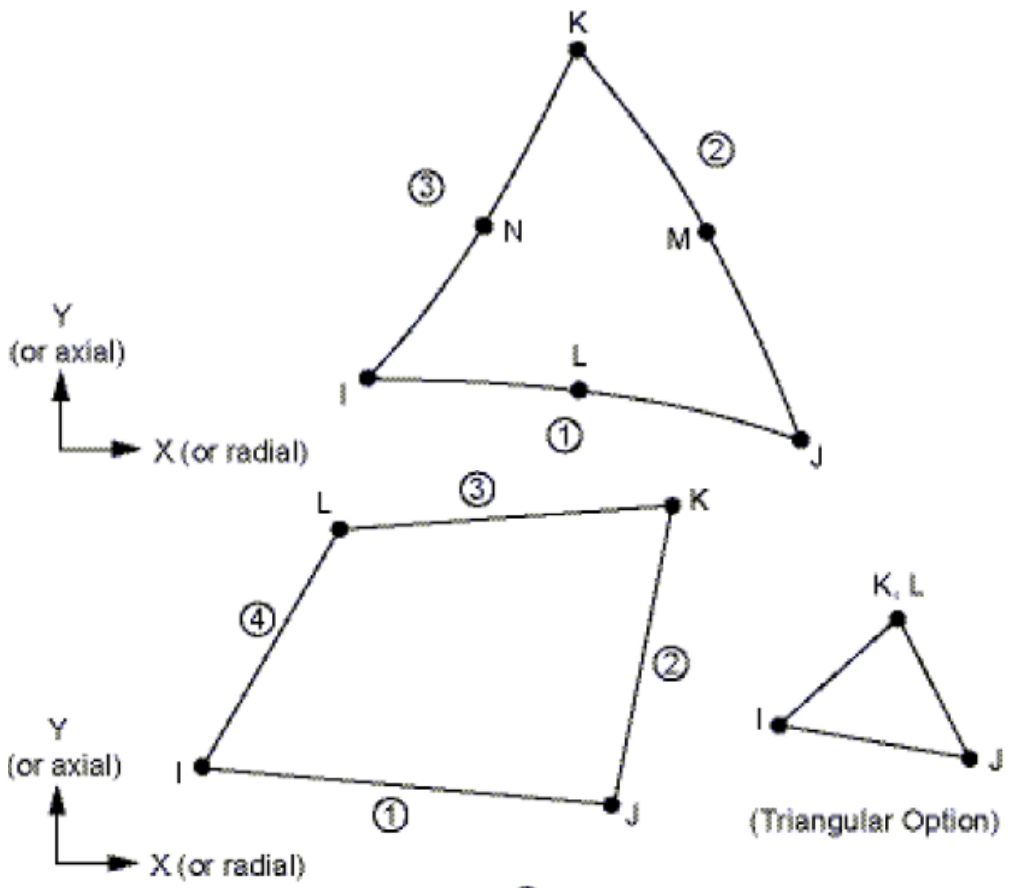

PLANE35

PLANE 55
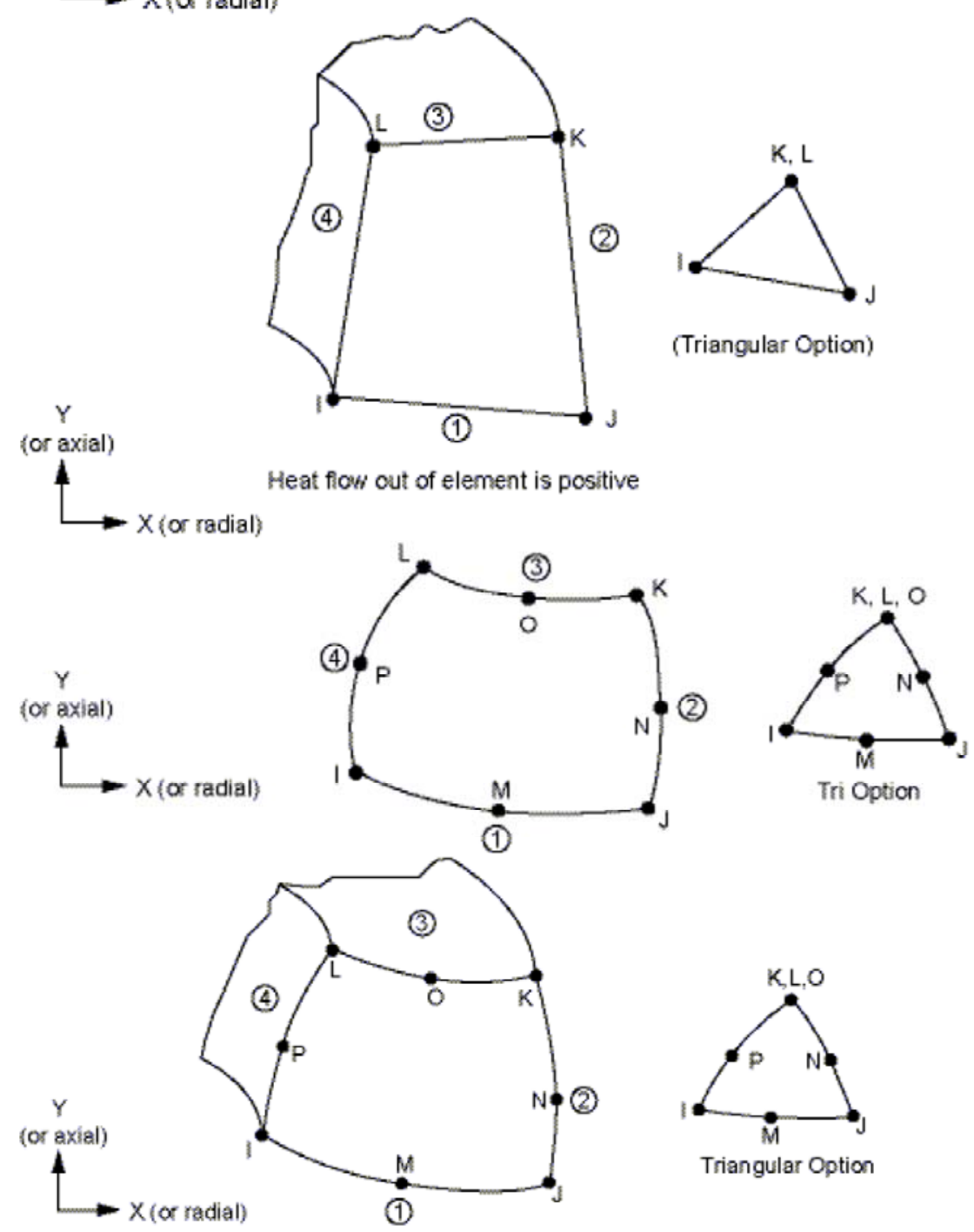

PLANE75

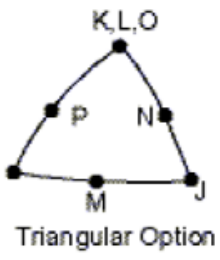

PLANE77

PLANE78 
K(Extra node, optional)

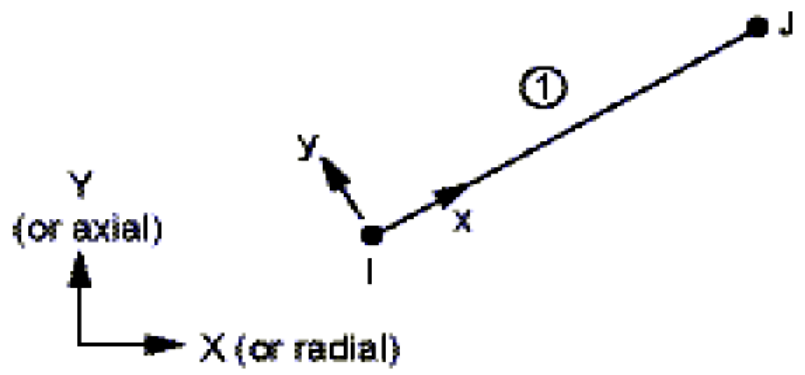

L (Extra node, optional)

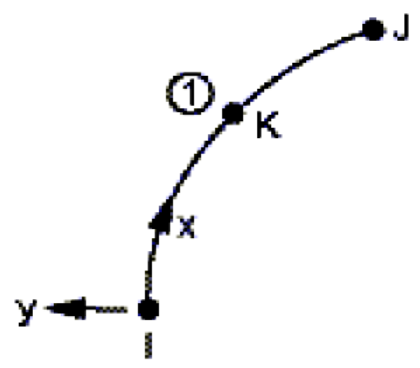

Figura 4.1: Elemento finito SURF151

\subsubsection{ANÁLISE TÉRMICA TRIDIMENSIONAL - Elementos finitos adotados}

A Tabela 4.3 apresenta as características dos elementos finitos aplicáveis aos modelos tridimensionais. Dentre eles, para o desenvolvimento dos modelos, optou-se pelo elemento SOLID70. A ilustração dos elementos pode ser vista na Tabela 4.4.

Tabela 4.3: Características dos elementos finitos tridimensionais.

\begin{tabular}{lcl}
\hline Elemento & Forma & \multicolumn{1}{c}{ Características } \\
\hline SOLID70 & Bloco; 8 nós & Elemento adequado para malhas regulares e relitíneas. \\
SOLID87 & Tetraédrico; 10 nós & $\begin{array}{l}\text { A forma tetraédrica faz com que esse elemento seja adequado para } \\
\text { modelos com malhas irregulares. }\end{array}$ \\
SOLID90 & Bloco; 20 nós & É ideal para modelos com contornos curvos \\
\hline
\end{tabular}

A aplicação da ação térmica é análoga ao modelo bidimensional, porém, aplicando o elemento SURF152. Esse elemento é sobreposto a qualquer dos elementos tridimensionais da Tabela 4.3 e é usado para várias aplicações de cargas e efeitos de superfície simultaneamente. O elemento é definido por um número de nós que varia de quatro a nove, além das propriedades do material. Os efeitos de convecção ou fluxo de calor são impostos como forças de superfície no elemento.

O elemento SURF152 leva em conta a radiação entre uma superfície e o nó extra. A emissividade da superfície é usada na matriz de condutividade da superfície de radiação. $\mathrm{O}$ fator de forma e a constante de Stefan-Boltzmann também são fornecidos para a matriz de 
condutividade da superfície de radiação. (Ansys thermal guide - Available Elements for Thermal Analysis). A Figura 4.2 ilustra o elemento finito SURF152.

Tabela 4.4: Forma dos elementos finitos tridimensionais.
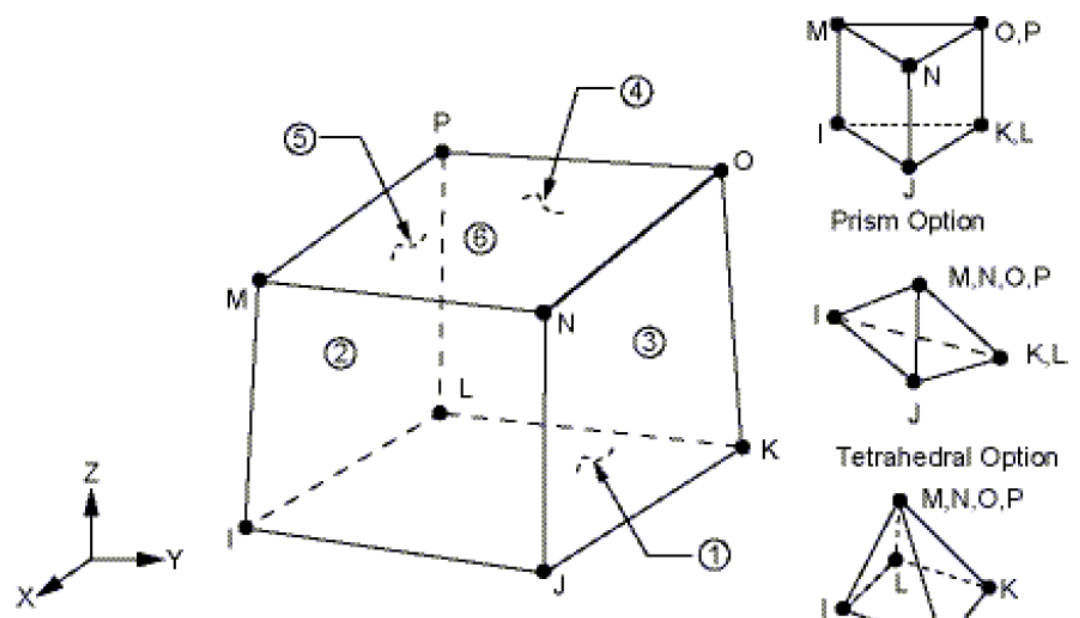

SOLID70
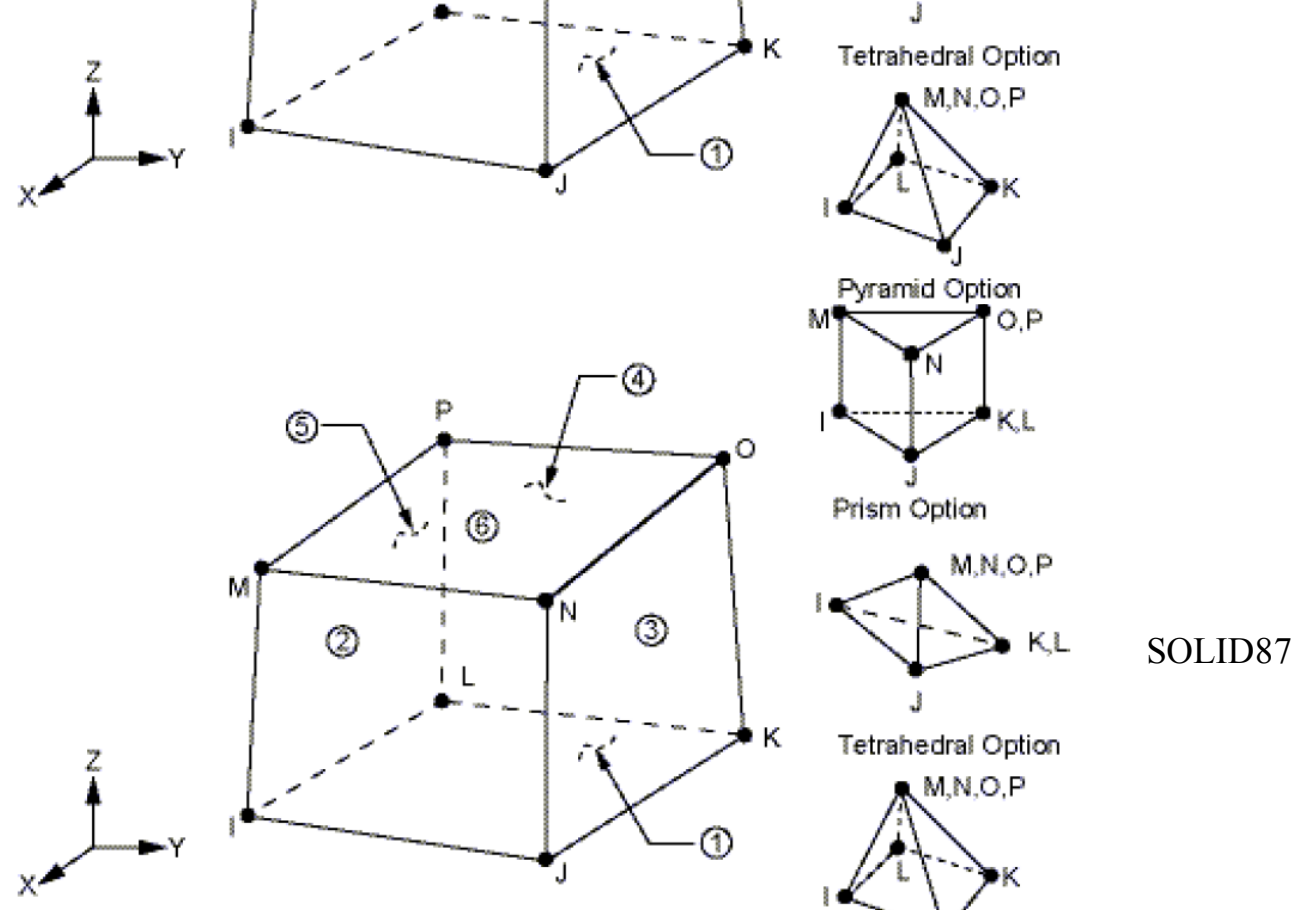

SOLID87

Tetrahedral Option

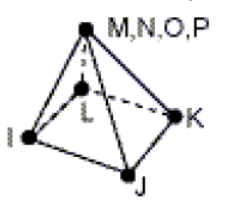

Pyramid Option
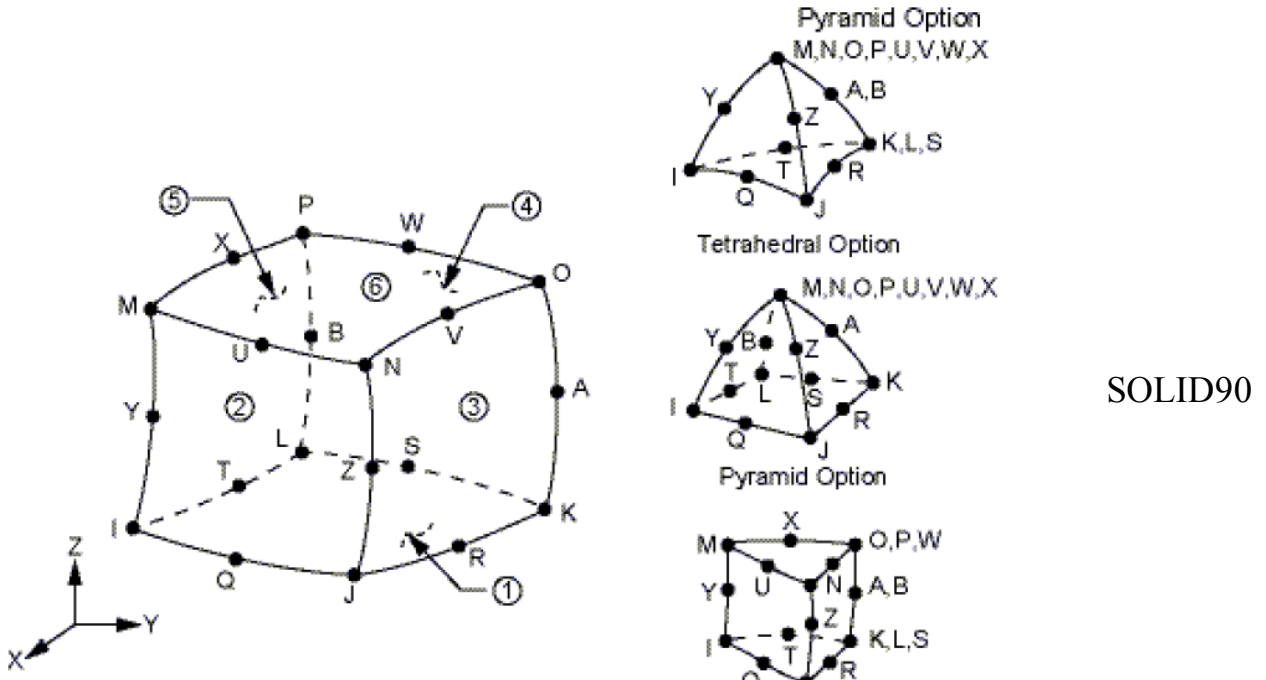

Pyramid Option

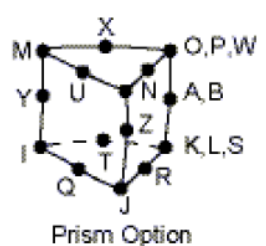



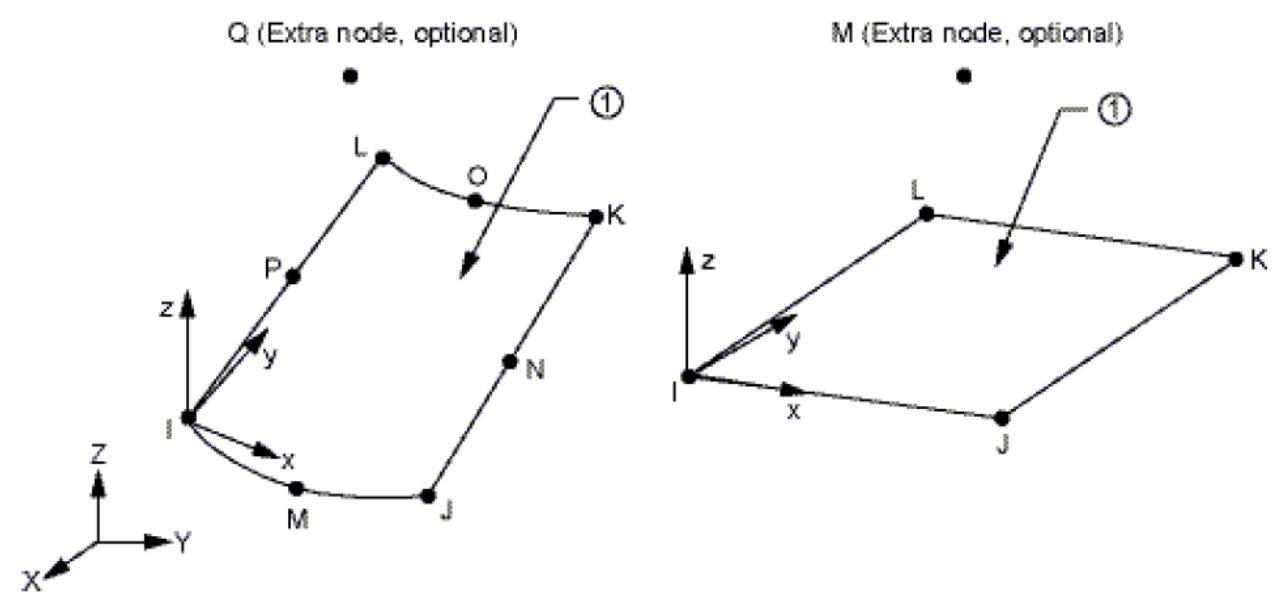

Figura 4.2: Elemento finito de aplicação da ação térmica - SURF152.

\subsection{ANÁLISE ESTRUTURAL - Considerações}

O pacote computacional do ANSYS é composto por sete tipos de análise estrutural. Os primeiros parâmetros desconhecidos calculados numa análise estrutural são os deslocamentos. As demais grandezas de interesse como as deformações, as tensões e reações, são obtidas com base nos valores dos deslocamentos nodais. Os tipos de análise estrutural são (Ansys analisys guide - Types of Structural Analysis):

- Análise estática: usada para determinar deslocamentos, tensões, deformações, etc., sob condições de carregamento estático, tanto para análises estáticas lineares como não-lineares. As não-linearidades podem incluir plasticidade, tensão de corpo rígido, grandes deslocamentos, grandes deformações, hiperelasticidade, superfície de contato e fluência;

- Análise modal: usada para calcular a freqüência natural de uma estrutura. São disponíveis diferentes métodos de modos de excitação;

- Análise harmônica: usada para determinar a resposta de uma estrutura submetida a forças variando no tempo harmonicamente;

- Análise dinâmica transiente: usada para determinar a resposta de uma estrutura submetida a forças que variam no tempo arbitrariamente. Todas as não-linearidades mencionadas na análise estática são permitidas;

- Análise espectral: uma extensão da análise modal, usada para calcular as tensões e as deformações devido à resposta espectral ou a uma vibração randômica imposta; 
- Análise de modos de flambagem: usada para calcular as cargas de flambagem e determinar a forma do modo de flambagem. São possíveis tanto a análise linear como a não-linear de autovalor.

- Análise dinâmica explícita: este tipo de análise estrutural é apenas aplicável no ANSYS LS-DYNA, que fornece uma interface ao programa de elementos finitos explícitos LSDYNA. A análise dinâmica explicita é usada para calcular soluções rápidas para grandes deformações dinâmicas e complexos problemas de contato.

\subsubsection{ANÁLISE DE INSTABILIDADE - CONSIDERAÇÃO DE IMPERFEIÇÕES}

O ANSYS dispõe de duas técnicas para prever a força e o modo de flambagem de uma estrutura: a análise não-linear de flambagem e a análise de autovalor (ou linear) de flambagem. Estes dois métodos podem conduzir a respostas muito diferentes. (Ansys analysis guide - Types of Buckling Analyses).

\subsubsection{Análise não-linear de flambagem}

Geralmente, é a aproximação mais precisa e emprega a análise estática não-linear com aumento gradual das ações para procurar o nível de força em que a estrutura se torna instável. Usando a técnica não-linear, seu modelo pode incluir respostas das imperfeições iniciais, comportamento plástico, e grandes deslocamentos.

Além disso, usando o deslocamento incremental como ação estática, é possível trilhar o comportamento pós-critico da estrutura, que pode ser útil nos casos onde a estrutura flamba dentro de uma configuração estável (como a instabilidade por ponto limite, "snap-through”). (Ansys guide — Performing a Nonlinear Buckling Analysis).

\subsubsection{Análise da flambagem por autovalor}

Prevê a resistência teórica à instabilidade (o ponto de bifurcação) de uma estrutura, considerando a fase elástica linear. O método corresponde à flambagem elástica, ou seja, a análise da flambagem por autovalor. Neste tipo de análise, as propriedades do material são definidas de forma linear, isotrópico ou ortotrópico, referente à temperatura ambiente. As propriedades não-lineares são ignoradas. 
O ANSYS requer que o usuário especifique o método de extração do autovalor. Neste trabalho, o método escolhido foi aquele denominado Block Lanczos, que é usado para problemas simétricos de autovalor e utiliza a matriz esparsa para extração dos autovalores. (Ansys guide — Procedure for Eigenvalue Buckling Analysis).

\subsubsection{ANÁLISE ESTRUTURAL ESTÁTICA}

A análise estática calcula o efeito das condições das forças estáticas na estrutura e não considera as ações que variam com o tempo. Pode incluir as forças de inércia (como a gravidade e a velocidade rotacional) e as ações dinâmicas podem ser aproximadas para ações estáticas equivalentes (ação do vento, por exemplo). As propriedades do material podem ser lineares ou não-lineares, isotrópico ou anisotrópico, e a temperatura pode ser constante ou variável no tempo. A malha deve ser capaz de capturar os efeitos da não-linearidade, como a plasticidade em áreas com alto gradiente de deformação.

A análise estática determina os deslocamentos, tensões, deformações e forças em estruturas ou elementos estruturais causados por ações que não induzem efeitos de inércia e salto significantes. Os tipos de ações que podem ser aplicados em análises estáticas incluem: pressões e forças aplicadas externamente, forças inerciais estacionárias (gravidade e velocidade rotacional), deslocamentos impostos, temperaturas (para deformações térmicas) e fluência (dilatação).

\subsubsection{ANÁLISES ESTRUTURAIS EM CAMPO TRIDIMENSIONAL - Elementos finitos utilizados}

Os tipos de elementos disponibilizados pelo ANSYS, empregados para fins de análise estrutural, cobrem desde os mais simples (elementos de barras e vigas) até aqueles utilizados em modelagens mais custosas numericamente, como, por exemplo, elementos de casca e sólidos de grande deformação. A biblioteca do ANSYS descreve as propriedades dos diversos elementos finitos para análise estrutural.

Neste sub-ítem são considerados apenas os elementos utilizados na elaboração dos modelos de análise estrutural propostos: o SHELL181 e o SOLID45. O SHELL181 é adequado para análises que envolvem elementos relativamente delgados. Este elemento é definido por quatro nós com seis graus de liberdade em cada nó, sendo eles três de rotação 
(nos eixos $\mathrm{x}, \mathrm{y}$ e z) e três de translação (nas direções $\mathrm{x}, \mathrm{y}$ e z). O SHELL181 é usado em análises linear de grandes rotações e não-linear de grandes deformações.

Em relação às análises térmicas visando o acoplamento com as análises estruturais, o ANSYS não permite a compatibilização entre o SHEL181 e o SOLID70 (da mesma forma que ocorre entre o SOLID45 e o SOLID70). Porém, no Capítulo 7, será visto que é possível o acoplamento das respostas obtidas na análise térmica tridimensional usando o elemento SOLID70 na análise termoestrutural elaborada com o elemento SHELL181.

Embora as características indiquem esse elemento como sendo o mais adequado para a modelagem apresentada no presente trabalho, algumas dúvidas em termos de deformação surgiram na resposta da análise utilizando o elemento do tipo casca. Dessa forma, para o desenvolvimento da análise termoestrutural, que foi o objetivo do presente projeto de pesquisa, optou-se pela modelagem utilizando o elemento SOLID45. A Figura 4.3 ilustra o elemento finito de casca SHELL181.

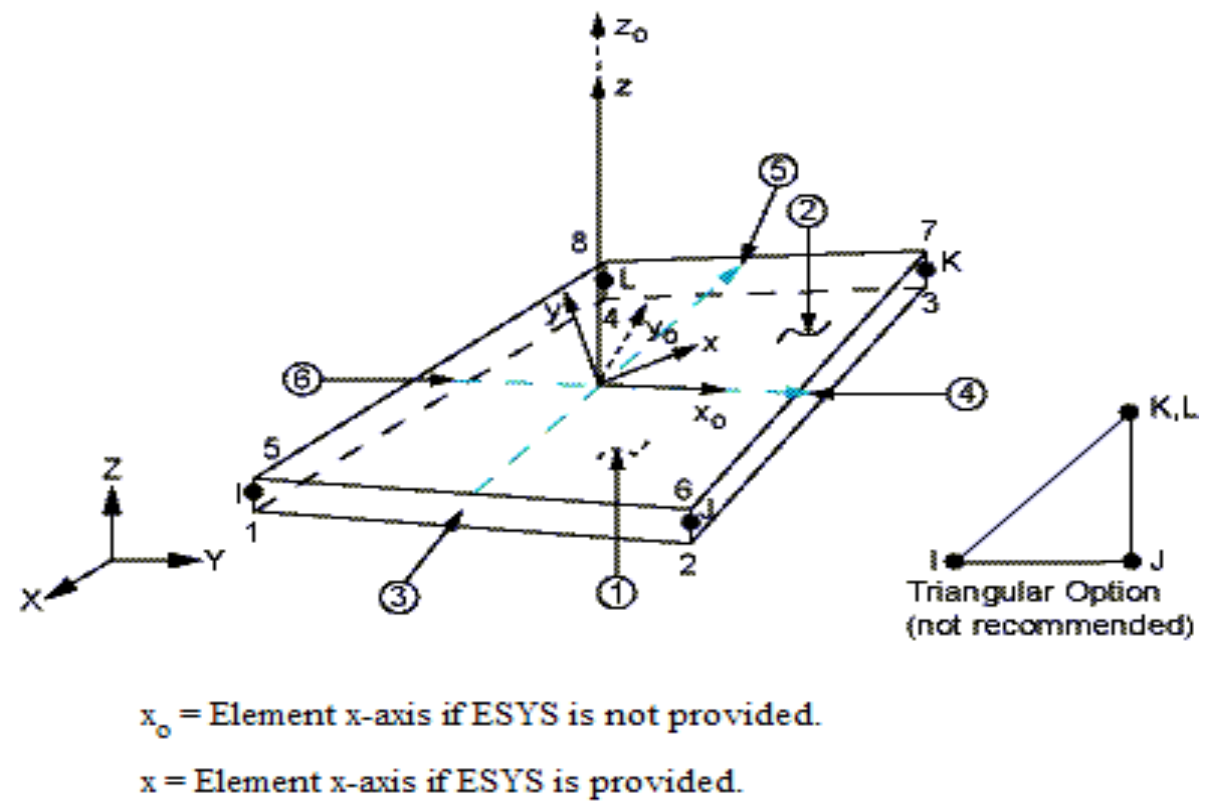

Figura 4.3: Elemento finito tridimensional de casca para análise estrutural SHELL181

O elemento SOLID45, utilizado para modelos estruturais sólidos tridimensionais é definido por oito nós com três graus de liberdade em cada nó: translação nas direções nodais x, y e z. O elemento é capaz de representar comportamentos em campos de plasticidade, fluência, dilatação, grandes deslocamentos e grandes deformações. As propriedades ortotrópicas do material são definidas na direção dos eixos coordenados do elemento (Ansys analisys guide - SOLID45). A Figura 4.4 ilustra o elemento finito SOLID45. 


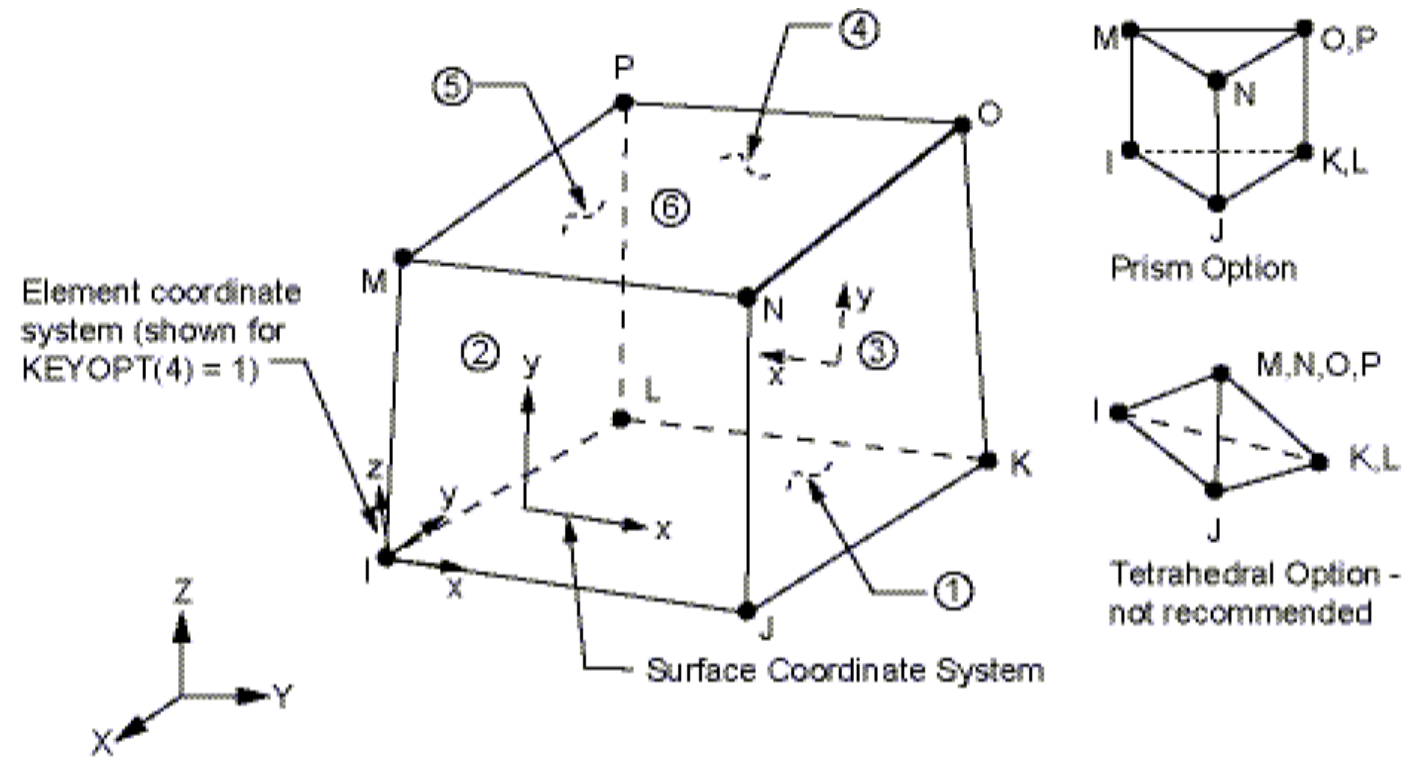

Figura 4.4: Elemento finito tridimensional para análise estrutural SOLID45.

\subsection{ANÁLISE ACOPLADA}

Trata-se da interação entre duas ou mais análises que englobam fenômenos físicos distintos a citar, com exemplos: interação entre os campos elétrico e magnético, estrutural e magnético, térmico e fluido, estrutural e térmico, entre outros.

Numa análise acoplada termoestrutural, objeto de interesse do presente trabalho, o campo de temperatura introduz deformações térmicas no campo estrutural, mas as deformações estruturais geralmente não afetam a distribuição da temperatura. Dessa forma, não há necessidade de um processo iterativo entre os dois campos de soluções.

Porém, existem casos mais complicados que envolvem acoplamento iterativo. Uma análise piezelétrica, por exemplo, que analisa a interação entre o campo estrutural e elétrico. Para a interação do tipo fluido-estrutura, a pressão do fluido causa deformação na estrutura, que, por sua vez ocasiona mudanças na resposta do fluido. Esse problema requer iteração entre ambos os campos físicos para convergência. (Ansys guide — Coupled-Field Analyses).

Os próximos capítulos serão destinados essencialmente a avaliar os modelos numéricos elaborados, desde os bidimensionais para validação do campo térmico aos tridimensionais com vistas às análises termo-estruturais. 


\section{MODELOS NUMÉRICOS EM CAMPO TÉRMICO - Avaliação da eficiência}

O presente capítulo tem como finalidade apresentar resultados de interesse de modelos numéricos, elaborados com base nos elementos apresentados no Capítulo 4, com relação ao campo térmico de algumas seções transversais de perfis metálicos submetidos à curva de incêndio-padrão proposta pela ISO 834:1975.

Os modelos numéricos apresentados nos exemplos que se seguem foram processados via ANSYS, e seus resultados comparados com os correspondentes obtidos utilizando o código computacional Super-Tempcalc (STC), gentilmente fornecidos por Valdir Pignatta e Silva, professor da Escola Politécnica da Universidade de São Paulo.

Segundo VELARDE (2007), o STC é um programa específico para determinação de campo térmico, formulado com base no método dos elementos finitos, desenvolvido na Suécia pelo pesquisador Yngve Anderberg do grupo FIRE SAFETY DESIGN. Esse programa faz parte do pacote computacional Temperature Calculation and Design (TCD). Além de realizar análise em campo térmico, esse programa também permite a determinação dos esforços resistentes de vigas metálicas ou de concreto e pilares de aço submetidos à compressão centrada, seguindo as prescrições da norma sueca e do Eurocode, considerando o campo de temperatura uniforme no sentido longitudinal.

\subsection{MODELOS NUMÉRICOS ANALISADOS-Parâmetros e resultados obtidos em campo térmico bidimensional}

Para todas as seções transversais a serem aqui analisadas, valem os seguintes parâmetros, conforme esquematizados na Figura 5.1:

d e $b_{\mathrm{f}}$ : altura total e largura da seção transversal do pilar, respectivamente;

h: altura interna da alma (distância entre mesas);

$t_{w}$ e $t_{f}$ : espessuras da alma e da mesa, respectivamente;

$r_{x}$ e $r_{y}$ : raios de giração, segundo os eixos x e y, respectivamente;

$\mathrm{A}_{\mathrm{g}}$ e L: área da seção transversal e comprimento do perfil, respectivamente;

$\mathrm{I}_{\mathrm{x}}$ e $\mathrm{I}_{\mathrm{y}}$ : momentos de inércias à flexão, segundo os eixos x e y, respectivamente; 
$\mathrm{W}_{\mathrm{el}, \mathrm{x}}$ e $\mathrm{W}_{\mathrm{el}, \mathrm{y}}$ : módulos elásticos de resistência à flexão, segundo os eixos $\mathrm{x}$ e $\mathrm{y}$, respectivamente;

$\mathrm{Z}_{\mathrm{x}}$ e $\mathrm{Z}_{\mathrm{y}}$ : módulos plásticos de resistência à flexão, segundo os eixos $\mathrm{x}$ e $\mathrm{y}$, respectivamente, para seções duplamente simétricas;

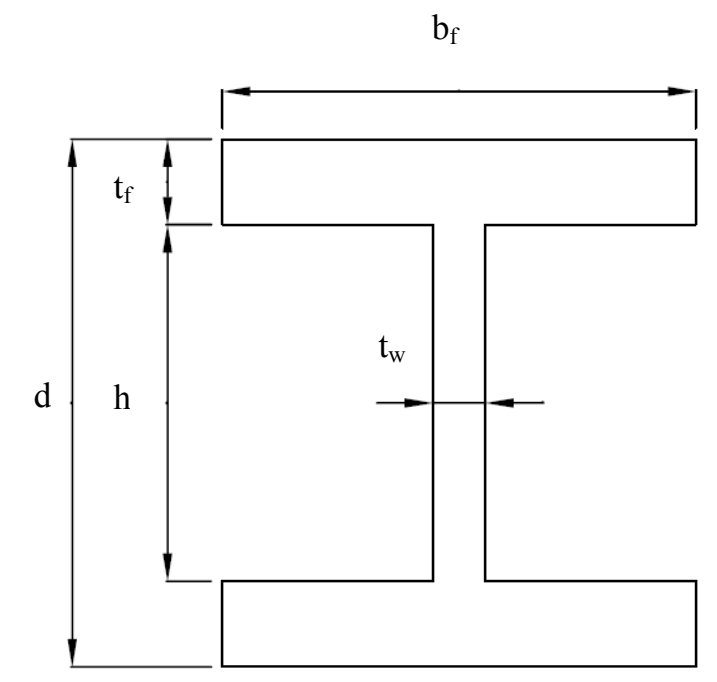

Figura 5.1: Notação empregada na descrição da geometria utilizada nos modelos numéricos.

As Figuras 5.2 (a) e (b) esquematizam as posições nas seções transversais em que foram extraídos os resultados de temperatura em resposta à variação térmica.
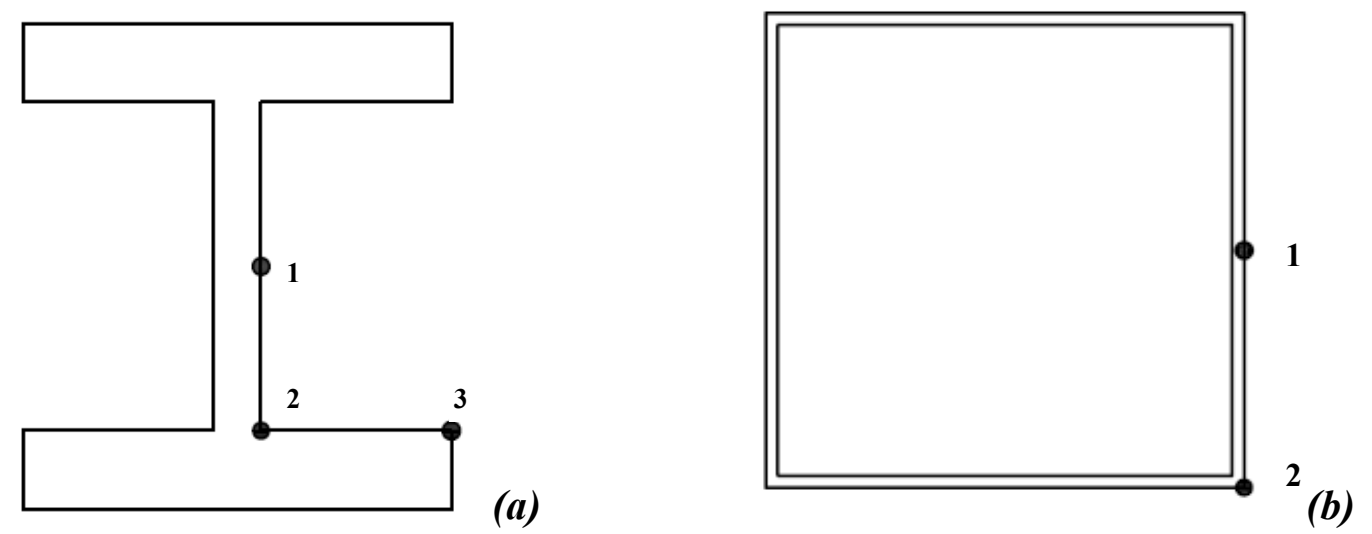

Figura 5.2: Pontos onde foram extraídos os valores da temperatura:

(a) Perfil I e (b) Seção caixão

Os pontos são os seguintes:

Ponto 1: ponto médio da alma;

Ponto 1: ponto médio da alma;

Ponto 2: encontro alma-mesa;

Ponto 2: vértice.

Ponto 3: extremidade da mesa. 
Exceto a geometria, os dados de entrada referentes às propriedades térmicas e aos mecanismos de transferência de calor são comuns para todos os exemplos. Esses parâmetros, com base na ABNT NRB 14323:1999 e no Eurocode 3: part 1.2, são:

Massa especifica do aço: $\rho_{a}=7850 \mathrm{~kg} / \mathrm{m}^{3}$;

Condutividade térmica: segue o gráfico apresentado na Figura 3.6;

Calor especifico: segue o gráfico representado na Figura 3.8;

Coeficiente de transferência de calor por convecção: $\alpha_{c}=25 \mathrm{~W} / \mathrm{m}^{2}{ }^{\circ} \mathrm{C}$;

Emissividade resultante: 0,5 (ABNT NBR 14323:1999);

Constante de Stefan-Boltzmann: 5,67x $\times 10^{-8} \mathrm{~W} / \mathrm{m}^{2} . \mathrm{K}^{4}$;

Fator de configuração: definido no Capitulo 3 como a fração da energia de radiação que deixa uma superficie e incide em outra superfície, adotado pelo Eurocode 3 como sendo igual a 1,0 .

\subsubsection{SEÇÃO TRANSVERSAL UB254 X 146 X 43}

Os perfis utilizados nas Figuras 5.3 e 5.6 foram elaborados com base no programa experimental apresentado em Wang (2002). A evolução térmica da temperatura dos gases seguiu a curva de incêndio padronizada pela ISO 834:1975. Abaixo, por meio da Figura 5.3, são listadas as propriedades geométricas do perfil, juntamente com a ilustração da malha utilizada na modelagem numérica em campo térmico.

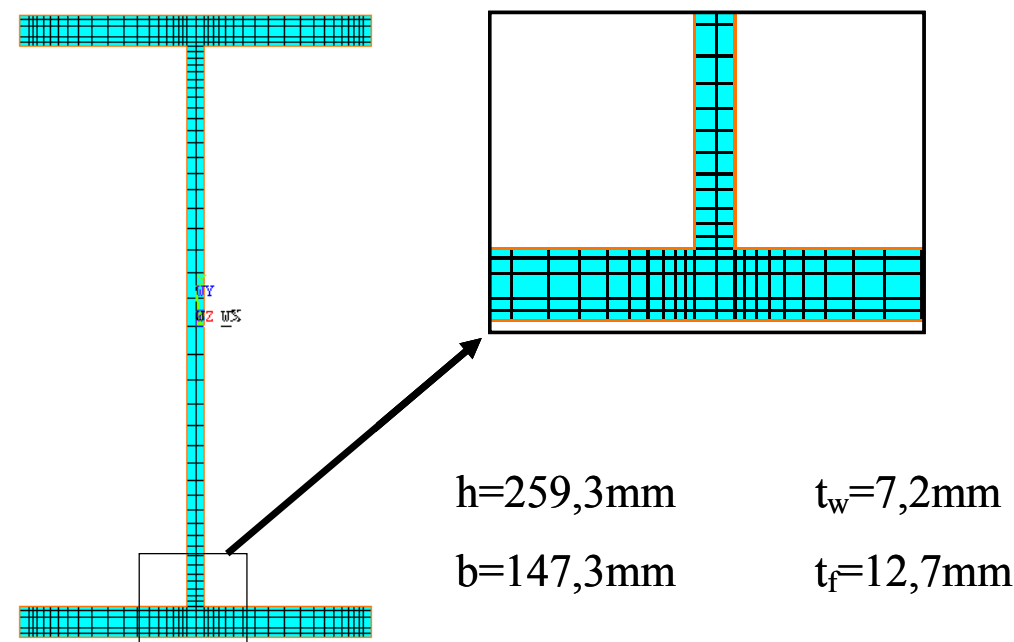

Figura 5.3: Geometria e malha de elementos finitos do perfil UB254 x 146 x 43 .

O campo térmico, ao final do intervalo de tempo considerado, obtido por meio do código Super-Tempcalc e do ANSYS é ilustrado nas Figuras 5.4 (a) e (b) respectivamente. 
O gráfico da Figura 5.5, apresenta a evolução térmica em três pontos particulares da seção transversal, onde se observa que o ponto médio da alma registrou os maiores valores gradientes térmicos. O ponto de intersecção entre a alma e a mesa geralmente consiste de uma região de concentração de materiais provenientes do processo de fabricação do perfil. Dessa forma, é esperado que essas regiões apresentem menores níveis de temperatura se comparado com as partes planas da seção. No entanto, a área curva entre a alma e a mesa resultante do processo de laminação, por simplificação, foi desconsiderada. Como se trata de uma região muito pequena em relação à seção transversal, essa simplificação não afetou os resultados.

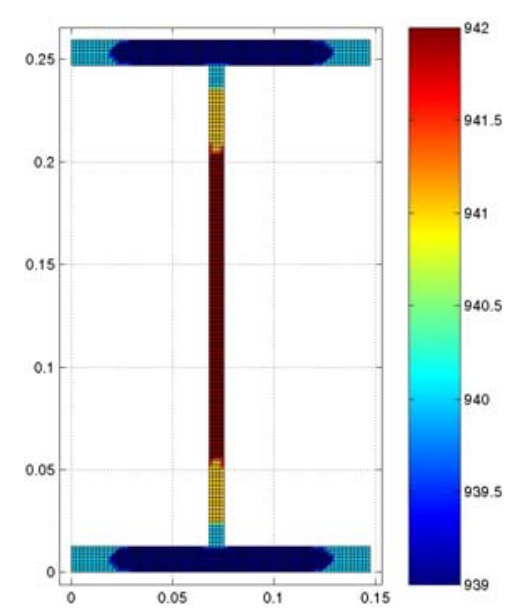

(a)

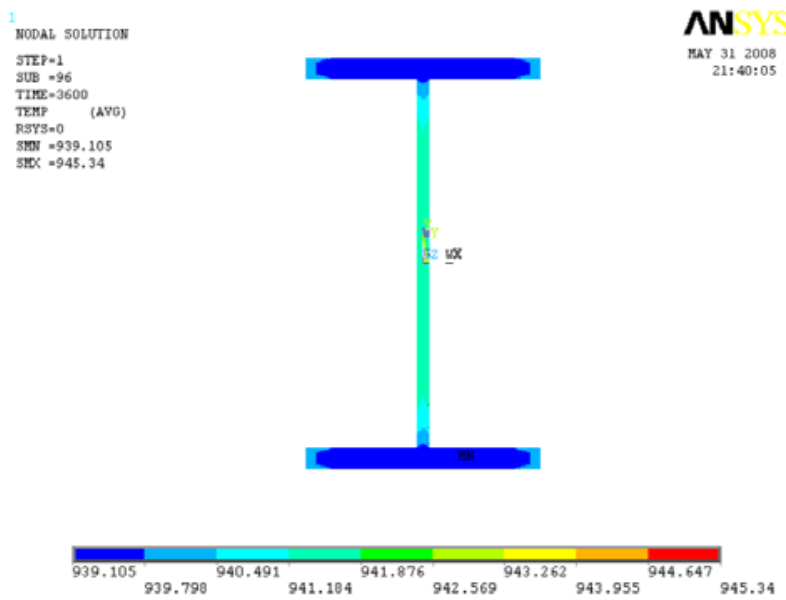

(b)

Figura 5.4: Campo térmico, em ${ }^{\circ} \mathrm{C}$, obtido por meio das simulações para o perfil UB254 $\mathrm{x}$ 146 x 43, para TRF de 60 minutos, obtido: (a) via STC e (b) via ANSYS

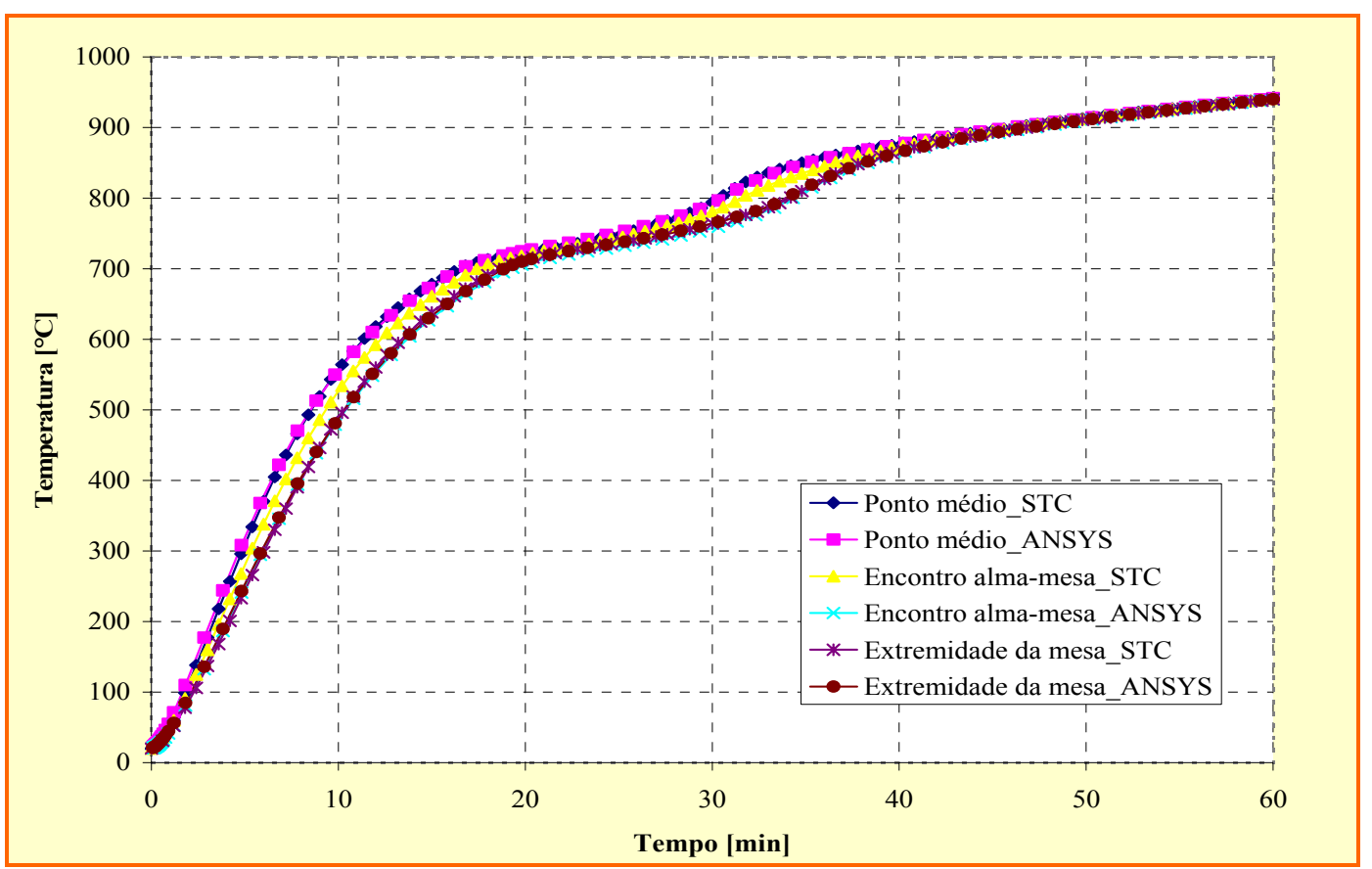

Figura 5.5: Gráfico da evolução térmica obtida vai STC e via ANSYS para o meio da alma, região entre a alma e a mesa e para a extremidade da mesa do perfil UB254 x 146 x 43. 


\subsubsection{SEÇÃO TRANSVERSAL UC203 X 203 X 46}

Trata-se de seção transversal cuja malha de elementos finitos foi definida no ANSYS, com dados da geometria da seção transversal conforme ilustra a Figura 5.6. De modo análogo à seção da Figura 5.3, a presente seção transversal também foi submetida a um campo de temperatura uniforme por todos os lados.

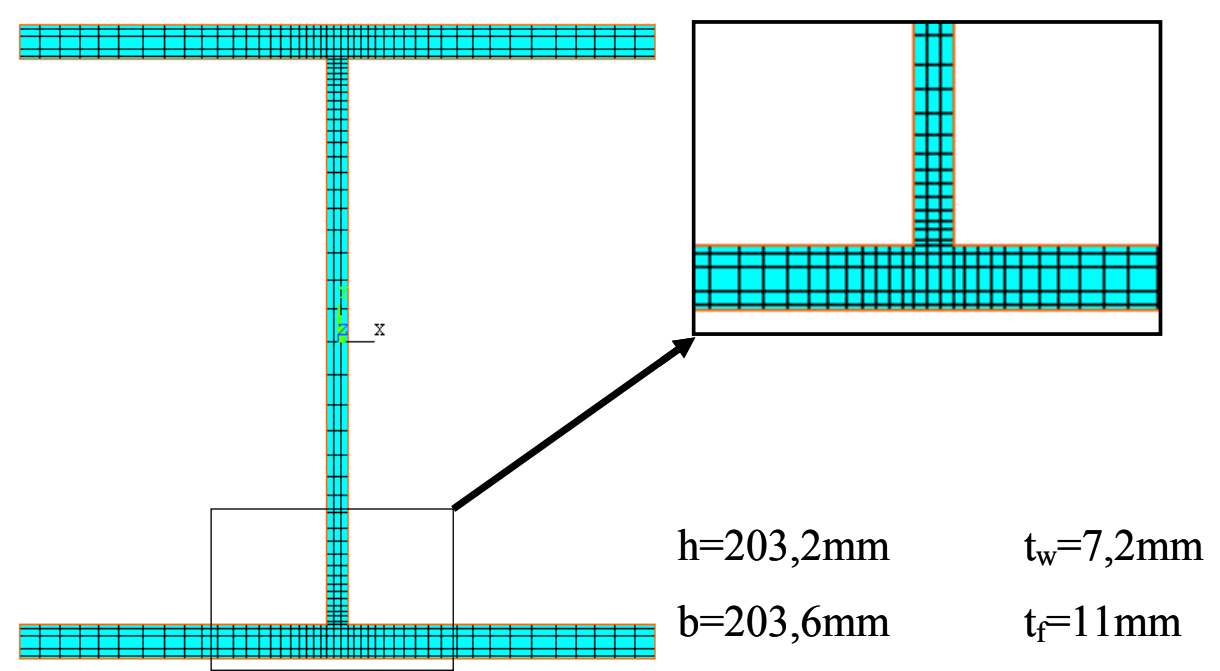

Figura 5.6: Geometria e malha de elementos finitos do perfil UC203 x 203 x 46.

As Figuras 5.7 (a) e (b) ilustram a distribuição da temperatura ao final do intervalo de tempo considerado, obtido utilizando o Super-Tempcalc e o ANSYS respectivamente.

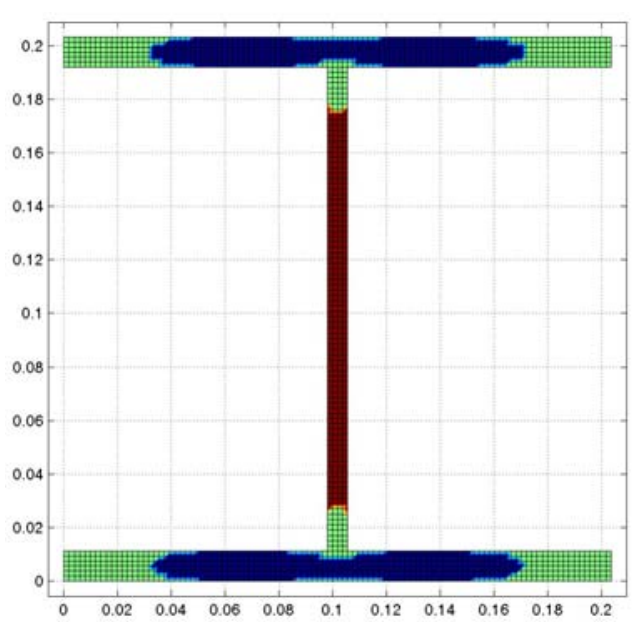

(a)
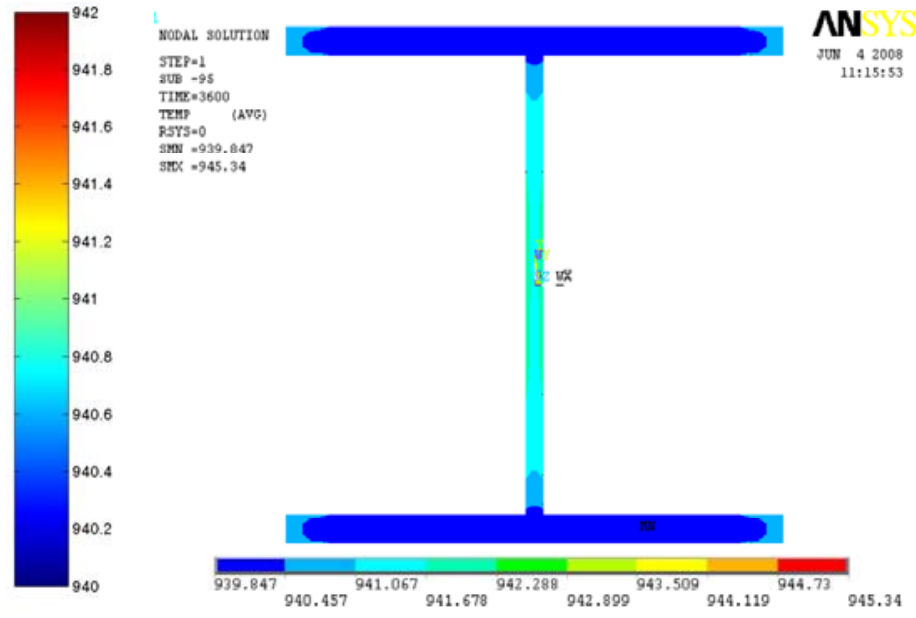

(b)

Figura 5.7: Campo térmico, em ${ }^{\circ} \mathrm{C}$, obtido por meio das simulações para o perfil UC203 x 203 x 46 para TRF de 60 minutos, obtido: (a) via STC e (b) via ANSYS

A Figura 5.8 apresenta a variação da temperatura ao longo do tempo, nos pontos de interesse na seção transversal. 


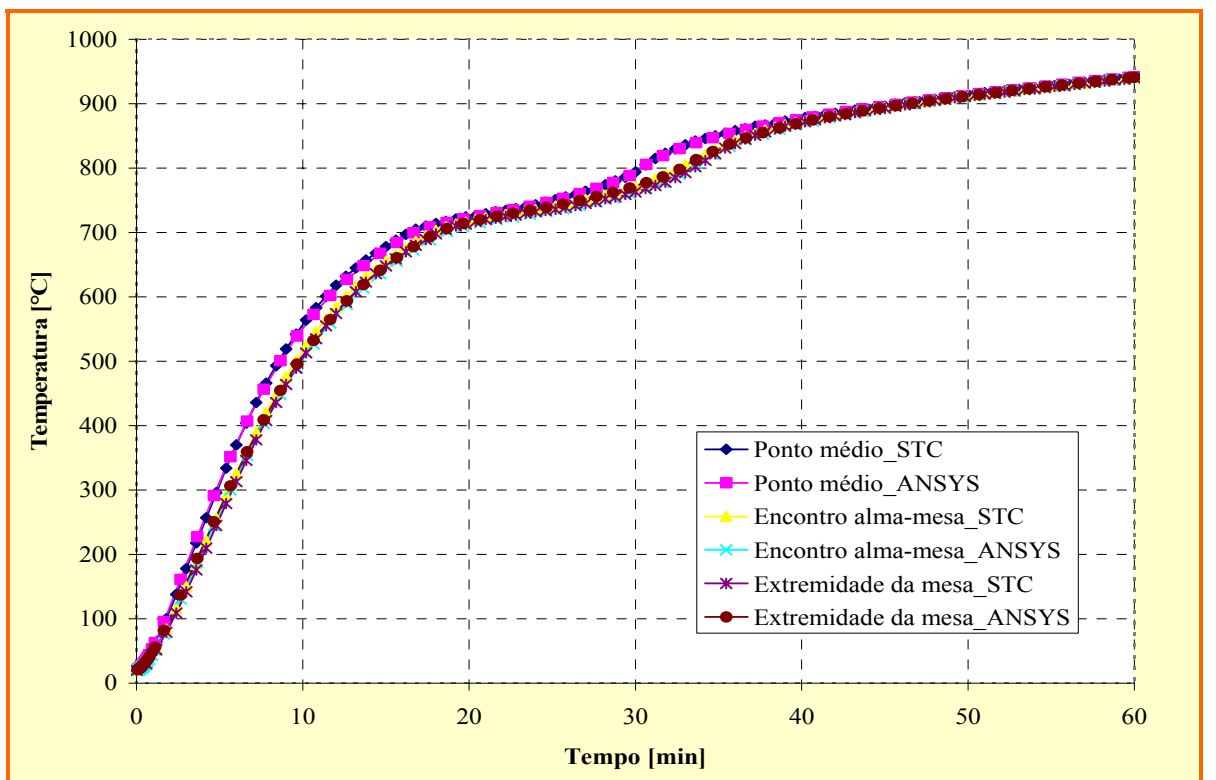

Figura 5.8: Gráfico da evolução térmica obtida vai STC e via ANSYS para o meio da alma, região entre a alma e a mesa e para a extremidade da mesa do perfil UC203 x 203 x 46.

\subsubsection{SEÇÃO TRANSVERSAL UB127X 76 X 13}

A seção transversal do exemplo em questão foi extraída de HUANG (2007). Porém, diferentemente da proposta apresentada na última referência, aqui se utilizou a curva de incêndio apresentada pela ISO 834 para avaliar, inicialmente, apenas o campo térmico. A Figura 5.9 ilustra a malha de elementos finitos considerada no ANSYS, a qual permitiu obter o campo térmico apresentado na Figura 5.10, referente ao SUPER-TEMPCALC e referente ao código ANSYS.

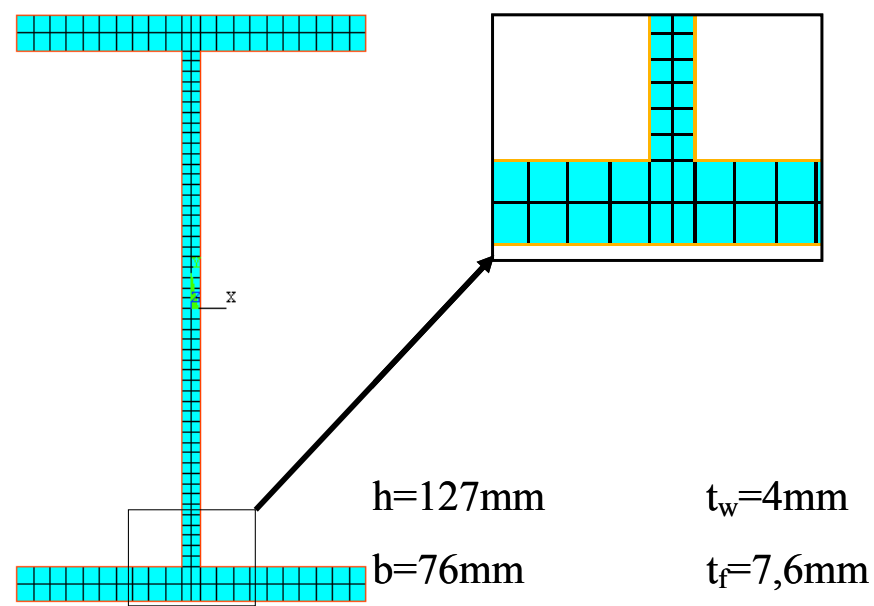

Figura 5.9: Geometria e malha de elementos finitos do perfil UB127 x 76 x 13 . 


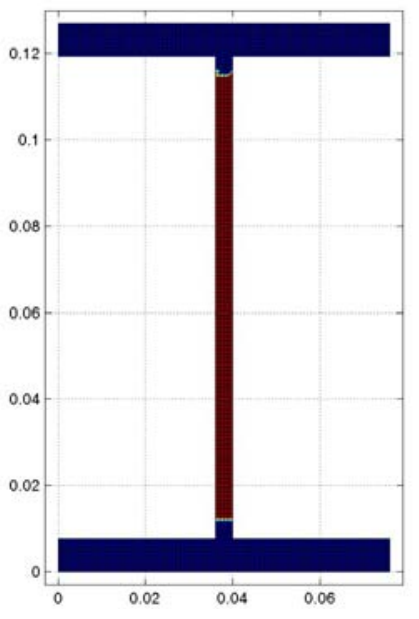

(a)
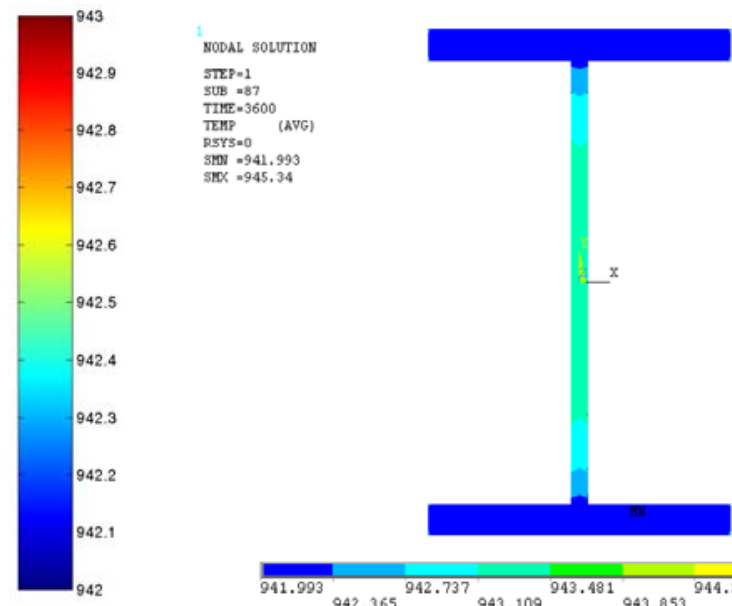

NN

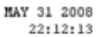

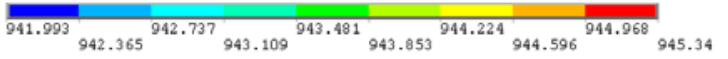

(b)

Figura 5.10: Campo térmico, em ${ }^{\circ} \mathrm{C}$, obtido por meio das simulações para o perfil UB $127 \mathrm{x}$ 76 x 13, para TRF de 60 minutos, obtido: (a) via STC e (b) via ANSYS

A Figura 5.11 mostra, em forma de gráfico, a variação de temperatura na alma, na região entre a alma e a mesa e na extremidade da mesa. Nota-se que, tanto no SUPERTEMPCALC (STC) como no ANSYS, as curvas temperatura x tempo nas três regiões da seção transversal apresentam comportamentos térmicos muito próximos. A diferença de temperatura entre essas três regiões em seções transversais mais delgadas resultou menor se comparado aos perfis mais robustos.

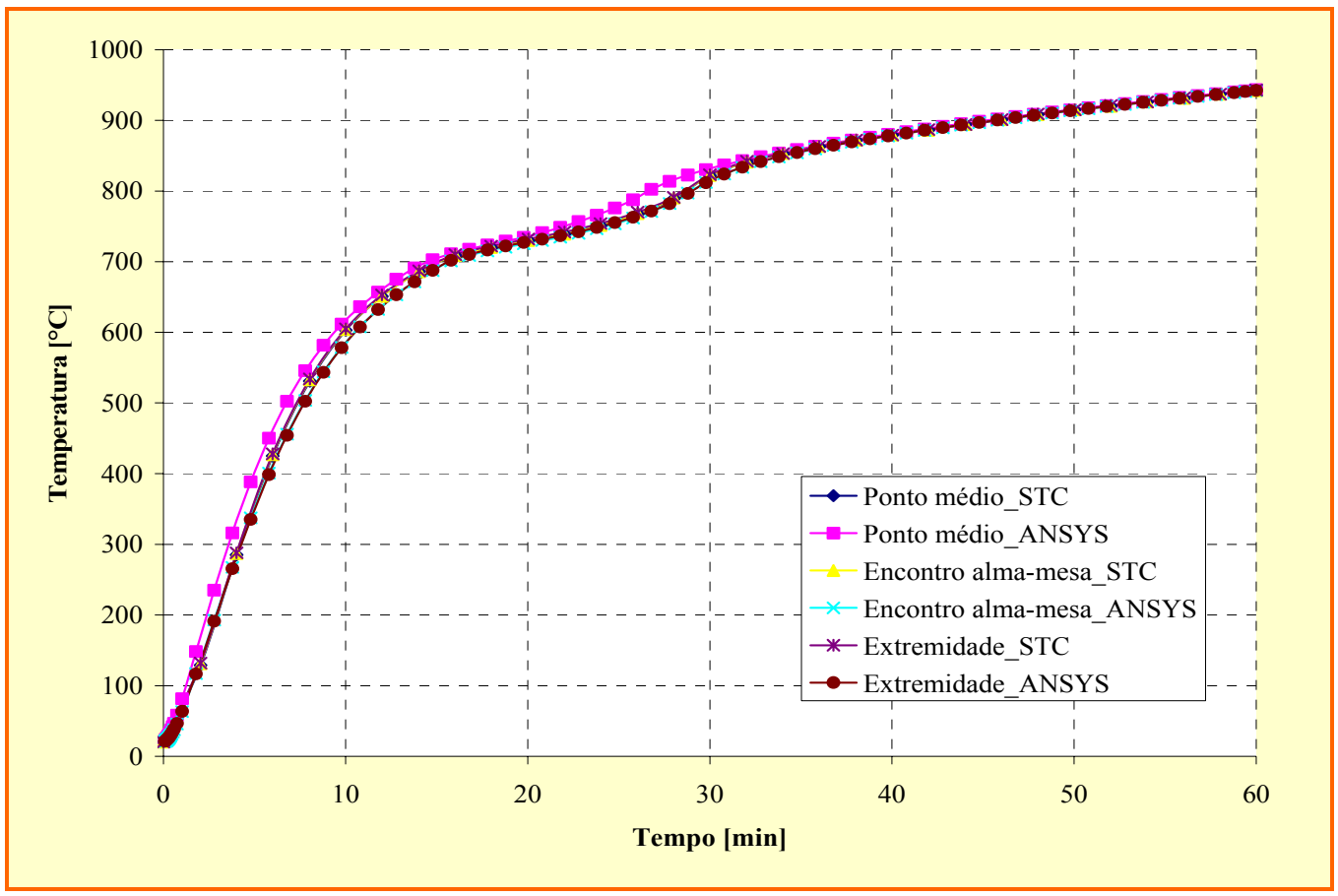

Figura 5.11: Gráfico da evolução térmica obtida vai STC e via ANSYS para o meio da alma, região entre a alma e a mesa e para a extremidade da mesa do perfil UB127 x 76 x 13. 


\subsubsection{SEÇÃO TRANSVERSAL CAIXÃO 200 X 200 FORMADO A FRIO}

O exemplo em questão foi extraído de FENG (2004). Embora não seja o objetivo do presente trabalho, este exemplo aborda situação de seção constituída por aço perfil formado a frio, na forma de seção transversal tipo caixão, com vistas a reproduzir o campo térmico. A discretização da malha de elementos finitos está ilustrada na Figura 5.12.

O campo térmico na seção transversal, obtido pelo SUPER-TEMPCALC e pelo ANSYS pode ser visto nas Figuras 5.13 (a) e (b), respectivamente. Como a forma corresponde a uma seção transversal delgada, a temperatura em todos os pontos, quando submetido a um campo térmico uniforme, permanece praticamente invariável.

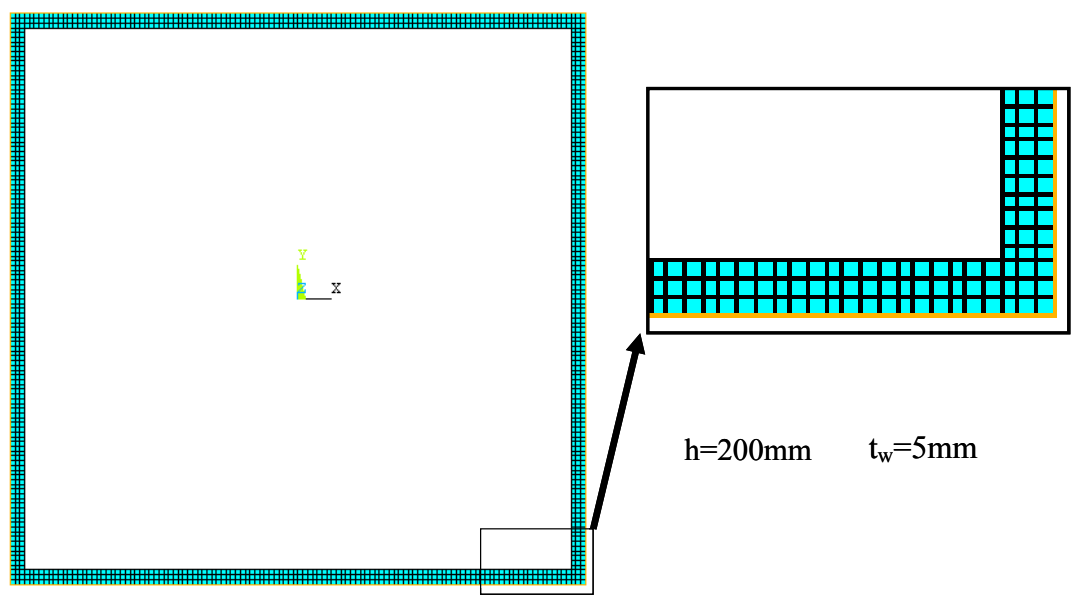

Figura 5.12: Geometria e malha de elementos finitos do perfil Caixão 200 x 200.

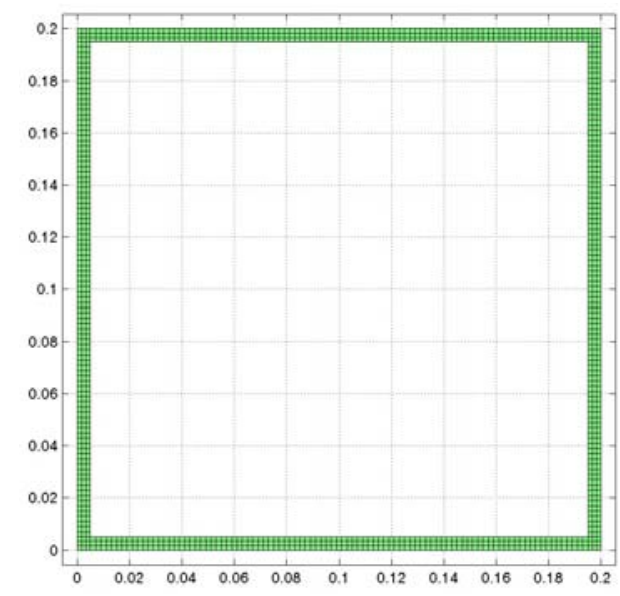

(a)
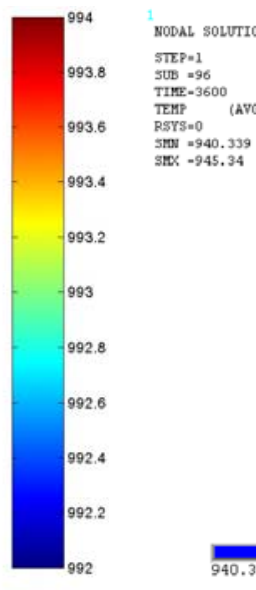

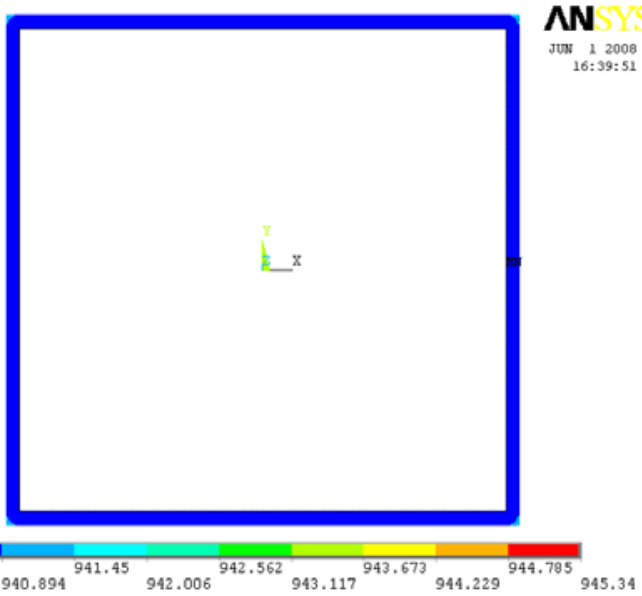

(b)

Figura 5.13: Campo térmico, em ${ }^{\circ} \mathrm{C}$, obtido por meio das simulações para o perfil Caixão 200 x 200, para TRF de 60 minutos, obtido: (a) via STC e (b) via ANSYS. 
A Figura 5.14 mostra o gráfico da evolução térmica obtida pela simulação numérica realizada utilizando o SUPER-TEMPCALC e o ANSYS, para pontos localizados na altura média de uma das almas e no vértice.

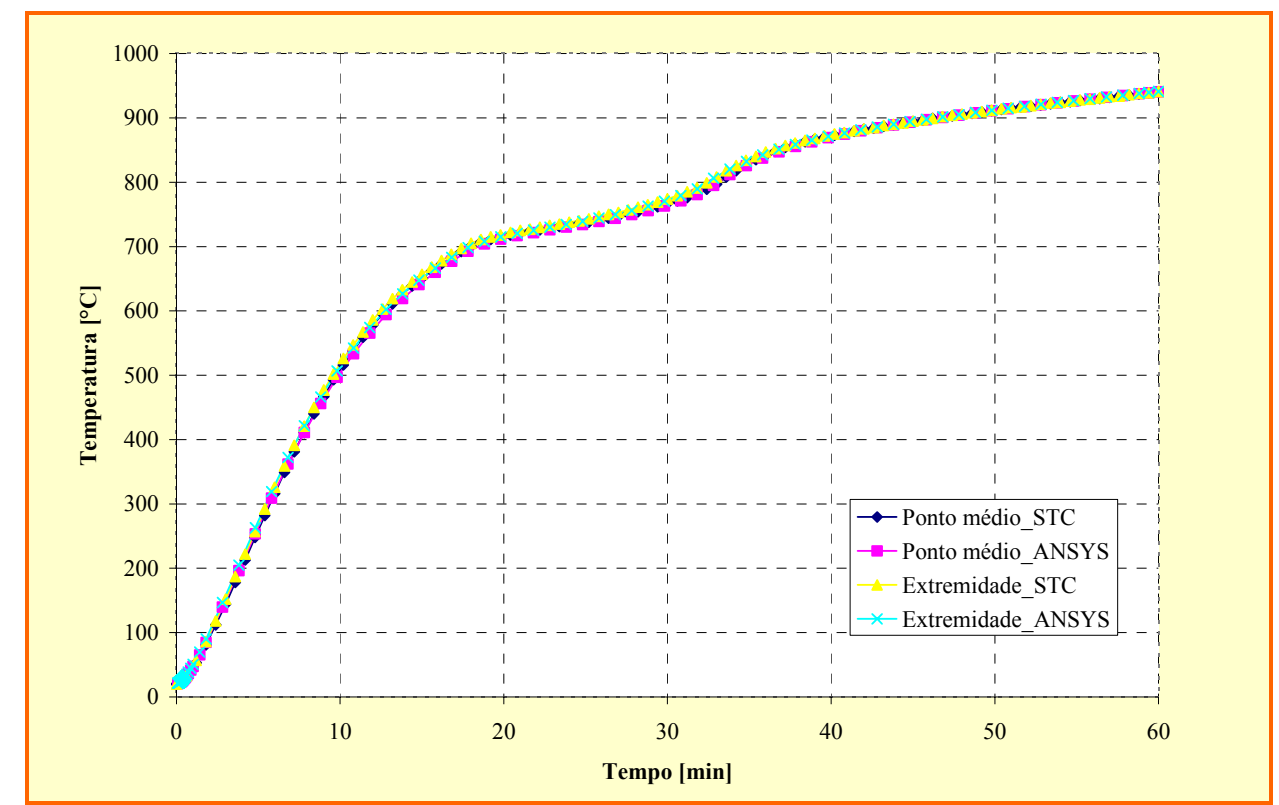

Figura 5.14: Gráfico da evolução térmica obtida vai STC e via ANSYS para o meio da alma, região entre a alma e a mesa e para a extremidade da mesa do perfil Caixão 200 x 200.

\subsubsection{SEÇÃO TRANSVERSAL UC305 X 305 X 137}

Este exemplo, cuja malha definida no ANSYS está ilustrado na Figura 5.15, consiste da mesma seção transversal dos pilares internos do edifício construído em escala real para o trabalho experimental no Building Research Establishment, em Cardington, relatado em Bailey (1999). Ressalta-se que o objetivo deste exemplo é apenas validar o campo térmico para uma situação simplificada de exposição às temperaturas elevadas.

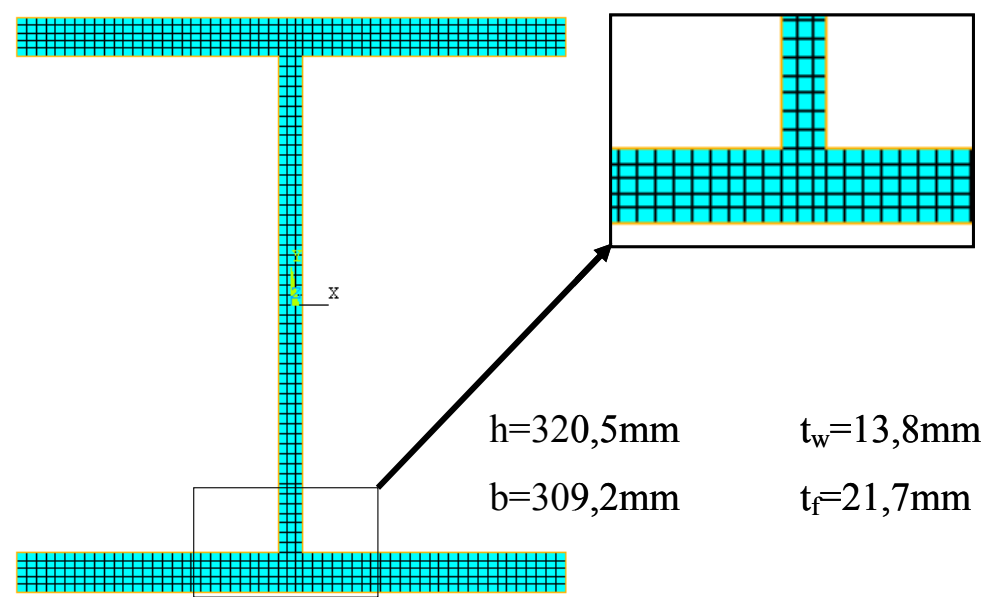

Figura 5.15: Geometria e malha de elementos finitos do perfil UC305 x 305 x 137. 
Os campos térmicos, ao final do intervalo de tempo definido, resultantes do SUPERTEMPCALC e do ANSYS são ilustrados nas Figuras 5.16 (a) e (b), respectivamente. A Figura 5.17 mostra a curva temperatura $\mathrm{x}$ tempo nos três pontos de interesse da seção transversal.

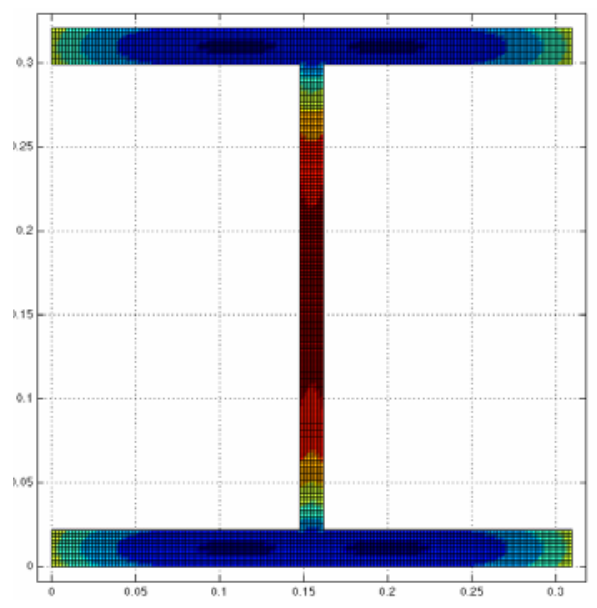

(a)
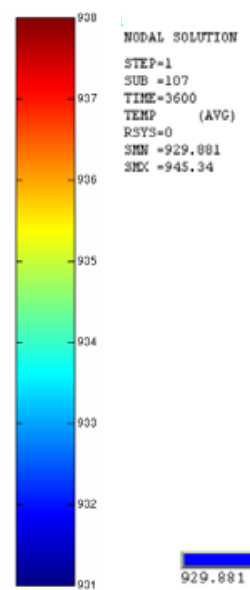

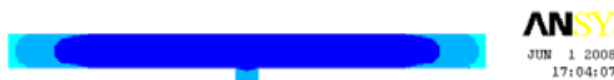

Jus $\begin{array}{r}12008 \\ 17: 04: 07\end{array}$

Figura 5.16: Campo térmico, em ${ }^{\circ} \mathrm{C}$, obtido por meio das simulações para o perfil UC $305 \mathrm{x}$ 305 x 137 para TRF de 60 minutos, obtido: (a) via STC e (b) via ANSYS

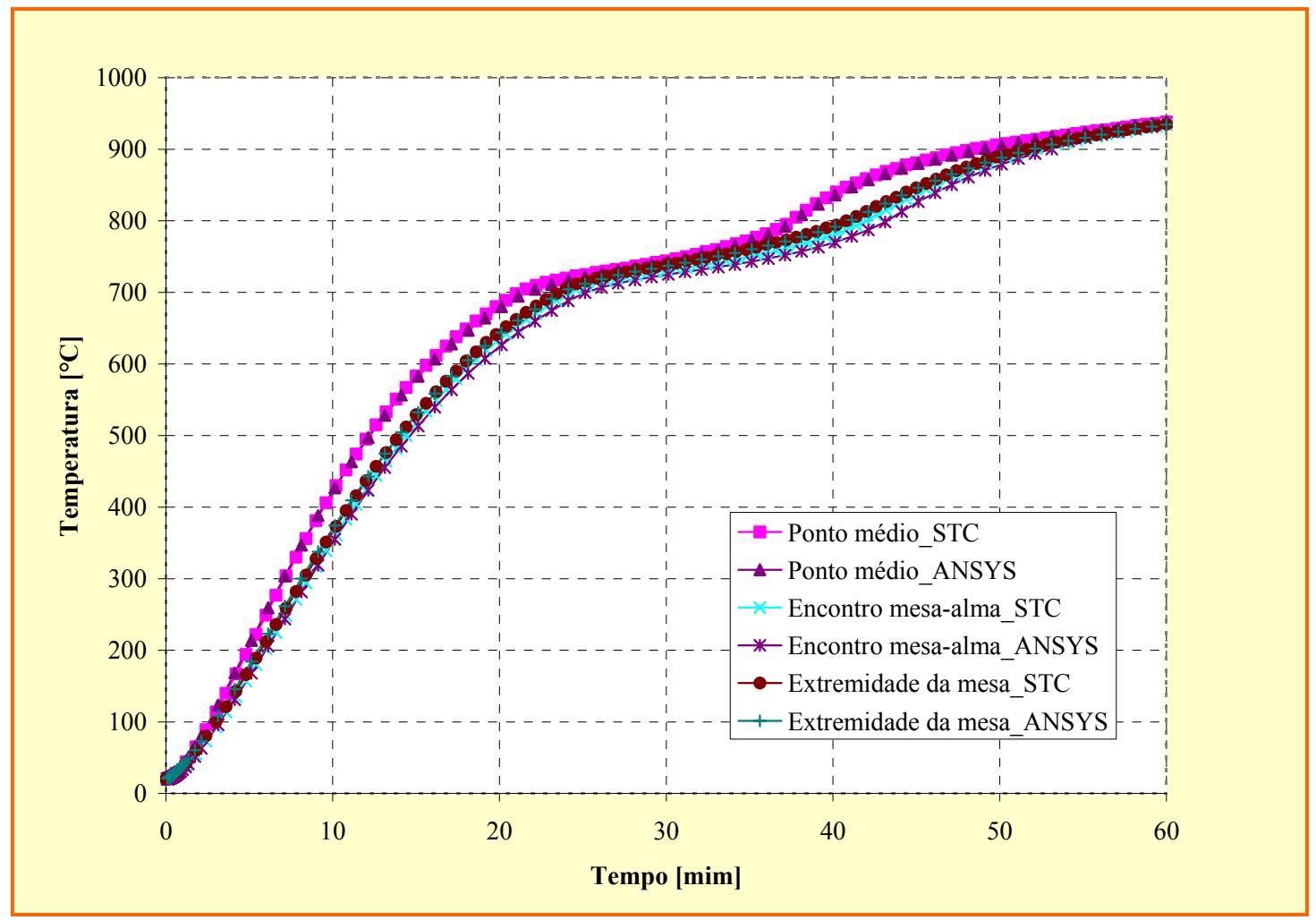

Figura 5.17: Gráfico da evolução térmica obtida vai STC e via ANSYS para o meio da alma, região entre a alma e a mesa e para a extremidade da mesa do perfil UC305 x 305 x 137. 


\subsubsection{RESULTADOS DA ANALLISE TÉRMICA APRESENTADA - Avaliação}

Do item 5.1.1 ao item 5.1.5 foram apresentados alguns tipos de perfis comumente utilizados na construção civil. Vale ressaltar ainda que, exceto o caso apresentado no sub-ítem 5.1.4 que trata da seção transversal do tipo caixão 200 × 200, as malhas de elementos finitos consideradas nos códigos ANSYS e STC não são coincidentes.

Com o código ANSYS, procurou-se elaborar uma rede de elementos finitos com maior grau de discretização (mais refinada) nas regiões não-planas, ou seja, na intersecção entre alma e mesa da seção transversal. Observou-se que os perfis mais delgados têm menor variabilidade do campo térmico entre os pontos nodais da seção transversal, aspecto já esperado e em concordância com aspectos mencionados em REGOBELLO (2007).

As comparações entre as curvas temperatura $\mathrm{x}$ tempo de todas as seções transversais submetidas à ação térmica por todos os lados, obtidas por meio do SUPER-TEMPCALC e do ANSYS, tanto no presente trabalho como em REGOBELLO (2007), se mostraram bastante satisfatórias, uma vez que a diferença máxima encontrada nas comparações entre as duas análises resultou próxima de $8 \%$. As Figuras 5.18 a 5.24, extraídas da última referência, trazem mais configurações de campo térmico obtidos para outras situações em correspondência aos respectivos tempos requeridos de resistência ao fogo (TRF).
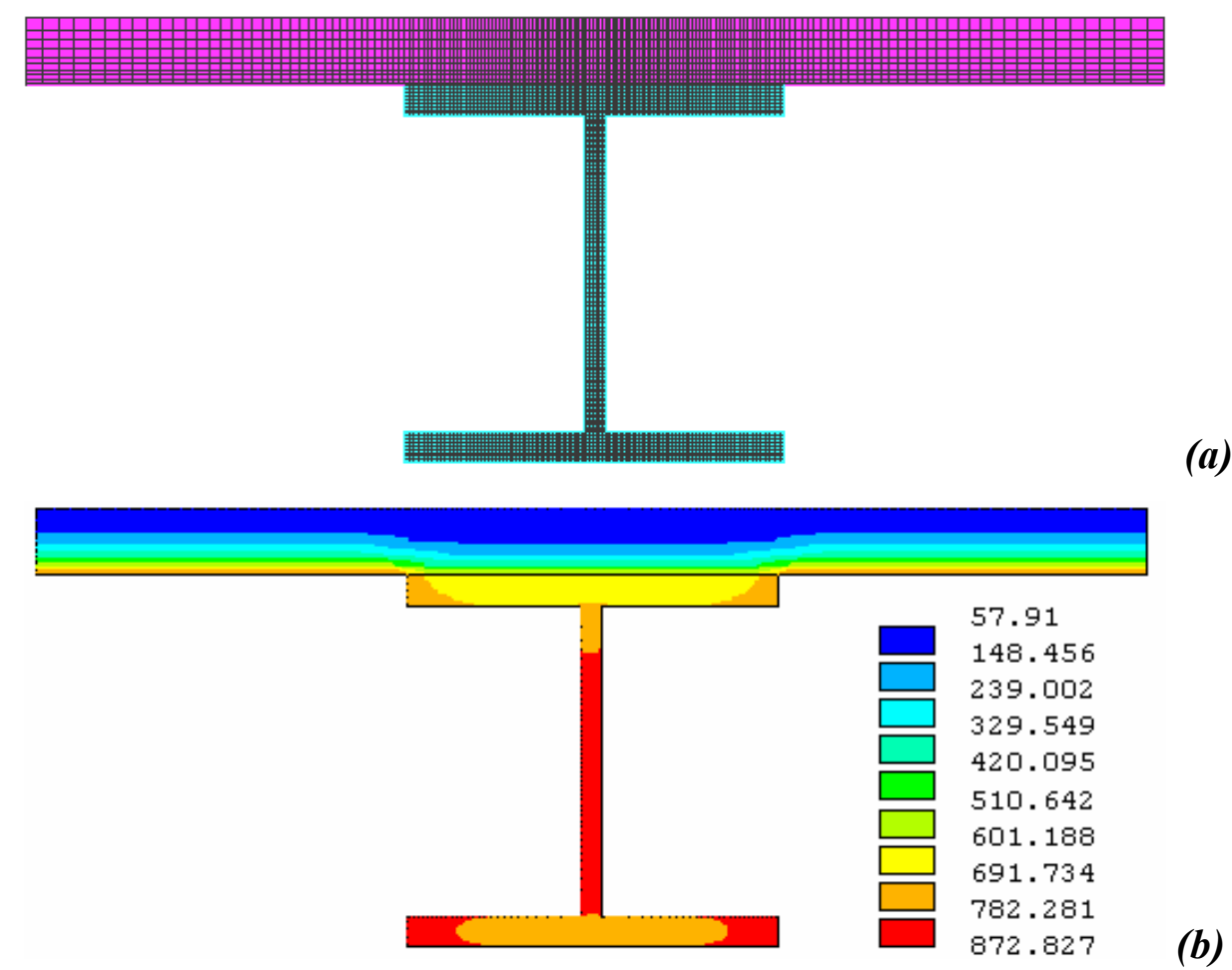

(a)

Figura 5.18: (a) Malha de elementos finitos e (b) Campo de temperaturas correspondente a um tempo (TRF) de 60 minutos para o perfil CS 550x502. 


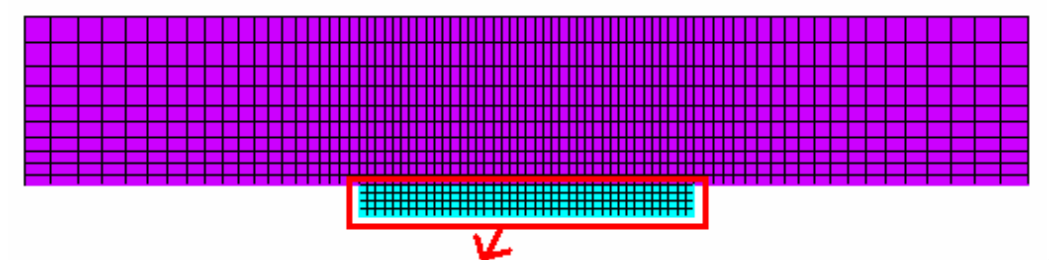

(a)
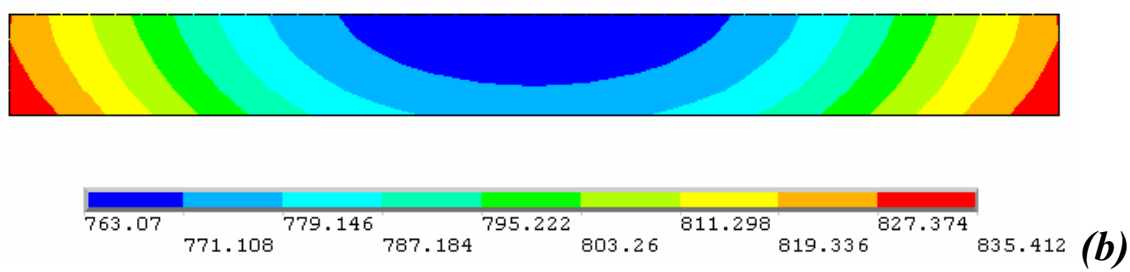

Figura 5.19: Mesa do perfil W 250x25,3 (a) Malha de elementos finitos e (b) Campo de temperaturas correspondente a um tempo (TRF) de 60 minutos
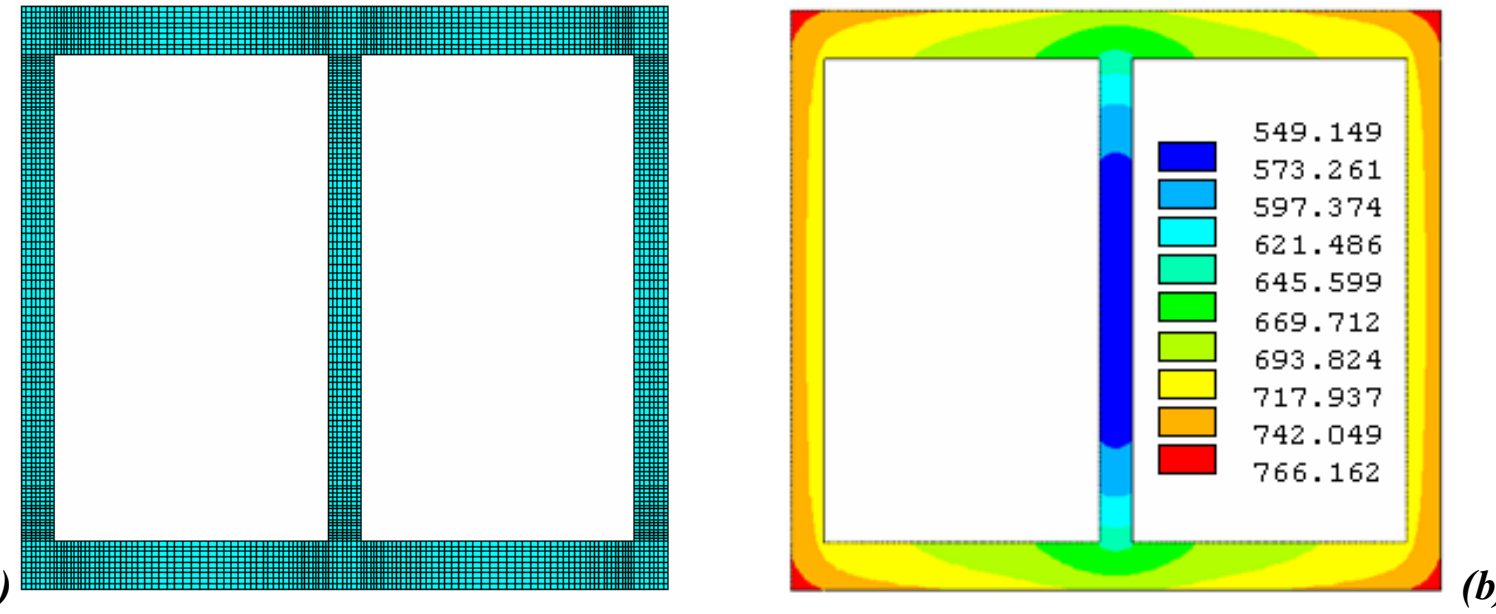

Figura 5.20: Perfil CS 550x502 com reforço em caixão (a) Malha de elementos finitos e (b) Campo de temperaturas correspondente a um tempo (TRF) de 60 minutos.
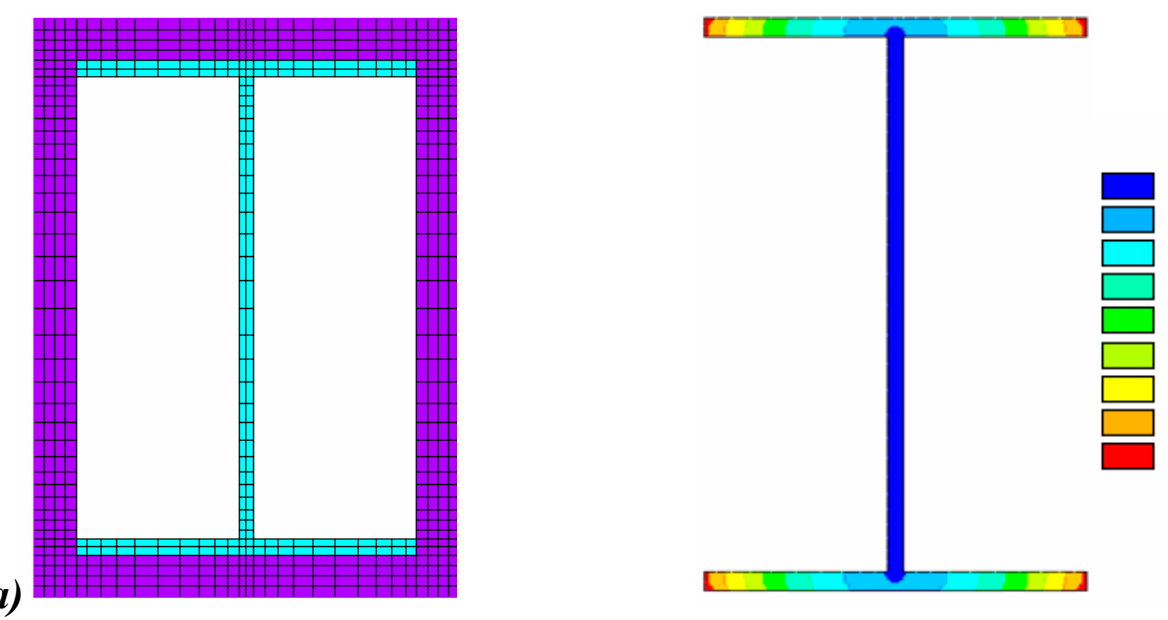

690.757

691.506

692.254

693.002

693.75

694.499

695.247

695.995

696.743

697.492

(a)

(b) 
Figura 5.21: Perfil W 150x13 com proteção tipo caixa de placa de gesso acartonado: (a) Malha de elementos finitos e (b) Campo de temperaturas correspondente a um tempo (TRF) de 60 minutos.

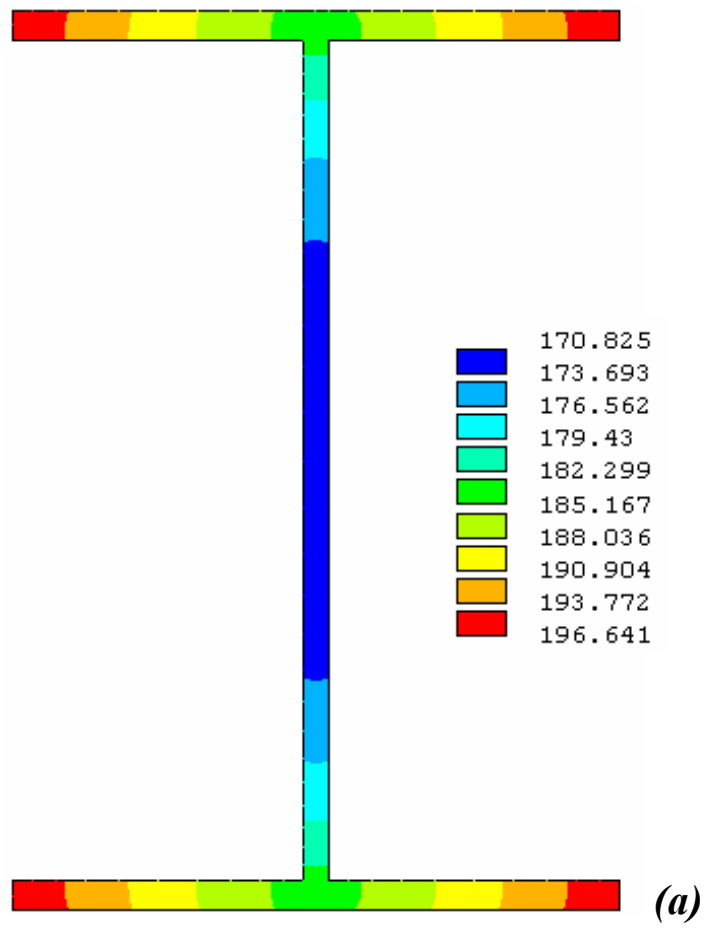

$15 \min$

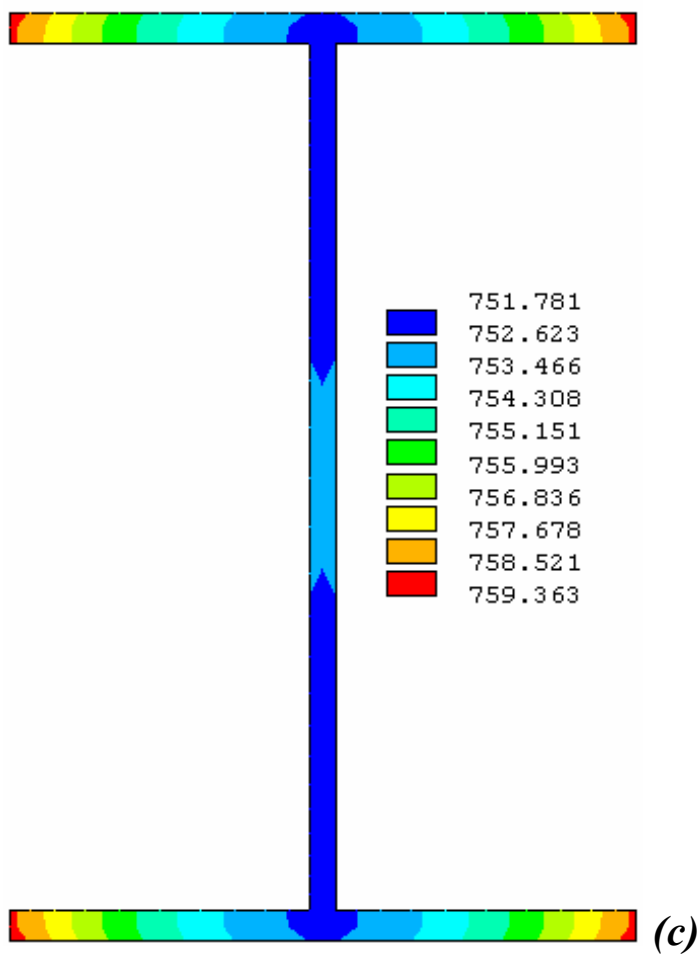

$90 \min$

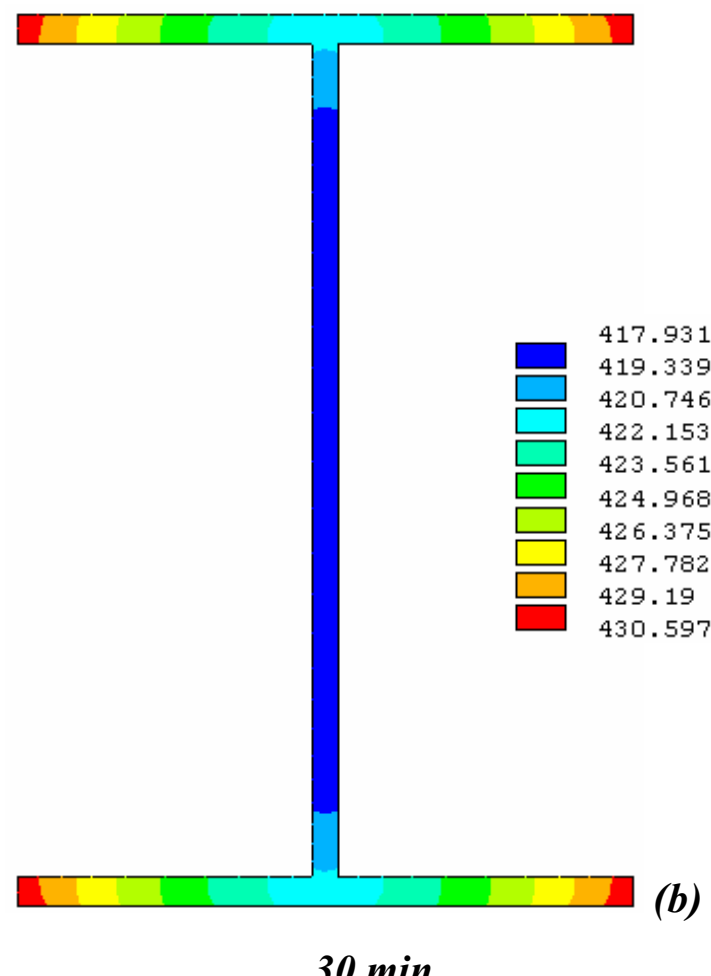

$30 \min$

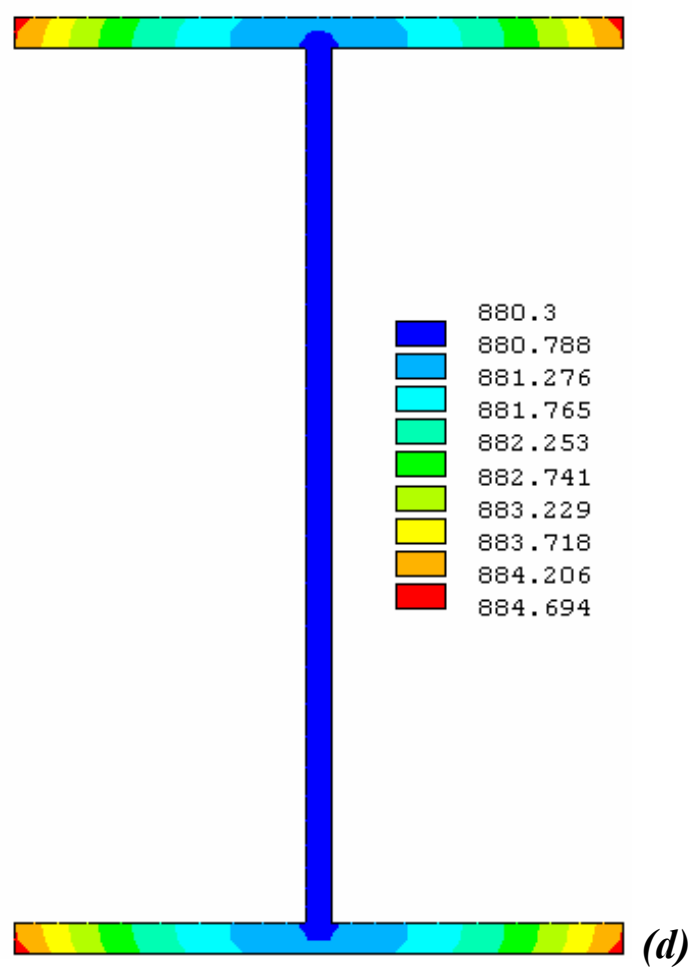

$120 \min$ 
Figura 5.22: Perfil W 150x13com proteção tipo caixa, de espessura uniforme, exposta ao incêndio por todos os lados para TRF de: (a) 15 minutos, (b) 30 minutos, (c) 90 minutos e (d) 120 minutos

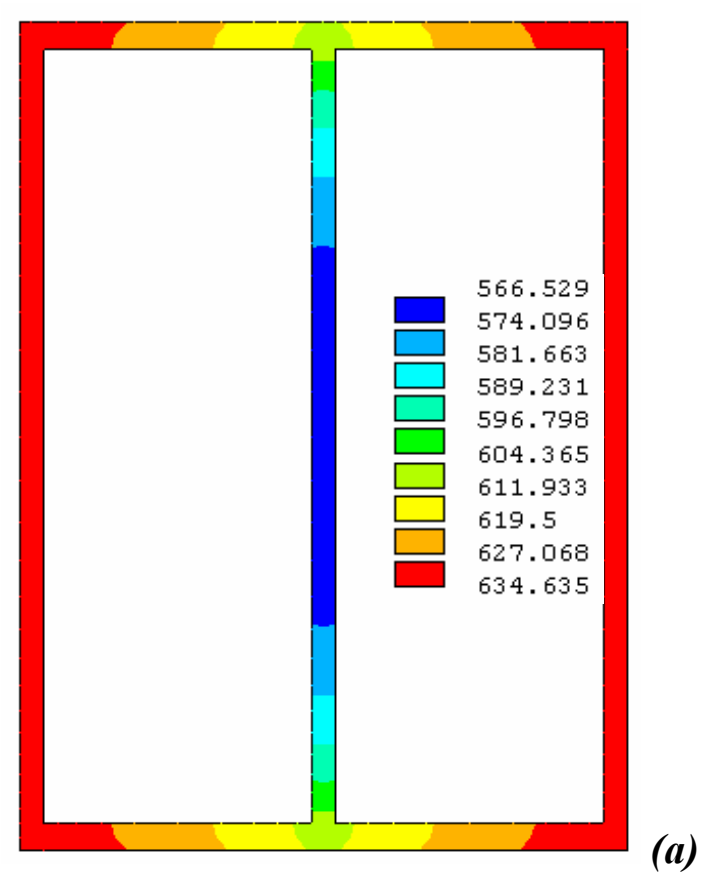

$15 \min$

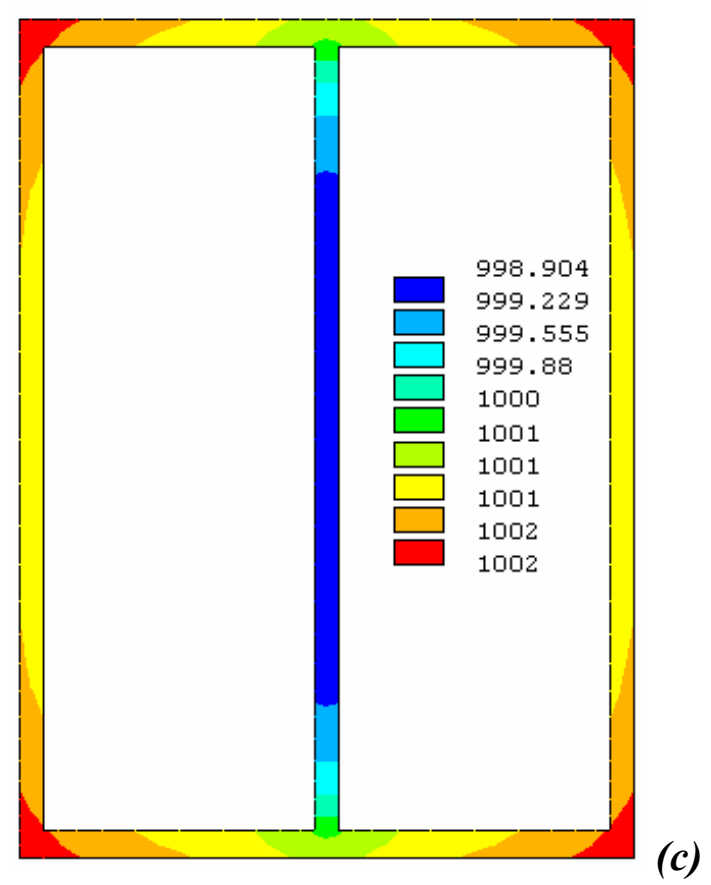

$90 \min$

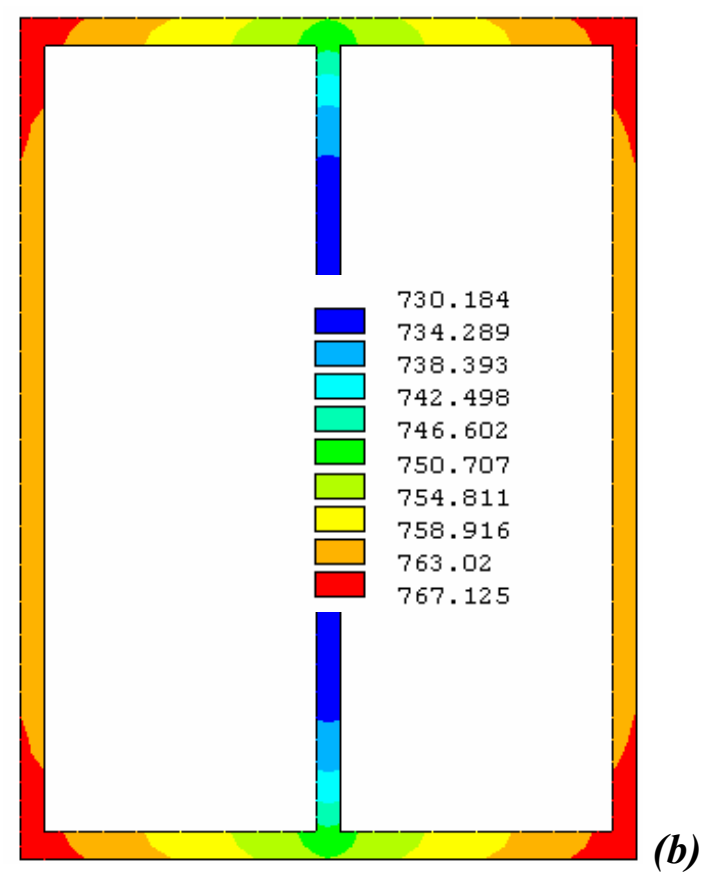

$30 \mathrm{~min}$

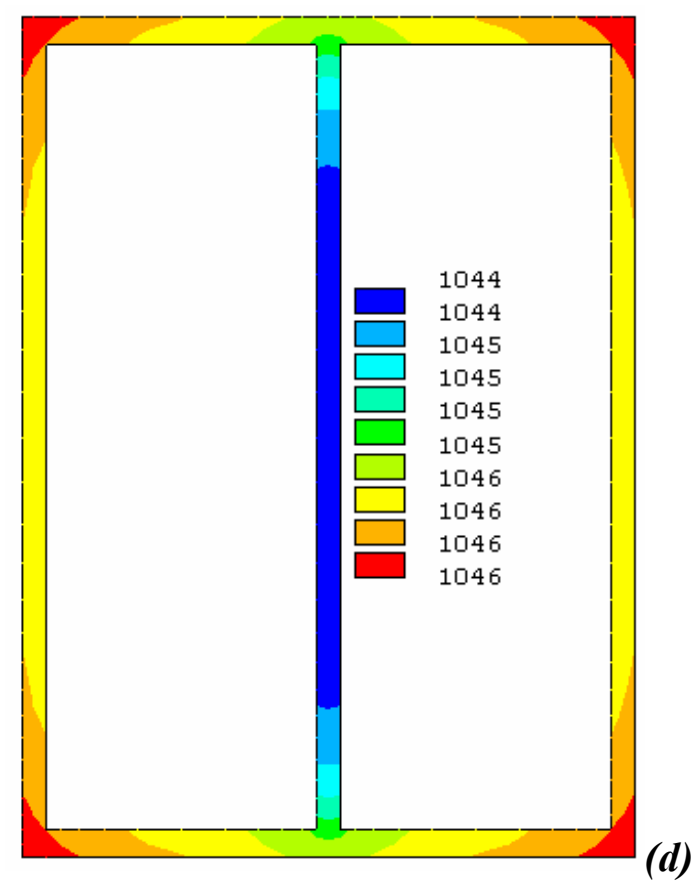

$120 \mathrm{~min}$

Figura 5.23: Perfil W 150x13 com reforço em caixão exposta ao incêndio por todos os lados para TRF de: (a) 15 minutos, (b) 30 minutos, (c) 90 minutos e (d) 120 minutos 


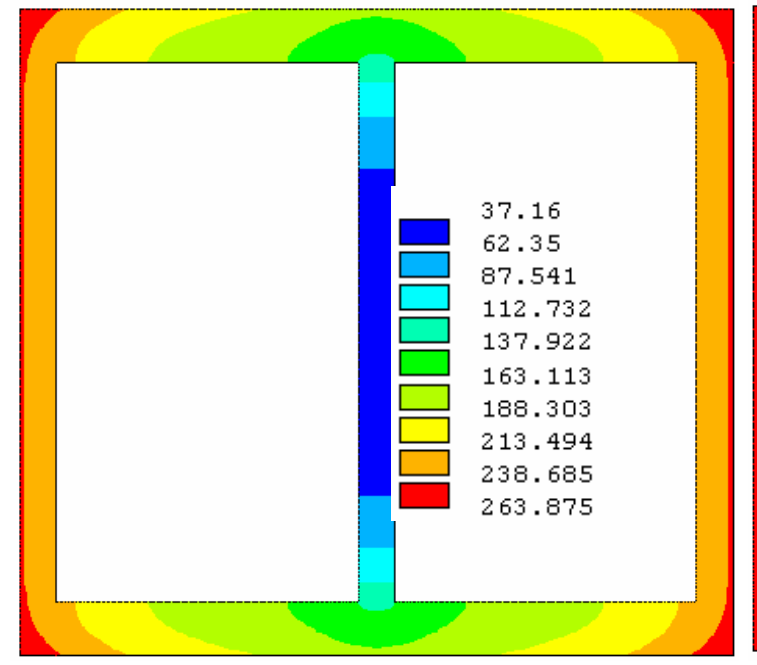

(a)

$15 \mathrm{~min}$

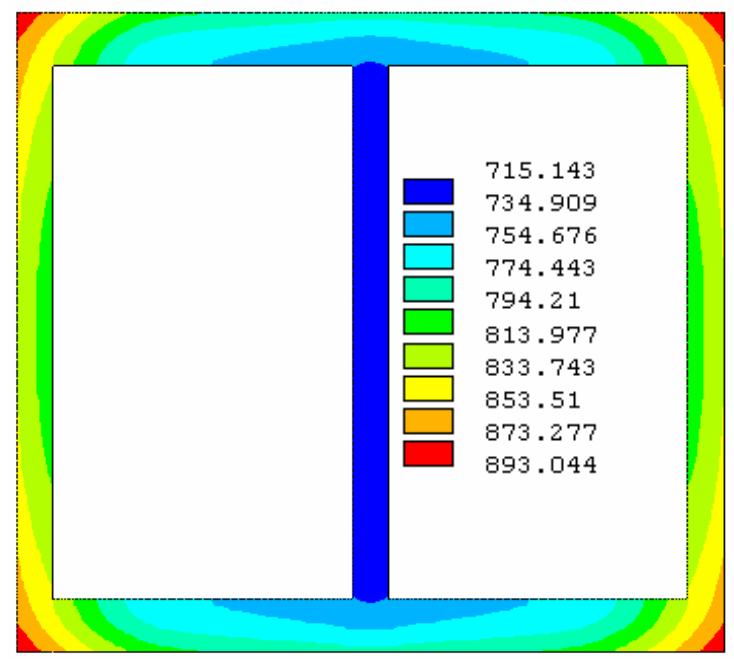

(c)

$90 \mathrm{~min}$

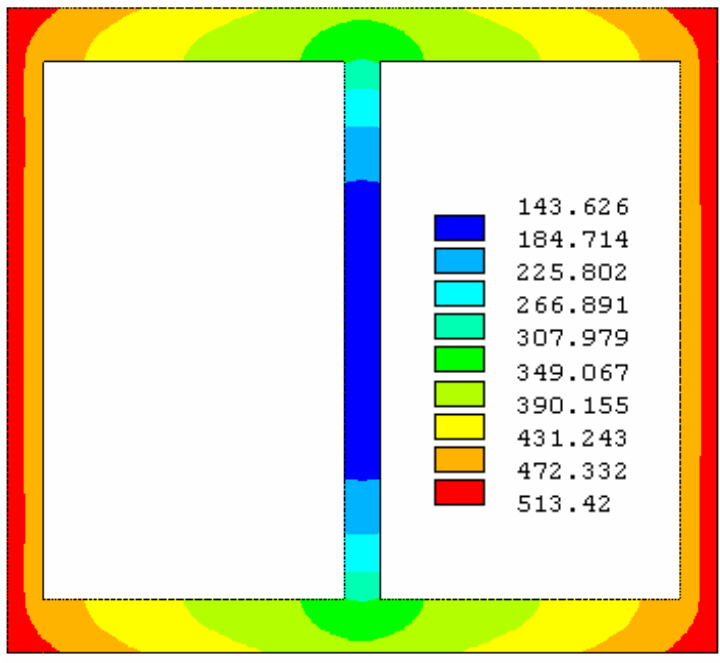

(b)

30 min

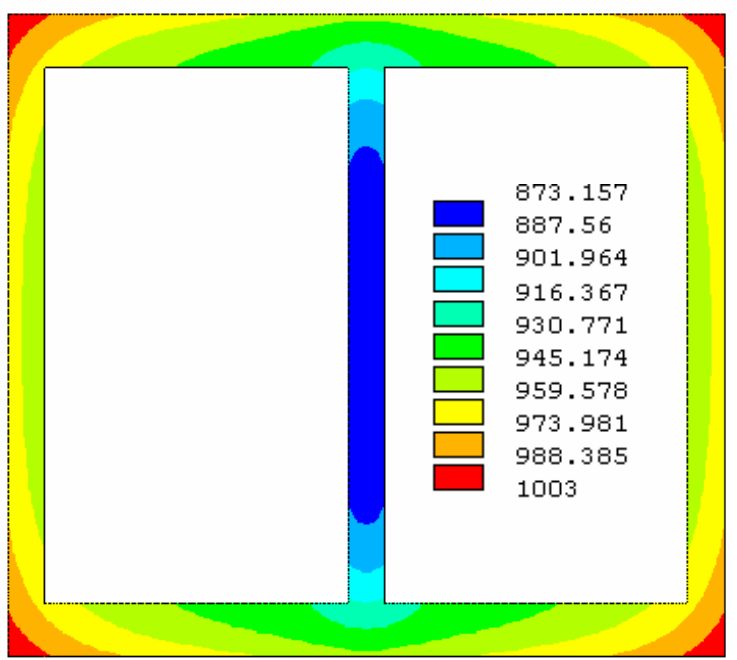

(d)

$120 \mathrm{~min}$

Figura 5.24: Perfil CS 550x502 com reforço em caixão exposta ao incêndio por todos os lados para TRF de: (a) 15 minutos, (b) 30 minutos, (c) 90 minutos e (d) 120 minutos 


\subsection{ANÁLISE TÉRMICA TRIDIMENSIONAL CONSIDERANDO A ASSIMETRIA DO CAMPO TÉRMICO}

Uma das formas de reproduzir situações mais realísticas da ação térmica é considerar a influência das paredes (compartimentação) na determinação do campo de temperatura no perfil e, consequentemente, sua influência nos esforços solicitantes de interesse.

O presente item apresenta algumas configurações de pilares submetidos a diferentes condições de assimetria de campo térmico, obtidos em decorrência da posição das paredes de alvenaria. Foram consideradas cinco condições de campo térmico para um mesmo perfil e dois estudos de caso realizados sobre uma edificação real. Por simplificação, a face dos materiais não exposta ao fogo foi considerada adiabática, o que significa que a face do elemento é perfeitamente isolante, ou seja, não permite interação térmica.

Vale lembrar que na direção longitudinal (eixo do pilar), por simplificação a variação térmica foi desconsiderada com campo térmico resultando uniforme. No entanto, a modelagem tridimensional do campo térmico utilizando elemento do tipo sólido, permitirá em trabalhos futuros a implementação do campo de temperatura de forma variável ao longo do comprimento.

Embora os elementos de aço sejam relativamente delgados, julgou-se interessante avaliar a temperatura não só na extremidade, mas também no ponto médio da sua espessura. Em REGOBELLO (2007) são descritos critérios que permitem avaliar a necessidade de se considerar o gradiente térmico em pontos internos de uma placa, conhecendo apenas a espessura e a condutividade térmica do material, possibilitando, dessa forma, determinar quando a hipótese de temperatura homogênea na seção pode ser adotada.

Todos os elementos estudados no presente trabalho poderiam ser analisados com distribuição uniforme de temperatura. Porém, vale lembrar que a obtenção da temperatura no plano central da espessura do elemento foi válida para a análise termoestrutural envolvendo elementos de chapa, que serão apresentados no próximo capítulo.

Em função da discretização dessa espessura, a ordem de grandeza da dimensão do elemento finito medido na seção transversal do perfil foi milimétrica. Para que a razão entre as dimensões dos elementos se mantenha o mais próximo possível da unidade, houve a necessidade de um grande refino na discretização da malha de elementos finitos em relação à direção longitudinal do perfil. Essa uniformidade na dimensão dos elementos finitos é importante para minimizar a influência da forma do elemento na convergência do processamento. 


\subsubsection{CONSIDERAÇÃO DA COMPARTIMENTAÇÃO NA DISTRIBUIÇÃO DA TEMPERATURA - Influência no campo térmico}

Para se avaliar a influência da disposição das paredes de compartimentação em contato com o pilar na determinação do campo térmico, tomou-se uma barra, cuja seção transversal é da serie inglesa UC203 x 203 x 46. Trata-se do mesmo perfil relatado em WANG (2003), em que cinco situações, apresentadas no que segue, são consideradas. As dimensões são:

\begin{tabular}{|c|c|}
\hline Área bruta da seção transversal & $\mathrm{A}_{\mathrm{g}}=58,7 \mathrm{~cm}^{2}$ \\
\hline Altura externa da seção transversal & $\mathrm{d}=203,2 \mathrm{~mm}$ \\
\hline Altura livre da alma & $\mathrm{d}^{\prime}=160,8 \mathrm{~mm}$ \\
\hline Altura interna & $\mathrm{h}^{\prime}=181,2 \mathrm{~mm}$ \\
\hline Largura da mesa & $\mathrm{b}_{\mathrm{f}}=203,6 \mathrm{~mm}$ \\
\hline Espessura da mesa & $\mathrm{t}_{\mathrm{f}}=11 \mathrm{~mm}$ \\
\hline Espessura da alma & $\mathrm{t}_{\mathrm{w}}=7,2 \mathrm{~mm}$ \\
\hline
\end{tabular}

Em relação à alvenaria de fechamento, suas propriedades térmicas foram consideradas constantes ao longo do tempo. Para a determinação do gradiente térmico, foram declaradas as seguintes constantes térmicas da alvenaria:

\begin{tabular}{|c|c|}
\hline Massa específica & $\rho_{\mathrm{alv}}=1600 \mathrm{~kg} / \mathrm{m}^{3}$ \\
\hline Calor específico & $\mathrm{c}_{\mathrm{alv}}=840 \mathrm{~J} / \mathrm{kg}^{\circ} \mathrm{C}$ \\
\hline Condutividade térmica & $\lambda_{\mathrm{alv}}=0,7 \mathrm{~W} / \mathrm{m}^{\circ} \mathrm{C}$ \\
\hline Emissividade resultante & $\varepsilon_{\mathrm{res}}=0,5$ \\
\hline Coeficiente de transferência de calor por convecção & $\alpha_{\mathrm{c}}=25 \mathrm{~W} / \mathrm{m}^{2 \circ} \mathrm{C}$ \\
\hline
\end{tabular}

\subsubsection{Situação I - Pilar isolado}

O primeiro exemplo para fins de análise térmica apresentado neste item é semelhante àquele apresentado no sub-ítem 5.1.2, porém, levando em consideração o comprimento do 
pilar. Como mostra a ilustração esquemática da Figura 5.25, o pilar isolado, que pode representar um pilar interno a um compartimento ou à edificação, é exposto ao incêndiopadrão por todos os lados, partindo da situação de temperatura ambiente $\left(20^{\circ} \mathrm{C}\right)$ e considerando a elevação de temperatura correspondente a um tempo requerido de resistência ao fogo (TRF) igual a 60 minutos.

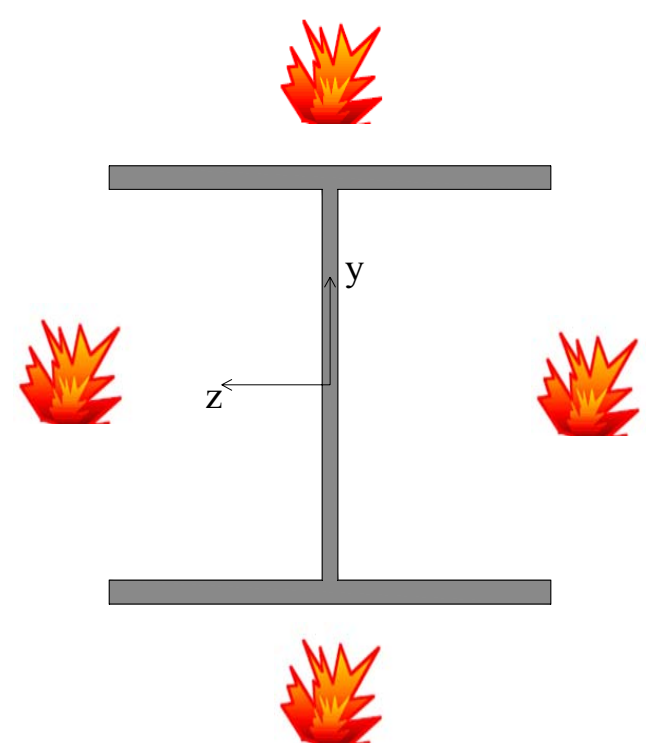

Figura 5.25: Configuração do campo térmico da seção transversal do perfil isolado sob aquecimento por todos os lados.

As Figuras 5.26 e 5.27 ilustram os campos de temperatura obtidos por meio do código STC e por meio do ANSYS, para TRF igual a 60 minutos.

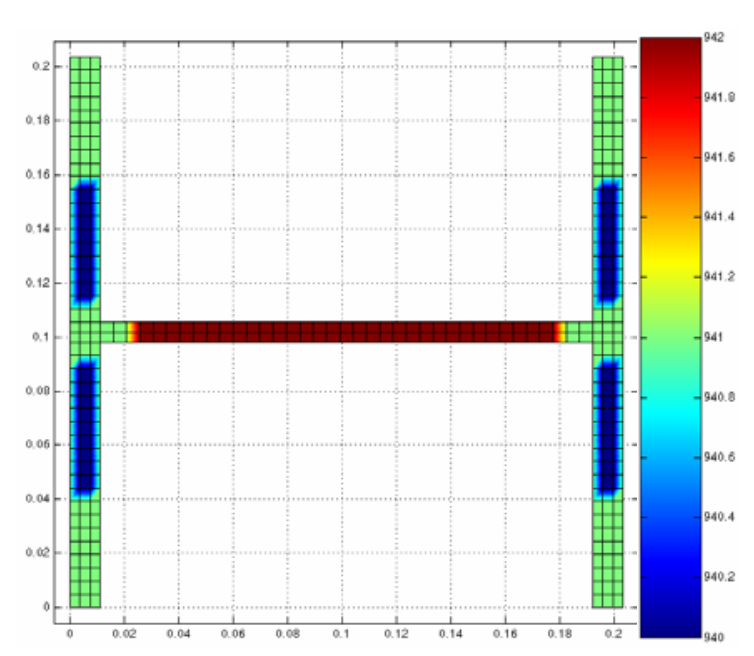

(a)

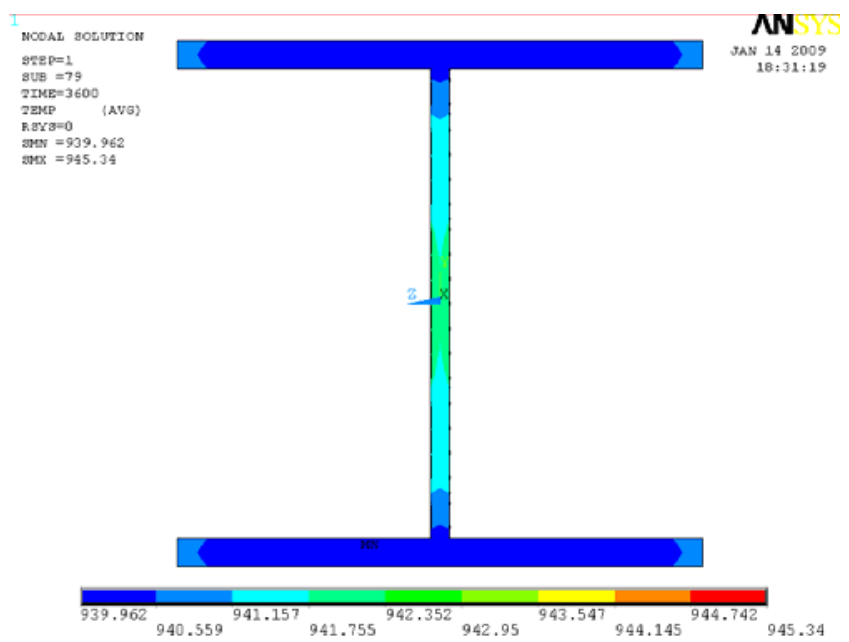

(b)

Figura 5.26: Campo térmico $\left(\mathrm{em}^{\circ} \mathrm{C}\right)$ da seção transversal do perfil isolado sob aquecimento por todos os lados obtido: (a) via SuperTempcalc e (b) via Ansys. 


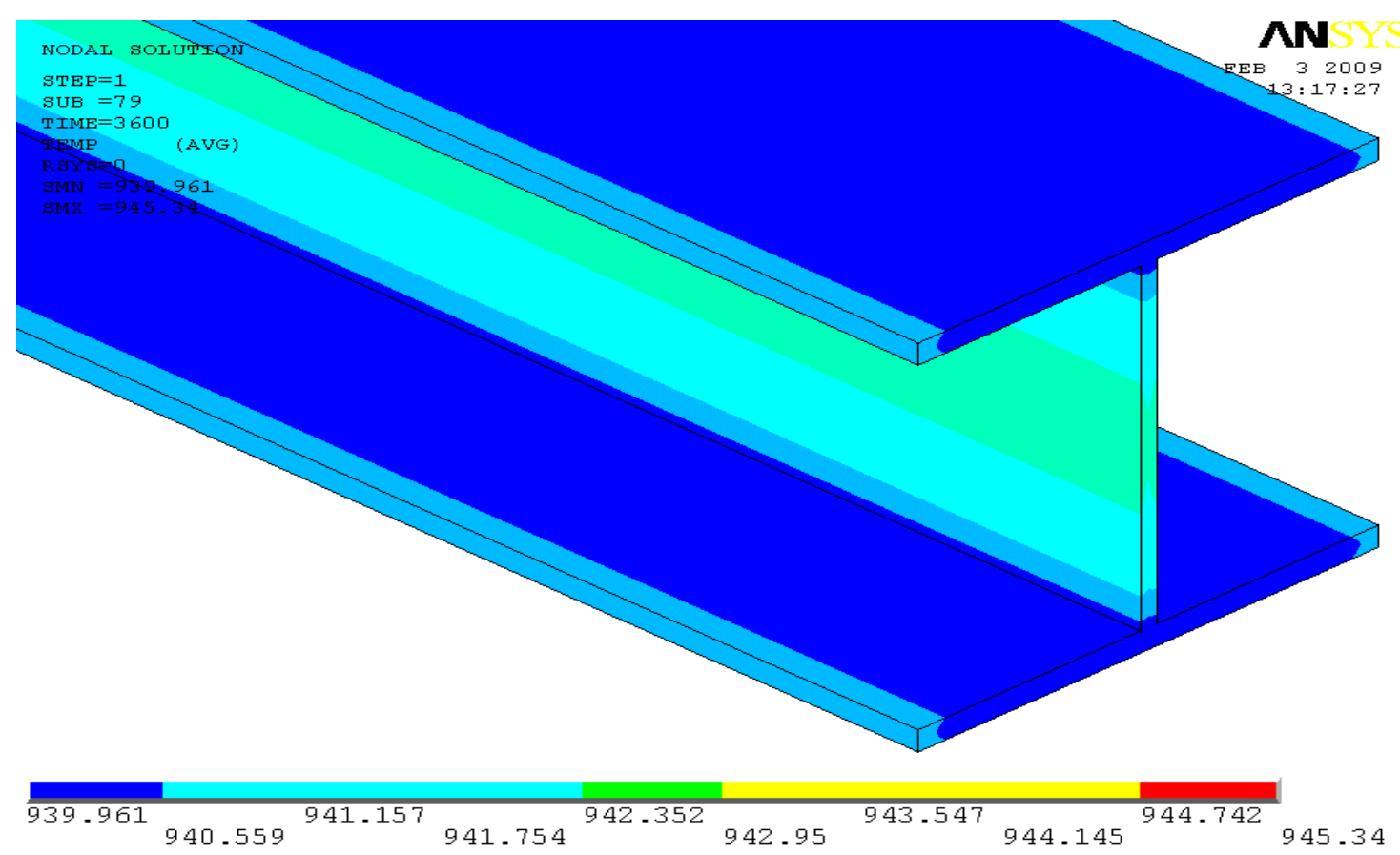

Figura 5.27: Campo térmico $\left(\mathrm{em}^{\circ} \mathrm{C}\right)$ na seção transversal e ao longo do comprimento do perfil isolado sob aquecimento por todos os lados.

\subsubsection{Situação II - Paredes de alvenaria em contato com ambas as mesas}

No presente capítulo, em que se consideram análises térmicas tridimensionais, para a inserção da alvenaria de fechamento nos modelos numéricos na forma de proteção térmica o grau de discretização não foi tão rigoroso quanto para aquele adotado para o perfil por se tratar de um elemento secundário, exceto na interface perfil-revestimento, em que foi necessário compatibilizar ambas as malhas.

A Figura 5.28 ilustra o esquema de um pilar externo com revestimento de alvenaria em contato com cada uma de suas mesas sujeito a situação de incêndio padrão por um dos lados. Nesse caso, os níveis de temperatura são obtidos considerando a exposição ao fogo de um dos lados simétricos ao eixo y. A exposição ao fogo de ambos os lados não foi considerada tendo em vista ser essa uma situação análoga àquela apresentada no item anterior.

A espessura adotada para a alvenaria neste exemplo resulta igual a 14 centímetros, em concordância com os padrões da norma ABNT NBR 7171:1992 para espessura de paredes externas. As Figuras 5.29 e 5.30 ilustram os campos térmicos obtidos por meio do código SUPER-TEMPCALC e do ANSYS, respectivamente, em correspondência a um TRF igual a 60 minutos, em que é possível observar a correspondência satisfatória entre ambos. 


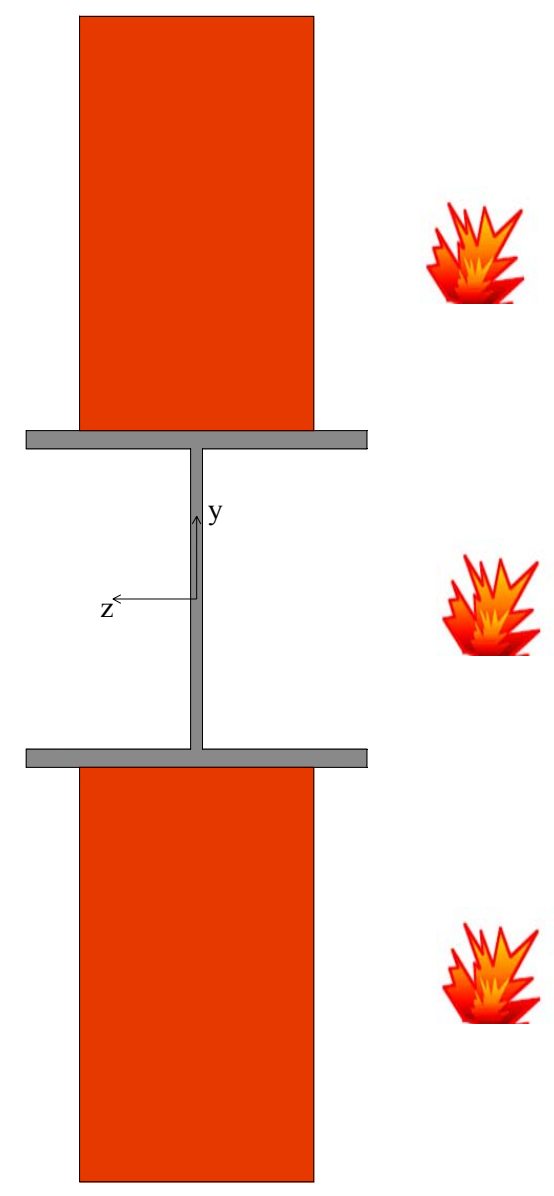

Figura 5.28: Configuração do campo térmico da seção transversal do perfil conectado por paredes em ambas as mesas sob aquecimento por um dos lados.

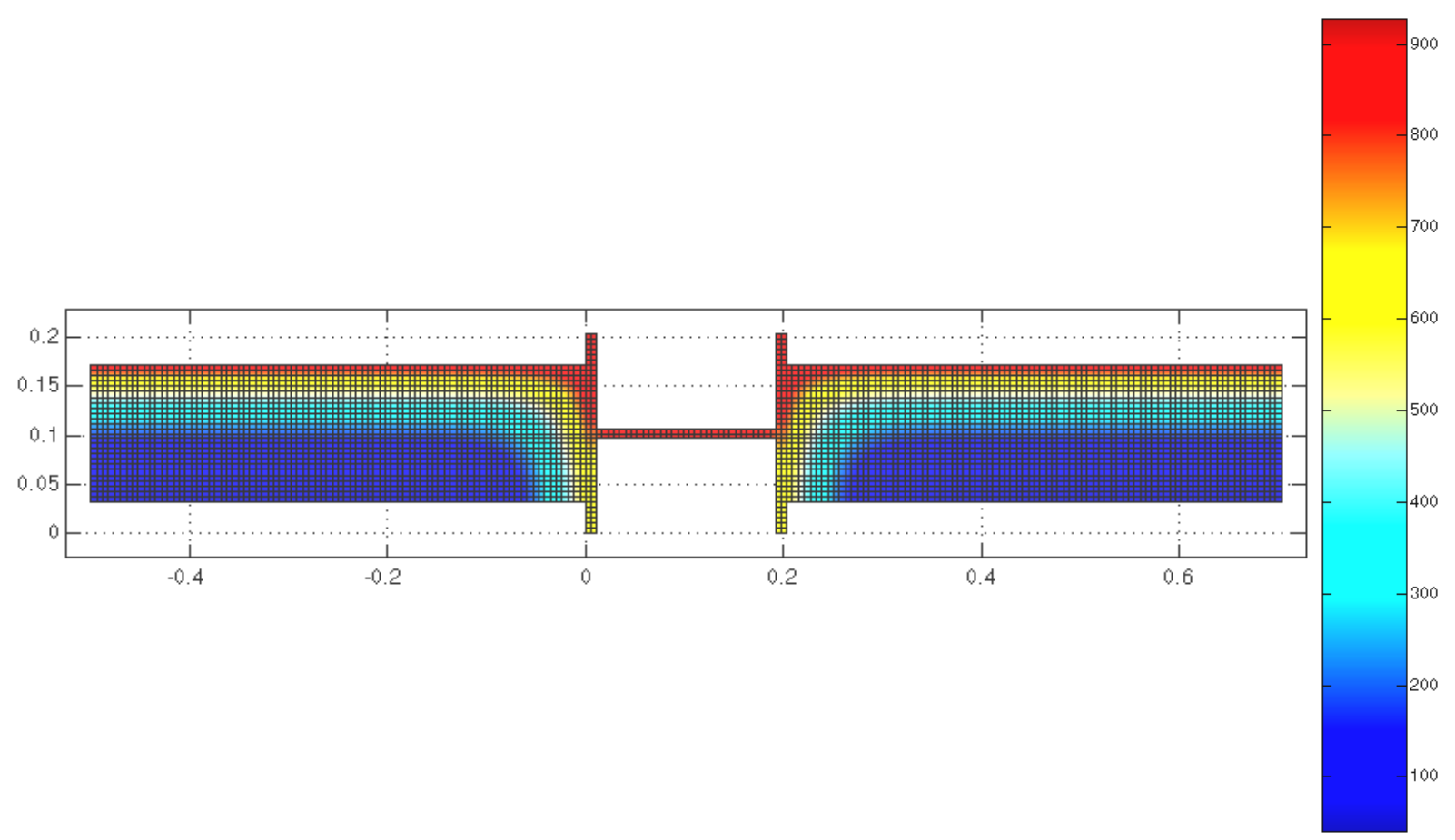

Figura 5.29: Campo térmico $\left(\mathrm{em}^{\circ} \mathrm{C}\right)$ da seção transversal em contato com as paredes em ambas as mesas sob aquecimento por todos os lados obtido via STC 

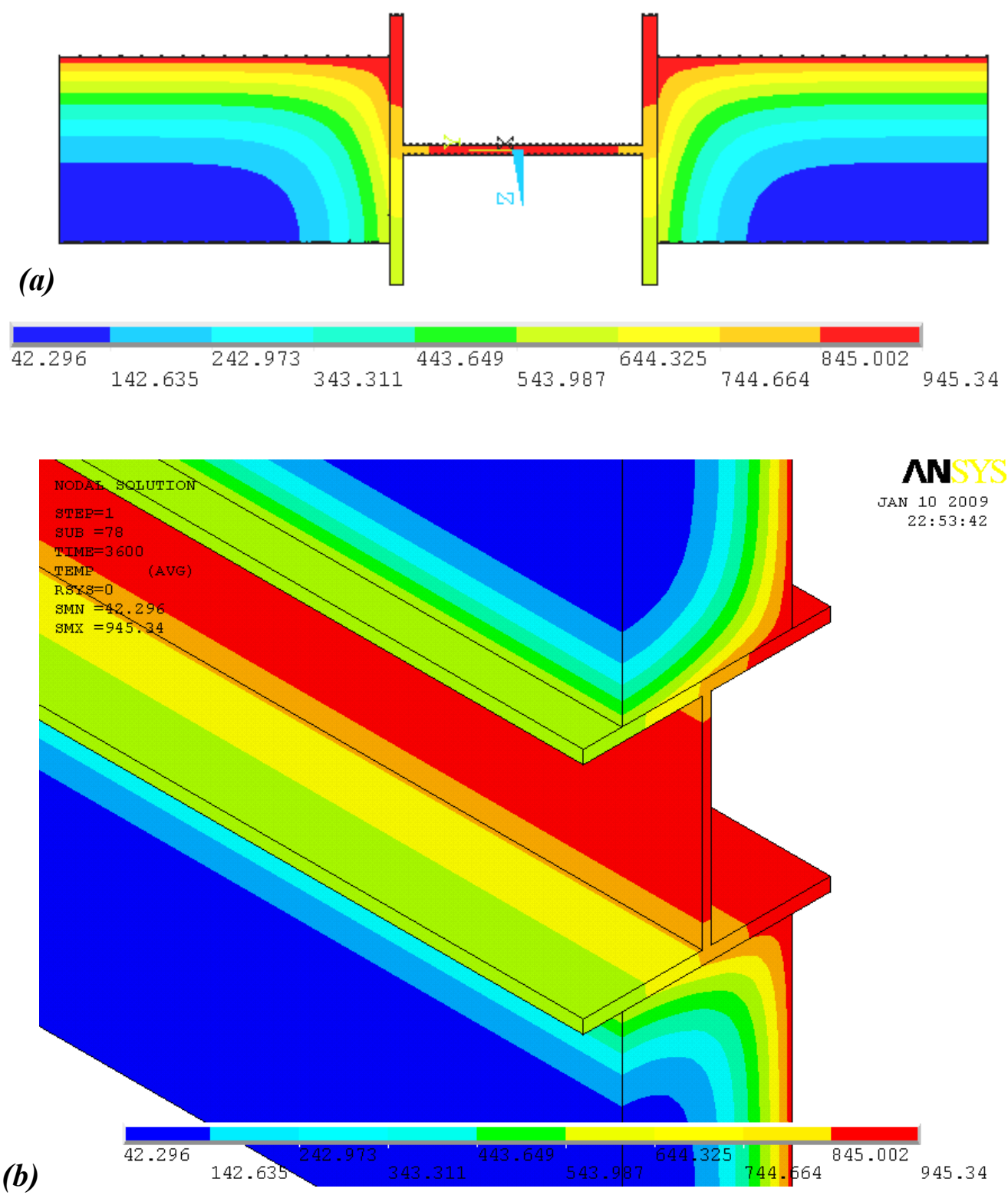

Figura 5.30: Campo térmico $\left(\mathrm{em}^{\circ} \mathrm{C}\right)$ da seção transversal do perfil em contato com as paredes em ambas as mesas sob aquecimento por todos os lados obtido via Ansys: (a) seção transversal e (b) perspectiva .

Para que seja possível a obtenção das respostas da estrutura em relação à variação temporal da temperatura, se optou por obter, por meio das simulações numéricas, campos térmicos desde a temperatura ambiente até um TRF igual a 150 minutos.

\subsubsection{Situação III - Paredes de alvenaria em contato com a alma}

No caso de paredes em contato com a alma, como ilustrado na Figura 5.31, o gradiente de temperatura é obtido a partir da aplicação da fonte de calor próximo a um dos lados 
simétrico em relação ao eixo z. A espessura da parede foi adotada igual a 14 centímetros, conforme a ABNT NBR 7171:1992, por se tratar de uma modelagem de parede externa.

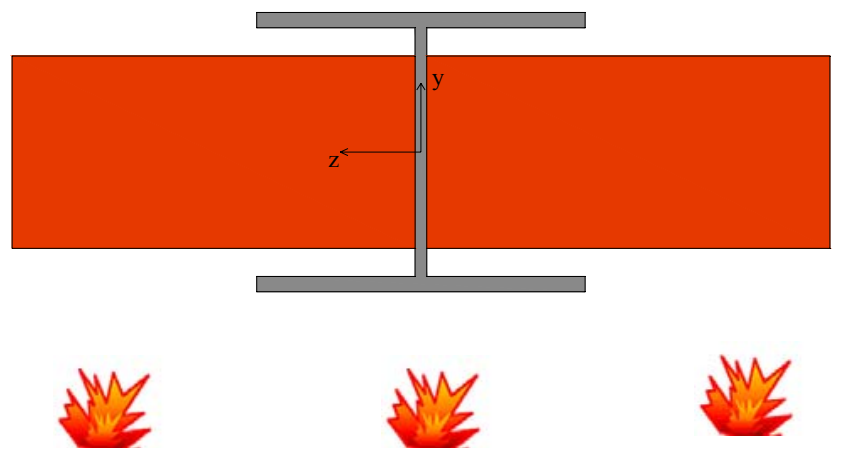

Figura 5.31: Configuração do campo térmico da seção transversal do perfil em contato com paredes em ambos os lados da alma sob aquecimento por um dos lados.

Para fins de futuras análises termo-estruturais, o campo térmico foi obtido por meio das simulações numéricas utilizando o Ansys, até um valor de tempo de referência (TRF) igual a 150 minutos. A Figura 5.32 ilustra o campo térmico para TRF igual a 60 minutos.
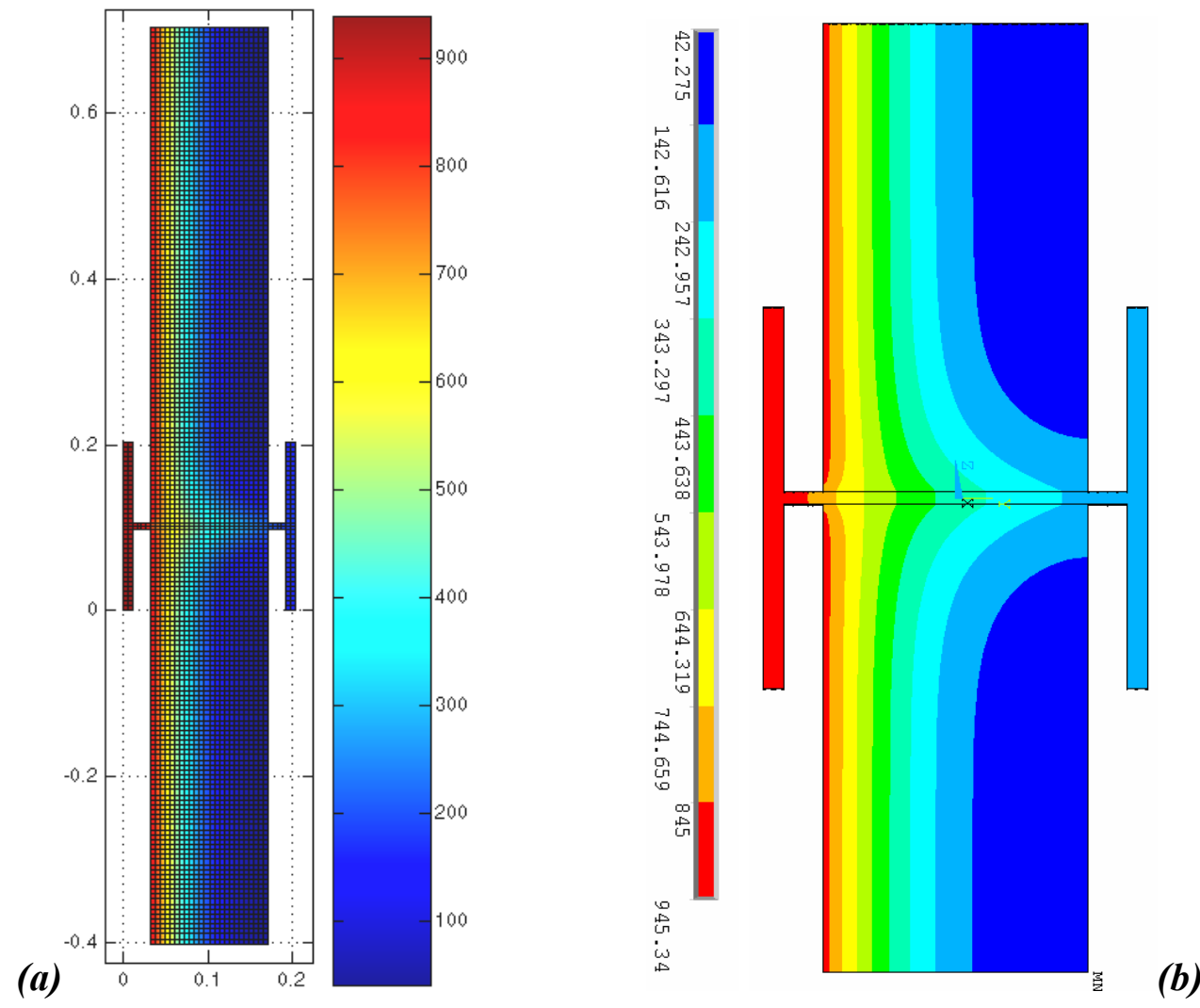

Figura 5.32: Campo térmico $\left(\mathrm{em}^{\circ} \mathrm{C}\right)$ da seção transversal do perfil em contato com paredes pela na alma sob aquecimento por um dos lados para um TRF de 60 minutos, via: (a) SuperTempcalc e (b) via Ansys 
Percebe-se que, enquanto o lado do perfil em contato com a fonte de calor apresenta uma temperatura que, praticamente reduziria totalmente suas propriedades de resistência e rigidez, a parte não-exposta apresenta uma temperatura que corresponde a uma redução máxima de, aproximadamente $20 \%$ da resistência ao escoamento e do módulo de elasticidade longitudinal. Se, em termos de elevação de temperatura, tal situação não resulta crítica, para fins de análise termoestrutural podem ser introduzidos esforços adicionais de flexão que podem, eventualmente, levar o pilar a uma situação de colapso prematuro.

\subsubsection{Situação IV - Pilar com paredes em contato com a alma e com uma das mesas}

No caso de um pilar em contato com alvenaria pela mesa e por ambos os lados da alma, apenas uma pequena área de aço é exposta à fonte de calor. Dessa forma, espera-se que, quando da análise termoestrutural, o tempo crítico de resistência em situação de incêndio seja retardado e, portanto, a favor da segurança.

A Figura 5.33 esquematiza um pilar em contato com paredes externas e com uma parede interna submetido a incêndio em um dos compartimentos. Conforme os padrões do código normativo ABNT NBR 7171:1992, a parede externa foi modelada com espessura igual a 14 centímetros, enquanto a parede interna (em contato com a mesa) foi modelada com espessura igual a 10 centímetros.

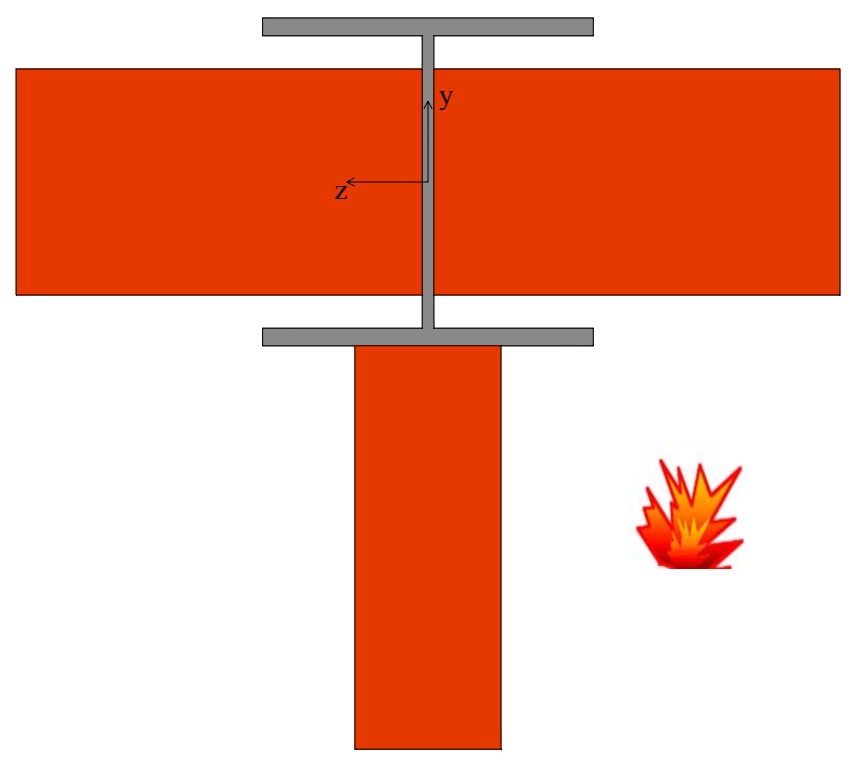

Figura 5.33: Configuração do campo térmico da seção transversal do perfil conectado por paredes na alma e em uma das mesas sob aquecimento por um dos lados. 
A Figura 5.34 ilustra a configuração do campo térmico na seção transversal em contato com a alvenaria de revestimento pela alma e por uma das mesas, submetido a um aquecimento durante um tempo (TRF) de 60 minutos.

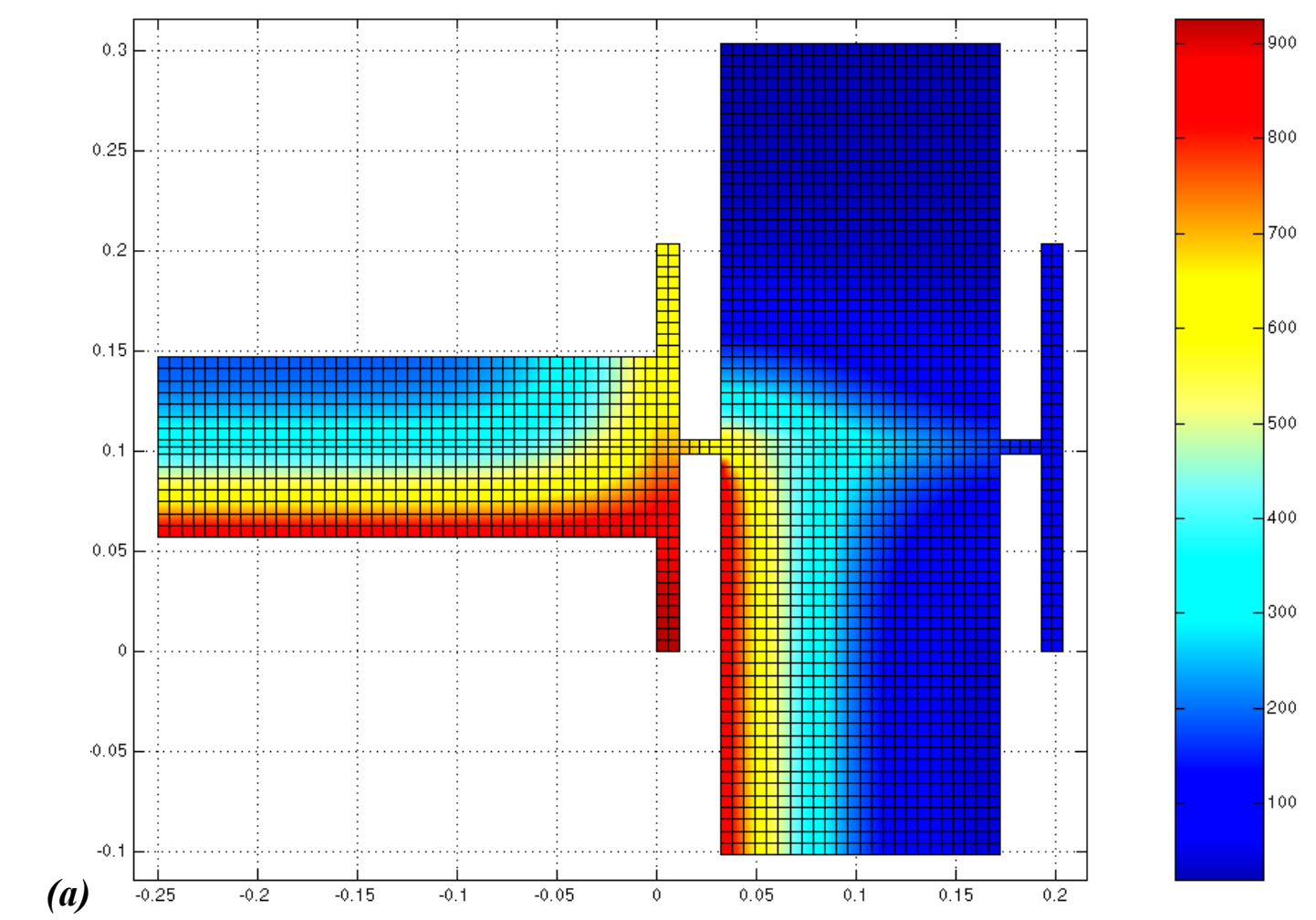

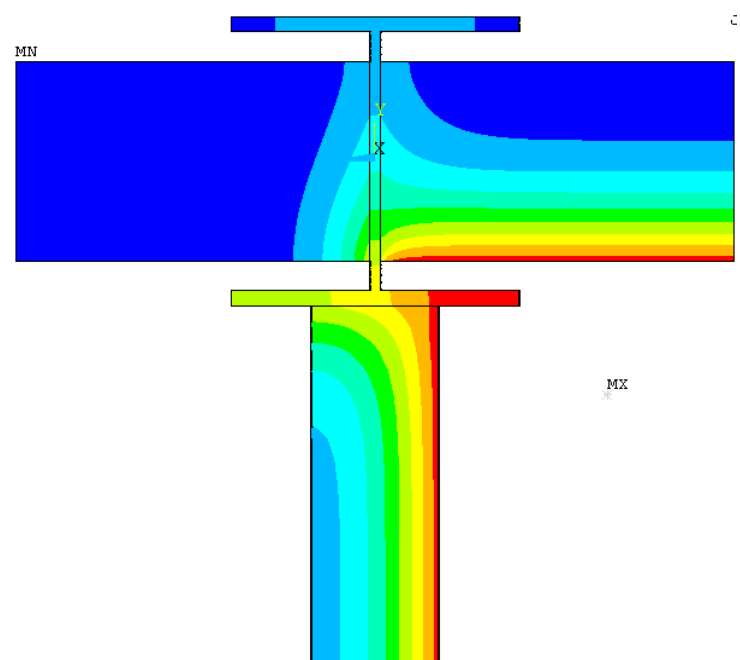

(b)

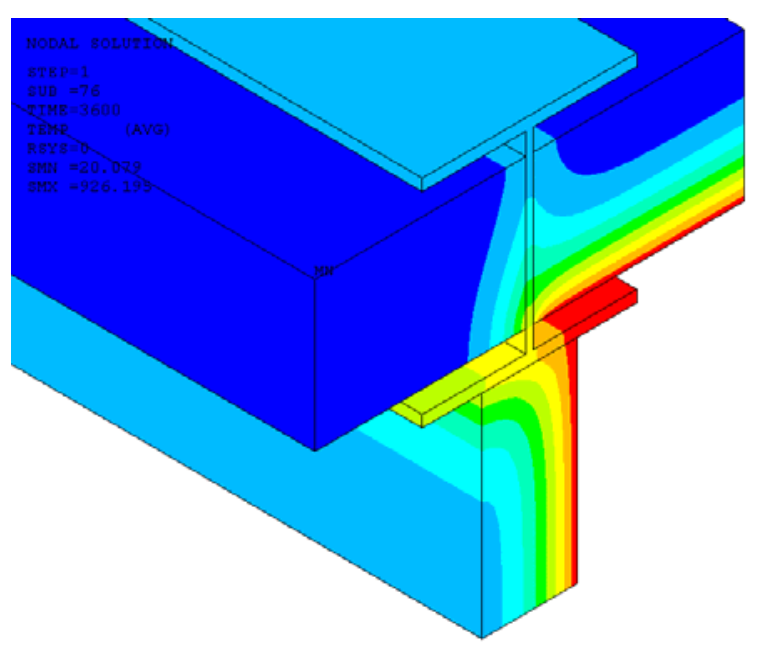

(c)

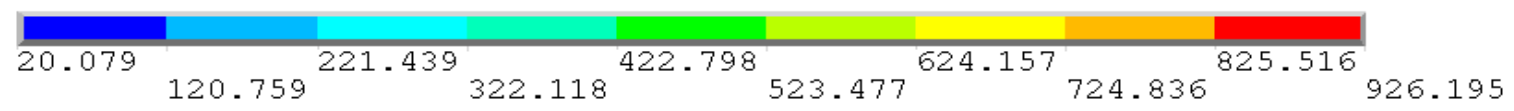

Figura 5.34: Campo térmico $\left(\mathrm{em}^{\circ} \mathrm{C}\right)$ da seção transversal do perfil em contato com três paredes sob aquecimento por todos os lados, durante um TRF de 60 minutos, obtido: (a) via SuperTempcalc, (b) via Ansys e (c) resposta do Ansys obtida ao longo do perfil. 
Por meio de análise com relação à figura 5.33, é possível perceber a correspondência satisfatória entre ambos os códigos, mostrando que as regiões do perfil mais distantes da fonte de calor e protegidas pela alvenaria de fechamento registram temperaturas máximas de aproximadamente $600^{\circ} \mathrm{C}$.

\subsubsection{Situação $V$ - Pilar de canto}

A análise apresentada neste item, conforme esquematiza a Figura 5.35 consiste num pilar em contato com duas paredes externas como elemento de compartimentação. A espessura dos revestimentos de alvenaria, igual a 14 centímetros, está em concordância com a ABNT NBR 7171:1992. A superfície do perfil exposta a fonte de calor é consideravelmente menor que aquela superfície não-exposta.

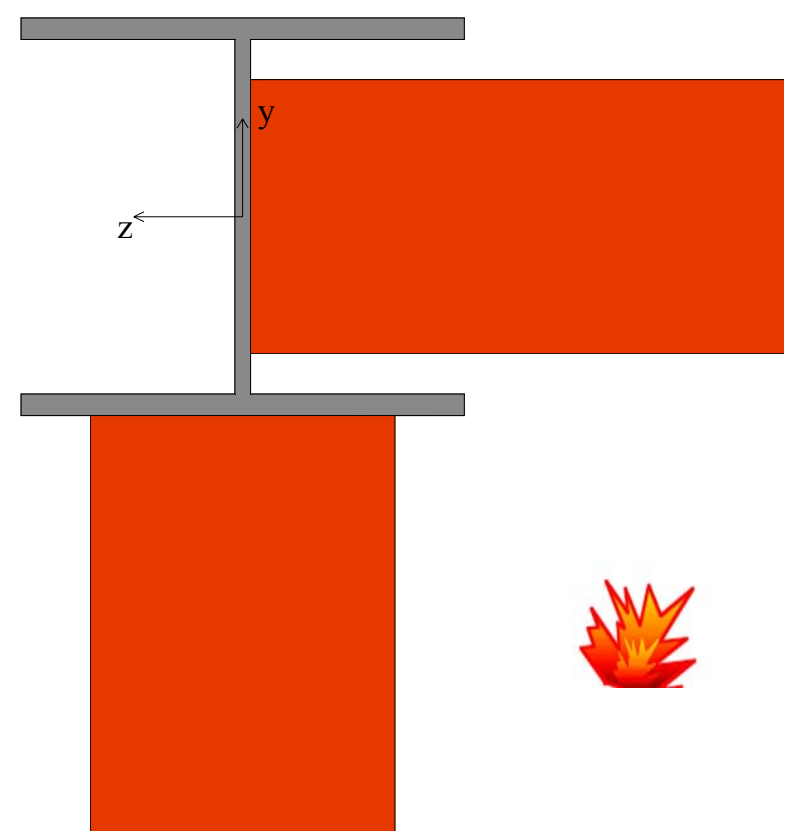

Figura 5.35: Configuração do campo térmico da seção transversal do perfil em contato com paredes em uma das mesas e em um lado da alma sob aquecimento por um dos lados.

Vale aqui destacar que os campos de temperatura gerados pela disposição das paredes em contato com o pilar não difere muito daquele apresentado no item anterior, correspondente à situação IV. A Figura 5.36 ilustra o campo térmico para um tempo de referência (TRF) de 60 minutos, fornecido pelo STC e o obtido pelo ANSYS, respectivamente. Para fins de análise acoplada termoestrutural, se optou por obter o campo térmico para um TRF igual a 150 minutos. 

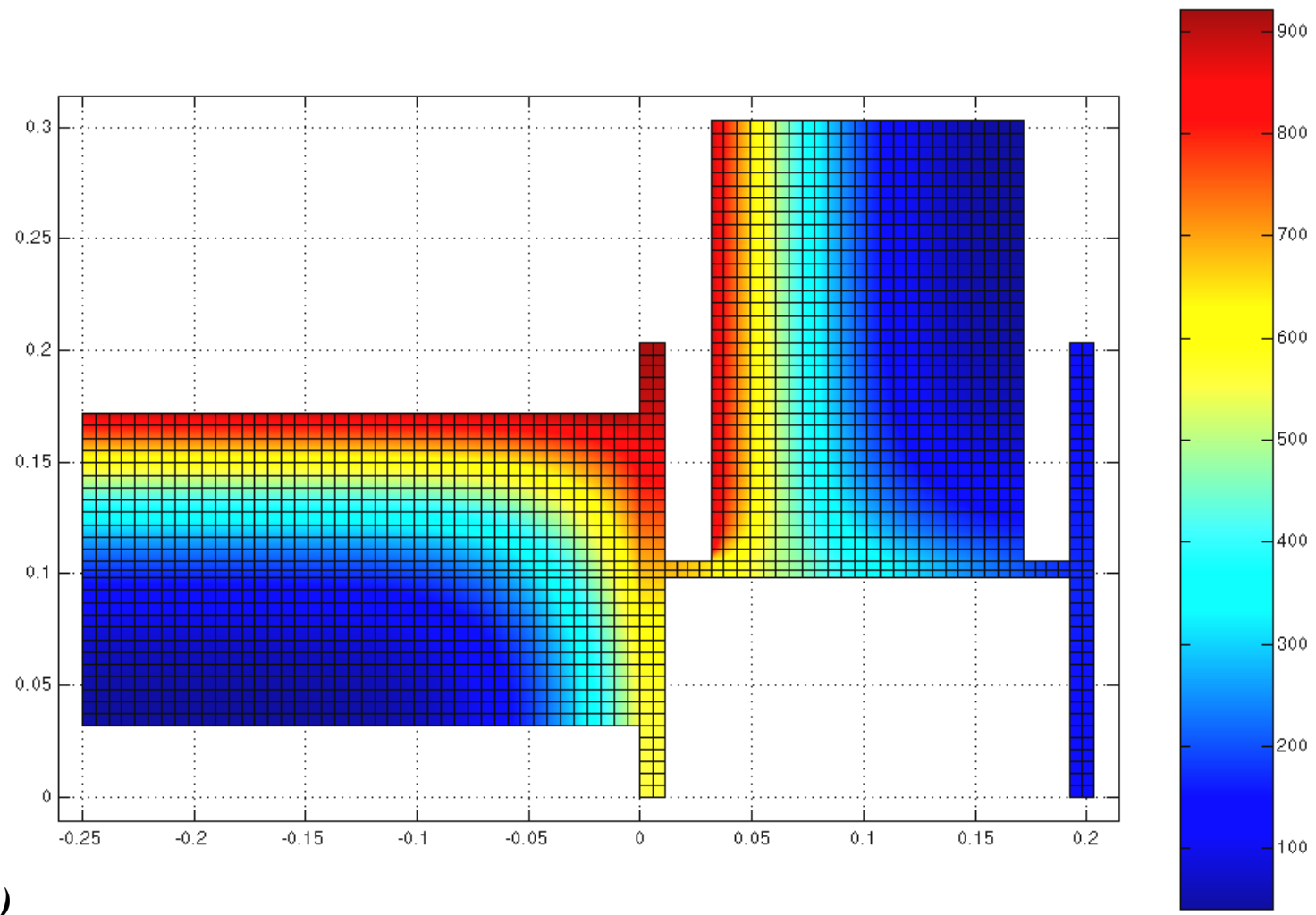

(a)

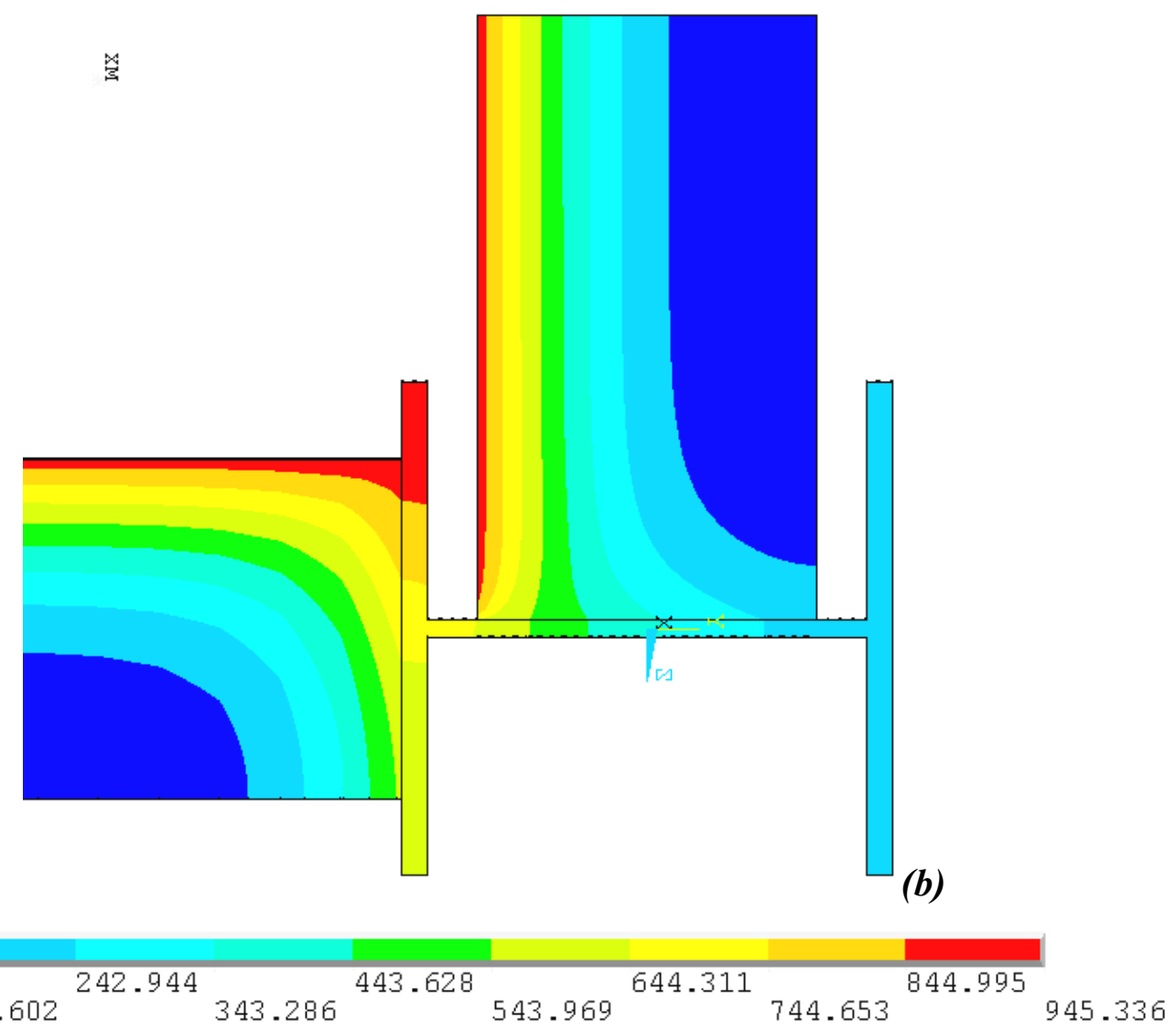

Figura 5.36: Campo térmico $\left(\mathrm{em}^{\circ} \mathrm{C}\right)$ da seção transversal do pilar de canto sob aquecimento por todos os lados obtido: (a) via Super-Tempcalc e (b) via Ansys. 


\subsubsection{ESTUDO DE CASO - INSTITUTO FÁBRICA DO MILÊNIO}

O presente item apresenta dois exemplos tomados com base no Instituto Fábrica do Milênio, o qual consiste de uma edificação mista de aço e concreto localizada no campus da USP em São Carlos. Serão consideradas duas simulações de compartimentação, com base na análise de pilares de aço com perfil W310 x 38,7, cujas dimensões estão apresentadas na tabela que se segue, com base na esquematização apresentada na Figura 5.37.

\begin{tabular}{|c|c|}
\hline Area bruta da seção transversal & $\mathrm{A}_{\mathrm{g}}=49,7 \mathrm{~cm}^{2}$ \\
\hline Altura externa da seção transversal & $\mathrm{d}=310 \mathrm{~mm}$ \\
\hline Altura livre da alma & $\mathrm{d}^{\prime}=271 \mathrm{~mm}$ \\
\hline Altura interna & $\mathrm{h}=291 \mathrm{~mm}$ \\
\hline Largura da mesa & $\mathrm{b}_{\mathrm{f}}=165 \mathrm{~mm}$ \\
\hline Espessura da mesa & $\mathrm{t}_{\mathrm{f}}=9,7 \mathrm{~mm}$ \\
\hline Espessura da alma & $\mathrm{t}_{\mathrm{w}}=5,8 \mathrm{~mm}$ \\
\hline
\end{tabular}

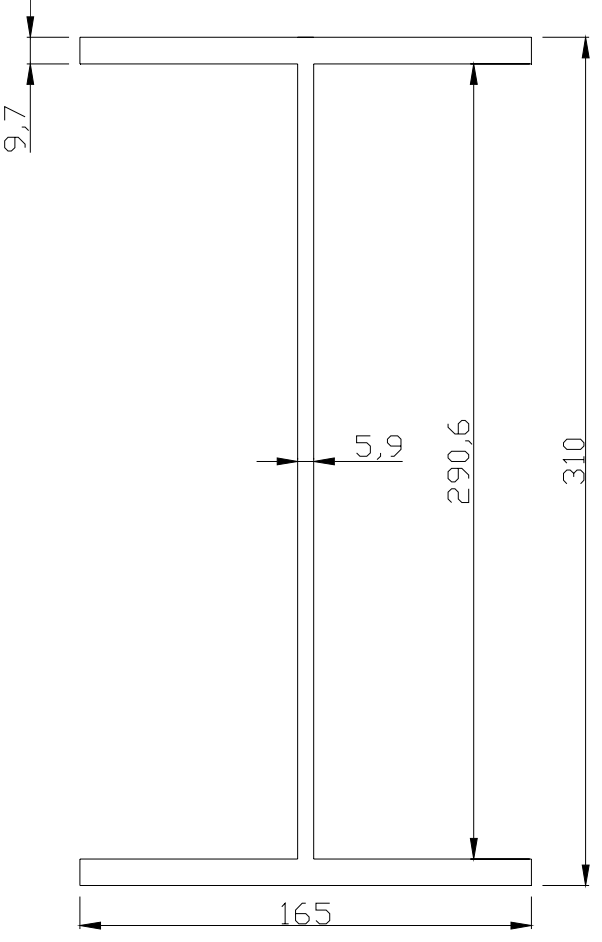

Figura 5.37: Dimensões da seção transversal do pilar W310 x 87 
Os pilares adotados para fins de análise estão localizados no primeiro pavimento, porém, em pontos distintos da edificação e, dessa forma, submetidos à situação de incêndio em compartimentos com condições distintas. O primeiro deles considera o incêndio localizado na área central (compartimento maior), onde a superfície do pilar em contato com o fogo é maior em relação à superfície não-exposta. O segundo exemplo considera um incêndio localizado num compartimento de menor área, cujo perfil exposto tem a área de superfície aquecida menor em relação à área não-exposta.

\subsubsection{Exemplo 1: pilar pertencente ao compartimento central}

Neste compartimento estão os equipamentos do Instituto Fábrica do Milênio, o que justifica a sua maior área. Na parte central, localiza-se a abertura principal da edificação. As Figuras 5.38 e 5.39 ilustram esquematicamente a posição do compartimento em incêndio em planta e do pilar no edifício já em funcionamento.

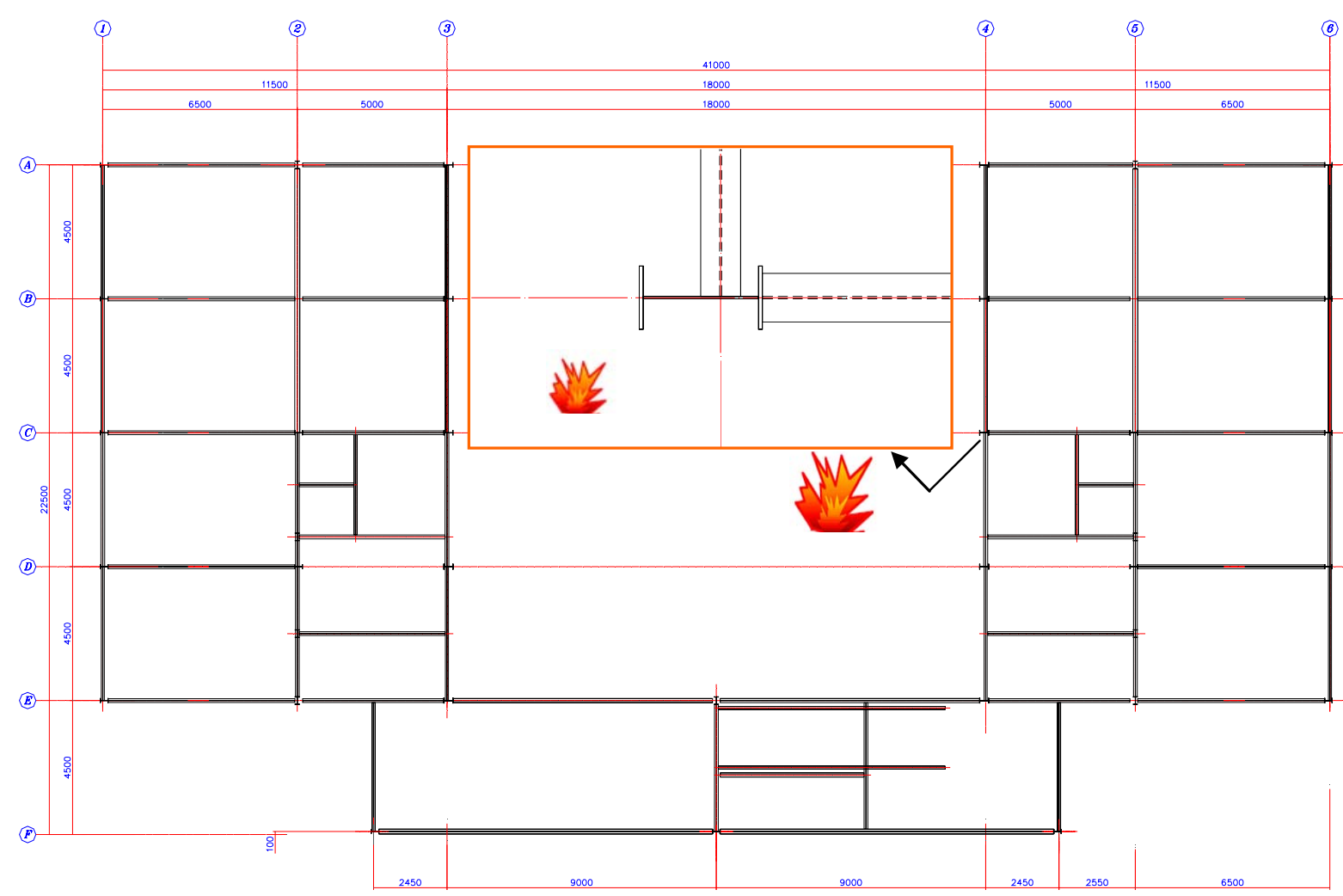

Figura 5.38: Localização em planta do pilar exposto ao incêndio no compartimento principal.

Ambas as paredes de revestimento tem espessura igual a $10 \mathrm{~cm}$. O pilar em questão é submetido à condição de incêndio padrão ISO 834. As propriedades térmicas, tanto do perfil como da alvenaria foram adotadas conforme os itens 5.1 e 5.2, respectivamente. As Figuras 
5.40 e 5.41 ilustram o campo de temperatura obtido por meio da simulação numérica para esse perfil para um tempo requerido de resistência ao fogo (TRF) igual a 60 minutos.
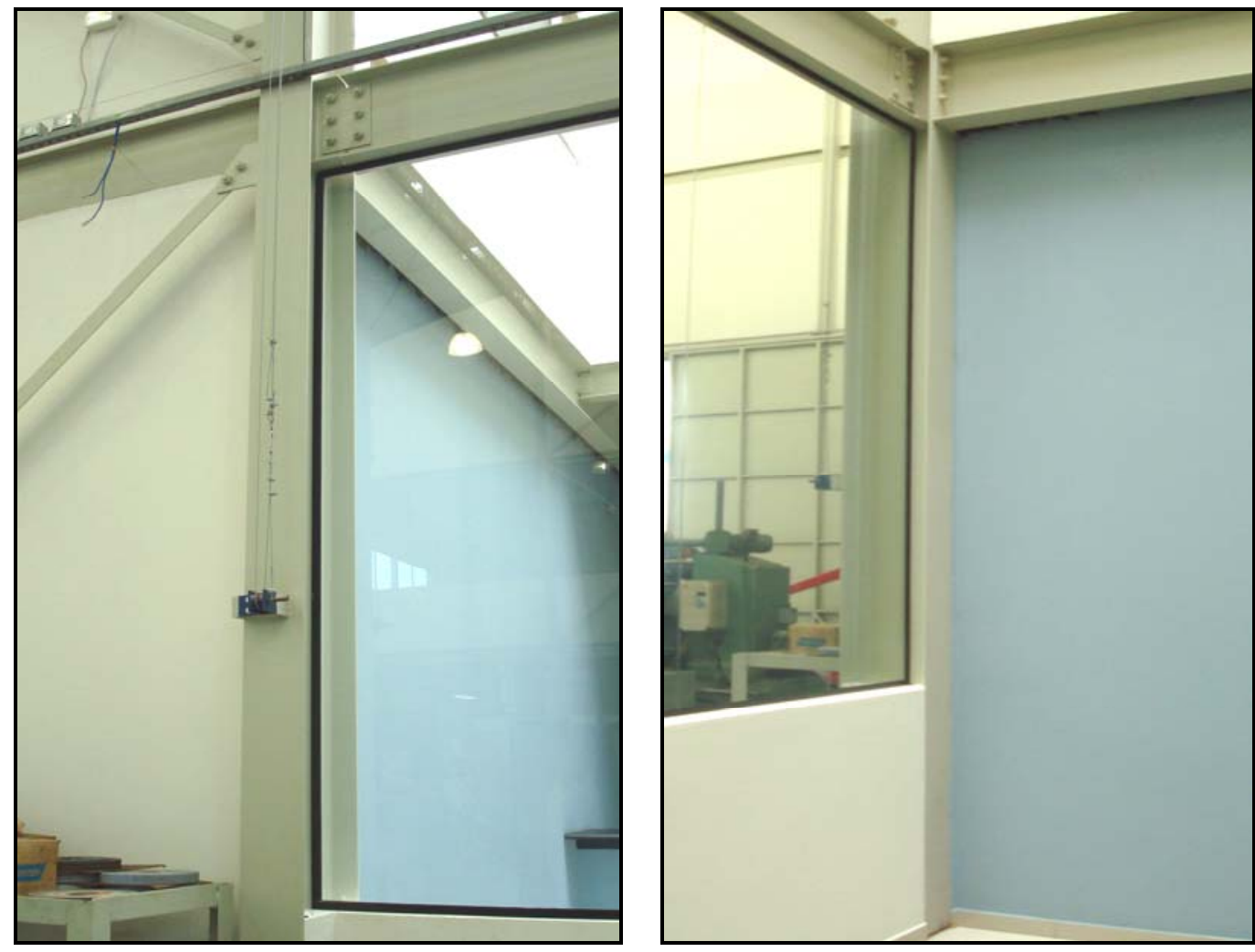

Figura 5.39: Localização do pilar sujeito a condição de incêndio no maior compartimento.

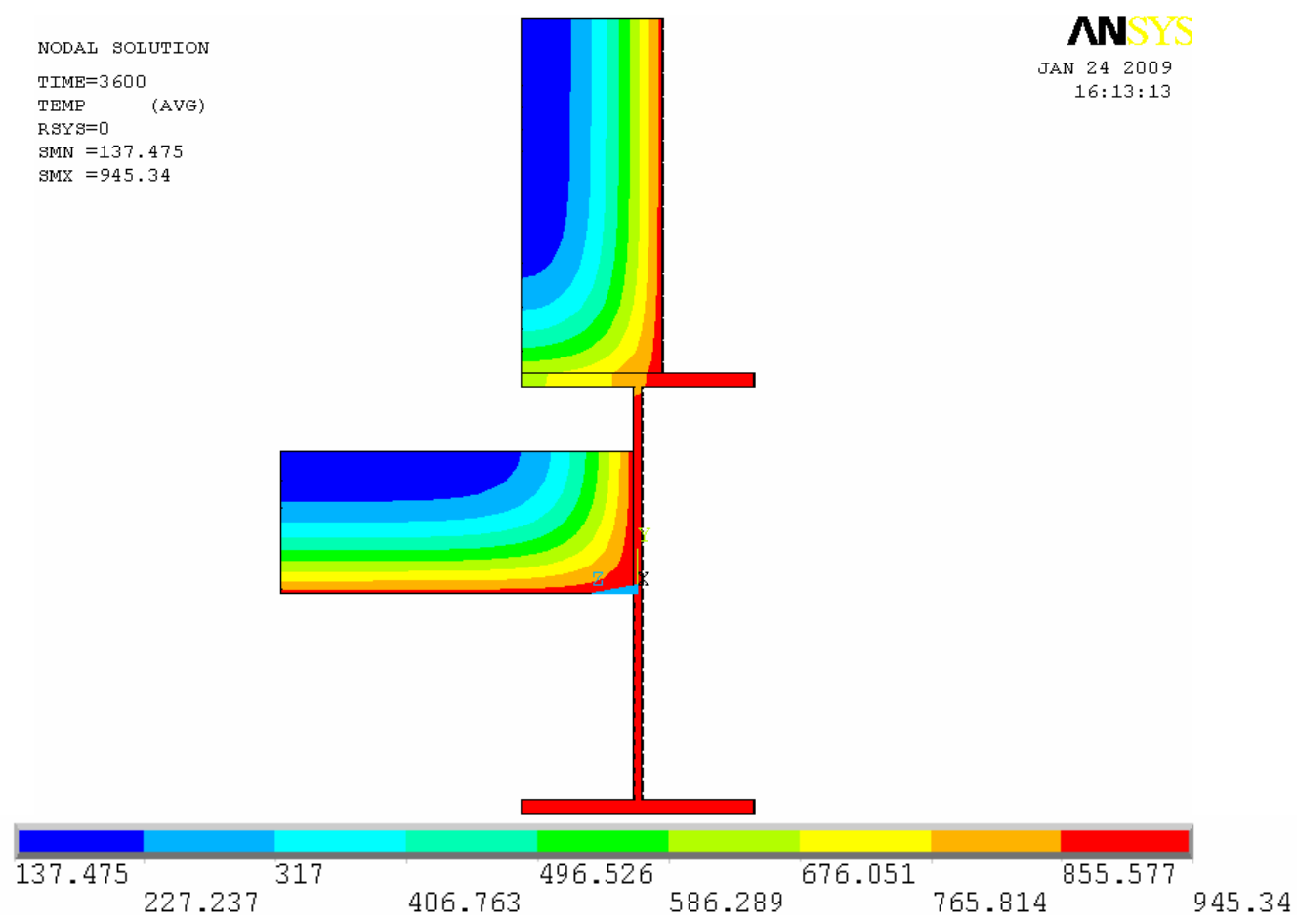

Figura 5.40: Campo térmico $\left(\mathrm{em}^{\circ} \mathrm{C}\right)$ obtido pelo Ansys para um TRF igual a 60 minutos, na seção transversal. 


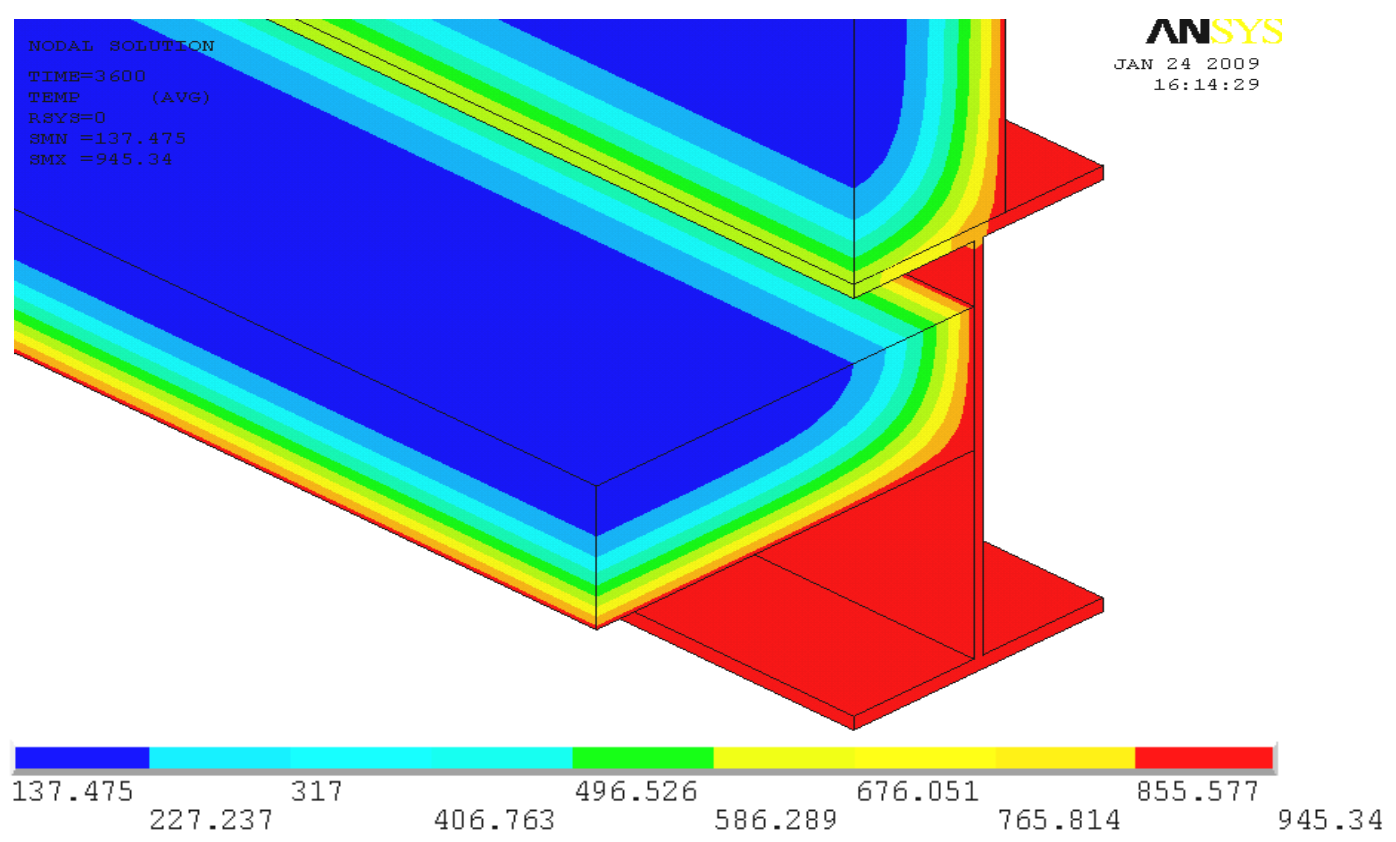

Figura 5.41: Campo térmico $\left(\mathrm{em}^{\circ} \mathrm{C}\right)$ obtido pelo código ANSYS para um TRF igual a 60 minutos, na direção longitudinal.

\subsubsection{Exemplo 2: pilar pertencente ao compartimento lateral}

O esquema da Figura 5.42 mostra a posição em planta (no nível do sistema de vigamento) do pilar em análise e do compartimento em chamas.

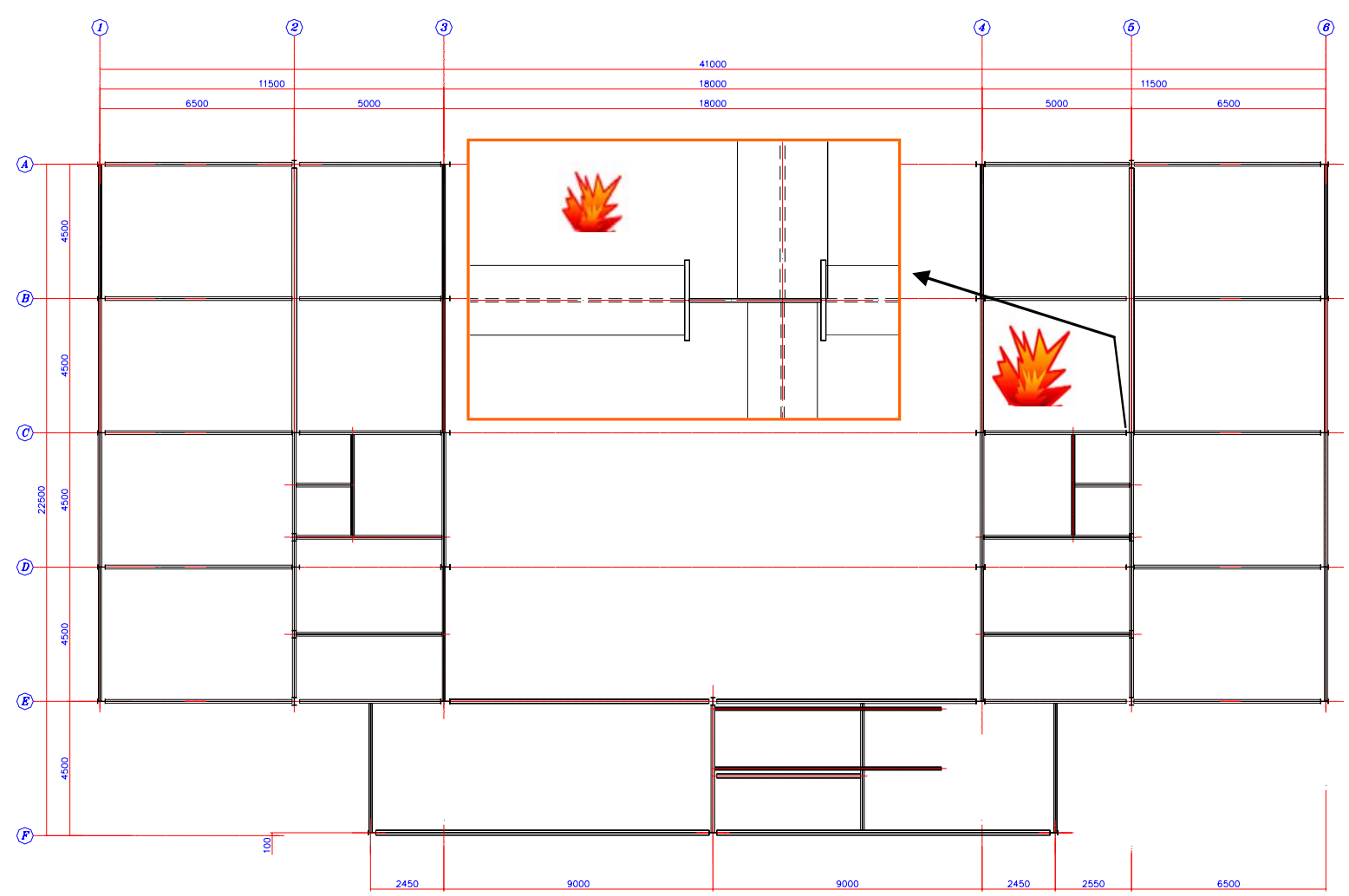

Figura 5.42: Localização em planta do pilar exposto ao incêndio no compartimento lateral. 
As paredes em contato com a mesa foram implementadas na simulação com espessura igual a 14 centímetros. A parede em contato com a alma possui 10 centímetros de espessura. A condição de aquecimento seguiu a curva de incêndio padrão ISO 834, por um intervalo de tempo (TRF) de 150 minutos. Nesse exemplo, a superfície de aço exposta a fonte calorífica é menor em relação à superfície não exposta. A Figura 5.43 ilustra o campo de temperatura obtido a partir das simulações realizadas com o ANSYS para TRF igual a 60 minutos.

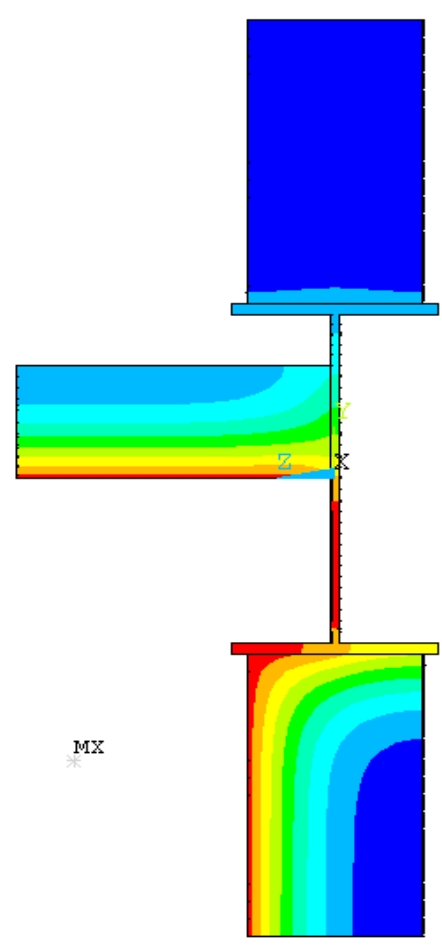

(a)

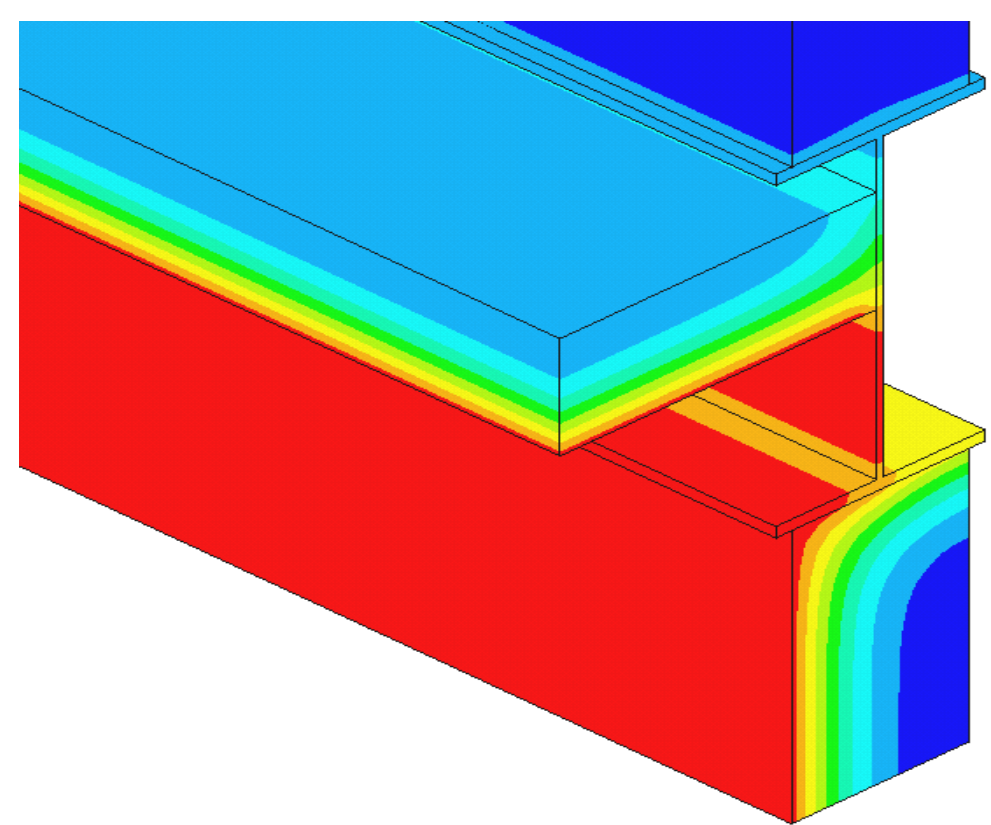

(b)

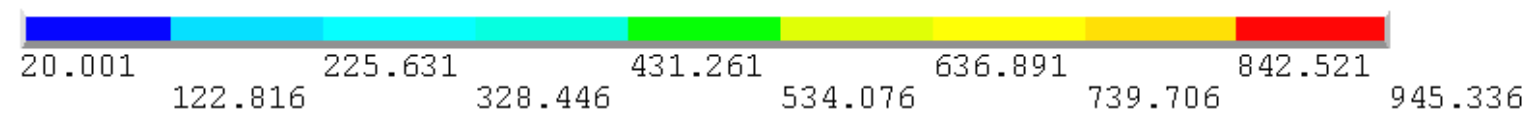

Figura 5.43: Campo térmico $\left(\mathrm{em}^{\circ} \mathrm{C}\right)$ obtido pelo ANSYS para um TRF igual a 60 minutos: (a) na seção transversal e (b) na direção longitudinal.

Com base nas análises bidimensionais de caráter introdutório apresentadas no item 5.1, bem como nas análises térmicas tridimensionais propostas no item 5.2, em que se considerou tanto os perfis isolados como a interação com paredes de alvenaria, e tendo como referência os valores numéricos fornecidos pelo STC, pode-se afirmar que os campos de temperatura identificados nos pilares de aço, obtidos pelo ANSYS se mostram válidos e podem ser acoplados à análise estrutural.

Os próximos passos consistem em elaborar modelos tridimensionais, para fins de análise estrutural em temperatura ambiente e em situação de incêndio de pilares metálicos constituídos de perfis com dimensões comumente encontrados na prática da construção civil. 


\section{ANALISE ESTRUTURAL EM TEMPERATURA AMBIENTE - Procedimentos e resultados}

A análise estrutural a ser apresentada no presente capítulo foi realizada com intuito de determinar a força axial que provoca o colapso nas mesmas barras utilizadas na análise térmica tridimensional do capítulo anterior, porém, em temperatura ambiente. No presente trabalho, tendo em vista a complexidade da modelagem proposta, foram adotadas as seguintes hipóteses simplificadoras:

- As condições de contorno para as extremidades do pilar serão consideradas inicialmente como rótulas ideais, ou seja, com apoios dos tipos fixo e móvel;

- Não serão consideradas restrições axiais ou rotacionais nas extremidades do pilar;

- Serão consideradas apenas imperfeições do tipo global;

- O carregamento será do tipo centrado, desconsiderando-se eventuais excentricidades;

- Os índices de esbeltez dos pilares analisados se mantiveram entre $60 \mathrm{e}$ 100, tendo em vista ser esse um valor encontrado usualmente na prática da construção de edifícios;

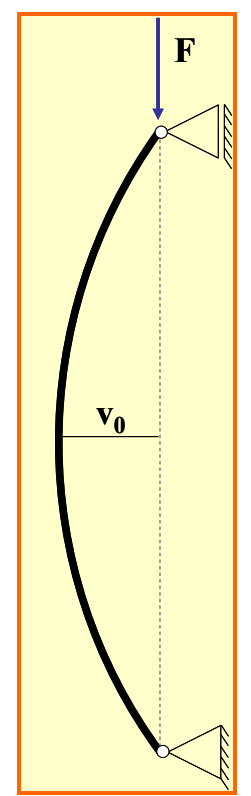

É importante aqui ressaltar que a proposta do presente trabalho se faz na forma de ponto de partida para trabalhos futuros, em níveis de mestrado e doutorado, em que serão contempladas imperfeições locais, restrições axial e rotacional, excentricidade da força, entre outros aspectos.

O esforço solicitante é aplicado sobre a barra com imperfeição geométrica global, cuja forma de obtenção é descrita no item seguinte. A análise estrutural consistiu em determinar qual seria a força que provocaria o colapso do pilar, em outras palavras, a força máxima em temperatura ambiente a que o pilar venha a resistir, para que o referido valor seja usado como referência para fins de comparação com posteriores análises termo-estruturais. 
O primeiro exemplo toma como base o mesmo perfil apresentado em WANG e DAVIES (2003), para o qual foi realizado estudo sobre qual o tipo de elemento finito, SHELL181 ou SOLID45, é o mais indicado para ser utilizado para as análises aqui de interesse. Nesse estudo experimental foi utilizado o aço S275, que apresenta resistência ao escoamento $\mathrm{f}_{\mathrm{y}}=27,5 \mathrm{kN} / \mathrm{cm}^{2}$. A referência citada não deixa explícita a força de compressão que provoca colapso no pilar, porém observa que as análises (experimentais) foram realizadas com aplicação de forças correspondentes a 30\%, 50\% e 70\% da força de colapso. Com base nessa informação, conclui-se que a força de compressão que provoca o colapso do pilar na referencia citada é em torno de $1200 \mathrm{kN}$.

A barra é inicialmente considerada com imperfeição global inicial, cuja configuração deslocada é obtida a partir de uma perturbação na geometria da barra, que consiste na consideração de imperfeições geométricas iniciais. O presente trabalho abordará apenas imperfeições do tipo global. Não serão introduzidas as imperfeições geométricas iniciais do tipo local, pois se espera que a ação térmica não-uniforme contribua para o surgimento de modos locais de falha.

Durante a construção dos modelos numéricos, foram testadas duas formas de introduzir a imperfeição global. A primeira delas é impondo um deslocamento lateral prescrito em todos os nós situados a meio vão no pilar, no sentido de menor inércia. Para tanto, foi elaborado, numa primeira etapa, um modelo estrutural com a imposição de um deslocamento lateral igual a L/1000 em todos os nós situados a L/2 do comprimento para se obter a geometria deformada da barra.

Em seguida, faz-se a atualização da geometria do perfil (ou seja, os nós são deslocados a fim de se trabalhar com a geometria imperfeita) e, em seguida, considera-se a análise estrutural estática com imposição da solicitação de interesse. Essa alternativa foi descartada, pois apresentou consideráveis deformações localizadas no meio do vão e nas extremidades, e não a configuração deformada global, como esperado. A Figura 6.1 ilustra a resposta obtida pelo ANSYS em termos de deslocamento lateral, expresso em metros.

Uma segunda forma de se introduzir a imperfeição geométrica global se faz por meio da análise de autovalor, adotada nos próximos modelos apresentados. A implementação da imperfeição geométrica inicial por meio dessa metodologia consiste na estratégia aplicada em ALMEIDA (2007), descrita, resumidamente nas seguintes etapas:

- estabelecer os modos de flambagem (autovetores) de interesse, correspondentes aos modos de imperfeição geométrica, por meio de uma análise de autovalor sobre uma barra retilínea 
(perfeita), ferramenta essa disponivel no pacote do ANSYS. Para o presente projeto de pesquisa, interessou somente o primeiro modo de instabilidade global;

- com base nos resultados da análise de autovalor, introduz-se a amplitude da imperfeição geométrica de interesse (neste caso, a global) à barra retilínea e executa-se a análise nãolinear geométrica e do material da estrutura, com a barra contendo as imperfeições de interesse geradas.

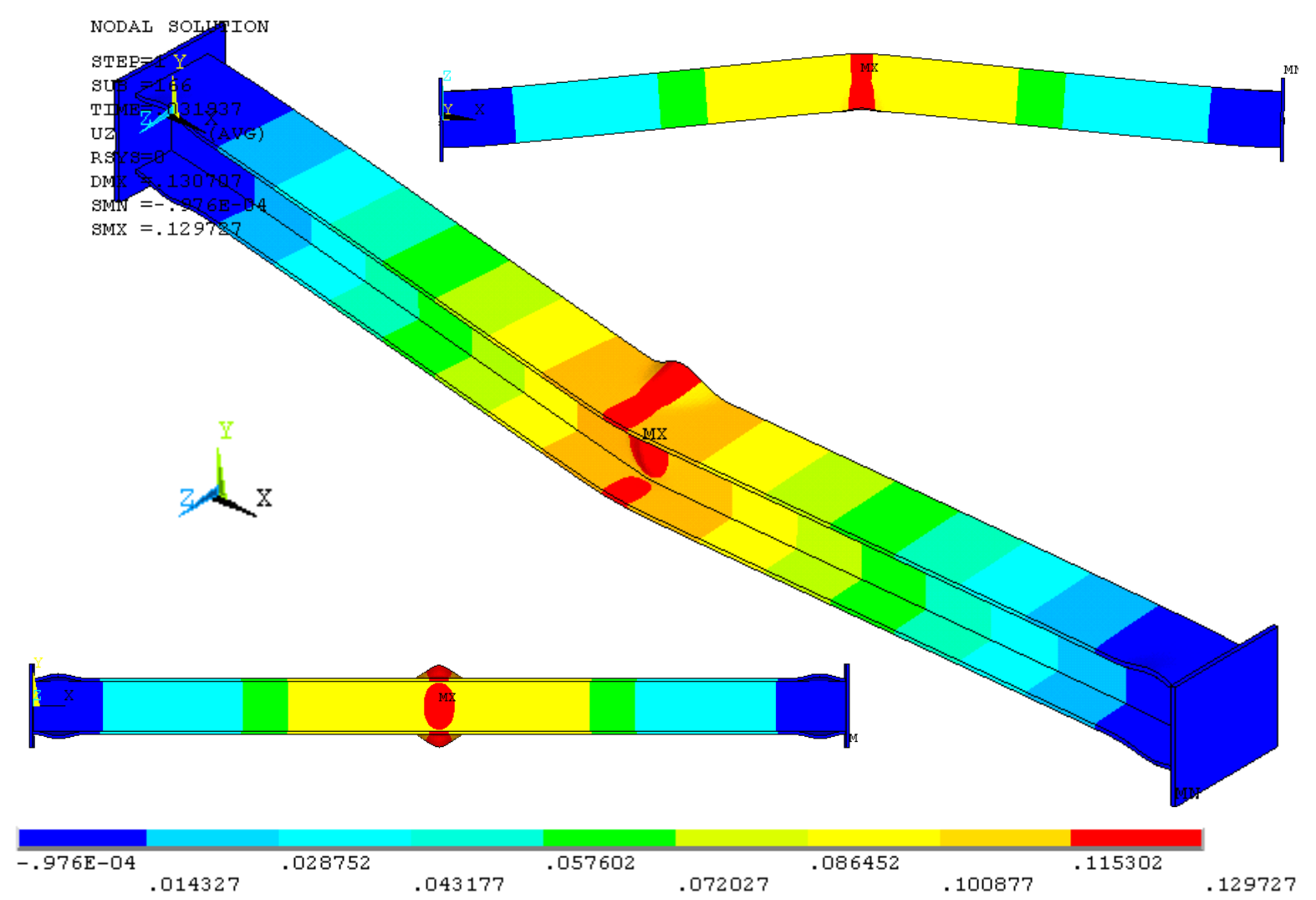

Figura 6.1: Configuração deformada utilizando deslocamento prescrito a meio vão do pilar.

A Figura 6.2 esquematiza a configuração de um pilar submetido ao primeiro modo de instabilidade, neste caso, do tipo global em torno do eixo de menor inércia, obtida por meio da análise de autovalor via código ANSYS. Maiores informações sobre os procedimentos adotados na análise de autovalores podem ser consultados em ALMEIDA (2007).

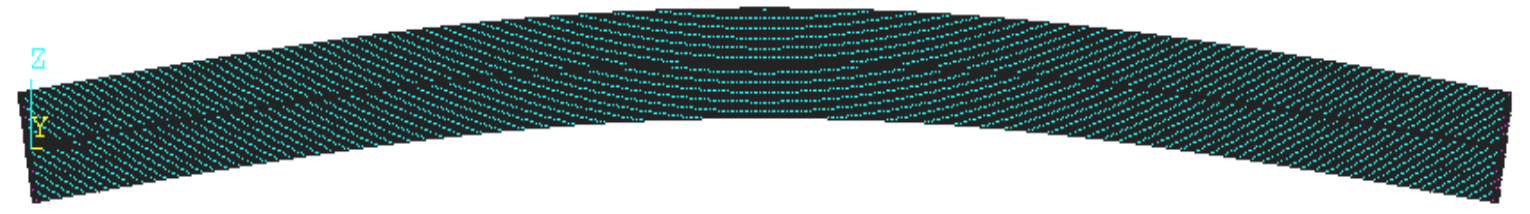

Figura 6.2: Primeiro modo de instabilidade da análise de autovalor: tipo global 


\subsection{ELEMENTOS FINITOS CONSIDERADOS - Comparações}

Embora não fosse objetivo do presente trabalho, no decorrer das simulações numéricas, sentiu-se a necessidade de simplificar a elaboração dos modelos numéricos no referente ao refino da rede de elementos finitos a fim de se reduzir o tempo de processamento.

Com a finalidade de poupar esforços computacionais e, dessa forma, otimizar o tempo de processamento, fez-se uma avaliação da eficiência de um elemento finito de casca. Para tanto, comparou-se os resultados, em termos de deslocamento lateral e axial entre os modelos constituídos por este tipo de elemento e aqueles construídos com elemento do tipo sólido, em análises estruturais em temperatura ambiente e em situação de incêndio, apresentadas futuramente.

\subsubsection{MODELOS ELABORADOS COM ELEMENTO FINITO TIPO CASCA}

Para barras compostas por elementos delgados, como é o caso dos perfis de aço de interesse no presente trabalho, esse tipo de elemento se mostra mais favorável por possuir graus de liberdade de rotação e translação e, dessa forma, permitir a analise não-linear que envolva grandes deformações. A Figura 6.3 ilustra o pilar aqui de interesse modelado com elemento de casca SHELL181.

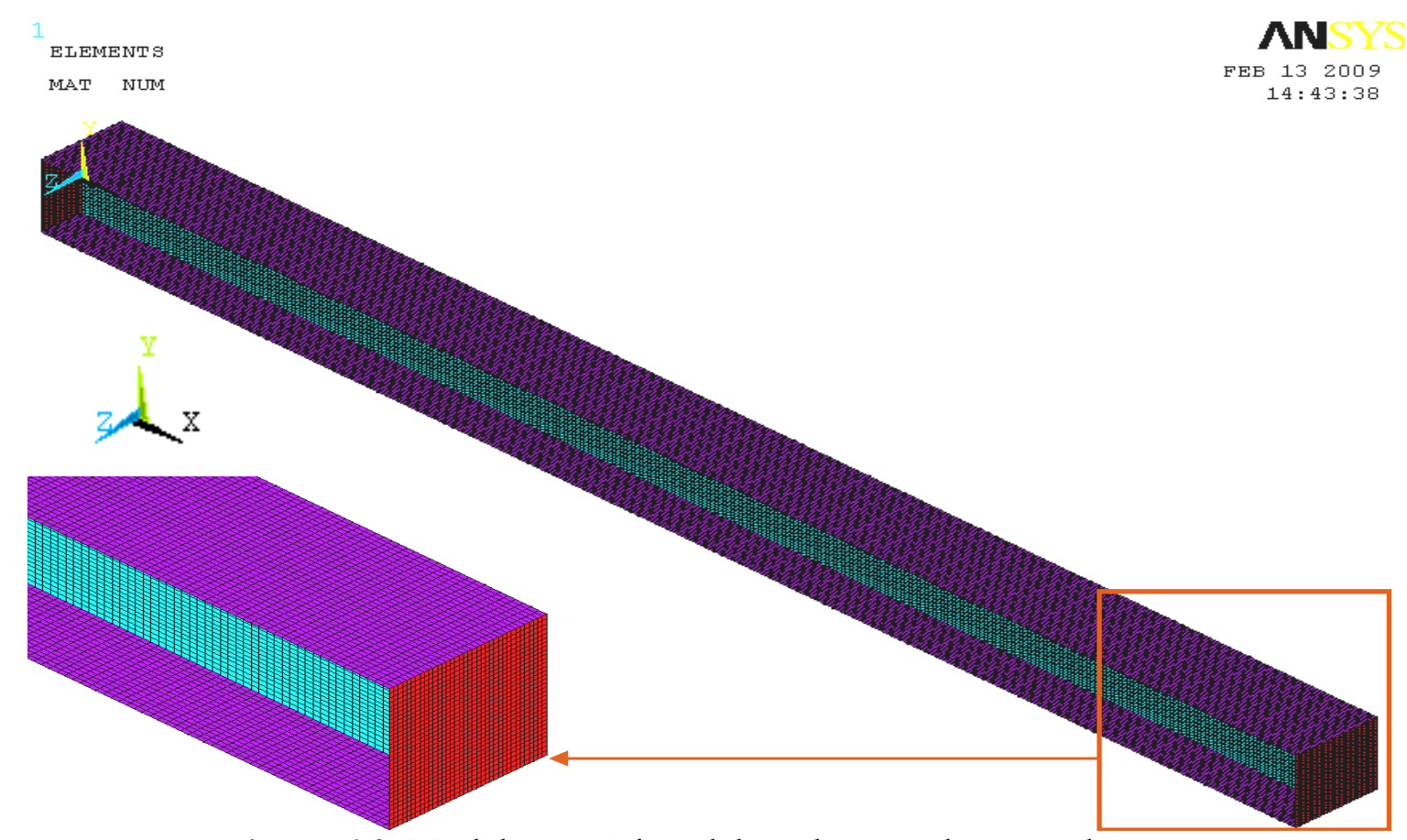

Figura 6.3: Modelo numérico elaborado com elemento de casca. 
No entanto, o problema encontrado ao elaborar modelos constituídos por elemento SHELL181 foi acoplá-lo ao modelo térmico elaborados com o elemento SOLID70. Como se sabe, o elemento SHELL181, assim como os demais elementos de casca tem seus parâmetros definidos para a superfície de esqueleto, e não para os vértices de cada elemento como ocorre no caso do SOLID70.

Na elaboração da malha, tomou-se precaução em fazer com que os nós da linha do esqueleto do modelo em SHELL181 resultassem coincidentes com os nós do esqueleto do modelo térmico em SOLID70. Esse cuidado garante a transferência correta da temperatura na análise termoestrutural, embora essa metodologia seja ainda mais complexa que a transferência entre modelos que utilizam elementos do tipo sólido.

Vale destacar, apenas em caráter complementar, que em TAKAGI e DEIERLIN (2007) analisaram-se numericamente perfis metálicos submetidos a um campo de temperatura uniforme em que foi utilizado um dos elementos de casca disponibilizados na biblioteca do pacote computacional ABAQUS. O objetivo desse estudo era fornecer uma avaliação dos métodos de dimensionamento de elementos de aço submetidos à ação térmica propostos pelo Eurocode 3 e pelo AISC.

\subsubsection{MODELOS ELABORADOS COM ELEMENTO FINITO DO TIPO SÓLIDO}

Em virtude dos elementos tipo sólido trabalhar apenas com graus de liberdade de deslocamento (e não de rotação como os elementos de casca), a discretização rede de elementos finitos exige um maior grau de refinamento em relação aos elementos supracitados. Como conseqüência, o processamento da análise demanda maior tempo e maior utilização da memória interna do computador.

A construção dos modelos com o SOLID45 se mostrou mais vantajoso na transferência do campo térmico obtido por meio das análises apresentadas no capítulo anterior. A Figura 6.4 ilustra o pilar modelado com elemento SOLID45. 


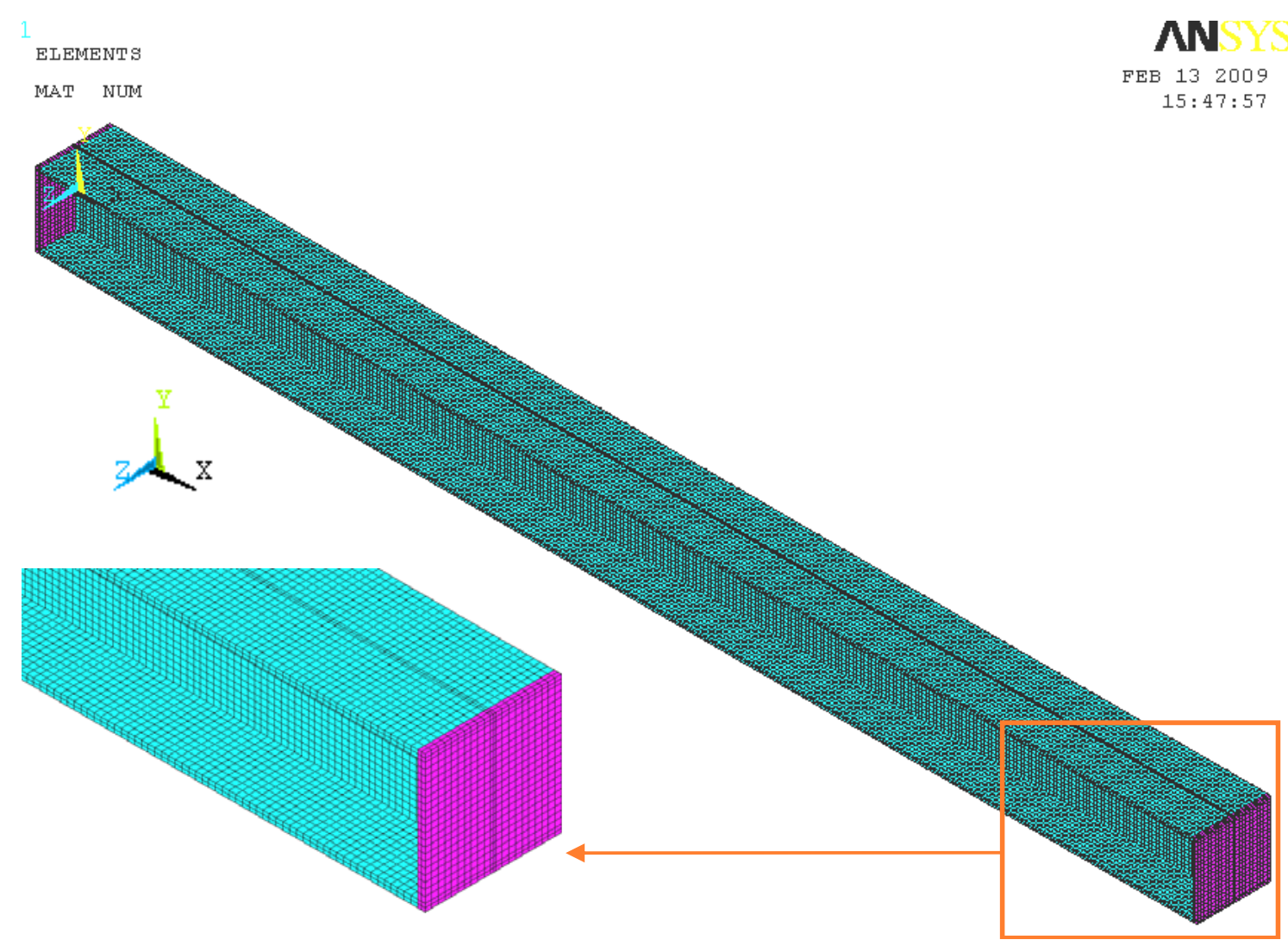

Figura 6.4: Modelo numérico elaborado com elemento sólido.

\subsection{CONSTRUÇÃO DOS MODELOS NUMÉRICOS}

\subsubsection{RELAÇÃO CONSTITUTIVA - tensão $x$ deformação}

\subsubsection{Perfil de aço}

O material segue o critério de plastificação de von Mises, para materiais isotrópicos elasto-plásticos com encruamento, representada por uma curva multilinear. A relação constitutiva utilizada nas simulações numéricas foi apresentada no sub-item 3.4.1.1 do terceiro capítulo. A Figura 6.5 esquematiza curvas Tensão x Deformação introduzida ao ANSYS a partir da equação do Eurocode 3 part 2, para a temperatura ambiente e para os diversos níveis de temperatura, entre $.20^{\circ} \mathrm{C}$ e $1100^{\circ} \mathrm{C}$. 


\subsubsection{Chapa de extremidade}

A curva tensão x deformação da chapa de extremidade levou em consideração apenas o comportamento elástico linear do material. Em ensaios mecânicos de perfís metálicos submetidos à compressão, a aplicação da ação solicitante não ocorre diretamente sobre o elemento. Este é posicionado entre aparelhos de apoio em um pórtico de reação.

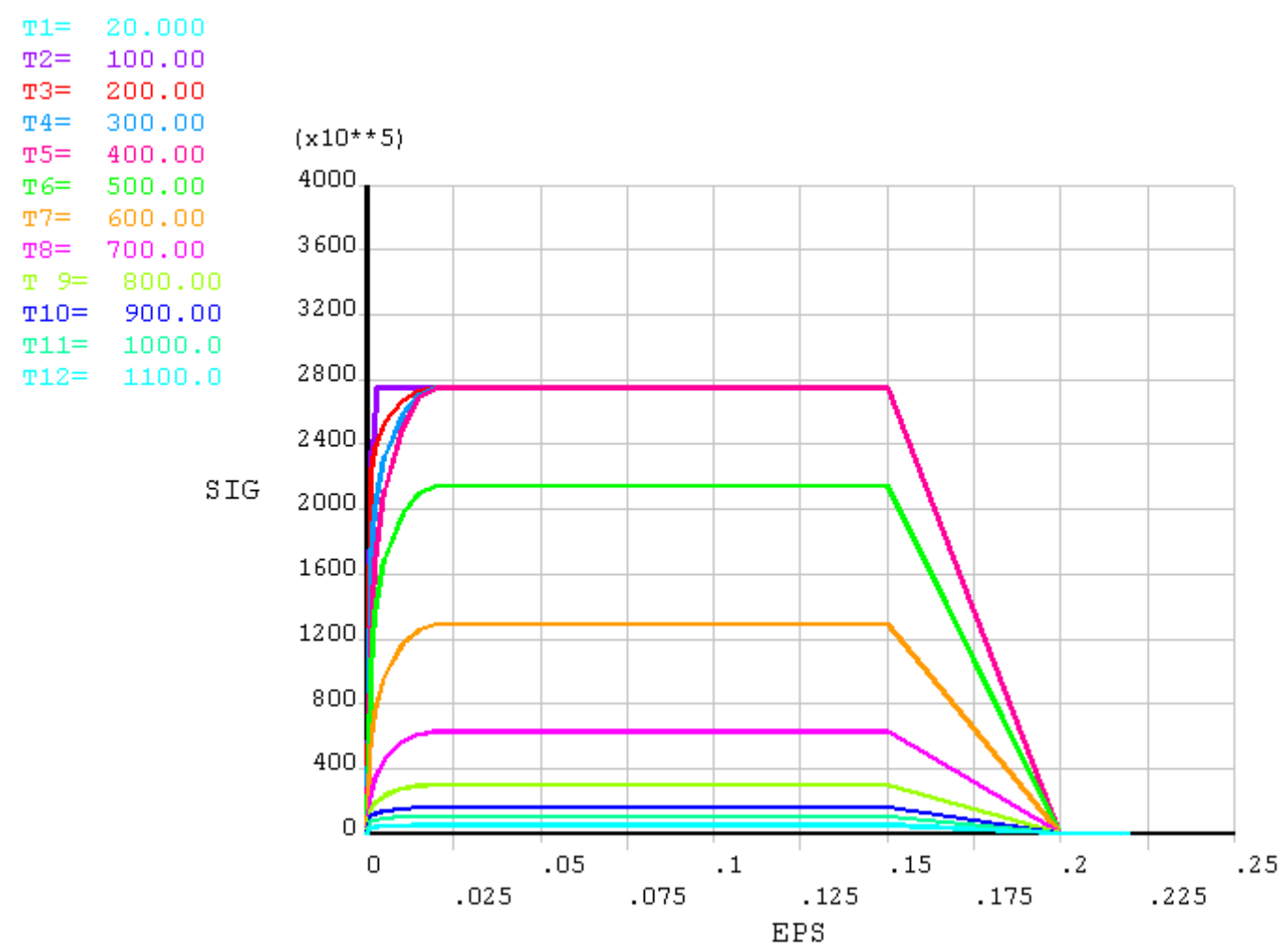

Figura 6.5: curva tensão x deformação do aço para vários níveis de temperatura.

A força ou deslocamento prescrito (como o que se buscou representar no presente estudo) é aplicado na barra por meio do pórtico de reação. Em ensaios produzidos em laboratório, os aparelhos de apoio consistem então de placas metálicas de elevada rigidez (espessura). $\mathrm{Na}$ análise numérica aqui apresentada, essa rigidez é conseguida elevando o módulo de elasticidade $\left(\mathrm{E}_{\mathrm{a}}\right)$ do aço. Vários testes foram realizados com diversos valores de $\mathrm{E}$ até que se encontrasse um valor para o qual a chapa de extremidade não apresentasse deformações. A análise paramétrica do módulo de elasticidade da chapa de extremidade foi realizada sobre a análise estrutural de autovalor.

Tanto para os modelos numéricos constituídos por SHELL181 como aqueles constituídos por SOLID45, utilizaram-se da seguinte relação $E_{c h}=10^{3}$. $E_{a}$, em que $E_{c h}$ é o modulo de elasticidade da chapa de extremidade e $\mathrm{E}_{\mathrm{a}}$ é o modulo de elasticidade do aço. 


\subsubsection{CONDIÇÕES DE CONTORNO}

A aplicação das restrições ao deslocamento e do carregamento externo nas extremidades foi avaliada de duas formas distintas.

\subsubsection{Condição de contorno diretamente sobre o perfil}

Neste caso, as chapas de extremidade foram dispensadas e as restrições aos deslocamentos transversal e longitudinal (este último apenas na base), bem como o deslocamento incremental prescrito, foram aplicadas de três formas distintas:

- Num único nó simulando uma rótula, para que o perfil "procure” a configuração estável pelo eixo de menor inércia;

- Introduzindo as restrições ao deslocamento em todos os nós da linha de esqueleto da alma, que corresponde ao eixo de menor inércia da seção transversal, e aplicando o deslocamento incremental prescrito de compressão apenas no nó central da alma;

- Introduzindo as restrições ao deslocamento em todos os nós da linha de esqueleto da seção transversal e aplicando o deslocamento incremental prescrito de compressão apenas no nó central da alma. Este caso não configura uma condição de rótula cilíndrica, mas sim um engaste perfeito.

Em todos os casos, ocorreram distorções localizadas excessivas dos elementos próximos ao ponto de aplicação do carregamento e, portanto, desconsiderados para fins de análises aqui de interesse.

\subsubsection{Condição de contorno nas chapas de extremidade}

Neste caso, as condições avaliadas para restrição ao deslocamento foram semelhantes àquelas apresentadas no sub-ítem anterior, porém, dessa vez, aplicadas na chapa de extremidade. A simulação dos apoios fixo na base e móvel no topo, em forma de rótula cilíndrica, ou seja, com as restrições impostas na linha paralela ao eixo y (de menor inércia), foi a opção que proporcionou melhor resposta da estrutura. 
Para evitar o deslocamento relativo entre os nós pertencentes a essa linha na direção axial, estes foram acoplados em relação à mesma direção. A figura 6.6 ilustra a estratégia usada para simular a condição de rotula cilíndrica.

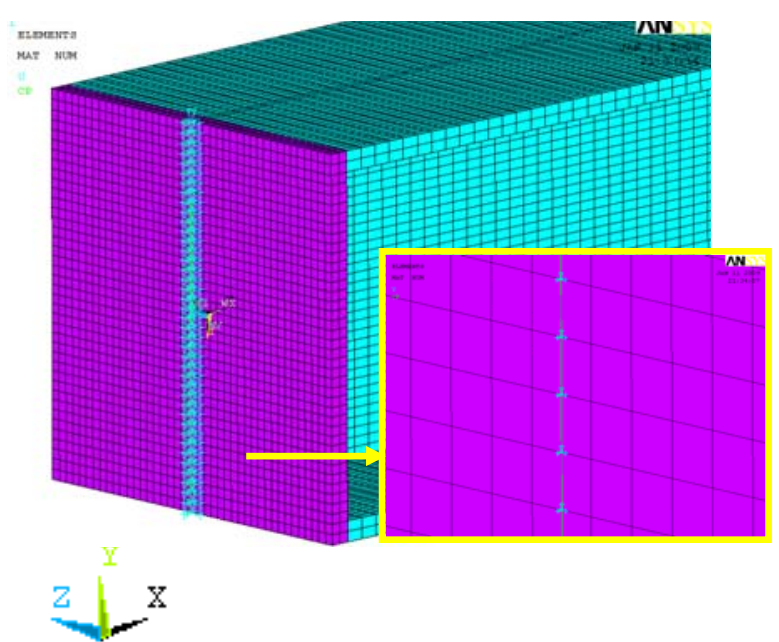

(a)

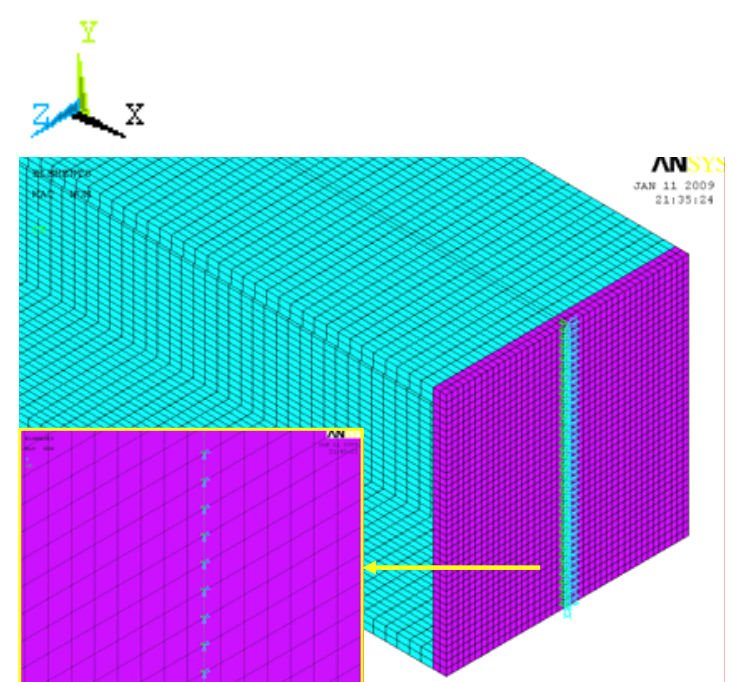

(b)

Figura 6.6: Aplicação da rótula cilíndrica no modelo construído com elemento SOLID45: (a) base e (b) topo.

Nos casos de modelos com elementos tipo SHELL181, além das restrições ao deslocamento, devem ser impostas as restrições às rotações. Dessa forma, os nós pertencentes à extremidade da alma, além dos deslocamentos UZ e UY, têm também impedidos as rotações ROTX e ROTZ. Os demais nós nas chapas da extremidade tem impedidos as rotações e o deslocamento UY. As Figuras 6.7 e 6.8 ilustram o procedimento adotado para a consideração da rótula cilíndrica fornecida pelo Ansys.

(a)
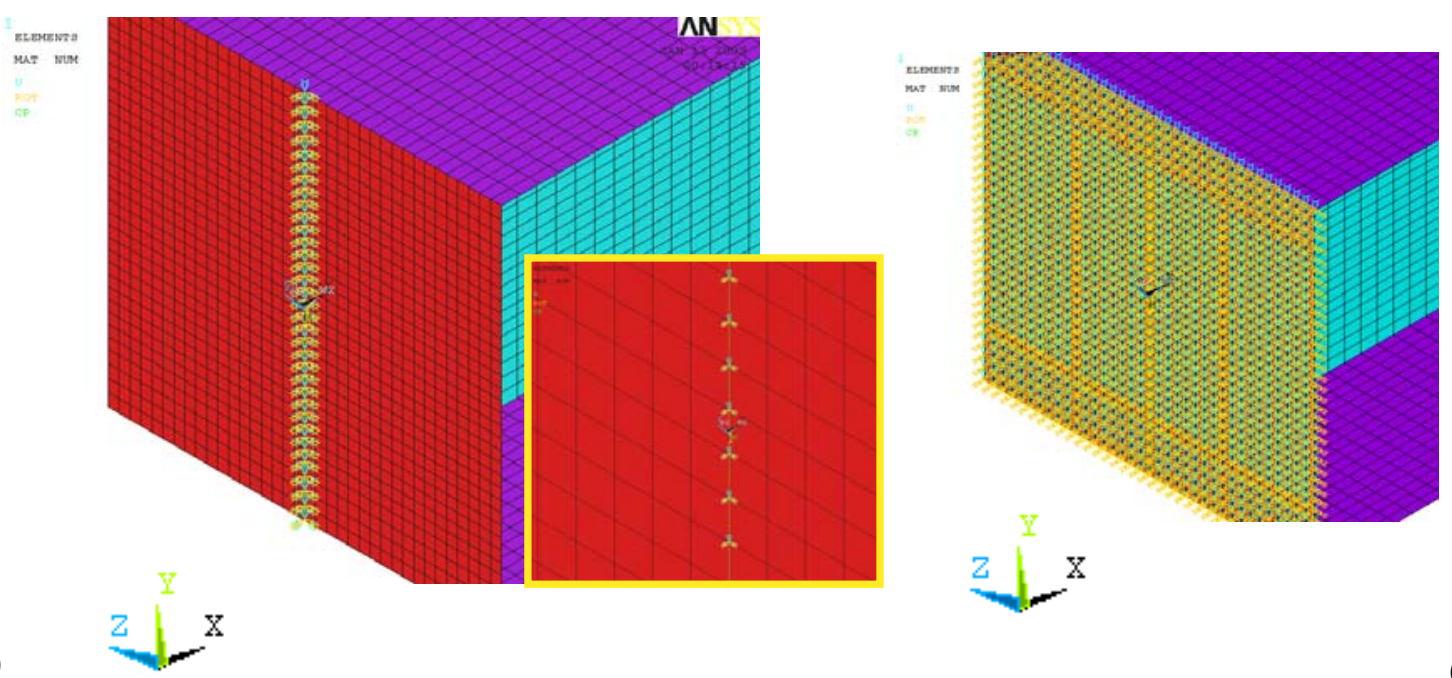

Figura 6.7: Aplicação das restrições aos deslocamentos e rotações no modelo construído com o SHELL181: (a) rótula cilíndrica na base e (b) chapa de base 

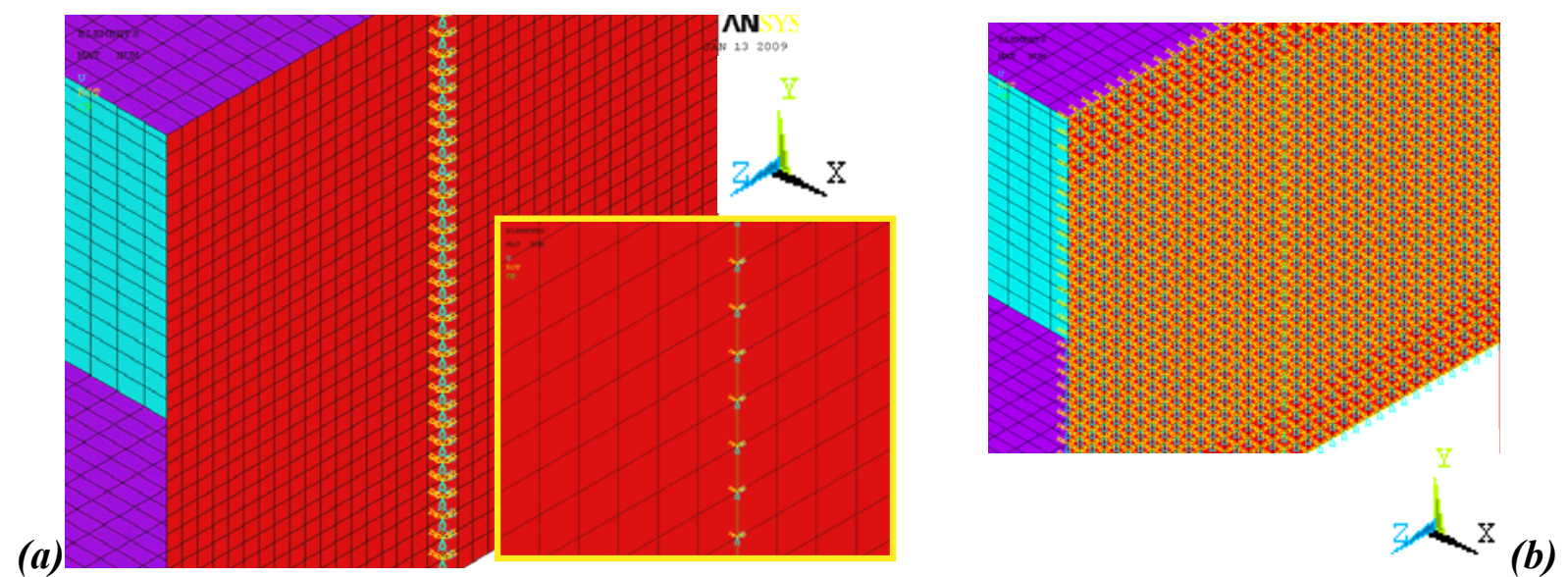

Figura 6.8: Aplicação das restrições aos deslocamentos e rotações no modelo construído com o SHELL181: (a) rótula cilíndrica no topo e (b) chapa de topo.

\subsubsection{APLICAÇÃO DO CARREGAMENTO ESTÁTICO}

Como comentado inicialmente, a força de colapso é obtida a partir da aplicação do deslocamento axial prescrito no topo da barra. O deslocamento é aplicado no nó de menor numeração entre os nós acoplados, como ilustra a Figura 6.9.

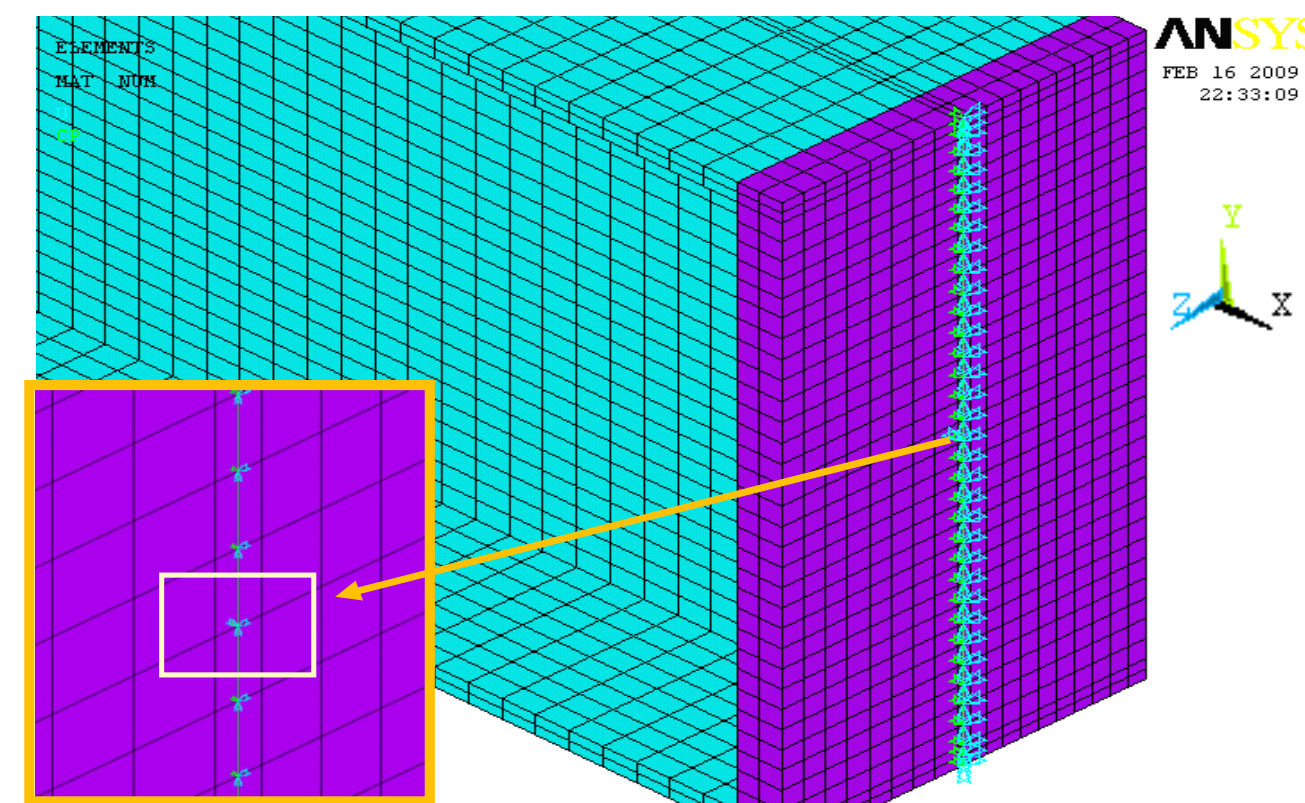

Figura 6.9: Posição do nó de mínima numeração, onde é aplicado o deslocamento prescrito.

Esse procedimento facilita a leitura da resposta em termos de reação de apoio. A máxima reação de apoio em módulo, fornecida pela curva reação x deslocamento corresponde à força de colapso do pilar, a ser considerada com valor de referência para fins de comparação com aquelas obtidas quando das análises termo-estruturais. 
Em relação ao método de resolução do problema não-linear, o ANSYS dispõe de recursos numéricos que, usados devidamente, conduz a repostas confiáveis. O método de resolução seguiu a estratégia incremental-iterativa ou estratégia de Newton-Raphson. O passo de carregamento foi proporcional ao que foi imposto. No caso da análise estrutural em temperatura ambiente, optou-se por controlar o tamanho do deslocamento incremental.

O processo iterativo é executado até que um critério de convergência para o problema seja atingido. Esse critério consiste de um vetor de deslocamentos e forças residuais que é satisfeito quando a norma desse vetor atinge valores menores ou iguais à tolerância estabelecida. No caso em que o carregamento se trata de um deslocamento nodal d, a tolerância estabelecida e de $0,1 \%$ do deslocamento aplicado.

\subsection{COMPARAÇÃO ENTRE ENSAIO EXPERIMENTAL E ANÁLISE NUMÉRICA}

Para fins de validação dos procedimentos acima comentados referentes à elaboração do modelo numérico, foi realizada uma análise numérica separadamente e a resposta do deslocamento lateral foi posta frente aos resultados experimentais apresentados em DE PAULA (2002).

O ensaio experimental em questão determinou a força máxima apenas em temperatura ambiente e foi realizado sobre um pilar cuja seção transversal é PS 200 x 25 e o comprimento efetivo é $1900 \mathrm{~mm}$. As dimensões de interesse estão na Tabela 6.1.

Tabela 6.1: Dimensões medidas da seção transversal PS $200 \times 25$.

\begin{tabular}{ccccccc}
\hline $\mathrm{e}[\mathrm{mm}]$ & $\mathrm{A}_{\mathrm{g}}\left[\mathrm{cm}^{2}\right]$ & $\mathrm{d}[\mathrm{mm}]$ & $\mathrm{h}[\mathrm{mm}]$ & $\mathrm{b}_{\mathrm{f}}[\mathrm{mm}]$ & $\mathrm{t}_{\mathrm{f}}[\mathrm{mm}]$ & $\mathrm{t}_{\mathrm{w}}[\mathrm{mm}]$ \\
\hline $\mathrm{L} / 938$ & 33,83 & 202 & 185,8 & 132 & 8,1 & 6,7 \\
\hline
\end{tabular}

O modelo numérico foi construído com o elemento SOLID45, conforme ilustram as Figuras 6.10 (a) e (b). A Figura 6.10 (c) ilustra a posição no perfil do transdutor que mediu a variação do deslocamento lateral.

A Figura 6.11(a) ilustra a configuração deformada da viga referente ao modelo numérico, enquanto a figura 6.11(b) esquematiza a curva de deslocamento lateral, medida no ponto médio da alma, e na posição $\mathrm{L} / 2$ na direção longitudinal, obtida pelo trabalho experimental da referência citada e a curva obtida pela análise numérica na mesma posição. 


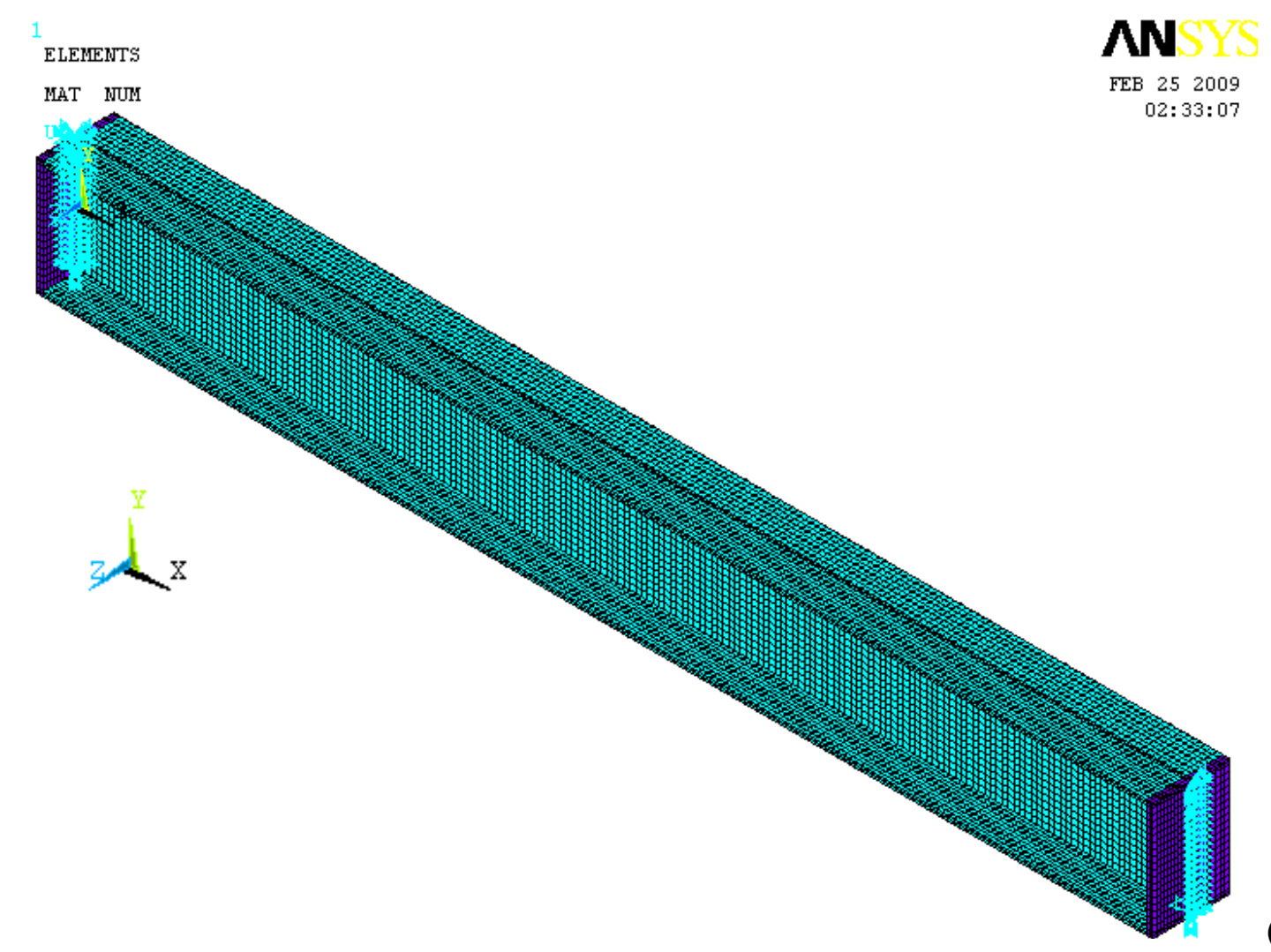

(a)

(b)
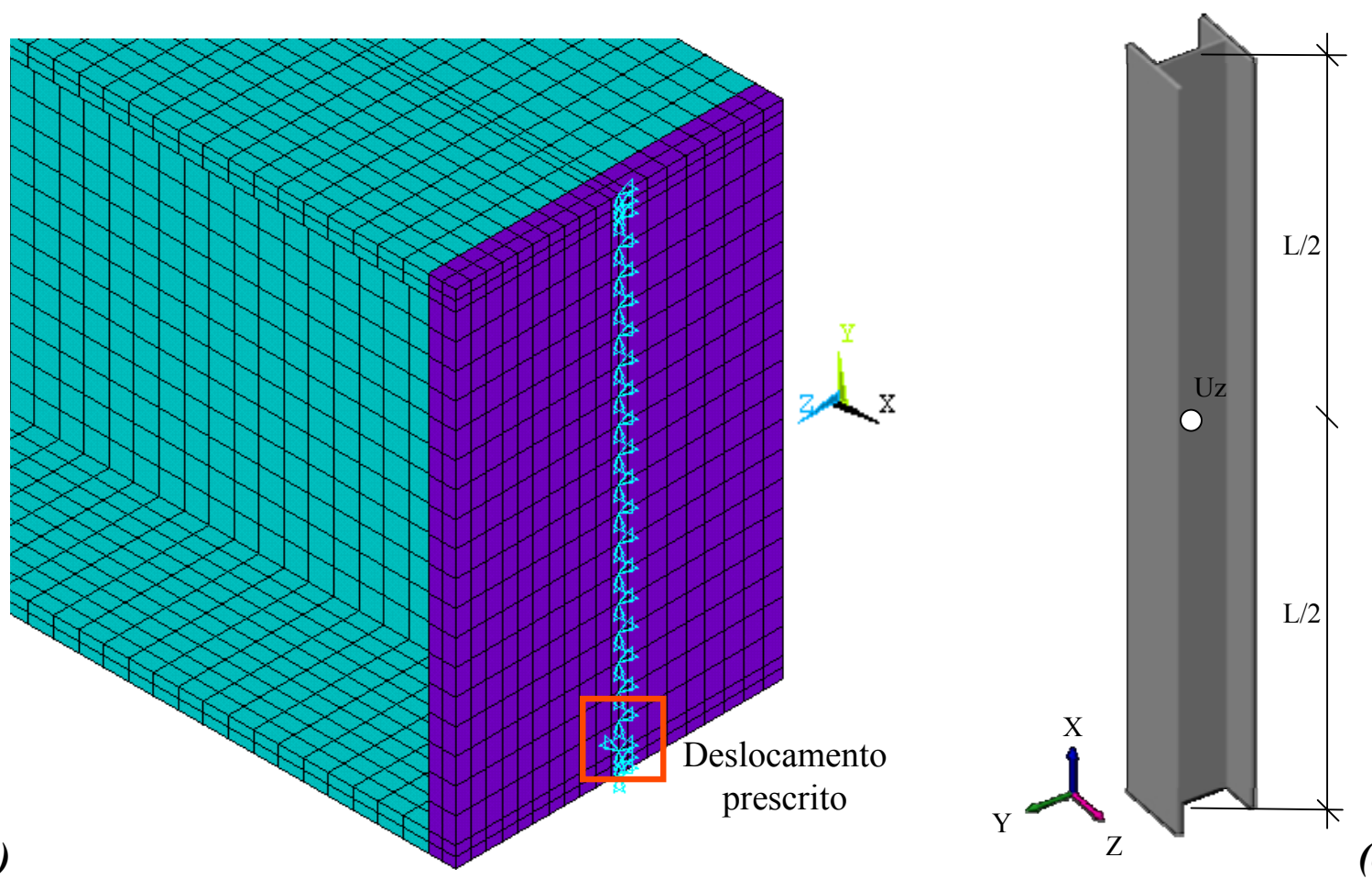

(c)

Figuras 6.10: (a) Construção do modelo com o elemento SOLID 45, (b) detalhe da condição de vinculação e imposição do deslocamento prescrito e (c) posição onde foi registrada a resposta do deslocamento lateral. 


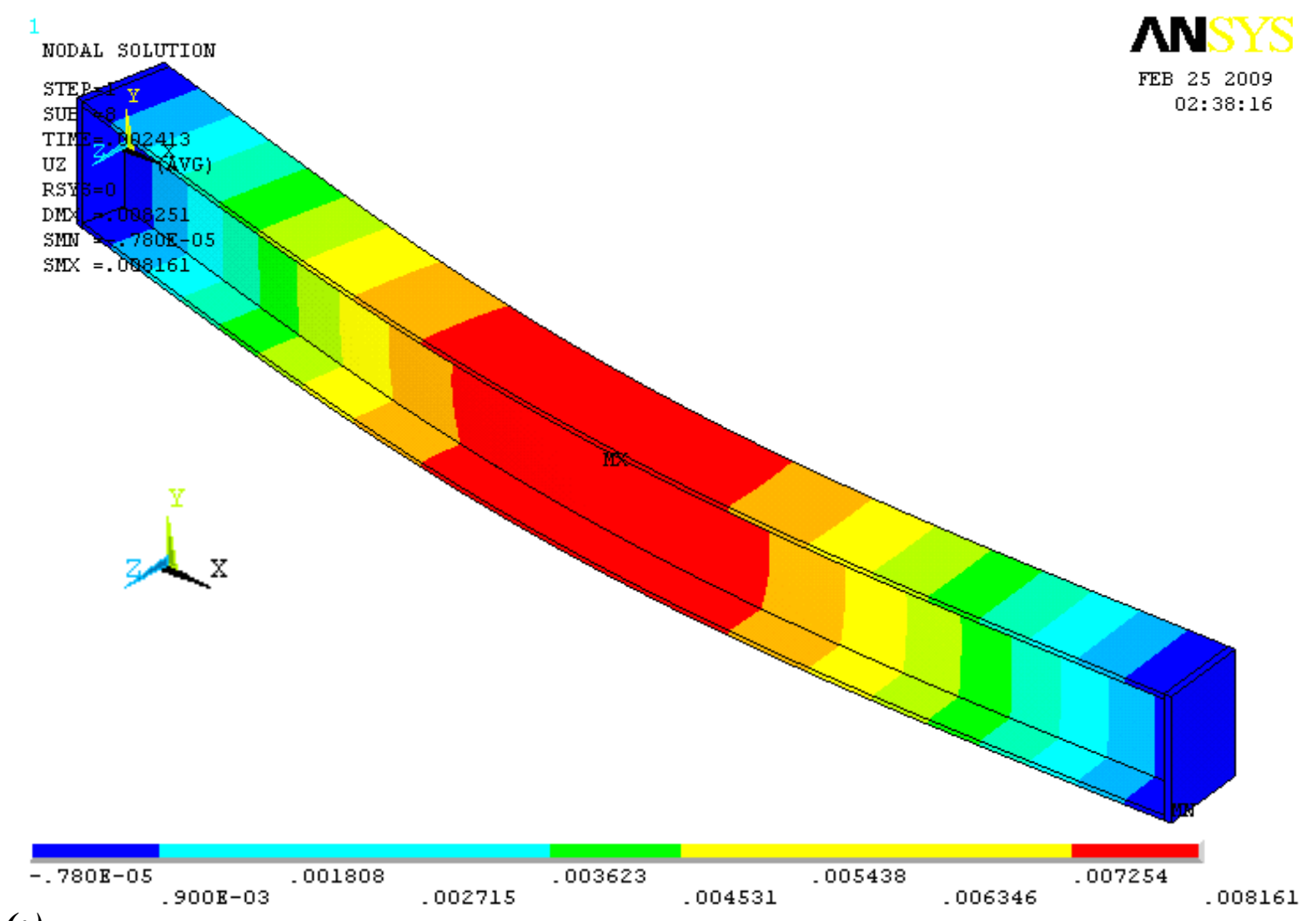

(a)

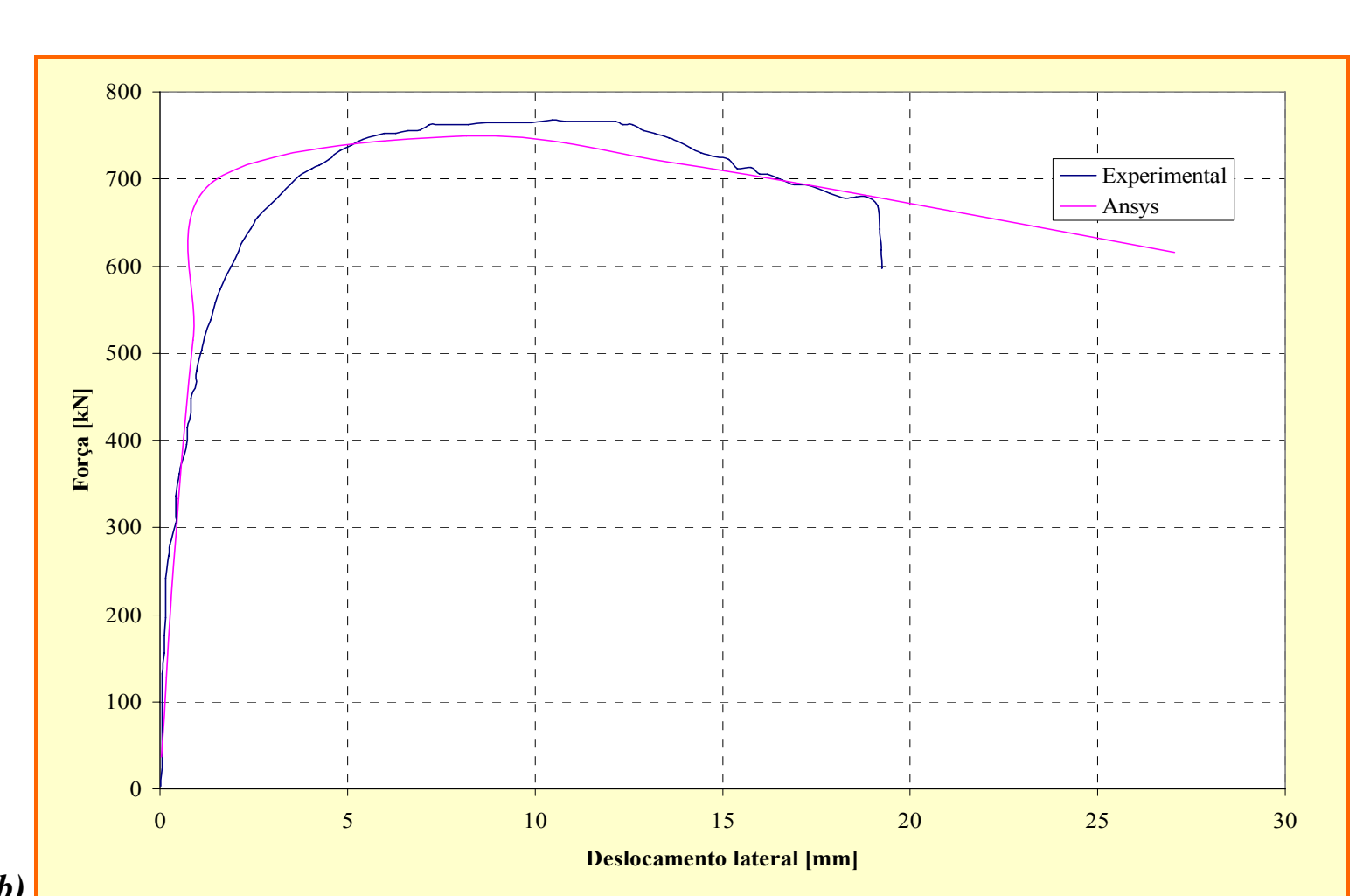

(b)

Figura 6.11: (a) Configuração deformada do pilar, em torno do eixo de menor inércia, obtida pelo ANSYS e (b) Gráficos "Força axial x Deslocamento lateral", considerando valores experimentais e numéricos (obtidos pelo ANSYS). 
Não foi possível fazer comparação análoga para o deslocamento axial, pois não foi fornecida a curva que relaciona o deslocamento axial imposto e a força aplicada pela máquina de ensaios servo-hidráulica. Portanto, com base neste resultado, observa-se uma representatividade satisfatória do ANSYS em análises estruturais em temperatura ambiente.

Nos itens que se seguem, alguns exemplos são analisados por meio da comparação dos resultados numéricos com os procedimentos analíticos propostos pelas principais normas nacionais em vigor. Por essa razão, no item 6.4 é feita uma breve apresentação das prescrições normativas propostas por algumas das normas (nacional e internacional) mais usadas no contexto da engenharia.

\subsection{DIMENSIONAMENTO EM TEMPERATURA AMBIENTE - Procedimentos dos principais códigos normativos}

Neste sub-item são apresentados os métodos de verificação da resistência à compressão propostos pelas normas nacionais ABNT NBR 8800:2008, Eurocode 3 part 1.1 e ANSI/AISC:2005. As equações são direcionadas para o dimensionamento dos perfis abordados nas análises numéricas do presente trabalho.

\subsubsection{SEGUNDO A ABNT NBR 8800:2008}

O método de dimensionamento da norma brasileira segue a mesma proposta apresentada pela ANSI/AISC:2005. A força resistente de cálculo de pilares de aço axialmente comprimidos é dada pela equação 6.1 .

$$
\mathrm{N}_{\mathrm{c}, \mathrm{Rd}}=\frac{\chi \mathrm{QA}_{\mathrm{g}} \mathrm{f}_{\mathrm{y}}}{\gamma_{\mathrm{a} 1}}
$$

$\mathrm{Na}$ equação 6.1, $\chi$ é o fator de redução associado à resistência a compressão, Q é o fator de redução associado à flambagem local, $\mathrm{f}_{\mathrm{y}}$ é a tensão de escoamento, $\gamma_{\mathrm{a} 1}$ é o coeficiente de ponderação da resistência ao escoamento, flambagem e instabilidade no estado limite último e $A_{g}$ é a área bruta da seção transversal. O fator de redução $\chi$ é calculado segundo a equação 6.2 . 
Para $\lambda_{0} \leq 1,5: \chi=0,658^{\lambda_{0}^{2}}$

Para $\lambda_{0}>1,5: \chi=\frac{0,877}{\lambda_{0}^{2}}$

Na equação $6.2, \lambda_{0}$ é o índice de esbeltez reduzido, dado por 6.3 .

$\lambda_{0}=\sqrt{\frac{\mathrm{QA}_{\mathrm{g}} \mathrm{f}_{\mathrm{y}}}{\mathrm{N}_{\mathrm{e}}}}$

$\mathrm{Na}$ equação 6.3, $\mathrm{N}_{\mathrm{e}}$ é a força de compressão de flambagem elástica que para cada eixo da seção transversal, vale, respectivamente:

$$
\begin{aligned}
& \mathrm{N}_{\mathrm{ex}}=\frac{\pi^{2} \mathrm{EI}_{\mathrm{x}}}{\left(\mathrm{K}_{\mathrm{x}} \mathrm{L}_{\mathrm{x}}\right)^{2}} \\
& \mathrm{~N}_{\mathrm{ey}}=\frac{\pi^{2} \mathrm{EI} \mathrm{y}_{\mathrm{y}}}{\left(\mathrm{K}_{\mathrm{y}} \mathrm{L}_{\mathrm{y}}\right)^{2}} \\
& \mathrm{~N}_{\mathrm{ez}}=\frac{1}{\mathrm{r}_{0}^{2}}\left[\frac{\pi^{2} \mathrm{EC}_{\mathrm{w}}}{\left(\mathrm{K}_{\mathrm{z}} \mathrm{L}_{\mathrm{z}}\right)^{2}}+\mathrm{GJ}\right]
\end{aligned}
$$

Em 6.4, tem-se:

$\mathrm{N}_{\mathrm{ex}}, \mathrm{N}_{\mathrm{ey}}$ e $\mathrm{N}_{\mathrm{ez}}$ são, respectivamente a força de compressão de flambagem elástica em relação aos eixos centrais de inércia x e y e ao eixo longitudinal z;

E é o módulo de elasticidade;

$I_{x}$ e $I_{y}$ são os momentos de inércia segundo os eixos x e y, respectivamente;

$\mathrm{K}_{\mathrm{x}} \mathrm{L}_{\mathrm{x}}, \mathrm{K}_{\mathrm{y}} \mathrm{L}_{\mathrm{y}}$ e $\mathrm{K}_{\mathrm{z}} \mathrm{L}_{\mathrm{z}}$ são os comprimentos de flambagem por flexão em relação aos eixos x e y e o comprimento de flambagem por torção, respectivamente;

$\mathrm{r}_{0}$ é definido como raio de giração polar da seção bruta em relação ao centro de cisalhamento, dado por 6.5 ;

G é o módulo de elasticidade transversal do aço;

J é a constante de torção da seção transversal; 
$\mathrm{C}_{\mathrm{w}}$ é a constante de empenamento da seção transversal

$$
\mathrm{r}_{0}=\sqrt{\mathrm{r}_{\mathrm{x}}^{2}+\mathrm{r}_{\mathrm{y}}^{2}+\mathrm{x}_{0}^{2}+\mathrm{y}_{0}^{2}}
$$

Da equação 6.5, são definidos:

$\mathrm{r}_{\mathrm{x}}$ e $\mathrm{r}_{\mathrm{y}}$ são os raios de giração em relação aos eixos x e y, respectivamente;

$\mathrm{x}_{0}$ e $\mathrm{y}_{0}$ são as coordenadas do centro de cisalhamento na direção dos eixos centrais $\mathrm{x}$ e y respectivamente.

O valor de Q, para as seções transversais aqui estudadas, é determinado conforme a equação 6.6.

$\mathrm{Q}=\mathrm{Q}_{\mathrm{s}} \mathrm{Q}_{\mathrm{a}}$

$\mathrm{Na}$ equação 6.6, $\mathrm{Q}_{\mathrm{s}}$ é a parcela do fator de redução referente ao elemento com borda livre (denominado $\mathrm{AL}$ ) e $\mathrm{Q}_{\mathrm{a}}$ é a parcela referente ao elemento com bordas apoiadas (elementos AA). Para elementos do grupo 4 da tabela F.1, que engloba a seção I laminado, $\mathrm{Q}_{\mathrm{s}}$ é calculado de acordo com a equação 6.6.

$$
\begin{aligned}
& Q_{s}=1,415-0,74 \frac{b}{t} \sqrt{\frac{f_{y}}{E}}, \quad \operatorname{para} 0,56 \sqrt{\frac{E}{f_{y}}}<\frac{b}{t}<1,03 \sqrt{\frac{E}{f_{y}}} \\
& Q_{s}=\frac{0,69 E}{f_{y}\left(\frac{b}{t}\right)^{2}}, \quad \operatorname{para} \frac{b}{t}>1,03 \sqrt{\frac{E}{f_{y}}}
\end{aligned}
$$

Para os elementos do tipo AA, a parcela do fator de redução relacionado a flambagem local é dada pela equação 6.7.

$$
\mathrm{Q}_{\mathrm{a}}=\frac{\mathrm{A}_{\mathrm{ef}}}{\mathrm{A}_{\mathrm{g}}}
$$

$\mathrm{A}_{\mathrm{ef}}$ é a área efetiva da seção transversal calculada pela equação 6.8 . 


$$
\mathrm{A}_{\mathrm{ef}}=\mathrm{A}_{\mathrm{g}}-\sum\left(\mathrm{b}-\mathrm{b}_{\mathrm{ef}}\right) \mathrm{t}
$$

$b_{\text {ef }}$ é a largura efetiva do elemento AA comprimido, dada pela equação 6.9. Para todas as seções, exceto tubulares retangulares, o coeficiente $c_{a}$ vale 0,34 .

$$
\begin{aligned}
& \mathrm{b}_{\text {ef }}=1,92 \mathrm{t} \sqrt{\frac{\mathrm{E}}{\sigma}}\left[1-\frac{\mathrm{c}_{\mathrm{a}}}{\mathrm{b} / \mathrm{t}} \sqrt{\frac{\mathrm{E}}{\sigma}}\right] \leq \mathrm{b} \\
& \sigma=\chi \mathrm{f}_{\mathrm{y}}
\end{aligned}
$$

A tensão atuante no elemento analisado, $\sigma$, determinada por meio da 6.10 , é obtida com $\chi$ sendo calculada considerando Q igual a 1. Opcionalmente, de forma conservadora, se considera $\sigma=f_{y}$.

\subsubsection{SEGUNDO O ANSI/AISC:2005}

A resistência a compressão nominal, $\mathrm{P}_{\mathrm{n}}$ é determinado com base na equação 6.15 .

$$
\mathrm{P}_{\mathrm{n}}=\mathrm{F}_{\mathrm{cr}} \mathrm{A}_{\mathrm{g}}
$$

$\mathrm{Na}$ 6.15, $\mathrm{F}_{\mathrm{cr}}$ é a tensão de flambagem. Para barras cuja seção transversal possui elementos esbeltos, valem os seguintes valores de $F_{\mathrm{cr}}$ :

$$
\begin{aligned}
& \operatorname{Para} \frac{\mathrm{KL}}{\mathrm{r}} \leq 4,71 \sqrt{\frac{\mathrm{E}}{\mathrm{QF}_{\mathrm{y}}}}\left(\text { ou } \mathrm{F}_{\mathrm{e}} \geq 0,44 \mathrm{QF}_{\mathrm{y}}\right) \Rightarrow \mathrm{F}_{\mathrm{cr}}=\mathrm{Q}\left[0,658^{\frac{\mathrm{QF}_{\mathrm{y}}}{\mathrm{F}_{\mathrm{c}}}}\right] \mathrm{F}_{\mathrm{y}} \\
& \operatorname{Para} \frac{\mathrm{KL}}{\mathrm{r}}>4,71 \sqrt{\frac{\mathrm{E}}{\mathrm{QF}_{\mathrm{y}}}}\left(\text { ou } \mathrm{F}_{\mathrm{e}}<0,44 \mathrm{QF}_{\mathrm{y}}\right) \Rightarrow \mathrm{F}_{\mathrm{cr}}=0,877 \mathrm{~F}_{\mathrm{e}}
\end{aligned}
$$

Nas equações 6.16 e $6.17, \mathrm{~F}_{\mathrm{e}}$ é a tensão crítica de flambagem elástica, calculado conforme 6.18, KL é o comprimento efetivo de flambagem, $\mathrm{r}$ é o raio de giração na direção mais instável, $\mathrm{f}_{\mathrm{y}}$ é a resistência ao escoamento, $\mathrm{Q}$ é o coeficiente de redução relativo à flambagem local. 
$\mathrm{F}_{\mathrm{e}}=\frac{\pi^{2} \mathrm{E}}{\left(\frac{\mathrm{KL}}{\mathrm{r}}\right)^{2}}$

O fator de redução $\mathrm{Q}$, como mostra a equação 6.19, é determinada de forma semelhante à 6.5.

$\mathrm{Q}=\mathrm{Q}_{\mathrm{s}} \mathrm{Q}_{\mathrm{a}}$

Em que $\mathrm{Q}_{\mathrm{s}}$ é a parcela referente a flambagem local de elementos $\mathrm{AL}$, determinada conforme a 6.20 a 6.22 .

$\operatorname{Para} \frac{\mathrm{b}}{\mathrm{t}} \leq 0,56 \sqrt{\frac{\mathrm{E}}{\mathrm{F}_{\mathrm{y}}}}, \mathrm{Q}_{\mathrm{s}}=1,0$

$\operatorname{Para} 0,56 \sqrt{\frac{E}{F_{y}}} \leq \frac{b}{t}<1,03 \sqrt{\frac{E}{F_{y}}}, Q_{s}=1,415-0,74\left(\frac{b}{t}\right) \sqrt{\frac{F_{y}}{E}}$

$\operatorname{Para} \frac{b}{t} \geq 1,03 \sqrt{\frac{E}{F_{y}}}, Q_{s}=\frac{0,69 E}{F_{y}\left(\frac{b}{t}\right)^{2}}$

$\mathrm{O}$ cálculo de $\mathrm{Q}_{\mathrm{a}}$, que é a parcela referente a flambagem local de elementos AA é equacionada em 6.23 .

$\mathrm{Q}_{\mathrm{a}}=\frac{\mathrm{A}_{\text {eff }}}{\mathrm{A}}$

Para elementos AA esbeltos sob compressão, exceto de seções quadradas e retangulares, de espessura uniforme:

Para $\frac{b}{t} \geq 1,49 \sqrt{\frac{E}{f}}, \quad b_{e}=1,92 t \sqrt{\frac{E}{f}}\left[1-\frac{0,34}{(b / t)} \sqrt{\frac{E}{f}}\right] \leq b$ 


\subsubsection{SEGUNDO O EUROCODE 3 - PART 1.1}

Para as seções de classe 1, 2 e 3 (definidas no item 5.5.2 do EC3) a força de compressão resistente de cálculo é dada pela equação 6.11 .

$\mathrm{N}_{\mathrm{b}, \mathrm{Rd}}=\frac{\chi \mathrm{Af}_{\mathrm{y}}}{\gamma_{\mathrm{M} 1}}$

Para as seções de classe 4, vale a equação 6.12, em que a determinação da área efetiva $\mathrm{A}_{\text {eff }}$ se faz de acordo com o procedimento descrito no Eurocode 3 part 1-5.

$\mathrm{N}_{\mathrm{b}, \mathrm{Rd}}=\frac{\chi \mathrm{A}_{\text {eff }} \mathrm{f}_{\mathrm{y}}}{\gamma_{\mathrm{M} 1}}$

Nas equações 6.11 e $6.12, \mathrm{~N}_{\mathrm{b}, \mathrm{Rd}}$ é a resistência de cálculo do pilar axialmente comprimido, $\gamma_{\mathrm{M} 1}$ fator de ponderação da resistência associado a instabilidade, tomado igual a unidade. $\mathrm{O}$ valor de $\chi$ pode ser calculado conforme a equação 6.13 .

$$
\begin{aligned}
& \chi=\frac{1}{\Phi+\sqrt{\Phi^{2}-\bar{\lambda}^{2}}} \operatorname{com} \chi \leq 1,0 \\
& \Phi=0,5\left[1+\alpha(\bar{\lambda}-0,2)+\bar{\lambda}^{2}\right]
\end{aligned}
$$

Os valores de $\alpha$ são dados pela Tabela 6.1 do EC3. $\bar{\lambda}$ é o índice de esbeltez reduzido, calculado conforme 6.15 , em que $\mathrm{N}_{\mathrm{cr}}$ é a força crítica de flambagem elástica, calculado conforme a equação 6.4 .

$$
\begin{aligned}
& \bar{\lambda}=\sqrt{\frac{\mathrm{Af}_{\mathrm{y}}}{\mathrm{N}_{\mathrm{cr}}}}, \text { para classes } 1,2 \text { e } 3 \\
& \bar{\lambda}=\sqrt{\frac{\mathrm{A}_{\mathrm{eff}} \mathrm{f}_{\mathrm{y}}}{\mathrm{N}_{\mathrm{cr}}}}, \text { para classe } 4
\end{aligned}
$$

\subsection{RESULTADOS OBTIDOS}

A primeira análise estrutural trata do perfil UC 203 × 203 × 46, cujas dimensões foram apresentadas em 5.2.1, de comprimento efetivo igual a $3170 \mathrm{~mm}$. O aço adotado foi o S275, 
que apresenta resistência ao escoamento $\mathrm{f}_{\mathrm{y}}=275 \mathrm{MPa}$. A segunda análise é realizada com relação ao perfil W 310 x 38,7, cuja seção transversal foi descrita em 5.2.2 e o comprimento efetivo é igual a $3811 \mathrm{~mm}$. A terceira análise também abordou o perfil com seção transversal descrito em 5.2.2 e possui comprimento efetivo de $3890 \mathrm{~mm}$. O tipo de aço utilizado nos dois últimos modelos é o ASTM A36, cuja tensão de escoamento é $25 \mathrm{kN} / \mathrm{cm}^{2}$.

A Tabela 6.1 apresenta os valores obtidos pela análise numérica frente aos valores determinados por meio das três normas descritas anteriormente.

Tabela 6.1: Força máxima obtidas pela análise numérica e pelos códigos normativos, em kN.

\begin{tabular}{|c|c|c|c|}
\hline Pilar & Análise numérica & $\begin{array}{c}\text { ABNT-NBR 8800:2008 / } \\
\text { ANSI/AISC:2005 }\end{array}$ & Eurocode 3 part 1 \\
\hline $\begin{array}{l}\text { UC } 203 \times 203 \times 46- \\
\qquad L=3170 \mathrm{~mm}\end{array}$ & 1215 & 1292 & 1255 \\
\hline $\begin{array}{l}\text { W } 310 \times 38,1- \\
L=3811 \mathrm{~mm}\end{array}$ & 675 & 734 & 738 \\
\hline $\begin{array}{l}\text { W } 310 \times 38,1- \\
L=3890 \mathrm{~mm}\end{array}$ & 661 & 718 & 718 \\
\hline
\end{tabular}

Para os três casos estudados, como pode ser observado, os códigos normativos superestimaram capacidade resistente obtida pela análise numérica, pois resultou numa força nominal de ruína maior que aquela determinada numericamente. A Figura 6.12 faz uma comparação em forma de um gráfico entre os três métodos, considerando os valores nominais N.

Em relação à resposta em temperatura ambiente, percebe-se que ambos os elementos finitos representam bem o desempenho de um perfil estrutural de aço comprimido. Porém, a construção de modelos numéricos utilizando elementos de casca, como o SHELL181 resultou em algumas incertezas nas respostas geradas pela análise termoestrutural.

Tais incertezas são referentes à dificuldade no acoplamento dos valores obtidos com os modelos térmicos, inicialmente construídos com elemento finito SOLID70, com o elemento finito SHELL 181 para fins de análise termoestrutural. Além disso, para a utilização do elemento SHELL, é importante destacar a necessidade de se estudar uma malha de elementos finitos ideal para o mesmo, uma vez que modelos constituídos desse tipo de elemento não exigem malhas com o mesmo grau de refinamento quando da utilização dos elementos do tipo SOLID. 


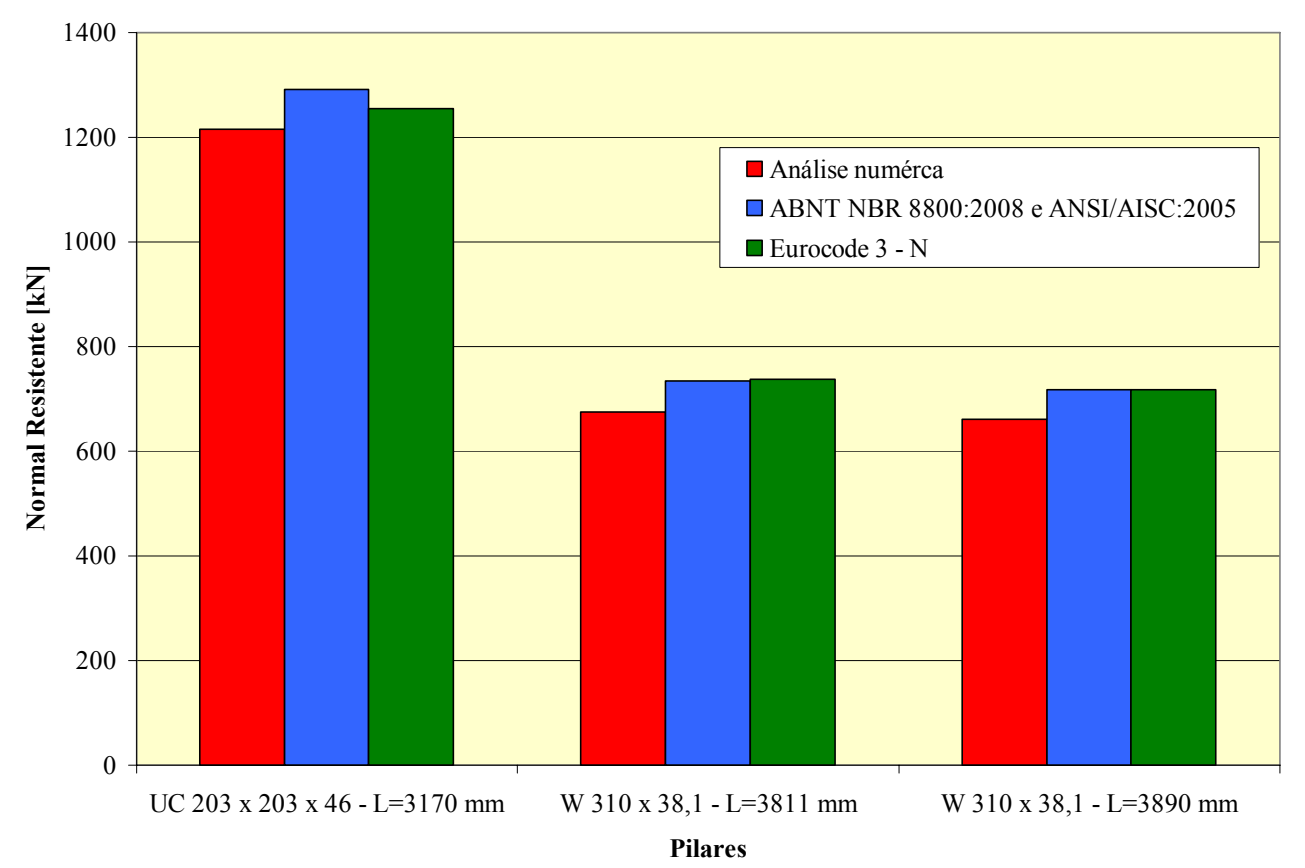

Figura 6.12: Comparação entre os métodos de determinação da força de colapso

A Figura 6.13 ilustra graficamente a resposta "força $x$ deslocamento axial" referente às simulações numéricas com relação aos três pilares estudados. A Figura 6.14 esquematiza as comparações entre as respostas obtidas utilizando elementos SHELL181 e SOLID45, realizadas para o primeiro exemplo da tabela 6.1, considerando análise estrutural em temperatura ambiente.

Para análise em temperatura ambiente, é importante notar que ambos os elementos fornecem resultados suficientemente satisfatórios. Analogamente, para análises acopladas do tipo termoestrutural onde se avalia a ação térmica numa estrutura solicitada com carregamento estático (nesse caso de compressão), em situações cujo comportamento seja mais uniforme, a exemplo dos pilares isolados submetidos ao incêndio por todos os lados, ambos os elementos também obtiveram comportamento satisfatórios quando da análise da trajetória de deslocamento axial em função do tempo. 


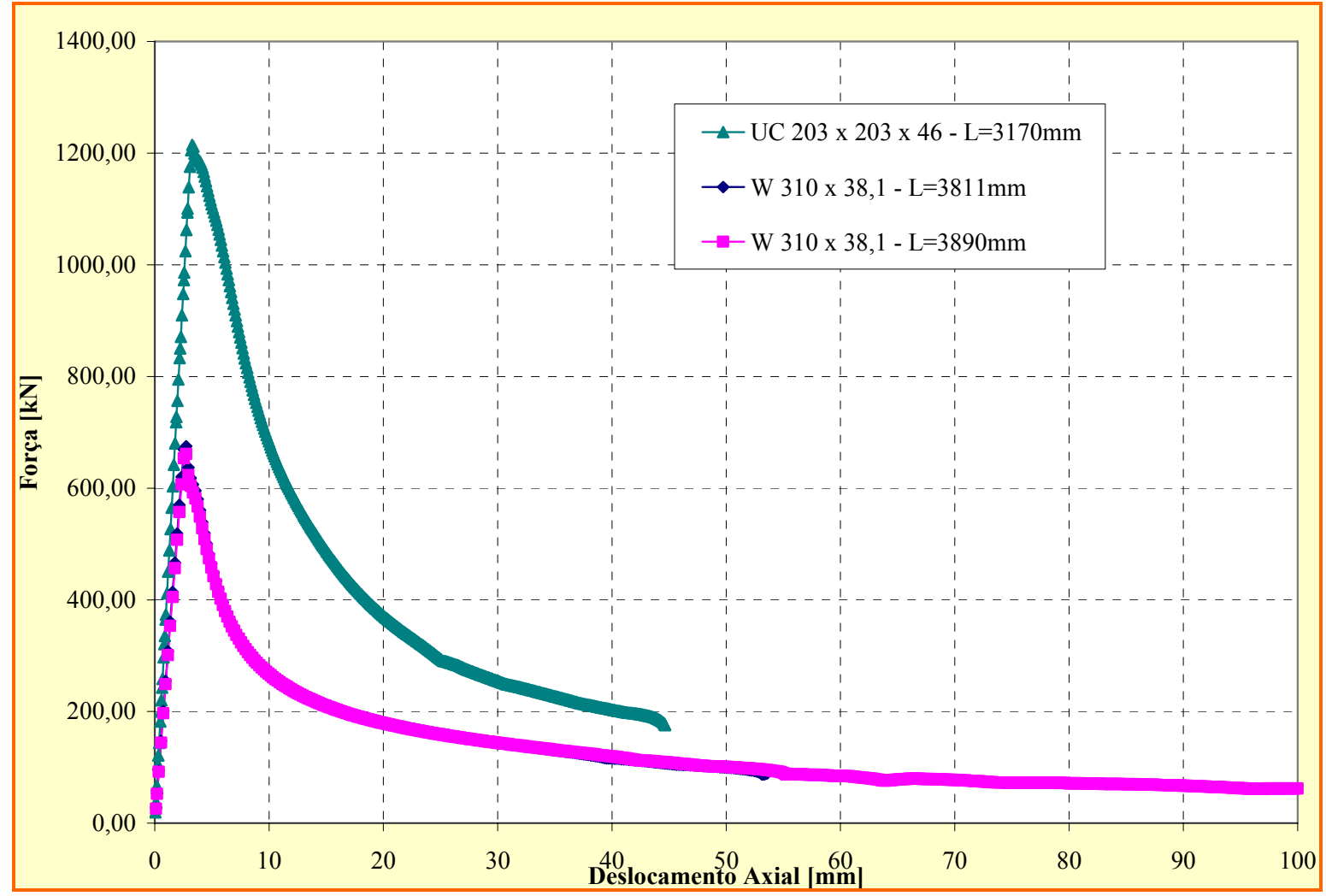

Figura 6.13: Curva força $\mathrm{x}$ deslocamento axial para os três exemplos analisados

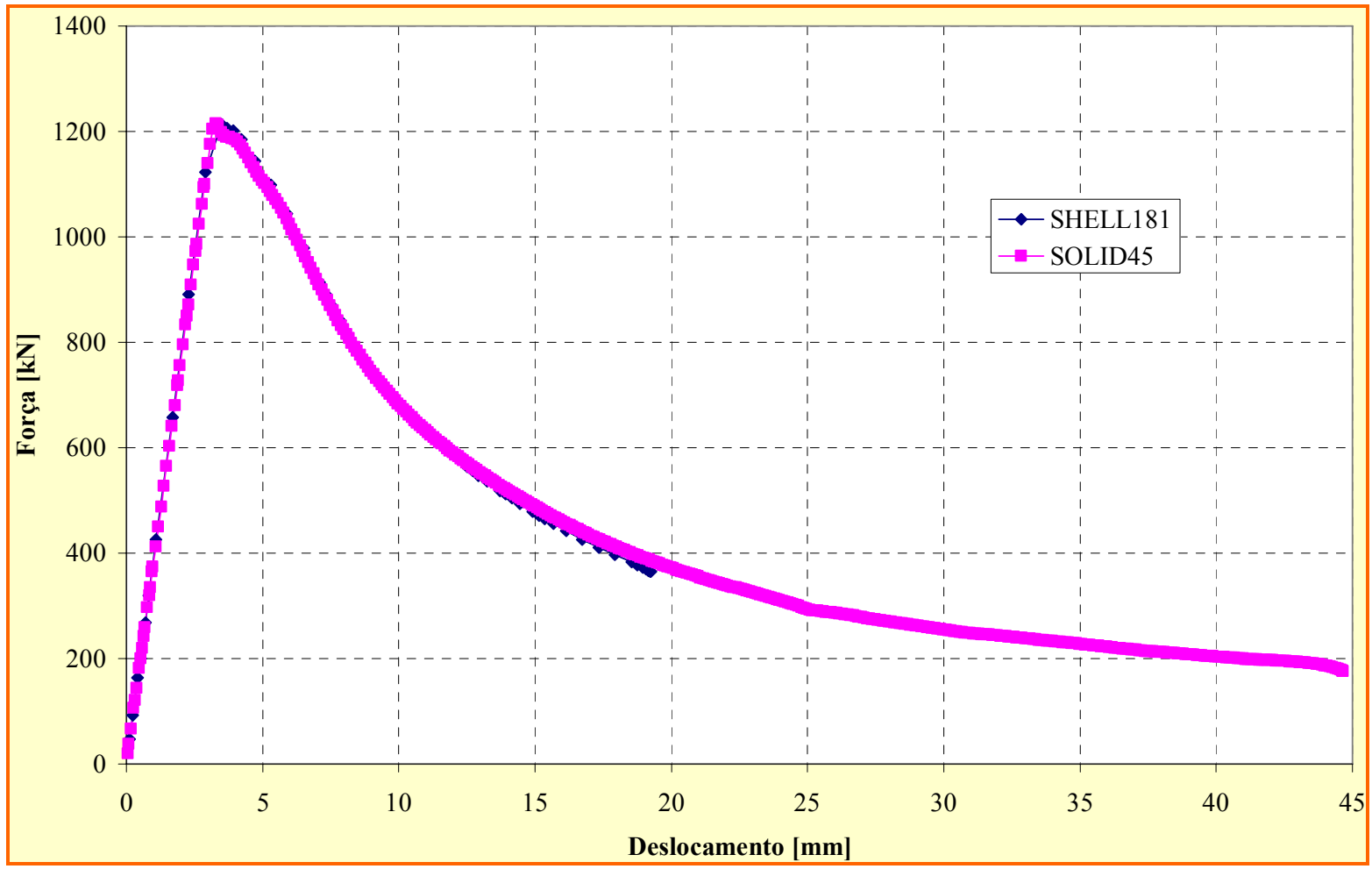

Figura 6.14: Curva força $\mathrm{x}$ deslocamento axial para o primeiro exemplo, comparando as respostas do elemento SHELL181 e SOLID45. 
Porém, é importante ressaltar que análises envolvendo campo térmico assimétrico apresentaram grandes divergências na trajetória do deslocamento e no tempo crítico (TRF). Essa discordância na resposta termoestrutural, no que se refere aos deslocamentos, fez com que a adoção do elemento finito SHELL181 fosse inicialmente evitada.

Portanto, no decorrer do próximo capítulo, para fins de análise termoestrutural será considerado apenas o elemento finito do tipo SOLID 45. Também são discutidas as demais análises termo-estruturais em que se levou em consideração a contribuição das paredes em contato com o pilar, observadas no Capítulo 5, bem como o sentido das imperfeições geométricas iniciais introduzidas na análise estrutural deste capítulo. 


\section{RESPOSTA NUMÉRICA DOS PILARES COM BASE EM ANÁLISE TERMOESTRUTURAL}

\subsection{COMENTÁRIOS PRELIMINARES}

Este capítulo expõe resultados obtidos por meio de análises do tipo termoestrutural realizadas com relação aos modelos numéricos tridimensionais já apresentados nos capítulos 5 e 6. Essas análises têm por finalidade avaliar o efeito da temperatura na resposta da estrutura (com imperfeição global) quando esta é solicitada axialmente. São apresentados valores referentes aos deslocamentos laterais no meio do vão e axiais no topo do pilar, bem como o tempo crítico (tempo requerido de resistência ao fogo - TRF) em que esses ocorrem.

$\mathrm{Na}$ análise termoestrutural, além da influência da disposição de paredes na determinação do campo térmico, procurou-se observar o sentido da imperfeição geométrica inicial em relação à localização da fonte de calor. Como carregamentos, tomaram-se as seguintes considerações:

- Inicialmente são aplicadas forças estáticas nodais em todos os nós pertencentes à alma no topo do pilar (extremidade superior), como mostra a Figura 7.1. Para cada exemplo de interesse, foram considerados nove diferentes níveis de carregamento aplicados, variando de $10 \%$ até $90 \%$ (obedecendo à razão de 10\%) daquela força de colapso do pilar obtida previamente em temperatura ambiente;

- Em seguida, já processada a parte estrutural em temperatura ambiente, se faz a consideração das análises termoestruturais com aplicação da ação térmica de forma transiente, por meio do acoplamento com o modelo térmico. Para isso, faz-se a chamada do arquivo de resultados das análises térmicas. As respostas finais têm influência da parcela estrutural inicialmente imposta (temperatura ambiente) e da parte térmica (temperaturas elevadas).

É importante aqui ressaltar que, por simplificação, a chapa de topo atribuída às extremidades do pilar não recebe ação térmica. A ela são atribuídas apenas as propriedades físicas em regime elástico e em temperatura ambiente. O incremento de temperatura se deu a 
cada 60 segundos para os níveis de força reduzidos, e a cada 30 segundos para os níveis de força mais próximos da ruptura. Para casos intermediários, se optou por introduzir o campo térmico transiente a cada 40 segundos. Para os pilares com menor superfície em contato com o campo térmico, o tempo crítico ultrapassava 150 minutos. Ressalta-se que o tempo crítico determinado em todas as análises apresentadas não se trata do tempo real, mas sim do tempo de resistência ao fogo, padronizado pela curva da ISO834.

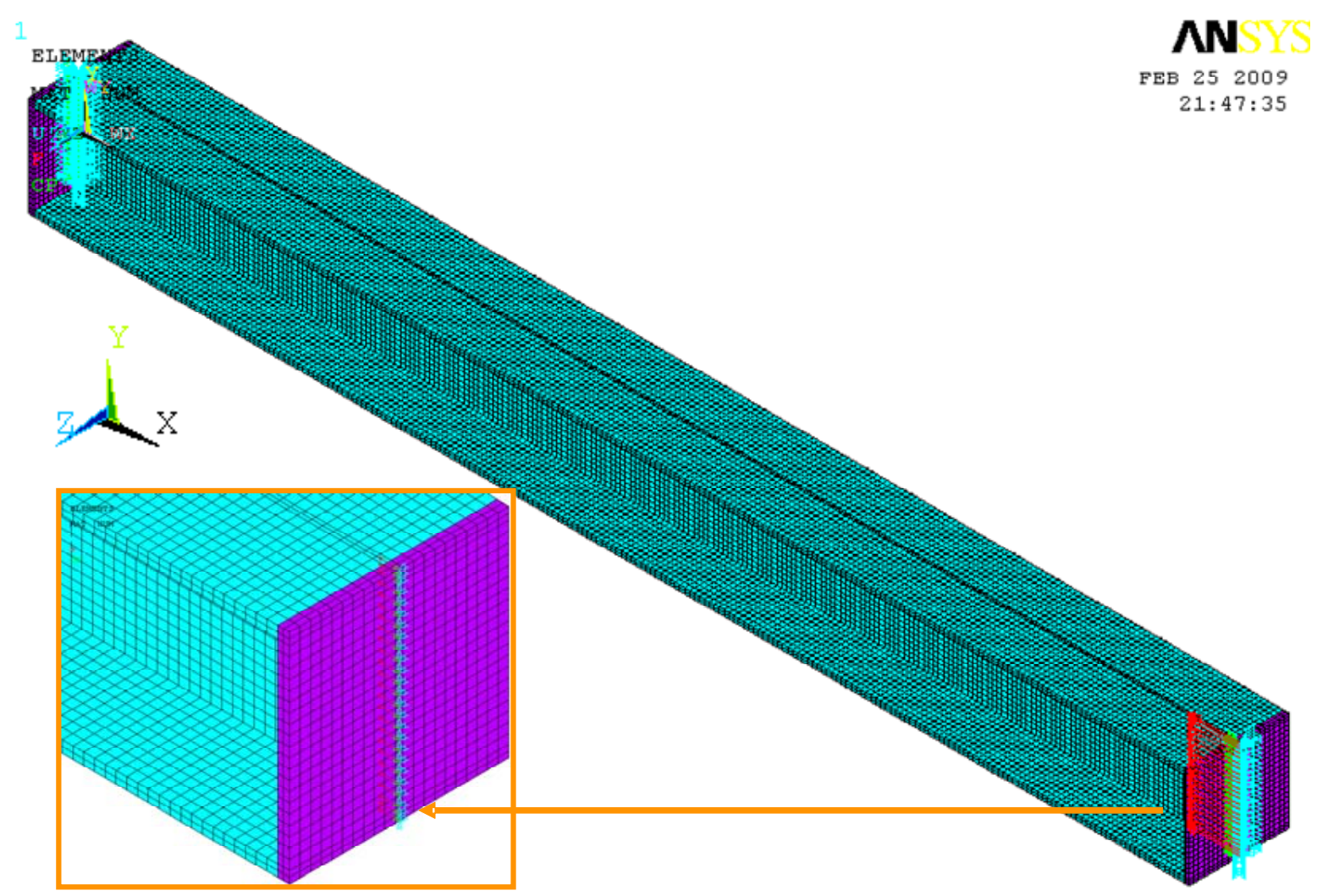

Figura 7.1: Detalhe do procedimento de aplicação da força sobre a chapa de topo na posição coincidente com a alma.

\subsection{INFLUÊNCIA DO SENTIDO DA IMPERFEIÇÃO GEOMÉTRICA INICIAL NA RESPOSTA ESTRUTURAL}

Nesse caso, o estudo da imperfeição geométrica voltou-se unicamente a observar se o sentido do deslocamento inicial interferiria no tempo crítico do pilar exposto ao incêndio, para situações de ação térmica assimétrica. Conforme esquema apresentado na Figura 7.2, convencionou-se como sentido positivo da imperfeição inicial global o deslocamento no sentido positivo do eixo $\mathrm{z}$ e como negativo o deslocamento no sentido negativo do eixo $\mathrm{z}$.

Em casos onde o campo térmico resulta assimétrico ou monossimétrico em torno do eixo de menor inércia, e que também apresenta a posição deslocada em torno do mesmo eixo, foi observada uma diferença no tempo crítico em relação à posição de ambos. 

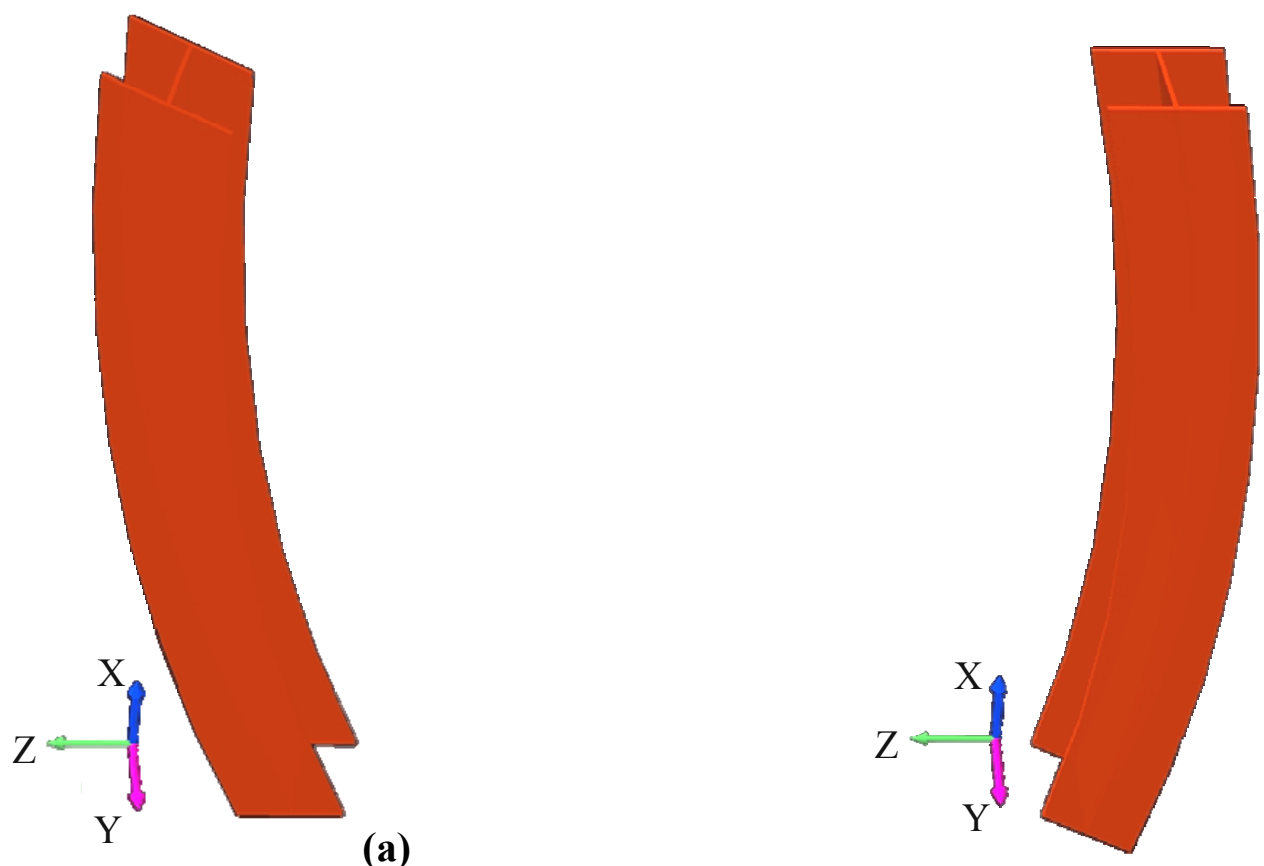

(a)

(b)

Figura 7.2: Sentido da imperfeição geométrica inicial: (a) positivo e (b) negativo.

Aparentemente, as situações em que o campo térmico atua no sentido oposto ao deslocamento inicial apresentam ligeira vantagem no TRF. Isso ocorre em razão de o lado do pilar exposto à situação de incêndio apresentar deformação de compressão no mesmo lado, em decorrência da força de compressão aplicada e do sentido do deslocamento inicial. $\mathrm{Na}$ presença da ação térmica, esse lado tende a apresentar deformações provocadas pela dilatação térmica no sentido oposto ao da compressão.

A deformação decorrente da dilatação térmica é inicialmente nula (em temperatura ambiente) e cresce com o aumento da temperatura. Em uma determinada temperatura, a deformação por dilatação anulará e, posteriormente, superará a deformação por compressão.

Quando o pilar se encontra com imperfeição global e em situação de incêndio no mesmo sentido, este já tem o lado com deformação de tração em contato com a ação térmica. Logo, a deformação por dilatação térmica será somada a essa deformação de tração ocasionada pelo deslocamento inicial. Assim sendo, o TRF tende a ser mais baixo em relação a ambos atuando em sentidos opostos. O pilar se deforma por efeito da ação térmica até que este apresente uma temperatura tal que suas propriedades de rigidez e resistência não sejam mais suficientes para suportar o carregamento estático imposto.

No que se segue, são ilustradas as coordenadas na seção transversal dos pilares analisados, para os quais foram monitorados os deslocamentos laterais em torno do eixo de menor inércia no meio do vão. Também são apresentados valores de deslocamentos axial e 
lateral resultantes da compressão centrada e da exposição ao incêndio-padrão préestabelecidos.

$\mathrm{Na}$ seqüência, é apresentado o gráfico com as trajetórias de deslocamento para os níveis de força externa aplicada entre 10\% e 90\% daquela força de colapso obtida em temperatura ambiente. $\mathrm{O}$ deslocamento axial foi tomado no nó de menor numeração no topo do pilar. Por último, é apresentado o a força de colapso $\left(\mathrm{N}_{\mathrm{fi}}\right)$ e o fator de redução em função do tempo $\left(\mathrm{N}_{\mathrm{fi}} / \mathrm{N}\right)$, definido pela relação entre o carregamento imposto na análise em situação de incêndio e o carregamento máximo alcançado pela estrutura em temperatura ambiente.

\subsection{PILAR ISOLADO - Carga térmica por todos os lados}

A temperatura e o deslocamento lateral no pilar foram medidos em determinados pontos, conforme ilustrados na Figura 7.3. Como o aquecimento é admitido uniforme ao longo do comprimento, o campo de temperatura não depende do valor de x (eixo do pilar). Nos itens que se seguem, serão apresentados resultados de análises numéricas e experimentais realizadas com referência à situação apresentada na figura 7.3.

\begin{tabular}{|c|c|c|c|c|}
\hline Nó & $\mathrm{X}$ & $\bar{Y}$ & $\bar{Z}$ & \\
\hline 1 & 1,5900 & $-0,1016$ & $-0,1018$ & \multirow{4}{*}{ Mesa } \\
\hline 2 & 1,5900 & 0,1016 & $-0,1018$ & \\
\hline 3 & 1,5900 & $-0,1016$ & 0,1018 & \\
\hline 4 & 1,5900 & 0,1016 & 0,1018 & \\
\hline 5 & 1,5900 & $-0,0544$ & 0,0000 & \multirow{3}{*}{ Alma } \\
\hline 6 & 1,5900 & $-0,0091$ & 0,0000 & \\
\hline 7 & 1,5900 & 0,0544 & 0,0000 & \\
\hline
\end{tabular}

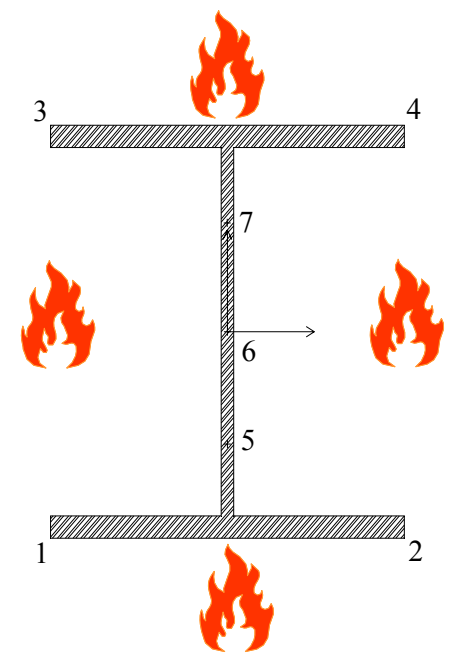

Figura 7.3: Nós em que foram medidos os deslocamentos laterais para o pilar isolado.

\subsubsection{RESULTADOS NUMÉRICOS - Com elemento finito SOLID45}

Aqui se apresenta os resultados referentes aos deslocamentos axial e lateral em função do tempo e da temperatura média. As Figuras 7.4 e 7.5 ilustram o campo de deslocamento axial e lateral da barra, respectivamente no instante de colapso, quando a mesma é submetida a uma solicitação de compressão equivalente a $60 \%$ da força resistente nominal. As Figuras 
7.6 a 7.7 ilustram a evolução dos deslocamentos axial e lateral em função do tempo e da temperatura considerando nove níveis de solicitação aplicados.

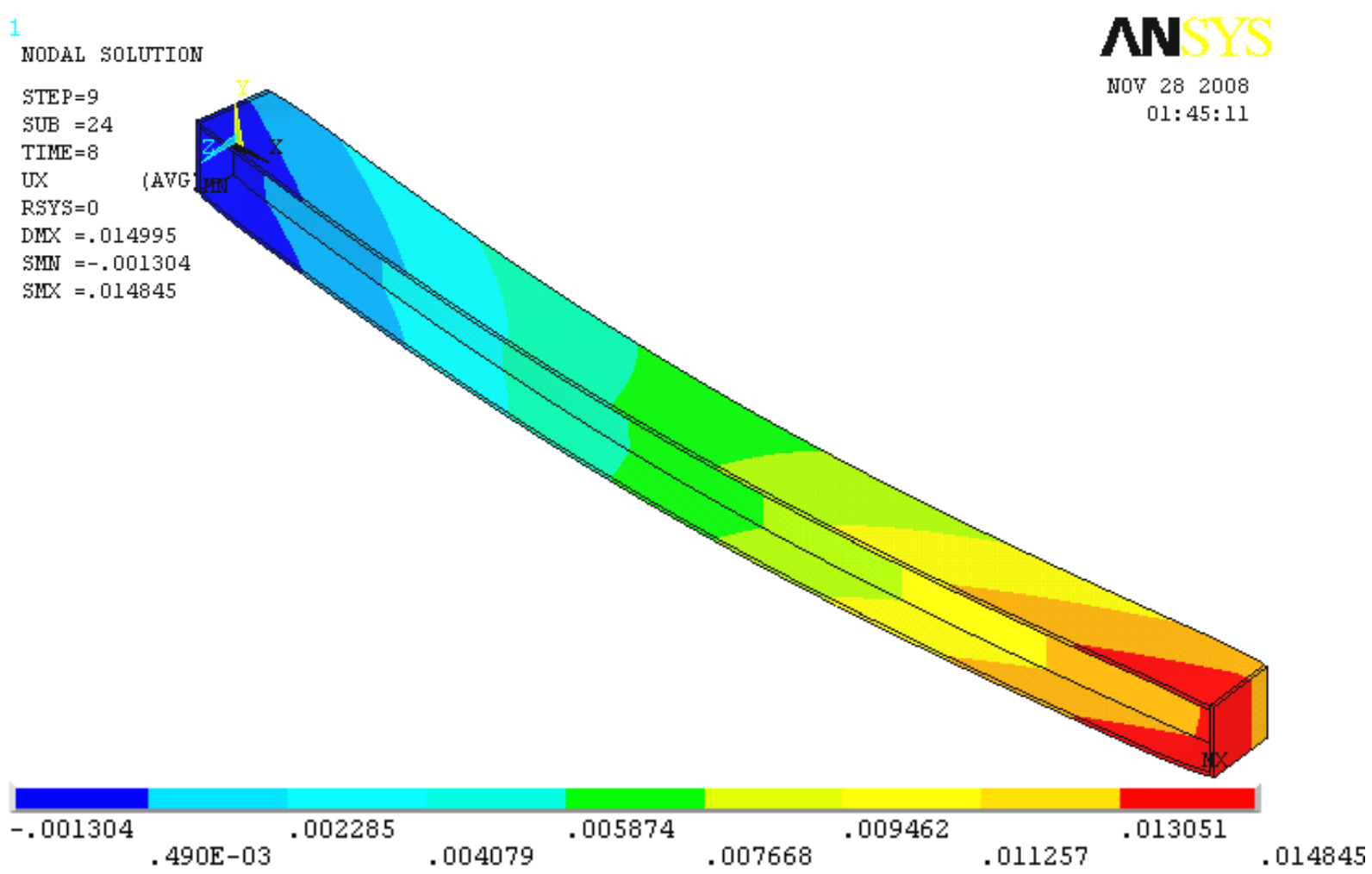

Figura 7.4: Deslocamento axial em situação de incêndio para uma força aplicada igual 727,7 $\mathrm{kN}$, para TRF igual a 8 minutos.

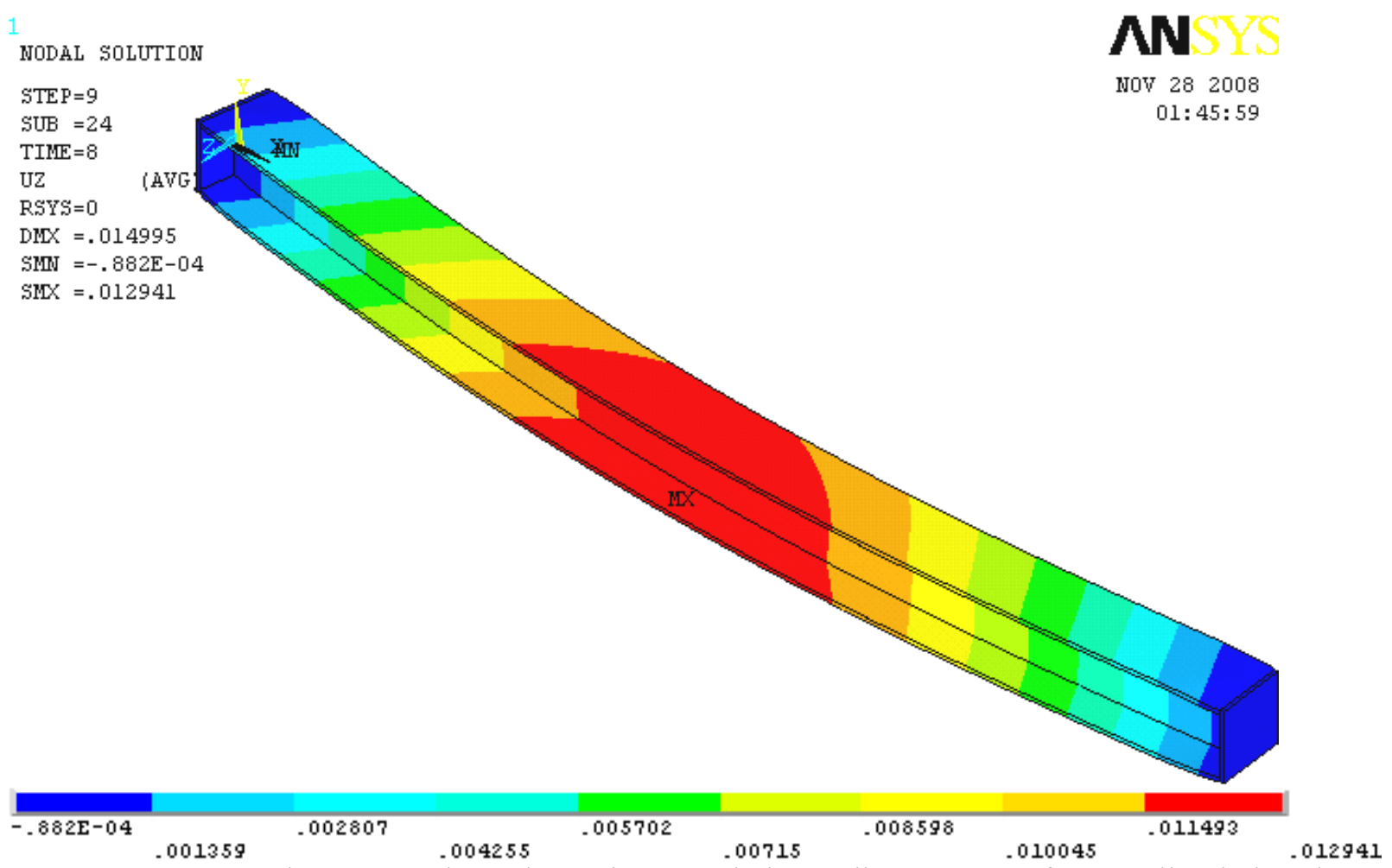

Figura 7.5: Deslocamento lateral em situação de incêndio para uma força aplicada igual $727,7 \mathrm{kN}$, para TRF igual a 8 minutos. 


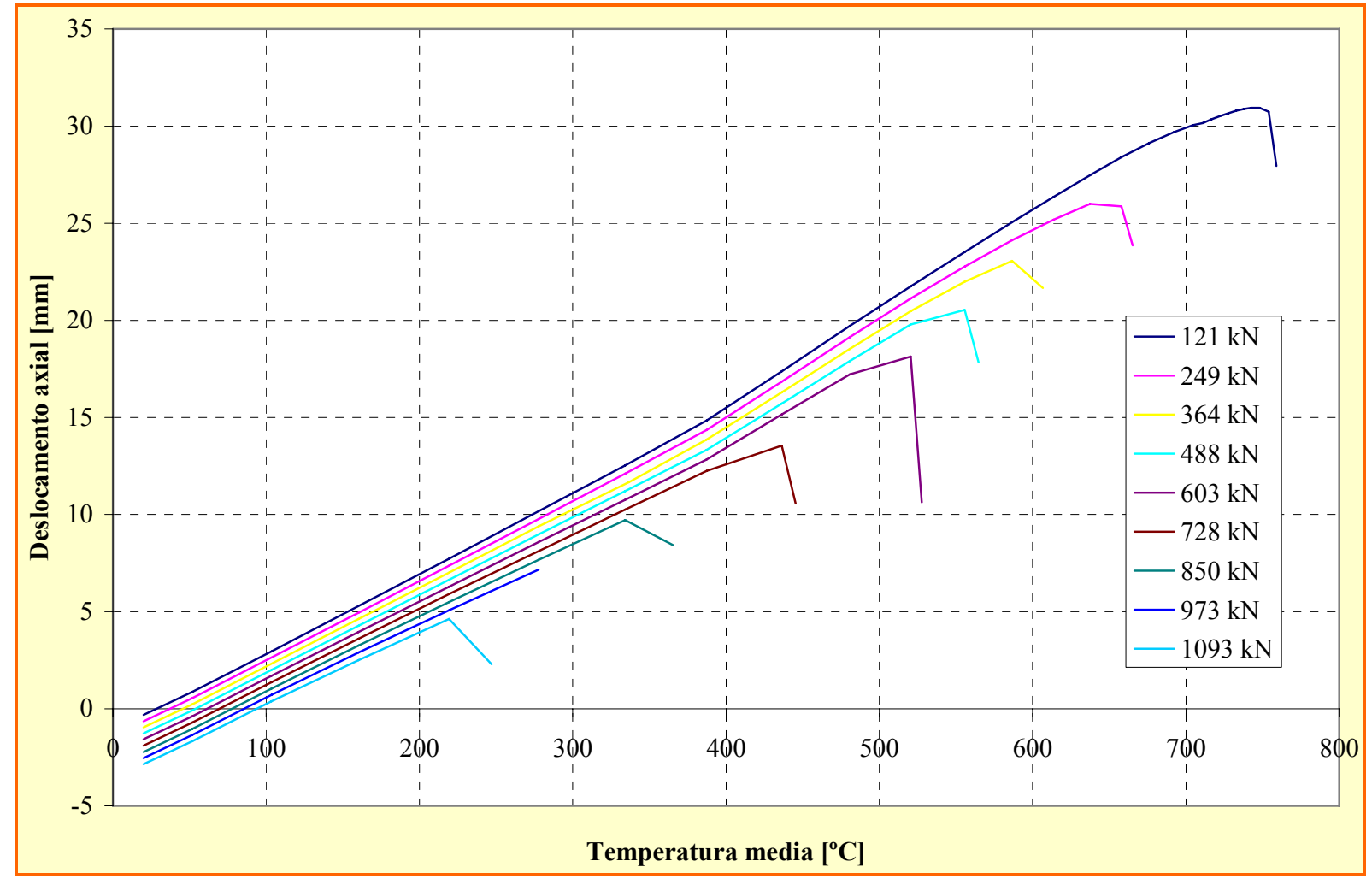

Figura 7.6: Gráfico Deslocamento axial $[\mathrm{mm}] \mathrm{x}$ temperatura média $\left[{ }^{\circ} \mathrm{C}\right]$ para os níveis de força aplicados correspondentes de $10 \%$ a $90 \%$ da força de colapso.

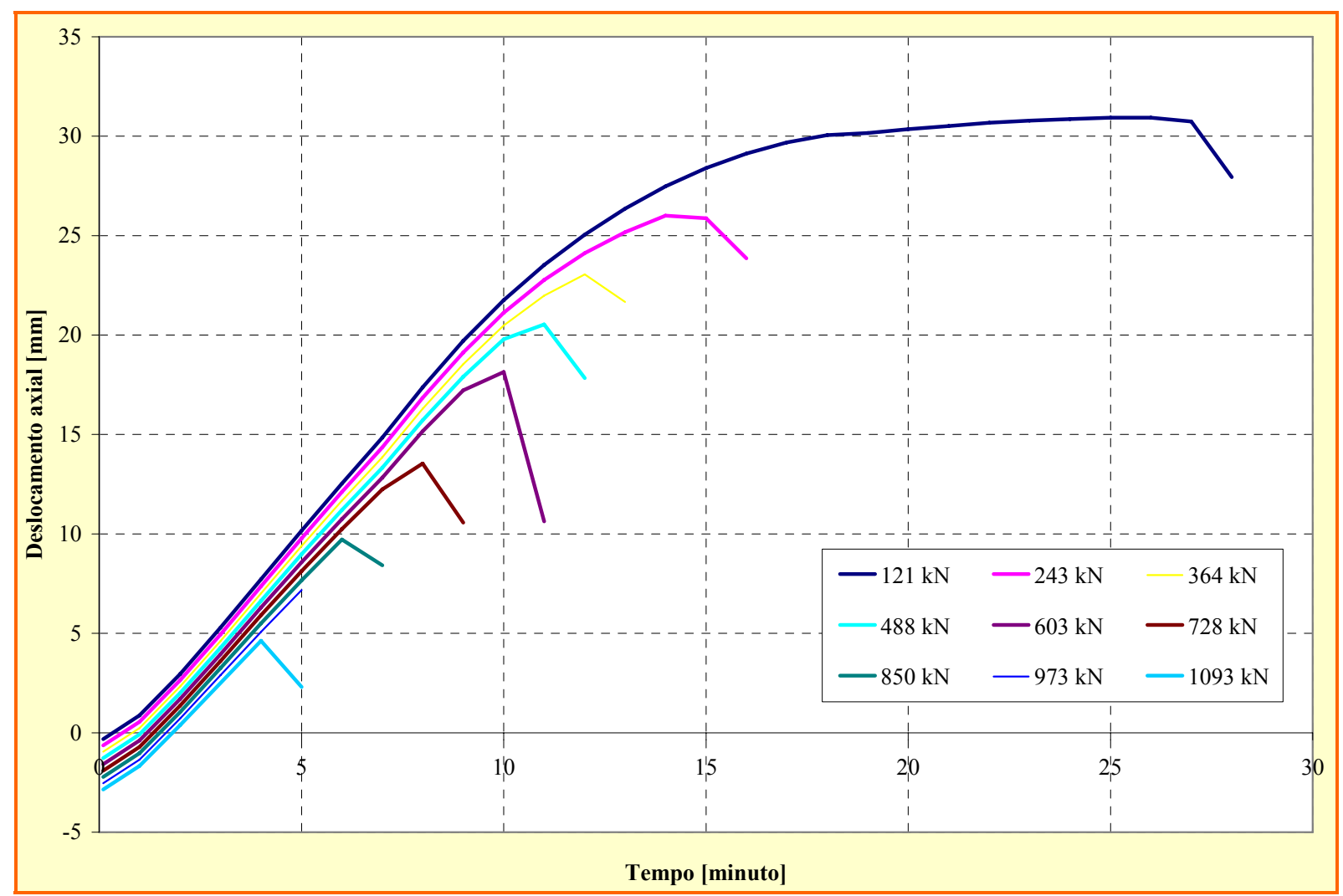

Figura 7.7: Gráfico Deslocamento axial [mm] x Tempo [minutos] para os níveis de força aplicados correspondentes de $10 \%$ a $90 \%$ da força de colapso. 


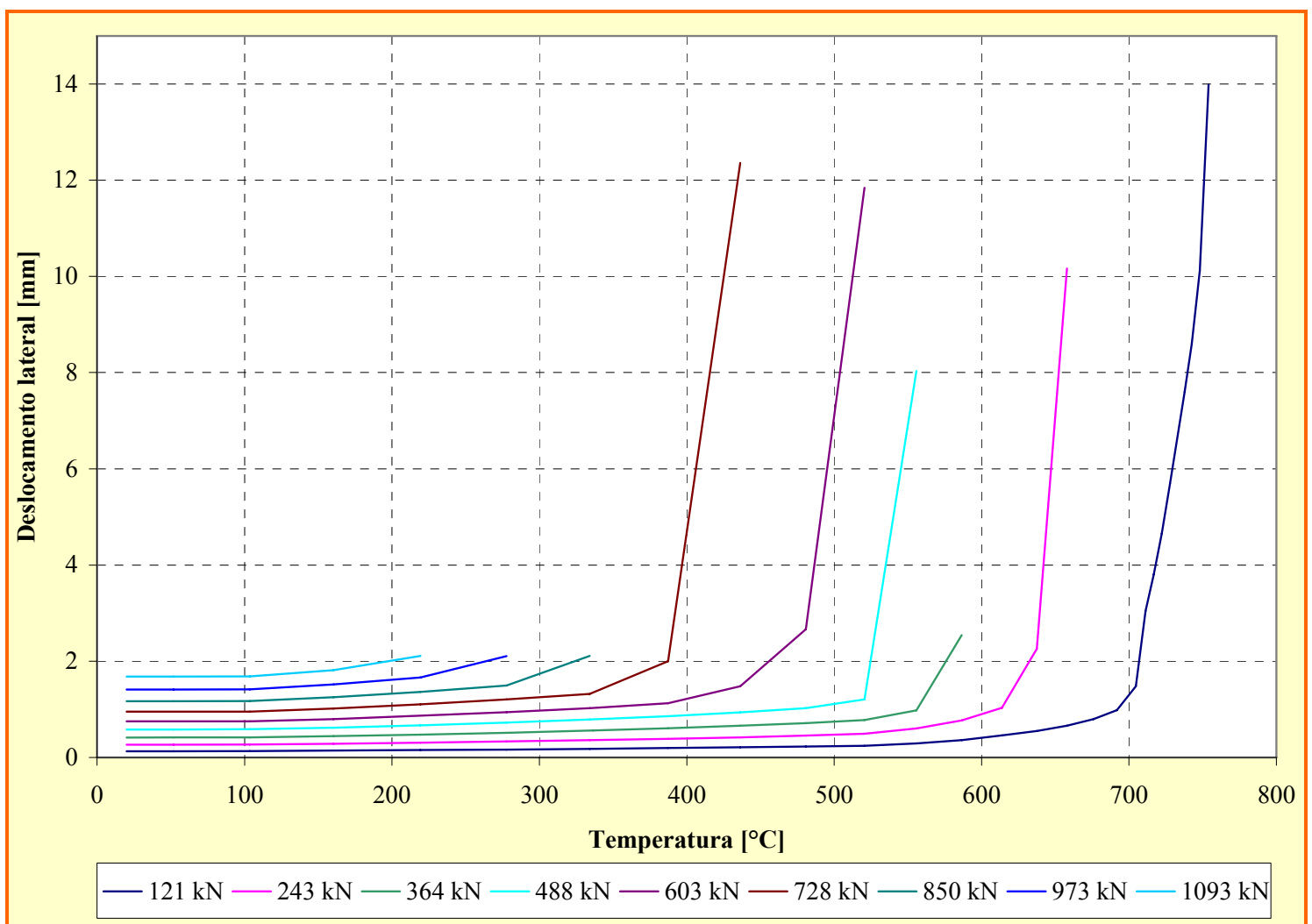

Figura 7.8: Gráfico Deslocamento lateral $[\mathrm{mm}] \mathrm{x}$ temperatura média $\left[{ }^{\circ} \mathrm{C}\right]$ para os níveis de força aplicados correspondentes de $10 \%$ a $90 \%$ da força de colapso.

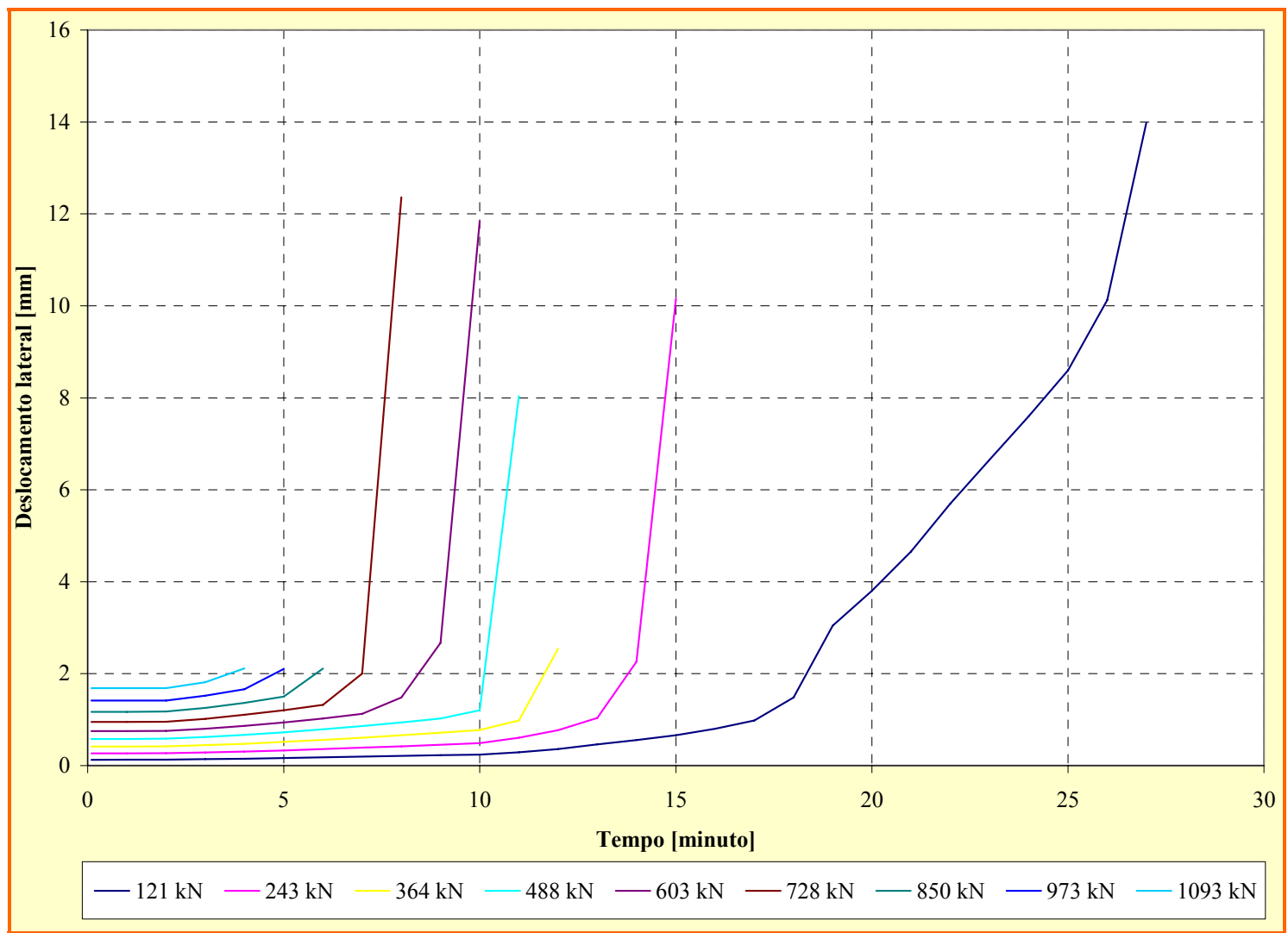

Figura 7.9: Gráfico Deslocamento lateral [mm] x TRF [minutos] para os níveis de força aplicados correspondentes de $10 \%$ a $90 \%$ da força de colapso. 


\subsubsection{RESULTADOS EXPERIMENTAIS - WANG E DAVIES (2003)}

Em concordância com o esquema apresentado na Figura 7.3, a Figura 7.10 apresenta resultados de deslocamentos axiais obtidos por análise experimental apresentada em WANG e DAVIES (2003). As quatro curvas são referentes a quatro pilares submetidos a uma força equivalente a $30 \%$ da força de colapso em temperatura ambiente. Tais pilares possuem duas vigas de reação conectadas a uma das extremidades com a finalidade de se introduzir força excêntrica de compressão e, consequentemente, momento fletor no pilar.

A construção dos modelos experimentais levou em conta a combinação de dois fatores: tipo de ligação viga/pilar (rígida ou flexível) e aplicação da força no sistema viga/pilar (em equilíbrio ou não). As curvas de 1 a 4 correspondem, respectivamente:

1- ligação viga/pilar do tipo flexível, com aplicação de forças excêntricas de igual intensidade, ou seja, momento fletor nulo no topo do pilar;

2- ligação viga/pilar do tipo flexível, com aplicação de forças excêntricas de diferentes intensidades, ou seja, momento fletor diferente de zero no topo do pilar;

3- ligação viga/pilar do tipo rígida, com aplicação de forças excêntricas de igual intensidade, ou seja, momento fletor nulo no topo do pilar;

4- ligação viga/pilar do tipo rígida, com aplicação de forças excêntricas de diferentes intensidades, ou seja, momento fletor diferente de zero no topo do pilar;

Comparando as quatro curvas do programa experimental, é possível fazer algumas observações. Ligações viga/pilar do tipo flexível provocam restrição axial inferior se comparadas às ligações do tipo rígida. Em ligações rígidas, a restrição axial faz com que o pilar atinja o colapso em temperaturas (TRF) reduzidas se comparada à restrição imposta pelas ligações flexíveis.

As forças, quando aplicadas em equilíbrio (situação de compressão simples), permitem maior deslocamento axial quando comparado ao pilar submetido à flexo-compressão (que se obtém com a situação não equilibrada). Na configuração não-equilibrada, como a das curvas 2 e 4, o pilar já apresenta uma posição deformada inicial. Quando em situação de incêndio, as deformações por dilatação térmica se somam as deformações iniciais e o pilar, consequentemente, tende a apresentar a configuração de colapso para um valor mais baixo de TRF. 
Ainda, de acordo com a referência em questão, o coeficiente de flambagem do pilar, quando nos níveis mais baixos de temperatura, se manteve próximo à unidade. À medida que o pilar se aproximava da situação crítica de incêndio, o coeficiente de flambagem se aproximou da condição correspondente a de apoio fixo na base e apoio engastado no topo.

Em caráter comparativo, foi realizada uma análise numérica do pilar submetido à mesma condição de aquecimento (simétrico e que obedece a curva de incêndio-padrão da ISO834), considerando o $\mathrm{K}=1,0$ (comprimento efetivo de flambagem igual ao comprimento real) e $\mathrm{K}=0,775$ (conforme valor tabelado na referência). Apenas a situação equilibrada foi reproduzida numericamente. Ambas as curvas foram comparadas na mesma figura 7.10. Para reproduzir o comportamento da primeira curva do modelo experimental, ou seja, compressão com ausência da restrição axial, mostrou-se mais adequado o uso do coeficiente de flambagem determinado para níveis mais baixos de temperatura, neste caso, igual à unidade. Dessa forma tem-se $\mathrm{L}_{\mathrm{ef}}=\mathrm{L}$.

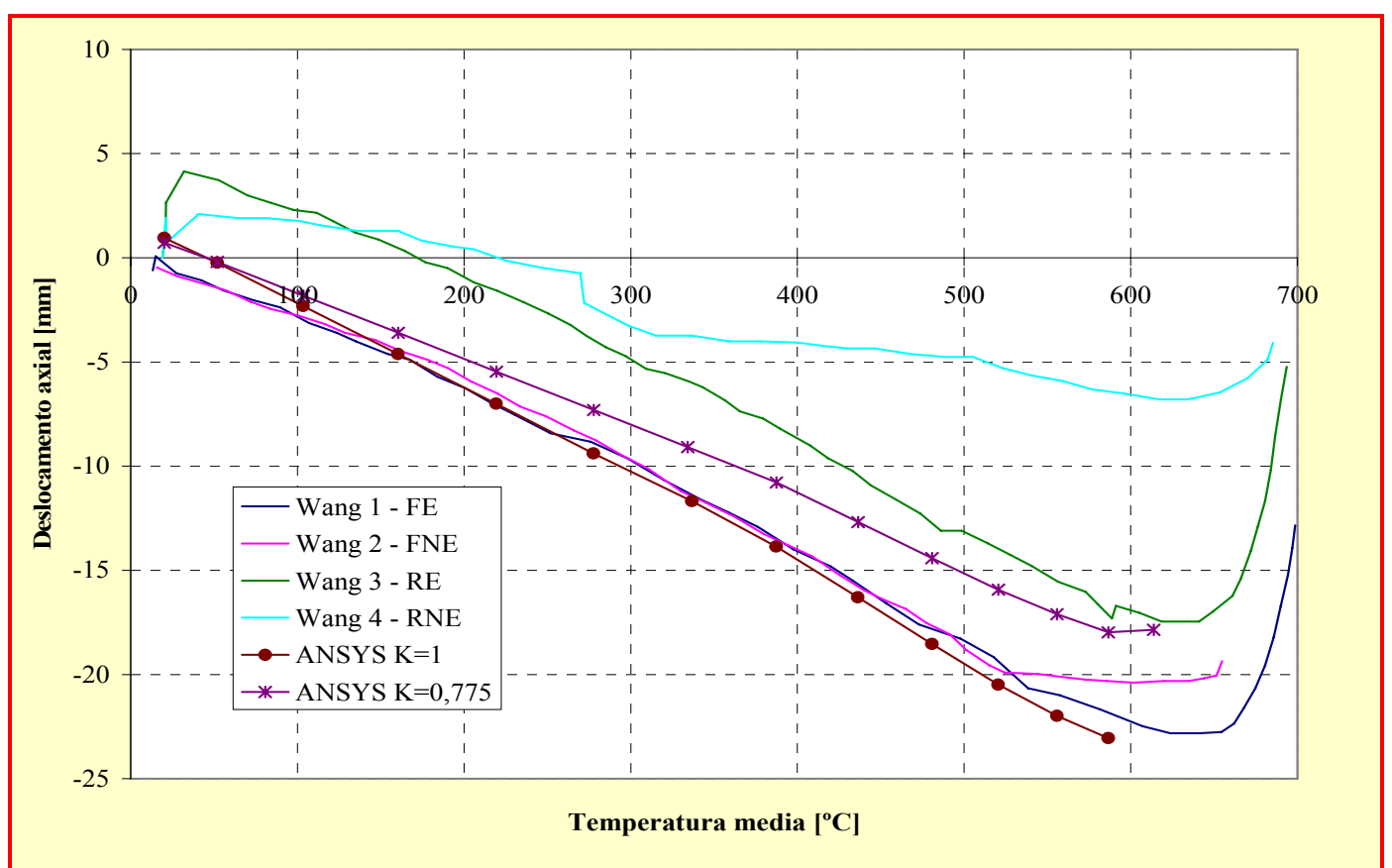

Figura 7.10: Gráfico Deslocamento axial $[\mathrm{mm}] \times$ Temperatura $\left[{ }^{\circ} \mathrm{C}\right]$ para força aplicada correspondente a $30 \%$ da força de colapso: comparação entre experimental e numérico.

Para maiores valores de força estática, como ilustra a Figura 7.11, a resposta da simulação numérica para ambos os comprimentos de flambagem analisados resultaram de forma bastante semelhante. Porém, a análise numérica não permite avançar até o comportamento pós-crítico devido o surgimento de distorções excessivas apresentadas em alguns elementos finitos em estágios iniciais. 
A comparação com o deslocamento lateral tomando a mesma condição de esforços e vinculação (neste caso compressão simples e sem restrição axial no topo) torna-se complexa em decorrência de fatores a exemplo da imperfeição geométrica. Como a referência em questão não cita os modos e o valor da imperfeição geométrica inicial, a análise numérica apresentada no presente trabalho arbitrou o valor de L/1000 para o modo global e desconsiderou o modo local. A Figura 7.12 ilustra a variação do deslocamento lateral relatado na referência citada e os valores obtidos pelo ANSYS.

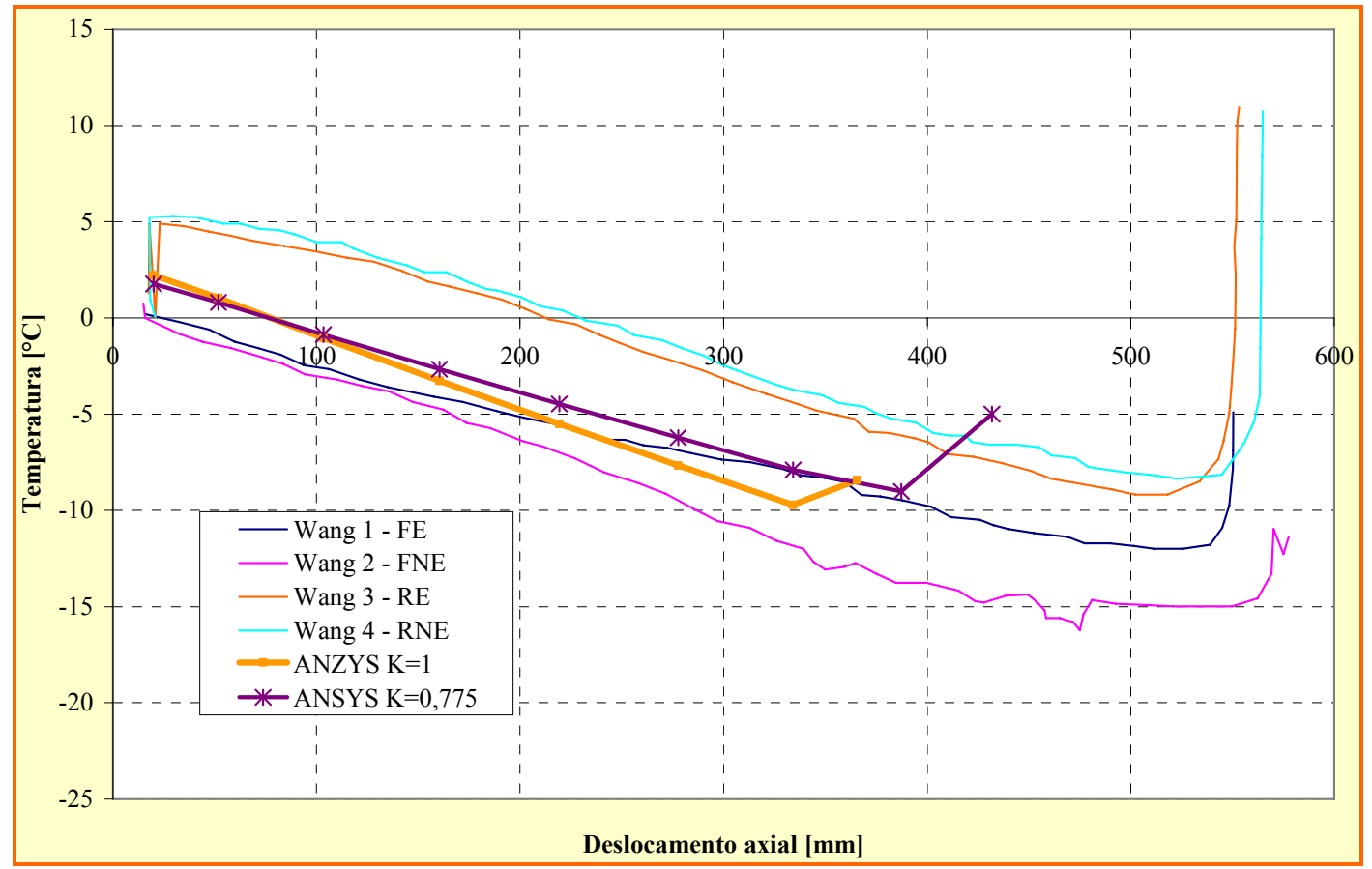

Figura 7.11: Gráfico Deslocamento axial $[\mathrm{mm}] \times$ Temperatura $\left[{ }^{\circ} \mathrm{C}\right]$ para força aplicada correspondente a $70 \%$ da força de colapso: comparação entre experimental e numérico.

A Figura 7.13 ilustra a variação da força de colapso em função do TRF. No gráfico da referida figura, a curva "Força $x$ Tempo" obtida numericamente foi confrontada com as mesmas curvas obtidas analiticamente pelo método simplificado da ABNT NBR 14323:1999 e do EC 3 - 1.2, com a força expressa em termos de valores característicos. No mesmo gráfico observa-se que a norma brasileira é mais conservadora. Porém, a pequena diferença entre os resultados apresentados por ambos os procedimentos normativos tende a reduzir com o TRF (o que implica no aumento da temperatura).

A Figura 7.14 ilustra as curvas dos fatores de redução obtidas para o perfil isolado, por meio do ANSYS e dos métodos simplificados da ABNT NBR14323:1999 e EC 3-1.2, além da curva fornecida pelo código TEMPERATURE CALCULATION AND DESIGN (TCD). Ressalta-se aqui que o método de cálculo de resistência a compressão do TCD foi 
formulado com base na norma européia Eurocode 4 part 1.2 (ENV1994 1-2), que é destinada a elementos mistos de aço e concreto, não aplicada, usualmente aos perfis puramente de aço.

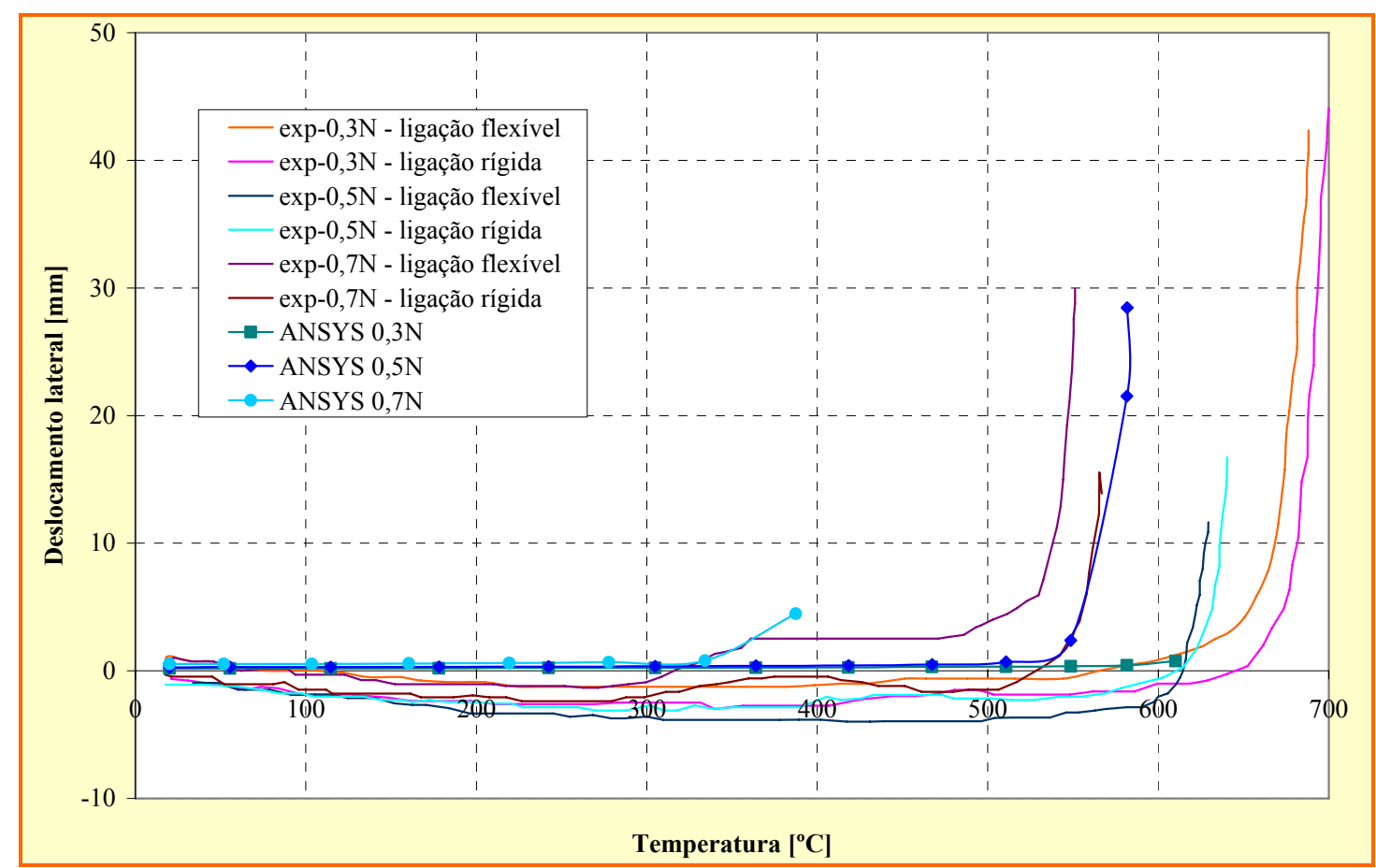

Figura 7.12: Gráfico Deslocamento lateral $[\mathrm{mm}] \mathrm{x}$ Temperatura $\left[{ }^{\circ} \mathrm{C}\right]$ para força aplicada correspondente a $30 \%, 50 \%$ e $70 \%$ da força de colapso: comparação entre experimental e numérico.

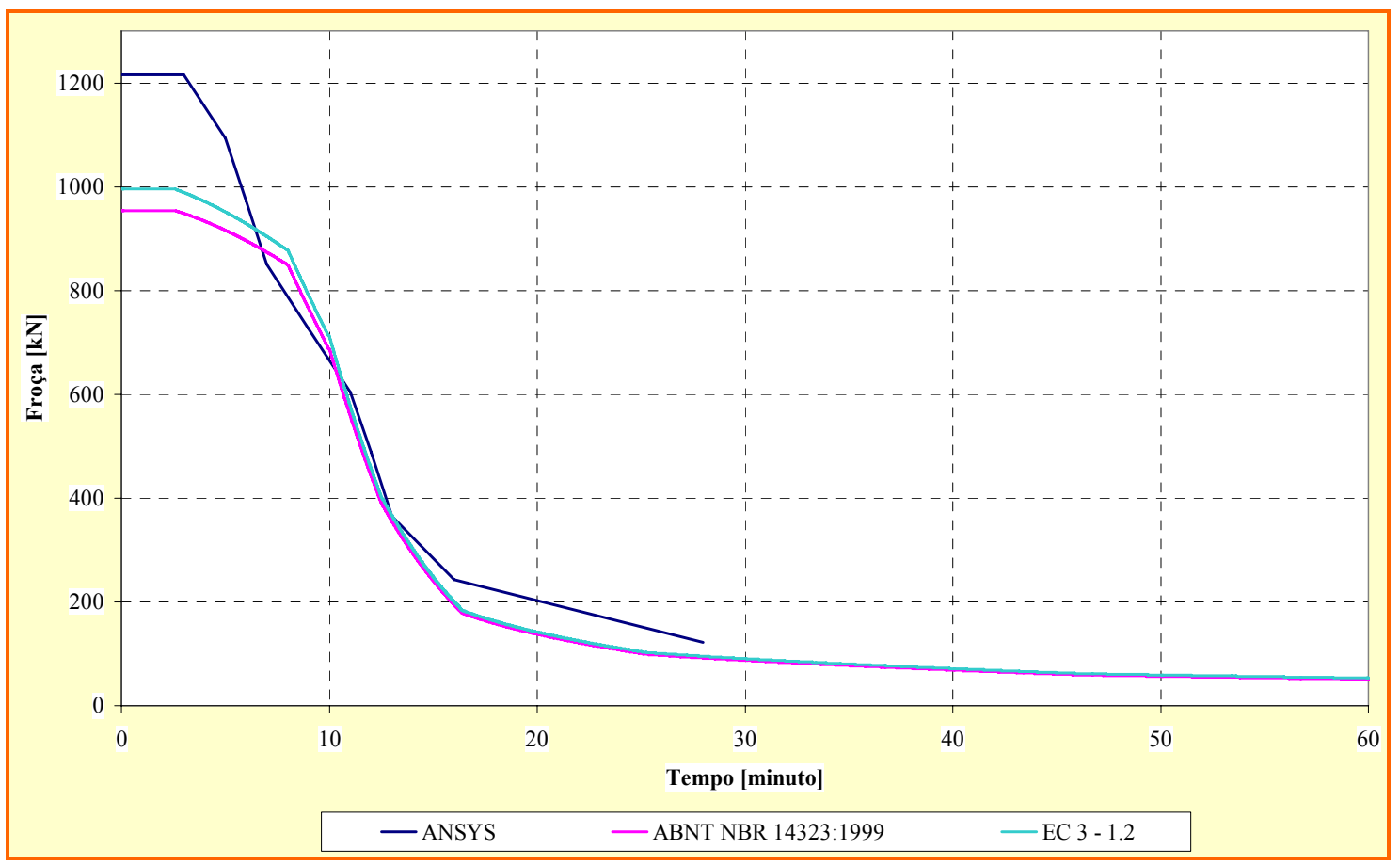

Figura 7.13: Variação da força de colapso [kN] em função do tempo (TRF) [minuto] obtido pelo ANSYS e por meio dos métodos simplificados da ABNT NBR 14323:1999 e do EC 31.2 . 


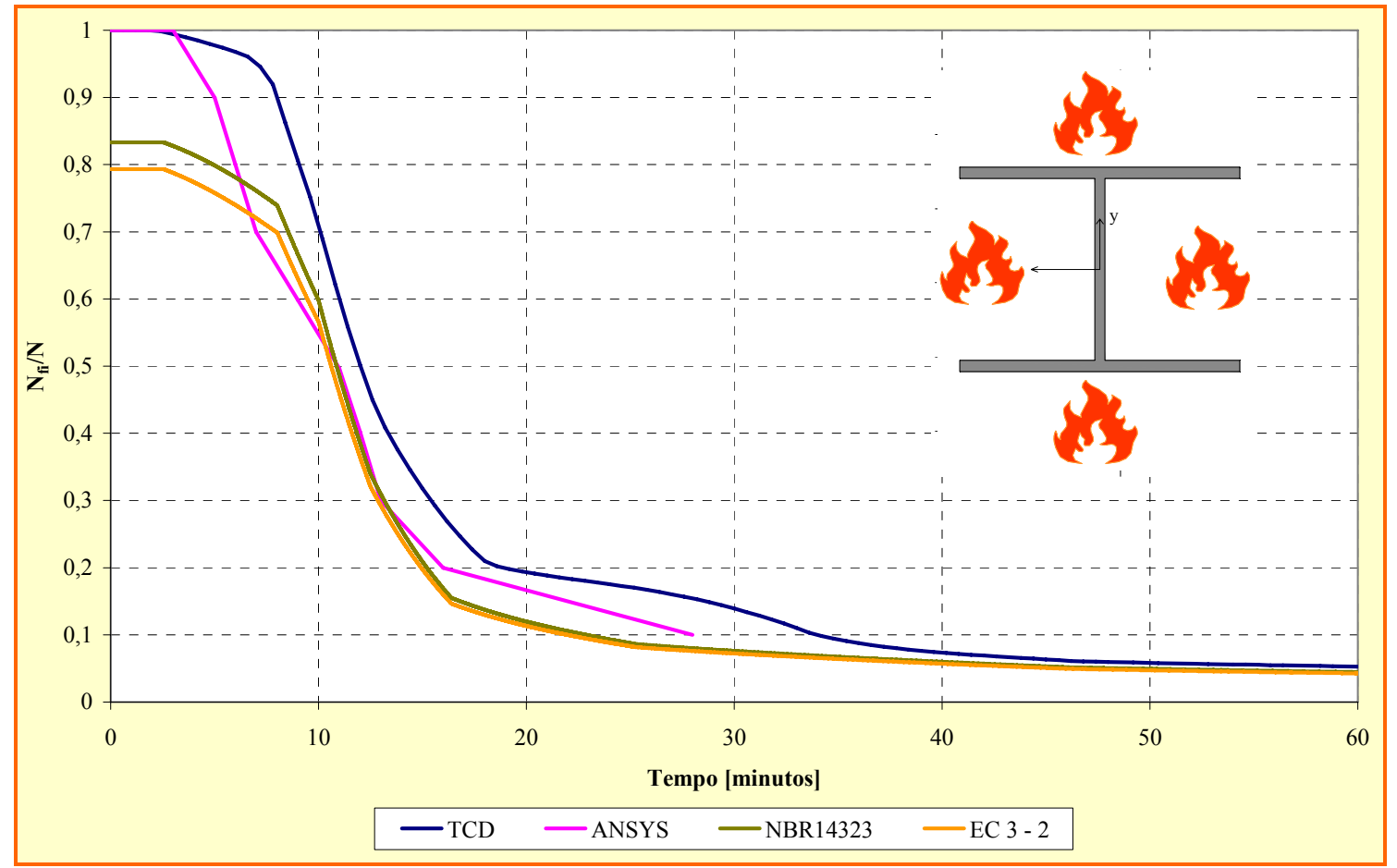

Figura 7.14: Fator de redução para a força axial de colapso em relação ao TRF, obtido pelo ANSYS, TCD e pelo método simplificado da ANBT-NBR14323.

\subsubsection{RESULTADOS NUMÉRICOS - Com elemento finito SHELL 181}

No presente item, se faz para o elemento SHELL 181 procedimento análogo aquele apresentado para o elemento SOLID 45, com vistas a comparar a eficiência entre ambos os elementos adotados, conforme Figuras 7.15 a 7.17.

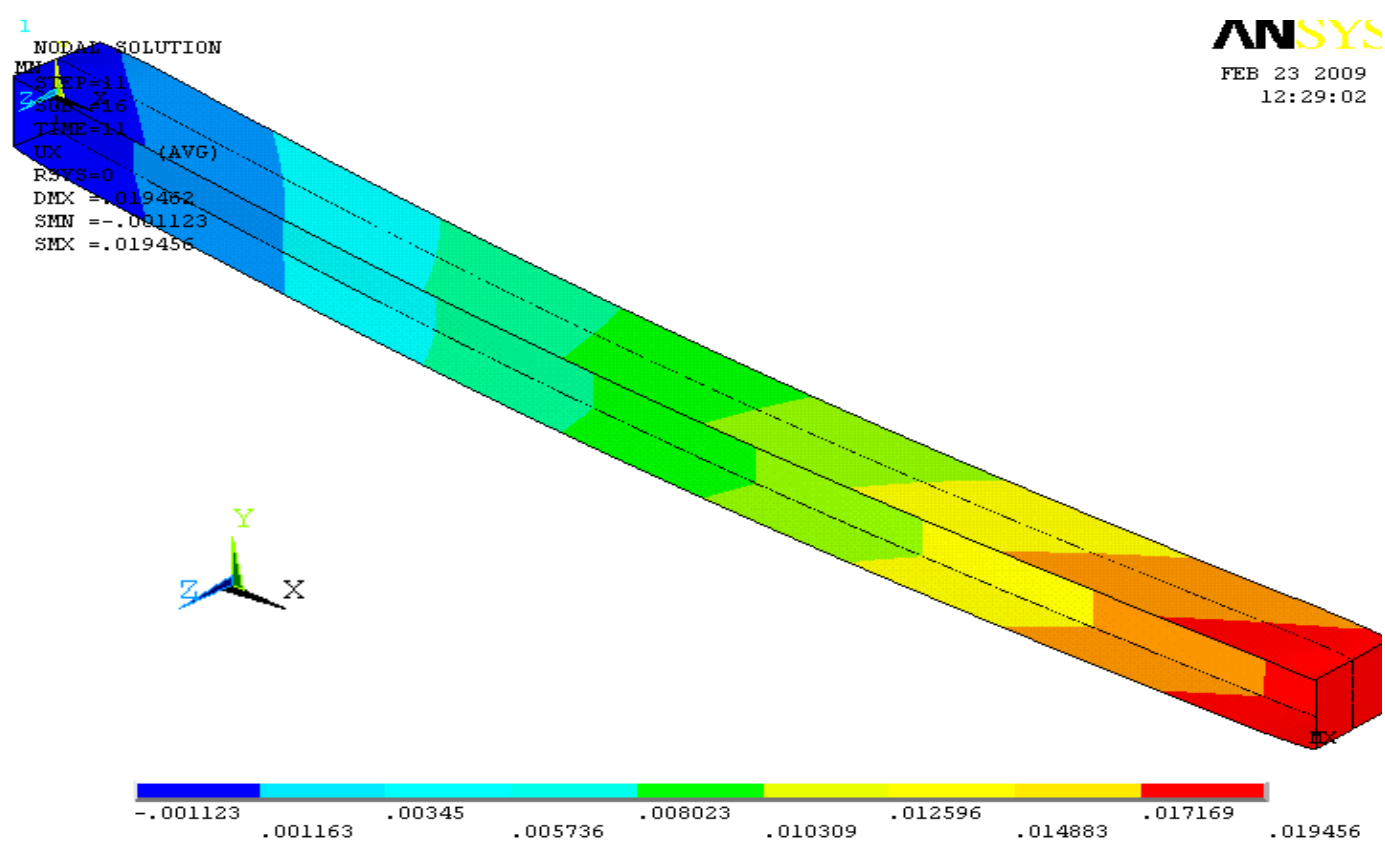

Figura 7.15: Configuração deformada em relação x para força externa aplicada igual a $0,5 \mathrm{~N}_{\mathrm{p} l}$, e TRF igual a 10 minutos. 


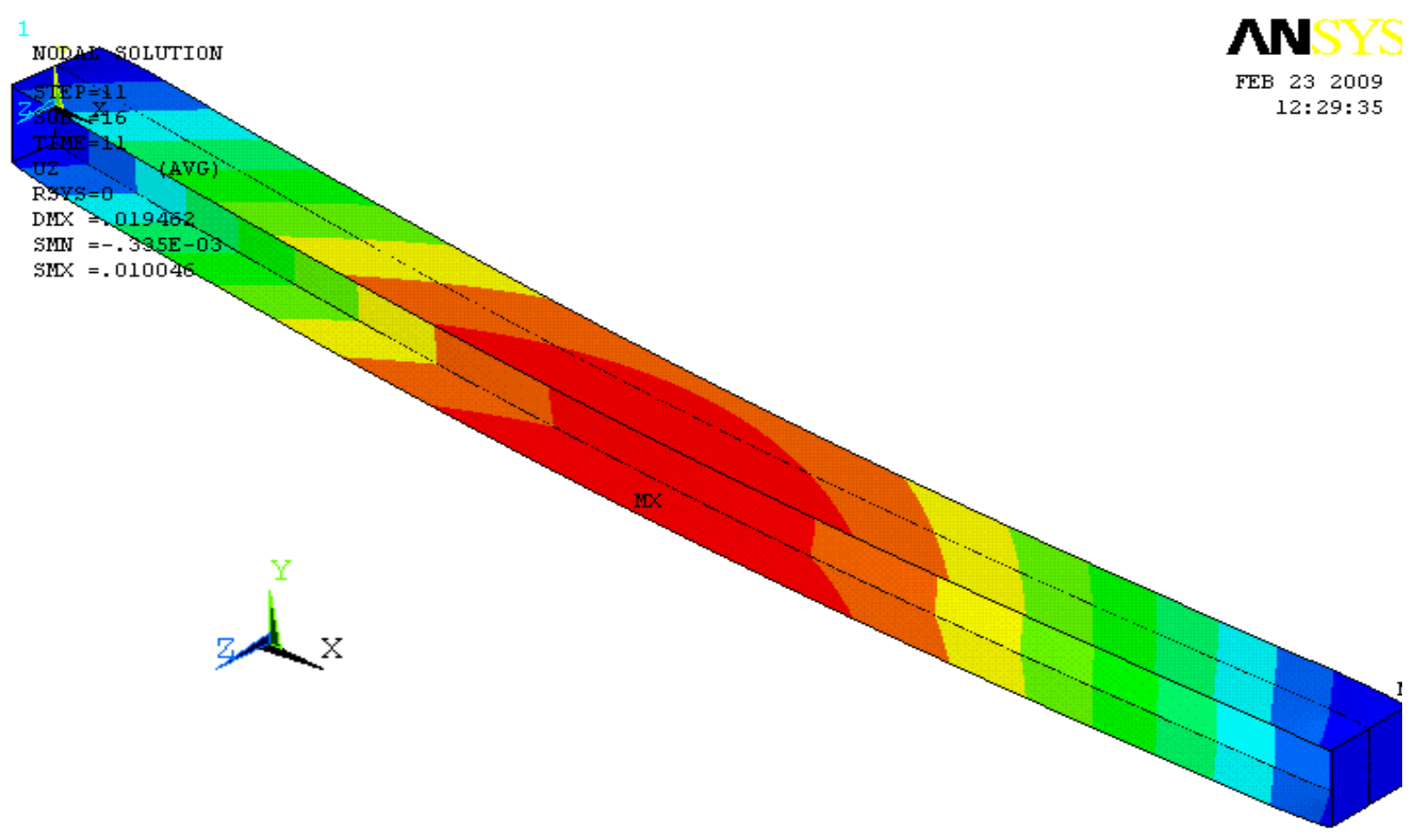

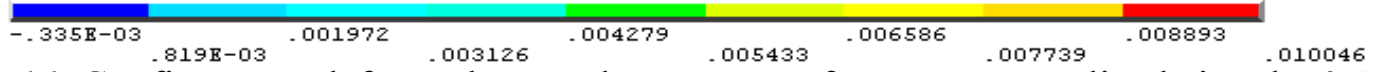

Figura 7.16: Configuração deformada em relação $\mathrm{z}$ para força externa aplicada igual a $0,5 \mathrm{~N}$, e TRF igual a 10 minutos.

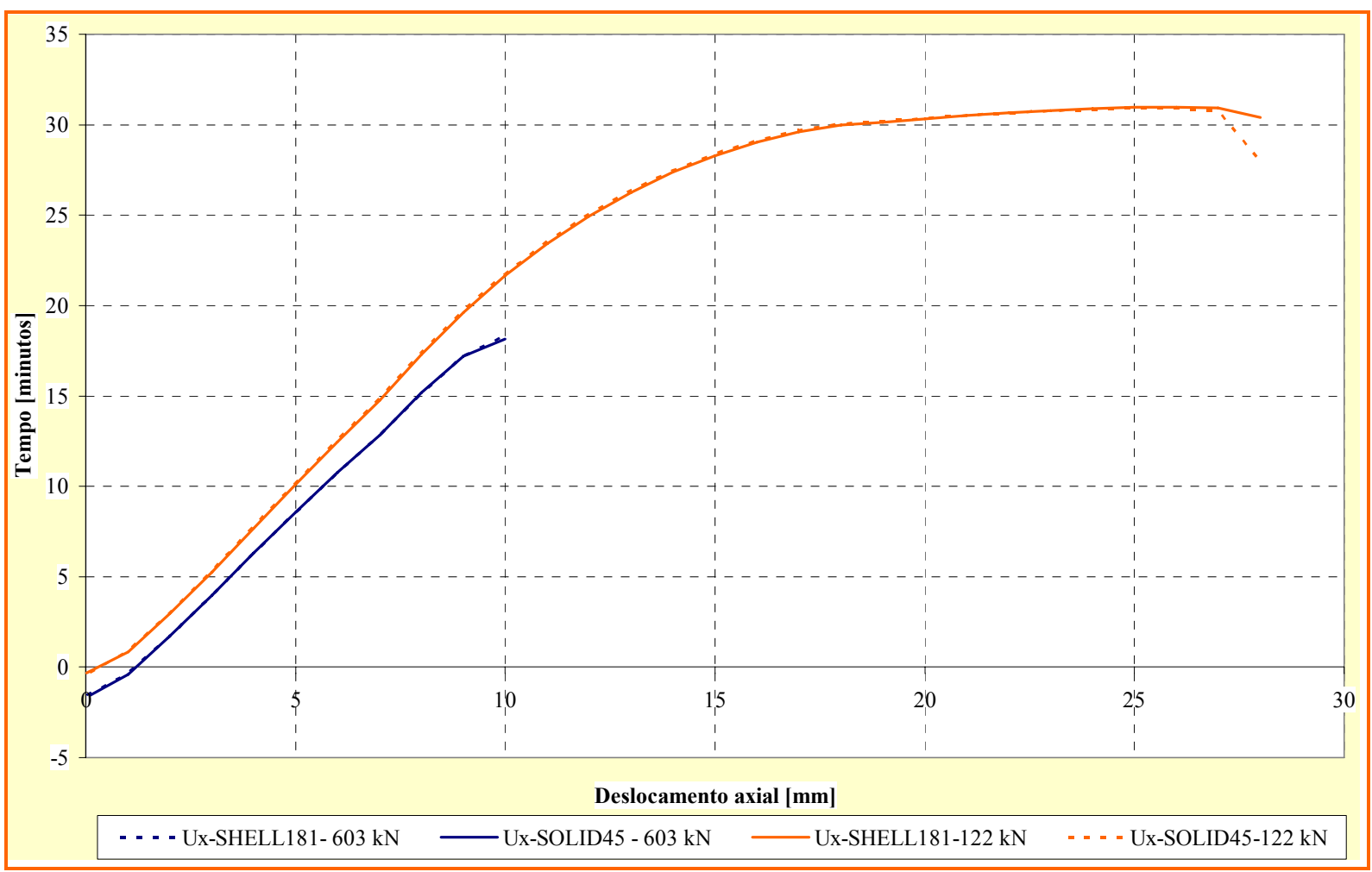

Figura 7.17: Comparação entre as respostas obtidas em relação ao deslocamento axial utilizando os elementos SHELL181 e SOLID45, para uma força aplicada de 603,303 kN.

É importante destacar novamente que a situação analisada ao longo do item 7.3 se caracteriza pela simetria do campo térmico em todas as direções e, consequentemente, como 
já esperado, os esforços internos (campo de deformações) somados a estrutura, provocados pelo aumento de temperatura, resultam uniformes em relação à seção transversal.

Neste caso, observando a concordância entre ambas as trajetórias de deslocamento axial, não houve discordância na comparação das respostas obtidas utilizando elemento SOLID45 ou elemento SHELL181. É válido afirmar que, para pilares isolados, no que tange a minimização de esforços computacionais, o uso do elemento SHELL181 mostra-se mais vantajoso.

\subsection{PILAR DE BORDA - Paredes na alma e em uma das mesas}

A temperatura e o deslocamento lateral no pilar foram medidos em determinados pontos, conforme ilustrados na Figura 7.18. O aquecimento ainda é admitido uniforme ao longo do comprimento, e o campo de temperatura não depende do valor de x (eixo do pilar).

\begin{tabular}{|c|c|c|c|c|}
\hline Nó & $\mathrm{X}$ & $\bar{Y}$ & $Z$ & \\
\hline 1 & 1,5900 & $-0,1016$ & $-0,1018$ & \multirow{6}{*}{ Mesa } \\
\hline 2 & 1,5900 & $-0,1016$ & $-0,0450$ & \\
\hline 3 & 1,5900 & $-0,1016$ & 0,0450 & \\
\hline 4 & 1,5900 & $-0,1016$ & 0,1018 & \\
\hline 5 & 1,5900 & 0,1016 & $-0,1018$ & \\
\hline 6 & 1,5900 & 0,1016 & 0,1018 & \\
\hline 7 & 1,5900 & $-0,0700$ & 0,0000 & \multirow{3}{*}{ Alma } \\
\hline 8 & 1,5900 & 0,0000 & 0,0000 & \\
\hline 9 & 1,5900 & 0,0700 & 0,0000 & \\
\hline
\end{tabular}

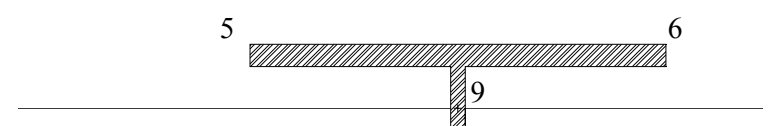

Figura 7.18: Nós em que foram medidos os deslocamentos laterais e a temperatura em relação ao TRF para o pilar em contato com três paredes.

No que se segue, serão apresentados resultados de análises numéricas realizadas com referência à situação apresentada na figura 7.18, considerando os elementos SOLID 45 e SHELL 181, conforme sub-ítens 7.4.1 e 7.4.2, respectivamente, lembrando que neste caso, diferentemente daquele apresentado no item 7.3, a carga térmica não é aplicada em todos os lados da seção, considerando agora a influência da compartimentação do ambiente. 


\subsubsection{RESULTADOS NUMÉRICOS - Com elemento finito SOLID45}

As ilustrações 7.19 e 7.20 são referentes ao deslocamento axial e lateral, respectivamente da barra no tempo (TRF) correspondente ao colapso, quando solicitado por uma ação estática equivalente a $50 \%$ da força de ruptura em temperatura ambiente. As Figuras 7.21 a 7.22 ilustram a evolução dos deslocamentos axial e lateral em função do tempo.

As Figuras 7.23 e 7.24 ilustram a variação da força de colapso em função do tempo, em termos de valor absoluto e valor relativo, respectivamente. Percebe-se que o procedimento da ABNT NBR 14323:1999 resulta em valores característicos mais conservadores quando comparado ao EC 3 - 1.2. Essa diferença tende a reduzir com o aumento da temperatura. Diferentemente do exemplo anterior, em situações de campo térmico assimétrico (como ocorre neste e nos exemplos posteriores) é possível notar a divergência na resposta do TCD em relação às demais, que pode ser atribuída à consideração do EC 4 na sua formulação.

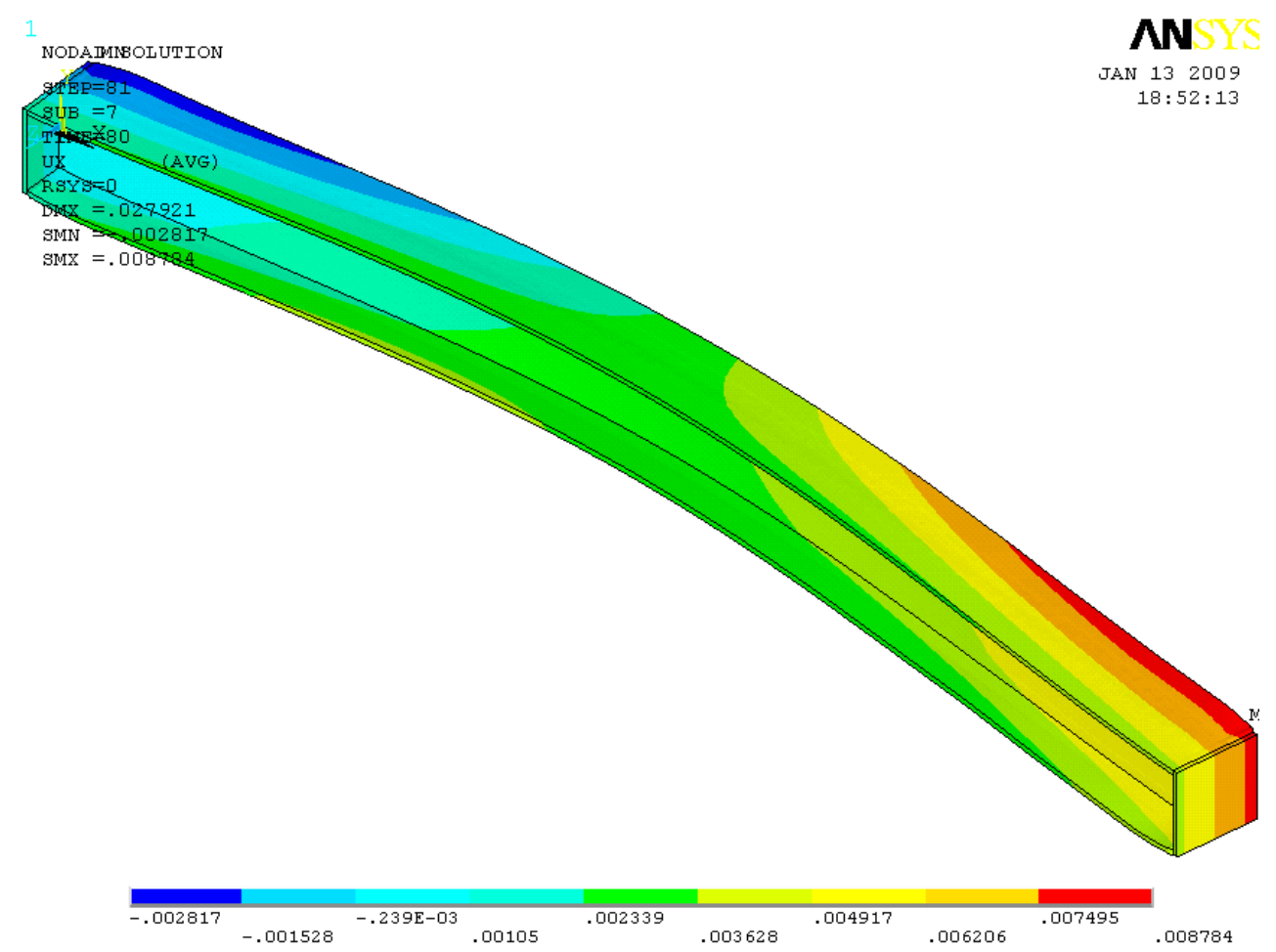

Figura 7.19: Deslocamento axial para uma força aplicada igual a $603,3 \mathrm{kN}$ para um TRF igual a 80 minutos. 


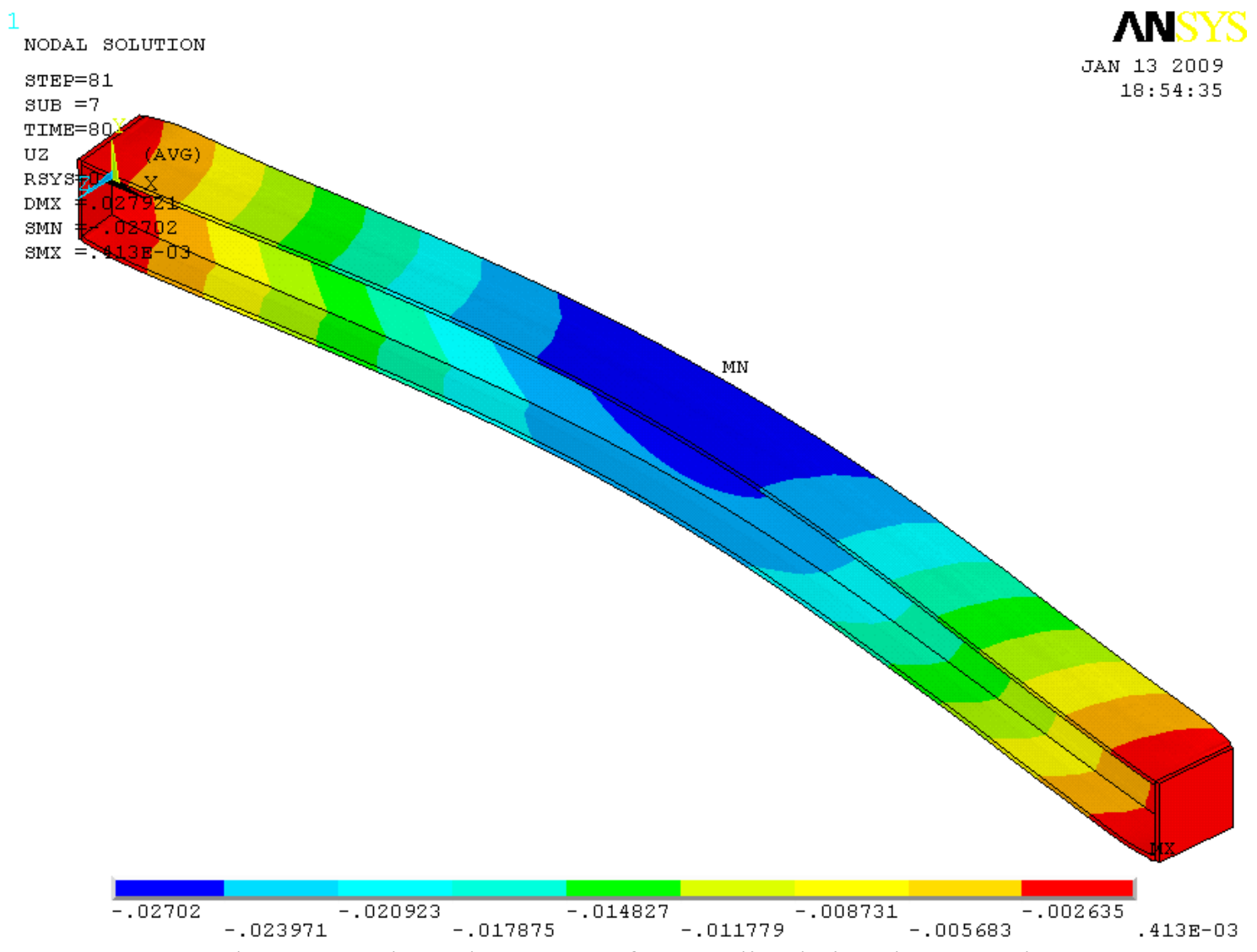

Figura 7.20: Deslocamento lateral para uma força aplicada igual a $603,3 \mathrm{kN}$ para um TRF igual ao tempo critico, ou seja, 80 minutos.

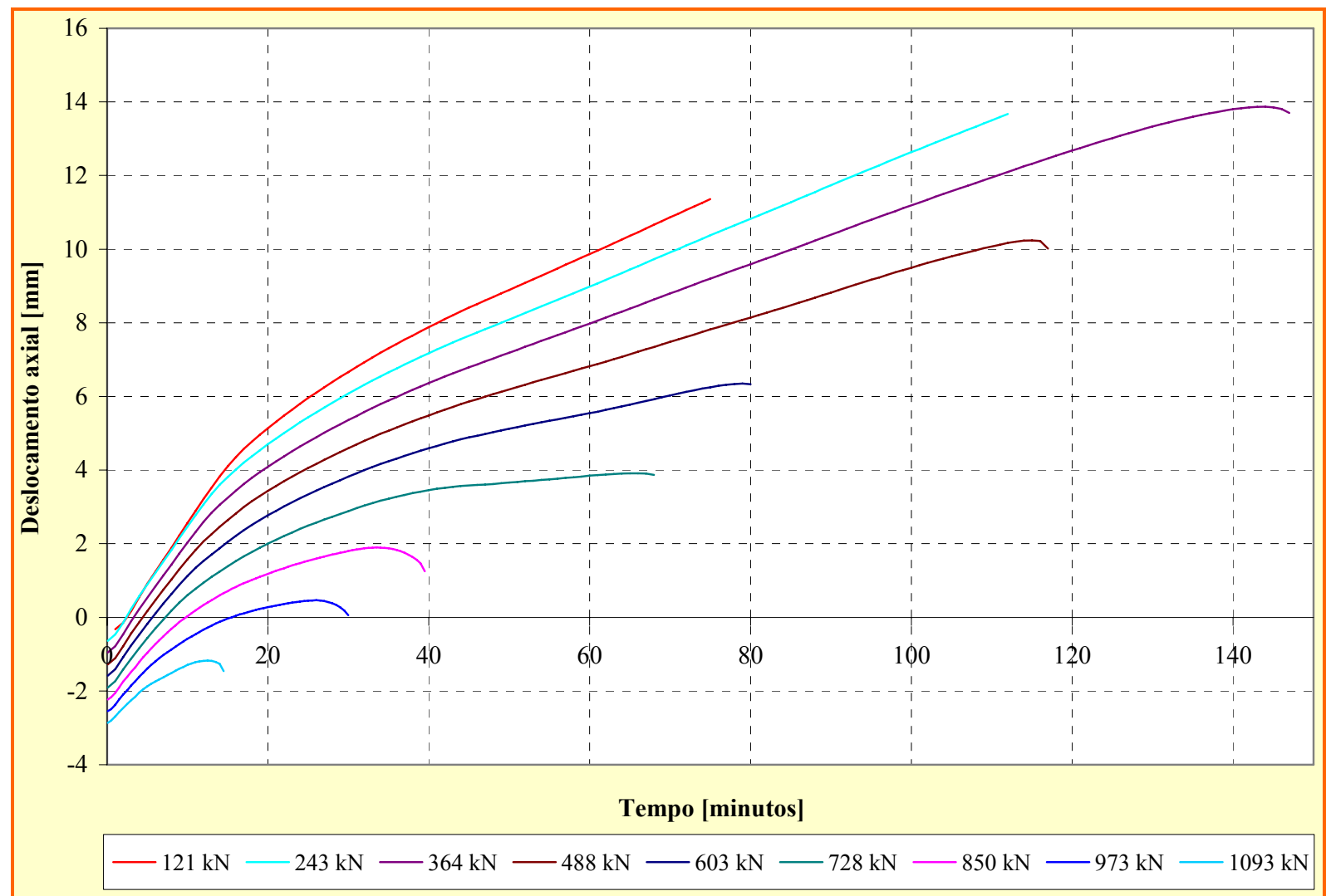

Figura 7.21: Deslocamento axial [mm] x TRF [minutos] para os níveis de força aplicados, variando de $10 \%$ a $90 \%$. 


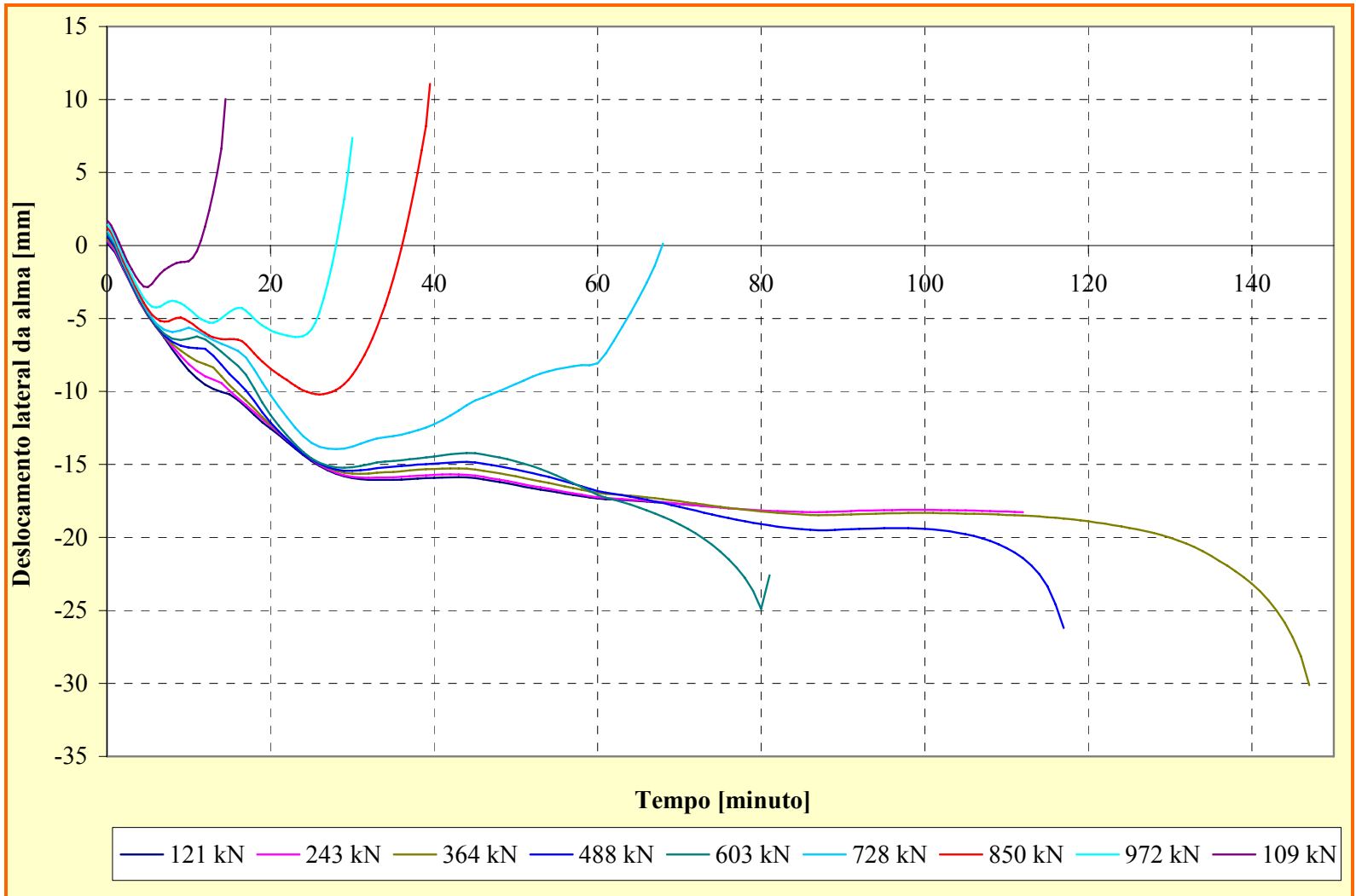

Figura 7.22: Deslocamento lateral [mm] x TRF [minutos] para os níveis de força aplicados variando entre $10 \%$ a $90 \%$.

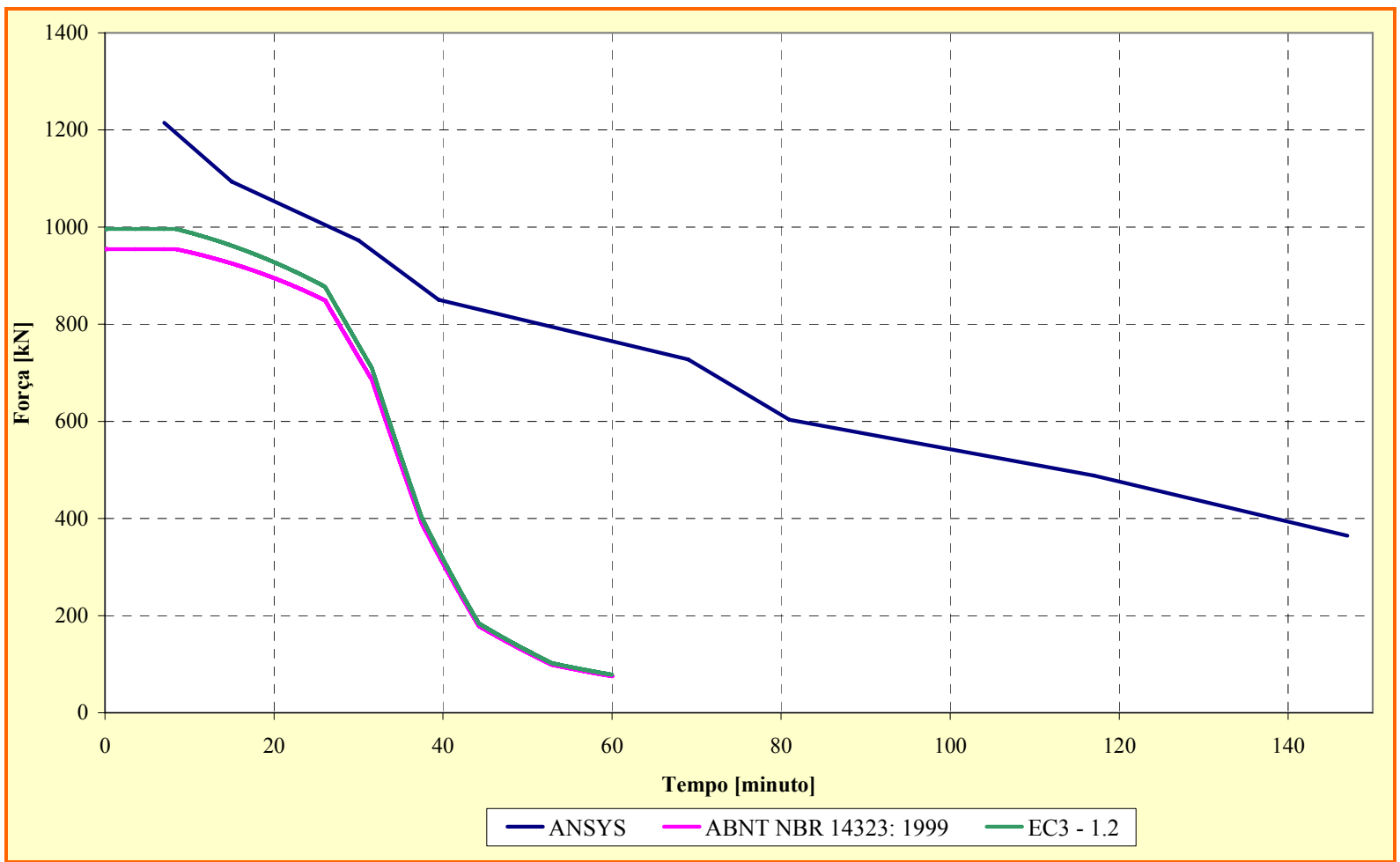

Figura 7.23: Variação da força de colapso [kN] em função do tempo (TRF) [minuto] obtido pelo ANSYS e por meio dos métodos simplificados da ABNT NBR 14323:1999 e do EC 3 1.2 . 


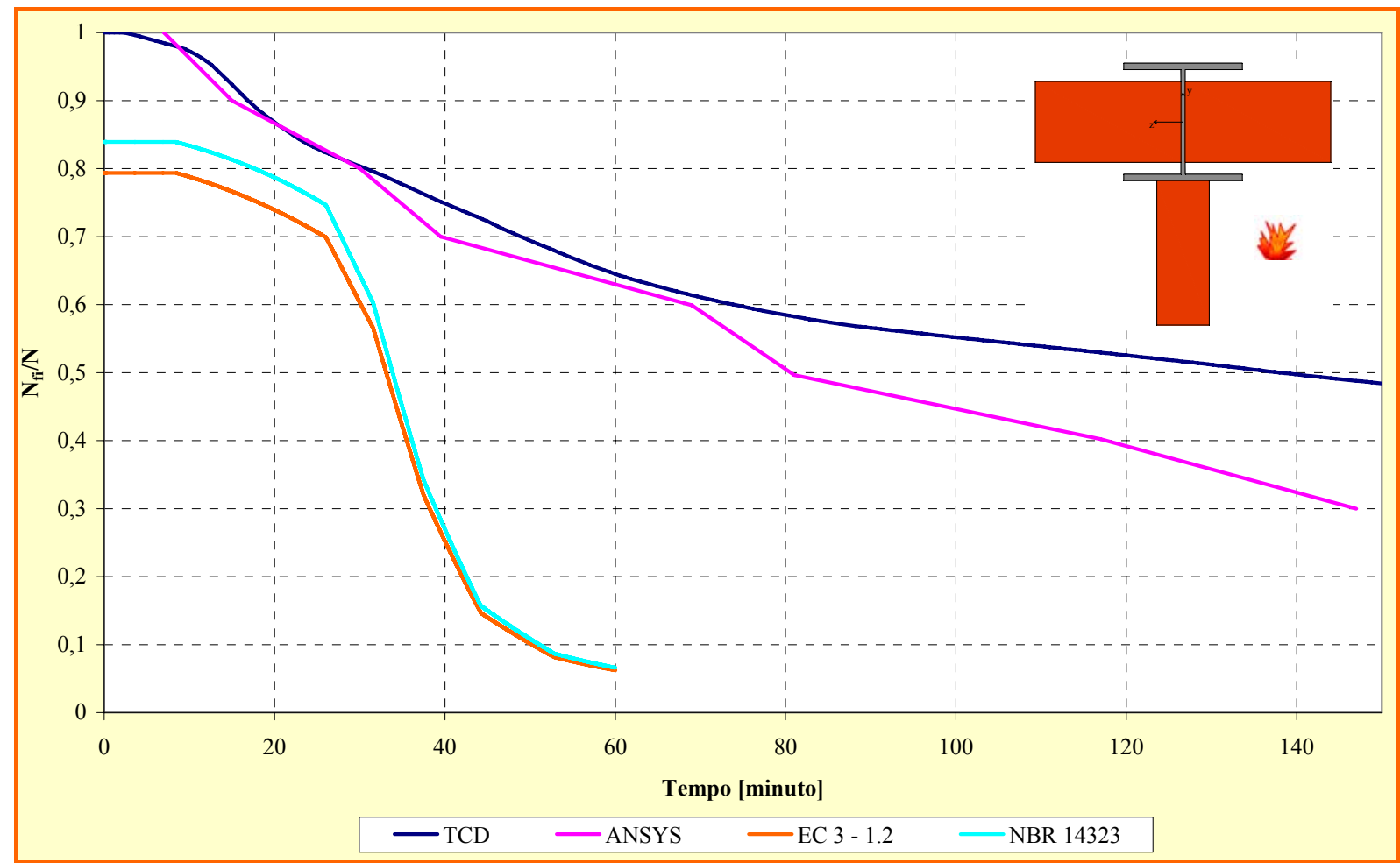

Figura 7.24: Comparativo entre o TCD e o ANSYS em relação ao fator de redução da força de colapso em relação ao TRF.

\subsubsection{RESULTADOS NUMÉRICOS-COm elemento SHELL181}

A título de comparação, o presente sub-item retoma a mesma análise exposta acima, porém, elaborada com o elemento finito SHEL181. A simulação numérica do comportamento estrutural foi realizada levando em consideração dois diferentes níveis de força: o primeiro equivalente a $10 \%$ e o segundo igual a $50 \%$ da força de colapso. A Figura 7.25 ilustra o deslocamento lateral resultante no instante da ruptura quando se aplica uma força igual a $10 \%$ da força de colapso. As Figuras 7.26 e 7.27 ilustram os deslocamentos axial e lateral, respectivamente para uma força aplicada equivalente a $50 \%$ da força ultima, no instante do colapso.

Como é possível perceber, pelo gráfico da Figura 7.28, o modelo elaborado com o elemento finito SOLID45 registrou um maior tempo critico (TRF) quando comparado à mesma análise realizada com o modelo construído com o elemento SHELL181. 


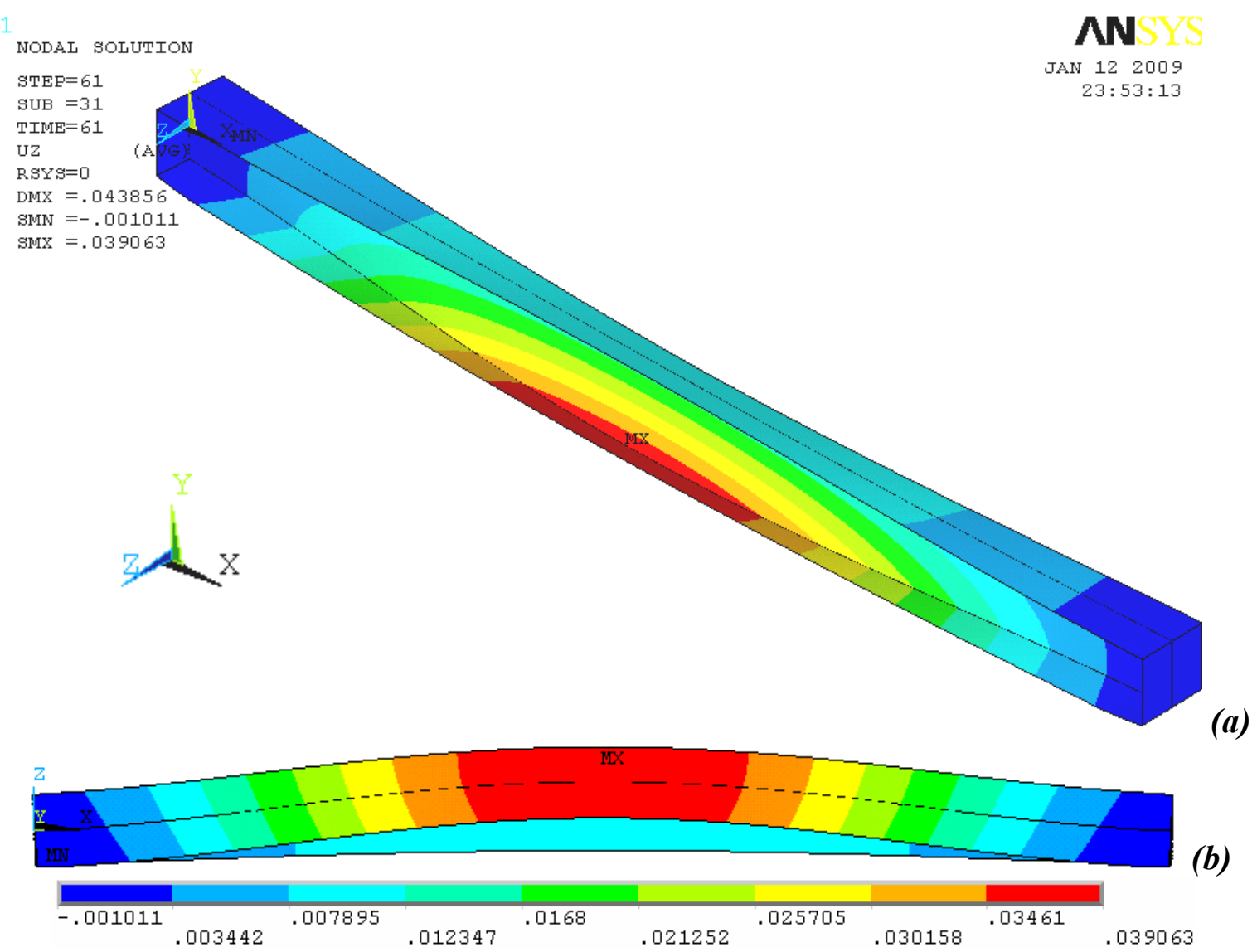

Figura 7.25: Deformada em relação ao eixo z para a força axial aplicada igual a $121,495 \mathrm{kN}$ : (a) perspectiva e (b) vista da mesa inferior.

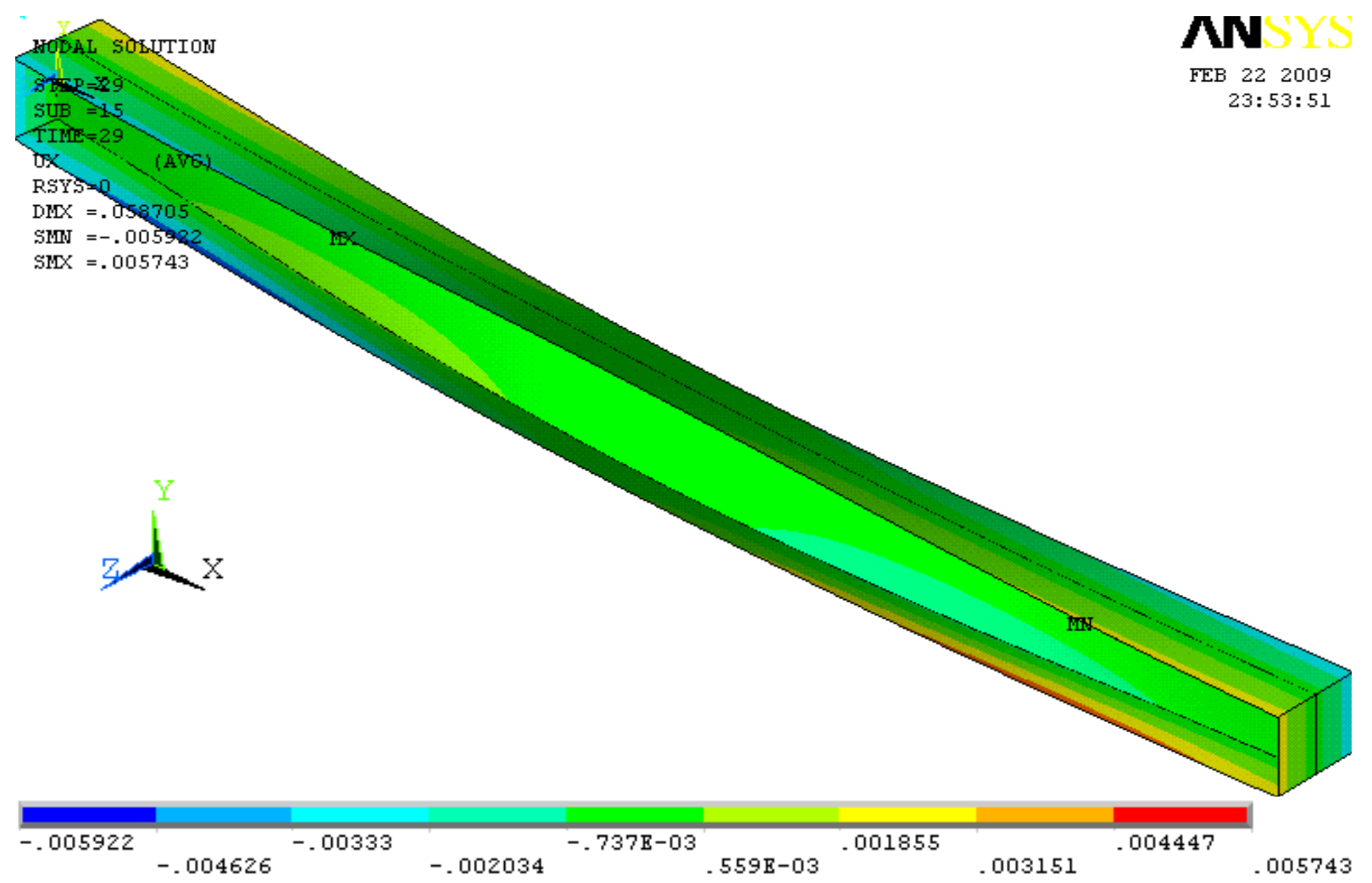

Figura 7.26: Deslocamento axial do pilar em contato com três paredes para uma força aplicada igual a $603,303 \mathrm{kN}$ para um TRF igual ao tempo critico, ou seja, 29 minutos. 


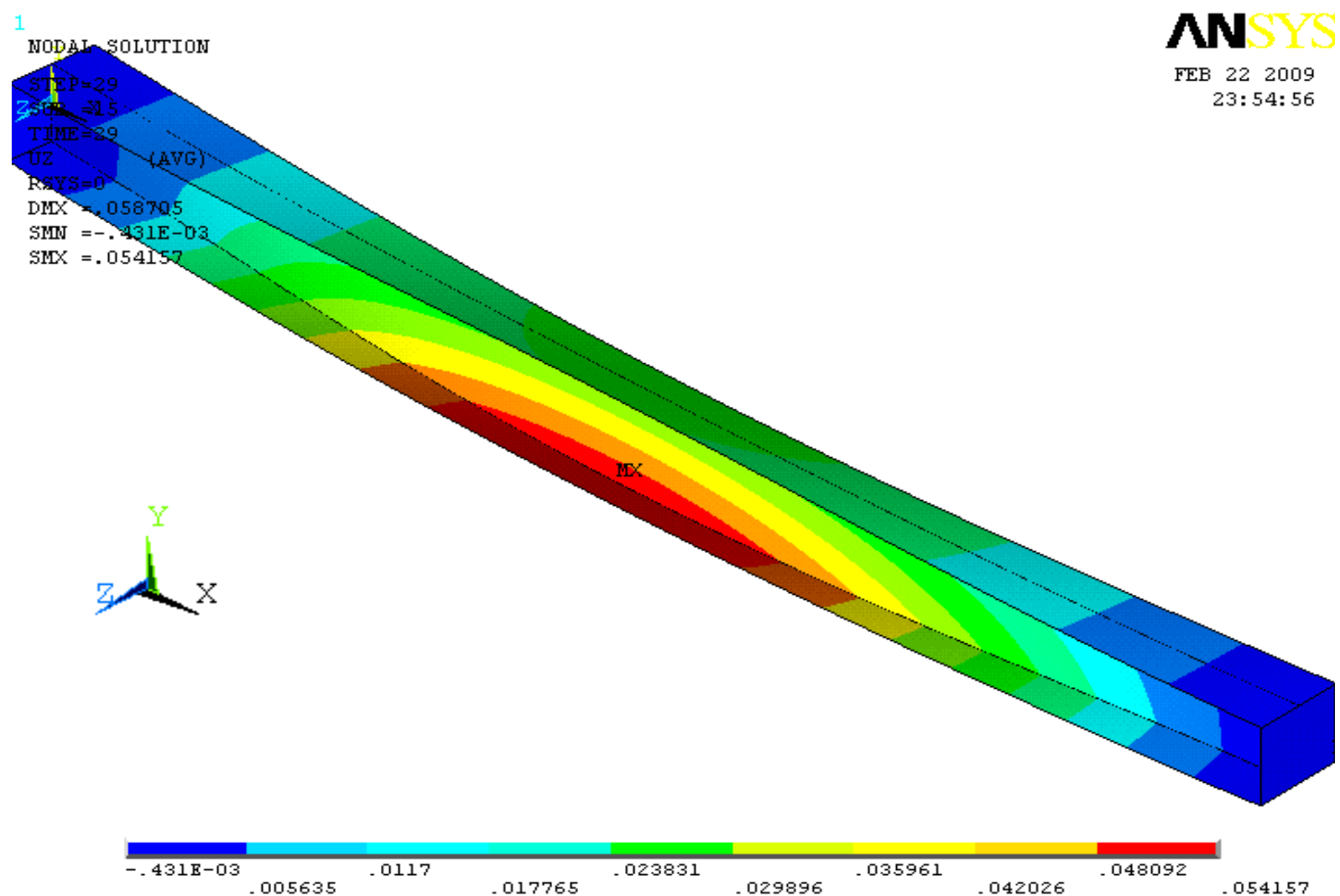

Figura 7.27: Deslocamento lateral do pilar em contato com três paredes para uma força aplicada igual a $603,3 \mathrm{kN}$, para um TRF igual a 29 minutos.

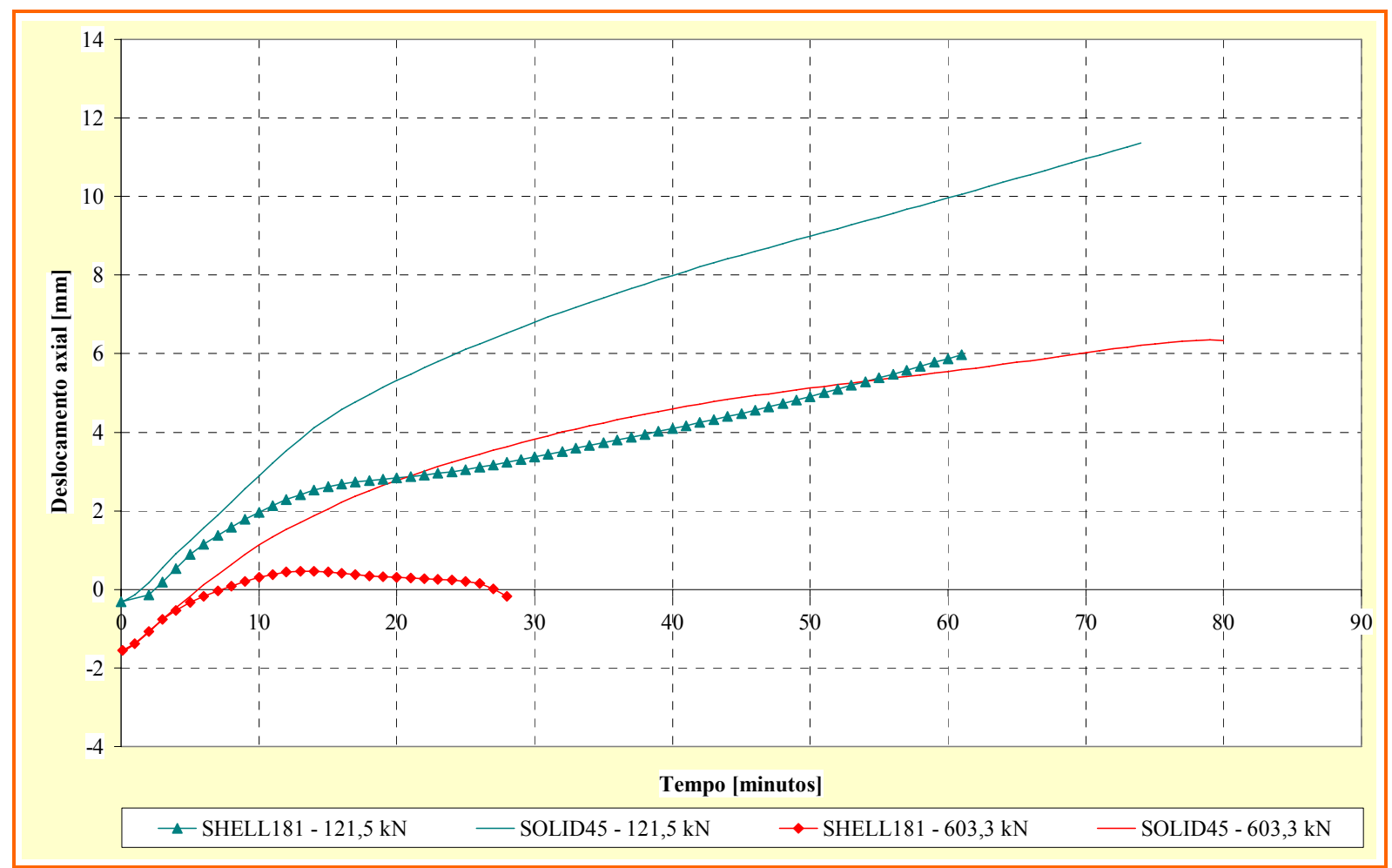

Figura 7.28: Comparação entre as respostas referentes ao deslocamento axial obtidas utilizando os dois tipos de elemento, SHELL181 e SOLID45. 
Diferentemente do pilar isolado, as respostas da análise termoestrutural para o pilar em contato com as paredes submetido à situação de incêndio utilizando SOLID45 e SHELL181 se mostraram conflitantes. Para o mesmo carregamento estático aplicado o modelo construído em SHELL181 atingiu um tempo crítico muito menor que aquele apresentado pelo modelo elaborado com SOLID45.

Diversos fatores podem ser a causa dessa divergência, conforme mencionado no Capítulo 6, ou seja, a dificuldade na transferência de campo térmico para fins de análise acoplada, bem como a discretização da rede em elementos finitos do modelo em SHELL181, que seguiu o mesmo grau de refinamento do modelo em SOLID45. Os resultados apresentados na Figura 7.28 foram determinantes para que se optasse pelo uso do elemento finito SOLID45 na continuidade das demais análises termo-estruturais.

\subsection{PILAR DE CANTO - Paredes na alma e em uma das mesas}

Para esse caso, a temperatura e o deslocamento lateral no pilar foram medidos em determinados pontos, conforme ilustrados na Figura 7.2, com aquecimento admitido uniforme ao longo do comprimento.

\begin{tabular}{|c|c|c|c|c|}
\hline Nó & $X$ & $Y$ & Z & \\
\hline 1 & 1,5900 & $-0,1016$ & $-0,1018$ & \multirow{6}{*}{ Mesa } \\
\hline 2 & 1,5900 & $-0,1016$ & $-0,0700$ & \\
\hline 3 & 1,5900 & $-0,1016$ & 0,0700 & \\
\hline 4 & 1,5900 & $-0,1016$ & 0,1018 & \\
\hline 5 & 1,5900 & 0,1016 & $-0,1018$ & \\
\hline 6 & 1,5900 & 0,1016 & 0,1018 & \\
\hline 7 & 1,5900 & $-0,0700$ & 0,0000 & \multirow{3}{*}{ Alma } \\
\hline 8 & 1,5900 & 0,0000 & 0,0000 & \\
\hline 9 & 1,5900 & 0,0700 & 0,0000 & \\
\hline
\end{tabular}

6 5

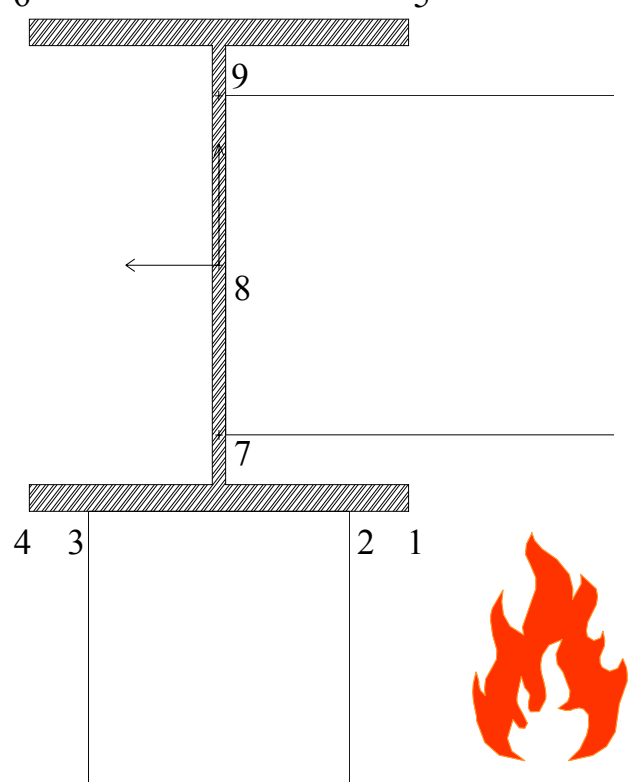

Figura 7.29: Nós em que foram medidos os deslocamentos laterais e a temperatura em relação ao TRF para o pilar de canto. 
No que se segue, serão apresentados resultados de análises numéricas realizadas com referência à situação apresentada na figura 7.29, considerando agora apenas o elemento finito SOLID 45, lembrando que neste caso, de forma análoga àquele apresentado no item 7.4, a carga térmica não é aplicada em todos os lados da seção, considerando agora a influência da compartimentação do ambiente.

NODAL SOLUTION

$\operatorname{STE} P=43$

$\operatorname{SUB}=6$

$\mathrm{TIME}=42$

$\mathrm{UZ}$

RTYS $=0$

$\mathrm{DNX}=.048184$

SMN $=-.889 \mathrm{E}-04$

$\operatorname{SMX}=.047988$

\section{N}

DEC 152008

$21: 12: 22$ 


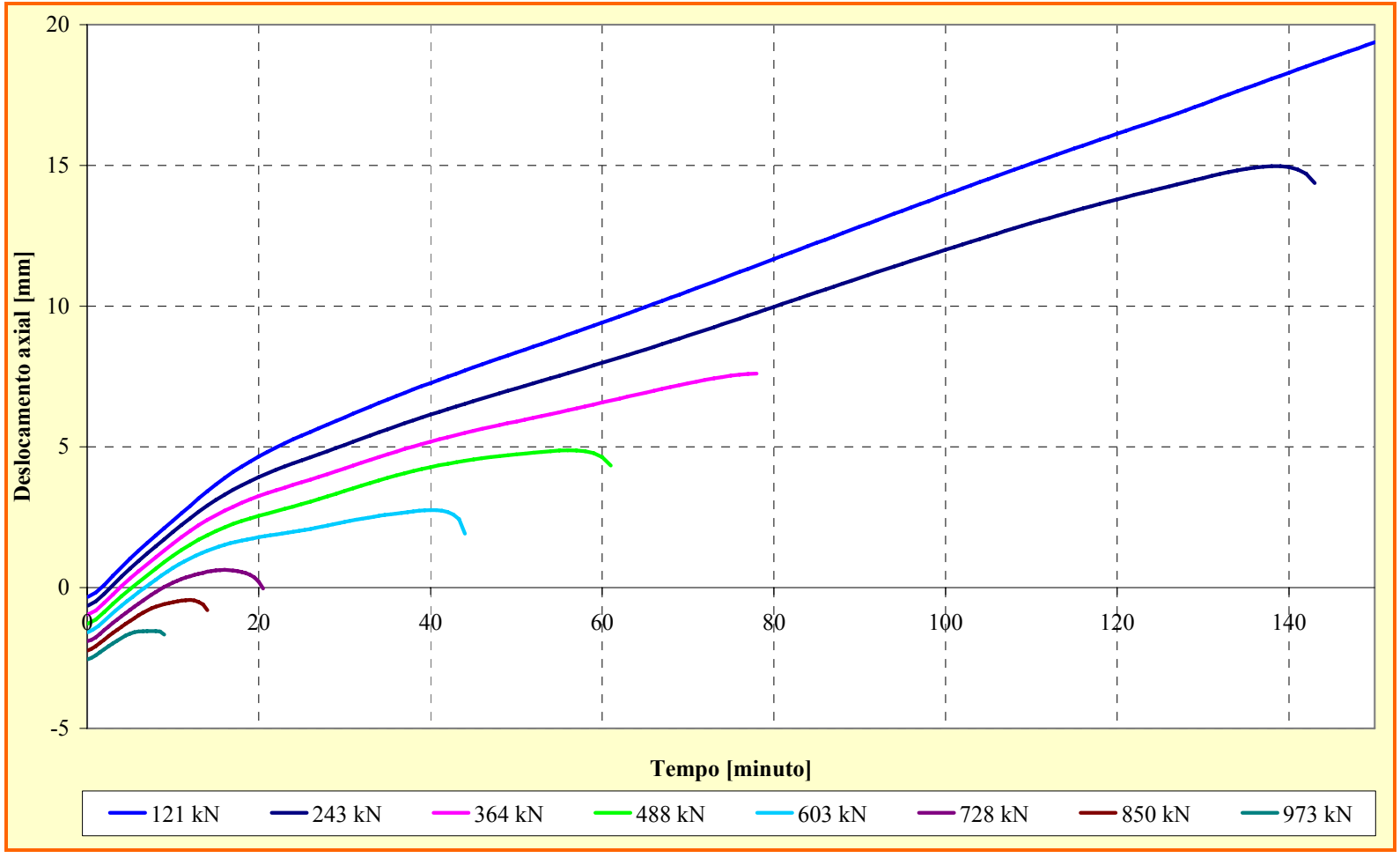

Figura 7.32: Deslocamento axial do pilar submetido ao um campo térmico no sentido znegativo e imperfeição geométrica no sentido z-positivo.

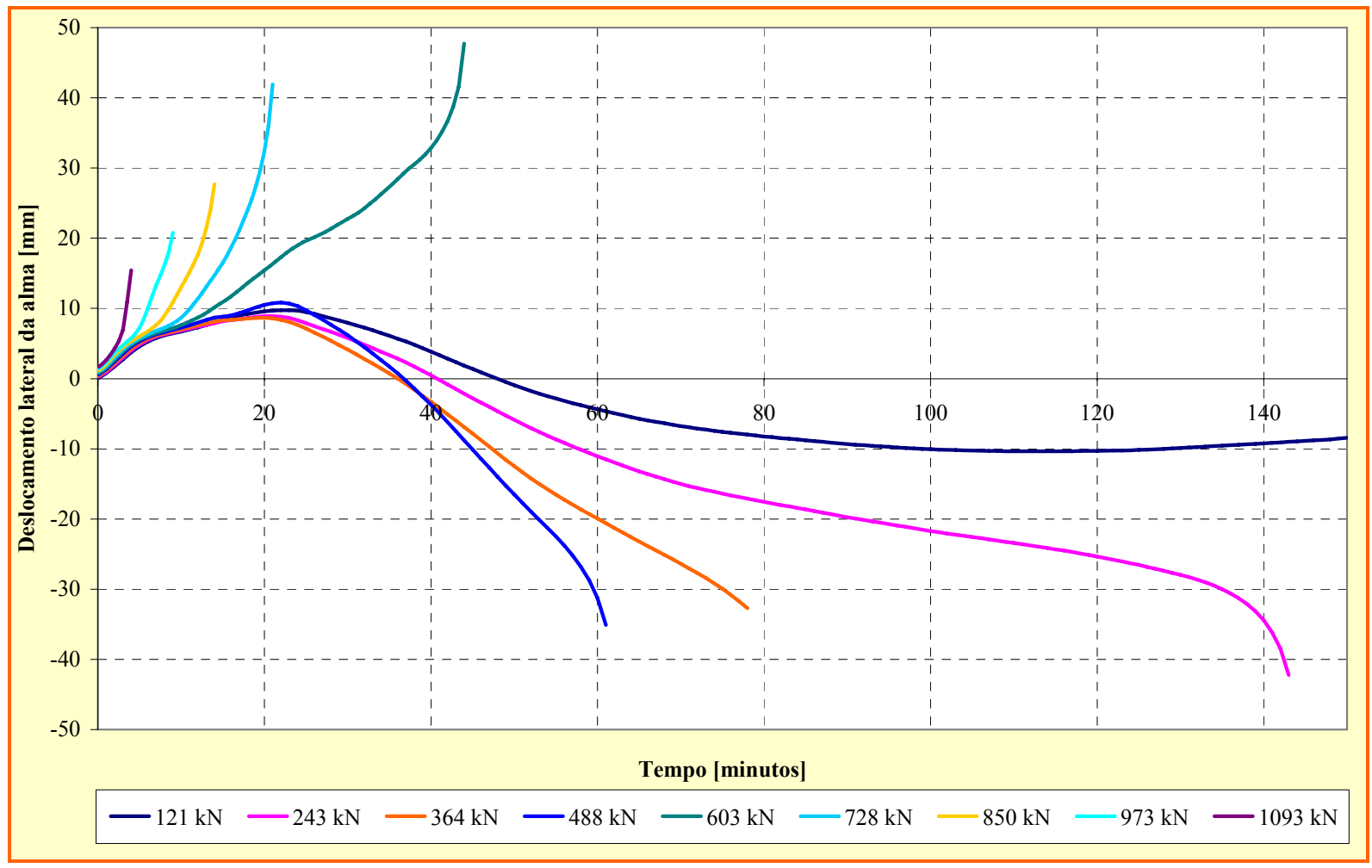

Figura 7.33: Deslocamento lateral do pilar submetido ao um campo térmico no sentido znegativo e imperfeição geométrica no sentido z-positivo. 


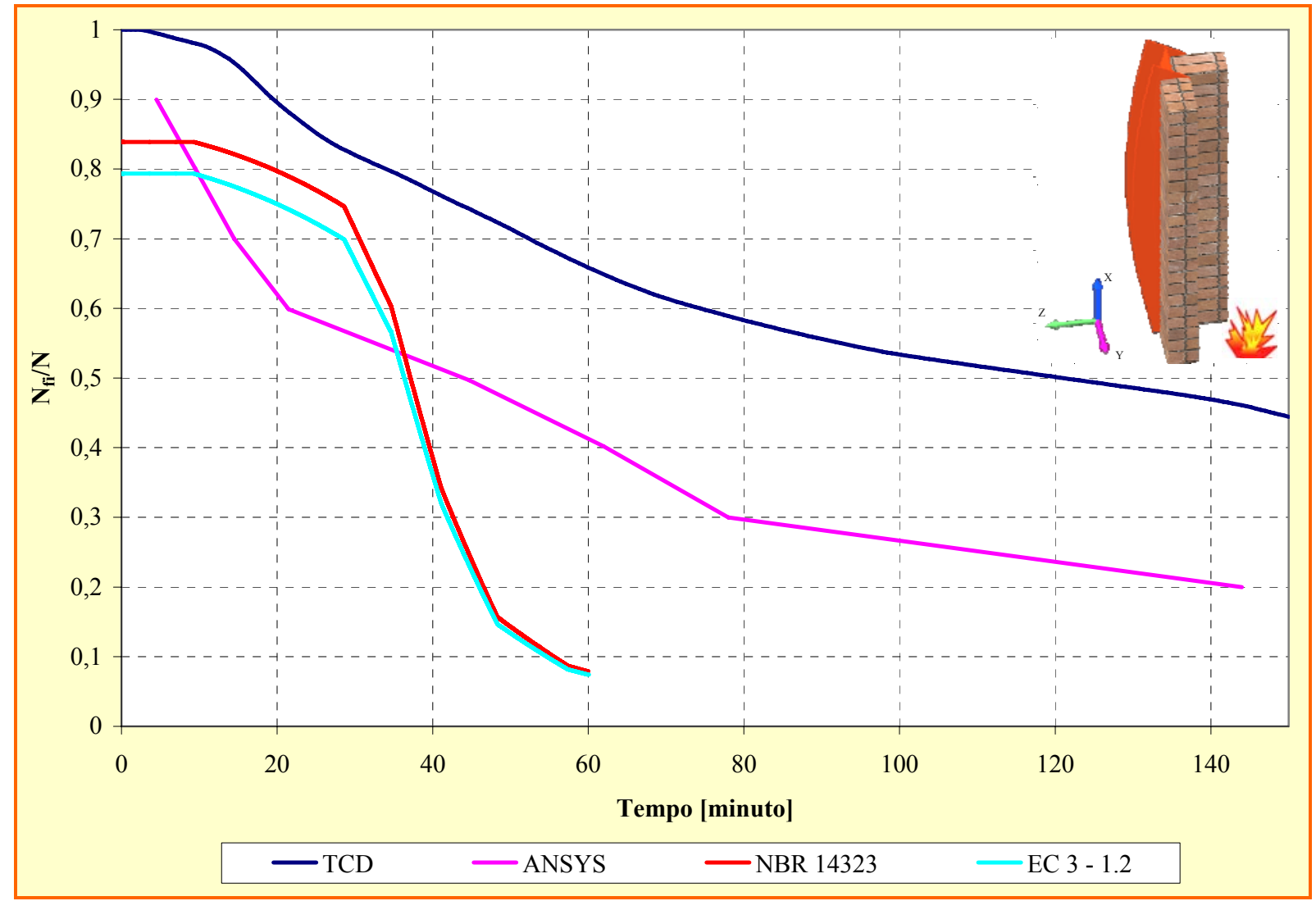

Figura 7.34: Fator de redução para a força axial de colapso em relação ao TRF, obtido pelo ANSYS e pelo TCD

Nesse item também foi considerada a variação no sentido do deslocamento inicial, com a finalidade de analisar a ação térmica do incêndio agindo diretamente, ora na face tracionada ora na face comprimida da barra. As figuras 7.35 e 7.36 ilustram o campo de deslocamento axial e lateral respectivamente e as figuras 7.37 e 7.38 mostram como o deslocamento varia com o aumento da temperatura em diferentes níveis de carregamento axial. As figuras 7.39 e 7.40 ilustram a redução da resistência à compressão em função do TRF, confrontando os valores obtidos pelo EC 3 - 1.2 e ABNT NBR 14323:1999 além da mudança no sentido da imperfeição global. 


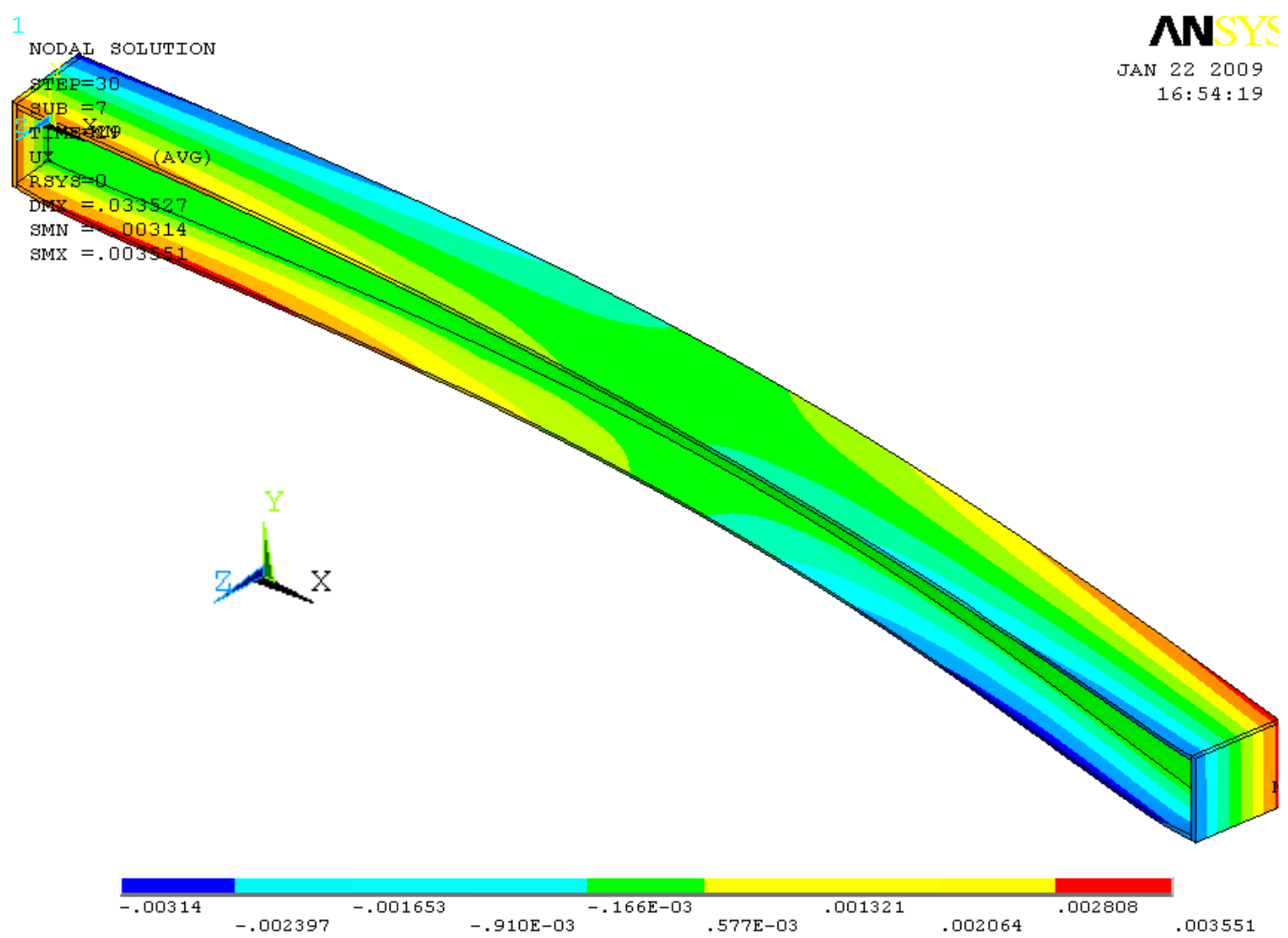

Figura 7.35: Configuração deformada em relação ao eixo x para força aplicada igual a $727,72 \mathrm{kN}$, considerando imperfeição global no sentido $\mathrm{Z}$ negativo (ver figura 7.3 , item 7.2)

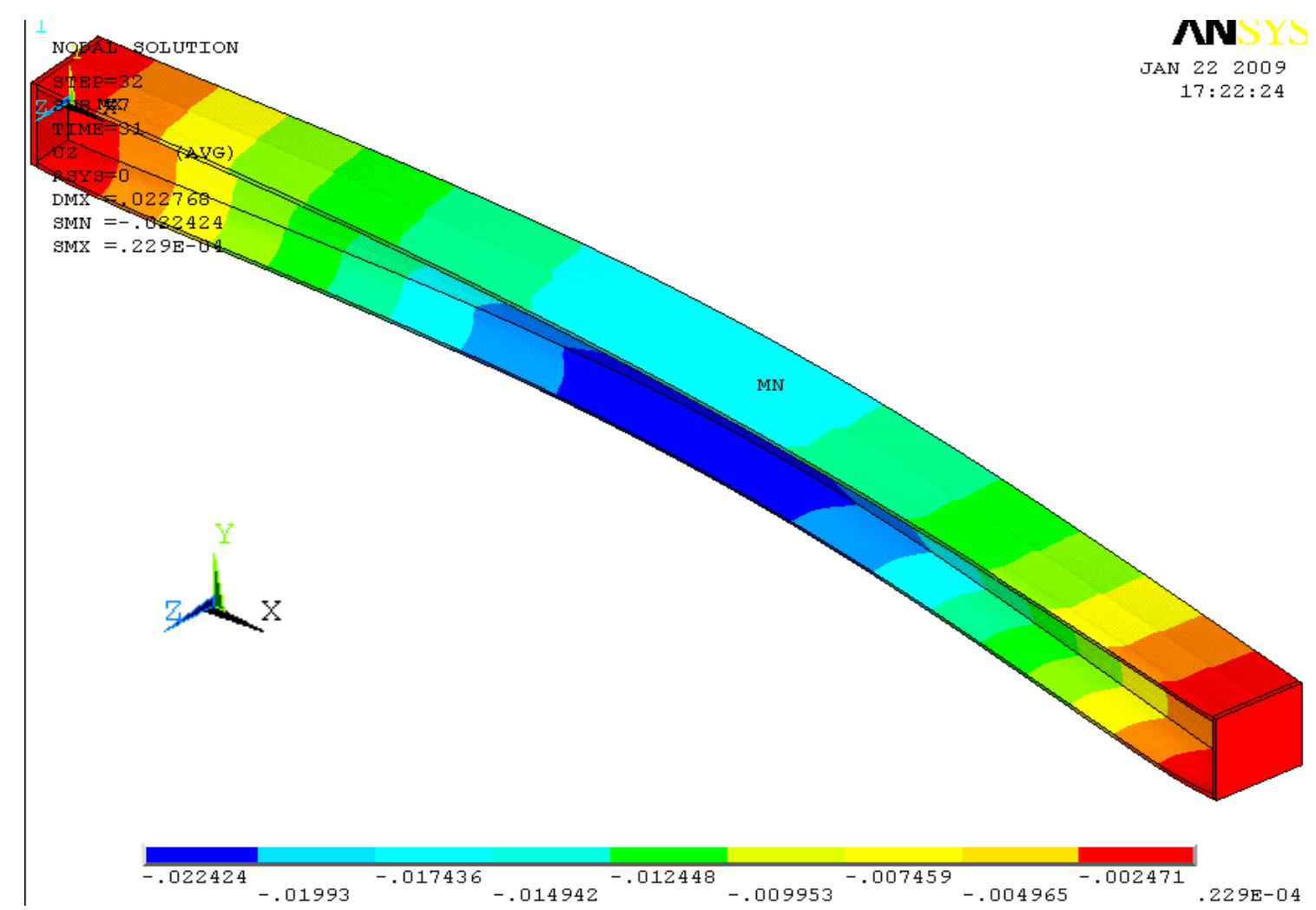

Figura 7.36: Deslocamento lateral para o pilar submetido a força axial igual a $972,56 \mathrm{kN}$, equivalente a $0,8 \mathrm{~N}$, considerando imperfeição global no sentido $\mathrm{Z}$ negativo (ver figura 7.3, item 7.2) 


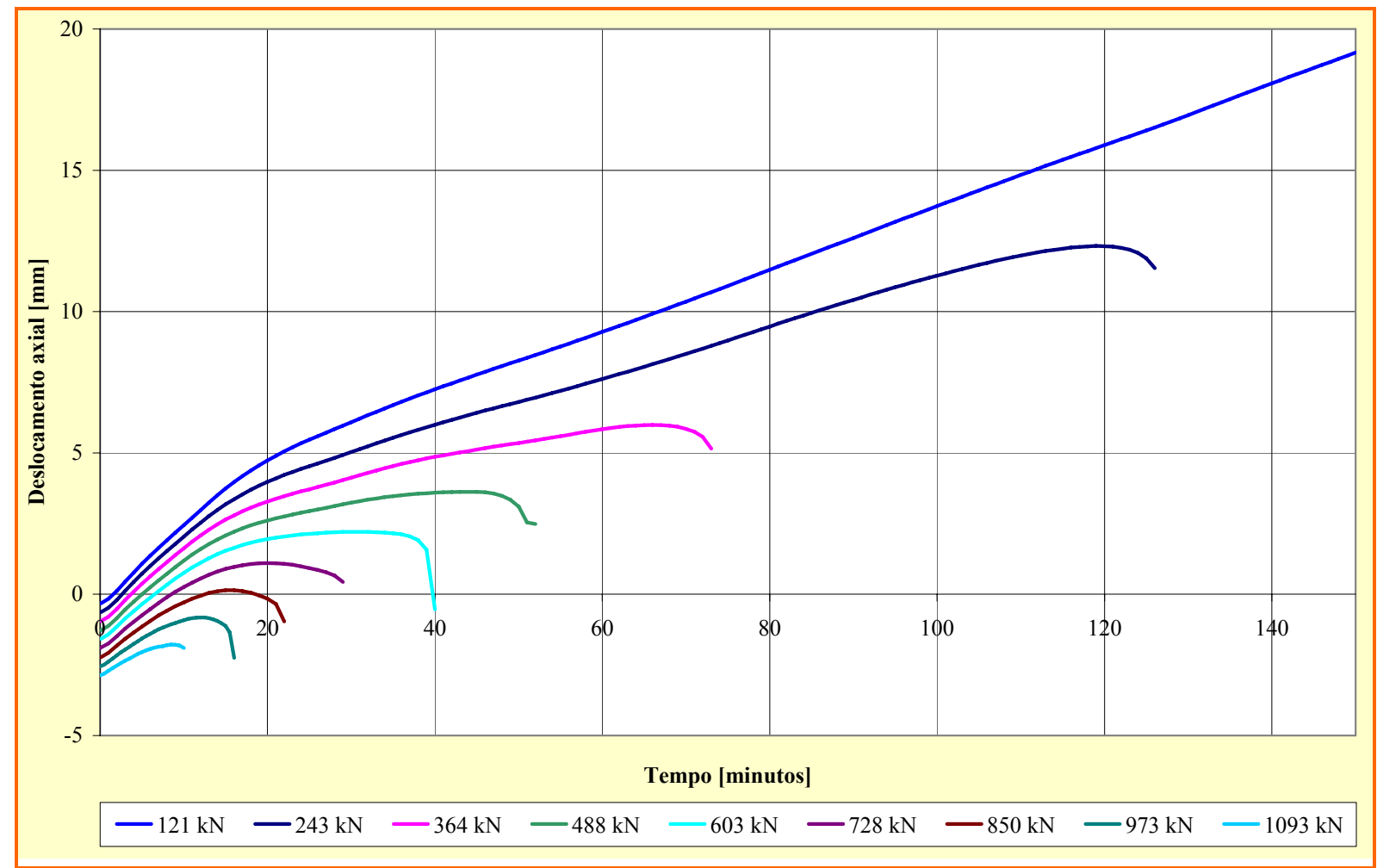

Figura 7.37: Deslocamento axial do pilar submetido ao um campo térmico com imperfeição geométrica no sentido z-negativo, com níveis de força aplicada variando entre $0,1 \mathrm{~N}_{\mathrm{p} l}$ e $0,9 \mathrm{~N}_{\mathrm{p} l}$.

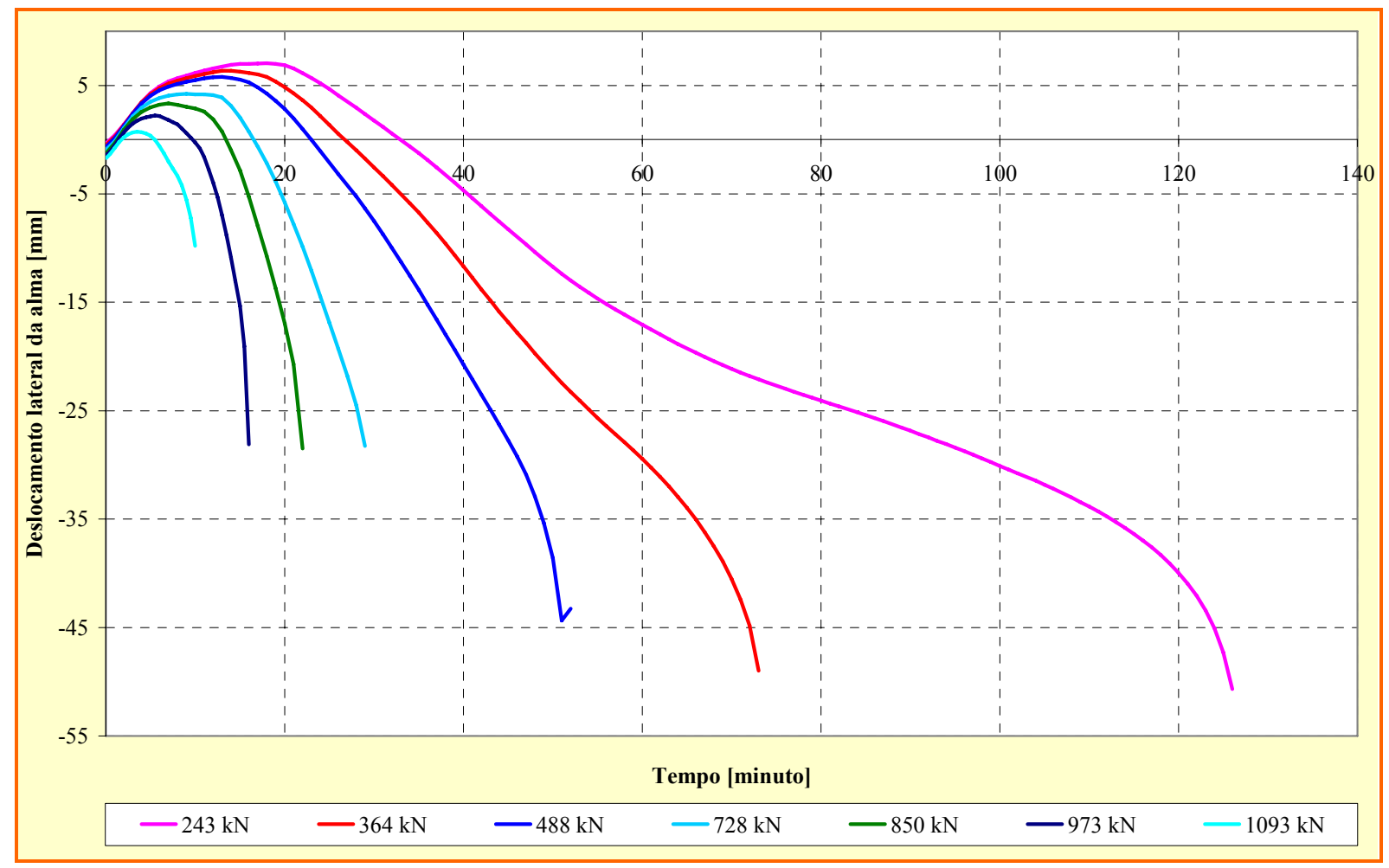

Figura 7.38: Deslocamento lateral do pilar submetido ao um campo térmico imperfeição geométrica ambos no sentido z-negativo, com níveis de força aplicada variando entre $0,1 \cdot \mathrm{N}$ e $0,9 \cdot \mathrm{N}$. 


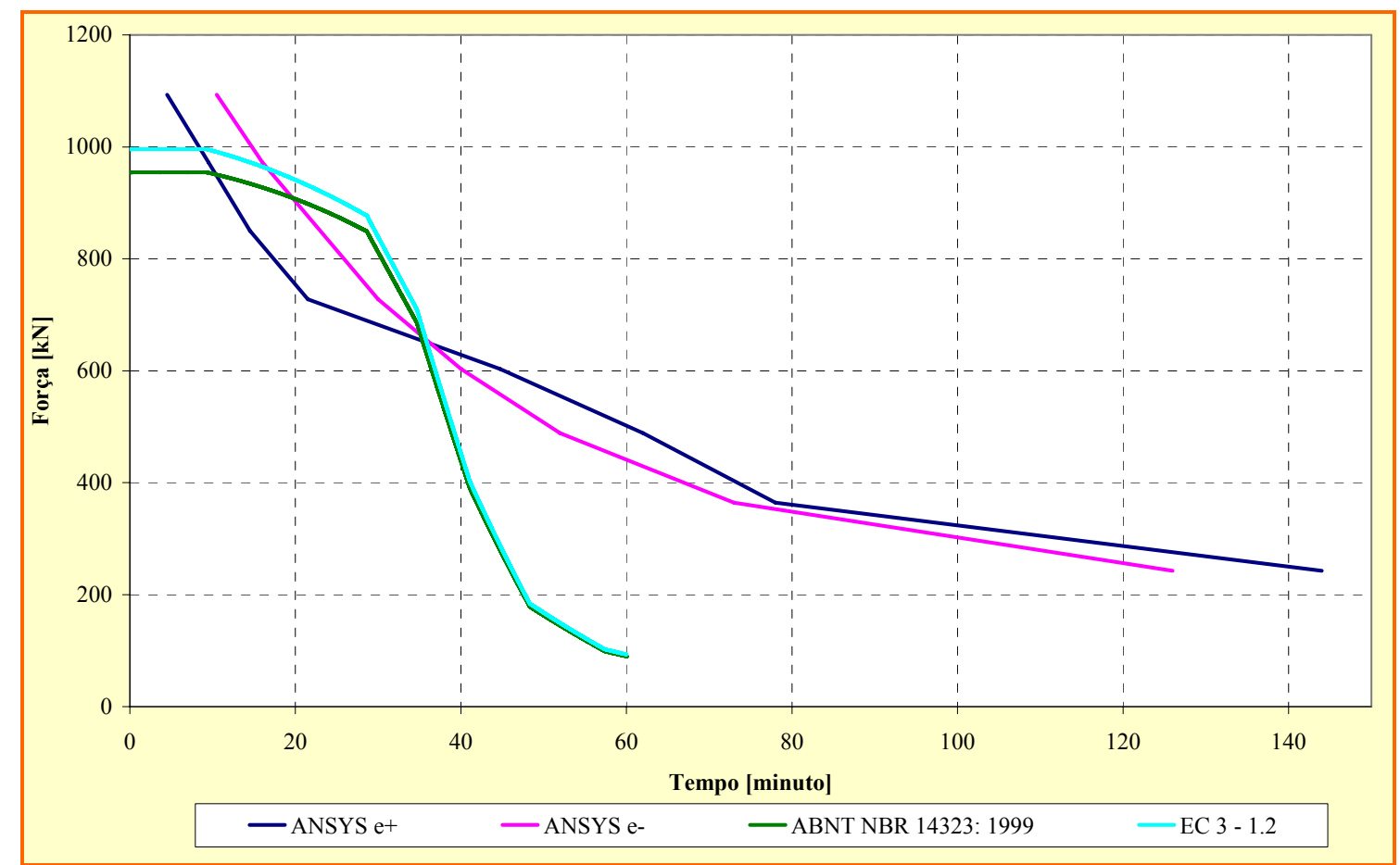

Figura 7.39: Variação da força de colapso [kN] em função do tempo (TRF) [minuto] obtido pelo ANSYS e por meio dos métodos simplificados da ABNT NBR 14323:1999 e do EC 31.2 .

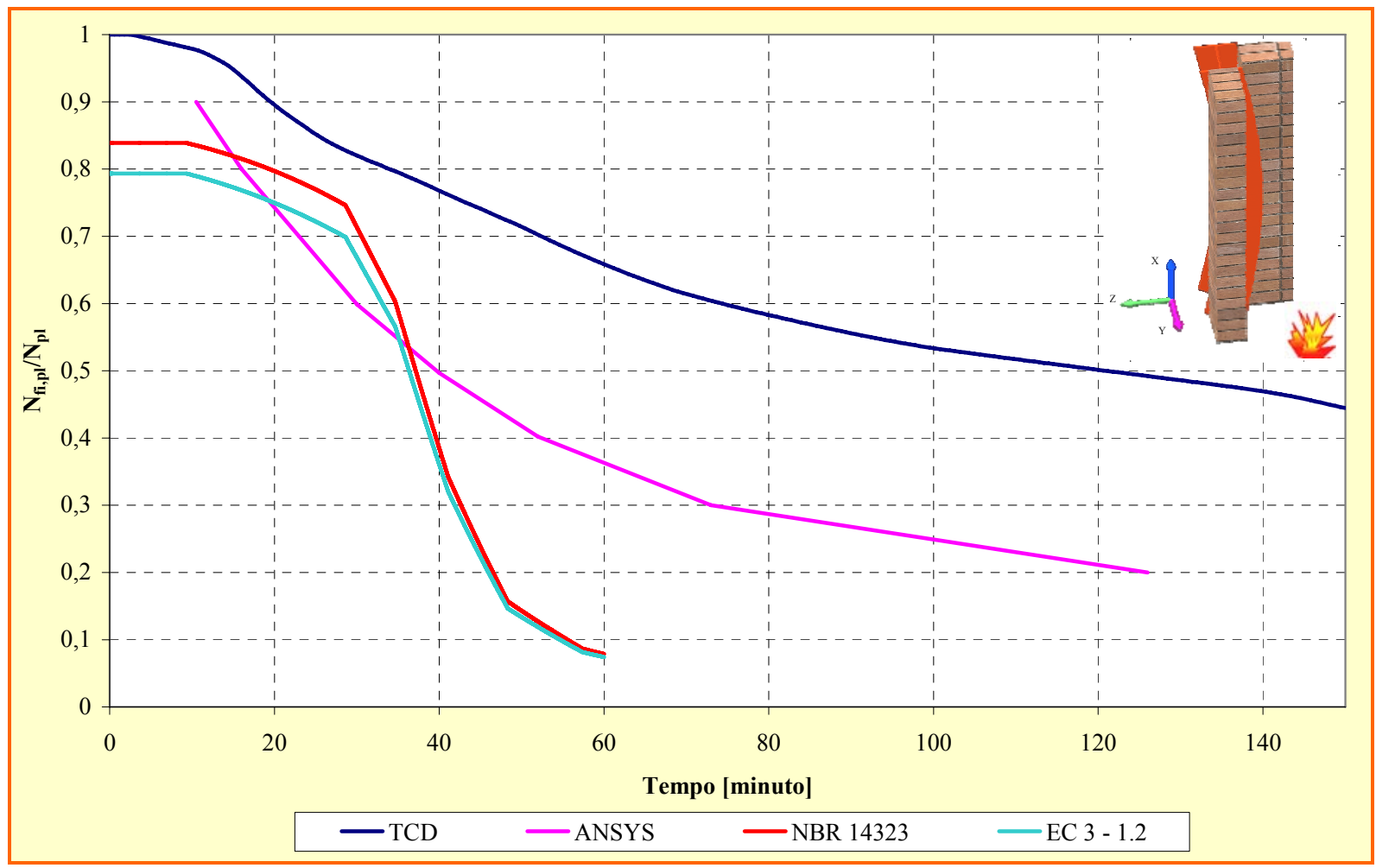

Figura 7.40: Comparação entre o TCD e o ANSYS relativo ao fator de redução da força de colapso em relação ao TRF, considerando o campo térmico e excentricidade no sentido znegativo. 
Para o pilar de canto, considerando forças aplicadas variando entre $0,2 \cdot \mathrm{N}$ e $0,5 \cdot \mathrm{N}, \mathrm{o}$ tempo obtido com campo térmico e imperfeição global aplicados em z-negativo resultou num TRF menor se comparado a imperfeição aplicado em z-positivo. O inverso aconteceu para forças aplicadas correspondentes a $0,6 \cdot \mathrm{N}$ e $0,7 \cdot \mathrm{N}$. A Figura 7.41 esquematiza a posição do campo térmico e o sentido da imperfeição geométrica. As figuras 7.42 e 7.43 referentes ao campo de deslocamento axial e lateral respectivamente ilustram uma comparação entre os valores máximos obtidos para cada nível de força.
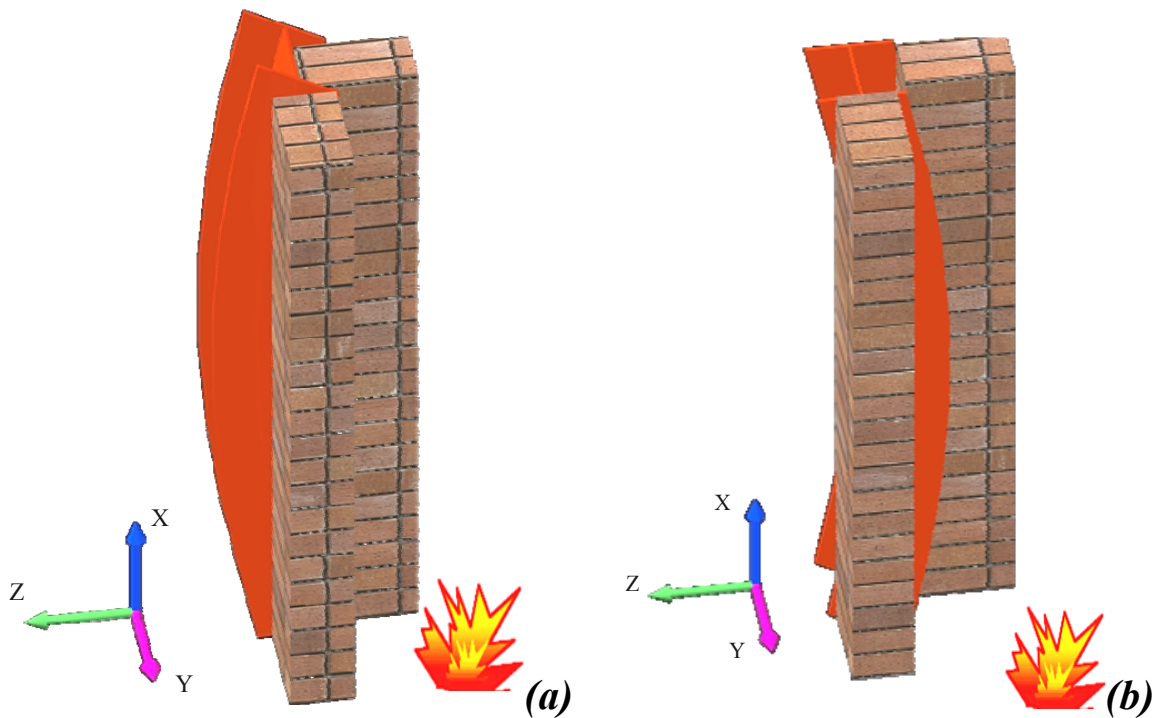

Figura 7.41: Imperfeição geométrica inicial e localização do campo térmico:

(a) em sentidos opostos e (b) no mesmo sentido.

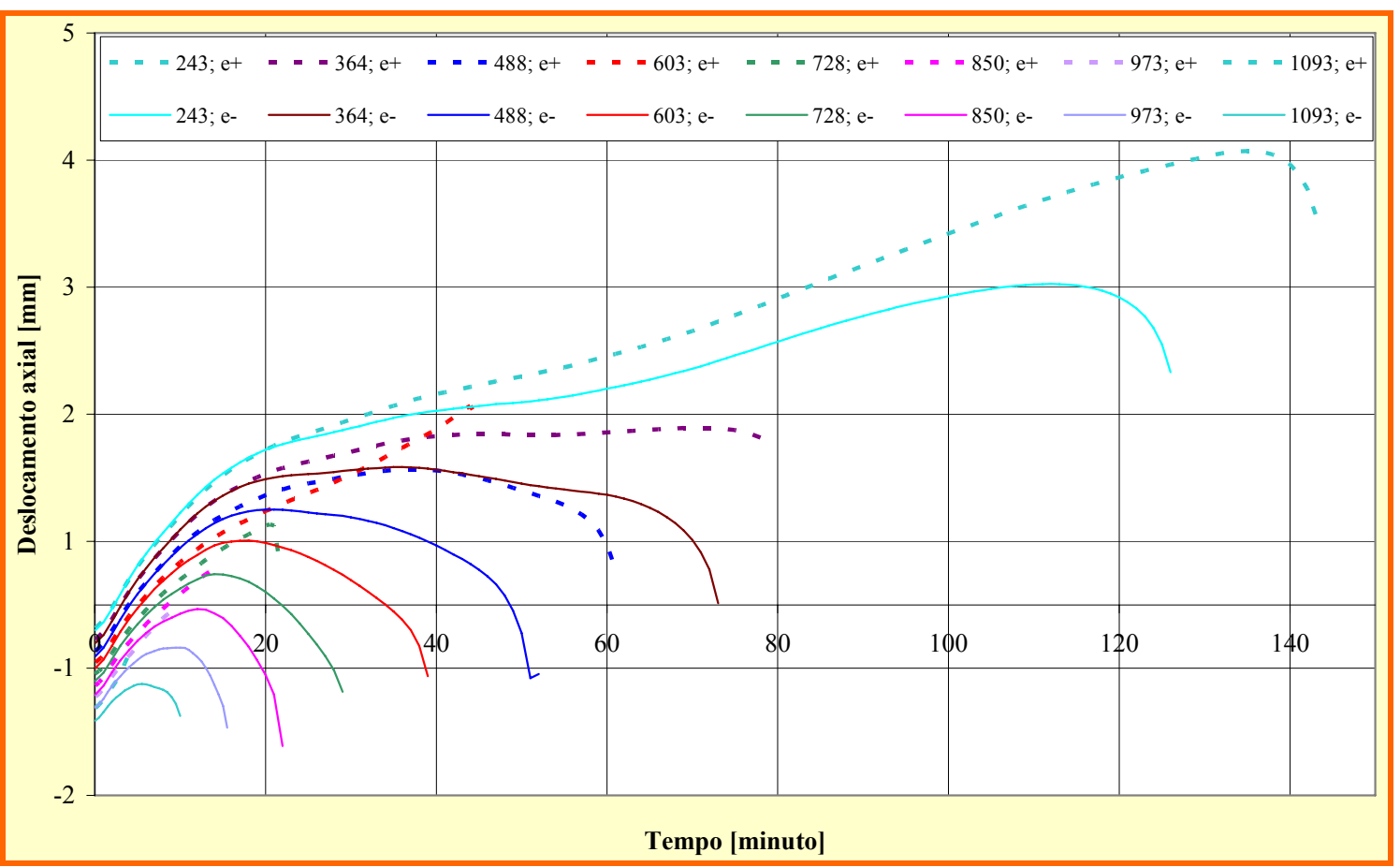

Figura 7.42: Curvas deslocamento axial x tempo (TRF) para os níveis de força entre $0,1 \mathrm{~N}$ e $0,9 \mathrm{~N}$ em que se compara o sentido da imperfeição global inicial. 


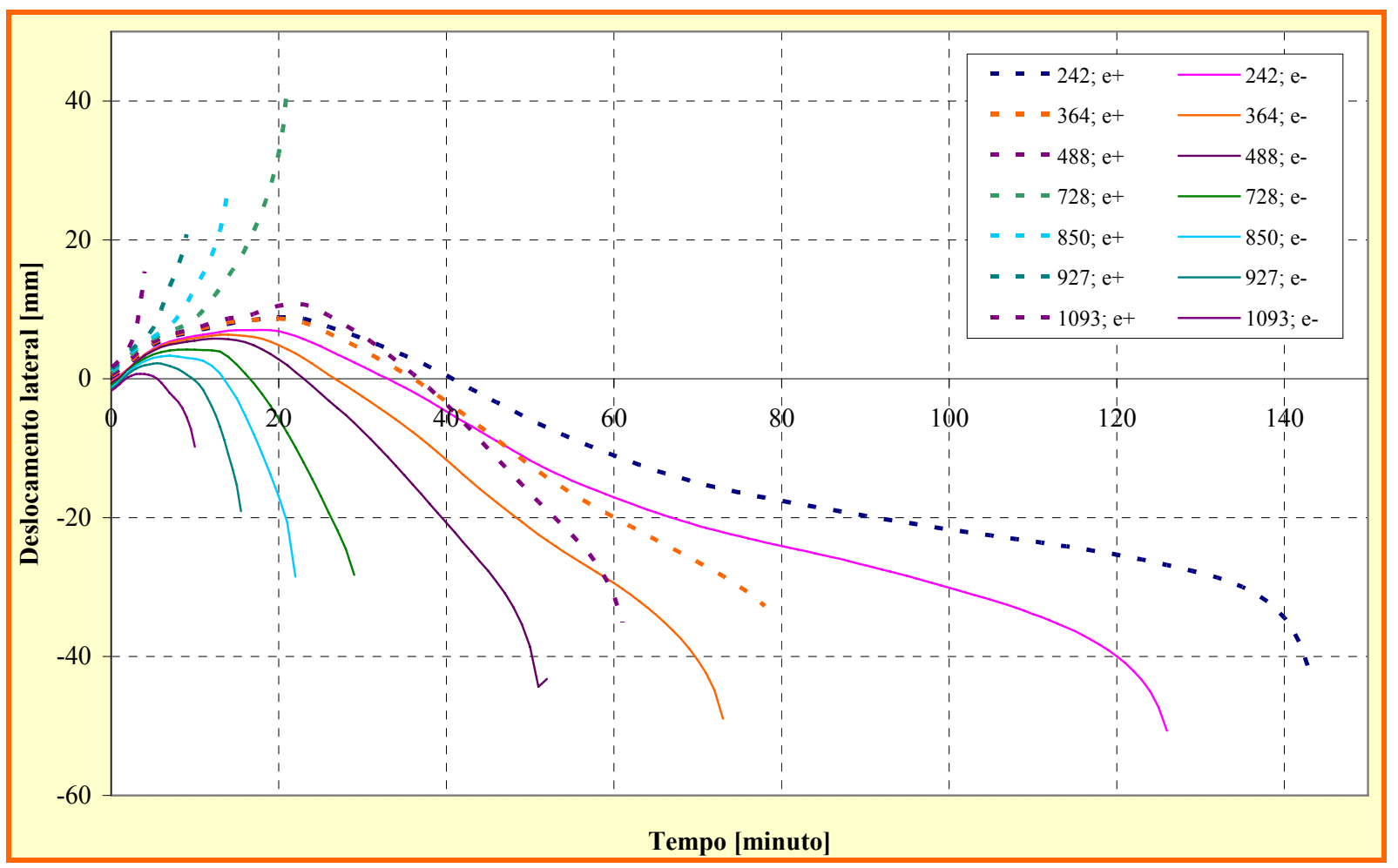

Figura 7.43: Curvas deslocamento lateral $\mathrm{x}$ tempo (TRF) para os níveis de força entre 0,1N e $0,9 \mathrm{~N}$ em que se compara o sentido da imperfeição global inicial.

\subsection{PILAR EXTERNO - Paredes apenas na alma}

Para esse caso, a temperatura e o deslocamento lateral no pilar foram medidos em determinados pontos na Figura 7.44, considerando aquecimento uniforme ao longo do comprimento. No que se segue, são apresentados resultados de análises numéricas realizadas com referência à situação apresentada na figura 7.44, considerando o elemento finito do tipo SOLID 45, no que se refere ao campo de deslocamento e variação da força correspondente ao colapso da barra.

\begin{tabular}{|c|c|c|c|c|}
\hline Nó & $\mathrm{X}$ & Y & Z & \\
\hline 1 & 1,5900 & $-0,1016$ & $-0,1018$ & \multirow{4}{*}{ Mesa } \\
\hline 2 & 1,5900 & $-0,1016$ & 0,1018 & \\
\hline 3 & 1,5900 & 0,1016 & $-0,1018$ & \\
\hline 4 & 1,5900 & 0,1016 & 0,1018 & \\
\hline 5 & 1,5900 & $-0,0700$ & 0,0000 & \multirow{3}{*}{ Alma } \\
\hline 6 & 1,5900 & 0,0000 & 0,0000 & \\
\hline 7 & 1,5900 & 0,0700 & 0,0000 & \\
\hline
\end{tabular}

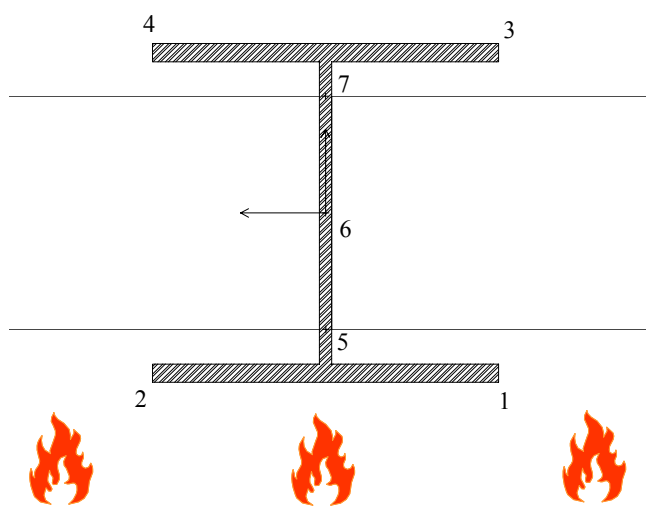

Figura 7.44: Nós em que foram medidos os deslocamentos laterais e a temperatura em relação ao TRF. 


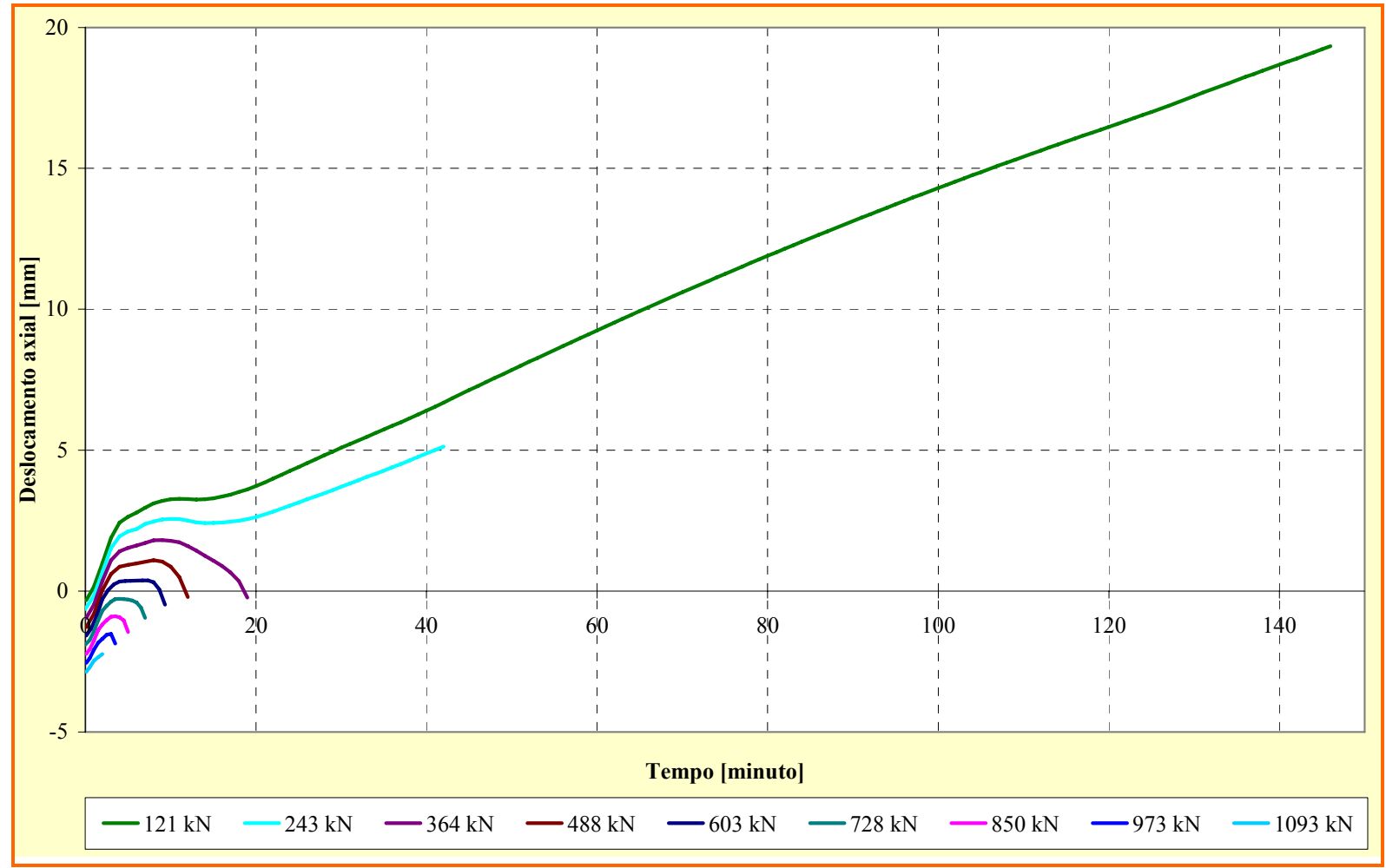

Figura 7.45: Deslocamento axial do pilar submetido ao um campo térmico em contato com a mesa inferior e imperfeição geométrica no sentido z-positivo.

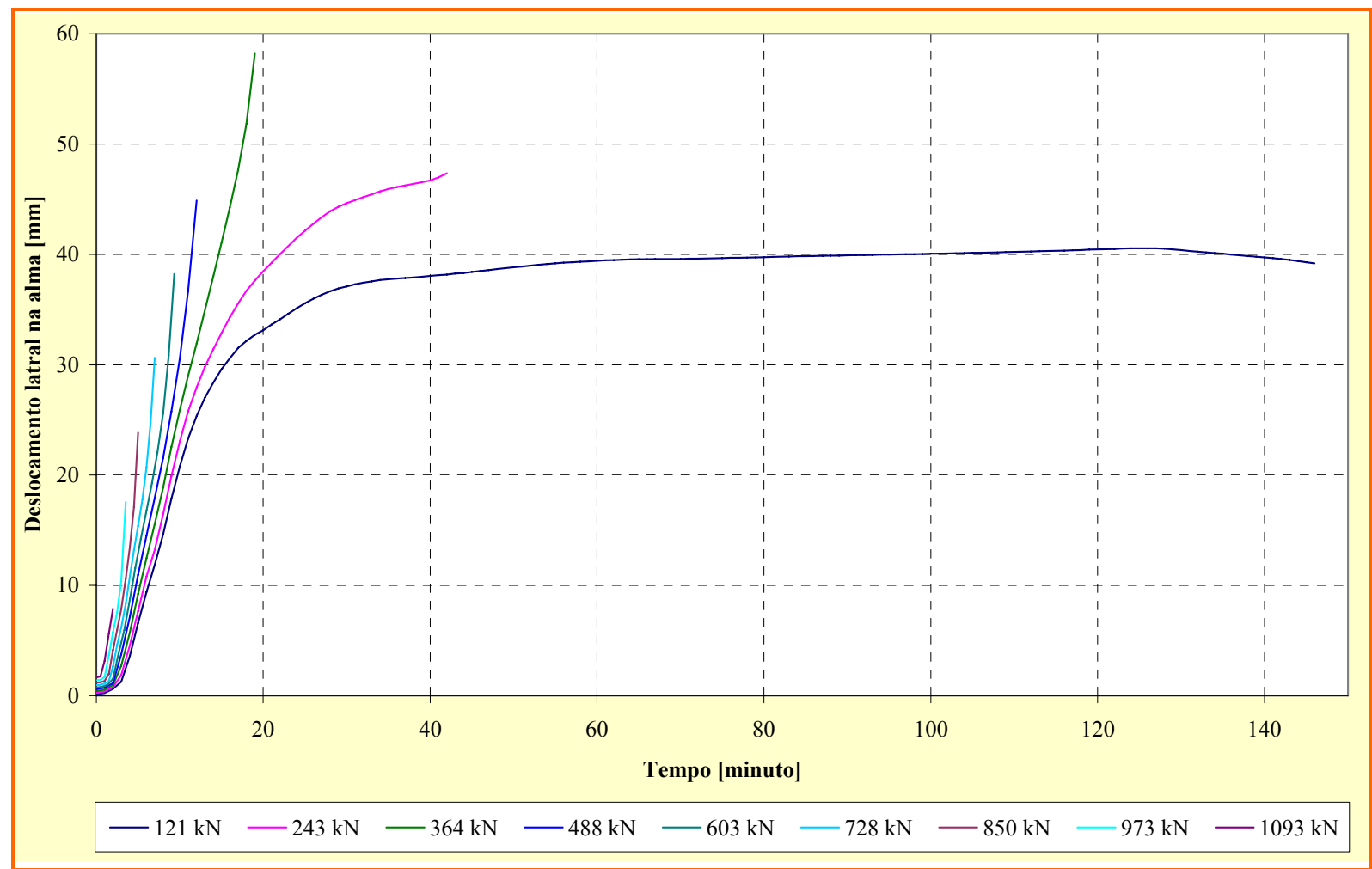

Figura 7.46: Deslocamento lateral do pilar submetido ao um campo térmico em contato com a mesa inferior e imperfeição geométrica no sentido z-positivo. 

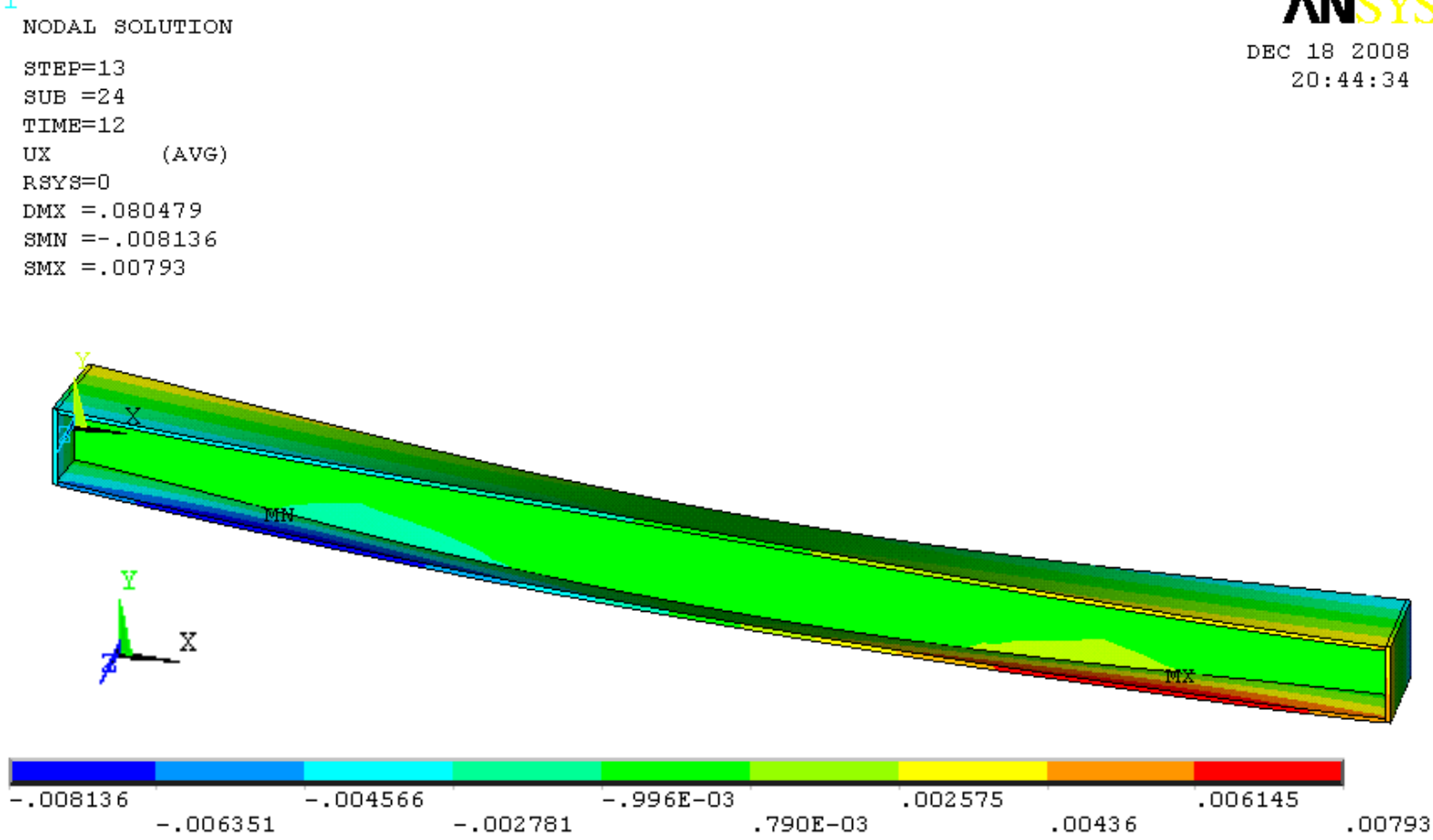

Figura 7.47: Deslocamento axial do pilar submetido a força de compressão igual a 488,4kN para TRF igual a 13 minutos, correspondente ao tempo critico.
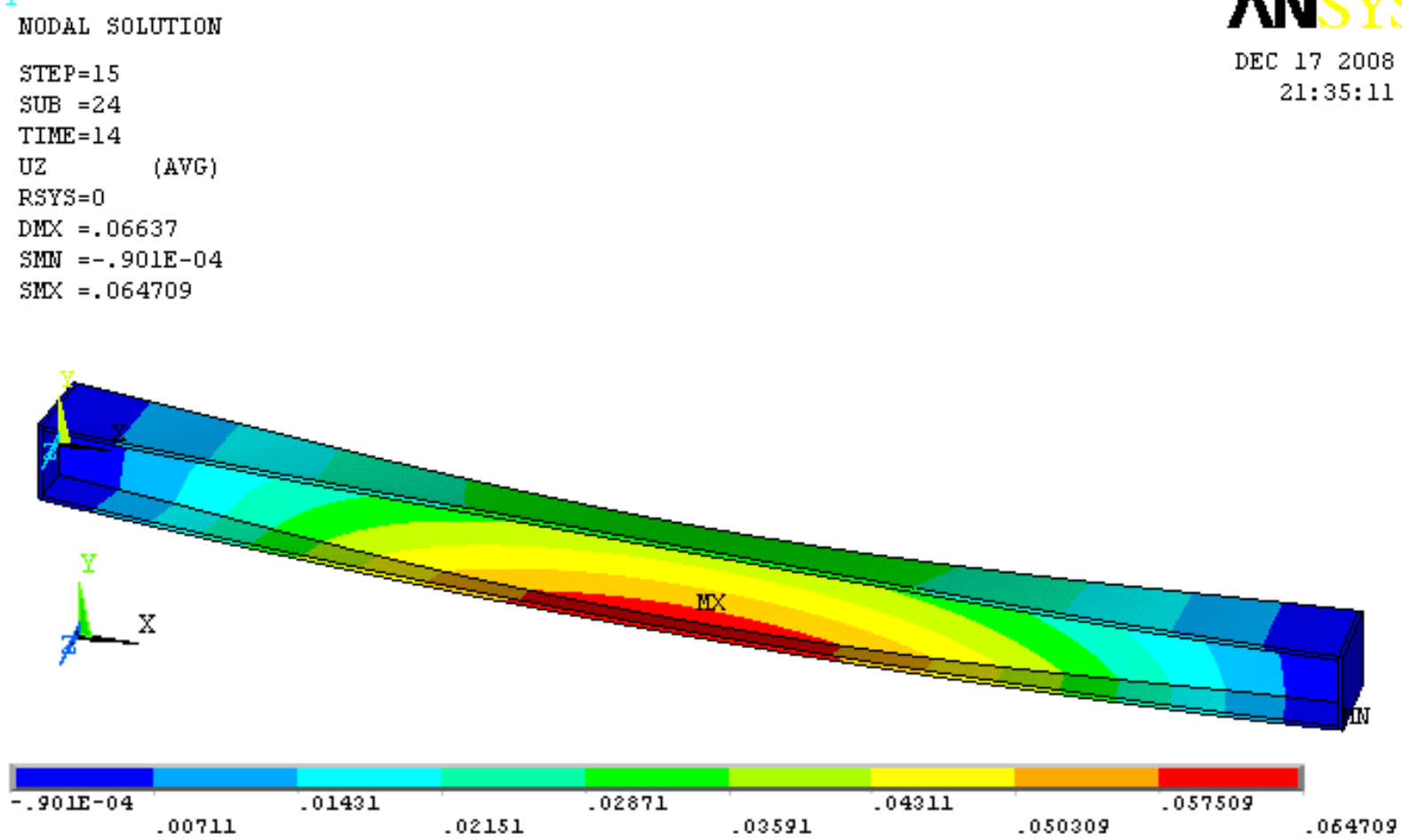

Figura 7.48: Deslocamento lateral do pilar submetido à força de compressão igual a $603,3 \mathrm{kN}$ para TRF igual a 10 minutos, correspondente ao tempo critico. 


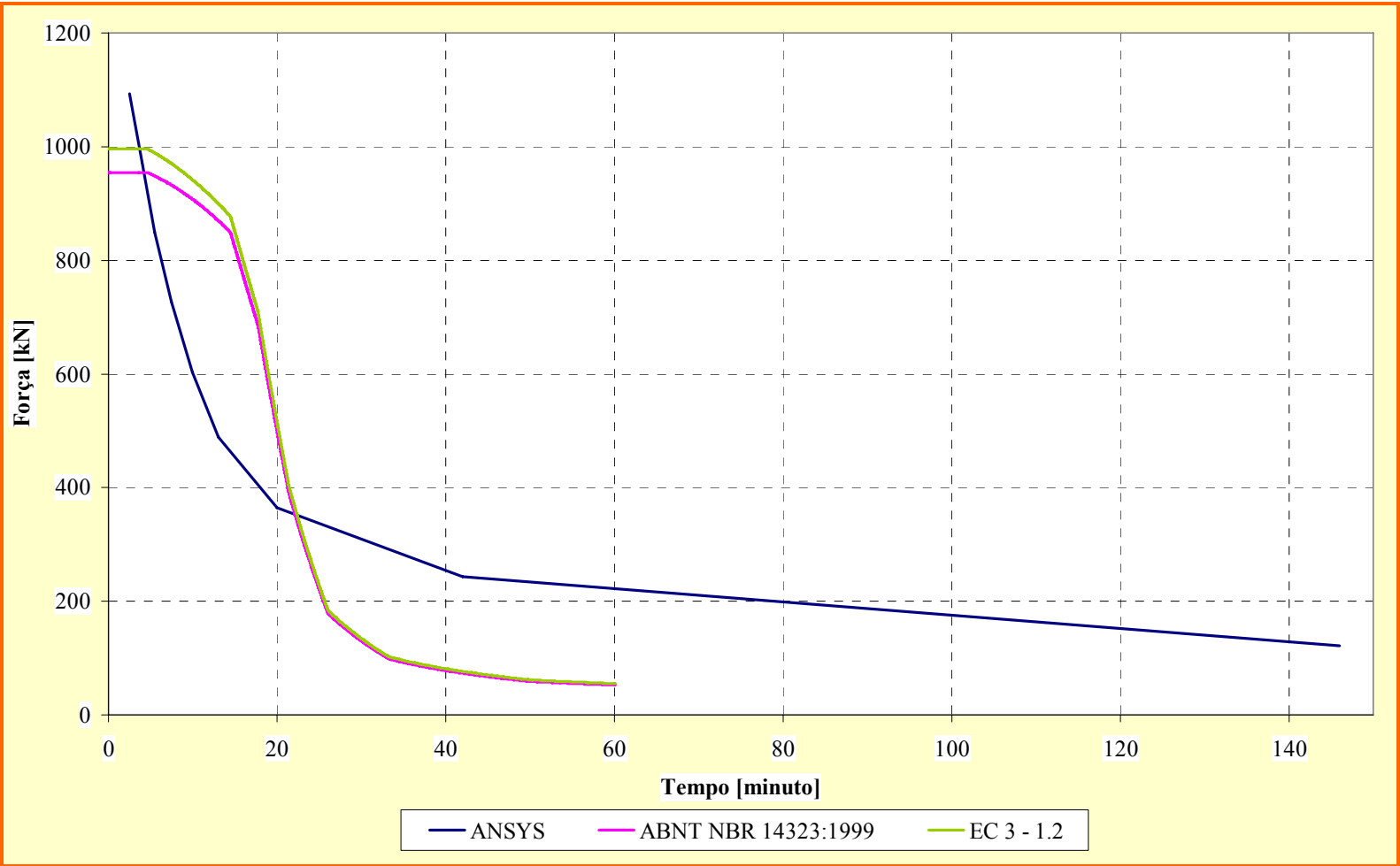

Figura 7.49: Variação da força de colapso [kN] em função do tempo (TRF) [minuto] obtido pelo ANSYS e por meio dos métodos simplificados da ABNT NBR 14323:1999 e do EC 31.2 .

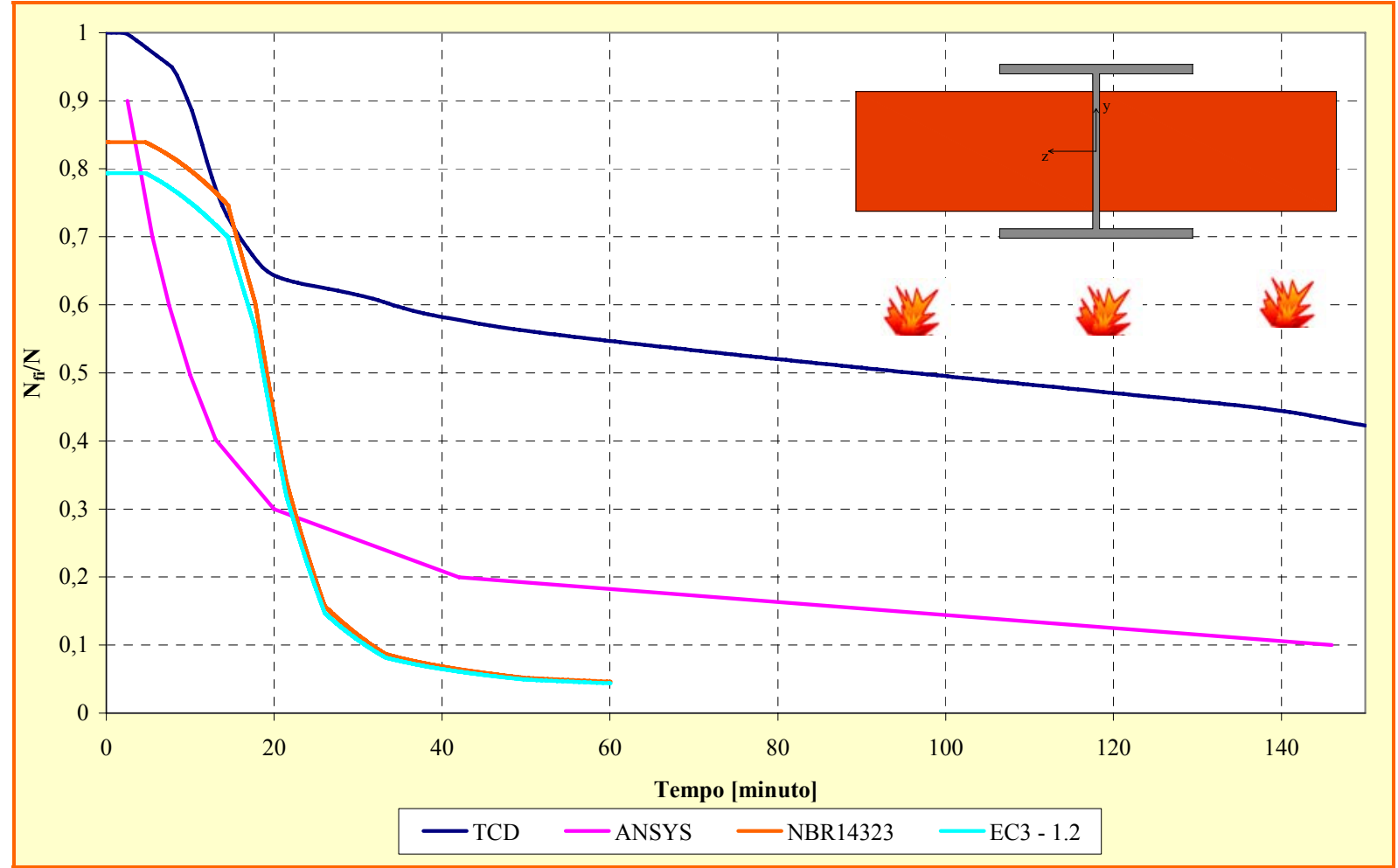

Figura 7.50: Comparação entre o TCD e o ANSYS relativo ao fator de redução da força de colapso em relação ao TRF. 


\subsection{PILAR DE BORDA OU INTERNO-Com paredes apenas na mesa}

Para esse caso, a temperatura e o deslocamento lateral no pilar foram medidos em pontos previamente estabelecidos e de interesse, conforme ilustrados na Figura 7.51, com aquecimento admitido uniforme ao longo do comprimento.

\begin{tabular}{|c|c|c|c|c|}
\hline Nó & X & Y & Z & \\
\hline 1 & 1,5900 & $-0,1016$ & $-0,1018$ & \multirow{8}{*}{ Mesa } \\
\hline 2 & 1,5900 & $-0,1016$ & $-0,0700$ & \\
\hline 3 & 1,5900 & $-0,1016$ & 0,0700 & \\
\hline 4 & 1,5900 & $-0,1016$ & 0,1018 & \\
\hline 5 & 1,5900 & 0,1016 & $-0,1018$ & \\
\hline 6 & 1,5900 & 0,1016 & $-0,0700$ & \\
\hline 7 & 1,5900 & 0,1016 & 0,0700 & \\
\hline 8 & 1,5900 & 0,1016 & 0,1018 & \\
\hline 9 & 1,5900 & $-0,0453$ & 0,0000 & \multirow{3}{*}{ Alma } \\
\hline 10 & 1,5900 & 0,0000 & 0,0000 & \\
\hline 11 & 1,5900 & 0,0453 & 0,0000 & \\
\hline
\end{tabular}

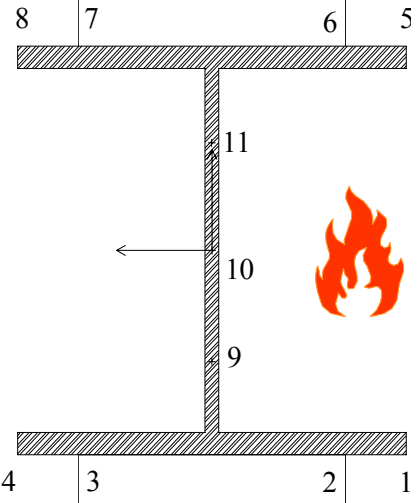

Figura 7.51: Localização dos nós em que foram medidos os deslocamentos laterais e a temperatura em relação ao TRF.

No que se segue, serão apresentados resultados de análises numéricas realizadas com referência à situação apresentada na figura 7.51, considerando agora apenas o elemento finito SOLID 45, lembrando que neste caso, diferentemente daquele apresentado no item 7.3, a carga térmica não é aplicada em todos os lados da seção, considerando, dessa forma a influência da compartimentação do ambiente.

Para as análises aqui realizadas, cujos resultados são apresentados no que segue, também serão consideradas as influências das direções das imperfeições globais, consideradas com sentidos em concordância com a figura 7.3 do item 7.2 do presente capítulo. 


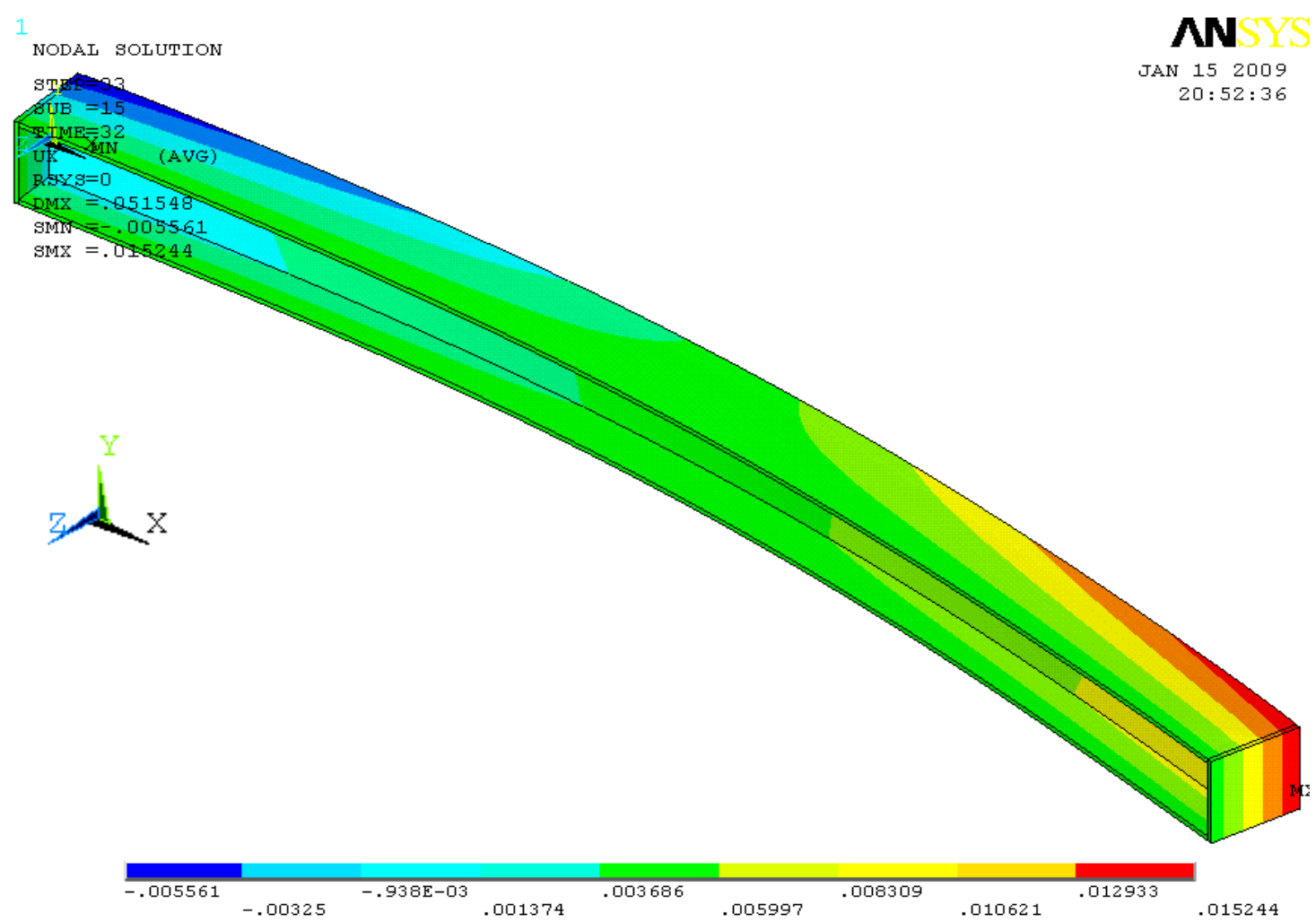

Figura 7.52: Configuração deformada em relação ao eixo x para uma força aplicada equivalente a $0,3 \mathrm{~N}$, ou seja, $364,4 \mathrm{kN}$ e TRF igual a 33 minutos, considerando campo térmico e imperfeição geométrica em sentidos opostos (imperfeição no sentido z-positivo)

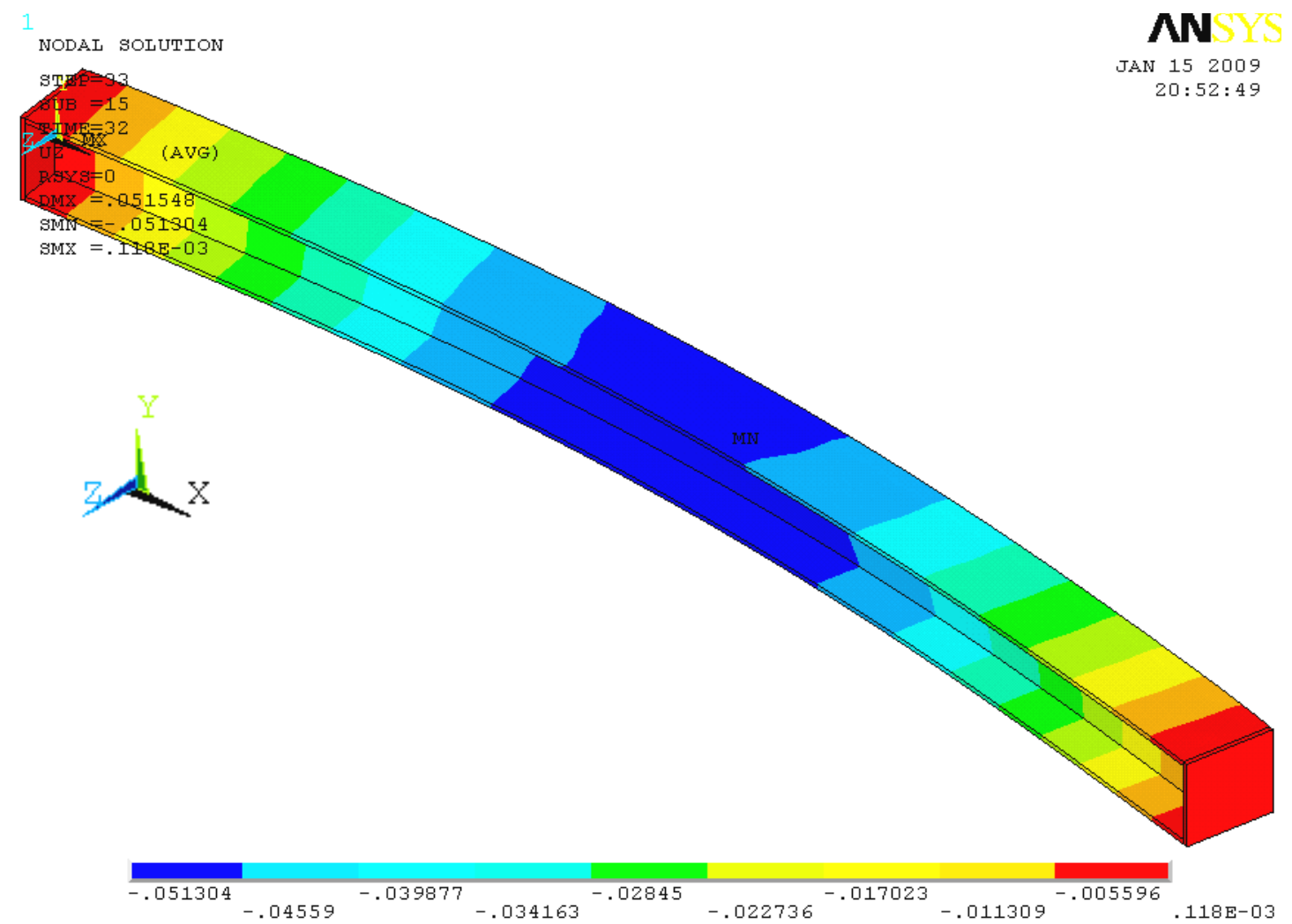

Figura 7.53: Configuração deformada em relação ao eixo z para uma força aplicada equivalente a $0,3 \mathrm{~N}$, ou seja, $364,4 \mathrm{kN}$ e TRF igual a 33 minutos, considerando campo térmico e imperfeição geométrica em sentidos opostos (imperfeição no sentido z-positivo). 


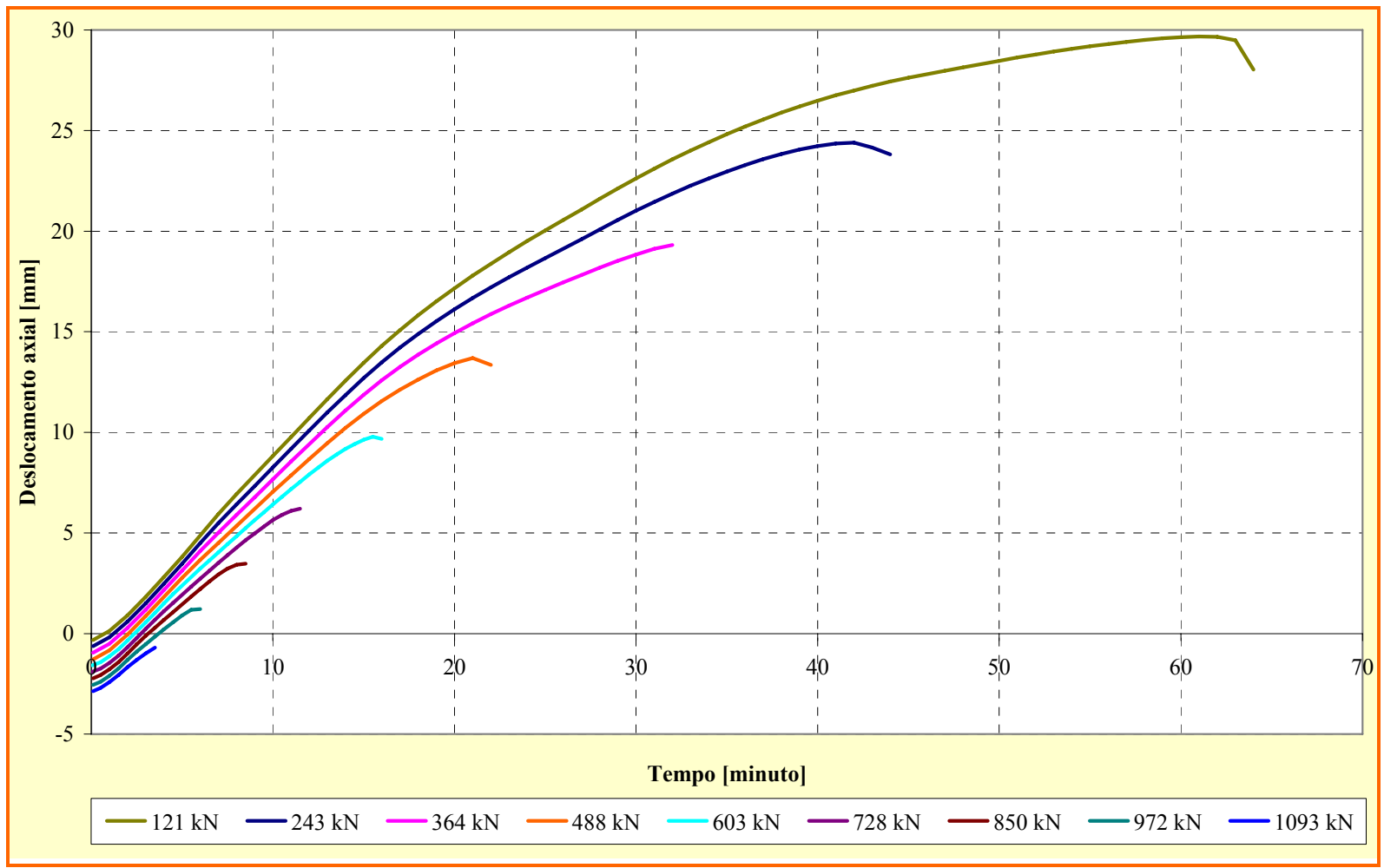

Figura 7.54: Deslocamento axial do pilar submetido ao um campo térmico no sentido znegativo e imperfeição geométrica no sentido z-positivo para os nove níveis de força aplicados.

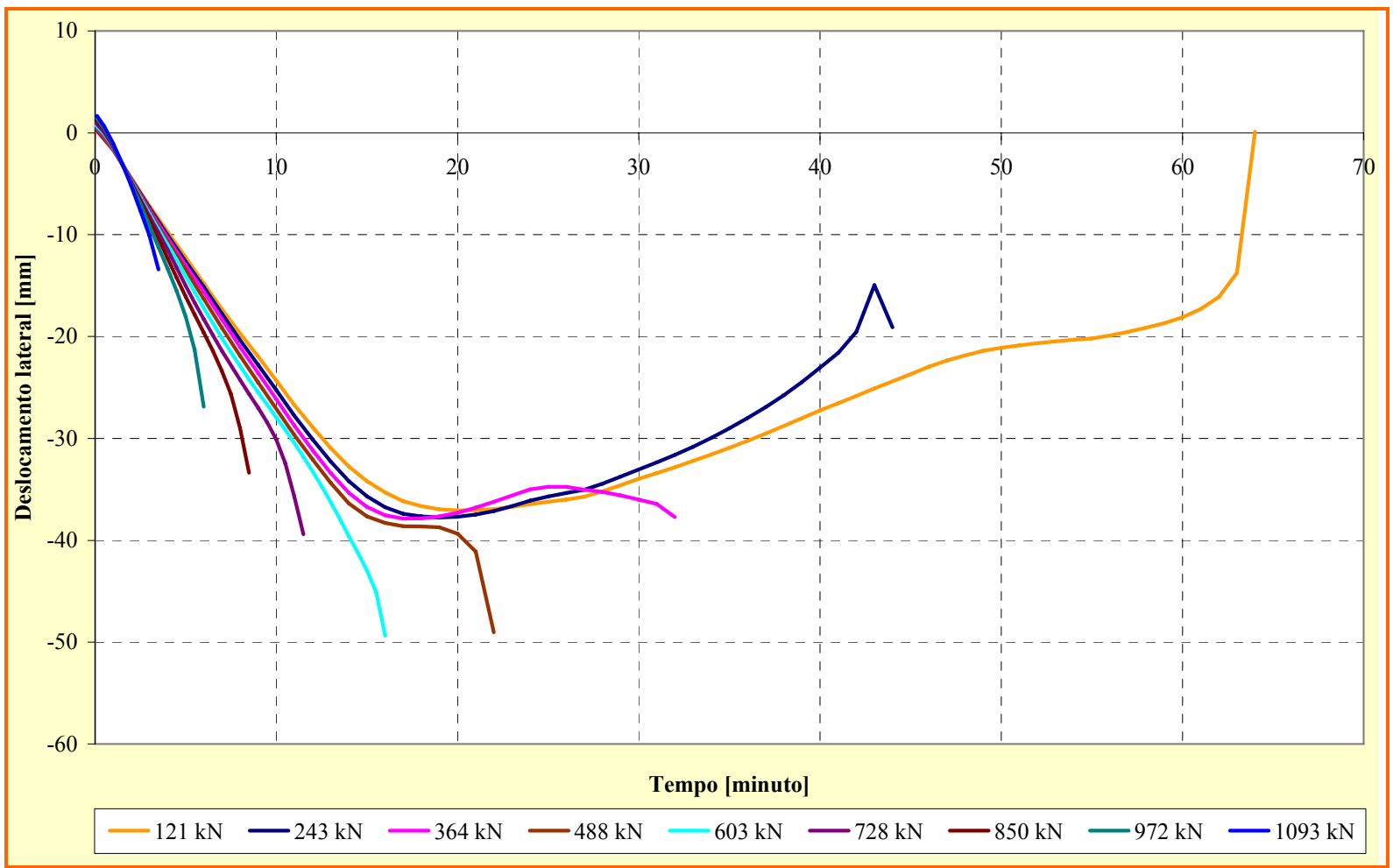

Figura 7.55: Deslocamento lateral do pilar submetido ao um campo térmico no sentido znegativo e imperfeição geométrica no sentido z-positivo para os nove níveis de força aplicados. 


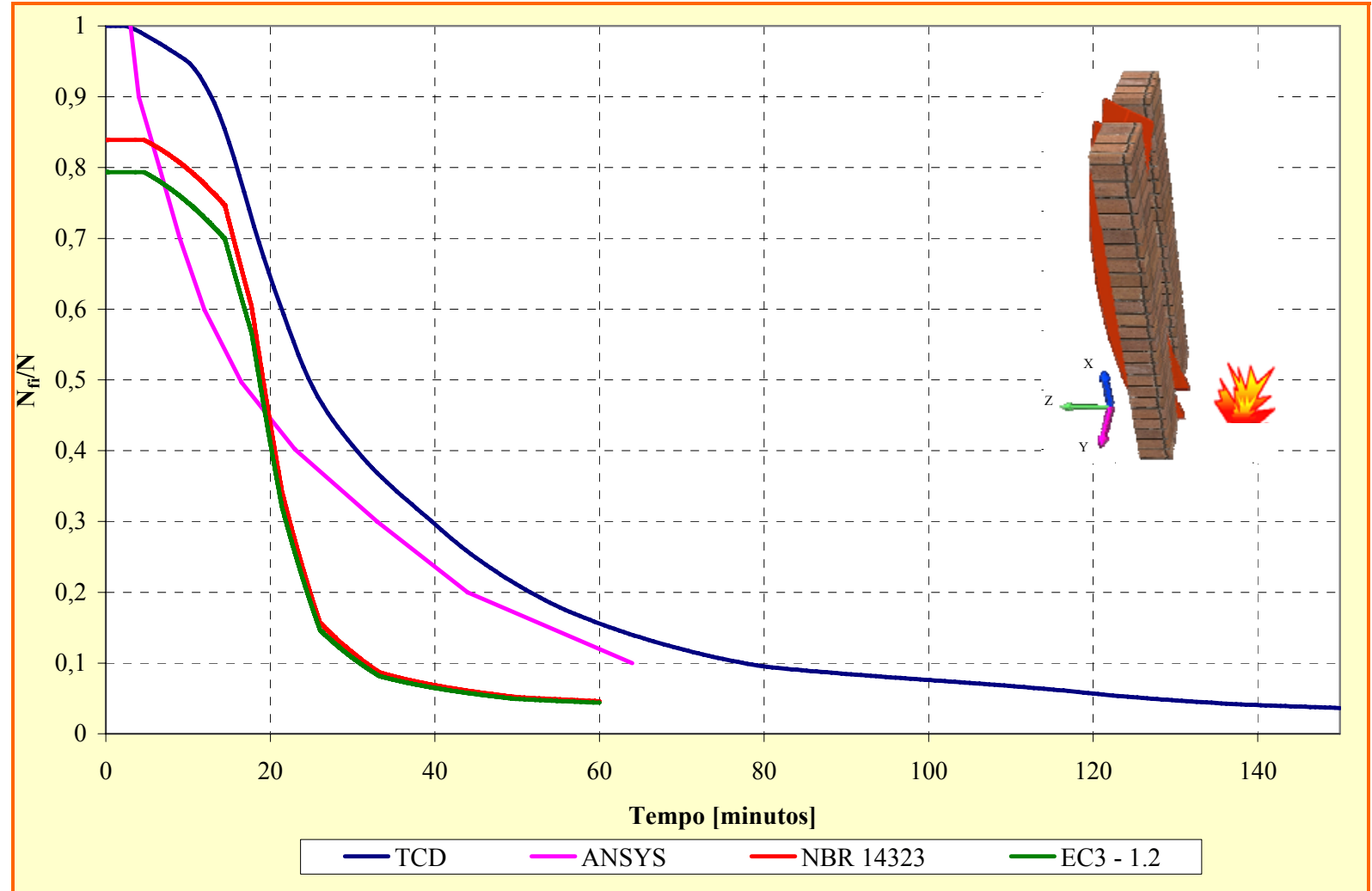

Figura 7.56: Comparação entre o TCD e o ANSYS relativo ao fator de redução da força de colapso em relação ao TRF, considerando campo térmico aplicado no sentido z-negativo e imperfeição geométrica em z-positivo.

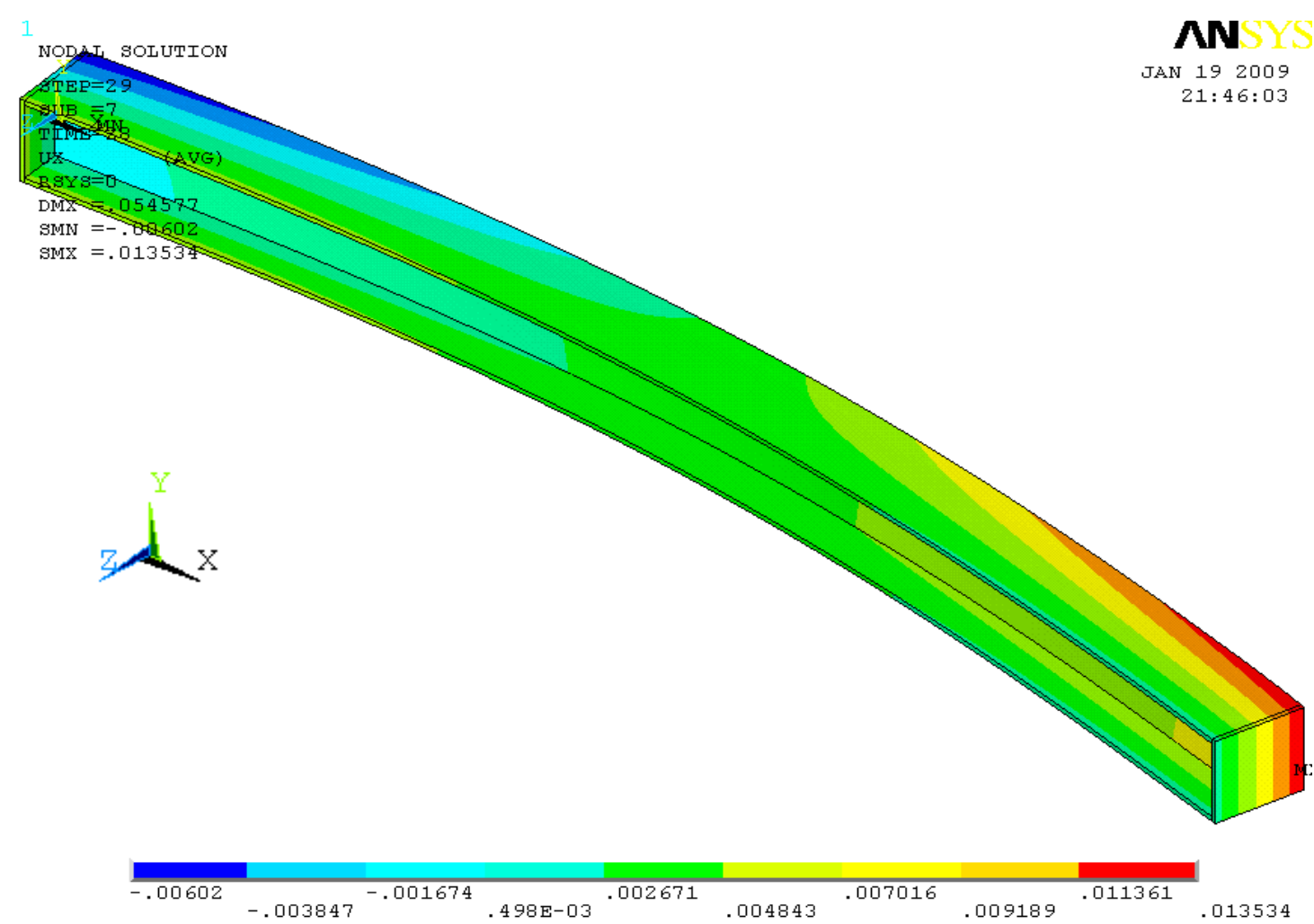

Figura 7.57: Configuração deformada em relação ao eixo x para uma força aplicada equivalente a $0,3 \mathrm{~N}$, ou seja, $364,4 \mathrm{kN}$ e TRF igual a 33 minutos, considerando campo térmico e imperfeição geométrica no sentido z-negativo. 

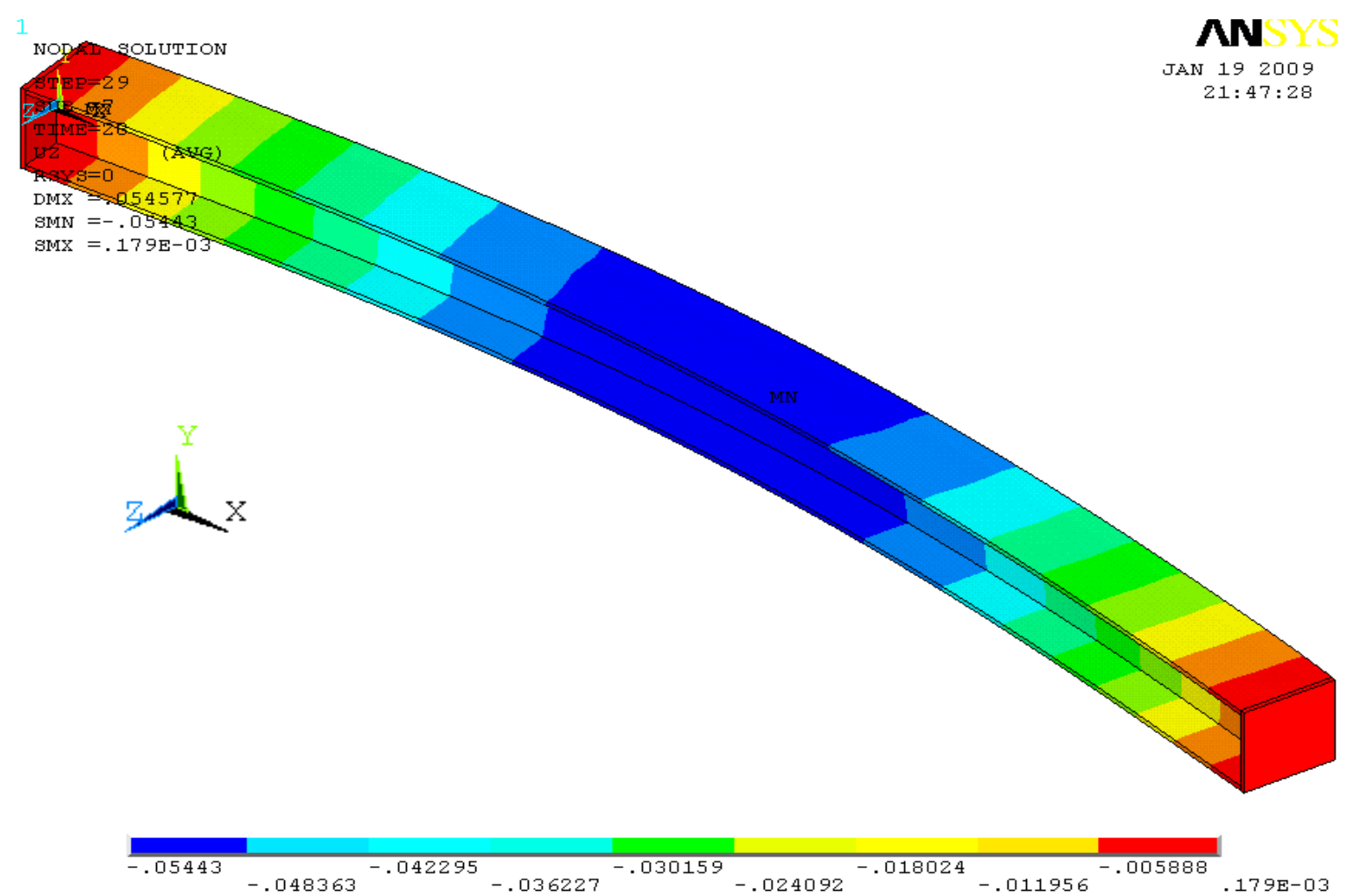

Figura 7.58: Configuração deformada em relação ao eixo z para uma força aplicada equivalente a $0,3 \mathrm{~N}$, TRF igual a 33 minutos, considerando campo térmico e imperfeição geométrica no sentido z-negativo.

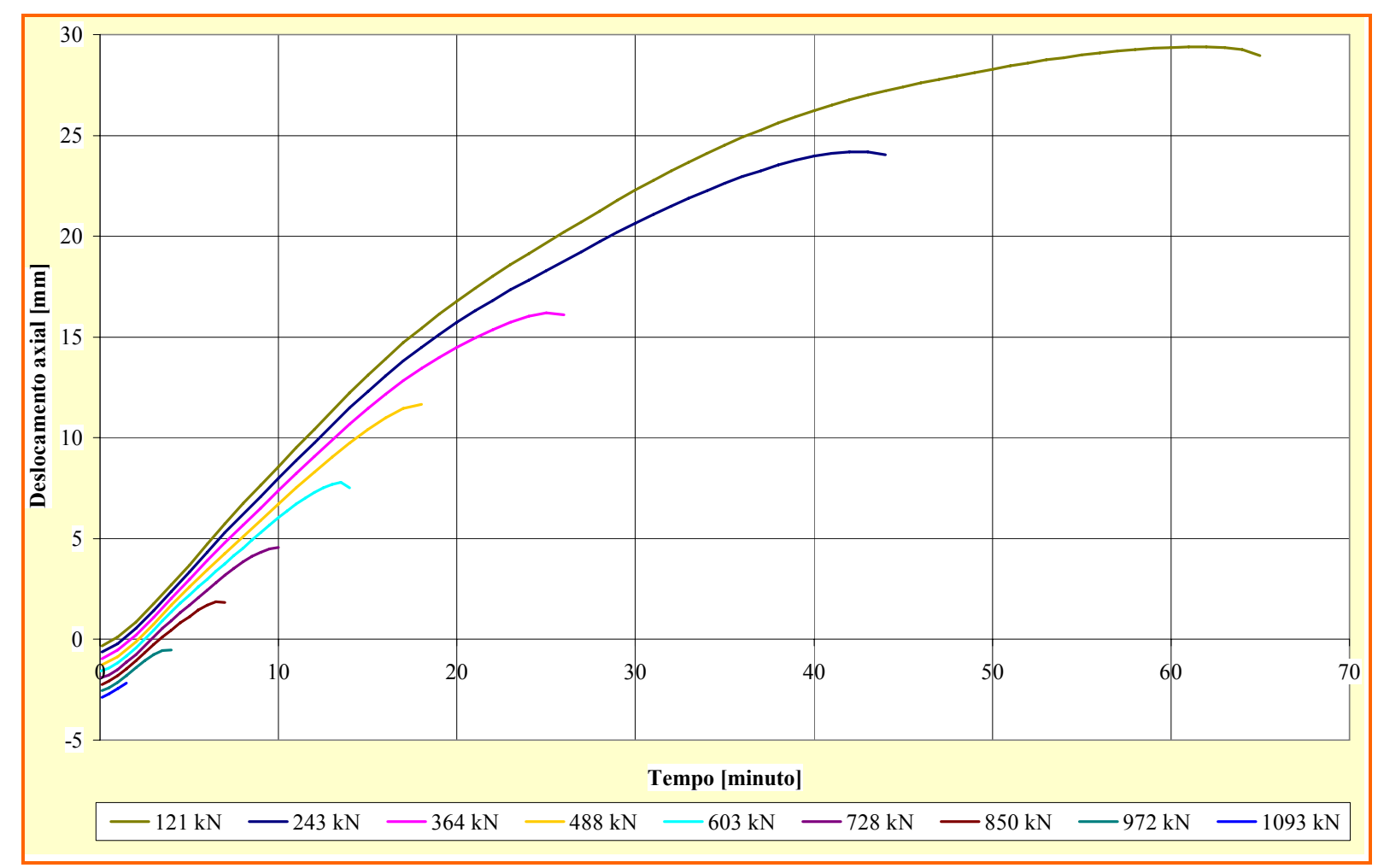

Figura 7.59: Deslocamento axial do pilar submetido ao um campo térmico e imperfeição geométrica no sentido z-negativo para os nove níveis de força aplicados. 


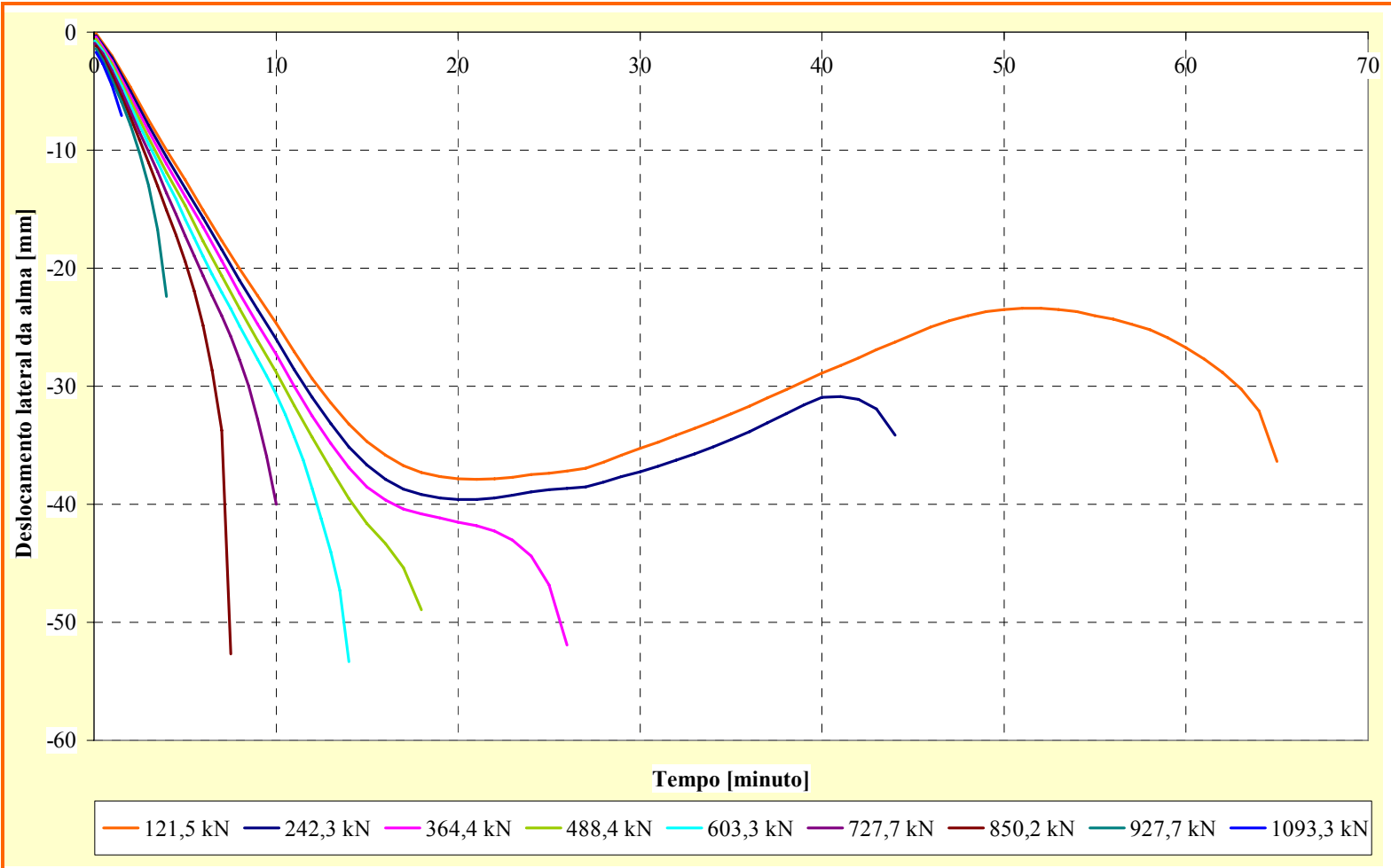

Figura 7.60: Deslocamento lateral do pilar submetido ao um campo térmico e imperfeição geométrica no sentido z-negativo para os nove níveis de força aplicados.

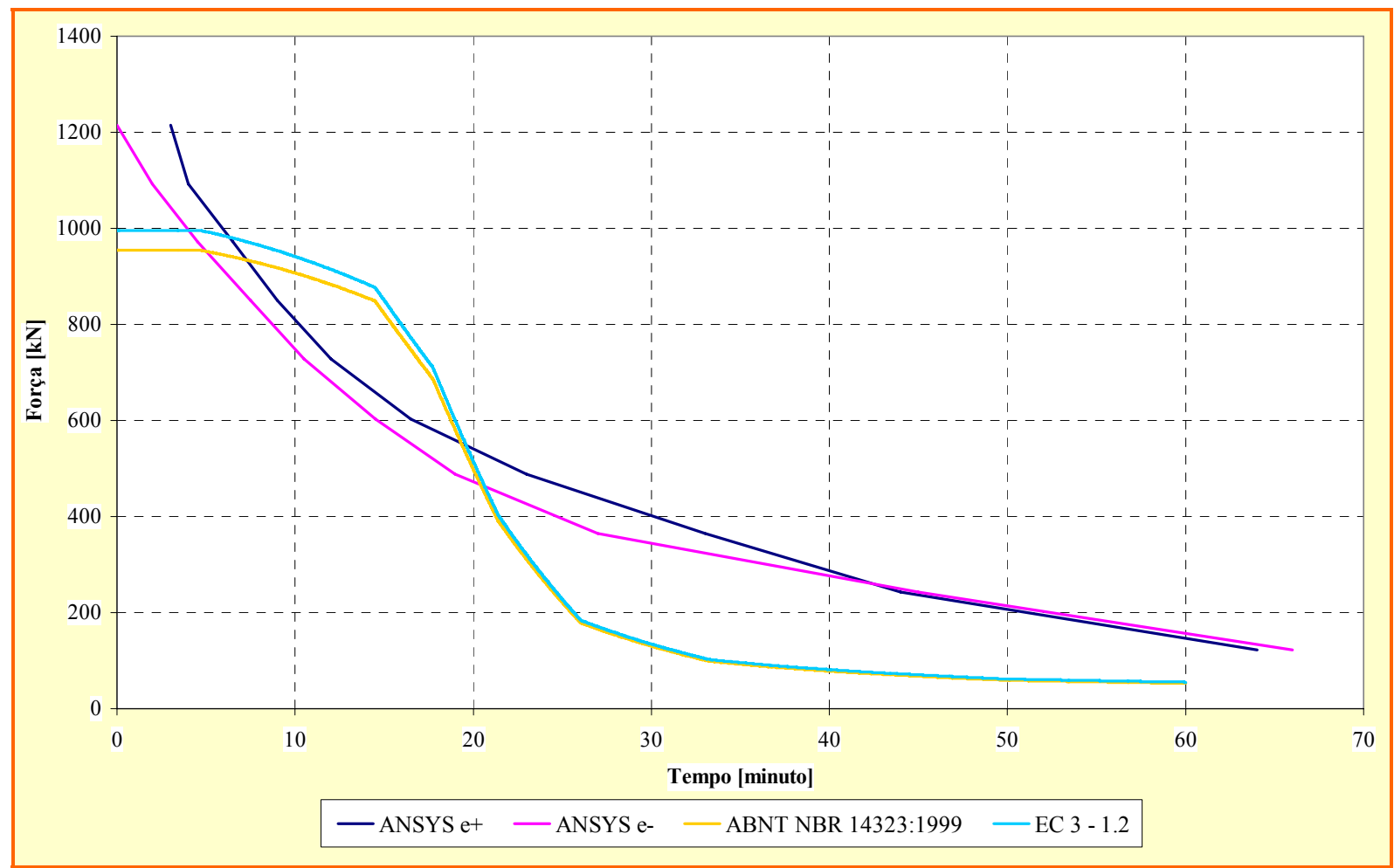

Figura 7.61: Variação da força de colapso [kN] em função do tempo (TRF) [minuto] obtido pelo ANSYS e por meio dos métodos simplificados da ABNT NBR 14323:1999 e do EC 31.2 . 


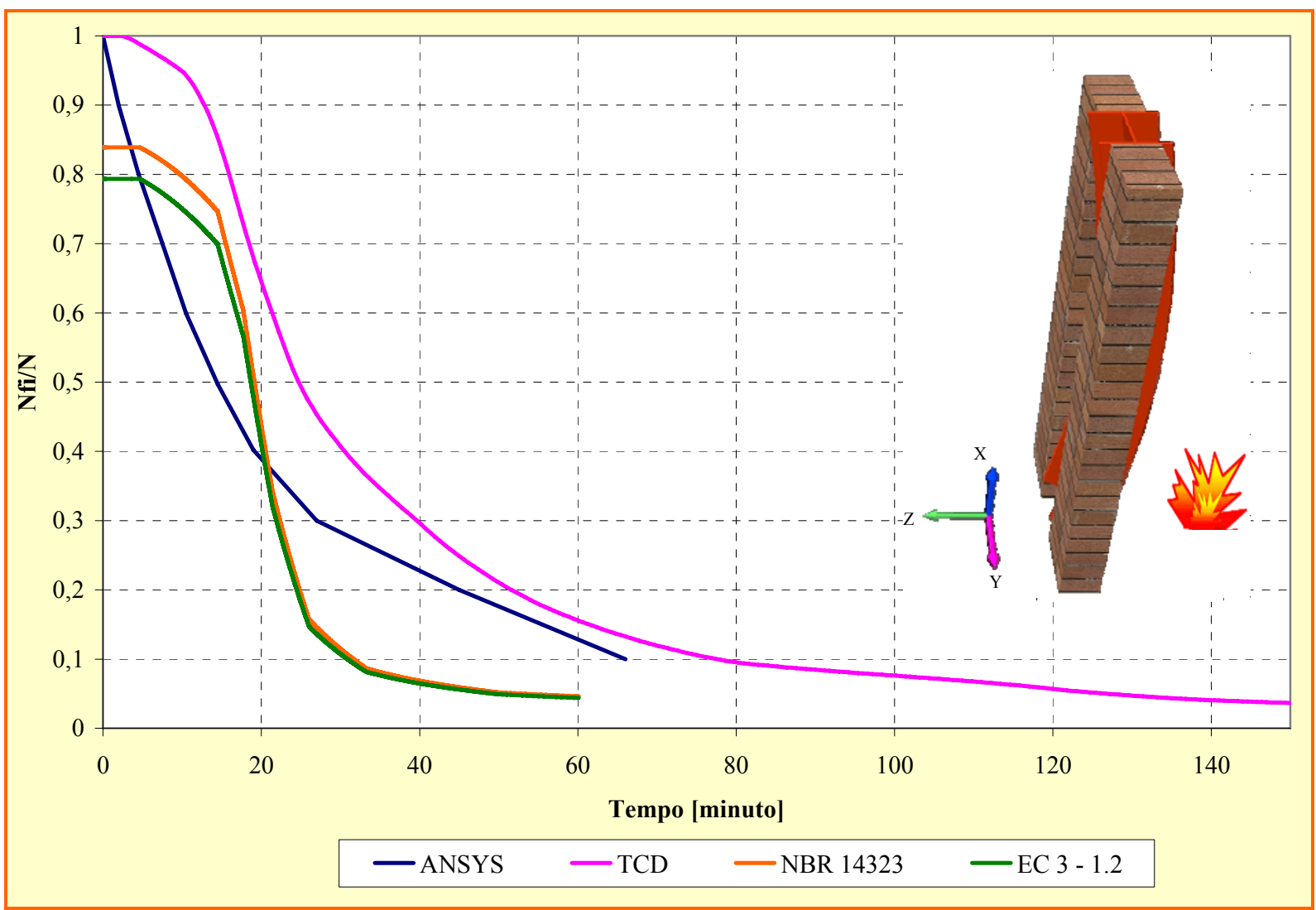

Figura 7.62: Comparação entre o TCD e o ANSYS relativo ao fator de redução da força de colapso em relação ao TRF, considerando campo térmico e imperfeição geométrica aplicados no sentido z-negativo.

Para os casos de pilares mais expostos ao campo térmico, como no presente caso, com paredes de alvenaria em contato com a mesa do perfil, para níveis mais baixos de força aplicada (entre $10 \%$ e $20 \%$ de $\mathrm{N}$ ) e pequenos valores de deslocamento lateral, não foi registrada diferença significativa no valor do tempo crítico para ambas as configurações. Essa comparação é ilustrada na Figura 7.61.

As Figuras 7.63 (a) e (b) ilustram o sentido da configuração deformada inicial e do campo térmico. A partir de valores de compressão aplicada equivalentes a $0,3 \cdot \mathrm{N}$ até $0,9 \cdot \mathrm{N}$, é possível observar mais claramente que o pilar submetido ao campo térmico e imperfeição global inicial no mesmo sentido apresenta TRF mais baixo. Os gráficos ilustrados na Figura 7.64 e 7.65 enfatizam a diferença na resposta estrutural obtida pela mudança no sentido do deslocamento inicial, por meio das curvas "Deslocamento $x$ tempo (TRF)". 
(a)
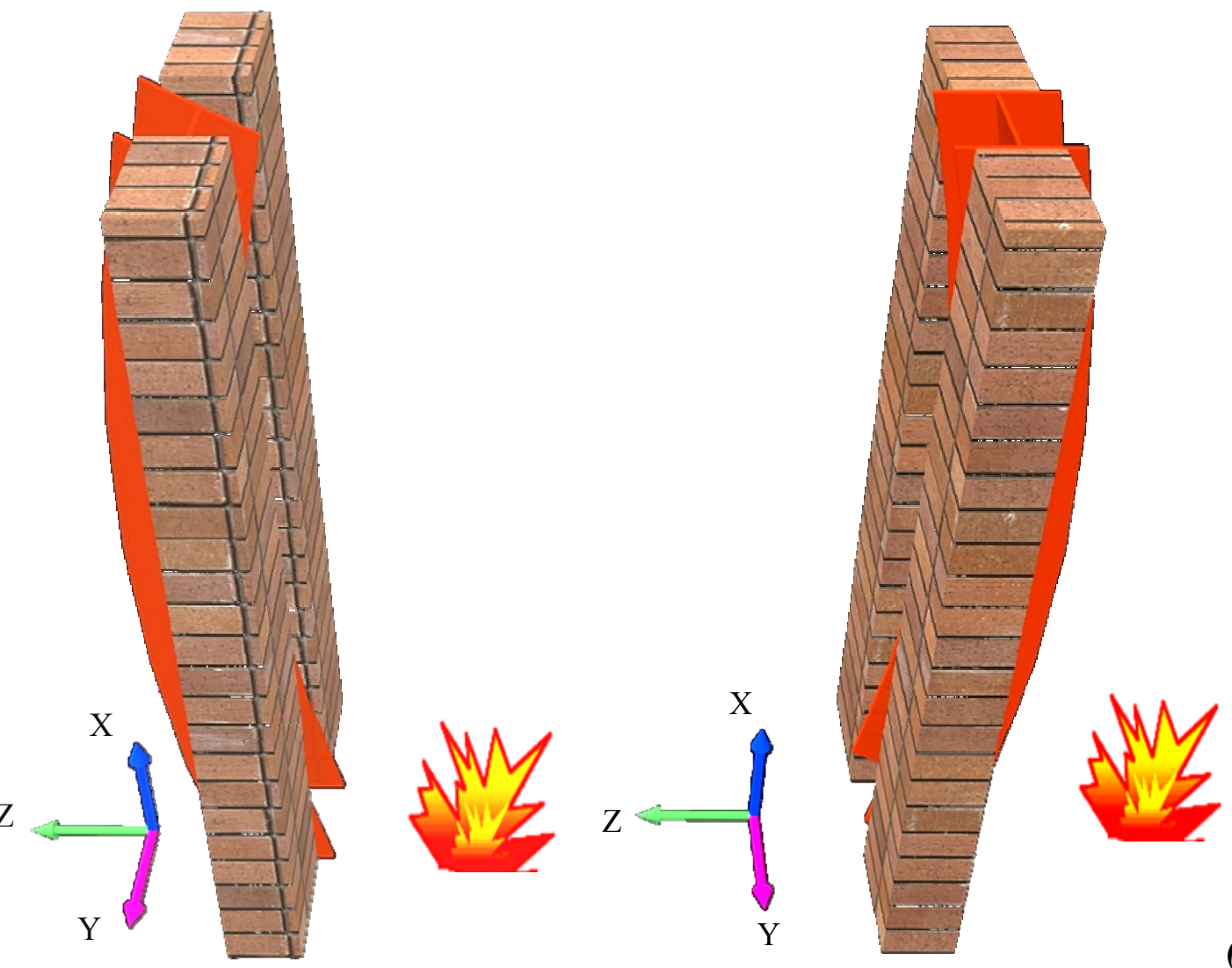

Figura 7.63: Imperfeição geométrica inicial e localização do campo térmico:

(b) (a) em sentidos opostos e (b) no mesmo sentido.

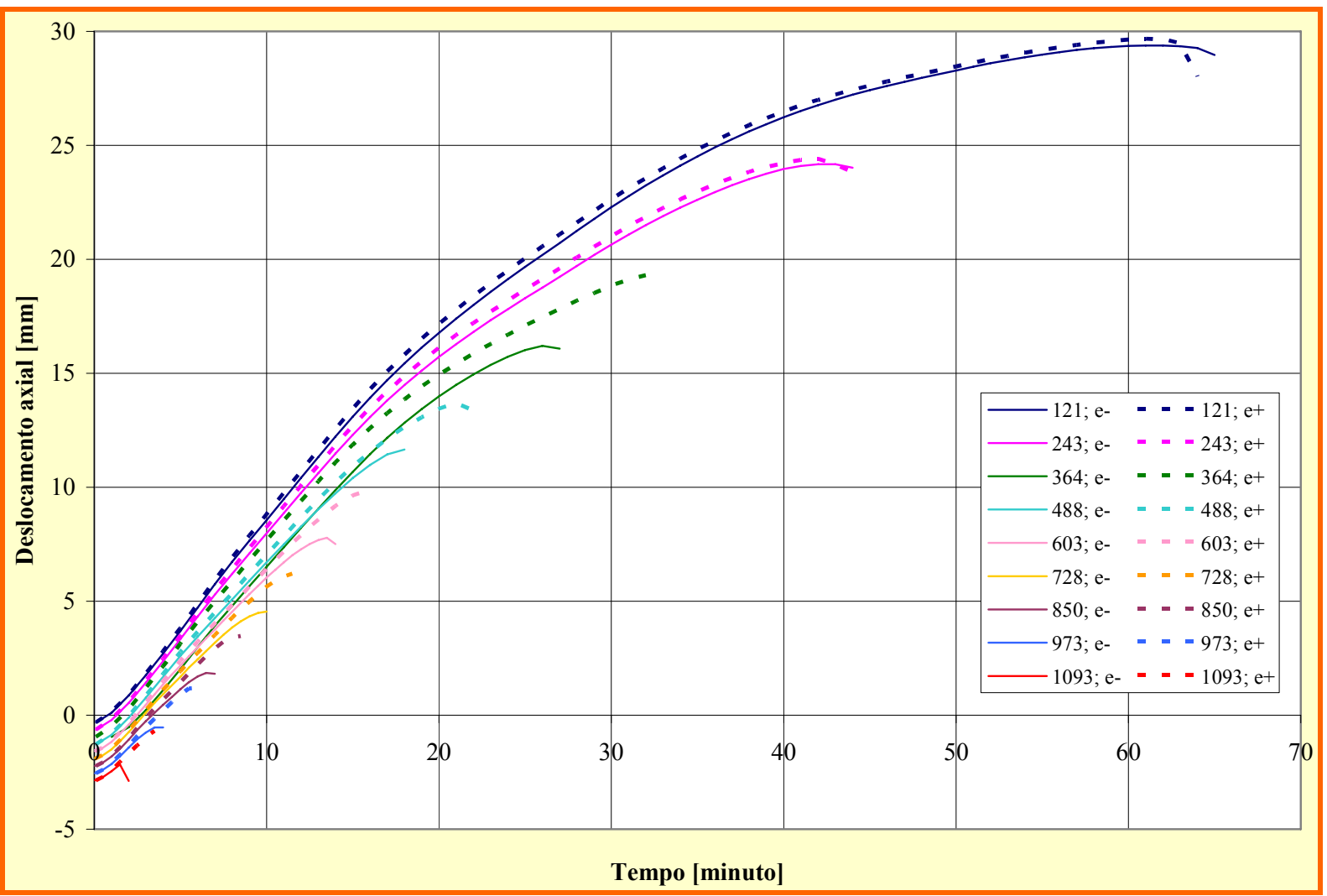

Figura 7.64: Comparativo entre o deslocamento axial considerando deslocamentos iniciais de sentidos opostos 


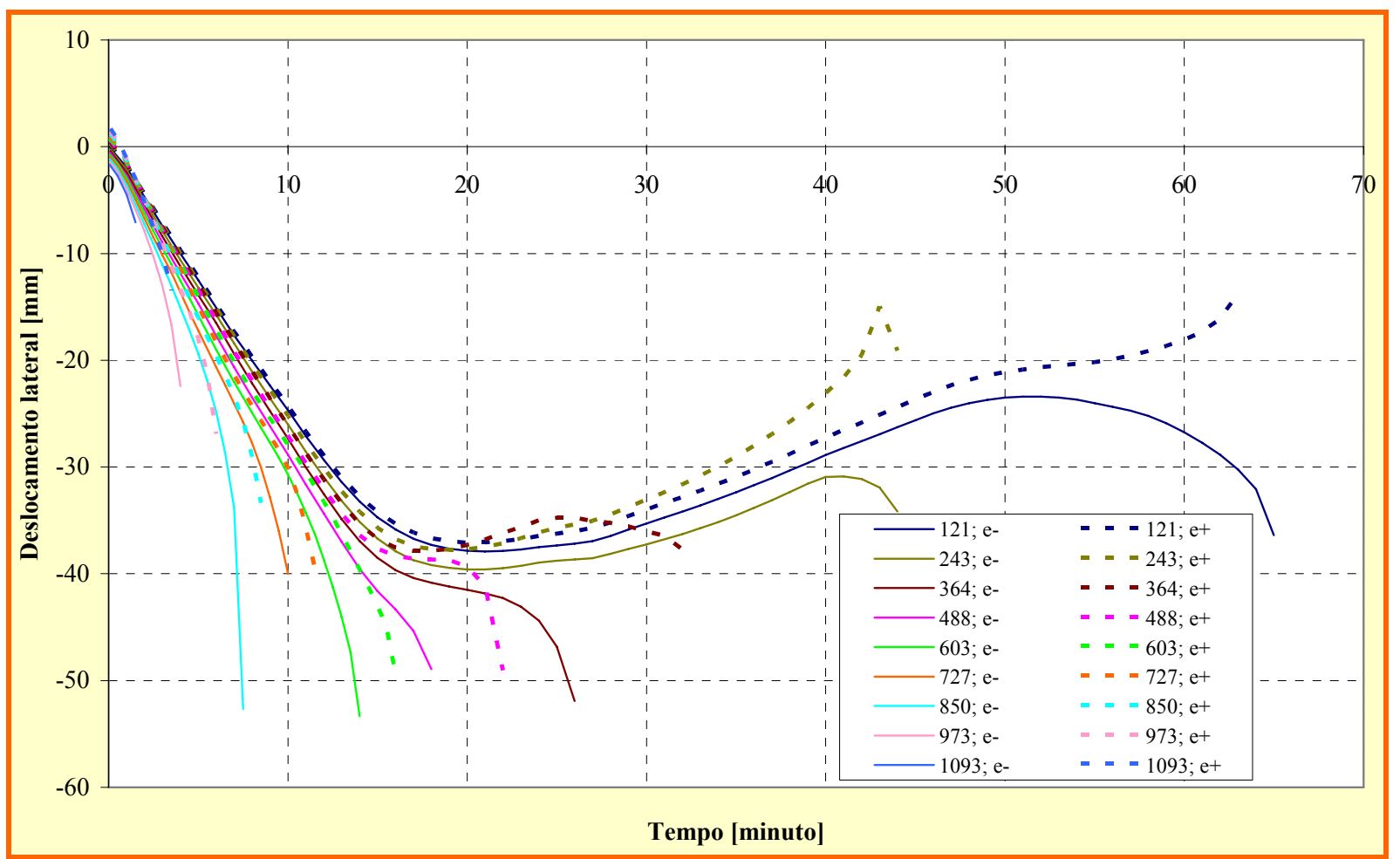

Figura 7.65: Comparativo entre o deslocamento lateral considerando deslocamentos iniciais de sentidos opostos

\subsection{Estudo de caso - INSTITUTO FÁBRICA DO MILÊNIO}

O exemplo apresentado no presente item se refere a um estudo de caso de uma edificação real, com disposições de pilares e vigas já estabelecidos, bem como com as condições de compartimentação estabelecidas. Trata-se do Edifício Fábrica do Milênio, integrado ao Departamento de Engenharia de Produção da EESC/USP, já em funcionamento, do qual foram escolhidos dois pilares pertencentes à parte interna com suas correspondentes condições de compartimentação. As Figuras 7.66 e 7.67 ilustram a edificação mencionada com vista da parte externa da mesma e durante a fase de construção. 


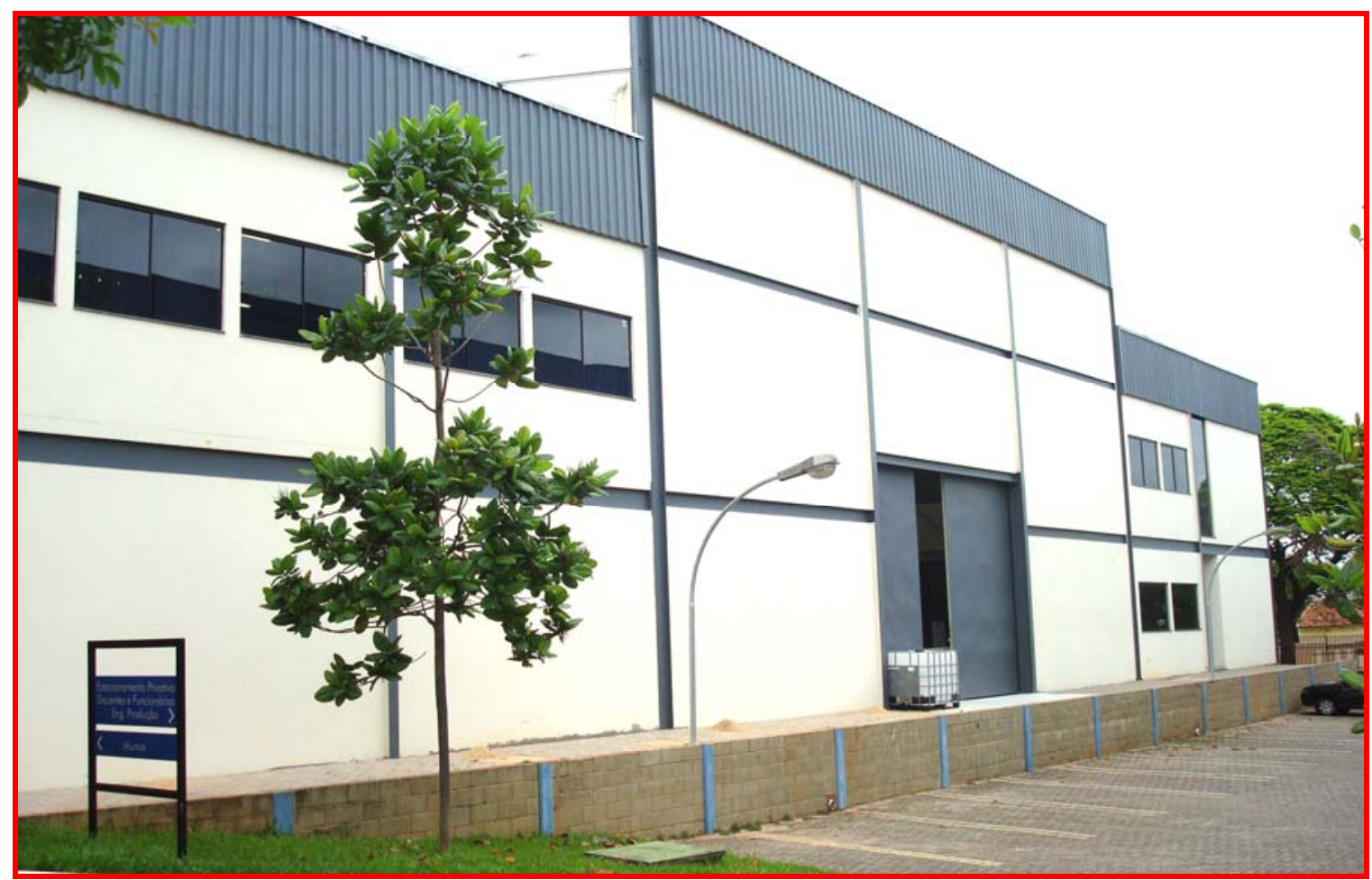

Figura 7.66: Vista geral do Edifício Fábrica do Milênio, Eng. Produção da EESC/USP

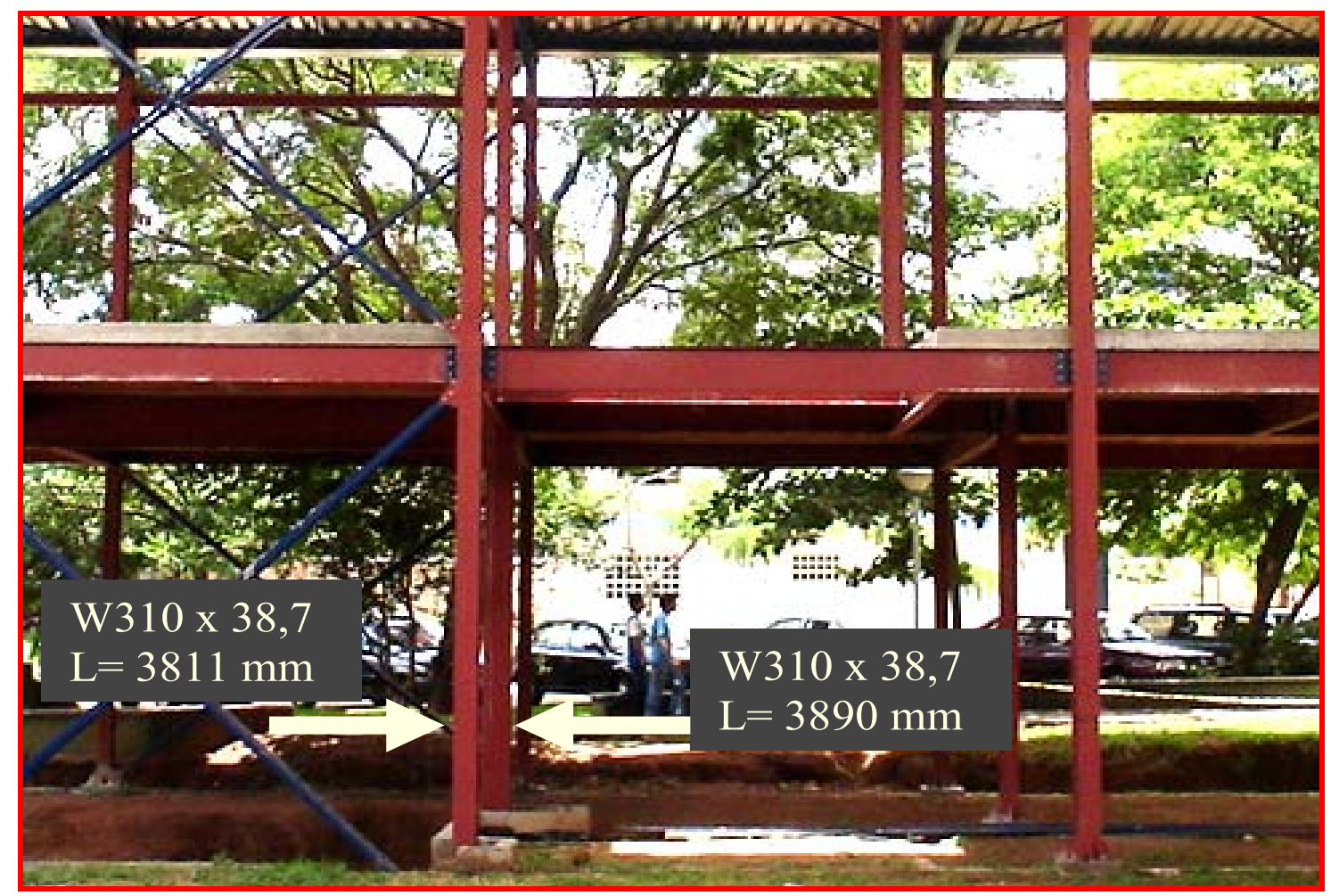

Figura 7.67: Localização dos nós em que foram medidos os deslocamentos laterais e a temperatura em relação ao TRF. 


\subsubsection{PILAR W310 X 38,7 L = 3811 mm}

Para esse caso, a temperatura e o deslocamento lateral no pilar foram medidos em pontos previamente estabelecidos e de interesse, conforme ilustrados na Figura 7.68, com aquecimento admitido uniforme ao longo do comprimento. A condição assimétrica de aquecimento é determinada pelas paredes em contato com a mesa superior e com a alma.

\begin{tabular}{|c|c|c|c|l|}
\hline Nó & $\mathrm{X}$ & $\mathrm{Y}$ & $\mathrm{Z}$ & \\
\hline 1 & 1,906 & $-0,155$ & $-0,083$ & \\
\cline { 1 - 4 } 2 & 1,906 & $-0,155$ & 0,083 & \multirow{2}{*}{ Mesa } \\
\hline 3 & 1,906 & 0,155 & $-0,083$ & \\
\hline 4 & 1,906 & 0,155 & $-0,018$ & \\
\hline 5 & 1,906 & 0,000 & $-0,003$ & \multirow{2}{*}{ Alma } \\
\hline 6 & 1,906 & 0,100 & $-0,003$ & \\
\hline
\end{tabular}

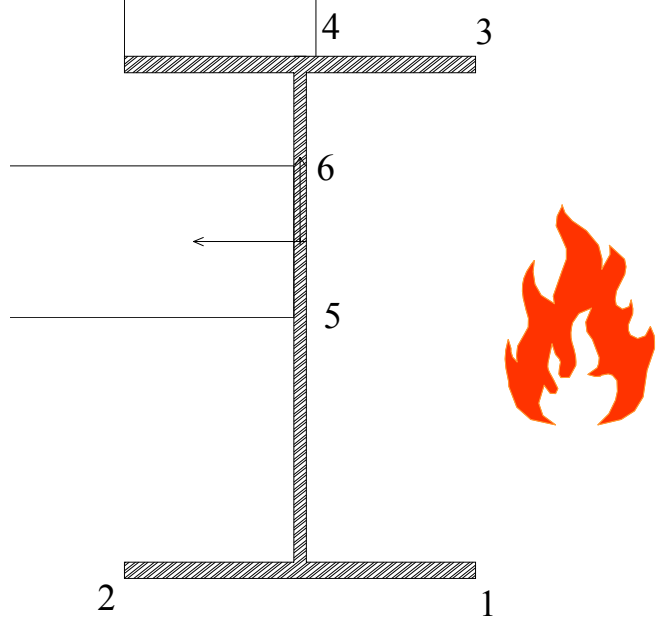

Figura 7.68: Nós em que foram medidos os deslocamentos laterais e a temperatura em relação ao TRF.

No que se segue, serão apresentados resultados de análises numéricas realizadas com referência à situação apresentada na Figura 7.68. Por meio das Figuras 7.69 a 7.72, são apresentadas as trajetórias de deslocamento em função do tempo (TRF), tanto axial do topo como lateral monitorado na seção transversal no meio da barra.

A trajetória dos deslocamentos laterais apresentados na Figura 7.72 diz respeito apenas daqueles monitorados na alma. Neste caso, a análise é realizada apenas considerando a imperfeição global aplicada em sentido oposto ao campo térmico. As figuras 7.73 e 7.74 correspondem a variação da força correspondente ao colapso (valores relativo e absoluto) em função do tempo (TRF). 


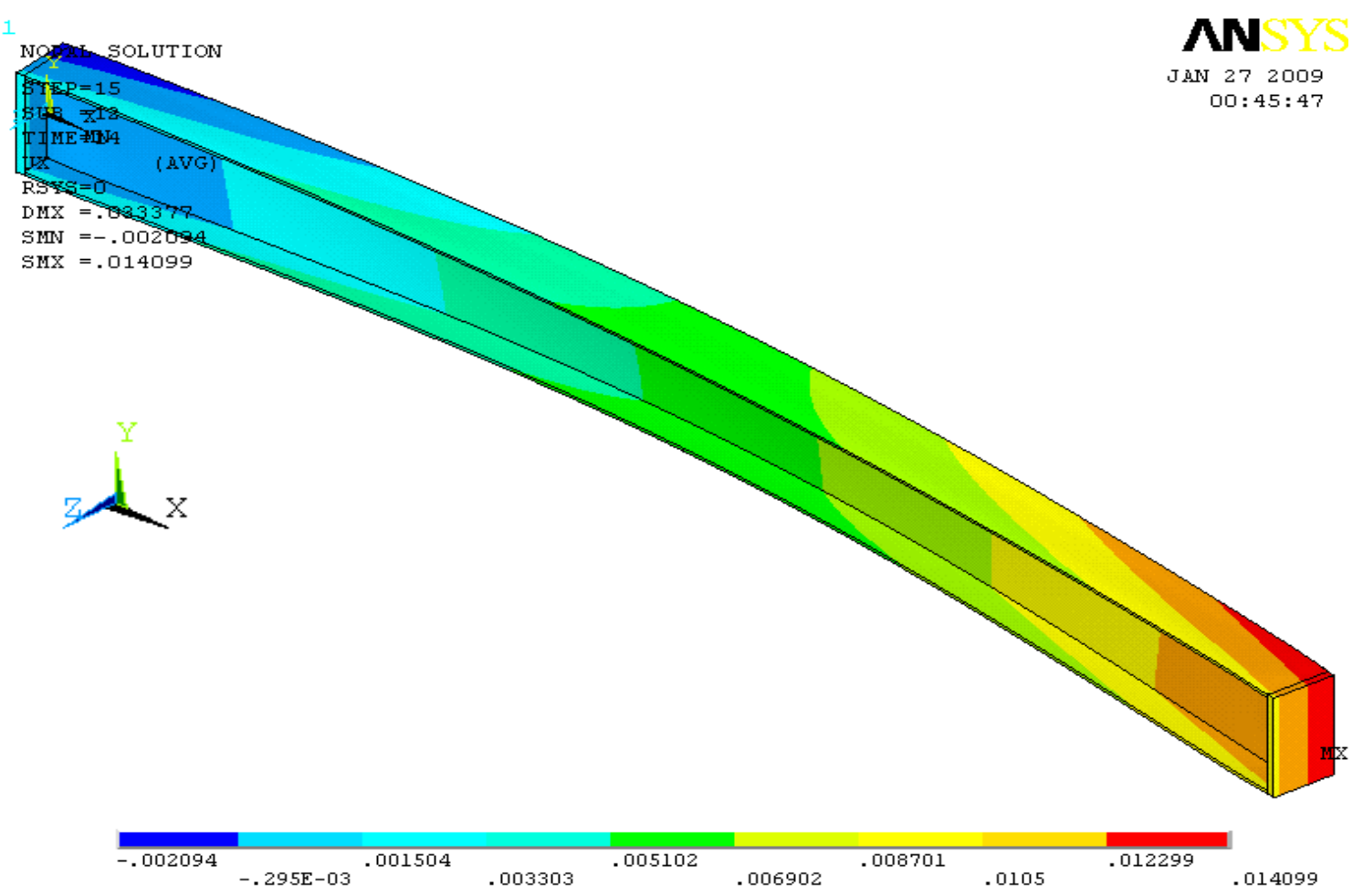

Figura 7.69: Configuração deformada em relação ao eixo x para uma força aplicada equivalente a $0,5 \mathrm{~N}$, ou seja, $337 \mathrm{kN}$ e TRF igual a 7,5 minutos, correspondente ao tempo crítico, considerando campo térmico e imperfeição geométrica no mesmo sentido.

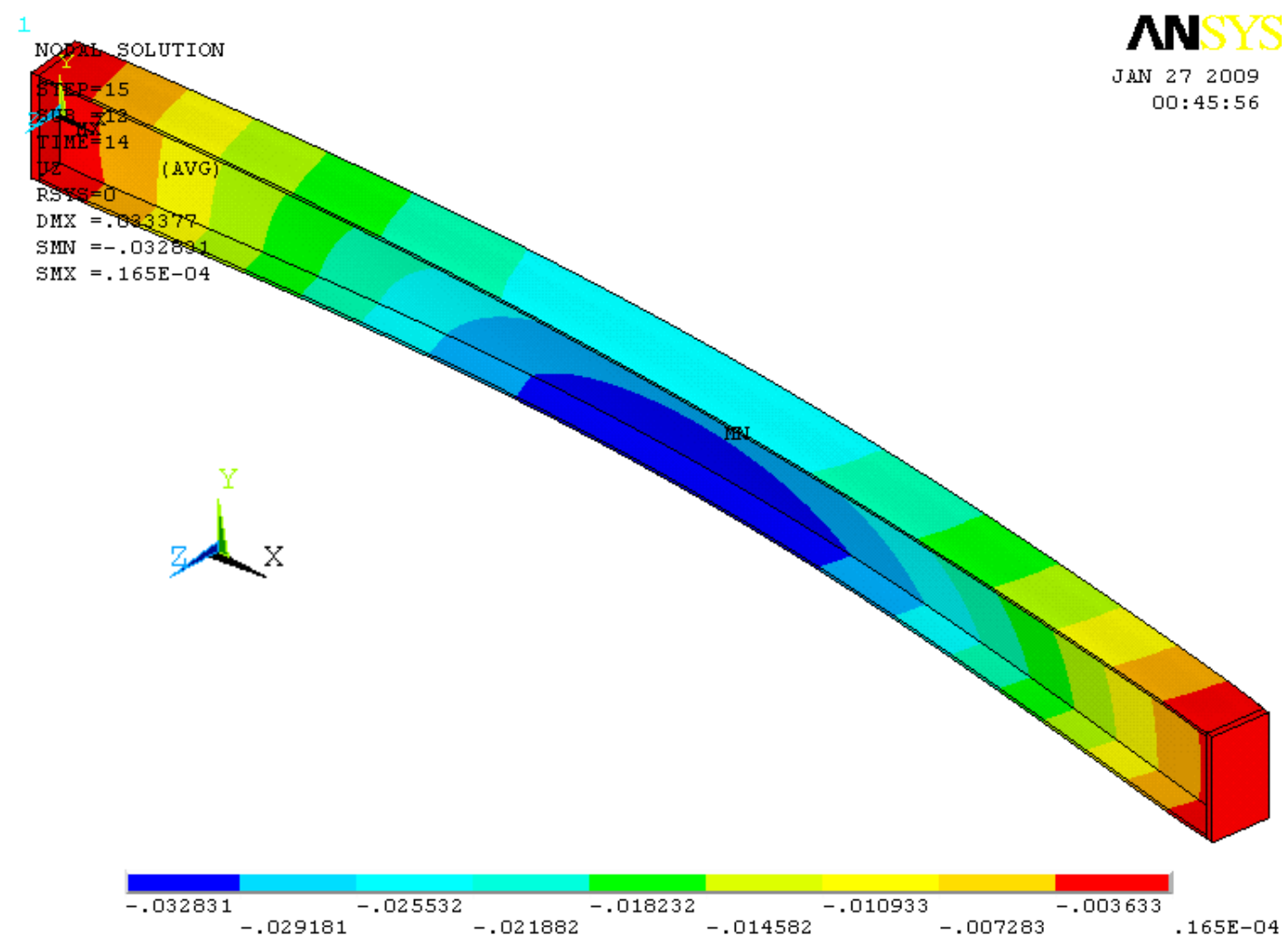

Figura 7.70: Configuração deformada em relação ao eixo $\mathrm{z}$ para uma força aplicada equivalente a $0,5 \mathrm{~N}$, TRF igual a 7,5 minutos, correspondente ao tempo crítico, considerando campo térmico e imperfeição geométrica no mesmo sentido. 


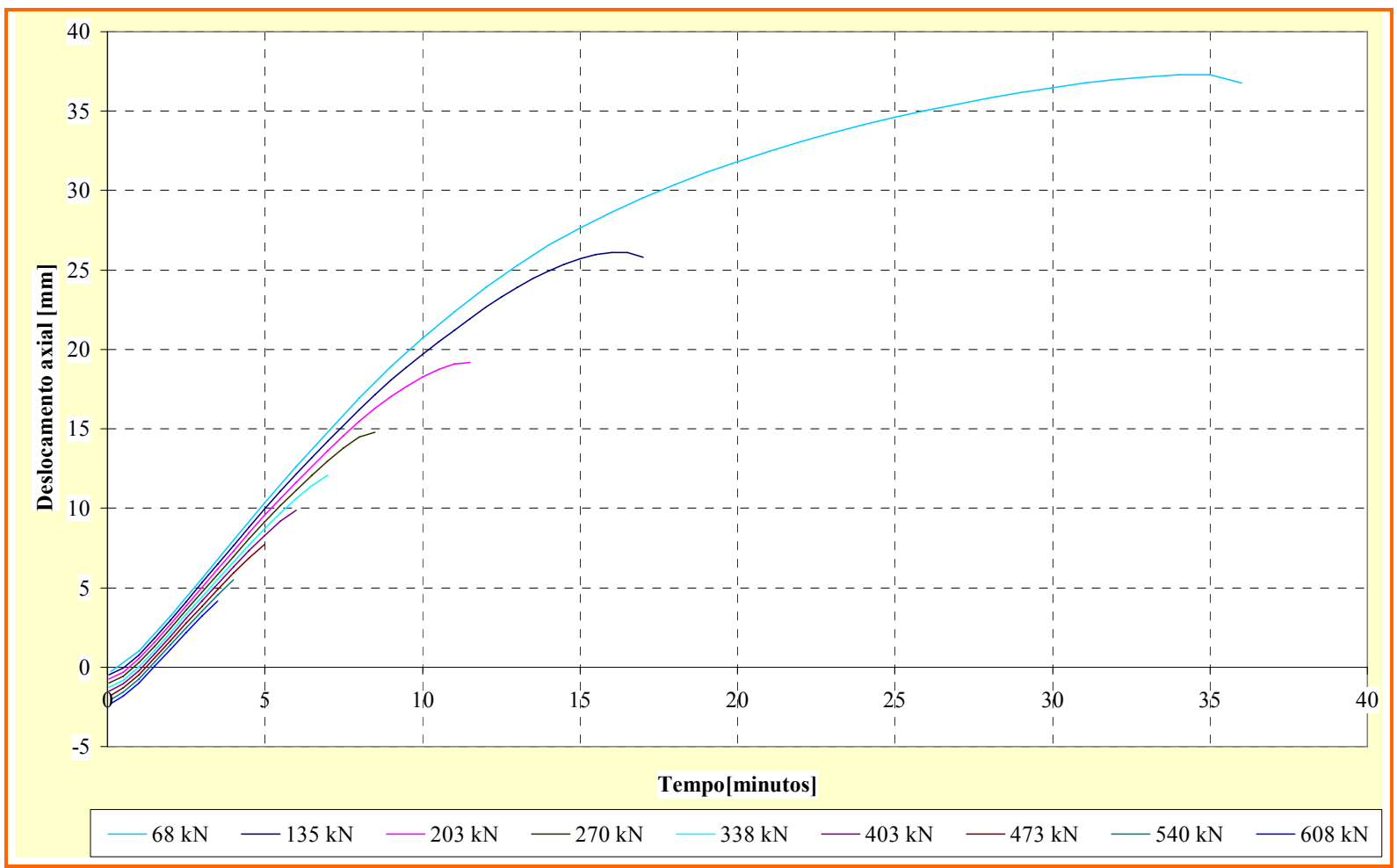

Figura 7.71: Deslocamento axial do pilar submetido ao um campo térmico e imperfeição geométrica no sentido z-negativo para os nove níveis de força aplicados.

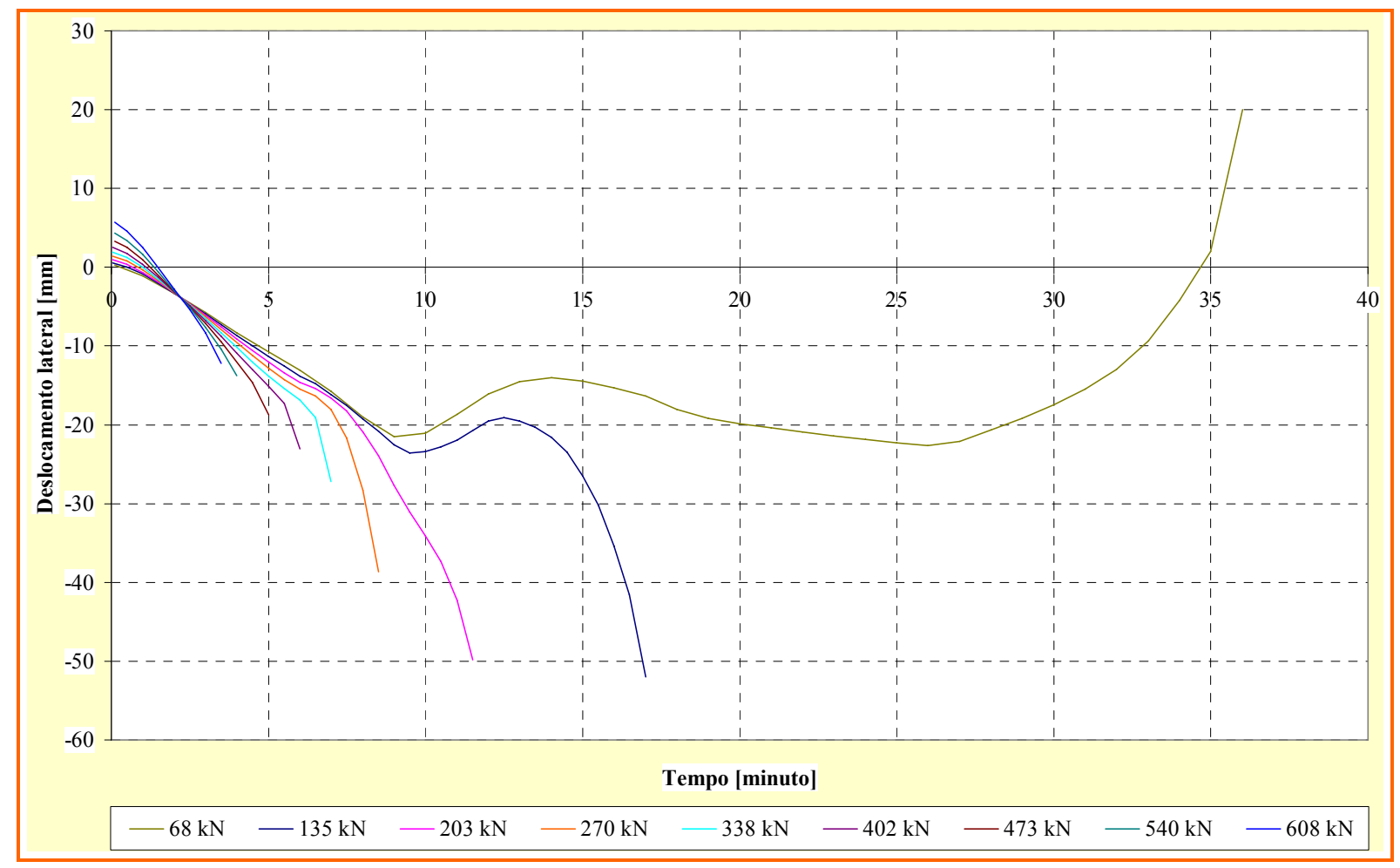

Figura 7.72: Deslocamento lateral do pilar submetido ao um campo térmico e imperfeição geométrica no sentido z-negativo para os nove níveis de força aplicados. 


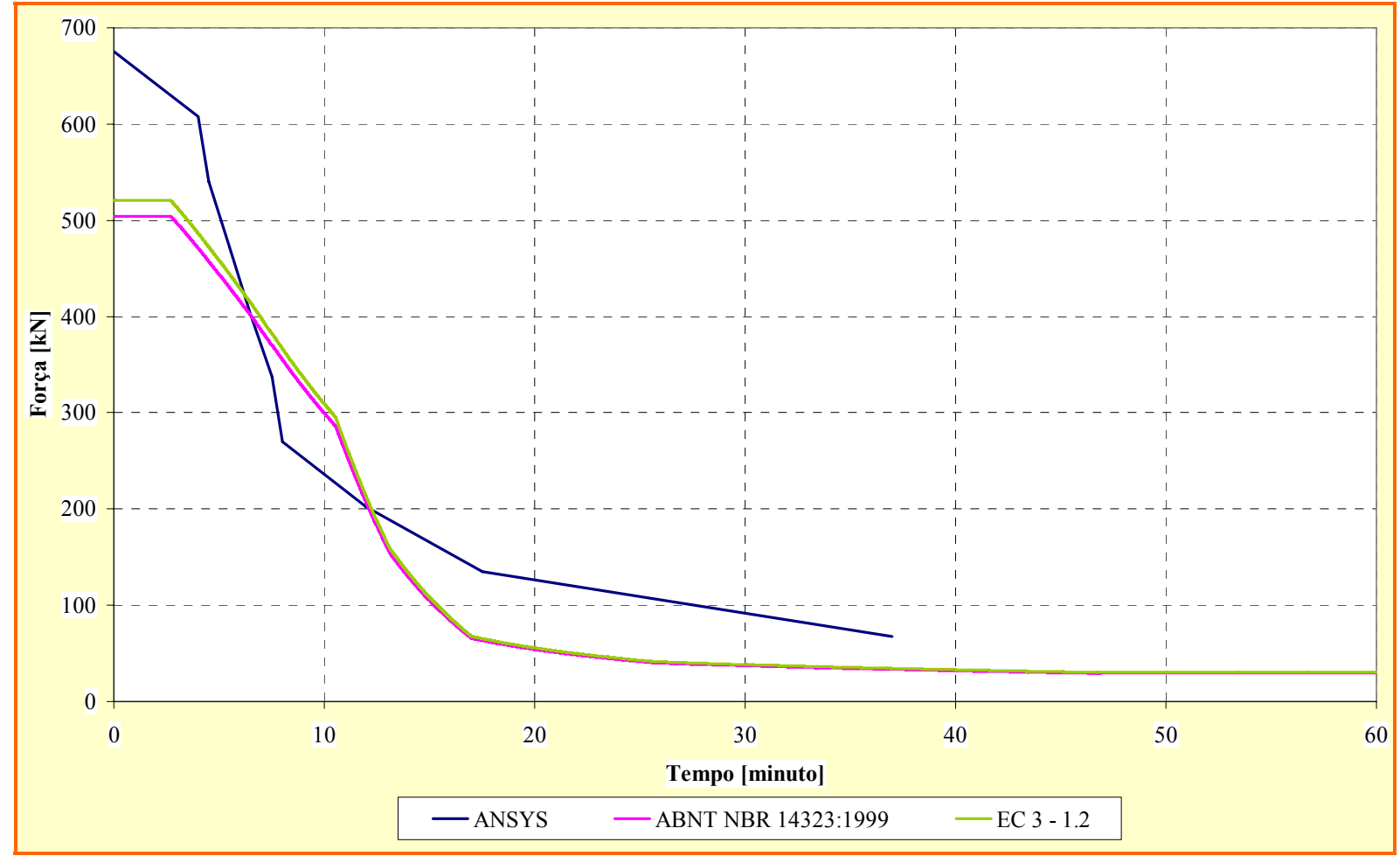

Figura 7.73: Variação da força de colapso [kN] em função do tempo (TRF) [minuto] obtido pelo ANSYS e por meio dos métodos simplificados da ABNT NBR 14323:1999 e do EC 3 1.2 .

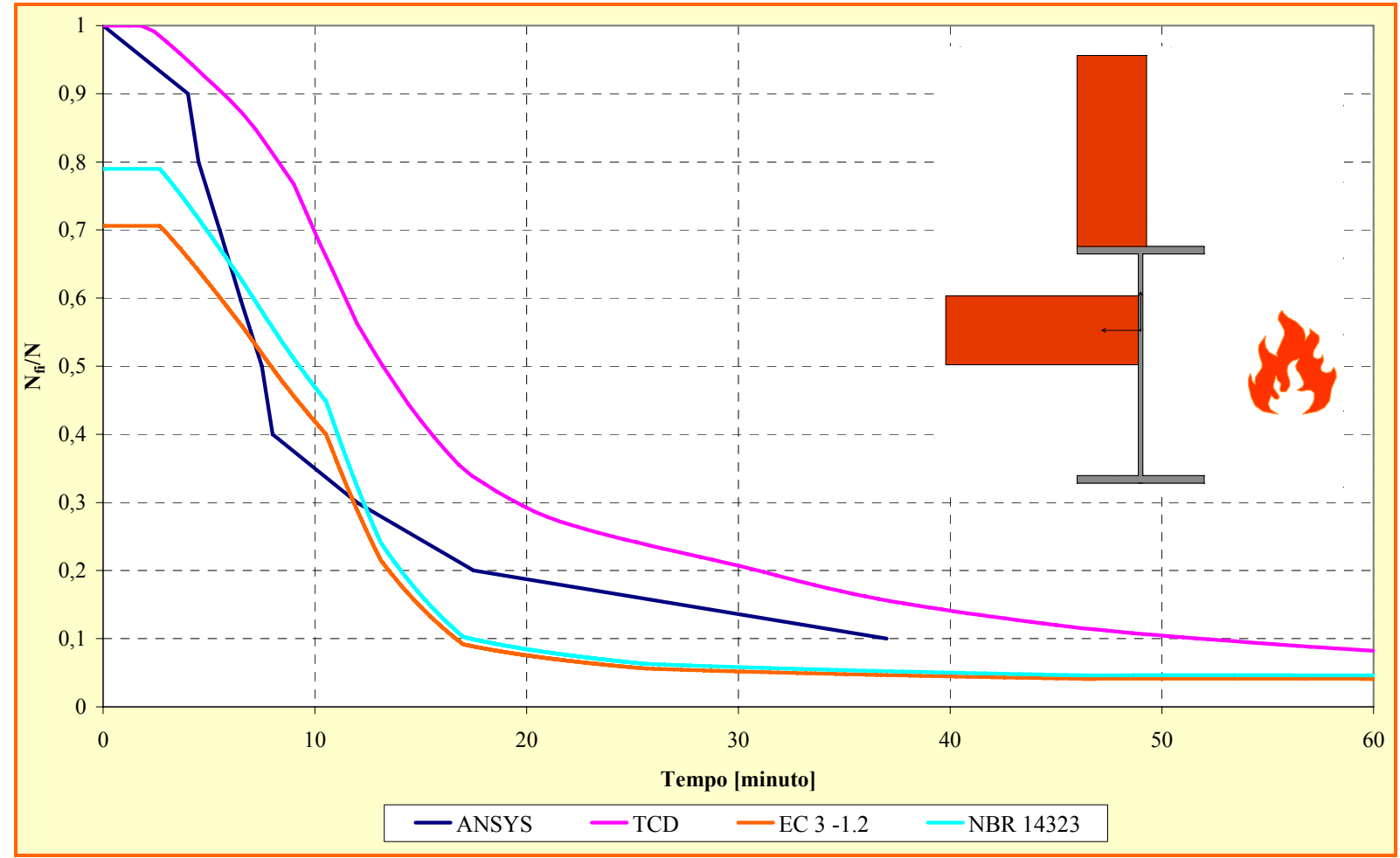

Figura 7.74: Comparação entre o fator de redução obtido via ANSYS, SuperTempcalc, métodos simplificados do Eurocode 3-2 e da ABNT NBR14323:1999. 


\subsubsection{PILAR W310 X 38,7 L $=3890 \mathrm{~mm}$}

Para esse caso, a temperatura e o deslocamento lateral no pilar foram medidos em determinados pontos, conforme ilustrados na Figura 7.75, com aquecimento admitido uniforme ao longo do comprimento.

\begin{tabular}{|c|c|c|c|c|}
\hline Nó & $X$ & $\mathrm{Y}$ & $Z$ & \\
\hline 1 & 1,945 & $-0,155$ & $-0,083$ & \multirow{8}{*}{ Mesa } \\
\hline 2 & 1,945 & $-0,155$ & $-0,070$ & \\
\hline 3 & 1,945 & $-0,155$ & 0,070 & \\
\hline 4 & 1,945 & $-0,155$ & 0,083 & \\
\hline 5 & 1,945 & 0,155 & $-0,083$ & \\
\hline 6 & 1,945 & 0,155 & $-0,070$ & \\
\hline 7 & 1,945 & 0,155 & 0,070 & \\
\hline 8 & 1,945 & 0,155 & 0,083 & \\
\hline 9 & 1,945 & 0,000 & 0,003 & \multirow{2}{*}{ Alma } \\
\hline 10 & 1,945 & 0,100 & 0,003 & \\
\hline
\end{tabular}

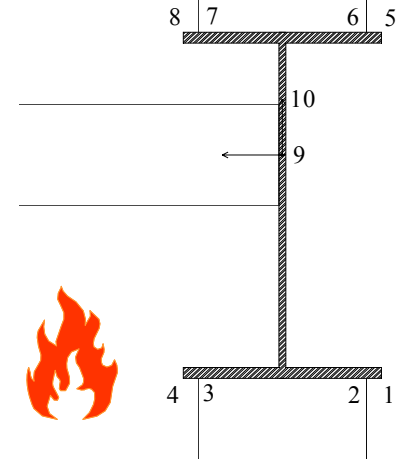

Figura 7.75: Localização dos nós em que foram medidos os deslocamentos laterais e a temperatura em relação ao TRF.

As figuras 7.76 a 7.79 ilustram resultados referentes aos deslocamentos, axial medido no topo e lateral médio registrado na alma, a altura de L/2 na direção x. Essa análise considerou apenas campo de temperatura e a imperfeição global no mesmo sentido do eixo z. As figuras 7.80 e 7.81 são referentes às forças máximas alcançadas no tempo (TRF) de colapso.

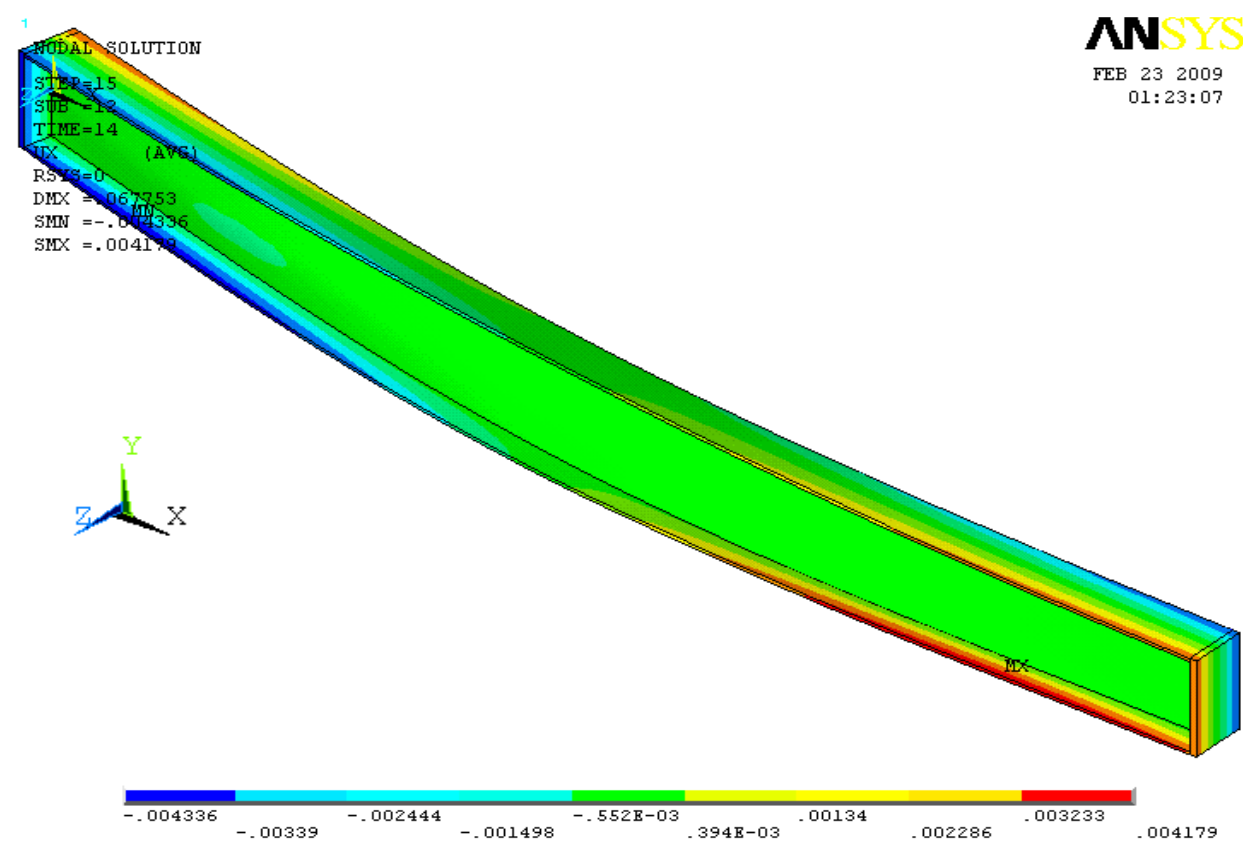

Figura 7.76: Configuração deformada em relação ao eixo x para uma força aplicada equivalente a $0,5 \mathrm{~N}$, ou seja, $333 \mathrm{kN}$ e TRF igual a 7,5 minutos. 


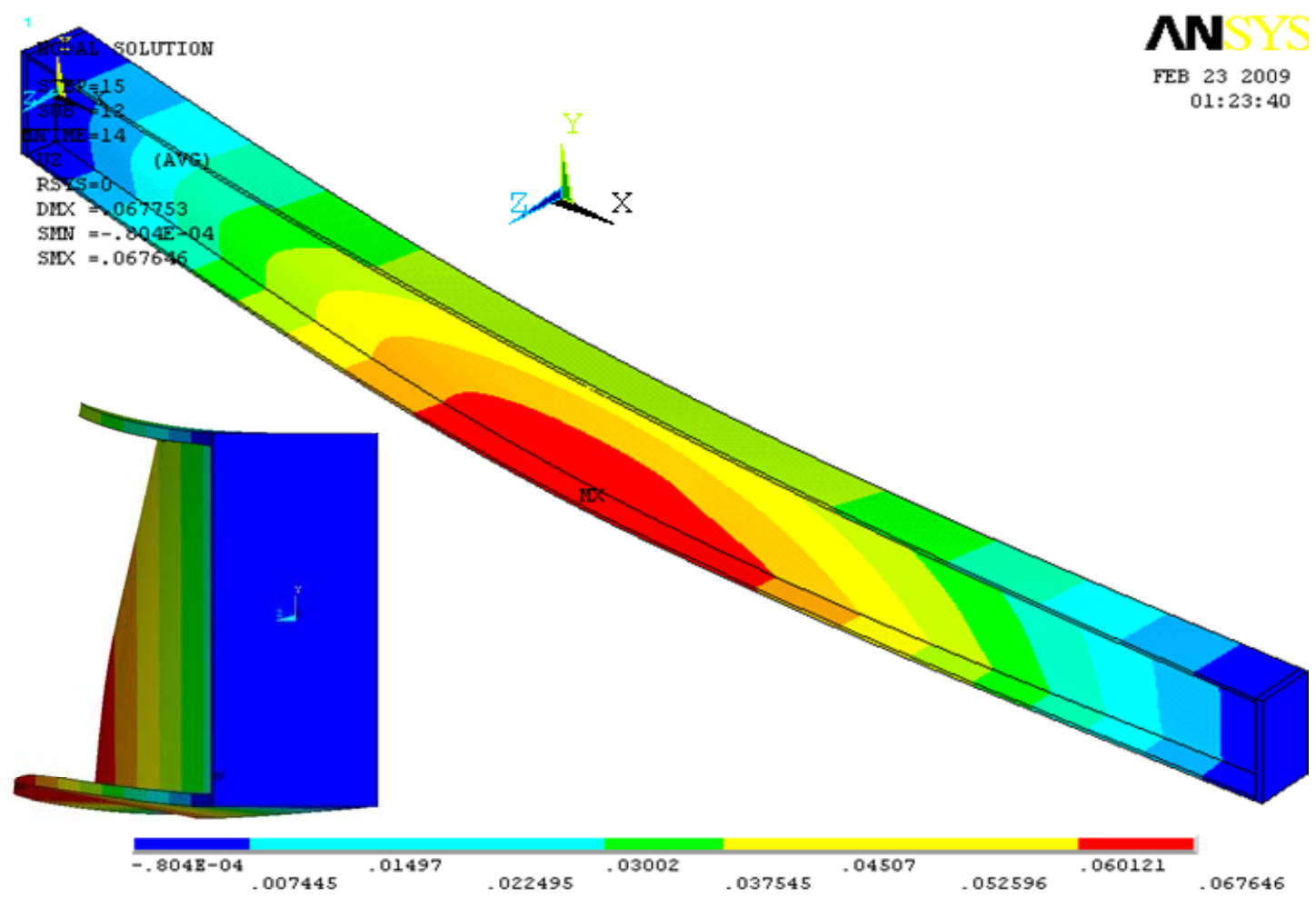

Figura 7.77: Configuração deformada em relação ao eixo z para uma força aplicada equivalente a $0,5 \mathrm{~N}$, ou seja, $333,54 \mathrm{kN}$ e TRF igual a 7,5 minutos.

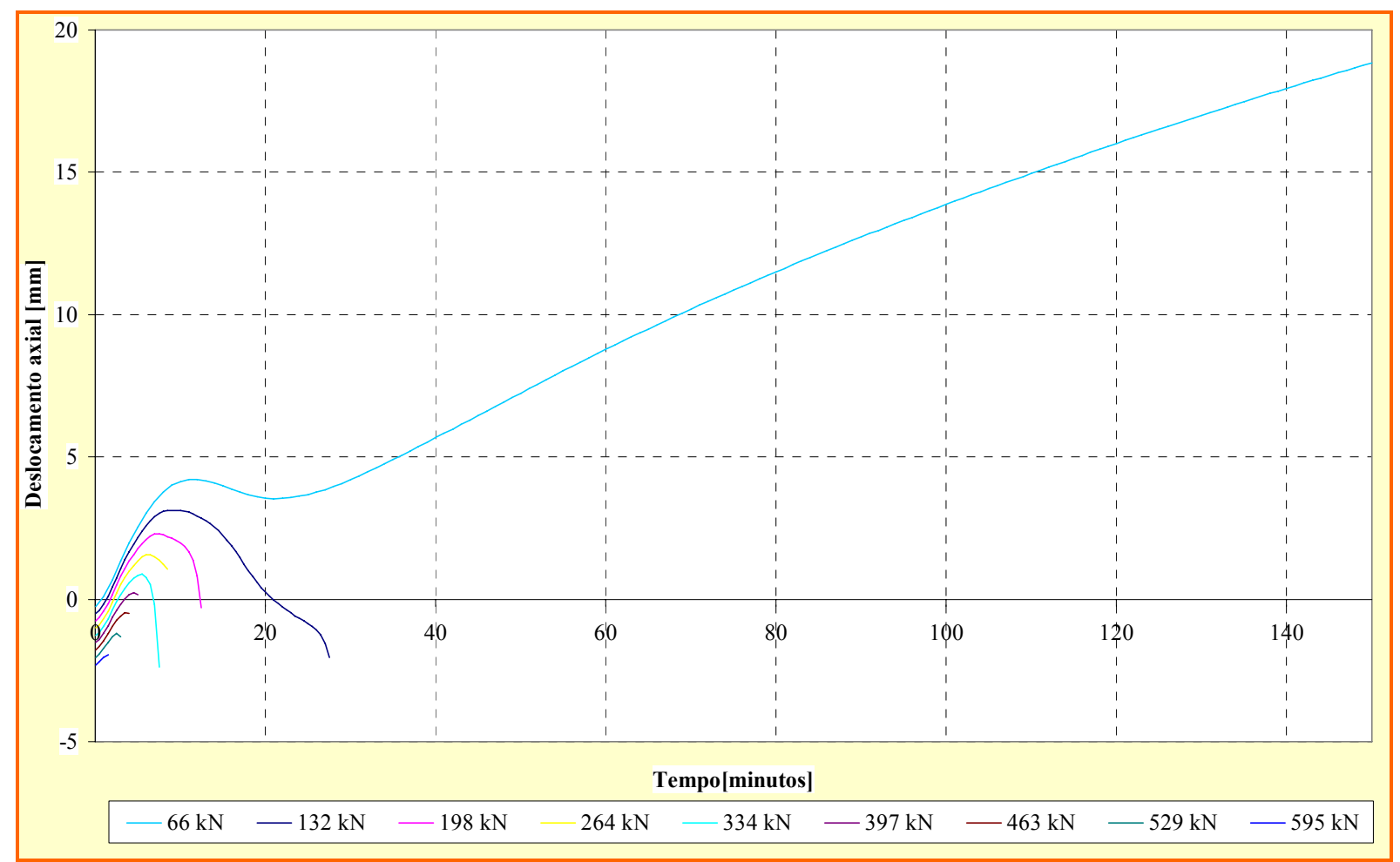

Figura 7.78: Deslocamento axial do pilar submetido ao um campo térmico e imperfeição geométrica no sentido z-negativo para os nove níveis de força aplicados. 


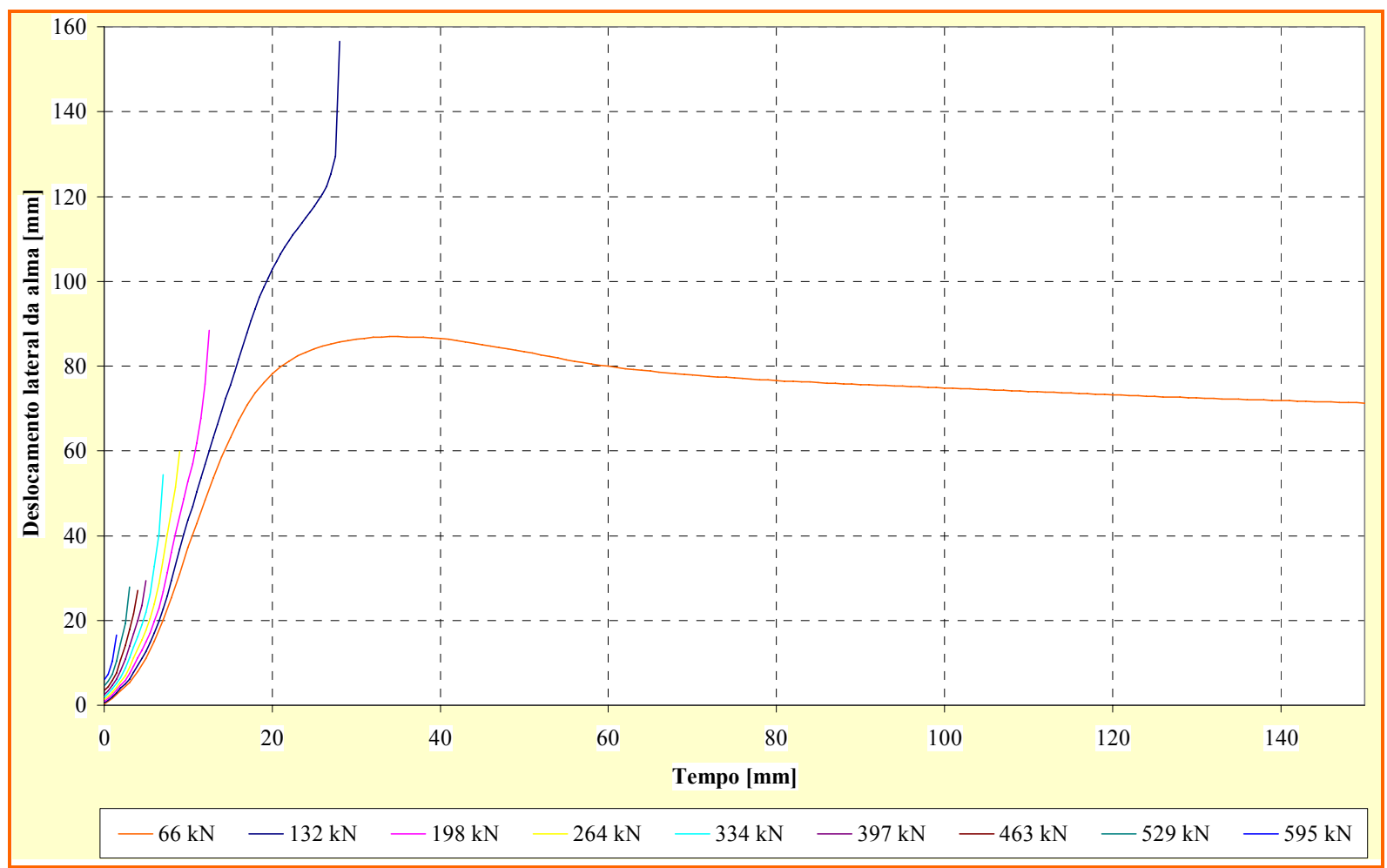

Figura 7.79: Deslocamento axial do pilar submetido ao um campo térmico e imperfeição geométrica no sentido z-negativo para os nove níveis de força aplicados.

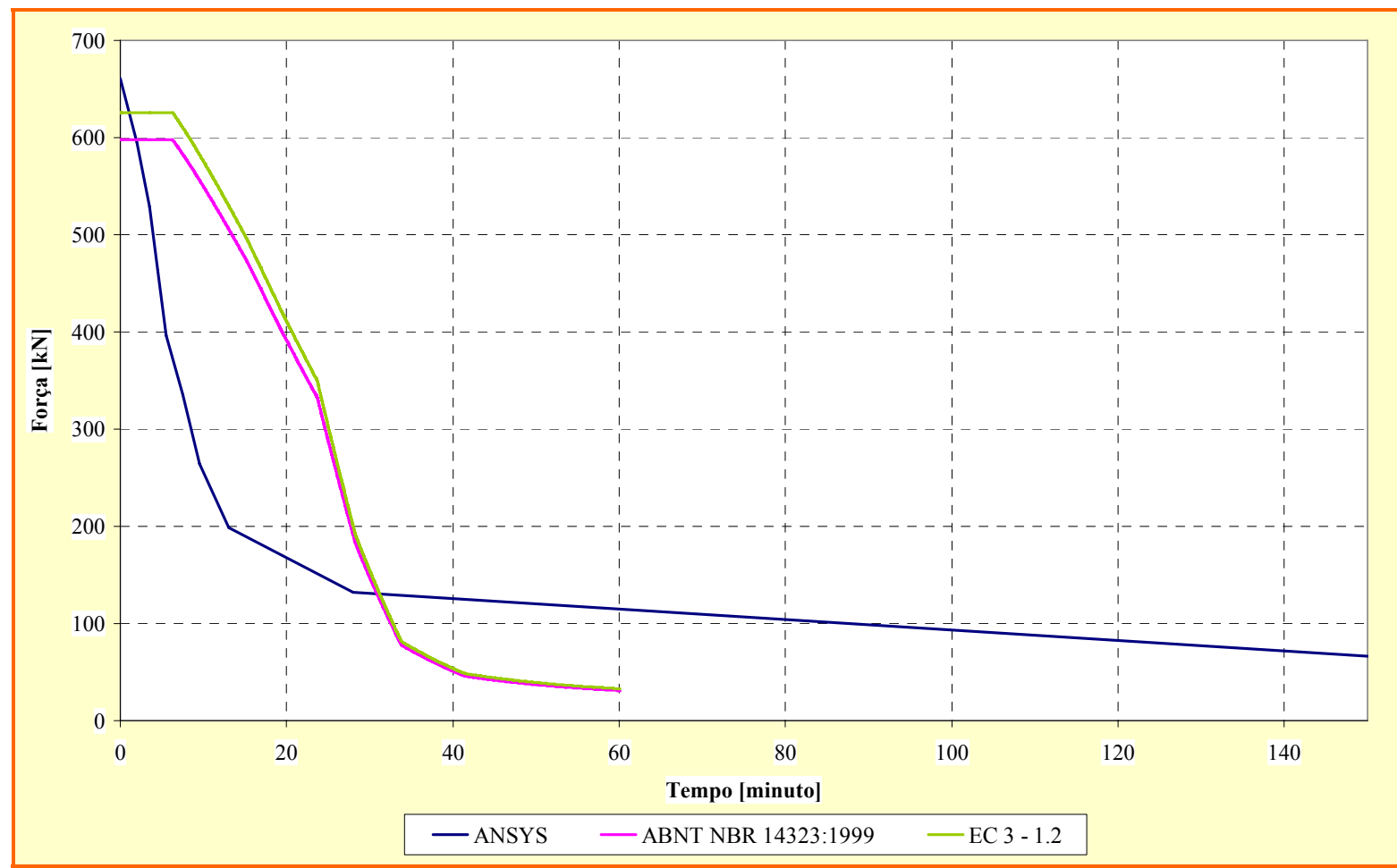

Figura 7.80: Variação da força de colapso [kN] em função do tempo (TRF) [minuto] obtido pelo ANSYS e por meio dos métodos simplificados da ABNT NBR 14323:1999 e do EC 3- 


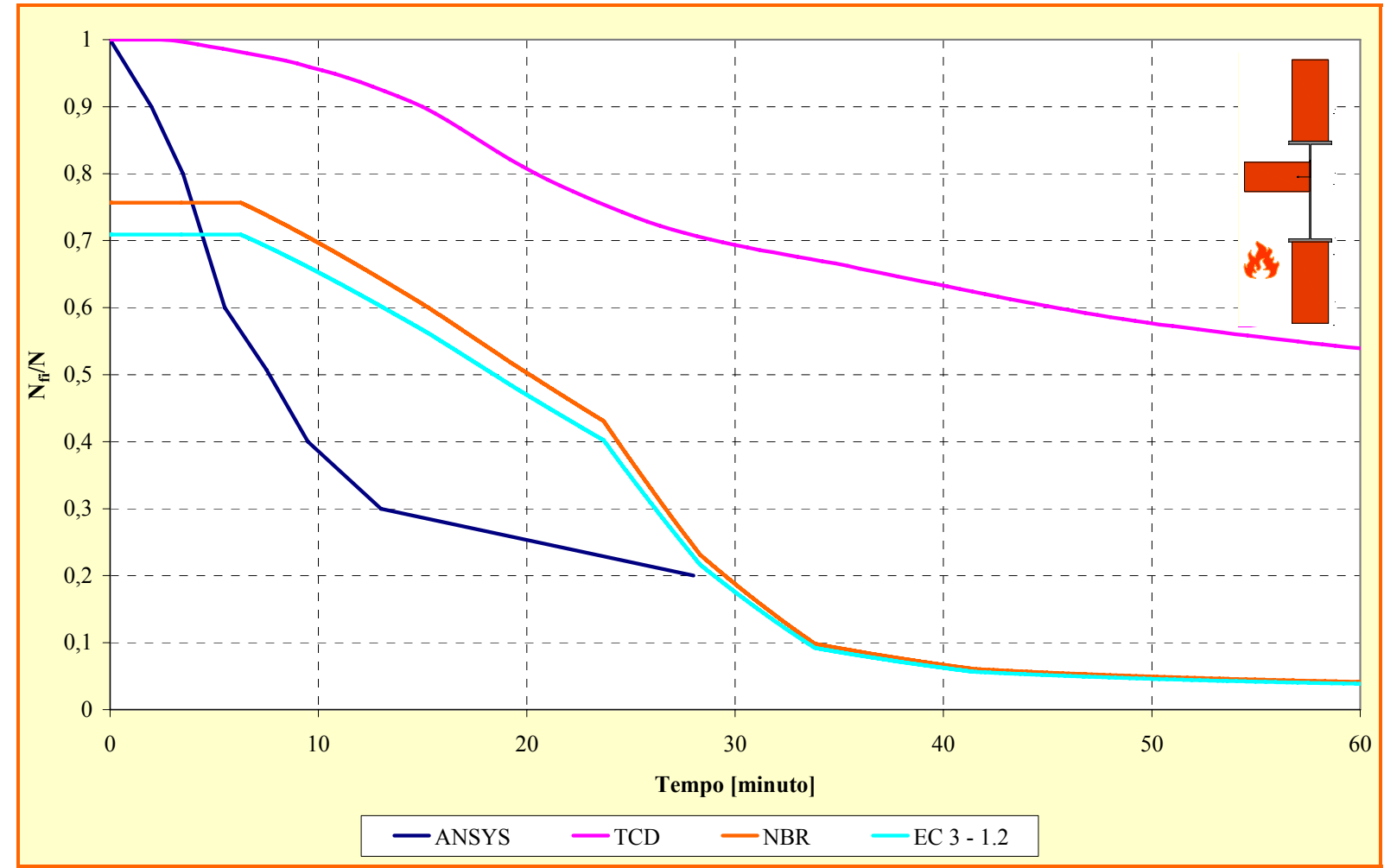

Figura 7.81: Comparação entre o fator de redução obtido via ANSYS, SuperTempCalc, métodos simplificados do Eurocode 3-2 e da ABNT NBR14323:1999.

Para fins de praticidade na identificação dos exemplos de pilares aqui analisados, foram adotadas as nomenclaturas, conforme estabelecida na Tabela 7.1 e ilustrada nas Figuras 7.82 a 7.85 apresentadas a seguir, na forma de referência para os gráficos das Figuras 7.86 a 7.89, os quais apresentam valores de fator de redução obtidos por meio de diferentes procedimentos: (a) ANSYS, (b) TCD - Temperature Calculation and Design, (c) método simplificado da norma brasileira ABNT:14323:1999 e (d) método simplificado do Eurocode 3 part 1.2.
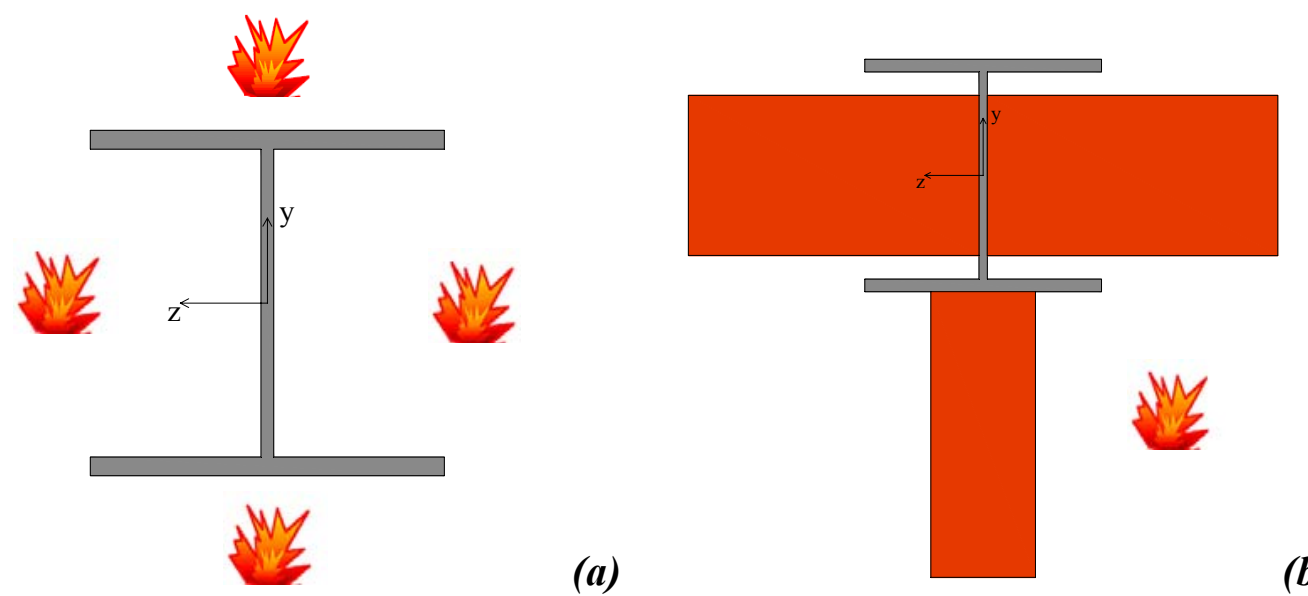

Figura 7.82: Nomenclaturas adotadas para os exemplos de pilares analisados: (a) P - UC $203 \times 203 \times 46-$ I e (b) P - UC $203 \times 203 \times 46-\mathrm{M}-\mathrm{A}$ 
Tabela 7.1: Nomenclatura adotada para os exemplos ilustrados nas figuras 7.76 a 7.77.

Pilar constituído pelo perfil UC 203 x 203 x 46, com as seguintes configurações de parede:

\begin{tabular}{|c|c|}
\hline P - UC $203 \times 203 \times 46-I$ & Isolado, submetido à ação térmica por todos os lados; \\
\hline P - UC 203 x 203 x $46-M-A$ & $\begin{array}{l}\text { Em contato com paredes pela alma e por ambas as } \\
\text { mesas; }\end{array}$ \\
\hline P - UC 203 x 203 x $46-C_{-}[+e]$ & $\begin{array}{l}\text { Pilar externo de canto submetido ao aquecimento pelo } \\
\text { lado menos exposto e imperfeição geométrica no } \\
\text { sentido oposto; }\end{array}$ \\
\hline P - UC 203 x 203 x $46-C_{-}[-\mathrm{e}]$ & $\begin{array}{l}\text { Pilar externo de canto submetido ao aquecimento pelo } \\
\text { lado menos exposto e imperfeição geométrica no } \\
\text { mesmo sentido; }\end{array}$ \\
\hline P - UC $203 \times 203 \times 46-A$ & $\begin{array}{l}\text { Pilar externo com paredes em contato pela alma, } \\
\text { submetido ao aquecimento nas proximidades da mesa } \\
\text { inferior; }\end{array}$ \\
\hline P - UC 203 x 203 x $46-$ M_[+e] & $\begin{array}{l}\text { Pilar externo com paredes em contato com ambas as } \\
\text { mesas, submetido ao aquecimento pelo lado oposto ao } \\
\text { da imperfeição geométrica inicial; }\end{array}$ \\
\hline P - UC 203 x 203 x 46-M_[-e] & $\begin{array}{l}\text { Pilar externo com paredes em contato pela mesa, } \\
\text { submetido ao aquecimento pelo lado correspondente ao } \\
\text { sentido da imperfeição geométrica inicial; }\end{array}$ \\
\hline
\end{tabular}

Tabela 7.2: Nomenclatura adotada para os exemplos ilustrados nas figuras 7.76 a 7.77.

Perfis analisados com base no Instituto Fábrica do Milênio:

$\mathrm{P}-\mathrm{W} 310 \times 38,7 \mathrm{~L} 3811 \mathrm{~mm}$

Pilar externo de canto submetido ao aquecimento pelo lado mais exposto à ação térmica;

$\mathrm{P}-\mathrm{W} 310$ x $38,7 \mathrm{~L} 3890 \mathrm{~mm}$

Pilar externo com paredes em contato com ambas as mesas e um lado da alma; 


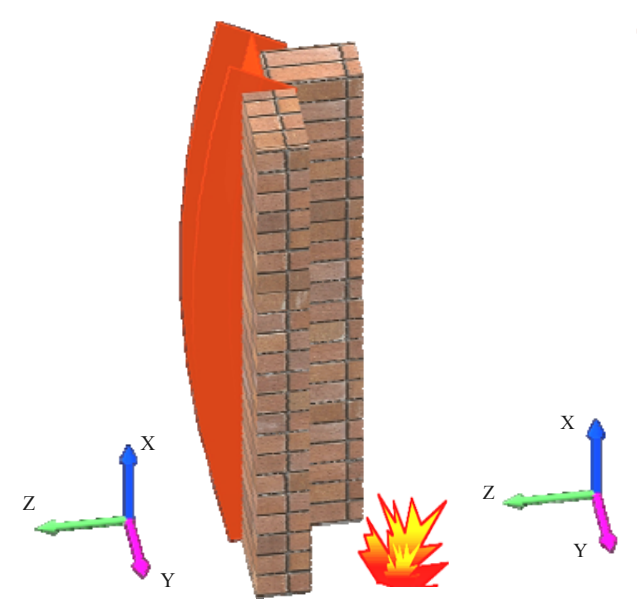

(a)

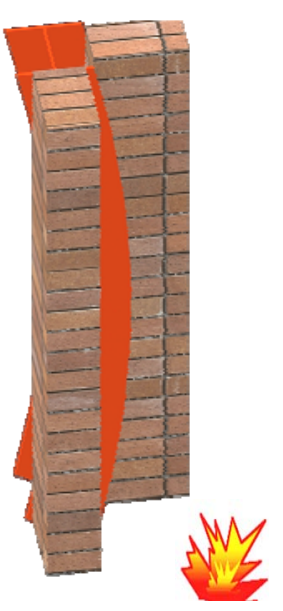

(b)

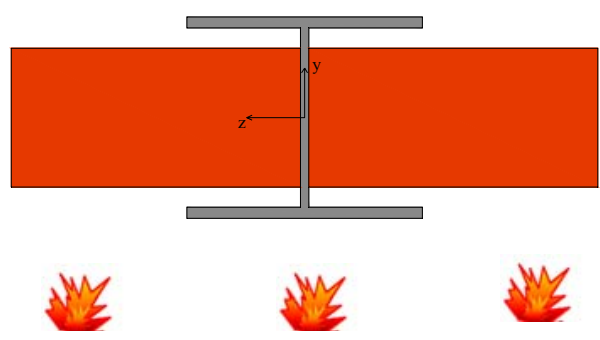

(c)

Figura 7.83: Nomenclaturas adotadas para os exemplos de pilares analisados: (a) P - UC 203 x 203 x 46 - C_[+e], (b) P - UC 203 x 203 x 46 - C_[-e] e (c) P - UC 203 x 203 x 46 - A

(a)
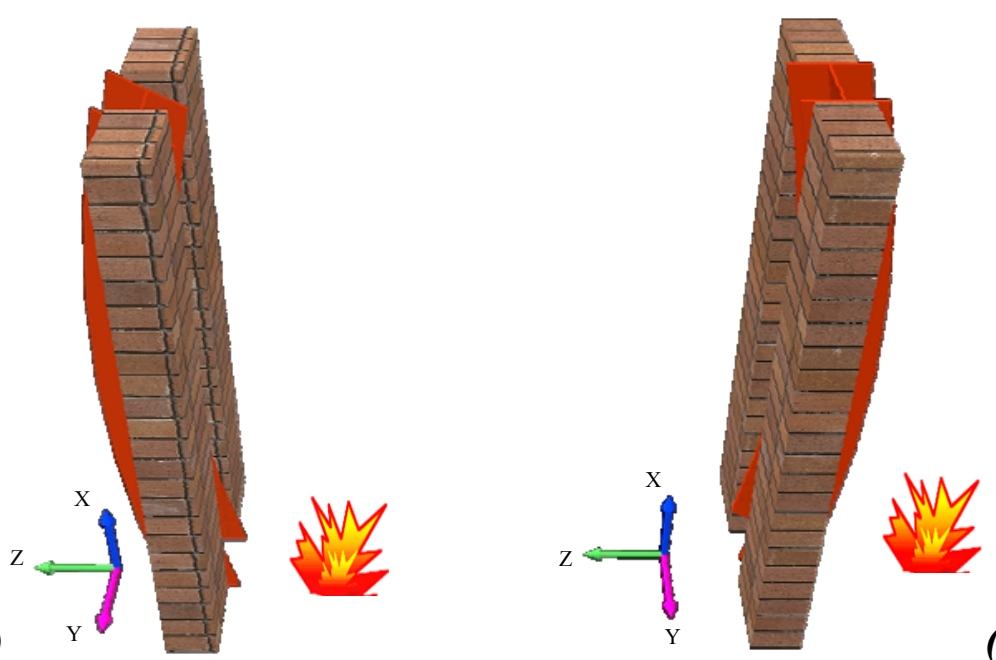

(b)

Figura 7.84: Nomenclaturas adotadas para os exemplos de pilares analisados:

(a) P - UC $203 \times 203 \times 46-$ M_[+e] e (b) P - UC 203 x 203 x 46 - M_[-e]
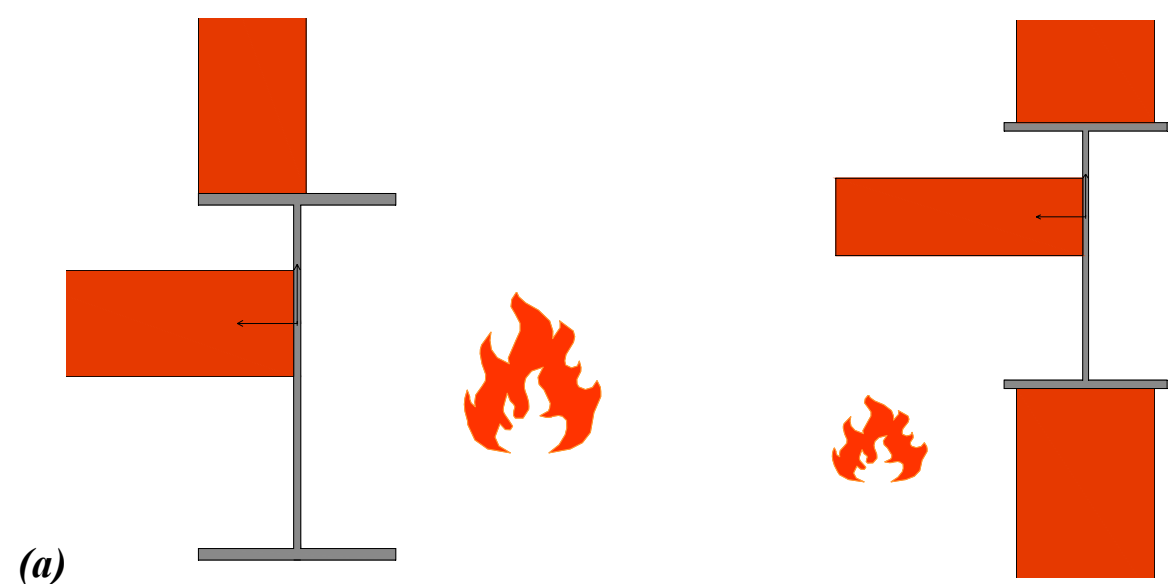

(b)

Figura 7.85: Nomenclaturas adotadas para os exemplos de pilares analisados:

(a) P - W310 x 38,7 L3811 mm e (b) P - W310 x 38,7 L3890 mm 


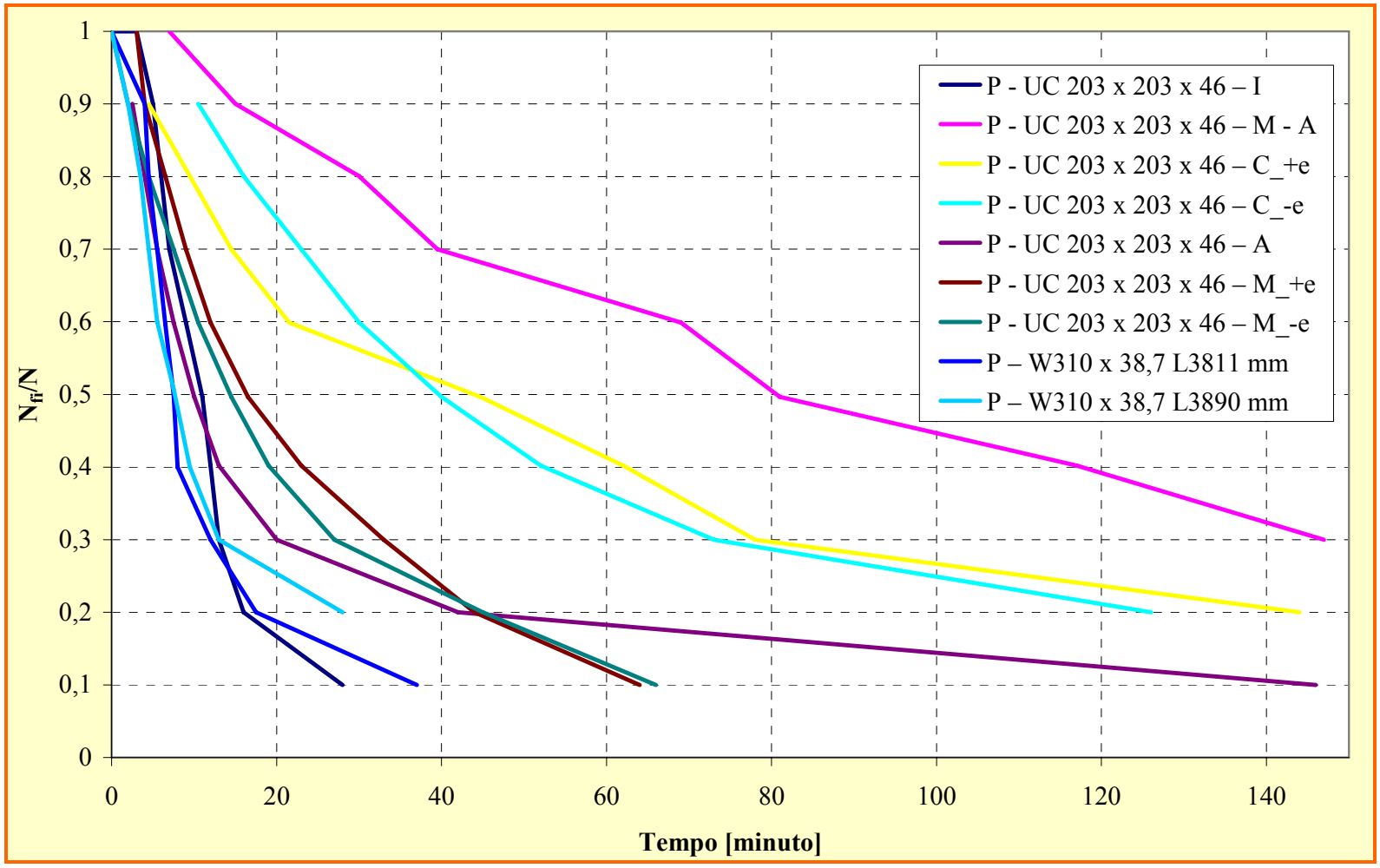

Figura 7.86: Fatores de redução dos exemplos estudados obtidos por meio do código computacional ANSYS v9.0

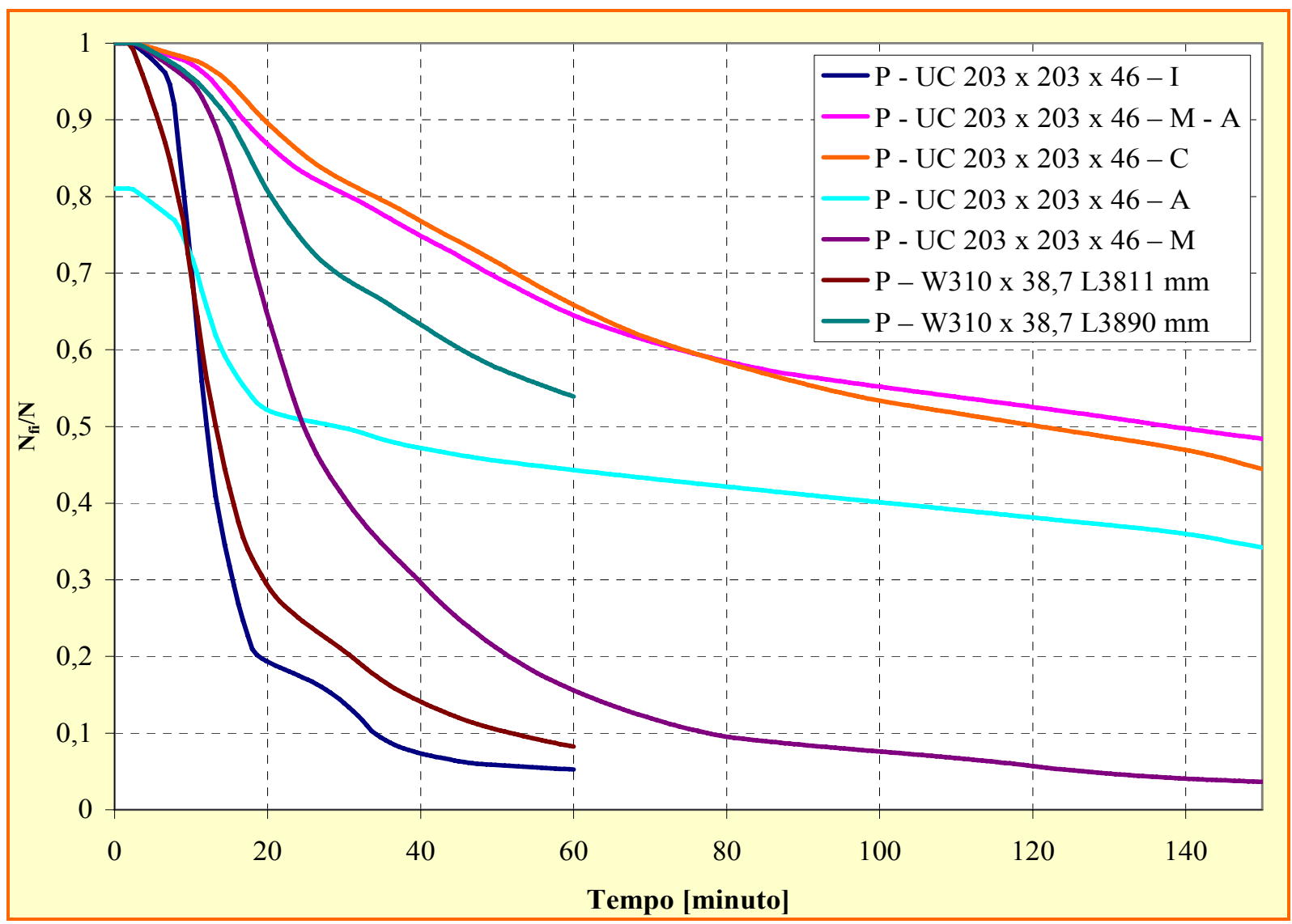

Figura 7.87: Fatores de redução dos exemplos estudados obtidos por meio do código computacional TCD v5.5. 


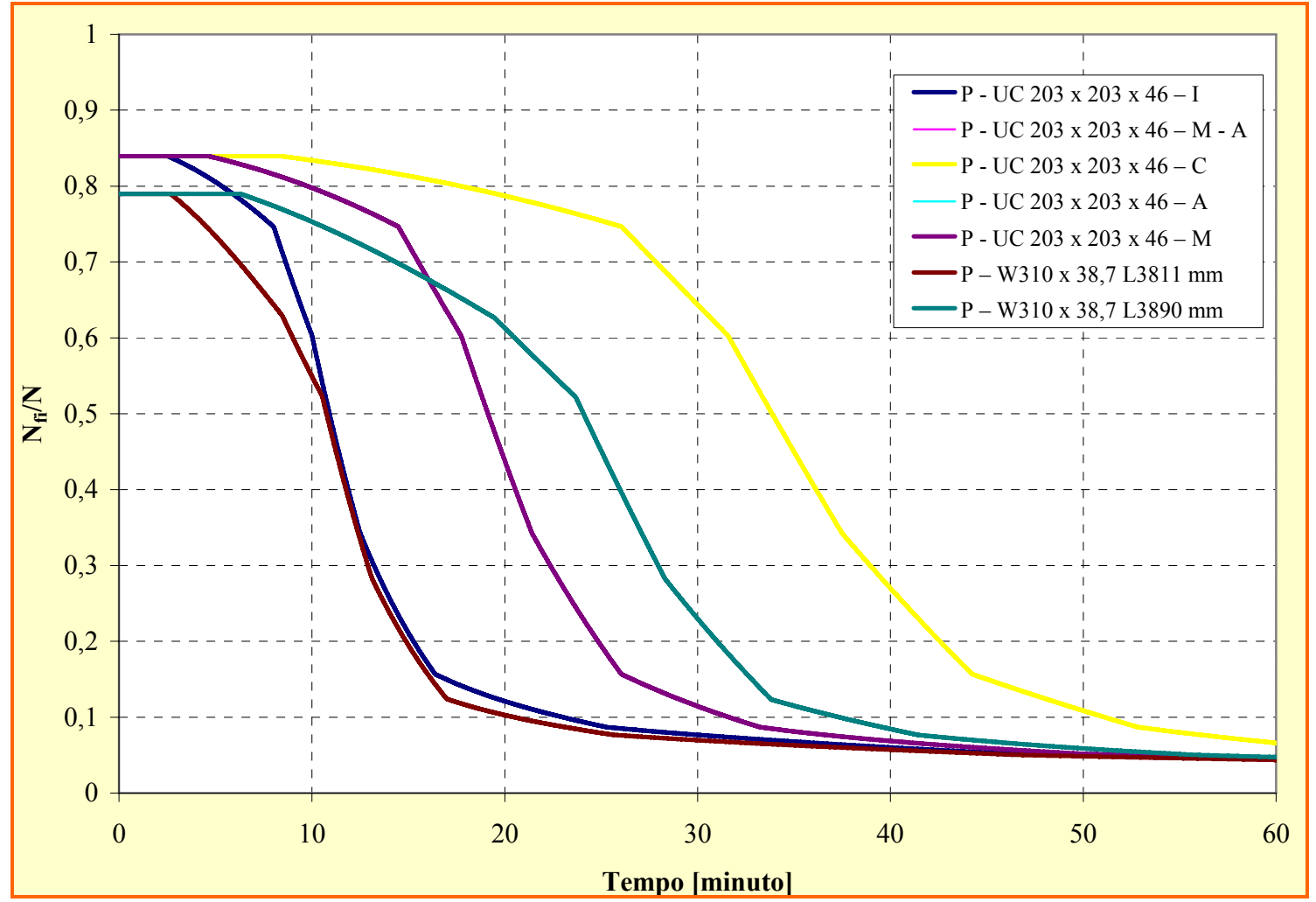

Figura 7.88: Fatores de redução dos exemplos estudados obtidos por meio do método simplificado da ABNT NBR14323:1999.

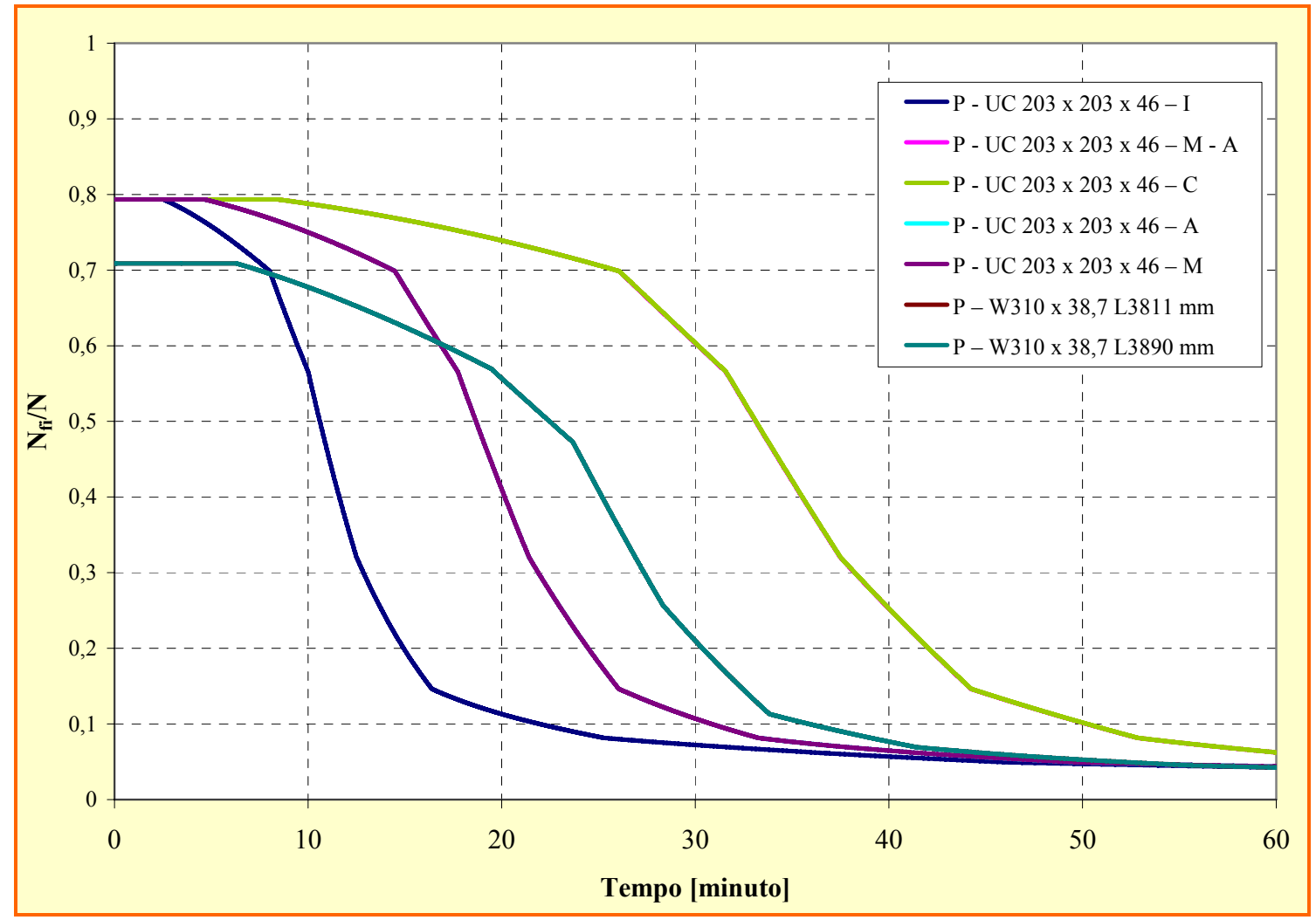

Figura 7.89: Fatores de redução dos exemplos estudados obtidos por meio do método fornecido pelo Eurocode 3 part 1.2. 


\subsection{OBSERVAÇÕES GERAIS - PRELIMINARES}

Dos casos estudados no presente trabalho, alguns pontos em comuns podem ser observados:

- Para os níveis reduzidos de força aplicada, os quais englobam valores correspondentes entre $10 \%$ e $20 \%$ da força máxima em temperatura ambiente, as deformações são, em grande parcela, atribuídas à elevação da temperatura. Deve-se ressaltar que na prática da construção civil dificilmente esse nível de carregamento é encontrado. Nos exemplos estudados, tal consideração, apesar de não constituir grande importância para fins práticos, foi necessária para a determinação do fator de redução em relação ao TRF.

- Os perfís com pouca superfície exposta à ação térmica em decorrência da situação de incêndio, como é o caso daqueles pilares apresentados nos itens 7.3, 7.4 e 7.5, quando submetidos aos níveis reduzidos de carregamento não apresentam regiões plastificadas dentro do TRF considerado (até 150 minutos), sinalizando um deslocamento axial crescente com o tempo em decorrência da dilatação. Porém, o TRF reduziu bruscamente a partir de $\mathrm{F}=0,3 \mathrm{~N}$.

- Com base nas análises apresentadas nos itens 7.4 e 7.6, observa-se a necessidade de que o mesmo teste seja feito para diferentes valores de deformação inicial. $O$ valor de imperfeição geométrica inicial adotada para esse trabalho, ou seja, de L/1000 corresponde a uma média do que usualmente se encontra na prática da construção civil e ao limite proposto pela ABNT NBR8800. 


\section{CONSIDERAÇÕES E CONCLUSÕES}

\subsection{CONSIDERAÇÕES GERAIS}

O presente trabalho foi proposto com a finalidade de se estudar pilares de aço submetidos a elevadas temperaturas e, consequentemente, evidenciar a importância do estudo desse tipo de elemento estrutural em situação de incêndio. Embora o presente trabalho tenha sido realizado dentro de um contexto puramente numérico, cujos resultados permitem sinalizar satisfatoriamente a respostas do elemento em incêndio, ressalta-se aqui a necessidade futura de estender a proposta aqui estabelecida dentro do contexto experimental.

Nos itens que se seguem serão estabelecidas, de modo bastante sucinto, considerações gerais com relação aos aspectos de interesse identificados em cada um dos capítulos que compõem o presente texto.

\subsubsection{Com relação ao CAPÍTULO 2}

Os casos de incêndio relatados no Capítulo 2, além daqueles documentados em outros meios de informação, levaram pesquisadores em nível mundial a estudar e buscar compreender o comportamento físico, tanto de estruturas como de materiais de proteção quando submetidos ao incêndio. Se o método simplificado de dimensionamento utilizado pelas normas atuais é restrito para uma quantidade limitada de estruturas em situação de incêndio, os trabalhos em campos experimental e numérico têm contribuído de forma valiosa nos casos que não são possíveis de serem abrangidos pelo mesmo método.

Alguns aspectos em comum são destacados na maioria dos trabalhos pesquisados, em relação aos fatores que influenciam no tempo de colapso da estrutura, como, por exemplo, as restrições axiais (que reduz a temperatura de colapso do pilar), as restrições rotacionais (que aumentam o tempo de colapso da estrutura), a interação do pilar com outros elementos estruturais e não-estruturais (contribui com o aumento do tempo de colapso), entre outros. Essas análises são fundamentais para o desenvolvimento e reformulações das normas de dimensionamento de estruturas em situação de incêndio no contexto mundial. 


\subsubsection{Com relação ao CAPÍTULO 3}

A ocorrência de incêndio em uma dada estrutura depende da presença de fonte de calor, o combustivel, o comburente para que ocorra a reação em cadeia. A coexistência desses fatores em quantidades diferentes, combinado com as características do compartimento, como fator de abertura e as propriedades térmicas da parede de vedação torna ainda mais complexa a determinação do gradiente térmico.

As curvas de incêndio-padrão propostas por normas internacionais, conforme relatadas no capítulo em questão, foram importantes no desenvolvimento das análises, tanto experimentais como numéricas, válidas para elementos estruturais e materiais de proteção. A importância de se conhecer o gradiente de temperatura implica no conceito de que as propriedades físicas de resistência e rigidez têm seus valores reduzidos em função do aumento da temperatura. As propriedades térmicas, mais especificamente a dilatação térmica, a condutividade térmica e o calor específico também variam em função da temperatura.

\subsubsection{Com relação ao CAPÍTULO 4}

A escolha do pacote computacional ANSYS $v 9.0$ para fins de modelagem numérica se justifica pela satisfatória representatividade quando se faz análises do comportamento dos elementos estruturais metálicos, como, por exemplo, os pilares de aço aqui de interesse. Dos elementos finitos disponíveis na biblioteca do ANSYS v9.0, se destacam como os mais adequados aqueles descritos no capítulo em questão, em que a análise térmica foi realizada com o elemento finito SOLID70, e análises estruturais e acopladas termo-estruturais desenvolvidas com o elemento SOLID45 (compatível com o SOLID70) e com o SHELL181.

\subsubsection{Com relação ao CAPÍTULO 5}

Para fins de validação da estratégia numérica implementada por meio do código ANSYS v9.0 para obtenção do campo térmico, foram utilizados para fins de validação os resultados obtidos por meio do código computacional SuperTempCalc (STC), pertencente ao pacote $\boldsymbol{T C D}$ 5.0, mundialmente reconhecido e consagrado para determinação do campo de temperatura, razão pela qual esse mesmo código é considerado adequado para fins de comparação com os resultados apresentados no presente trabalho. 
Com a validação da estratégia considerada, utilizando o ANSYS v9.0 para determinação do gradiente de temperatura, tanto para modelos bidimensionais como tridimensionais, em futuros projetos de pesquisa será possível considerar a distribuição não uniforme da temperatura na seção transversal e também ao longo do comprimento.

\subsubsection{Com relação ao CAPÍTULO 6}

As simplificações adotadas para elaboração do modelo estrutural em temperatura ambiente, prevendo considerá-las também para as análises em situação de incêndio, permitiram reproduzir respostas de análises experimentais de pilares comprimidos em termos de "força x deslocamento" de maneira satisfatória. A determinação da força última (colapso) do pilar, bem como seu comportamento pós-crítico foi possível com aplicação de deslocamentos impostos por meio do método incremental-iterativo de Newton-Raphson. Vale ressaltar que o comportamento pós-crítico foi de difícil obtenção quando a força externa aplicada foi utilizada como variável de controle para fins de convergência numérica.

De uma forma geral, o uso dos elementos finitos do tipo casca como, por exemplo, SHELL 181, é mais comum na modelagem numérica envolvendo barras flexão compostas por seções transversais esbeltas, a exemplo dos perfis de aço. Neste trabalho, os elementos SHELL181 e SOLID45 foram testados, tendo em vista o elemento SHELL 181 ser o mais adequado para modelar elementos esbeltos, e o SOLID45 por ser compatível com o elemento SOLID70 (utilizado na análise térmica) para fins de na análise acoplada do tipo termoestrutural.

\subsubsection{Com relação ao CAPÍTULO 7}

A complexidade em transferir as temperaturas nodais, de uma análise térmica realizada com elementos SOLID70, para os elementos finitos SHELL 181 com vistas à análise estrutural, conforme relatado no capítulo em questão, inviabilizou o uso deste tipo de elemento no presente trabalho.

Um outro aspecto que inviabilizou o uso do elemento de casca pode estar relacionado ao refinamento da malha do modelo com o elemento finito SHELL181. Para que houvesse coincidência nas coordenadas entre todos os nós do modelo estrutural em SHELL181 e os nós da linha de esqueleto do modelo SOLID70, a rede de elementos finitos em SHELL181 foi definida com elevado grau de discretização, fato que não permitiu utilizar de maneira 
otimizada as vantagens inerentes de elementos de casca para esse tipo de análise. O uso de uma malha consideravelmente discretizada (muito refinada) pode ser adequado para o SOLID70, mas pode não ser, e em geral não é, aplicável ao elemento SHELL.

A solução desse problema implicaria em determinar uma rede de elementos finitos capaz de atender satisfatoriamente tanto o modelo térmico (em SOLID70) como o estrutural (em SHELL181), aspecto que não foi abordado no presente trabalho. À medida que essa rede fosse definida, as análises termo-estruturais poderiam ser realizadas utilizando o SHELL181, o que poderia reduzir de maneira significativa os custos computacionais.

\subsection{CONCLUSÕES DO TRABALHO}

Com relação às análises puramente térmicas aqui realizadas, foi possível constatar a viabilidade do acoplamento das temperaturas obtidas da análise térmica ao modelo estrutural, mesmo utilizando elementos não-compatíveis, como no caso do presente trabalho, em que se acoplou o campo térmico do modelo em SOLID70 ao modelo estrutural constituído pelo SHELL181. A semelhança dos resultados do ANSYS quando comparados àqueles obtidos pelo STC, tanto para perfis isolados como para aqueles em contato com as paredes, comprovam a eficiência da estratégia apresentada no presente trabalho, possibilitando o acoplamento com o modelo estrutural em análises posteriores.

Com relação às análises em temperatura ambiente, o modelo elaborado em SOLID45 descrito em 6.3 obteve respostas satisfatórias quando comparado com o experimental apresentado em DE PAULA (2002). Os modelos elaborados em SHELL181 e em SOLID45, para o pilar cuja seção transversal pertence à série inglesa UC $203 \times 203 \times 46$, apresentaram respostas em termos de curvas do tipo "Força $x$ Deslocamento" consideravelmente semelhantes. Assim, foi possível constatar inicialmente que ambos os elementos, SOLID 45 e SHELL 181, possuem capacidade de reproduzir o comportamento da estrutura quando submetida à ação estática e à ação térmica.

Já para as análises acopladas termo-estruturais, se observou que a transferência de temperatura de um elemento do tipo sólido para um elemento do tipo casca resulta factível, porém, de considerável complexidade para o presente trabalho. Por essa razão, embora o esforço computacional com o SOLID 45 resulte maior, optou-se por realizar todas as análises numéricas subsequentes com esse mesmo elemento. 
Em relação ao pilar do item 7.5 (sobre o pilar de canto em contato com o incêndio pela superfície inferior no sentido z-), para os níveis reduzidos de força de compressão aplicada, ou seja, até $0,5 \mathrm{~N}$, o deslocamento inicial na mesma direção e sentido em que está aplicada a ação térmica resultou em menores valores de TRF quando comparado a ambos aplicados em sentidos opostos. No entanto, para os valores mais elevados de força de compressão aplicada, a partir de $0,6 \mathrm{~N}$, houve uma inversão e essa configuração resultou em valores maiores para o TRF.

O mesmo exemplo sugere que, para um nível de força mais baixo, o pilar tende a apresentar maior deformação por dilatação antes que a redução da resistência e rigidez, proveniente do aumento de temperatura, seja suficiente para que ocorra a ruína (colapso). Dessa forma, pilares que apresentam imperfeição inicial global no mesmo sentido onde ocorre a ação térmica (situação em que as fibras tracionadas estão em contato direto com a ação do incêndio) têm somado ao seu deslocamento inicial, aquele provocado pela dilatação. Esse fenômeno faz com que pilares que apresentam a face tracionada diretamente submetida a ação térmica apresente um tempo de resistência (TRF) menor, do que aqueles que apresentam a face comprimida em contato com o fogo.

Em contrapartida, ainda para o exemplo do item 7.5, quando se aplica uma força de compressão de maior magnitude o pilar atinge o colapso, devido à redução pequena, mas suficiente de $f_{y}$ e $E$, ainda que para baixos níveis de deformação térmica. Nesses casos o pilar com face comprimida em contato com o fogo atingiu o colapso mais rapidamente se comparado àquele que apresenta incêndio na face tracionada.

No exemplo relatado em 7.7 (paredes em contato com ambas as mesas), pode-se concluir que a configuração menos favorável é aquela em que a face tracionada se encontra em contato com a ação térmica de incêndio, pois resultou em menor TRF. Deve-se observar que o caso apresentado em 7.7 apresenta superfície exposta a ação térmica maior que aquela do exemplo 7.5.

Para as análises apresentadas, foram obtidas as curvas " $N_{f i} x$ tempo" e as curvas de redução " $N_{f i} / N x$ tempo" e realizou-se também a comparação às curvas fornecidas pelo pacote computacional TEMPERATURE CALCULATION AND DESIGN - TCD. Porém, esse pacote aplica o procedimento de cálculo do EC4-1.2. Dessa forma, a determinação da forma resistente de compressão segue a formulação para estruturas mistas de aço e concreto, porém, considerando inexistente a presença e, consequentemente a contribuição do material concreto. A análise numérica também foi confrontada com os métodos simplificados da NBR14323:1999 e EC3 - 1.2, em que se observou pequena diferença na reposta estrutural. 
Embora os resultados das análises numéricas, via ANSYS, indiquem diferentes valores da curva de redução " $N_{f i} / N \times T R F$ ” para os casos apresentados em 7.6 e 7.7 que tratam, respectivamente de paredes em contato com a alma e com as mesas do perfil, os resultados obtidos por meio dos métodos simplificados tanto do EC3-1.2 e NBR14323:1999 são idênticos. Isso se deve ao fato de ambas, coincidentemente apresentarem o mesmo valor de fator de massividade, embora, a forma de incidência da ação térmica sobre o elemento seja diferente. Como foi possível notar nos exemplos apresentados, a ABNT NBR14323:1999 fornece valores de resistência mais conservadoras que o EC 3.

Exceto para o exemplo P - UC 203 x 203 x 46 - I, os fatores de redução obtidos pelo ANSYS resultaram maiores que aqueles obtidos via TCD, e bem diferentes das curvas obtidas por meio dos procedimentos simplificados nos códigos normativos. Muito provavelmente, tal fato está relacionado à formulação mais precisa do ANSYS (quando comparado às prescrições normativas), uma vez que o código computacional permite levar em conta alguns aspectos particulares como: efeitos localizados, detalhes das condições de vinculação, modos e amplitudes de imperfeições geométricas iniciais.

As características relacionadas às imperfeições geométricas iniciais têm certa influência na determinação do tempo crítico de resistência ao fogo (TRF). Em condições assimétricas ou monossimétricas em que a ação térmica e imperfeição global respeitam o mesmo eixo de simetria, a imperfeição global na mesma direção e sentido em que ocorre o incêndio resulta num valor diferente de TRF quando comparado a ambos atuando em sentidos opostos.

A comparação entre a magnitude dos valores de TRF resultantes das duas configurações implica em conhecer o carregamento externo imposto, bem como o gradiente de temperatura que ocorre no pilar. Os resultados apresentados sinalizam, ou mesmo indicam, a necessidade de se explorar de maneira mais aprofundada a questão das imperfeições geométrica iniciais, tanto locais quanto globais, em magnitude e sentido, em estruturas onde se terá somado o fator temperatura.

Ressalta-se também que, no presente trabalho foi possível realizar apenas uma comparação ao trabalho de caráter experimental em situação de incêndio, realizado por outros pesquisadores e relatado em 7.1.1, fato esse que se justifica pela dificuldade de reproduzir experimentalmente análises termo-estruturais com assimetria de campo térmico. 


\subsection{SUGESTÕES PARA TRABALHOS FUTUROS}

Com base nos aspectos mencionados ao longo do presente trabalho, conclui-se que o campo das estruturas em situação de incêndio pode ser mais bem explorado em diversas vertentes, tanto em caráter experimental como numérico, considerando as seguintes possibilidades de otimização, principalmente em contexto numérico:

- Otimização da análise termoestrutural utilizando elementos do tipo sólido para a análise térmica e do tipo casca para análise estrutural;

- Influência da rigidez das restrições axiais e rotacionais na resposta estrutural em situação de incêndio;

- Influência das imperfeições geométricas iniciais em estruturas em situação de incêndio;

- Estudo das ligações viga/pilar em situação de incêndio;

- Análise experimental de pilares em contato com paredes de alvenaria submetidos à situação de incêndio. 


\section{REFERÊNCIAS}

ALMEIDA, S. J. C de (2007). Análise numérica de perfis de aço formados a frio comprimidos considerando as imperfeições geométricas iniciais. São Carlos. Dissertação (Mestrado) - Escola de Engenharia de São Carlos - Universidade de São Paulo. 2007.

AMERICAN INSTITUTE OF STEEL CONSTRUCTION, (2005) ANSI/AISC 360-05 Specifications for structural steel buildings. Chicago.

AMERICAN SOCIETY TESTING AND MATERIALS. (2000) ASTM E119 - Standard test methods for fire tests of building construction and materials. West Conshohohocken.

ANSYS INC. (2004). Ansys Release 9.0 - Documentation.

ASSOCIAÇÃO BRASILEIRA DE NORMAS TÉCNICAS (1986). ABNT NBR 8800 - Projeto de estruturas de aço e estruturas mistas de aço e concreto de edifícios. Rio de Janeiro.

ASSOCIAÇÃO BRASILEIRA DE NORMAS TÉCNICAS (1999). ABNT NBR 14323 Dimensionamento de estruturas de aço de edifícios em situação de incêndio - Procedimento. Rio de Janeiro;

ASSOCIAÇÃO BRASILEIRA DE NORMAS TÉCNICAS (2000). ABNT NBR 14432 - Exigências de resistência ao fogo de elementos construtivos de edificações - Procedimento. Rio de Janeiro;

ASSOCIAÇÃO BRASILEIRA DE NORMAS TÉCNICAS (2008). ABNT NBR 8800 - Projeto $e$ execução de estruturas de aço de edifícios. Rio de Janeiro.

AZEVEDO, M. S.; FERREIRA, W. G.; SILVA, V. P. (2006). Determinação da temperatura em pilares de aço externos a edificações em situação de incêndio. Anais das XXXII Jornadas Sulamericanas de Engenharia Estrutural, Campinas 2006: 1320 - 1329.

BAILEY, C. G., MOORE D. B. LENNON (1999). The structural neharior of steel columns duraing a compartment fire in a multi-storey braced frame. Journal of constructional research 52 (1999)137 157.

BAILEY, C. G. (2000). The influence of the thermal expansion of beams on the structural behaviour of columns in steel-framed structures during a fire. Engineering structures. 22: 755 - 768.

BEJAN, A. (1996) Transferência de calor. Edgard Blucher. São Paulo.

BUCHANAN A. H. (2002). Structural design for FIRE safety. John Wiley \& Sons; Chichester

CLARET, A.M. (2000) Resistência ao fogo de vigas mistas aço-concreto modeladas pelo método dos elementos finitos. In: Jornadas Sudamericanas de Ingenieria Estructural, Punta Del Este 2000. Anais.

DRYSDALE, D. (1998). An introduction to fire dynamics - second edition. John Wiley \& Sons; Chichester 
ENCICLOPÉDIA: http://pt.wikipedia.org/wiki/P\%C3\%A1gina principal. (acessado em dezembro/2007).

EUROPEAN COMMITTEE FOR STANDARDIZATION (2002). prEN 1991-1-2: Eurocode 1 Basis of design and actions on structures. Part 1-2: Actions on structurs - Actions on structures exposed to fire, final draft, Brussels.

EUROPEAN COMMITTEE FOR STANDARDIZATION (2005). EN 1993-1-1:2005 Eurocode 3 Design of steel structures. Part 1-1: General rules and rules for buildings. Stage 34 draft, Brussels

EUROPEAN COMMITTEE FOR STANDARDIZATION (2005). EN 1993-1-2:2005 Eurocode 3 Design of Steel Structures. Part 1-2: General rules - Structural Fire Design. Brussels.

EUROPEAN COMMITTEE FOR STANDARDIZATION (2005). EN 1994-1-1:2005 Eurocode 4 Design of composite steel and concrete structures. Part 1-2: General rules - Structural Fire Design. Brussels.

EUROPEAN CONVENTION FOR CONSTRUCTIONAL STEELWORK (ECCS) (1985). Design manual on European Recomendations for the fire safety of steel structures. Brussels, ECCS.

EUROPEAN CONVENTION FOR CONSTRUCTIONAL STEELWORK (ECCS) (2001) - Technical Committee 3 - Model Code on Fire Engineering, N ${ }^{\circ} 111$, Brussels, ECCS.

FENG, M.; WANG, Y. C.; DAVIES, J. M. (2004). A numerical imperfection sensitivity study of coldformed thin-walled tubular steel columns at uniform elevated temperatures. Thin-walled structures. 42: $533-555$.

FENG, M.; WANG, Y. C.; DAVIES, J. M. (2003). Structural behaviour of cold-formed thin-walled short steel channel columns at elevated temperatures. Part 1: experiments. Thin-walled structures. 41: $543-570$.

HUANG, Z. F.; TAN, K. H. (2007). Structural responses of restrained steel columns at elevated temperatures. Part 2: FE simulation with focus on experimental secondary effects. Engineering structures. 29: $2036-2047$.

HUANG, Z. F.; TAN, K. H.; TING, S. K. (2006). Heating rate and boundary restraint effects on fire resistance of steel columns with creep. Engineering structures. 28: 805 - 817.

INTERNATIONAL STANDARD (1999). Fire-resistance tests - Elements of building construction - Part 1: General requirements. ISO 834-1:1999

KIRCHHOF, L. D. (2004). Uma contribuição ao estudo de vigas mistas aço-concreto simplesmente apoiadas em temperatura ambiente e em situação de incêndio. 141p. Dissertação de Mestrado Universidade de São Paulo, Escola de Engenharia de São Carlos, São Carlos, Brasil.

LANDESMANN, A.; BATISTA, E. M. (2005). Análise de pórticos planos em situação de incêndio pelo método das rótulas plásticas. Revista Escola de Minas. 58: 147 - 153.

MALITE, M., SALES, J. J. de (2001). Estruturas de aço constituídas por perfis de chapa dobrada: dimensionamento das barras. São Carlos. Notas de aula - Escola de Engenharia de São Carlos Universidade de São Paulo. 2007.

NEVES, I. C.; VALENTE, J. C., RODRIGUES, J. P. C. (2002). Thermal restraint and fire resistance of columns. Fire safety journal. 37: $753-771$. 
REGOBELLO, R. (2007). Análise numérica de seções transversais e de elementos estruturais de aço e mistos de aço e concreto em situação de incêndio. São Carlos. Dissertação (Mestrado) - Escola de Engenharia de São Carlos - Universidade de São Paulo. 2007.

ROYMECH. Perfis padrão europeu. (Acessado em abril/2008). http://www.roymech.co.uk/ Useful Tables/Sections/steel_section_index.htm

SEITO, A. I.; GILL, A. A.; PANNONI, F. D.; ONO, R.; SILVA, S. B. DA; CARLO, U.; SILVA, V. P. e (2008). Segurança contra incêndio no Brasil. São Paulo, Projeto Editora.

SILVA, V.P. (2001). Estruturas de Aço em Situação de Incêndio. São Paulo, Zigurate;

SILVA, V. P.; FILHO, H. S. C. (2007). Índice de segurança contra incêndio para edificações. Ambiente Construído, Porto Alegre. 7: 103 - 121.

Structural material behaviour in fire: steel: hot rolled carbon steel mechanical properties. http://www.mace.manchester.ac.uk/project/research/structures/strucfire/materialInFire/Steel/HotRolle dCarbonSteel/mechanicalProperties.htm. University of Manchester. (Acessado em maio/2008)

Supertempcalc

TAN, K. H.; TOH, W. S.; HUANG, Z. F.; PHNG, G, H. (2007). Structural responses of restrained steel columns at elevated temperatures. Part 1: Experiments. Engineering structures. 29: 1641 - 1652.

TAN, K. H.; YUAN, W. F. (2008). Buckling of elastically restrained steel columns under longitudinal non-uniform temperature distribution. Journal of constructional steel research. 64: $51-61$.

VALENTE, J. C.; NEVES, I. C. (1999). Fire resistance of steel columns with elastically restrained axial elongation and bending. Journal of constructional steel research. 52: 319-331.

VARGAS, M. R.; SILVA, V. P. (2003). Resistência ao fogo das estruturas de aço. Instituto Brasileiro de Siderurgia - IBS / Centro brasileiro da construção em aço - CBCA. Rio de Janeiro. 2003

VELARDE, J. L. S. (2007). Sobre o comportamento dos pilares de aço em situação de incêndio. São Carlos. Dissertação (Mestrado) - Escola Politécnica - Universidade de São Paulo. 2007.

VILA REAL, P. (2003). Incêndio em Estruturas Metálicas - Cálculo Estrutural. Edições Orion, Mafra.

MET@LICA. Perfis soldados. http://www.metalica.com.br/pg_dinamica/bin/pg_dinamica.php

WANG, Y. C. (2000). An analysis of the global structural behavior of the Cardington steel-framed during the two BRE fire tests. Engineering structures. 22: $401-412$.

WANG, Y. C. (2002). Steel and Composite Structures - Behavior and Design for Fire Safety. Spon Press, London

WANG, Y. C.; DAVIES, J. M. (2003). An experimental study of non-sway loaded and rotationally restrained steel column assemblies under fire conditions: analysis of test results and design calculations. Journal of constructional steel research. 59: 291 - 313.

WICKSTROM, U. (1982). Temperature calculation of insulated steel columns exposed to natural fire. Fire Safety Journal 4 (4): 219-225 
WICKSTROM, U. (1985). Temperature analysis of heavily-insulated steel structures exposed to fire. Fire Safety Journal 9: 281-285

ZENG, J. L.; HUANG, Z. F.; TAN, K. H. (2003). Primary creep buckling of steel columns in fire. journal of constructional steel research. 59: $951-970$. 


\section{APÊEDICE A}

Neste anexo são apresentados alguns casos reais de acidentes envolvendo incêndio em estruturas. 
Tabela A.1: Casos de incêndio documentados na história. Período: 80 a 1889 (d.C.) Fonte: www.ponteiro.com.br

\begin{tabular}{|c|c|}
\hline $00 / 00 / 80$ & Grande incêndio de Roma \\
\hline & Século XVI \\
\hline $07 / 04 / 1588$ & Incêndio em Istambul (Turquia) \\
\hline $21 / 11 / 1595$ & Francis Drake incendeia a cidade de San Juan - Puerto Rico \\
\hline & Século XVII \\
\hline $24 / 11 / 1631$ & Holandeses incendeiam a cidade de Olinda - PE \\
\hline $16 / 12 / 1635$ & Incêndio em New York destrói mais de 500 construções \\
\hline $02 / 09 / 1666$ & Incêndio em Londres destrói mais de 13.000 residências \\
\hline & Século XVIII \\
\hline $17 / 12 / 1785$ & Incêndio destrói o teatro de Montpellier (França) \\
\hline $23 / 08 / 1789$ & Incêndio destrói o Recolhimento de Nossa Senhora do Parto (Rio de Janeiro) \\
\hline 00/00/1790 & Incêndio destrói parte do acervo do Arquivo Geral da Cidade do Rio de Janeiro \\
\hline & Século XIX \\
\hline $27 / 12 / 1904$ & Incêndio destrói o ajuntamento de Sagua la Grande, em Cuba \\
\hline $14 / 02 / 1836$ & Incêndio em São Petersburgo - Rússia (700 vítimas) \\
\hline $05 / 05 / 1842$ & Incêndio em Hamburgo - Alemanha (100 vítimas) \\
\hline $12 / 06 / 1846$ & Incêndio em Quebec - Canadá (200 vítimas) \\
\hline $18 / 08 / 1846$ & Incêndio destrói a Oregon State Penitentiary (Estados Unidos) \\
\hline $25 / 04 / 1849$ & Incêndio no Parlamento de Montréal, no Canadá \\
\hline 24/12/1851 & Incêndio na biblioteca do Congresso (Washington - Estados Unidos) \\
\hline $26 / 01 / 1856$ & Incêndio do Imperial Teatro de São Pedro de Alcântara (Rio de Janeiro) \\
\hline $12 / 03 / 1856$ & A cidade de San Miguel é destruída por um incêndio \\
\hline $18 / 10 / 1857$ & Incêndio destrói o Teatro Isabel II em Cienfuegos \\
\hline 08/12/1863 & Incêndio em Santiago - Chile (2000 vítimas) \\
\hline $12 / 01 / 1869$ & Incêndio na cidade de Bayamo - Cuba \\
\hline $08 / 12 / 1870$ & Incêndio destrói o Teatro Municipal de Santiago \\
\hline $05 / 04 / 1871$ & Incêndio destrói a Igreja Matriz de Anajatuba - MA \\
\hline $08 / 10 / 1871$ & Grande incêndio de Chicago (Estados Unidos) \\
\hline $08 / 12 / 1881$ & Incêndio em Viena - Áustria (600 vítimas) \\
\hline $01 / 10 / 1882$ & Incêndio destrói a Igreja Matriz de Campo Grande - RJ \\
\hline $13 / 01 / 1883$ & Incêndio em Berdichev - Rússia (270 vítimas) \\
\hline 04/09/1887 & Incêndio em Exeter - Inglaterra (200 vítimas) \\
\hline 19/12/1888 & Incêndio destrói a Dotys Tavern - Stoughton - Massachusetts \\
\hline $10 / 12 / 1889$ & $\begin{array}{l}\text { Incêndio destrói o Teatro Romea - Murcia - Espanha (reinaugurado em } \\
16 / 02 / 1901 \text { ) }\end{array}$ \\
\hline
\end{tabular}


Tabela A.2: Casos de incêndio documentados na história. Período: 1892 a 1959 Fonte: www.ponteiro.com.br

\begin{tabular}{|c|}
\hline 15/06/1892 : Incêndio no edifício Santiago Lyon em Valparaiso - Chile \\
\hline 26/01/1896 : Incêndio destrói escola em Antofagasta - Chile \\
\hline 12/03/1896 : Incêndio na Detroit Lodge, nos Estados Unidos \\
\hline 04/05/1897 : Incêndio em Paris - França (150 vítimas) \\
\hline 08/08/1898 : Incêndio destrói prédio na Rua do Ouvidor (Rio de Janeiro) \\
\hline 2/1/1900 : Incêndio destrói o Mercado Modelo do Derby (Recife) \\
\hline Século XX \\
\hline 18/6/1901 : Incêndio destrói a empresa Betteley y Cia em Valparaiso - Chile \\
\hline 15/3/1902 : Incêndio no armazém $n^{\circ} 2$ do Arsenal da Marinha em Valparaiso - Chile \\
\hline 22/1/1904: Incêndio destrói a cidade de Alesund (Noruega) \\
\hline 27/5/1904 : Incêndio destrói o Teatro Betancourt em Chihuahua, no México \\
\hline 15/11/1904 : Incêndio destrói a praça de touros de Almada \\
\hline 2/3/1905 : Incêndio na Faculdade de Medicina da Bahia \\
\hline 16/10/1905 : Incêndio em Oliveira de Azeméis, em Portugal \\
\hline 13/2/1907 : Incêndio destrói o 'general Valdés' ( $3^{\circ}$ navio espanhol com este nome) \\
\hline 4/3/1908 : Incêndio em escola da Lakewood - Ohio \\
\hline 15/2/1909 : Incêndio no Teatro Flores em Acapulco - México (250 vítimas) \\
\hline 13/12/1909: Grande incêndio de Valdivia, no Chile \\
\hline 7/1/1910: Incêndio destrói palácio real de Atenas (Grécia) \\
\hline 25/6/1914 : Incêndio em Salem - Massachusetts, EUA \\
\hline 20/6/1919 : Incêndio em San Juan - Porto Rico (150 vítimas) \\
\hline 8/1/1920 : Incêndio no Colegio de Los Padres Franceses - Santiago - Chile \\
\hline 9/4/1905 : Incêndio destrói a Igreja de Santa Catalina Mártir em Arenas \\
\hline 7/4/1926 : Relâmpago causa incêndio que durou 5 dias em San Luis Obispo - Califórnia \\
\hline 29/9/1928 : Incêndio no Teatro Novedades em Madrid - Espanha (64 vítimas) \\
\hline 27/2/1933 : Incêndio no prédio do Reichstag, na Alemanha - nazistas acusam os comunistas \\
\hline 28/2/1933 : Incêndio destrói Parlamento alemão (Reichtag) \\
\hline 22/3/1934 : Incêndio destrói a cidade de Hakodate - Japão \\
\hline 9/2/1936 : Incêndio destrói o Teatro Regio - Turin - Itália \\
\hline 29/10/1939 : Incêndio destrói o hotel Llao Llao - Patagônia - Argentina \\
\hline 23/4/1942 : Incêndio no edifício da Câmara Municipal de Coimbra \\
\hline 6/11/1946 : Incêndio na Estação da Luz - São Paulo \\
\hline 18/9/1951 : Incêndio atinge o Tribunal de Justiça Eleitoral do Maranhão \\
\hline 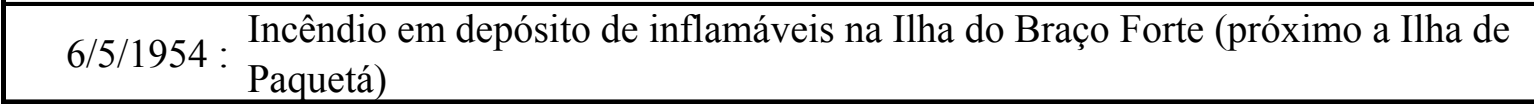 \\
\hline 10/8/1959 : Incêndio destrói a secretaria do Londrina Country Club \\
\hline
\end{tabular}


Tabela A.3: Casos de incêndio documentados na história. Período: 1960 a 2003 Fonte: www.ponteiro.com.br

\begin{tabular}{|c|}
\hline 13/11/1960: Incêndio em um cinema de Amude - Síria (150 vítimas) \\
\hline 29/7/1966 : Incêndio destrói, em São Paulo, as instalações da TV Record. \\
\hline 18/12/1970: Incêndio na fábrica da Volkswagen em São Bernardo do Campo \\
\hline 24/2/1972 : Incêndio no Edificio Andraus - São Paulo (16 vítimas) \\
\hline 2/5/1972 : Incêndio na Sunshine Mine em Kellogg - Shoshone County - Idaho, nos EUA \\
\hline 1/2/1974 : Incêndio do edifício Joelma (São Paulo) causando a morte de 188 pessoas \\
\hline 3/11/1974 : Incêndio em discoteca de Seul - Coréia do Sul (88 vítimas) \\
\hline 18/2/1977 : Incêndio em cinema na cidade de Xinjinag (China) - 694 vítimas \\
\hline 8/7/1978 : Incêndio no Museu de Arte Moderna (MAM - Rio de Janeiro) \\
\hline 12/7/1979: Incêndio em hotel de Zaragoza, na Espanha \\
\hline 10/2/1981 : Incêndio no Las Vegas Hilton - Estados Unidos \\
\hline 14/2/1981 : Incêndio no edifício Grande Avenida - Av. Paulista - São Paulo \\
\hline $\begin{array}{l}\text { 9/4/1983: Incêndio destrói o arquivo de imagens da Fundação Televisão Educativa do Rio } \\
\text { Grande do Sul }\end{array}$ \\
\hline 17/12/1983 : Incêndio na discoteca Alcalá 20 - Madrid \\
\hline 10/1/1984 : Incêndio destrói Mercado Modelo (Salvador - BA) \\
\hline 17/2/1986 : Incêndio do edifício Andorinha (Rio de Janeiro) \\
\hline 31/12/1986 : Incêndio no Dupont Plaza Hotel - San Juan - Porto Rico \\
\hline $\begin{array}{l}\text { 21/5/1987: Incêndio no prédio da CESP (Companhia Energética de São Paulo) na Avenida } \\
\text { Paulista }\end{array}$ \\
\hline 20/11/1992: Incêndio no castelo de Windsor (Inglaterra) \\
\hline 1/8/1994 : Incêndio destrói a Norwich Central Library, na Inglaterra \\
\hline 30/9/1999 : Incêndio em prédio na cidade de Inchon - Coréia do Sul \\
\hline Século XXI \\
\hline $\begin{array}{l}\text { 8/4/2001: Explosão na lanchonete Burger King provoca incêndio no Aeroporto de Schiphol - } \\
\text { Amsterdã, Holanda }\end{array}$ \\
\hline 18/8/2001 : Incêndio destrói hotel em Manila - Filipinas (75 vítimas) \\
\hline $\begin{array}{l}\text { 8/2/2002: Incêndio no prédio histórico do Ministério do Trabalho, no centro do Rio de } \\
\text { Janeiro. }\end{array}$ \\
\hline $\begin{array}{l}\text { 3/6/2002: Incêndio provoca o desabamento de um prédio de } 9 \text { andares em São Petersburgo - } \\
\text { Rússia }\end{array}$ \\
\hline $\begin{array}{l}\text { 4/9/2002: Autoridades informam que a Ponte Cedar (Condado de Madison-Iowa, nos EUA) } \\
\text { foi destruída por incêndio }\end{array}$ \\
\hline 5/9/2002 : Incêndio destrói a igreja Nossa Senhora do Rosário (Pirenópolis - GO) \\
\hline 13/9/2002 : Incêndio destrói prédio histórico do Mercado da Capixaba (Vitória - ES) \\
\hline 29/10/2002 : Incêndio consome prédio comercial em Ho Chi Minh - Vietnã (48 vítimas) \\
\hline 20/11/2002 : Incêndio no prédio do Banco Itaú em São Paulo (2 vítimas) \\
\hline 2/1/2003 : Incêndio no Palácio de Luneville - França \\
\hline
\end{tabular}


Tabela A.4: Casos de incêndio documentados na história. Período: 2003 a 2006 Fonte: www.ponteiro.com.br

\begin{tabular}{|c|}
\hline 16/2/2003 : Incêndio na indústria de produtos químicos Genco - Guarulhos - SP \\
\hline 15/5/2003 : Incêndio em hotel de Marselha - França (6 vítimas) \\
\hline 8/9/2003 : Incêndio em fábrica de pneus em Kuroiso - Japão \\
\hline 26/2/2004 : Incêndio no prédio da Eletrobrás - Rio de Janeiro \\
\hline 9/4/2004 : Incêndio no Edifício Inglaterra - Taubaté - SP \\
\hline 1/5/2004 : Incêndio no hotel Parco dei Principi - Roma \\
\hline 10/5/2004 : Incêndio no Shopping Estação - Curitiba - PR \\
\hline 11/5/2004 : Incêndio no centro olímpico em Atenas \\
\hline 17/5/2004 : Incêndio em presídio de Honduras (105 vítimas) \\
\hline 19/5/2004 : Incêndio destrói o $25^{\circ}$ andar de prédio da Petrobrás no Rio de Janeiro \\
\hline 2/8/2004 : Incêndio em fábrica de pneus em Guarulhos - SP \\
\hline 17/10/2004 : Incêndio no edifício Parque Central - Caracas - Venezuela \\
\hline 6/12/2004 : Incêndio em hotel de Shenyang - China \\
\hline 30/12/2004: $\begin{array}{l}\text { Incêndio em casa de espetáculos (Bartolomé Mitre, 3070) de Buenos Aires (190 } \\
\text { vítimas) }\end{array}$ \\
\hline 10/1/2005 : Incêndio no Edifício CBI - Vale do Anhangabaú - SP \\
\hline 13/2/2005 : Incêndio destrói o Edifício Windsor - Madrid - Espanha \\
\hline 26/2/2005 : Incêndio no edifício Golden Plaza Tower - Taichung - Taiwan \\
\hline 14/4/2005 : Incêndio no Hotel Paris-Opéra, na França \\
\hline 10/6/2005: Incêndio em hotel de Shantou, na China \\
\hline 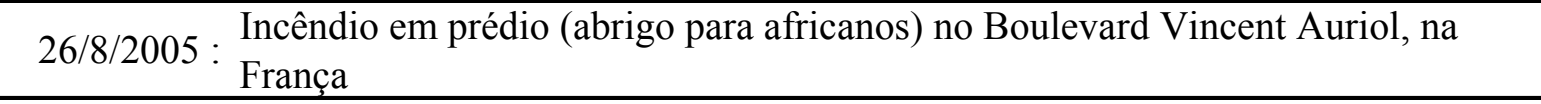 \\
\hline 29/8/2005 : Incêndio em prédio ocupado por imigrantes (Marais - Paris) \\
\hline 4/9/2005 : Incêndio em prédio de Paris (15 vítimas) \\
\hline 5/9/2005 : Egito Incêndio em teatro na cidade de Beni Sueif, no Egito (32 vítimas) \\
\hline 3/12/2005 : Incêndio no edifício Canova - Barra da Tijuca - Rio de Janeiro \\
\hline 15/12/2005 : Incêndio em hospital de Liaoyuan (mais de 30 vítimas) \\
\hline 16/1/2006 : Incêndio em edifício de Vladivostok - Russia \\
\hline 31/1/2006 : Incêndio no prédio da Telemar em Belo Horizonte - MG \\
\hline 7/2/2006 : Incêndio destrói armazém da Marinha em Campo Grande - RJ \\
\hline 16/2/2006 : Incêndio no Centro Comercial das Olaias - Lisboa \\
\hline 18/3/2006 : Incêndio em hotel na cidade de Yanji, na China \\
\hline 19/4/2006 : Incêndio em dormitório mata 10 operários em Pashinsk, na Russia \\
\hline 30/5/2006 : Incêndio no prédio mais alto de Astana - Cazaquistão \\
\hline 20/8/2006 : Incêndio destrói parte do pavilhão 41 do Ceasa do Rio de Janeiro \\
\hline 20/8/2006 : Incêndio em edifíio de Roubaix, na França \\
\hline
\end{tabular}


Tabela A.5: Casos de incêndio documentados na história. Período: 2006 a 2008 Fonte: www.ponteiro.com.br

\begin{tabular}{|c|}
\hline $\begin{array}{l}\text { 25/8/2006 : Incêndio destrói cúpula da Catedral da Santíssima Trindade em São Petersburgo, } \\
\text { na Rússia }\end{array}$ \\
\hline 6/12/2006 : Incêndio destrói prédio histórico no Pelourinho - Salvador - BA \\
\hline 8/12/2006 : Incêndio em clínica de recuperação de viciados em Moscou (45 vítimas) \\
\hline $\begin{array}{l}\text { 2/1/2007: } \begin{array}{l}\text { Incêndio destrói silo da Cooperativa Agrícola de Coimbra em São Silvestre, } \\
\text { Portugal }\end{array} \\
\end{array}$ \\
\hline 5/1/2007 : Incêndio destrói fábrica de Valentin Alsina, na Argentina \\
\hline 9/1/2007 : Incêndio no $11^{\circ}$ andar do Juizado Especial Federal de São Paulo \\
\hline 16/1/2007 : Incêndio em prédio da rua dos Correeiros (Baixa de Lisboa) \\
\hline 3/2/2007 : Incêndio em hotel de Punta Arenas, no Chile (12 vítimas) \\
\hline 4/2/2007 : Incêndio no oitavo andar de prédio em Faro, Portugal \\
\hline 24/2/2007 : Incêndio em edifício da comuna de Providencia, no Chile \\
\hline 5/3/2007 : Incêndio no hipermercado DB da rua Paraíba - Manaus - AM \\
\hline 7/3/2007 : Incêndio em edifício de três andares no Bronx - New York (8 vítimas) \\
\hline 28/3/2007 : Incêndio em edifício da avenida Urdaneta em Caracas, na Venezuela \\
\hline 9/5/2007 : $\begin{array}{l}\text { Explosão na fábrica Aerosoles Argentinos em Virrey del Pino, na Argentina (6 } \\
\text { vítimas) }\end{array}$ \\
\hline 18/6/2007 : Incêndio destrói o Shopping Center Holanda - São Paulo \\
\hline $\begin{array}{l}22 / 6 / 2007: \begin{array}{l}\text { Raio causa incêndio em dois tanques da Petróleos Mexicanos em Cadereyta, no } \\
\text { México }\end{array} \\
\end{array}$ \\
\hline 25/6/2007 : Incêndio em prédio no bairro da Graça - Salvador - BA \\
\hline 26/7/2007 : Incêndio no hotel S. Giusto em Roma \\
\hline 13/8/2007 : Incêndio em edifício da Ciudad Empresarial, no Chile \\
\hline 18/8/2007 : Incêndio em hotel de Newquay, na Inglaterra \\
\hline 18/9/2007 : Incêndio na sede do Banco Central de la República Argentina \\
\hline 29/9/2007 : Incêndio destrói 3 prédios antigos na rua Frei Caneca - Rio de Janeiro \\
\hline 30/9/2007 : Incêndio na Reitoria da Universidade do Estado do Rio de Janeiro \\
\hline 12/10/2007 : Incêndio no prédio da Ciretran de Suzano - SP \\
\hline 5/11/2007 : Incêndio no edifício da Primeira Zona Naval em Valparaíso, no Chile \\
\hline 11/11/2007 : Incêndio destrói escritório da Petrobras em Recife \\
\hline $\begin{array}{l}1 / 12 / 2007: \begin{array}{l}\text { Incêndio provoca o fechamento temporário da ponte do complexo Zárate-Brazo } \\
\text { Largo, na aArgentina }\end{array} \\
\end{array}$ \\
\hline $\begin{array}{l}\text { 3/12/2007: Incêndio destrói prédio da Faculdade de Ciências da Universidad Austral de } \\
\text { Valdivia, no Chile }\end{array}$ \\
\hline 12/12/2007 : Incêndio em arranha-céu de Wenzhou, na China (21 vítimas) \\
\hline 16/12/2007 : Incêndio no Edifício Júpiter - Vitória - ES \\
\hline 25/12/2007 : Incêndio no prédio dos ambulatórios do Hospital das Clínicas - São Paulo \\
\hline $\begin{array}{l}\text { 1/1/2008: Incêndio em edifício da Rua Desembargador Macedo Vieira - Aclimação - São } \\
\text { Paulo }\end{array}$ \\
\hline
\end{tabular}


Tabela A.6: Casos de incêndio documentados na história. Período: 1/2008 a 5/2008 Fonte: www.ponteiro.com.br

\begin{tabular}{|c|}
\hline 17/1/2008: Incêndio em prédio de Almada, em Portugal \\
\hline 19/1/2008: Incêndio em agência do banco Itaú no Alto de Pinheiros - zona oeste de São Paulo \\
\hline 28/1/2008: Incêndio destrói o banco central iraquiano em Bagdá \\
\hline 31/1/2008: Incêndio no Complejo Petroquímico de Pajaritos, no México \\
\hline $2 / 2 / 2008:$ Incêndio em prédio na rua Roberto Simonsen - São Paulo \\
\hline $3 / 2 / 2008:$ Incêndio em prédio de Ludwigshafen, na Alemanha (9 vítimas) \\
\hline $5 / 2 / 2008:$ Incêndio destrói prédio da Universidade Tuiuti do Paraná (campus Champagnat) \\
\hline em Curitiba \\
\hline $10 / 2 / 2008:$ Incêndio em cobertura de difício na rua Barata Ribeiro - Copacabana - Rio de \\
\hline $20 / 2 / 2008:$ Incêndio destrói o templo de Namdaemun em Seul \\
\hline $2 / 3 / 2008:$ Fatos Brasil Incêndio destrói parte do prédio da prefeitura de Patos de Minas - \\
\hline $20 / 3 / 2008:$ Incêndio em armazém de Hualmay, no Peru (5 vítimas) \\
\hline $23 / 3 / 2008:$ Incêndio na fábrica de fertilizantes Yara em Canoas - RS \\
\hline $25 / 3 / 2008:$ Incêndio em edifício de Boulevard de Sabana Grande - Caracas \\
\hline $27 / 3 / 2008:$ Incêndio no Fórum João Mendes em São Paulo \\
\hline $3 / 4 / 2008:$ Incêndio destroi fábrica de Albergaria-a-Velha, em Portugal \\
\hline $4 / 4 / 2008:$ Incêndio destrói estação dos correios no Largo dos Penedos em Braga, Portugal \\
\hline $4 / 4 / 2008:$ Incêndio destrói 5 estabelecimentos comerciais em Valdivia, no Chile \\
\hline $26 / 4 / 2008:$ Incêndio em fábrica de colchões em Casablanca - Marrocos (55 vítimas) \\
\hline $26 / 4 / 2008:$ Incêndio na indústria química IPESA em Zárate, na Argentina \\
\hline $27 / 4 / 2008:$ Queda de balão causa incêndio em prédio no bairro da Prosperidade - São Caetano \\
\hline $6 / 5 / 2008:$ Incêndio em prédio de Moscavide, em Portugal \\
\hline
\end{tabular}

